\title{
Serialität der Romanhefte
}

\author{
Dissertation \\ zur Erlangung des philosophischen Doktorgrades an der \\ Philosophischen Fakultät der Georg-August-Universität Göttingen
}

vorgelegt von

Björn Lorenz

aus Hamburg

Göttingen 2014 


\section{Inhaltsverzeichnis}

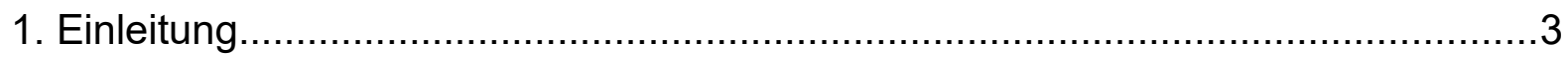

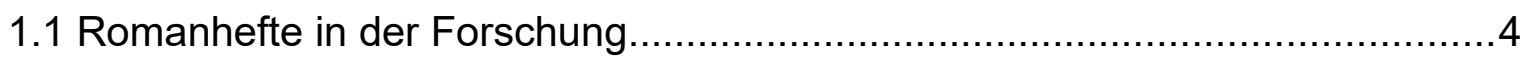

1.1.1 Romanheftserien und -reihen in der Forschungsliteratur .........................4

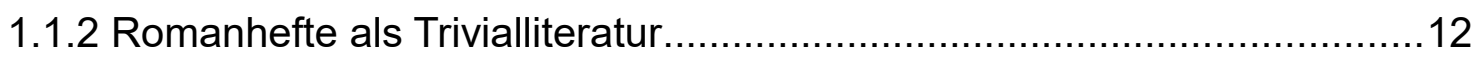

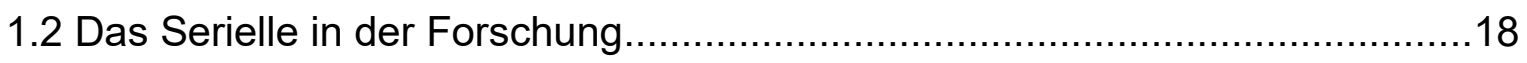

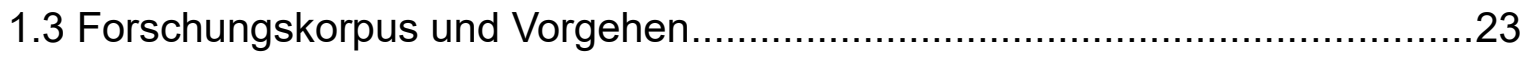

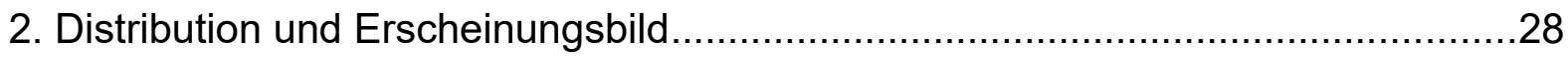

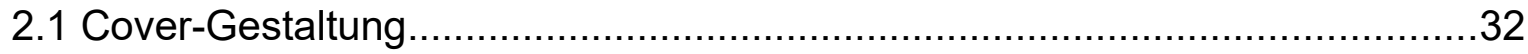

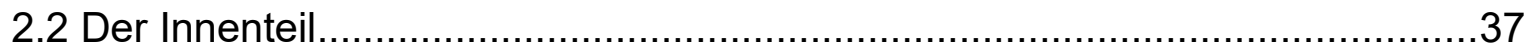

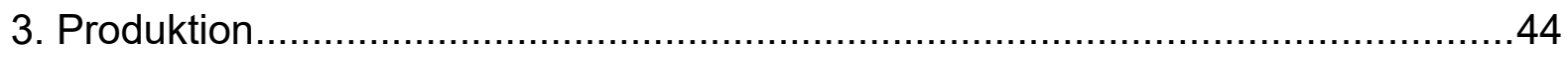

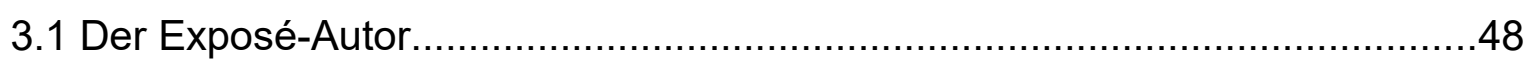

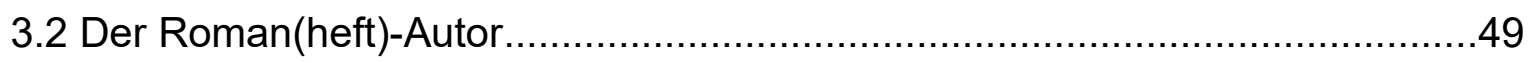

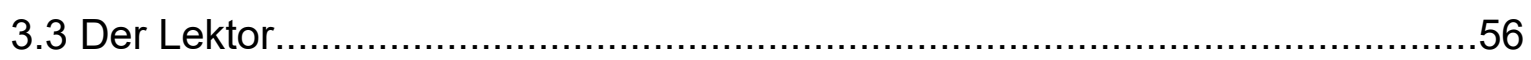

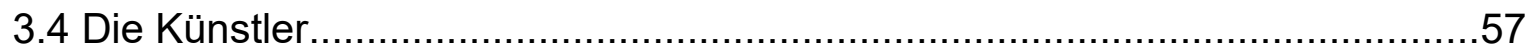

4. Genres der Romanhefte und ihre Besonderheiten ........................................61

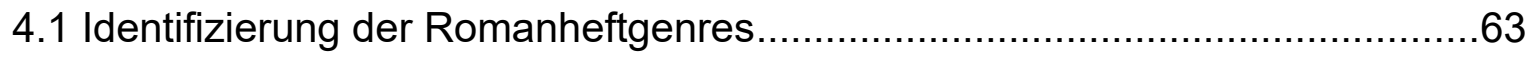

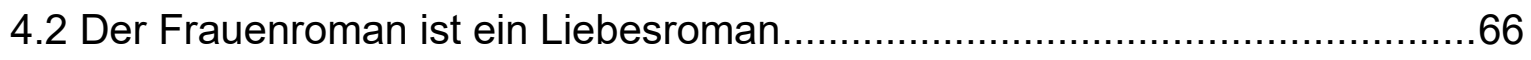

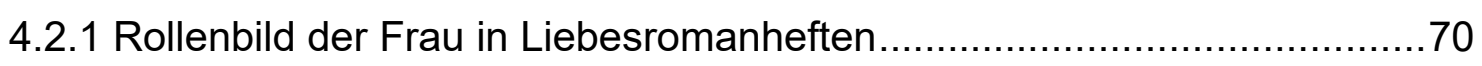

4.2.2 Subgenres der Liebesromanhefte..................................................... 74

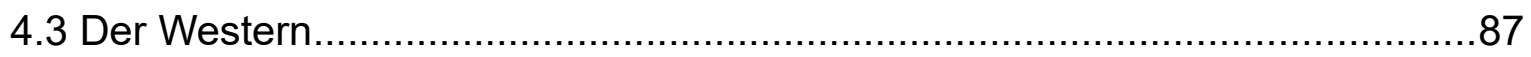

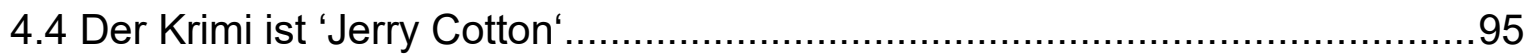

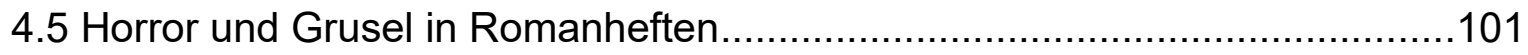

4.5.1 Romanhefthorror beginnt im Kriminalromanheft..................................102

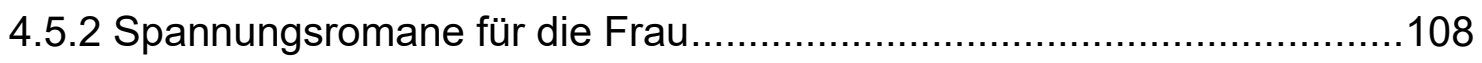

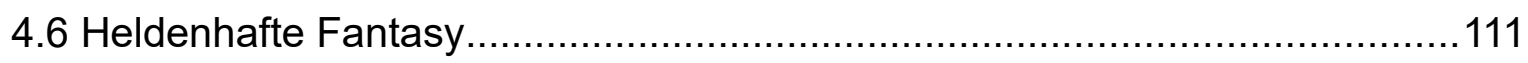

4.7 Science Fiction und Space Opera....................................................... 118

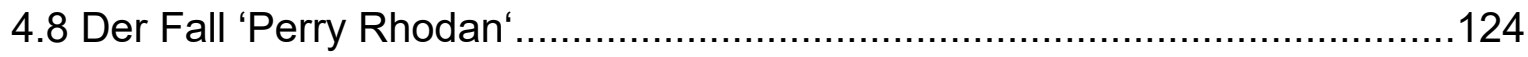

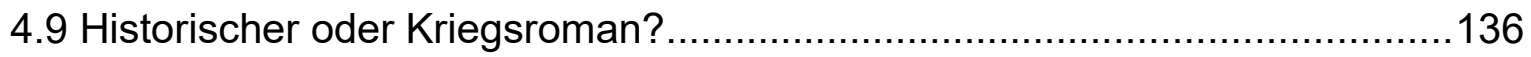


5. Erzählökonomie und Serieninsider

5.1 Erzählökonomie.

5.2 Serieninsider

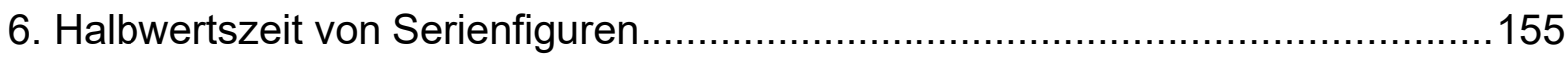

7. Narrativer Rahmen der seriellen Narration.............................................169

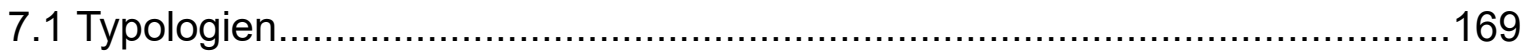

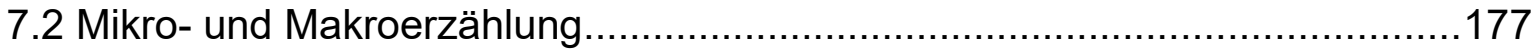

8. Innere Verknüpfung. Oder: Die serielle Narration......................................183

8.1 Die drei Phasen - Einführung, Verlauf und Ende...................................183

8.2 Erste Bestimmung serieller Regelmäßigkeiten.........................................193

8.3 Das Kalkül von Konstanz und Variation................................................203

8.4 Redundanzen während der Rezeption...............................................207

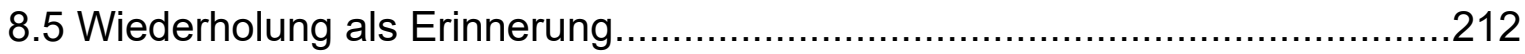

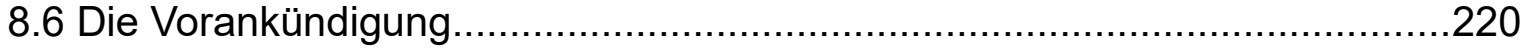

9. Das serielle Produkt als Massenkunstwerk ...............................................224

9.1 Eine Serie 'massenmedialästhetisch' untersucht......................................224

9.2 Massenkunstwerk oder nur Produkt? ....................................................239

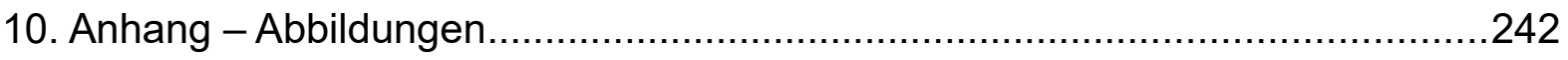

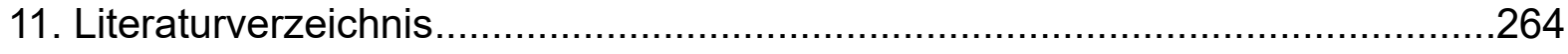

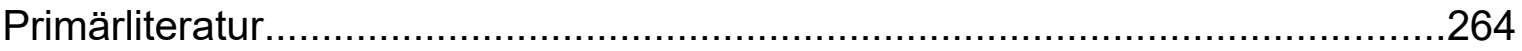

Romanhefte (nach Verlag) ..............................................................264

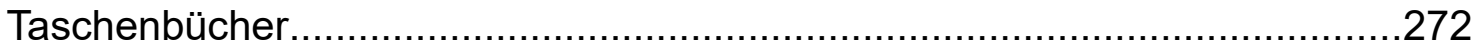

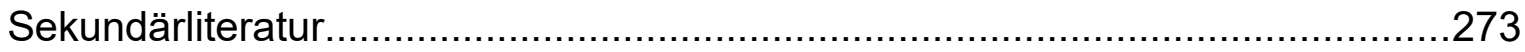

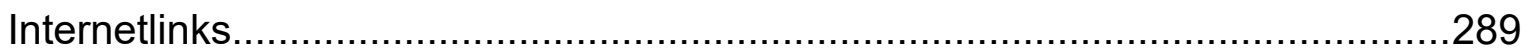

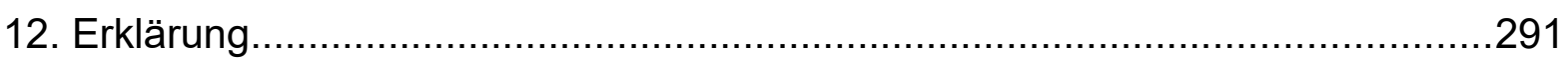




\section{Einleitung}

Geschichten in Serienformat finden nicht nur großen Anklang im Fernsehen und auf den Video-On-Demand-Plattformen (VOD), sondern auch in der Wissenschaft. Jedoch widmete sich in der Vergangenheit hauptsächlich die Medienwissenschaft den seriellen Erzählformen und dabei auch eher den TV- oder VOD-Serien. Nur wenige Literaturwissenschaftler richteten ihr Interesse auf die serielle Erzählform als solche. Dabei bieten gerade die Romanhefte (auch Groschenhefte genannt) zahlreiche verschiedene Ausprägungen serieller Narrationen: Serien mit durchgehenden Handlungssträngen, Serien mit abgeschlossenen Folgen aber wiederkehrenden Figuren, oder Reihen mit antologischem Charakter. Allerdings sahen Literaturwissenschaftler das Romanheft lange Zeit nicht als „erforschenswert" an und bedachten es hauptsächlich mit Ideologiekritik. Selbst Feuilletonromane wurden intensiver hinsichtlich ihrer Wirkung auf den Literaturbetrieb und weniger rein auf ihre „narrative Bauweise“ hin untersucht. Der sogenannte "Cliffhanger" wird zwar vielfach thematisiert, doch wie gestückeltes Erzählen abseits davon im Detail funktioniert untersuchte bisher kein deutscher Literaturwissenschaftler umfassend für Narrationen im gedruckten Medium.

Die Romanhefte, massenhaft für Kioske und Bahnhofsbuchhandlungen produziert, ähneln in ihrer Produktionsart stark den TV-Serien: Eine Redaktion plant folgenübergreifende Handlungsstränge und reicht diese Pläne anschließend an ein Autorenteam, das die Folgen produziert. Die einzelnen Folgen beziehungsweise Hefte haben, ähnlich einer TV-Folge, einen Vorspann und diverse Elemente, um den Rezipienten an vorangegangene Ereignisse zu erinnern. Doch wurden Romanheftserien kaum unter seriell-narrativen Aspekten wie TV-Serien untersucht. Dies will die vorliegende Arbeit unter anderem nachholen und sich von Wertungen sowie ideologiekritischen Sichtweisen, die in der Romanheftforschung immer noch präsent sind, distanzieren.

Romanhefte hatten zwar ihre Hochzeit in den 1970er bis 1980er Jahren, aber noch heute sind sie zuverlässig in jedem Kiosk zu finden und es werden weiterhin neue Serien produziert. Daher ist es für die Literaturwissenschaft längst überfällig, diese massenhaft produzierten Erzählungen hinsichtlich ihrer narrativen Strategien zu 
untersuchen: Schließlich ist die "serielle Narration" als Forschungsgebiet nicht nur Aufgabe der Medienwissenschaft, sondern aller Wissenschaftszweige, die sich mit Erzählformen jeglicher Art auseinandersetzen. Die Literaturwissenschaft hat im Fall der Romanhefte die Chance, auf den Erkenntnissen der Medienwissenschaft zu Serienformen aufzubauen. Demgemäß zieht die vorliegende Arbeit auf interdisziplinäre Art Forschungsergebnisse zu Rate und verknüpft diese miteinander, um darzustellen, wie sich serielle Narration konkret in Romanheften ausprägt.

\subsection{Romanhefte in der Forschung}

\subsubsection{Romanheftserien und -reihen in der Forschungsliteratur}

Überblickt man die Forschungsliteratur zum Romanheft, dann fällt schnell auf, dass der Großteil in den 1970ern und 1980ern Jahren entstanden ist. Einige Forscher konzentrierten sich auf einen thematischen Bereich wie Wildwest- oder Liebesgeschichten, andere hingegen auf konkrete Serien wie Jerry Cotton oder Perry Rhodan.

Um mit den narrativ-thematisch orientierten Arbeiten zu beginnen, nahm sich beispielsweise Jens-Ulrich Davids 1975 in „Das Wildwest-Romanheft in der Bundesrepublik" eben jenen Bereich konzentriert vor. ${ }^{1}$ Systematisch stellt er Ursprünge dieses narrativen Themas sowie inhaltliche Strukturen der Western-Romanhefte dar, wobei er aus dem Material heraus mit zahlreichen Zitaten argumentiert. In seiner Arbeit identifiziert er für die damaligen Hefte wiederkehrende Figurentypen und Figurenkonstellationen sowie typische Erzählweisen. In erster Linie interessiert inn, wie diese Hefte ihre narrativen Elemente einsetzen. Wertende Betrachtungen, die Bezug auf den didaktischen und moralischen Wert der Hefte sowie ihre Leserschaft nehmen, spielen in seiner Arbeit nur am Rande eine Rolle. Wie sich im Folgenden vereinzelt zeigen wird, ist das bei anderen Forschungsarbeiten nicht der Fall. Der didaktische sowie moralische Wert der Hefte - also ihr ideologischer Kern - werden dort wortreich diskutiert.

Den Bereich der Liebesromane untersuchte Dorothee Bayer 1971 in „Der triviale

1 Jens-Ulrich Davids: Das Wildwest-Romanheft in der Bundesrepublik. 2. erw. Aufl. Tübingen 1975. 
Familien- und Liebesroman im 20. Jahrhundert“. ${ }^{2}$ Aus einer Stichprobe von fünf Romanen, die unter anderem auch Liebesromanhefte umfasst, leitet sie einzelne „Struktur und Formelemente dieser Gattung“ ab. ${ }^{3}$ Ihre Analyse zielt dabei darauf ab, anhand der Liebesromane allgemein Aussagen über die Trivialliteratur zu treffen. Bayer stellt folgende These auf, „daß die wesentlichen Charakteristika des Trivialromans relativ konstant bleiben und im allgemeinen nur strukturell unwesentliche Details dem jeweiligen Zeitgeist unterworfen sind.“4 Konkreter geht Liselotte Brodbeck 1974 mit ihrer Monographie „Roman als Ware - Zur Anaylse der Liebesromanhefte" auf den Liebesroman in Heftform ein. ${ }^{5}$ Ihr Anspruch ist es, aus den formalen und inhaltlichen Strukturen der Hefte abzuleiten, wie diese das Bewusstsein der Leser beeinflussen. ${ }^{6}$ Sie kommt zu dem Schluss, dass die Romanhefte lediglich einen ausbeutenden Kapitalismus fördern würden. ${ }^{7}$ Unter einem ähnlichen Schwerpunkt untersucht Franziska Ruloff-Häny 1976 in ihrer Dissertation ebenfalls Liebesromanhefte: „Vor allem interessiert hierbei die Frage, wie es kommt, daß leere Sätze, Klischees, Stereotypen eine solche ungeheure Kraft haben."8 Jene Klischees und Stereotypen seien dem Leser - so Ruloff-Häny - bekannt, weshalb er sie nicht hinterfragen müsse. Genau dies animiere „den potentiellen Käufer zum Zugriff“. 9

Einen explizit didaktischen Anspruch legt Hans-Herbert Wintgens 1979 in seine Untersuchung „Trivialliteratur für die Frau“. ${ }^{10}$ Seine Arbeit bietet durchaus eine systematische Darstellung inhaltlicher Strukturen der Liebesromane, ähnlich wie Jens-Ulrich Davids Untersuchung zum Westernroman (s.o.). Allerdings sind seine Einsichten in narrative Elemente der Liebesromanhefte stark moralisch getönt. Weniger Wirkungsannahmen äußernd und stärker auf inhaltliche Strukturen der Liebesromanhefte fokussierend, argumentiert Christian Thiel 1991 in „Liebe, Sex,

2 Dorothee Bayer: Der triviale Familien- und Liebesrom im 20. Jahrhundert. 2. erw. Aufl. Tübingen 1971.

3 Ebd. S. 15. Auf das Gattungsverständnis von Bayer soll hier nicht eingegangen werden. In der vorliegenden Arbeit, wird das Liebesromanheft als ein Genre der Romanhefte behandelt. Inwiefern sich "Genre" hierbei von "Gattung" abgrenzt, ist Thema in Kapitel 4. "Genre der Romanhefte und ihre Besonderheiten".

4 Ebd.

$5 \quad$ Liselotte Brodbeck: Roman als Ware. Zur Analyse der Liebesromanhefte. Basel 1974.

6 Ebd. S. 5.

7 Vgl. ebd. S. 63f.

8 Franziska Ruloff-Häny: Liebe und Geld. Der moderne Trivialroman und seine Struktur. Dissertation. München 1976.

9 Ebd. S. 72f.

10 Hans-Herbert Wintgens: Trivialliteratur für die Frau. Stuttgart 1979. 
Karriere“..11 Diese Arbeit stellt eine der aktuellsten (und wertungsfreien) Werke zum Liebesromanheft dar.

Wie viel von Heimatromanen des 19. Jahrhunderts in den Heimatromanheften noch vorhanden ist, untersucht Maria Present in „Wohlfeiles heimatliches Waldesrauschen“. ${ }^{12}$ Das Besondere an ihrer Arbeit ist, dass sie die dem Bereich der Liebesromanhefte zugehörigen Hefte nicht nur unter dem Gesichtspunkt der Liebesromane untersucht, sondern ebenso analysiert, inwieweit die Hefte auf historischen Vorgängern basieren. Auch sie bietet einen Überblick zu typischen inhaltlichen Elementen der Heimatromanhefte anhand von Textbeispielen.

Umfassende Untersuchungen, die sich konzentriert entweder Horror-, Fantasy- oder nur Science Fiction-Romanheften widmen, finden sich nicht. Die Forschung setzte bisher ihren Fokus auf diese Heften nur im Zuge der Betrachtung einer Literaturgattung. Dementsprechend wählte Klaus-Peter Klein 1976 in „Zukunft zwischen Traum und Mythos: Science-fiction“ Romanhefte lediglich als ein Beispiel stellvertretend für alle Publikationsformen der gesamten „trivialen Science-fictionLiteratur". ${ }^{13}$ Jedoch untersuchte er nicht, wie sich die Science Fiction nur im Bereich Romanheft ausprägte; also nicht wie sich das Romanheft-Genre „Science Fiction“ zur Science Fiction-Literatur verhält. ${ }^{14}$

Gerd Hallenberger und Heinrich Keim setzen, ähnlich wie Klein, Science Fiction um 1975 in Deutschland gleichbedeutend mit Science Fiction-Romanheften und kritisieren sie als „permanent faschistoides Gedankengut“, ${ }^{15}$ das nicht „[mehr] als erste Ansätze zu einer fortschrittlichen SF“ angesehen werden könne. ${ }^{16}$ Hallenberger und Keim fassen zudem Fantasy- sowie Horrorromanhefte unter den weiten Begriff „Science Fiction“: „Diese [...] Formen stellen in ihrer Reihenfolge eine Progression dar, von regressiver Infantilität bis zu direkt faschistischer Reaktion“. ${ }^{17}$ Belege für ihre

11 Christian Thiel: Liebe, Sex, Karriere. Die Modernisierung des trivialen Liebesromans. Hamburg 1991.

12 Maria Present: Wohlfeiles heimatliches Waldesrauschen. Wien 1993.

13 Klaus-Peter Klein: Zukunft zwischen Trauma und Mythos: Science-fiction Zur Wirkungsästhetik, Sozialpsychologie und Didaktik eines literarischen Massenphänomens. Stuttgart 1976.

14 Gudrun Weiland hat zwar nicht untersucht, wie sich „Krimi“ als Romanheftgenre in den Heften ausprägt, allerdings, wie sich serielle Praktiken in den Kriminalromanheften der 1920er Jahre niederschlagen. Vgl. „'Von einem sensationellen Erlebnis zum anderen getrieben...': Kriminalheftromane und die Zeitgestalt 'Serialität' in den 1920er und 1930er Jahren." Göttingen 2017.

15 Gerd Hallenberer und Heinrich Keim: Die Zukunft als Ware. In: Kürbiskern Literatur, Kritik, Klassenkampf. Hrsg. Von W. Fritzsche. Heft 1/75. München 1975. S. 76-90.

16 Ebd. S. 89.

17 Ebd. S. 86ff. 
Thesen bleiben hingegen aus.

Kriegsromanhefte werden von der Forschung hauptsächlich in Verbindung mit der mittlerweile eingestellten Landser-Reihe wahrgenommen. Ernst Antoni untersuchte 1979 in "Landser-Hefte Wegbereiter für den Rechtsradikalismus“ den ideologischen Gehalt der Romanheftreihe. ${ }^{18}$ Walter Nutz widmete sich 1977 in "Der Krieg als Abenteuer und Idylle. Landser-Hefte und triviale Kriegsromane" stärker dem inhaltlichen Aufbau der Kriegsromanhefte und ihrer Narrationsweisen. ${ }^{19}$ Nutz verweist dabei auch auf den systematischen Ansatz Klaus F. Geigers, der 1974 einen Überblick über typische Inhalte der Kriegsromanhefte der damaligen Zeit erstellte. ${ }^{20}$

Betrachtungen und Studien zu konkreten Romanheftserien oder -reihen finden sich besonders für die Serie Perry Rhodan. 1979 unterzog Claus Hallmann die Serie, laut eigener Aussage, einer literaturwissenschaftlichen Untersuchung in „Perry Rhodan Analyse einer Science-Fiction-Romanheftserie". ${ }^{21} \mathrm{Er}$ stellte unter anderem wertungsfrei die Produktionsbedingungen der Serie vor und gibt in seiner Monographie Einblicke in die wichtigsten Handlungsstränge, Themen sowie Figuren. 1986 folgte Rainer Staches „Perry Rhodan - Überlegungen zum Wandel einer Heftromanserie". Stache verhandelt in seinem Buch verkürzt ähnliche Aspekte wie Hallmann, wobei er ideologische Veränderungen der Serie aufzeigt. ${ }^{22}$ In der 2017 erschienenen Dissertation von Mirjam Nast wird der Frage des Perry Rhodan-Konsumenten als Serienleser nachgegangen. ${ }^{23}$ Auf Basis wissenschaftlicher Interviews stellt sie Lektüre- und Sammel-Praktiken der Perry Rhodan-Leser dar. Ihr besonderer Schwerpunkt ist, wie sich die Praktiken in Wechselwirkung mit der seriellen Struktur der Romanhefte entwickeln: „Der Fokus liegt dabei auf den serialitätsbezogenen Prozessen und Praktiken der Lektüre. “24

Zu der Romanheftserie Jerry Cotton finden sich mehrere wissenschaftliche Artikel,

18 Ernst Antoni: „Landser“-Hefte Wegbereiter für den Rechtsradikalismus. München 1979.

19 Walter Nutz: Der Krieg als Abenteuer und Idylle. Landser-Hefte und triviale Kriegsromane. In: Gegenwartsliteratur und Drittes Reich. Hrsg. von Hans Wagener. Stuttgart 1977, S. 265-283.

20 Klaus F. Geiger: Kriegsromanhefte in der BRD - Inhalte und Funktionen. Tübingen 1974.

21 Claus Hallmann: Perry Rhodan - Analyse eine Science-Fiction-Romanheftserie. Frankfurt 1979.

22 Rainer Stache: Perry Rhodan - Überlegungen zum Wandel eine Heftromanserie. Tübingen 1986.

23 Mirjam Nast: „Perry Rhodan“ lesen. Zur Serialität der Lektürepraktiken einer Heftromanserie. Dissertation. Bielefeld 2017.

24 Ebd. S. 31. 
bislang jedoch kaum Monographien. Ein Großteil der Artikel entstand in den 1970ern und widmet sich hauptsächlich der Kritik, dass der Romanheftserie ein didaktischer Wert fehle, die meist auch auf alle Romanhefte übertragen wird. So heißt es beispielsweise im Jahr 1972 im Artikel „Verwertbare Unmündigkeit: Zur Romanheftserie Jerry Cotton“:

„[Die] Lektüre von Romanheften motiviert offenbar nur selten zum Gespräch über sie. Solch asozialer Gebrauch hebt die Romanhefte nochmals von den informativen Medien wie von der Belletristik ab: sie steuern sozialer Desintegration zu. ${ }^{25}$

Einen Schritt weiter geht im gleichen Jahr Gerhard Bierwirth, indem er aus der bloßen Lektüre einiger Jerry Cotton-Romanhefte ableitet, dass die Hefte ihre Leser entmündige:

„Die Ununterscheidbarmachung von Schein und Realität, die diese Literatur zum Ziel hat, geht mit der herrschaftlichen Tendenz zur totalen Entpolitisierung der Massen zusammen. [...] Mit Drogen hat diese Literatur Suchtsymptome wie Entziehungsqualen und Wiederholungszwang gemeinsam. " 26

Aktiver, aus dem Forschungsmaterial heraus argumentierend, arbeitet 1976 Peter Wesollek in seiner Monographie „Jerry Cotton oder 'Die verschwiegene Welt'“' ${ }^{27}$ Mit Textbeispielen bietet er einen eingangs wertungsfrei belegten Überblick zu Entstehungsbedingungen der Jerry Cotton-Hefte sowie ihren wichtigsten inhaltlichen Elementen. Ähnlich wie Bierwirth und die Arbeitsgruppe Massenliteratur geht er jedoch bei Romanheftlesern grundsätzlich von unmündigen Konsumenten aus, ohne dies zu belegen:

„Die Methode dabei besteht darin, dass ein Sachverhalt als außerordentlich hingestellt oder benannt wird, in der Hoffnung, dass die Leser, die ohnehin nicht zum Denken erzogen, angehalten und ermuntert wurden und deren anerzogene Unmündigkeit durch die Cotton-Hefte mit allen Kräften unterstützt wird, gar nicht auf den Gedanken kommen, nach der tatsächlichen Beschaffenheit des Sachverhaltes zu fragen [...]." ${ }^{28}$

25 Arbeitsgruppe Massenliteratur: Verwertbare Unmündigkeit: Zur Romanheftserie Jerry Cotton. In: Ästhetik \& Kommunikation. Beträge zur politischen Erziehung. Jg. 2, H. 5-6, Rowohlt. Reinbek Februar 1972. S. 49-57. S. 50.

26 Gerhard Bierwirth: Zum Beispiel Jerry Cotton. Trivialliteratur als Chance der Literaturwissenschaft. In: Zeitschrift für Literaturwissenschaft und Linguistik. Heft 6 1972. Hrsg. von Helmut Kreuzer et al., S. 95-104. S. 104.

27 Peter Wesollek: Jerry Cotton oder 'Die verschwiegene Welt'. Bonn 1976.

28 Ebd. S. 245. 
Frei von jeglicher Wertung der Leser untersucht Martin Bell die Romanheftserie Dämonenkilller. ${ }^{29} \mathrm{Er}$ deckt unter anderem wiederkehrende narrative Elemente in der Serie auf und arbeitet Bezüge zum phantastischen Roman des 18. Jahrhunderts heraus.

Abseits der Forschung zum Romanheft bieten die Werke einiger professionalisierter Romanheftliebhaber und -sammler hilfreiche Hinweise und Überblicke zu einzelnen Serien oder Romanheftgenres. ${ }^{30} \mathrm{Zu}$ nennen ist hier vor allem der Romanheftsammler Heinz J. Galle, der mit seinem 1988 erschienen Werk „Groschenhefte“ einen kompakten Überblick über den historischen Werdegang der Romanhefte in Deutschland bietet. ${ }^{31}$ Einen bebilderten Einblick in die Anfänge des Romanheftes gewährt Galle mit „Populäre Lesestoffe. Groschenhefte, Dime, Novels und Penny Dreadfuls aus den Jahren 1850 bis 1950“. ${ }^{32}$ Wesentlich umfassender ist sein dreibändiges Kompendium „Volksbücher und Heftromane“. ${ }^{33}$ Die Bände sind grob chronologisch sortiert und decken einen Zeitraum von 1850 bis 2000 ab. Galle geht auf historische Einflüsse sowie Verlagsgeschichte der Romanheft-Produzenten ein, wobei er die Charakteristika zahlreicher einzelner Serien und Reihen umreißt.

Einen ähnlich strukturierten Einblick gewährt Jochen Bärtle in seinem Werk „Grusel, Grüfte, Groschenhefte“ für Horrorromanhefte von 1968 bis $2008 .{ }^{34} \mathrm{Er}$ verweist auf zeitgenössische Markttrends, Hintergründe zur Entstehung sowie Niedergang einzelner Serien und vermittelt somit umfassende Kenntnisse zum Feld der Horrorromanhefte. In der Online-Publikation „Geister, Gaslicht, Gänsehaut“ richtet Bärtle seinen Fokus in gleicher Manier auf eine Hybridform von Horror- und Liebesromanheften, den sogenannten „Spannungsromanen für die Frau“. ${ }^{35}$

29 Martin Bell: Muster des Unheimlichen. Struktur und Ideologie des Heftromans am Beispiel der Gruselserie Dämonenkiller. Uelvesbüll 2011.

30 Auf den Genrebegriff wird in Kapitel 4. „Genres der Romanhefte" der vorliegenden Arbeit näher eingegangen.

31 Heinz J. Galle: Groschenhefte - Geschichte der deutschen Trivialliteratur. Berlin 1988.

32 Heinz J. Galle: Populäre Lesestoffe. Groschenhefte, Dime, Novels und Penny Dreadfuls aus den Jahren 1850 bis 1950. Köln 2002.

33 Heinz J. Galle: Volksbücher und Heftromane. Bd. 1 bis 3. 2. durchges. Aufl. Lüneburg 2009.

34 Jochen Bärtle: Grusel, Grüfte, Groschenheft. Der deutsche Gruselheftroman von 1968 bis 2008 - Eine Serienübersicht zum 40-jährigen Jubiläum. Norderstedt 2008.

35 Jochen Bärtle: Geister, Gaslicht, Gänsehaut. Mysteriöse Romanzen, romantische Gothics - Der Spannungsroman für Frauen (1971-2013). Version 1.1, als kostenlose PDF downloadbar: http://www.groschenhefte.net/news01.htm (Zugriff: 22.03.2013). Die Erweiterte Version 3.2 konnte hier nicht mehr berücksichtigt werden: 
Einen rein bibliographischen Überblick zum Horrorromanheft hat Thomas König im „Geisterwald Katalog - Horror/ Grusel \& Mysterie“ erstellt. ${ }^{36}$ In einem zweiten Band widmet sich König dem Bereich der Märchen- und Fantasyromanheften. ${ }^{37}$ Die „Geisterwald Kataloge“ bieten eine Übersicht zu (beim Erscheinen 2009) aktuellen Marktpreisen, Erscheinungsdaten und Autorschaften einzelner Romanhefte. In sorgfältiger Recherche stehen sie dem von einem Händlerkollektiv erstellten „Allgemeinen Roman-Preiskatalog“ in nichts nach. ${ }^{38}$ Sie stellen somit eine zuverlässige Informationsquelle dar.

Die ebenfalls privat erstellte Monographie von Robert Hector „Die dunkle Zukunft der Menschheit" widmet sich der Maddrax-Serie. ${ }^{39}$ Gebündelt hebt er von 250 Bänden die wichtigsten Handlungsstränge hervor und bietet so eine rein inhaltliche Handreichung zu Romanheftserie. Überblickswerke dieser Art produzieren sonst eher die Verlage selbst. Am aktivsten ist die Perry Rhodan-Redaktion. Als besonders umfangreich erweist sich die mehrbändige Perry Rhodan-Chronik, in der Michael Nagula und Hermann Urbanek nicht nur Einblicke in die Produktion der Perry Rhodan-Serie bieten, sondern auch auf historische Ereignisse oder Trends hinweisen, die die Autoren beeinflussten. ${ }^{40}$ Da viele der Perry Rhodan-Autoren zudem für andere Serien schrieben, eröffnet die „Chronik“ ebenfalls Hintergrundinformation zu weiteren Romanheftproduktionen, die in der Vergangenheit erfolgreich waren, wie beispielsweise Mythor oder Dragon ${ }^{41}$. In dem bildreichen Buch „Allmächtiger! Faszi-

http://www.groschenhefte.net/ggg buecher main.html (Zugriff: 04.05.2019). In zwei weiteren Monographien stellt Bärtle jeweils die Entwicklung der Fantasy- und der Abenteuerromanhefte vor, die hier ebenfalls nicht mehr systematisch bedacht werden konnten. Zum Fantasyromanheft vgl. Bärtle: Goblins, Götter, Greifenreiter. Fantasy im deutschen Heftroman von 1973 bis 2012 - über die seltenen Ausflüge in phantastische Welten. Norderstedt 2017. Zum Abenteuerromanheft vgl. Bärtle: Götzen, Gold und Globetrotter. Deutsche AbenteuerHeftromane von 1960 bis 2015 - mit Übersicht der wichtigsten Nachkriegsserien. Norderstedt 2016.

36 Thomas König: Geisterwald Katalog. Die Heftroman-Bibliographie. Bd. 1 Horror/ Grusel \& Mysterie. 2. Aufl. Berlin 2009.

37 Thomas König: Geisterwald Katalog. Die Heftroman-Bibliographie. Bd. 2 Märchen/Sagen \& Fantasy. Berlin 2001.

38 Joachim Knüppel, Werner Knüppel und Helmut Rhode: Allgemeiner Roman-Preiskatalog. 11. erw. Aufl. Hamburg 2016.

39 Robert Hector: Die dunkle Zukunft der Menschheit. 250 Mal MADDRAX. Norderstedt 2009.

40 Michael Nagula: Perry Rhodan. Die Chronik. Bd.1. Höfen 2011 sowie Bd. 2. im Jahr 2012. Bd 3. von Hermann Urbanek erschien 2013. Bereits in vorangegangenen Werken hatte der Verlag viel Mühe in die Darstellung einer legendären Entstehungsgeschichte gesteckt. So beispielsweise 1986 der „Werkstattband“ von Horst Hoffmann oder 1996 „Das große Perry Rhodan Fanbuch“ von Klaus N. Frick (Hg.).

41 Der Weltbild-Verlag versuchte 1990 die Serie in Taschenbuch-Format wieder populär zu machen und produzierte einen dünnen Band zu den Hintergründen der Serie mit Hans Kneifel 
nation Perry Rhodan“ zollt der Verlag dem umfangreichen Merchandise seiner Serie Aufmerksamkeit. Visuell und in einzelnen Auflistungen entfaltet sich die breite Palette von Perry Rhodan-Produkten. ${ }^{42}$

Ähnlich vielfältig ist die Veröffentlichung „G-Man Jerry Cotton“ des Lübbe-Verlags zu der gleichnamigen Romanheftserie. ${ }^{43}$ Das Buch informiert grob über die Entstehungsgeschichte, Hintergründe zu Verfilmungen und Probleme mit der Zensur. Einen tieferen Einblick in Produktionshintergründe gewährt „G-man Jerry Cotton. Nichts als Wahrheit und Legenden" von dem Jerry Cotton-Autoren Friedrich Jakuba. ${ }^{44}$ Er berichtet, wie Autoren zu ihren Geschichten finden und wie sich ihre Zusammenarbeit innerhalb der redaktionell vorgegebenen Richtlinien gestaltet. Der Horrorromanheftserie John Sinclair widmet der Verlag ein Lexikon, das nicht nur in wichtige Begriffe und Handlungsstränge ebenjener Serie einführt, sondern auch eine Bibliographie der Sinclair-Romanhefte vorweist. ${ }^{45}$ Im Jahr 2004 richtete die UrsulaLübbe-Stiftung zusammen mit der Stiftung „Haus der Geschichte der Bundesrepublik Deutschland“ ein Symposion zum Romanheft aus. ${ }^{46}$ Der daraus entstandene Band thematisiert unter anderem Hintergründe zur Jerry Cotton-Serie, aber auch allgemeine Themen wie den Stellenwert des Romanhefts in der „Schmutz und SchundDebatte“, da an dem Symposion aktiv Romanheftautoren, Romanheft-Kenner wie auch Kulturwissenschaftler teilnahmen. ${ }^{47}$

Insgesamt fällt auf, dass die Forschung versucht, Figuren, Figurenkonstellationen und Handlungsstränge der Hefte hauptsächlich in einen Wertzusammenhang zu bringen: Einige Forschungsarbeiten kritisieren eine subversive, ideologische Beeinflussung der Leser. In diesem Zuge fallen häufig die Begriffe „Schemaliteratur“, „Klischees“ oder „Stereotypen“ abwertend eingesetzt. Hierbei wird jedoch außer Acht gelassen, welchen erzählökonomischen Nutzen Schemata oder Stereotype für eine

und Roman Sander als Herausgeber: Dragons Welt. Hintergründe. Inhalte. Lexikon. Augsburg 1990.

42 Eckhard Schwettmann: Allmächtiger! Faszination Perry Rhodan. Höfen 2006.

43 Compart, Martin: G-man Jerry Cotton. Köln 2010. Das Phänomen um die Verfilmung der Cotton-Romanhefte in den 1960ern beleuchten Kramp und Naumann in: Die Jerry-CottonFilme. Als Jerry Cotton nach Deutschland kam. Stuttgart 2011. Äquivalent dazu widmet sich Josef Hilger in „Raumpatrouille. Die phantastischen Abenteuer des Raumschiffes ORION“ einer TV-Serie, die später als Romanheftserie fortgeführt wurde. Erw. Neuauflage Berlin 2005.

$44 \quad$ Friedrich Jakuba: G-man Jerry Cotton. Nichts als Wahrheit und Legenden. Köln 2003.

45 Rainer Delfs und Michael Mette: John Sinclair-Lexikon. Bergisch Gladbach 1997.

46 Vgl. Franz-Heinrich Hackel: Die schwere Kunst der leichten Unterhaltung. Köln 2004.

47 Vgl. ebd. u.a. Kaspar Maase. 
Narration haben können.

\subsubsection{Romanhefte als Trivialliteratur}

Wie eingangs bereits erwähnt entstand in den 1970er und 1980er Jahren die meiste Forschungsliteratur zum Romanheft, wobei die Forschung daraus Erkenntnisse zur sogenannten „Trivialliteratur“ im Allgemeinen zu gewinnen hoffte. Damit bezeichnete die einschlägige Forschung in jenem Zeitraum Werke, die von der „Hochliteratur“ abgegrenzt und häufig auch abgewertet werden sollten. ${ }^{48}$ Unter den Begriff „Trivialliteratur" fallen zudem verschiedene Publikationsformen wie Leihbücher, Romanhefte oder Taschenbücher. ${ }^{49}$ Aber auch zahlreiche unterschiedliche Bezeichnungen wie Schema- oder Schundliteratur kursieren in der Forschung, die unter anderem 1975 Wolfgang Schemme auflistete und kommentierte. ${ }^{50}$

Was das 'Triviale' ist, bleibt bei diversen Untersuchungen unausgesprochen. Der Sammelband „Trivialliteratur" von Gerhard Schmidt-Henkel, Horst Enders, Friedrich Knilli und Wolfgang Maier beispielsweise enthält zwar diverse Artikel, die sich mit einem Aspekt der sogenannten 'Trivialliteratur' beschäftigen, doch wird in ihnen nicht eindeutig geklärt, was für die Autoren das 'Triviale' ausmacht. ${ }^{51}$ Walter Nutz hatte dies bereits 1962 als eine „Desorientierung“ bezeichnet, wenn „Kitsch, Schund, Schmutz, Seichtheit und Triviales in einen Topf geworfen“ wird. ${ }^{52}$ Im Zuge dieser Kritik schlägt er eine Definition vor:

„Wir wollen unter dem Begriff Trivialroman eine ganz festumrissene Art von Druckerzeugnissen begreifen, nämlich nur jene Romane in Buchform, die von vertraglich bestallten Autoren geschrieben, von bestimmten Herausgebern gedruckt und verlegt und nur in Leihbüchereien gegen eine gewisse Gebühr

48 Gerhard Teuscher: Perry Rhodan, Jerry Cotton und Johannes Mario Simmel. Stuttgart 1999. S. 9ff.

49 Die verschiedenen Publikationsformen im Bereich der Trivialliteratur stellt Peter Domagalski u.a. in „Trivialliteratur. Geschichte. Produktion. Rezeption.“ (Freiburg 1981) kompakt vor. Auf verschiedene Publikationsformen bis hin ins 17. Jahrhundert geht Hainer Plaul in "Illustrierte Geschichte der Trivialliteratur" ein (Leipzig 1983).

50 Wolfgang Schemme: Trivialliteratur und literarische Wertung. Stuttgart 1975. S. $138 \mathrm{ff}$.

51 Gerhard Schmidt-Henkel, Horst Enders, Friedrich Knilli und Wolfgang Maier (Hg.): Trivialliteratur. Berlin 1964. Gemäß dieser Praxis empfehlen Annamaria Rucktäschel und Hans Dieter Zimmermann auch, dass man „von den allgemeinen Klassifikationsuntersuchungen zu Einzeluntersuchungen [übergehen] sollte. Vgl. Annamaria Rucktäschel und Hans Dieter Zimmermann (Hg.): Trivialliteratur. München 1976. S. 9.

52 Walter Nutz: Der Trivialroman seine Formen und seine Hersteller. Köln 1962. (Kunst und Kommunikation 4). S. 9. 
für eine befristete Zeit entliehen werden." 53

Jedoch räumte Nutz ein, dass die so definierten Trivialromane die "gleichen Romanarten [...] [sind], die auch in Zeitschriften, in Illustrierten und im Sortimenthandel zu finden sind“, ${ }^{54}$ womit die Definition wiederum an Eindeutigkeit verliert.

Günter Waldmann stellte 1977 heraus: „Trivialliteratur ist keine Literatur oder Textsorte, sondern ein wertungsästhetisches Phänomen“, ${ }^{55}$ das, wenn es literaturwissenschaftlich untersucht werden soll, in Hinblick auf seine "gesellschaftlichen Bedingungen" untersucht werden muss. ${ }^{56}$ Demgemäß forderte Waldmann, die Trivialliteratur hinsichtlich ihrer Rezeptions- und Verbreitungsweise als „Massenliteratur“ anzusehen. ${ }^{57}$

1991 empfahl Peter Nusser, beim Begriff „Trivialliteratur“ zu bleiben, da er die ästhetischen und gesellschaftlichen Aspekte angemessen impliziere. ${ }^{58}$ Hierbei sah er den ästhetischen als den Aspekt des leicht Eingängigen und den gesellschaftlichen als den des weit Verbreiteten an, ${ }^{59}$ womit er Waldmanns Forderung indirekt unterstützt. Das Problem an Nussers Festhalten an dem Begriff „Trivialliteratur“ ist, dass in ihm nach wie vor die Kritik des Minderwertigen mitschwingt. ${ }^{60}$ Diverse Autoren beschäftigten sich mit diesem „Wertungsproblem“61. Allerdings setzte sich keiner der anderen Ansätze endgültig durch. In der vorliegenden Arbeit liegt das Augenmerk hauptsächlich auf Forschungsarbeiten, die sich explizit zum Romanheft äußern. ${ }^{62}$ Aufgrund der großen Verbreitung in der Literaturwissenschaft soll im Folgenden der Begriff „Trivialliteratur“ wertungsfrei zum Einsatz kommen. Trivialliteratur ist nach Nusser „leichtverständliche, ein breites Publikum ansprechende Literatur“, die

53 Ebd. S. 13.

54 Ebd. S. 15.

55 Günther Waldmann: Theorie und Didaktik der Trivialliteratur. 2. erg. Aufl. München 1977. S. 7.

56 Ebd. S. 8.

57 Ebd.

58 Peter Nusser: Trivialliteratur. Stuttgart 1991. S. 3.

59 Ebd.

60 Vgl. hierzu u.a. Helmut Kreuzer: Trivialliteratur als Forschungsproblem. In: Texte zur Trivialliteratur. Über Wert und Wirkung von Massenware. Hrsg. von Ekkehart Mittelberg, Klaus Peter und Dieter Seiffert. Stuttgart 1971. S. 142-154. S. 142.

61 Vgl. hierzu u.a. Günther Fetzer: Wertungsprobleme in der Trivialliteraturforschung. München 1980. Oder Hans-Dieter Zimmermann: Trivialliteratur? Schema-Literatur! 2. Aufl. Stuttgart 1982.

62 Einen ausführlichen Überblick zu den Forschungsarbeiten, die sich den Anfängen der Trivialliteratur widmen, finden sich bei Peter Nusser (Trivialliteratur. Stuttgart 1991) sowie bei Gerhard Teuscher. 
allerdings von einer sogenannten „Hochliteratur" abzugrenzen sei. ${ }^{63}$ Diesem Ansatz folgt vorliegende Arbeit insofern, dass unter Trivialliteratur Erzeugnisse fallen, die die Hersteller an ein breites Publikum richten und die sich nicht explizit an der Hochliteratur orientieren.

Den meisten Beiträgen aus der Zeit Schemmes Monographie ist gemein, dass sie einen „Wert“ der Trivialliteratur untersuchten. Doch im Schwerpunkt unterscheiden sie sich: In einigen steht der literarisch-ästhetische Wert und in anderen der ideologisch-didaktische im Fokus. So betonten beispielsweise Rucktäschel und Zimmermann 1976, dass die Trivialliteratur „Zu Recht“ kritisiert werden müsse, da sie „vielmehr für die Mehrheit produziert“ werde. ${ }^{64}$ Produktionsweisen, die auf eine große Menschenmenge abzielen, sind für sie demnach per se ein Abwertungskriterium. Ihr Sammelband beinhaltet eine nicht systematisierte, breite Palette an Artikeln, die sich narrativen Themenbereichen wie Kriminal- oder Abenteuergeschichten und Publikationsformen wie Romanheften oder Schlagertexten widmen, um dabei jeweils eine spezialisierte Kritik zu entfalten.

Wernsing und Wucherpfennig betrachteten 1976 das Wesen der Romanhefte in ihrem Produktionszusammenhang, ${ }^{65}$ ein Ansatz, der auch in der vorliegenden Arbeit teilweise verfolgt wird. Allerdings leiteten sie daraus einen alle Hefte betreffenden Schematismus ab, da diese „standardisierte Wirklichkeiten“ repetieren würden. ${ }^{66}$ Sie unterscheiden dabei keine verschiedenen Schemata für die unterschiedlichen Romanheftgenres. Zdenko Skreb und Uwe Baur widmeten hingegen einen ganzen Sammelband den „Erzählgattungen der Trivialliteratur“ ${ }^{67}$ Doch der vorherrschende Tenor in der damaligen Forschung ist eher eine gezielte Abwertung der Romanhefte, denen meist auch eine unbelegte Wirkungsmacht zugeschrieben wurde. In diesem Sinne schrieb Nusser 1976: „Die Heftromane locken den Leser mit den materiellen Erzeugnissen des Wohlstands, binden ihn [...] an die Ideologie der Warenwelt, suchen ihn zum ergebenen Konsumenten zu erziehen. “68

63 Vgl. Peter Nusser: Trivialliteratur. In: Reallexikon der deutschen Literaturwissenschaft. Bd. III PZ. Neubearb. Hrsg. von Jan-Dirk Müller. Berlin 2007, S. 691- 695. S. 691.

64 Annamaria Rucktäschel und Hans Dieter Zimmermann (Hg.): Trivialliteratur. München 1976. S. 7.

65 Armin Volkmar Wernsing und Wolf Wucherpfennig: Die Groschenhefte: Individualität als Ware. Wiesbaden 1976. S. 3f.

66 Ebd. S. 32f.

67 Skreb und Baur: Erzählgattungen der Trivialliteratur. Innsbruck 1984.

68 Peter Nusser: Massenpresse, Anzeigenwerbung, Heftromane. Stuttgart 1976. S. $26 \mathrm{f}$. 
Auf diese Weise setzte sich die Forschung bis zu den 1980ern mit den Inhalten jener Hefte und ihrer vermeintlichen Wirkung auf die damalige Leserschaft auseinander. Jedoch differenzieren die Arbeiten zu der Zeit nur selten, aus wem sich die sogenannte "Leserschaft" zusammensetzt. ${ }^{69}$ Beispielsweise schlagen Albert Klein und Heinz Hecker für die Untersuchung der Trivialliteratur eine unvoreingenommene Haltung vor, die der Literaturwissenschaftler dadurch einnehmen könne, wenn er die Blickrichtung des Lesers einnähme und die Texte ohne jegliche Kenntnis von Ästhetik rezipiere ${ }^{70}$ da sie „für das Leseverhalten der meisten Rezipienten von Trivialliteratur keine Rolle [spielt]."71 Hier wird, ohne dass sie auf eine empirische Erhebung verweisen, von einem konkreten Leser ausgegangen. Doch auch bei der Verwendung von Erhebungen wurde die Leserschaft der Trivialliteratur meist nur ungenau berücksichtigt: 1981 bezog sich Peter Domagalski auf Studien von 1971 und $1974 .{ }^{72}$ Ähnlich ging auch Kathrin Buck in ihrem Werk von 2011 vor und stützte sich auf Studien von 1986, 1991 sowie 1999. ${ }^{73}$ Sie legitimiert dies durch die unveränderte Entwicklung des Romanheft-Marktes seit den 1970ern. ${ }^{74}$ Wie die Absatzzahlen der Romanhefte Aufschluss über die Leserschaft geben sollen, klärt sie nicht auf. Dies zeigt, wie in der Trivialliteraturforschung veraltete Erkenntnisse über eine vermeintliche (empirische) Leserschaft tradiert werden. Aus diesem Grunde soll in der vorliegenden Arbeit hauptsächlich von einem 'Modell-Leser' die Rede sein, ${ }^{75}$ zumal auch nur eine literatursoziologische Studie wie die von Mirjam Nast adäquat einen Romanheftleser

69 Ohne empirische Grundlage schließt beispielsweise 1973 Peter Nusser aus seiner Textlektüre von Romanheften auf ihre Leserschaft. Vgl. Peter Nusser: Romane für die Unterschicht. Stuttgart 1973. Mirjam Nast verweist in diesem Zusammenhang auch auf eine Studie von Ellerbrock und Thieße. Vgl. Nast: Perry Rhodan lesen. S. $19 f$.

70 Albert Klein und Heinz Hecker: Trivialliteratur. Opladen 1977. (Grundstudium Literaturwissenschaft Hochschuldidaktische Arbeitsmaterialien Bd. 10). S. $10 f$.

71 Ebd. S. 10.

72 Vgl. Peter Domagalski: Trivialliteratur. Geschichte. Produktion. Rezeption. 1981 Freiburg. S. $111 \mathrm{ff}$.

73 Buck: Der Heftroman, S. 84f.

74 Ebd. S. 84.

75 Vgl. u.a. Umberto Eco: Über Spiegel und andere Phänomene. Übersetzt von Burkhart Kroeber. 3. Aufl. München 1993. S. 167f. Eco unterscheidet zwei Arten von Modell-Lesern: den unkritischen, oder auch naiven, und den kritischen Lesern. Die Problematik des Modell-Lesers kann man auch in folgendem Text Ecos nachlesen: Zwischen Autor und Text. In: Texte zur Theorie der Autorschaft. Übersetzt von Hans Günter Holl. Hrsg. von Fotis Jannidis, Gerhard Lauer, Matias Martinez und Simone Winko. Stuttgart 2012. S. 279-294. Die Herausgeber führen Ecos Position auf sein Kommunikationsmodell zurück, ,in dem der empirische Autor zwar der Urheber des Textes ist, der Text aber nach seiner Entstehung autonom ist [...]. Der Text zielt auf einen exemplarischen Leser." (vgl. ebd. S. 276). Der Sammelband bietet zudem weiterführende bibliographische Hinweise zu der Problematik von: Autor, Werk und Leser. 
darstellen kann. 1999 erstellte außerdem Walter Nutz eine umfassende Studie über Romanheftleser: „Trivialliteratur und Popularkultur. Vom Heftromanleser zum Fernsehzuschauer“" ${ }^{76}$ in der er die Ergebnisse vorurteilsfrei präsentiert. Dies mag selbstverständlich klingen, war es, laut Nutz, zuvor jedoch nicht, denn „frühere Untersuchungen gingen per se davon aus, daß die Trivialliteratur ausschließlich der Lektüre der Unterschicht zugeordnet werden muß". ${ }^{77}$

Nach Kaspar Maase wurde die sogenannte „Schund-Debatte“ dem Forschungsgegenstand 'Romanheft' nicht immer gerecht. ${ }^{78}$ Auch Reinhold Krämer prognostizierte 1990 für die Romanheftforschung:

„In der Folge erscheinen weitere Überblicksartikel oder Monographien, die den Heftroman mit einbeziehen, in denen sich insgesamt der Rückgriff auf ältere Literatur als Defizit bemerkbar macht." ${ }^{79}$

Demnach wurden und werden ältere Untersuchungsergebnisse tradiert und als aktuelle klassifiziert. Daher muss der Blick auf die bestehende Literatur zum Bereich 'Romanheft' stets kritisch bleiben. Kontrastierend hierzu bieten die Publikationen einiger Sammler einen wesentlich differenzierteren Blick auf populäre Lesestoffe, wie beispielsweise Heinz J. Galles dreibändiges Werk „Volksbücher und Heftromane“.

Neuere Forschungswerke widmen sich dem Romanheft und der Trivialliteratur nicht in Hinblick ihres didaktischen Werts, sondern vielmehr als Elemente einer Populärkultur: Eine von der Bildungselite bisher nicht anerkannte Kulturform, die sich, nach Maase, besonders in den 1950er Jahren emanzipierte. ${ }^{80}$ Hügel machte darauf aufmerksam, dass in der „angelsächsischen Forschung“ die Cultural Studies der Birmingham School bereits 1964 diese Forschungsrichtung forcierte. ${ }^{81}$

76 Walter Nutz: Trivialliteratur und Popularkultur. Vom Heftromanleser zum Fernsehzuschauer. Eine literatursoziologische Analyse unter Einschluß der Trivialliteratur der DDR. Wiesbaden 1999.

77 Ebd. S. 94. Außerdem, in der Studie „Lesen, Sehen, Hängenbleiben“ gehen Regina Bendix, Christine Hämmerling, Kaspar Maase und Mirjam Nast ebenfalls vom Rezipienten aus und untersuchen die Rezeptionsgewohnheiten von Tatort-Zuschauern und Perry Rhodan-Lesern hinsichtlich der periodischen Form des jeweiligen Rezeptionsgegenstandes. Damit bieten sie die aktuellste Untersuchung über Romanheftleser und nehmen die Rezipienten nicht als Konsumenten trivialer Narrationen war, sondern als 'Serienrezipienten'. Vgl. hierzu Bendix: Lesen, Sehen, Hängenbleiben.

78 Kaspar Maase: Was macht Populärkultur politisch? Wiesbaden 2010.

79 Krämer: Die gekaufte 'Zukunft'. S. 127.

80 Maase: Was macht Populärkultur politisch? S. $110 \mathrm{f}$.

81 Hans-Otto Hügel: Einleitung. In: Handbuch Populäre Kultur. Hrsg. von Hans-Otto Hügel. Stuttgart 2003, S. 1-22. S. 1. 
1999 beschrieb Nutz die „trivialen Stoffe [...] als Teil einer Popularkultur“82, womit er zwar keinen neuen Begriff formte, allerdings hervorhob, in welchem Zusammenhang die "trivialen Stoffe" betrachtet werden sollten. Demnach forderte er, dass die Forschung sie nicht ausschließlich in einem Wertungszusammenhang untersuche, also nicht als ein "Produkt mißlungener Kunst", ${ }^{83}$ sondern in ihrer tatsächlichen Funktion, denn: „[die] triviale Literatur gehört, wie die 'anerkannte' Literatur, zur deutschen Gesamtkultur. ${ }^{\text {"84 }}$

Gemäß einer wertfreien Ausrichtung betonte Teuscher 1999 in seiner vergleichenden Untersuchung der beiden Romanheftserien Perry Rhodan und Jerry Cotton: „Aber der Autor [Teuscher selbst; Anm. d. Autors] möchte die zu untersuchende Literatur erst einmal so hinnehmen, wie sie ist“ ${ }^{85} 2007$ empfahl Hügel zudem „auf Augenhöhe mit dem Leser" Romanhefte zu erforschen und kritisierte damit explizit die didaktisch sowie ideologiekritisch ausgerichtete Forschung der 1970er und 1980er, die „sich gegenüber den Rezipienten überlegen [fühlte].“86

Hügel attestierte außerdem, dass die ältere Romanheftforschung sich lediglich mit den Genres oder der Sparte auseinandersetzte ${ }^{87}$ und im Allgemeinen eine Ideologiekritik an den Romanheften ausübte. ${ }^{88}$ Daher widmet sich laut Hügel ein Großteil der bisherigen Romanheftforschung nicht differenziert dem Forschungsgegenstand. ${ }^{89}$ Die meisten Forscher sehen das in dem "Seriencharakter" der Romanhefte an sich legitimiert, so Hügel. Das bloße Vorhandensein des „Seriencharakters“ bot innen genügend Informationen, ohne den Gegenstand selbst hinreichend zu untersuchen. ${ }^{90}$ Doch gerade der "Seriencharakter" der Romanhefte bietet der Literaturwissenschaft diverse Anhaltspunkte für einen differenzierten Forschungsansatz. So weist beispielsweise Stockinger auf die „komplexen, intertextuell aufgeladenen Erzähl-

$82 \quad$ Nutz: Trivialliteratur und Popularkultur, S. 8 Vorwort.

83 Ebd. S. 64.

84 Ebd. S. 8.

85 Teuscher: Perry Rhodan, Jerry Cotton und Johannes Mario Simmel. S. 10.

86 Hans-Otto Hügel: Durchsichtigkeit des Populären. Welterfahrung und Kennerschaft im Romanheft. In: Lob des Mainstreams. Zu Begriff und Geschichte von Unterhaltung und Populärer Kultur. Hrsg. von Hans-Otto Hügel. Köln 2007, S. 246-271. S. 251 f.

87 Hügel: Lob des Mainstreams. S. 248.

88 Ebd. S. 249.

89 Vgl. ebd. S. 248.

90 Vgl. ebd. 
welten“ der Romanhefte hin. ${ }^{91}$ In einem weiteren Artikel bietet Stockinger erste Ansätze, wie serielle Erzählstrategien der Romanhefte aufgearbeitet werden können und verweist dabei auf bereits etablierte Narrationsweisen des Feuilletonromans:

„Es gehört zu den frühen Leserbindungsstrategien seriellen Erzählens, soziale Distinktionen auszustellen, die den Leser / die Leserin immer wieder auch auf durchaus wohltuende Distanz zu weniger privilegierten Schichten der Gesellschaft halten - eine Form der Solidarisierung, die bereits zum Programm eines der ersten und zugleich erfolgreichsten Feuilletonromane des 19. Jahrhunderts gehörte: zu Eugène Sues Les mystères de Paris $(1842 / 43) . "{ }^{\prime 92}$

Stockinger und Hügel verlagern die Sichtweise auf den seriellen Aspekt, dem sich 2010-2016 eine komplette Forschungsgruppe widmete: die DFG-Forschergruppe 1091 „Ästhetik und Praxis Populärer Serialität“. Dementsprechend sollen die Romanhefte in der vorliegenden Arbeit gemäß ihrer Funktionalität als Serien und in ihrer Werkästhetik als Massenerzeugnis untersucht werden, um sich auf diese Weise dem seriellen Aspekt der Hefte zu nähern.

\subsection{Das Serielle in der Forschung}

Wenn in vorliegender Arbeit von 'Serie' die Rede ist, so folgt dieser Begriff einer Definition der DFG-Forschergruppe 1091. Frank Kelleter umreißt dies wie folgt:

„Unter dem Titel 'Populäre Serialität' geht es um einen Erzähltypus, [...] der aber erst seit dem ersten Drittel des 19. Jahrhunderts zu einem auffälligen, in bestimmten Zusammenhängen sogar vorherrschenden Merkmal kultureller Praxis wird. Es geht um Fortsetzungsgeschichten mit Figurenkonstanz, die produktionsökonomische standardisiert, d.h. in der Regel arbeitsteilig und mit industriellen Mitteln, sowie narrativ hochgradig schematisiert für ein Massenpublikum hergestellt werden." ${ }^{\text {"3 }}$

Allerdings räumt Kelleter ein, dass eine Abweichung jederzeit möglich und die Funktion jener „Serienerzählungen“ immer kommerzieller Natur sei, da „die Möglich-

91 Claudia Stockinger: Das All dort draußen zeigt uns, wer wir sind. Die Leseuniversen der Groschenhefte. In: Gelesene Literatur: Populäre Lektüre im Zeichen des Medienwandels. Hrsg. von Steffen Martus und Carlos Spoerhase. München 2018. (Text+Kritik. Zeitschrift für Literatur. Sonderband XII/18). S. 83-95. S. 84.

92 Claudia Stockinger: Die Logik seriellen Erzählens. Der Groschenroman. In: Logik der Prosa. Hrsg. von Astrid Arndt, Christoph Deupmann und Lars Korten. Göttingen 2012, S. 91-108. S. 96.

93 Frank Kelleter: Populäre Serialität. Eine Einführung. In: Populäre Serialität. Narration Evolution - Distinktion. Zum seriellen Erzählen seit dem 19. Jahrhundert. Hrsg. von Frank Kelleter. Bielefeld 2012, S. 11-46. S. $18 f$. 
keit fortgesetzten Erzählens [...] entscheidend vom Markt- oder Publikumserfolg“ abhänge. ${ }^{94}$ Kurzum: 'Serie' meint hier mehrteilige Narrationen, die mit kommerziellen Absichten für ein großes Publikum produziert wurden. Diese spezielle (Serien-)Erzählform wurde hauptsächlich von Medienwissenschaftlern im Bereich Fernsehserien untersucht, ${ }^{95}$ obschon sich dieser Ansatz auf Romanhefte leicht übertragen lässt.

Umberto Eco hat bereits 1984 in seinem Artikel „Die Innovation im Seriellen“96 einen Ansatz geliefert, der offen genug ist, um narrative Serialität rudimentär zu typologisieren. Er unterteilt in „Reprise“, „Kopie“, „Serie“ und „Saga“, die sich auf alle Medienformen anwenden lassen, beziehungsweise bezieht sich Eco auf Beispiele aus verschiedenen Bereichen wie Literatur, Kino oder Comic. Ecos Typologie ist einer der ersten und wenigen Ansätze, serielle Erzählformen in einer Systematik zu erfassen, die auch Werke aus der Literatur einbeziehen. Er konzentriert sich hauptsächlich auf inhaltliche wiederkehrende Elemente und bezieht nur am Rande die Produktionsumstände mit ein. Sein Serien-Begriff entspricht aber grob dem von Kelleter umrissenen: Eine für die Unterhaltung konzipierte mehrteilige Narration mit einem konstanten Figurenrepertoire. ${ }^{97}$

Hans Krah bietet in seinem Artikel „Erzählen in Folge“ einen Systematisierungsansatz für narrative Fortsetzungszusammenhänge, der diverse serielle Narrationsformen erfassen soll. ${ }^{98}$ Sein Modell zielt hauptsächlich auf die Differenzierung von audiovisuellen seriellen Narrationsformen ab, wobei er anmerkt, dass sein Modell „auch auf andere Medien zu übertragen sein [dürfte]. " ${ }^{99}$ Allerdings ist sein Ansatz, dessen Nutzbarkeit er mit wenigen Beispielen illustriert, rein theoretischer Natur. ${ }^{100}$ Zudem schlägt er Begrifflichkeiten für serielle Formen vor, die sich eher für den Film-

94 Ebd. S. $18 f$.

95 Ebd. S. 19. Lediglich die literaturwissenschaftliche Monographie Christine Mielkes von 2006 widmet sich dem Phänomen der zyklisch seriellen Narration an sich, wobei sie ihren Schwerpunkt mehr auf eine Todesmotivik legt, als auf eine Systematik der seriellen Narration (vgl. Christine Mielke: Zyklisch - serielle Narration. Erzähltes Erzählen von 1001 Nacht bis zur TV-Serie. Berlin 2006).

96 Vgl. Eco: Spiegel und andere Phänomene, S. $155 \mathrm{ff}$.

97 Vgl. ebd. S. 159f.

98 Hans Krah: Erzählen in Folge. Eine Systematisierung narrativer Fortsetzungszusammenhänge. In: Strategien der Filmanalyse - reloaded. Hrsg. von Michael Schaudig. München 2010, S. 85114.

99 Ebd. S. 85.

100 Krah nennt bspw. die „Null-Narration“ als grundlegende Struktur für die Endlosserie, ohne jedoch auszuführen, wie eine Narration keine Narration aufweisen kann (vgl. ebd. S. 98f.). 
und Fernsehbereich eignen, wobei das Medium in der Systematisierung nicht explizit berücksichtigt wird. ${ }^{101}$ Krahs Systematisierung erfasst zwar Serienmischformen als „Interdependenzen“, jedoch bleibt hierbei unklar, wie sie sich in das Systematisierungsraster einbetten. ${ }^{102}$ So erweisen sich Ecos Begrifflichkeiten in ihrer Verwendung bezüglich des Mediums der Narration (Print, TV etc.) offener. ${ }^{103}$

Die Wechselwirkung zwischen Medium und Serie hat Knut Hickethier 1991 in seiner viel beachteten Monographie "Die Fernsehserie und das Serielle des Fernsehens"104 anhand von TV-Serien in Bezug zu ihrer Erscheinungsumgebung (dem Programm des Senders) untersucht. ${ }^{105}$ Laut Hickethier beziehen sich die einzelnen Folgen auf einen Gesamtzusammenhang, der nicht immer ein inhaltlicher sein muss: ${ }^{106}$ Er nennt es "doppelte Formstruktur" der Serien, ${ }^{107}$ da Inhalt und Form in der Serie einander beeinflussen. Daran anknüpfend spricht Werner Faulstich von „Serie als Formprinzip des Erzählens (vom Produkt zur medienübergreifenden Erzähltradition)“108 und bezieht sich dabei auf die Auswirkungen der seriellen Erscheinungsform auf die Narration.

Hickethiers Konzept vom Seriellen des Programms verdeutlicht, dass auf die Narration massenhaft verbreiteter Erzählungen die Produktionsbedingungen und Erscheinungsumgebung - der Distributionsort - maßgeblichen Einfluss haben. Dass dies nicht nur für den TV-Bereich anwendbar ist, offenbart Claudia Stockingers Monographie zur Serialität des Familienblatts „Gartenlaube“:

„Vielmehr findet Serialität auf allen Ebenen des Familienblatts statt: auf der

101 Bspw. spricht Krah von "traditioneller Serie“, wobei er sich auf traditionelle Fernsehserien bezieht (vgl. ebd. S. 97f.) und schreibt zudem, dass die „Endlosserien“ keine lange Tradition haben (vgl. ebd. S. 98ff.). Bezogen auf ein anderes Medium, wie bspw. die Zeitung und ihren Feuilletonroman, wäre diese Typisierung nicht nutzbar (vgl. u.a. hierzu Jörg Türschmann: Aspekte einer Typologie von Fernsehserien. In: medien - zeit - zeichen. Hrsg. von Chr. Hißnauer und A. Jahn-Sudmann. Marburg 2007, S. 100-108.).

102 Vgl. Krah: Erzählen in Folge, S.103f. In diesem Zusammenhang fällt auf, dass er auf keine aktuellen TV-Serien eingeht oder am Rande verweist. Zudem verweist er auf keine der anderen Typologien wie die Ecos, Türschmanns oder Weber und Junklewitz' (die noch im Folgenden erwähnt werden).

103 Krah spricht bspw. von „traditioneller Serie“ (vgl. Krah: Erzählen in Folge, S. 97), womit er jedoch traditionelle Fernsehserien meint. Eco würde hier hingegen lediglich von "Serie" sprechen (vgl. Eco: Spiegel und andere Phänomene, S. 159f.).

104 Knut Hickethier: Die Fernsehserie und das Serielle des Fernsehens. Lüneburg 1991.

105 Ebd. S. 10. Hickethier sieht die Serie als Teil des Programms, allerdings ist das Programm auch durch eine eigene Serialität strukturiert (vgl. ebd. S. 11ff.).

106 Ebd.

107 Ebd. S. 8ff.

108 Werner Faulstich: Serialität aus kulturwissenschaftlicher Sicht. In: Endlose Geschichten. Hrsg. von Günter Giesenfeld. Hildesheim 1994, S. 46-71. S. 50. 
Mikroebene der einzelnen Hefte, der Mesoebene des Heftverbunds im Jahresverlauf und der Makroebene jahrgangsübergreifender Vernetzung.“"109

Stockinger geht davon aus, dass "die Serie“ an sich keine Erscheinungsform der Massenmedien sei, sondern, dass die Massenmedien lediglich „spezielle Formen und Verfahren des Seriellen ausprägten“. ${ }^{110}$

Günter Giesenfeld vertieft Hickethiers Aspekt der „Serialität des Programms“111 mit seiner These der "dauerhaften Parallelisierung von Alltag und fiktiven Erlebnisräumen“" ${ }^{112}$ da der Konsument seinen Alltag an die Erfüllung seines Serienkonsums anpasst. ${ }^{113}$ Mittels der Parallelisierung erklärt Giesenfeld inwiefern der Konsument sich an eine Serie bindet. Ausgehend von diesem Aspekt wird Bezug auf die SerienProduzenten und wie diese gemäß dem Konsumenten ihr Produkt 'Serie' konzeptionieren genommen. Allerdings verliert dieser Ansatz mit zunehmenden Video-ondemand-Angeboten wie Netflix und Amazons Prime-Video an Relevanz, da die Nutzer nun eine vollständige Serie zu beliebiger Zeit abrufen können. ${ }^{114}$

Auf Hickethiers Ansatz aufbauend formen Weber und Junklewitz eine rudimentäre Serien-Definition, in der die medialen Spezifikationen berücksichtigt werden sollen. ${ }^{115}$ Sie plädieren daher für folgende offene, minimale Definition:

„Eine Serie besteht aus zwei oder mehr Teilen, die durch eine gemeinsame Idee, ein Thema oder ein Konzept zusammengehalten werden und in allen Medien vorkommen können.“116

Tanja Weber und Christian Junklewitz formen zwar am konkreten Beispiel der TVSerien eine Definition von Serie aus, doch ist ihr Ansatz variabler nutzbar als der von

109 Claudia Stockinger: An den Ursprüngen populärer Serialität. Das Familienblatt Die Gartenlaube. Göttingen 2018. S. 13. Auf das Werk kann im Weiteren nicht systematisch eingegangen werden, denn der Entstehungszeitraum vorliegender Arbeit (2008 bis 2014) erlaubt keine umfassende nachträgliche Aktualisierung.

110 Ebd. S. 12.

111 Hickethier: Die Fernsehserie und das Serielle des Fernsehens, S. 11ff.

112 Günter Giesenfeld: Serialität als Erzählstrategie in der Literatur. In: Endlose Geschichten. Hrsg. von Günter Giesenfeld. Hildesheim 1994, S. 1-11.

113 Ebd. S. 5.

114 In diesem Zusammenhang hat sich der Begriff „Binge-Watching“ etabliert: Das komplette Durchschauen einer Serie oder zumindest viele Folgen am Stück. Dadurch, dass auch viele Fernsehsender ihre Sendungen in Online-Mediatheken zur Verfügung stellen, unterstützen sie den Trend zum zeitlich unabhängigen, selbstbestimmten TV-Programm.

115 Christian Junklewitz und Tanja Weber: Das Gesetz der Serie - Ansätze zur Definition Analyse. In: MEDIENwissenschaft 25.1. (2008), S. 13-31. S. 26.

116 Ebd. S. 18. 
Krah, da historische, kulturelle und mediale Besonderheiten in der offenen Definition Raum finden. ${ }^{117}$

Als eine der wenigen Literaturwissenschaftler widmete Christine Mielke schon im Jahr 2006 eine Forschungsarbeit dem Phänomen der zyklisch seriellen Narration, wobei sie ihren Schwerpunkt auf eine Todesmotivik legt, und nicht auf eine Systematik der seriellen Narration. ${ }^{118}$ Einen pragmatischen Ansatz liefert Jörg Türschmann wenn er Hickethiers „doppelte Formstruktur“ auf Spannungsbögen von Feuilletonromanen anwendet (dies wird in Kapitel 7.1 „Typologien“ vertieft). ${ }^{119}$ Auf den Abbruch beziehungsweise die gezielten Unterbrechung von Spannungsbögen, den sogenannten Cliffhangern, konzentriert sich unter anderem Vincent Fröhlich in seiner Monographie „Der Cliffhanger und die serielle Narration: Analyse einer transmedialen Erzähltechnik“. ${ }^{120}$ Fröhlich bietet einen umfassenden Überblick über verschiedene Cliffhanger aus unterschiedlichen Jahrhunderten.

Die Handhabung von Spannungsbögen und Erzählsträngen ist ein essentieller Aspekt in der Auseinandersetzung serieller Narration. Daher hat sich Jason Mittell der sogenannten narrativen Komplexität gewidmet (narrative complexity), die in den 1990er Jahren im amerikanischen Fernsehen entstanden sein soll. ${ }^{121}$ Narrative Komplexität ist für Mittell nicht einfach eine mit vielen Ereignissen angereicherte Erzählung, sondern „narrativ komplexe Sendungen stellen Handlungsentwicklungen

117 Vgl. Junklewitz und Weber: Gesetz der Serie, S. 26. Die meisten Aspekte des Ansatzes lassen sich bereits der Typologie Ecos entnehmen (vgl. Eco: Spiegel und andere Phänomene, S. 155ff.).

118 Christine Mielke: Zyklisch - serielle Narration. Erzähltes Erzählen von 1001 Nacht bis zur TVSerie. Berlin 2006.

119 Jörg Türschmann: Spannung und serielles Erzählen. Vom Feuilletonroman zur Fernsehserie. In: Gespannte Erwartungen. Hrsg. von Kathrin Ackermann und Judith Moser-Kroiss. Berlin 2007, S. 201-219. Sowie: Jörg Türschmann: Spannung in Zeitungsliteratur. Romananfang und serielles Erzählen am Beispiel des frühen französischen Feuilletonromans. In: Zwischen Text und Leser. Hrsg. Von Ingo Irsigler, Christoph Jürgensen und Daniela Langer. München 2008, S. 225-246.

120 Vincent Fröhlich: Der Cliffhanger und die serielle Narration: Analyse einer transmedialen Erzähltechnik. Bielefeld 2015. Wie oben bereits erwähnt, kann auch auf dieses Werk hier nicht systematisch eingegangen werden. In Hinblick auf Cliffhanger sind hier aber auch Christian Junklewitz und Tanja Weber zu erwähnen: To be continued ... Funktion und Gestaltungsmittel des Cliffhangers in aktuellen Fernsehserien. In: 'Previously on ...' Zur Ästhetik der Zeitlichkeit neuerer TV-Serien. Hrsg. von Arno Meteling, Isabell Otto und Gabriele Schabacher. München 2010, S. 111-132.

121 Vgl. hierzu u.a. Jason Mittell: Narrative Complexity in Contemporary American Television. In: The Velvet Light Trap, no. 58, Fall 2006, S. 29-40. Oder: Jason Mittell: Narrative Komplexität im amerikanischen Gegenwartsfernsehen. In: Populäre Serialität. Hrsg. von Frank Kelleter. Übersetzt von Frank Kelleter, Christiane Focking und Annika Lamer. Englisches Original: Narrative Complexity in Contemporary American Television. In: the Velvet light trap, no. $\quad 58$, Fall 2006. S. 29-40. Bielefeld 2012, S. 97-122. 
deutlicher in den Vordergrund als Seifenopern; Beziehungs- und Figurendram[en] entwickeln sich aus dem Plot heraus, nicht umgekehrt, wie bei Soaps." ${ }^{122}$ Mittell schlussfolgert aus dem Erfolg mehrerer Serien, die nach seiner Auffassung der „komplexen Narration“ entsprechen, „dass anspruchsvolles Erzählen zunehmend massenkompatibel ist". ${ }^{123}$

Inwieweit Kunstwerke massenkompatibel sein können untersucht Noël Carroll in seinem philosophischen Werk zum Massenkunstwerk: „A Philosophy of Mass Art“. ${ }^{24}$ Sein Konzept soll in vorliegender Arbeit dabei behilflich sein, zu ermitteln, durch welche Beschaffenheit sich ein solches Kunstwerk auszeichnen muss und nach welchem Reglement es hergestellt wird. ${ }^{125}$ Des Weiteren soll der Frage nachgegangen werden, inwieweit Serien diesem Konzept entsprechen und ob eine Serie sich demnach mehr einem Massenprodukt oder mehr einem Massenkunstwerk annähert (vgl. Kapitel 9. „Das serielle Produkt als Massenkunstwerk“). ${ }^{126}$

\subsection{Forschungskorpus und Vorgehen}

Im Fokus dieser Arbeit liegen hauptsächlich Romanheftserien und -reihen, die im Zeitraum von 2008 bis 2014 im öffentlichen Handel erschienen. Ergänzend werden Erzeugnisse herangezogen, die diesen Heften vorangingen, da sich in ihnen Aufschlüsse über Trends im Romanheftsektor finden lassen. Hierbei kommt der Perry Rhodan-Serie ein besonderer Stellenwert zu, da sie von allen Romanheftserien die am längsten bestehende Fortsetzungsserie ist, die konsequent einen fortlaufenden Handlungsstrang verfolgt und demnach viele charakteristische Merkmale der seriellen Narration aufweist. Entsprechend häufig war die Perry Rhodan-Serie auch Forschungsgegenstand und bietet daher die einzigartige Möglichkeit, die umfassen-

122 Mittell: Narrative Komplexität im amerikanischen Gegenwartsfernsehen. S. 105

123 Ebd. S. 119.

124 Noël Carroll: A Philosophy of Mass Art. Oxford 1998.

125 Zur Beschaffenheit des massenmedialen Kunstwerks vgl. ebd. S. 184ff.

126 In diesem Zusammenhang geht es nicht um die Frage, inwieweit eine Serie 'Werkcharakter' wie ein Kunstwerk annimmt, sondern in erster Linie um die Bedingungen, die ein massenmediales Produkt/Werk mit sich bringt. Die Untersuchung zur TV-Reihe Tatort „Föderalismus in Serie“ legt beispielsweise in Bezug auf den Tatort nahe, dass mit einem polarisierenden „entweder serienästhetischen oder werkästhetischen Beschreibungsmodell“ der Komplexität dieser spezifischen Serienstruktur nicht beizukommen sei (vgl. Hißnauer, Scherer, Stockinger: Föderalismus in Serie. Die Einheit der ARD-Reihe Tatort im historischen Verlauf. Paderborn 2014. S. 200f.). Vgl. hierzu auch Hißnauer, Scherer, Stockinger (Hg.): Zwischen Serie und Werk. Fernseh- und Gesellschaftsgeschichte im „Tatort“. Bielefeld 2014. 
den Handlungsstränge und den nahezu unüberschaubaren Fundus an Figuren angemessen zu erfassen. Hierbei haben die zahlreichen Begleitbände und sonstigen Sonderbände, welche die wichtigsten Fakten der Serie dokumentieren, nicht unwesentlichen Anteil. Da die Perry Rhodan-Serie seit ihrem Beginn den Romanheftmarkt dominierte, sind in diesen dokumentarischen Bänden auch etliche Hinweise zu zeitgenössischen Romanheftserien enthalten. Weswegen eine Auseinandersetzung mit der Perry Rhodan-Serie immer auch eine Auseinandersetzung mit ihrer ursprünglichen Gattung ist: dem 'Romanheft'.

Gemäß des oben genannten Verständnisses der DFG-Forschungsgruppe 1091 von 'Serie' wird das Romanheft hier als ein Erzeugnis der Populärkultur angesehen. Wenn im Folgenden von populärer 'Serie' gesprochen wird, ist hier also generell eine Erzählung gemeint, die in Teilen, einem großen Publikum zugänglich, herausgegeben wird. Diese Teile können sowohl in sich abgeschlossen (episodal) als auch offen (fortsetzend) sein. Da dies nicht immer eindeutig zu bestimmen ist, werden die Serien gemäß ihrer Tendenzen charakterisiert: Es gibt beispielsweise rein episodale Serien oder tendenziell episodale Serien sowie reine Fortsetzungsserien oder tendenzielle Fortsetzungsserien. Des Weiteren soll der Begriff 'Serie' hauptsächlich in einem engeren Sinne Verwendung finden und sich vom Begriff 'Reihe' unterscheiden. Eine 'Reihe' ist hier als eine 'Serie im weitesten Sinne' zu verstehen, deren Teile nur lose miteinander verknüpft sind und in der Regel nur thematische Bezüge zu einander beinhalten. Dies ist gemäß einem Ansatz, dem Hißnauer und Klein in „Klassiker der Fernsehserie“ folgen: „Deshalb soll hier der Vorschlag gemacht werden, den Terminus 'Reihe' lediglich für die anthologische serielle Form zu verwenden“. ${ }^{127}$ Damit beziehen sie sich auf Produktionen, „die lediglich durch ein Sujet und ein gemeinsames Titelsignet verbunden sind“. ${ }^{28}$

Vorliegende Arbeit hat den Anspruch herauszuarbeiten, was das Serielle im Bereich der Romanhefte ausmacht. Dabei sollen Theorien der Medienwissenschaft wie Hickethiers „doppelte Formstruktur" sowie Weber und Junklewitz' minimale SerienDefinition als „Werkzeuge“ der Serienforschung erprobt und angepasst werden.

Die Untersuchung erfolgt wertfrei und grenzt sich damit von einem Großteil der bis zu

127 Christian Hißnauer und Thomas Klein (Hg.): Klassiker der Fernsehserie. Stuttgart 2012. S. 12.

128 Ebd. S. 11. 
den 1980ern entstandenen Romanheft- und Trivialliteraturforschung $a b,{ }^{129}$ die hauptsächlich den moralischen und didaktischen Wert - also den ideologischen Kern - jener Werke zu ergründen suchte. Dabei stand meist auch der Leser in der Kritik, über den von der damaligen Forschung mit nur geringer Datenbasis ein Urteil gefällt wurde. ${ }^{130}$ Der Diskurs über Leser von Romanheften ist zu groß, um hier angemessen aufgenommen zu werden, weshalb in der vorliegenden Arbeit nur von einem ModellLeser ausgegangen und sich ausschließlich auf serielle Elemente konzentriert werden soll, die sich aus den Romanheften selbst erschließen lassen. ${ }^{131}$ Somit steht das Romanheft einerseits in seiner physischen Erscheinungsform im Fokus, andererseits aber auch die darin transportierte Narration.

Da wie bereits erwähnt nicht nur Inhalte die serielle Narration bestimmen, sondern auch ihre Erscheinungsform Einfluss besitzt, wird letztere zunächst eingehend aufbereitet (Kapitel 2. „Distribution und Erscheinungsbild“), wobei sich diese Form wiederum aus ihrer Produktionsweise erklärt (Kapitel 3. „Produktion“). Wernsing und Wucherpfennig haben in ähnlicher Betrachtung ihre Argumentation in „Die 'Groschenhefte' Individualität als Ware" strukturiert:

„Gegenüber unreflektiert moralisierenden Wertungen ist zu betonen, daß der literarische Text erst verstanden ist, wenn er erklärt ist. Zu erklären ist er aus seiner Entstehung, das heißt aus seinen Produktionsbedingungen." ${ }^{132}$

Nach der Sichtung formaler Bedingungen des 'Serien-Produkts' folgt eine vertiefende Untersuchung der Narration. Hierbei müssen die Genres der Romanhefte kurz beleuchtet und ihre Position zum in der Forschung diskutierten Genre neu bewertet werden, da wie bereits oben erwähnt in der Forschung einige Ungenauigkeiten tradiert werden. Dies ist für die Erschließung der seriellen Narration nicht unwichtig, da die korrekte Darstellung der Genres Aufschluss darüber gibt, welche Zielgruppe von einer Romanheftserie oder -reihe angestrebt wird (Kapitel 4. „Genres der Romanhefte und ihre Besonderheiten“). Dies ist bereits eine der Schnittstellen, an

129 Vgl. hierzu Kapitel 1.1 „Romanhefte in der Forschung“.

130 Vgl. ebd.

131 Nast verweist für die Erfassung einer konkreten Leserschaft auf die empirische Studie von Walter Nutz, dass Romanheftleser in allen „sozialen Schichten“ zu finden seien. Damit wäre die Leserschaft nicht auf ein bestimmtes „Klientel festgelegt“ (vgl. Nast: „Perry Rhodan“ lesen. S. 28f.).

132 Armin Volkmar Wernsing und Wolf Wucherpfennig: Die Groschenhefte: Individualität als Ware. Wiesbaden 1976. S. 3. 
denen die Wahl des Inhalts - und somit des Genres - auch die äußere Gestaltung der Hefte beeinflusst. Genres bringen diverse Konventionen mit sich, doch muss unterschieden werden, welche Phänomene den Genrekonventionen oder der Serienform geschuldet sind (Kapitel 5. „Erzählökonomie und Serieninsider“ sowie Kapitel 6. „Halbwertszeit von Serienfiguren“). Es wird sich zeigen, dass gewisse Romanheftgenres zu bestimmten Serienformen tendieren, weshalb es notwendig ist, diese Serienformen zu differenzieren (Kapitel 7. „Narrativer Rahmen der seriellen Narration“) und seriell narrative Elemente erzähltheoretisch zu erfassen (Kapitel 8. „Innere Verknüpfung. Oder: Die serielle Narration“).

Die Analyse ebenjener seriell narrativen Elemente fußt auf einem von Genette entwickelten ${ }^{133}$ und von Matias Martinez und Michael Scheffel ${ }^{134}$ popularisierten Modell, in dem zwischen dem „Wie“ und dem „Was“, also zwischen Form und Inhalt einer Erzählung, unterschieden wird („discours“ und „histoire“ bei Genette). Gemäß des Modells bieten die drei Aspekte „Stimme“, „Modus“ und „Zeit“ grundlegende Ansatzpunkte, eine Erzählung zu analysieren. In der vorliegenden Arbeit ist besonders die "Zeit“ relevant, da einige Romanhefte auf vorangegangene (Serien-)Ereignisse verweisen und so Redundanzen bilden. Oder um es nach Hans Krah zu formulieren: Es geht hierbei um die diegetische Chronologie zwischen den Folgen $^{135}$ (Kapitel 8.1 „Die drei Phasen - Einführung, Verlauf und Ende“ und 8.2 „Erste Bestimmung serieller Regelmäßigkeiten“). „Stimme“ und „Modus“ können bei den Romanheften hingegen von Autor zu Autor variieren. Zudem betont Genette, dass die „Erzählstimme“ nicht immer einem konkreten Erzähler zugeordnet ist ${ }^{136}$ und seine Präsenz davon abhängig, wie viel Anteil er an der Geschichte nimmt. ${ }^{137}$ Um die Variation und Konstanz der narrativen Motivik darzustellen, werden die Romanhefttexte gemäß dem Begriff der „Schemaliteratur“ auf die Erfüllung narrativer Grundmuster hin untersucht (Kapitel 8.2 „Erste Bestimmung serieller Regelmäßigkeiten“). ${ }^{138}$ Besonders das Verhältnis von Konstanz und Variation ist maßgebend für den

133 Vgl. Gérard Genette: Die Erzählung. 3. durchgesehene korrigierte Aufl. Übersetz. Andreas Knop. Überprüft und berichtigt von Isabel Kranz. Paderborn 2010.

134 Matias Martinez und Michael Scheffel: Einführung in die Erzähltheorie. 6. Aufl. München 2005.

135 Hans Krah: Serie. In: Reallexikon der deutschen Literaturwissenschaft. Bd. III P-Z. Hrsg. von Jan-Dirk Müller. Berlin 2003, S. 431-435.

136 Gérard Genette: Stimme. In: Moderne Erzähltheorie. Hrsg. von Karl Wagner. Wien 2002, S. 213-270.

137 Ebd. S. 258.

138 Martinez und Scheffel: Einführung in die Erzähltheorie. S. 136. 
Aspekt der „Zeit“, weil dieses Verhältnis regelt, in welcher Reihenfolge erzählt wird, wie lange die Erzählung andauert und wie häufig erzählt wird. Der Aspekt der „Zeit“ muss zudem eine ausführlichere Behandlung als die anderen Aspekte erfahren, da der realen Zeit, in welcher Leser einen Text konsumieren, eine „Pseudozeit“ gegenübersteht, ${ }^{139}$ die besonders in der seriellen Narrationsform Komplikationen erzeugt (Kapitel 8.4 „Redundanzen während der Rezeption“).

Nach Harald Weinrich ist die Lektüre eines Textes ein „linearer" Vorgang, bei dem auf Informationen verwiesen wird. ${ }^{140}$ Dies hat man sich wie eine Kette aus Verweisen auf Informationen vorzustellen. Jedoch liegt, wie Karlheinz Stierle dargestellt hat, narrativen Texten in der Regel eine achronische Struktur zugrunde. ${ }^{141}$ Somit verweisen diese „narrativen Ketten“ in der Zeit vor und zurück. Die Primärtexte der vorliegenden Arbeit (die Romanhefte) müssen demnach auf Rückblicke und Vorwegnahmen hin untersucht werden (Kapitel 8.5 „Wiederholung als Erinnerung“ und 8.6 „Die Vorankündigung“).

Durch die Problematik einer auf Konstanten angewiesenen Narrationsform, wie die der seriellen Narration, werden Variationen zu einem diffizilen Unterfangen für Romanheftautoren (Kapitel 8.7 „Die Variation und die Innovation“). Allerdings zeigt sich erst unter diesem Aspekt das Potenzial der Romanheftserien, die nur unter dem reinen Aspekt der „Schemaliteratur“ zu oberflächlich untersucht wären.

Gerade die Analyse des Zusammenspiels von Produkthaftem und kreativer Arbeit offenbart, was serielle Narration ausmacht (Kapitel 9. „Das serielle Produkt als Massenkunstwerk“). Aus der Analyse der seriellen Narration der Romanhefte lassen sich elementare Eigenschaften der seriellen Narration an sich aufdecken. Durch die Verknüpfung der gängigen Erkenntnisse über serielle Erzählungen liefert diese Arbeit einen Ansatz zu einer umfassenden Analyse von Romanheftserien. Sie arbeitet Grundelemente seriellen Erzählens im Bereich der Romanhefte heraus und stellt dar, wie die serielle Erzählung als massenmediales Produkt funktioniert. Auf diese Weise kann 'Serie' als eigenständiges Erzählkonzept beschrieben werden.

139 Paul Ricœur: Die Spiele der Zeit. In: Moderne Erzähltheorie. Hrsg. von Karl Wagner. Wien 2002, S. 363-388.

140 Harald Weinrich: Tempus. Besprochene und erzählte Welt. 6. Aufl. München 2001. S. 74f.

141 Karlheinz Stierle: Die Struktur narrativer Texte. In: Moderne Erzähltheorie. Hrsg. von Karl Wagner. Wien 2002, S. 293-322. 


\section{Distribution und Erscheinungsbild}

Die 'Groschenhefte', heute auch 'Romanhefte' genannt, sind Produkte, die über Presse-Grossisten vertrieben werden und daher in erster Linie den Gepflogenheiten der Presse-Branche unterliegen und nicht denen des Buchhandels. Dies bringt einige Besonderheiten mit sich, da auf dem 5. Artikel des Grundgesetzes (Pressefreiheit) ${ }^{142}$ aufbauende Gesetze den Vertrieb regulieren und somit auch die Romanhefte. ${ }^{143}$ Die Grossisten haben sich daher einige Regelungen auferlegt, um die Aspekte des 5. Artikels des Grundgesetzes zu gewährleisten. ${ }^{144}$ Daraus entsteht unter anderem eine „Preisbindung“, die gewährleistet, dass die Produkte „der Preisspekulation entzogen werden. “145 Für die Verlage bedeutet dies, dass sie den Preis der Romanhefte nicht beliebig setzen können und der finanzielle Rahmen von vornherein festgesetzt ist. Sie müssen innerhalb dieser Parameter kalkulieren.

Weitere Regelungen sind die "Gebiets- und Verwendungsbindung“, die sicherstellen, dass die Presseprodukte für Verbraucher zugänglich sind. ${ }^{146}$ Dies bedeutet für das Romanheft, dass es nur dort verkauft werden darf, wo Presseartikel vertrieben werden. Zwar lassen sich einige Romanhefte auch in Buchhandlungen finden, doch ist dies nur der Fall, wenn diese Buchhandlungen entsprechend Presseprodukte anbieten.

Alle (aktuellen) Romanhefte sind keine Einzelwerke, das heißt, sie erscheinen entweder innerhalb einer Serie oder einer Reihe. Das gilt auch für abgeschlossene Romane. ${ }^{147}$ Diese sind in der Regel einer Reihe zugeordnet, welche sich wiederum einem Romanheftgenre verschrieben hat. Somit sind alle Serien und Reihen auch im

142 Für die aktuellste Version des GG Art. 5 vgl.: http://www.gesetze-im-internet.de/gg/art_5.html (Zugriff: 17.08.2019).

143 Vgl. hierzu u.a. die offizielle Homepage des Bundesverband Deutscher Buch-, Zeitungs- und Zeitschriften-Grossisten e.V.: https://www.pressegrosso.de/branche/pressevertrieb.html (Zugriff: 17.08.2019). Die Grossisten sehen ihre „Gemeinsame Erklärung“ als die „Magna Charta für den Pressehandel" an (vgl. https://www.pressegrosso.de/branche/gemeinsame-erklaerung.html (Zugriff: 17.04.2014)) und regulieren darüber ihre Beziehungen mit den Verlagen.

$144 \mathrm{Vgl}$. auf https://www.pressegrosso.de/branche/pressevertrieb.html (Zugriff: 17.08.2019) im Detail.

145 Ebd.

146 Ebd.

147 Früher wurden zwar einzelne Geschichten einiger namhafter Autoren gedruckt, jedoch geschah auch dies innerhalb einer Reihe. So wurden beispielsweise "Der Leichenräuber" von R.L. Stevenson innerhalb der Blaulicht-Reihe als Bd. 36 gedruckt. 1. Aufl. Berlin 1963. Hier ist allerdings zu beachten, dass diese Reihe in der DDR erschien. Natürlich lassen sich weitere Beispiele auch für Westdeutschland aufführen, besonders im Bereich der Science Fiction. 
Abo zu beziehen, und die meisten mittlerweile auch als E-Books erhältlich. Vergriffene Hefte können nachbestellt werden, sogar von Reihen, die abgeschlossene Geschichten ohne reihenübergreifende Hauptfiguren haben (Abb. 9). Es wird extensiv mit einem Service geworben, dem Kunden weitere Hefte liefern zu können, denn das Abo sichert den Verlagen feste Absatzzahlen.

Die meisten Hefte erscheinen wöchentlich oder alle zwei Wochen. Ein längerer Turnus ist eher ungewöhnlich. Sie zeigen eine ähnliche kurzweilige Anbindung wie Zeitschriften und weniger - wie die sonst bekannteren narrativen Werke - als das Taschenbuch.

Von der Seite des potenziellen Konsumenten her betrachtet ist das Romanheft ein leicht erschwingliches Produkt - die Preise schwanken grob zwischen 1,50€ und $5,00 €$ - das zudem jederzeit leicht erhältlich ist: ${ }^{148}$ Sei es bei einem Kiosk, der auch am Wochenende geöffnet hat, auf Reisen im Bahnhof oder von Zuhause aus als Abo oder im Internet. Die Verlage achten stets auf eine wahrnehmbare Werbung des Services ihrer Distribution sowie auf die Bandbreite ihrer Produktpalette. Besonders die Perry Rhodan-Serie, die mit ihren Nebenprodukten breit aufgestellt ist, wirbt innerhalb eines Heftes vermehrt für diese.

Die Perry Rhodan-Serie birgt einige Ausnahmen in sich: In Deutschland erscheint sie wöchentlich ununterbrochen seit über 45 Jahren, wohingegen diverse andere Serien nach wenigen Bänden abgesetzt oder der Turnus verändert wurde. Neben den Heften bringt der Verlag ebenfalls Perry Rhodan-Taschenbücher und Taschenhefte heraus, die eine Ergänzung zu der Heftserie darstellen. Es sind Spin-offs, in denen meist Nebencharaktere aus der Hauptserie die Hauptrolle spielen. Beispielsweise bekam die Figur „Atlan“ eine eigene Serie, die genauso erfolgreich geworden ist wie die Perry Rhodan-Serie selbst. Sie trug den Namen des Helden Atlan und erschien ebenso im Heftformat, allerdings werden die Atlan-Geschichten nun in einer „Silberband“-Edition weiter vermarktet. Neben dieser Tochter-Serie erscheinen zirka vierteljährig die sogenannten „Silberbände“. ${ }^{149}$ Der Name rührt von ihrem silbernen Einband her. Diese Bücher fassen zwischen fünf bis zehn Perry Rhodan-Romanhefte

148 Die einzelnen Reihen haben allerdings gemäß des Zeitschriftenbereichs einen eigenen Festpreis.

149 Die Atlan-Bände gelten im Fachjargon der Perry Rhodan-Kenner allerdings nicht als DIE Silberbände, auch wenn sie nach dem gleichen Prinzip editiert werden und einen silbernen Einband haben. 
zusammen und ermöglichen Neueinsteigern einen rascheren Zugang zu der Serie. ${ }^{150}$ Auch in Serien anderer Genres gab es Versuche, im Taschenbuch-Sektor Fuß zu fassen, doch hat sich kaum einer dieser Versuche lange gehalten. ${ }^{151}$

In den Silberbänden wurde nur der Haupterzählstrang herausgearbeitet, zudem sollte „[d]er Sinngehalt der Originalromane und deren 'Atmosphäre'“152 erhalten bleiben. In der Tat kommt eine hohe Homogenität innerhalb der Silberbände zu Tage, die unter anderem nur aufgrund der strengen Vorgaben für die Autoren möglich ist hierzu im Folgenden Kapitel 3 „Produktion“ mehr. Des Weiteren gibt es diverse Sondereditionen, Minizyklen und Fanbücher, welche keine eigenen Haupthandlungsstränge entwickeln, sondern weiterhin die Hauptserie in den Vordergrund rücken und ergänzen. Die Nebenprodukte nehmen immer wieder Bezug auf ihre Ursprungsserie: Perry Rhodan. Da diese Produkte, wie zum Beispiel die Silberbände, auch in Buchhandlungen ausliegen dürfen, verweisen sie mit ihrem Serientitel explizit auf die gleichnamige Heftserie am Kiosk.

Die Perry Rhodan-Serie erscheint seit dem ersten Heft jeden Freitag im Zeitschriftenhandel und liegt in der Regel bei den Romanheften oder den Jugendzeitschriften aus. Aufgrund des anhaltenden Erfolges der ersten Auflage sind dort auch die Hefte der dritten und fünften Auflage zu finden. ${ }^{153}$ Die zweite und vierte Auflage wurden aus unbekannten Gründen eingestellt. Da der Verlag den erfolgreichen Verkauf seit der ersten Ausgabe von 1961 ausweiten wollte, versuchte man in anderen Ländern Fuß zu fassen. Abgesehen von einigen inoffiziellen Ausgaben von 1965 erschien 1966 die erste offizielle Perry Rhodan-Ausgabe außerhalb Deutschlands in Frankreich. Es folgten Holland, die USA, Japan, Brasilien, Tschechien und andere. Jedoch erscheint

150 In den Silberbänden werden eventuelle Wiederholungen oder Fehler in der Kontinuität korrigiert, welche innerhalb der Hefte gefunden wurden. Da es für einen neuen Leser möglich sein soll bei jeder beliebigen Heftnummer einzusteigen, sind Wiederholungen der Basisfakten in jedem Heft unvermeidbar. Die Fehler sind Produkte des Zeitdrucks, unter dem die Romanheft-Autoren stehen. Die Autoren der Silberbände hingegen übernehmen den Text der Romanhefte zum Teil Wort für Wort und streichen lediglich längere Textpassagen heraus, die nur für unbedeutende Nebenerzählungen wichtig waren. Als Ersatz für diese gestrichenen Stellen und die Lücken zwischen den einzelnen Romanheften werden Übergänge geschaffen, so dass die zusammengesetzten Teile wie ein homogener Text erscheinen und nicht wie eine Textcollage.

151 Vgl. hierzu beispw. die Horror-Serien Torn oder John Sinclair in: Joachim Knüppel, Werner Knüppel und Helmut Rhode: Allgemeiner Roman-Preiskatalog. 10. erw. Aufl. Hamburg 2011.

152 William Voltz (Hg.): Perry Rhodan - Der Robotregent. Rastatt 1980. S. 6; Die Silberbände wurden vom Bertelsmann Verlag nochmals in einem blauen Einband herausgebracht, sie entsprechen jedoch eins zu eins den Silberbänden vom Pabel-Moewig Verlag.

153 Übersicht der Auflagen in: Eckhard Schwettmann: Allmächtiger! Faszination Perry Rhodan. Höfen 2006. S. 238. 
Perry Rhodan in den jeweiligen Ländern nicht unbedingt wöchentlich wie in Deutschland, sondern zum Teil monatlich, oder wie in den USA alle vierzehn Tage, in Form eines Taschenbuches. In den USA versuchte man das Heft zunächst in Magazinformat zu vermarkten, jedoch blieb die Buchform die erfolgreichere Variante. Dieses Format scheiterte an den dortigen Marktverhältnissen. ${ }^{154}$

Der Pabel-Moewig-Verlag hatte sich nicht mit dem Vertrieb von den Printmedien begnügt. Angesichts des Erfolges versuchte der Verlag, die Vermarktungsmöglichkeiten von Perry Rhodan vollends auszuschöpfen. Es wurden frühzeitig Fanartikel hergestellt und zusätzlich angeboten: So gibt es T-Shirts, Buttons, Plüschtiere, Modellbausätze, CD-Roms, Karten- und Rollenspiele. In einem einzigen Heft lassen sich beispielsweise folgende Anzeigen finden: ${ }^{155}$ Perry Rhodan-E-Books (Abb. 10), Nachbestellung verpasster Hefte (Abb. 11), eine generelle Einstiegshilfe (Abb. 12), diverse Events (Abb. 13), ein Abo mit Geschenken (Abb. 14) sowie das Perry Rhodan-Strategiespiel (Abb. 15) und die Spin-off-Serie Atlan (Abb. 16).

Kaum eine andere Serie im Bereich der Romanhefte hat solch eine breite Aufstellung erfahren. Nur die Serien Jerry Cotton und John Sinclair können auf einen Erfolg zurückblicken, der an den der Perry Rhodan-Serie heranreicht. In den 1970ern gab es unter anderem eine Jerry Cotton-Filmreihe in den Kinos, ebenso erfolgten diverse Taschenbücher. Die John Sinclair-Serie kann mittlerweile ebenfalls auf Verfilmungen, Taschenbücher und Hörspiele aufbauen. Zwar finden sich von diversen anderen Romanheftserien und -reihen ähnliche Medienwechsel, jedoch sind dies meist nur vereinzelte Erzeugnisse (bspw. einzelne Hörbücher aus der Lassiter-Serie von Frank Zander vorgelesen).

154 Schwettmann: Allmächtiger, S. 326-337.

155 Beispiel ist hier: Perry Rhodan Bd. 2686. Angriff der Nanokrieger. Leo Lukas. 1. Aufl. PabelMoewig-Verlag. - Die konventionelle Zitierweise der Literaturwissenschaft weicht zugunsten einer leichteren Identifikation der Romanhefte einer neuen Sortierung: Reihen-Titel Bandnummer. Episoden-Titel. Autor oder Autoren-Pseudonym. Auflage und Verlag. Der Kurzbeleg sieht im Folgenden so aus: Reihen- oder Serien-Titel Bandnummer. Die Reihenfolge entspringt der Relevanz der Daten, denn im Bereich der Romanhefte ist der Reihen- oder Serien-Titel hilfreicher, da einige Serien und Reihen den Verlag wechselten, aber trotzdem Konsequent weitergeführt wurden. Eine Sortierung nach Autor ist ebenfalls hinfällig, da hier zumeist Pseudonyme genutzt werden und nicht das Werk eines Autors, sondern die Serien und Reihen als Ganzes erfasst werden sollen, daher ist der Titel eines Romanheftes weniger relevant als seine Eingliederung in die Serie oder Reihe durch eine Bandnummer. 


\subsection{Cover-Gestaltung}

Die im weitesten Sinne gesetzliche Bindung des Romanheftes an die Regelungen der Presse-Branche und ihre Distributionsorte bedingt, dass das Romanheft auch sein Erscheinungsbild dieser Produktsparte anpassen muss: Somit darf das Romanheft nur neben Zeitungen, Zeitschriften sowie diversen weiteren Presseartikeln ausliegen und nicht neben beispielsweise Taschenbüchern aus dem Romanhandel. Daraus ergibt sich außerdem, dass das Romanheft in seiner äußerlichen Erscheinungsweise (Heftumschlag, Titelblattgestaltung etc.) mit den Presseerzeugnissen in Konkurrenz tritt.

Die Distributionsform, also die äußerliche beziehungsweise physische Erscheinungsform im Handel, ist das erste, was der potenzielle Leser von den Heften wahrnimmt. Dies umfasst nicht nur das Umschlagblatt, sondern auch die visuelle Gestaltung des Textes in Spalten oder beispielsweise Schriftgröße und Informationsboxen. Allein durch den visuellen Aufbau des Produktes 'Romanheft' (Umschlagblatt, visueller Aufbau des Innenteils) lassen sich ohne eine Analyse der Romanheft-Texte bereits hinreichende Erkenntnisse über die Art und Weise ihrer Distribution gewinnen.

Die Produkte zeigen buchstäblich ihre Verwandtschaft zu anderen Presseerzeugnissen, da ihre Cover mit Preisangaben und Barcode statt einer ISBN, Reihen-Nummer sowie Werbebannern versehen sind. In der Regel hat jedes Romanheft 64 Seiten, die sich aus der Anzahl von vier Druckbögen einer Zeitungsdruckerei ergeben. ${ }^{156}$ Eine Ausnahme bilden hierbei die Hefte der Hedwig Courths-Mahler-Reihe mit 80 Seiten. Das Papier entspricht nicht dem der Bücher oder Taschenbücher, sondern dem der Zeitungen, und der Fließtext innerhalb der Hefte ist deshalb auch in Spalten geteilt, zudem sind sie geheftet.

Gemäß ihrer Zielgruppe sind Romanhefte mit einschlägiger Werbung gespickt, daher wird in den Reihen, die tendenziell ein häusliches Publikum ansprechen wollen, mit Rezepten geworben (Abb. 1), oder in Reihen, die an historischen Aspekten interessiert sind, mit scheinbarem dokumentarischen Material (Abb. 2). Des Weiteren wird für Produkte innerhalb des jeweiligen Romanheftgenres geworben (Abb. 3).

156 Dietger Pforte: Bedingungen und Formen der materiellen und immateriellen Produktion von Heftromanen. In: Trivialliteratur. Hrsg. von Annamaria Rucktäschel und Hans Dieter Zimmermann. München 1976, S. 30-60. Vgl. S. 35. 
Die meisten Hefte fallen durch ihr Deckblatt schnell ins Auge, da oft auffällige Farben gewählt werden. In der Regel befindet sich in der Kopfzeile des Covers der Serientitel, der in ein Banner oder auffälligen Farbblock gesetzt wurde. Im Zentrum des Covers ist immer ein Motiv, das dem Genre angemessen ist. Dieses ist entweder ein Foto oder ein gemaltes Bild, wobei Romanhefte aus dem Bereich der Liebesromane zumeist Fotos vorweisen und Hefte aus den übrigen Genres von Künstlern gestaltete Bilder. Die Motive sind entsprechend des Romanheftgenres dramatisch, idyllisch, düster oder hell gestaltet. Beispielsweise zeigen Hefte der Sternenfaust-Serie Science Fiction-Elemente und -Szenen, wie sonderbar geformte Wesen oder dramatisch startende Raumschiffe (vgl. Abb. 4).

In der Kopfzeile der Perry Rhodan-Hefte befindet sich zum Beispiel der charakteristische schwarze Schriftzug „Perry Rhodan“ auf einem roten Rechteck (vgl. Abb 17). Darunter folgt in weißer Schrift auf blauem Grund: „Die größte Science FictionSerie“. ${ }^{157}$ Neben dem Serientitelblock befinden sich der Barcode, die Folgennummer und der Preis. Je nach Motiv ist der Titel der aktuellen Folge, samt Autorenname auf dem Titelbild platziert. Die drei Blöcke Serientitel, Folgentitel, Barcode mit Folgennummer (inklusive Preis) sind stets für den Betrachter schnell auffindbar und gut zu lesen. Sie werden in der Regel nie dergestalt von dem Titelbild vereinnahmt, dass der Folgentitel nicht lesbar wäre, weil der Hintergrund zu viele Elemente der gleichen Farbe wie der Schriftzug aufwiese. Hier kann Perry Rhodan mustergültig für die Serien gesehen werden, die hauptsächlich Fortsetzungsromane führen. Bei Heften aus dem Bereich der Liebesromane ist das Cover allerdings nicht so übersichtlich strukturiert. Sie weisen diverse farbintensive Elemente auf sowie Schnörkel, Blumen oder Kronen, die das jeweilige Motiv umranken und wie Schmuck garnieren.

Eine kleine Bildanalyse soll zeigen, wie massiv ein Cover der Fortsetzungsserie Perry Rhodan auf Benutzerfreundlichkeit zugeschnitten ist (vgl. auch Abb 17): Die Komposition der Elemente auf einem Perry Rhodan-Cover folgt der gewohnten Leserichtung der deutschsprachigen Leser: Von links nach rechts und von oben nach unten. Links oben prangt der Serientitel „Perry Rhodan“ in einem roten Block unter dem ein schmaler blauer Block die Ergänzung „Die größte Science Fiction-Serie“ enthält. Neben dem Titel-Block liegt der für Presseerzeugnisse typische Barcode

157 Früher hieß es: „Die größte Weltraumserie“ und „Die große WELTRAUM - SERIE von K.H. Scheer und Clark Darlton". 
unter dem die Ausgaben-Nummer sowie Preise unterschiedlicher Länder abgedruckt sind. Diese beiden Blöcke (Titel- und Presseerzeugnis-Block) füllen das obere Fünftel des Covers aus. Im untersten Fünftel finden sich Autorenname und Folgentitel, die eine Einheit bilden. Hinter all diesen Elementen liegt das Titelbild, das im Raum zwischen dem oberen und dem unteren Block so viel Platz erhält, um genügend von seiner eigenen Komposition zu zeigen. Die Blöcke verdecken also keine entscheidenden Elemente des Titelbildes. Auf dem Cover des Perry RhodanBandes 2380 (vgl. Abb. 17) verdeckt der obere Block nur Teile eines Raumschiffes, das zwei kleinere Raumschiffe überragt. Dieser Bereich ist in gedeckten Rot- und Brauntönen gehalten, vor denen die weiße Schrift der Preise und der Ausgabennummer gut lesbar bleiben. Dieses größere Raumschiff rahmt lediglich die beiden anderen Raumschiffe ein, die den Mittelpunkt der Bildfläche umspielen. Hier ist die Bildkomposition unruhiger, da geradlinige Elemente des größten Raumschiffes als Linien an der linken Bildfläche von unten nach oben führen. Das kleinste der kleineren Raumschiffe bildet in seinem länglichen Aufbau eine diagonale Linie zu diesen Elementen. Das dritte (mittelgroße) Raumschiff schneidet wiederum mit seinem horizontal gelegenen, länglichen Aufbau beide Linien. Zusammen ergeben die Linien eine dreieckige Komposition, die leicht neben dem Bildmittelpunkt liegt. Dies vermittelt einen Eindruck von Auf und Ab. Außerdem treffen in dem mittleren Bildbereich auch die unterschiedlichen Farbbereiche aufeinander: Rotbraune Elemente des größten Raumschiffes ragen in den linken Bildmittelteil hinein. Aus dem unteren Bildteil ragen gelbe Elemente in den Bildmittelteil. Außerdem sind im Hintergrund des Bildmittelteils eine kreisrunde Sphäre in Grün- und Blautönen sowie der Weltraum in schwarz dargestellt. Somit ist neben der Komposition der Elemente auch die Aufteilung der Farben im Bildmittelteil vielfältig.

Das untere Fünftel des Covers enthält die Darstellung einer Sonne, die die Raumschiffe von unten beleuchtet, sodass diese in weiten Teilen gelb koloriert sind. Dadurch bleibt der untere Teil in Gelbtönen und der Titel sowie der Autorenname heben sich vor einem gedeckt gelben Hintergrund gut lesbar ab.

Die Farbwahl und die Bildkomposition sind so gewählt, dass alle Textelemente erkennbar und schnell lesbar bleiben. Außerdem wird die Komposition des Titelbildes selbst nicht durch die Textelemente gestört. Vielmehr umrahmen der obere und der 
untere Block das Titelbild. Dadurch sind zusätzlich die Funktionsbereiche sichtbar aufgeteilt: Das obere Fünftel sortiert das Heft in die entsprechende Serie oder Reihe ein (hier: Perry Rhodan) und nennt Ausgabennummer sowie den Kaufpreis. Damit ist diese Ausgabe auch für unerfahrene Perry Rhodan-Leser sofort identifizierbar: beispielsweise Perry Rhodan-Band 2380.

Die folgenden drei Fünftel nimmt das Titelbild ein, welches dem Leser einen ersten Spannungsmoment präsentiert. Auf diese Weise muss der potenzielle Käufer das Heft nicht einmal lesen, denn er sieht, was inn in dem Heft erwartet beziehungsweise erwarten könnte. Die Bildkomposition des Titelbildes (nicht des gesamten Covers) der Perry Rhodan-Ausgabe 2380 (vgl. Abb. 17) visualisiert buchstäblich ihren Folgentitel "Es kam aus der Sonne“: Das mittelgroße der drei Raumschiffe ist in der unteren Bildhälfte dargestellt. Den Hintergrund nimmt in diesem Bildbereich die Darstellung einer Sonne ein. Das Raumschiff ist so gemalt, dass es von der Front zu sehen ist und seine Querachse diagonal im Bild liegt. Diese Achse verläuft von links unten nach rechts oben. Die Diagonale der dargestellten Sonne verläuft jedoch von rechts unten nach links oben. Beide Diagonalen kreuzen sich und der Rumpf des Raumschiffes überragt so den Rand der Sonne. Es liegt damit zu einem Teil sichtbar außerhalb des Sonnenbereiches. Da die Diagonale des Raumschiffes nach oben führt, also weg von dem Sonnenbereich, erweckt die Darstellung den Eindruck, dass das Raumschiff von der Sonne weg fliegt und gegebenenfalls aus der Sonne kam.

Zuletzt erfolgt im unteren Fünftel Autorenname und Folgentitel, der nur für Serienkenner relevant ist. Die Reihenfolge entspricht einer Informations-PrioritätenReihenfolge (das Wichtigste zuerst), die auch unserer gewohnten Leserichtung entspricht: Von oben nach unten. Ohne Vorkenntnisse wird jeder Kunde, der das Perry Rhodan-Cover im Kiosk erblickt, gemäß der Prioritäten-Reihenfolge 'lesen'. Außerdem sind die Ausgaben in den Heftständern besser auffindbar, da sie in der Regel an der Oberseite aus der Halterung gezogen werden. Ein Käufer braucht nicht das ganze Heft herauszuziehen, sondern kann gleich am oberen Rand ablesen, ob es die Serie ist, die er gerade sucht. Somit offenbart sich auch die tiefere Bedeutung des Untertitels "Die größte Science Fiction-Serie“, da Nicht-Kenner der Perry Rhodan-Serie sofort erfahren, dass sie ein Heft aus dem Science Fiction-Bereich herausgezogen haben. 
Es ist auffällig, dass Serien mit durchgehenden Handlungssträngen tendenziell weniger Werbung auf den Covern aufweisen als Reihen, die nur über eine The matik oder eine Serienfigur zusammengehalten werden. Das Titelbild eines Heftes aus der Mami-Reihe (Abb. 1) wirkt gegenüber dem Perry Rhodan-Cover eher überladen:

Der komplette Hintergrund des Mami-Covers ist in Altrosa gefärbt, das in der unteren Hälfte einen blauen Farbverlauf aufweist. Flankiert wird das gesamte Titelbild von einem durchgehenden roten Streifen an der linken Seite, auf der in vertikaler Ausrichtung der Reihen-Titel, internationale Preise und die Bandnummer notiert sind. Über dem altrosa Hintergrund liegen die einzelnen Bildelemente wie folgt: Im oberen Sechstel der Mami-Ausgabe prangt der Reihen-Titel in weißen Buchstaben auf einer dunkelrosafarbenen Banderole. Links über dem Titel finden sich der Preis sowie das Verlagssymbol. Rechts des Titels ist ein gelbes Textband mit schwarzer und rosafarbener Schrift, das über Spezialinhalte des Heftes informiert („Alle 14 Tage jetzt neu mit Sonnenwinkel“). Unter dem Titelblock befindet sich das ovale Cover-Bild beziehungsweise Foto, das von vier Blumenmotiven gerahmt wird. Auf dem Foto ist eine junge Frau im Zentrum zu sehen, vor der zwei Kinder sitzen. Das Ensemble Foto und Blumenelemente nimmt ungefähr Dreiviertel des gesamten Titelblatts ein.

Das letzte Sechstel enthält den Folgentitel in schwarzer Schrift („Wir gehören zusammen ...wenn wir schon keinen Papi haben“) und das Autoren-Pseudonym „Patricia Vandenberg“. Unter dem Folgentitel findet sich ein dunkelrosa, ovales Element mit gelber Schrift („Mit Rezept“) daneben in ebenfalls dunkelrosafarbener Schrift „Gefühle kann man lesen“ und zum Abschluss ein Strichcode-Block.

Ähnlich wie beim Perry Rhodan-Cover sind zwar alle zwingenden Elemente wie Strichcode und Preise auf dem Heft vermerkt, jedoch am Rande des Titelbildes verteilt (oben, unten sowie im linken, roten Streifen) und nicht übersichtlich gebündelt. Zusätze wie der Hinweis auf „Sonnenwinkel“ oder ein Rezept sind mit der Farbkombination Gelb-Dunkelrosa einem Warnsignal ähnlich auffällig am Rande des zentralen Bildes platziert, sodass sie sich schnell von den anderen Bildelementen abheben.

Diese beiden unterschiedlichen Romanheft-Cover können mustergültig als zwei Pole einer Skala angesehen werden: Das Perry Rhodan-Cover als schlicht und das MamiCover als besonders überladen. Zwischen den Polen bewegen sich die Cover der 
anderen Serien und Reihen.

Die Aufmachung der Hefte orientiert sich außerdem an dem jeweiligen Romanheftgenre und somit auch an den potenziellen Käufern. Beispielsweise haben die Hefte der Bergpfarrer-Serie ein farbenfrohes Cover (Abb. 5), wohingegen die LandserReihe eine verhältnismäßig schlichte Aufmachung vorweist (Abb. 6). Die Covergestaltung ist verlagsübergreifend ähnlich und scheint an der anvisierten Zielgruppe orientiert zu sein. Durch ähnliche Gestaltung der Produkte können diese von den Kunden miteinander in Verbindung gebracht werden.

Entsprechend haben die Adels-Serien von Bastei und Kelter alle einen goldenen Einband (Abb. 7 und Abb. 8). Dies lässt sich bei den Arzt-Romanheftserien (blau) und den Berg- und Heimat-Romanheftserien (rot und gelb) ebenfalls beobachten. Daraus folgt, dass die Verlage mit diesen Reihen eher auf Käufer setzen, die sich nur für das jeweilige Romanheftgenre interessieren und weniger für die einzelne Serie, da sie lediglich mit einem „Farbcode“ auf sich aufmerksam machen (beispielsweise roter, blauer oder goldener Heftrücken).

Serien, die einen hohen Fan-Anteil vorweisen, also Stammleser, haben meist Bilder auf dem Cover, welche die Frontseite komplett ausfüllen und somit nicht über eine Signal-Farbe im Regal zu finden sind (vgl. hierzu beispielsweise Abb. 4 mit Abb. 5). Bei diesen Heften muss der Käufer also wissen wonach er sucht.

Daraus lässt sich folgern, dass die Verlage auf zwei Sorten von Lesern abzielen: Erstens auf Genre-Leser, welche weniger an einer spezifischen, fortsetzenden Handlung interessiert sind und sich lediglich in erster Linie grob am Romanheftgenre orientieren. Und zweitens auf eine Gruppe, die sich für eine spezielle Serie interessiert und danach sucht (beispielsweise Perry Rhodan-Leser, Maddrax-Leser oder John Sinclair-Leser). Auf die Besonderheiten der jeweiligen Romanheftgenres wird in Kapitel 4. eingegangen.

\subsection{Der Innenteil}

Romanhefte, egal welchem Romanheftgenre sie angehören, weisen ähnliche Elemente auf: Werbendes Deckblatt, Prolog, Romantext, Leserkontaktseite, Abo, 
Informationsblock zu der Serie und Werbung. Diese sind nicht zwingend in jeder Serie oder jedem einzelnen Heft zu finden, allerdings sind diese Elemente im Romanheftbereich massiv verbreitet. Im Folgenden soll nun betrachtet werden, warum sie die Distribution unterstützen und inwiefern sie für eine serielle Narration von Interesse sein können.

Auf der Innenseite sowie auf der Rückseite des Einbandes der Hefte befindet sich Werbung, die bei großem Erfolg einer Serie gelegentlich vollständig für verlagsinterne Produkte wirbt und nicht auf Produkte anderer Verlage oder Hersteller angewiesen ist. Hier stellt die Perry Rhodan-Serie wieder einmal den Sonderfall dar, denn die meisten anderen Serien und Reihen führen Werbung, die nichts mit dem eigenen Verlagsprogramm zu tun hat, sodass sich in einigen Heften Werbung für Medikamente oder Schmuck finden lässt. Zu einem früheren Zeitpunkt, als die Perry Rhodan-Serie sich noch nicht etabliert hatte, fand sich in ihren Heften auch verlagsfremde Werbung. Es wurde in den Perry Rhodan-Heften zuvor wahllos für diverse Produkte geworben, ohne erkennbare Zielgruppe. In einer Werbeanzeige des Perry Rhodan-Bandes Nummer $656^{158}$ sollten ältere Leute angesprochen werden: „'Glückliches Altern' ein Gesundheitsprogramm“. Auf der Rückseite folgt hingegen eine Werbung für Zigaretten mit einem Bild von zwei jungen Leuten. Die Perry Rhodan-Serie wirbt in den aktuellen Heften größtenteils nur noch für Serien, Hörspiele und weitere Produkte, die zu der Hauptserie Perry Rhodan gehören.

Auch wenn es gelegentliche Abweichungen gibt, zeigt sich jedoch, dass die Verlage ihre aktuellen Werbebeiträge in Romanheften stärker an einer Zielkundschaft orientieren, als beispielsweise in der Stichprobe aus Perry Rhodan Band 656. Dementsprechend finden sich in der Mami-Reihe eher Kochrezepte und in der Perry Rhodan-Serie eher Werbung für Videospiele oder Science-Fiction-Serien.

Nach dem Aufschlagen des Heftes beginnt bei den meisten Heften auf der ersten Seite ein Prolog. Dieser wird von den Serien und Reihen unterschiedlich eingesetzt, je nach Bedarf der jeweiligen Erzählweise der Serie oder Reihe. Dieser Prolog enthält entweder einen Überblick über das, was in der Serie bisher geschah oder er führt mit einer Spannungssituation in das Heft ein. Dies soll später noch genauer

158 Perry Rhodan Bd. 656. Der Geheimnisträger. Clark Darlton. 3. Aufl. Pabel-Verlag. Im Folgenden werden die einzelnen Hefte-Nummern jeweils als „Band“ bezeichnet. 
untersucht werden (vgl. Kapitel 8. „Innere Verknüpfung. Oder: Die serielle Narration“). Des Weiteren findet sich auf der ersten Seite meist der Folgentitel, der in Szene gesetzt wird. Dies geschieht mit Ornamenten, Schnörkeln oder mittels farbiger Abgrenzung zum Fließtext. Da das Cover die Zuordnung zur jeweiligen Serie hergestellt hat, kann nun der Prolog den Schwerpunkt zu dem Plot der jeweiligen Folge überleiten. Hierbei zeigt sich, ob ein Schwerpunkt auf die Hierarchisierung der einzelnen Episode Wert gelegt wird oder nicht. Doch die meisten Prologe führen in eine Spannungssituation ein, woraus sich schließen lässt, dass nur wenige Serien und Reihen der Romanhefte auf eine genaue Hierarchisierung ihrer Folgen Wert legen. ${ }^{159}$ Die Perry Rhodan-Serie ist eine von jenen Serien, die auf eine genaue Verortung der einzelnen Folgen bedacht ist und dies mit hoher Kontinuität seit Beginn der ersten Folge fortgeführt hat. Andere Reihen hingegen ändern ihre Struktur oder verschwinden ganz aus dem Programm eines Verlages. Die Perry Rhodan-Serie verfolgt ihre Praxis nunmehr seit über 50 Jahren und gibt daher einen Einblick in eine erfolg reiche Serien-Produktion.

Auf der ersten Seite befinden sich unter anderem der Prolog sowie Serientitel, Nummer des Heftes und Folgentitel, außerdem stets ein Portrait des Titelhelden Perry Rhodan. Unterhalb des Folgentitels und dem Perry Rhodan-Kopf befindet sich der jeweilige Untertitel. Die Folgentitel bestehen in der Regel aus semantisch ungewöhnlichen Kombinationen, wie zum Beispiel: „Rekruten des Chaos“160 oder „Atem der Finsternis.“" ${ }^{61}$ Sie sollen die Fantasie des potenziellen Lesers anregen und Neugierde erwecken. Der Untertitel, der bei früheren Ausgaben noch auf dem Deckblatt erschien, enthält dramatisch anmutende Andeutungen auf den Inhalt - zum Beispiel: „Sie sind ein Kristall und ein Geistwesen - sie dienen dem Chaos und werden zu Gejagten“162 oder: „Entscheidung im Hayok-Sternenarchipel - verzweifelte Menschen planen die Flucht“. ${ }^{163}$ Darunter befindet sich ein Textteil, der ungefähr ein Drittel der Seite einnimmt und den Leser kurz über die wichtigsten vorhergehenden Ereignisse informiert, die er kennen muss, um die folgende Geschichte verstehen zu können (vgl. Abb. 18).

159 Dies wird detailliert in Kapitel 7. „Narrativer Rahmen der seriellen Narration“ und Kapitel 8. „Innere Verknüpfung. Oder: Die serielle Narration“ untersucht.

160 Perry Rhodan Bd. 2367. Rekruten des Chaos. Arndt Ellmer. 1. Aufl. Pabel-Moewig-Verlag.

161 Perry Rhodan Bd. 2363. Atem der Finsternis. Horst Hoffmann. 1. Aufl. Pabel-Moewig-Verlag.

162 Perry Rhodan Bd. 2367.

163 Perry Rhodan Bd. 2363. 
Der Prologseite folgt der Haupttext auf der nächsten Seite. Dieser ist in zwei Spalten aufgeteilt, über denen sich eine Kopfzeile befindet, in der die Seitenzahl, Verlagskürzel sowie Autor beziehungsweise Titel stehen; Autor auf den geraden und Titel auf den ungeraden Seiten alternieren in der Kopfzeile. Es stehen also die Seitenzahlen stets außen und zur Mitte hin der Autorenname beziehungsweise der Titel. ${ }^{164}$ Auf der ersten Seite des Haupttextes wird die Spaltenform durch einen Textblock aufgebrochen, in dem die wichtigsten Charaktere kurz vorgestellt werden. Des Weiteren ist der Haupttext in Kapitel unterteilt, die entweder durchnummeriert sind, ein Datum tragen oder einen Titel, je nach Gusto des Autors. Abgesehen von der Kapiteleinteilung wird der Text häufig durch Absätze unterbrochen, die in der Regel durch ein Sternchen $\left({ }^{*}\right)$ hervorgehoben werden (vgl. Abb. 19). Dies macht den Text übersichtlicher, da es nur kurze Textblöcke gibt und der Leser kleine Einheiten schneller überblicken kann. Der Text in kleinen 'Text-Portionen' wird so, vom optischen Standpunkt her, leichter konsumierbarer als ein breiter und langer Textblock, bei dem das Auge schnell die Zeile verlieren kann.

Der Fließtext und somit der Plot endet sprichwörtlich mit dem Wort „ENDE“, worauf ein Fazit folgt, das im Durchschnitt fünf Sätze umfasst. In dem Fazit wird erwähnt, welche Ereignisse entscheidend für den Verlauf der Gesamthandlung waren und gleichzeitig eine Überleitung zum nächsten Heft hergestellt, dessen Titel im Anschluss genannt wird. Beispiel:

„Wie es im Gebiet der Raphanen weitergeht und welche zusätzlichen Hindernisse zu überwinden sind, das schildert Horst Hoffmann in seinem PERRY RHODAN-Roman, der in der nächsten Woche unter folgendem Titel erscheinen wird: DER STERNENFINDLING“165

Darunter befindet sich das Impressum in einer Fußzeile (vgl. Abb. 20). Die vorgestellten Elemente werden von den anderen Serien unter anderem auch genutzt, jedoch nur gelegentlich und nicht mit solch einer Kontinuität. Daraus lässt sich schließen, dass die Perry Rhodan-Redaktion allein durch die Heftstruktur versucht, dem Leser ein höchstmögliches Potenzial an Orientierung innerhalb des Heftes zu gewährleisten. Diesen Dienst bieten andere Hefte kaum bis gar nicht. Nur diejenigen Serien,

164 Dies ist hauptsächlich typisch für die beiden einzigen Romanheftserien beim Pabel-MoewigVerlag. Sprich: auch für Der Landser.

165 Perry Rhodan Bd. 2370. Die Milliardenstadt. Michael Marcus Thurner. 1. Aufl. Pabel-MoewigVerlag. S. 63. 
die wie die Perry Rhodan-Serie vermehrt heftübergreifende Handlungsstränge führen arbeiten vermehrt mit den vorgestellten Elementen, daher lassen sich in der Maddrax-Serie sogar Fußnoten finden, die dem Leser zur Orientierung dienen. Diese Orientierungsstützen sind beispielsweise in den sogenannten Frauen- beziehungsweise Liebesromanen und Westernromanen nicht zu finden.

Einige Hefte führen ein „Extra“ mit sich, das dem Leser beziehungsweise Konsumenten einen Mehrwert zusätzlich zum eigentlichen Heft bietet. Wie bereits erwähnt haben die Hefte der Mami-Reihe gelegentlich Rezepte im Einband. Diese findet man ebenfalls in einigen Ausgaben der Berg- und Heimathefte sowie in diversen anderen Reihen, die in den Bereich der Liebesromane fallen. Allerdings vertiefen diese „Extras“ nicht die in den Heften enthaltene Geschichte, sie bilden lediglich einen Zusatz.

Anders verhält es sich mit vermeintlich historischen Zusatzmaterialien. Beispielsweise wirbt die Ringo-Reihe „Mit historischen Bildern“"166, was im Bereich der Westernhefte zwar nicht ungewöhnlich, aber selten ist. Der historische Zusatz hat nicht zwingend mit dem Inhalt der jeweiligen Episode zu tun, sondern er trägt lediglich zum Flair des jeweiligen Genres bei. Wesentlich aufwendiger wurde dies in der Landser-Reihe betrieben, denn in diesen Heften erläuterten die Autoren historische Personen per Endnote. ${ }^{167}$ Die historischen Bilder sind hier, wie bei den Westernheften, lediglich ein Zusatz, der keinen direkten Bezug zur Handlung hat.

In den Jerry Cotton-Heften finden die Leser scheinbar aktuelle Artikel aus Amerika über Verbrechen und Verbrechensbekämpfung. Doch gibt es auch hier keinen direkten Bezug zu dem Plot der jeweiligen Folge. Lediglich die Serien, welche vermehrt mit einer Fortsetzungsstruktur arbeiten, nutzen die Möglichkeit, mit einem Zusatz einen Bezug zum Inhalt der eigenen Serie herzustellen.

Die John Sinclair-Serie ist zwar noch stark episodal aufgebaut, doch hat die Serie eine Art Gedächtnis, weshalb diverse Gegner, die nicht besiegt wurden, immer wieder auftauchen. ${ }^{168}$ In dieser Serie, ebenso wie in ihrem Genre-Vetter Professor

166 Vgl. Abb. 2; Ringo Bd. 48. Er kam über den Pecos. Ringo. Aufl. unbek. Kelter-Verlag.

167 Näheres zum Problem der "historischen Fakten“ in Kapitel 4.9 „Historischer oder Kriegsroman?".

168 Solche Phänomene werden im Kapitel 8. „Innere Verknüpfung. Oder: Die serielle Narration“ detailliert untersucht. 
Zamorra, werden regelmäßig Leserbriefe als Zusatz abgedruckt und beantwortet. Innerhalb dieser Diskurse werden Inhalte der Serien besprochen. Dies geschieht in Form von Nachfragen, Leser-Zusammenfassungen oder kritischen Spekulationen die Bandbreite derer ist Legion.

Besonders die Serien mit Fortsetzungscharakter, um sie hier abermals explizit von den Reihen abzugrenzen, nutzen Zusätze nicht als singuläre „Extras“, sondern verwenden sie gekoppelt in einer Auseinandersetzung mit dem Serien-Plot. In Serien wie Maddrax, Professor Zamorra oder Perry Rhodan ist stets ein Forum zu finden, das den Lesern die Möglichkeit zum Austausch bietet - entweder direkt mit den Autoren oder über Umwege mit anderen Lesern. ${ }^{169}$ Beispielsweise werden bei der Maddrax-Serie zusätzlich Informationen für interessierte Neu-Leser geboten, daher gibt es neben dem einführenden Prolog am Anfang auf den darauf folgenden Seiten einen Block, der mit der Überschrift „Was bisher geschah" in eben dies einführt. Darüber hinaus sind in den Maddrax-Heften erläuternde Fußnoten gestreut und in unregelmäßigen Abständen druckt der Verlag Serien-Chronologien ab, die dem Leser helfen sollen, sich zu orientieren. Diese Chronologien bieten Aufschluss darüber, in welcher Reihenfolge sich welche Abenteuer der Helden zugetragen haben. Dies betrieb in ähnlicher Form auch die Sternenfaust-Serie. Diese Serie nutzte dafür jedoch nur sporadisch ihre Leserkontaktseite und etablierte solche Erinnerungselemente nicht als einen festen Bestandteil ihrer Folgen.

Hier wird demnach auf zwei unterschiedliche Modell-Leser abgezielt: Zum einen auf den Leser, der sich nur für "sein" Genre interessiert und weniger an einer Verortung des jeweiligen Heftes innerhalb seiner Reihe interessiert ist als an der Erfüllung der zu erwartenden Genrekonventionen. Zum anderen auf einen Leser, der ein reiner Serien-Leser ist. Diesem Leser wird einiges geboten, damit er das jeweilige Heft innerhalb der Serie seiner Wahl verorten kann. Außerdem hat er die Möglichkeit, sich über die jeweiligen Inhalte mit anderen Serienlesern auszutauschen. Über ein Forum kann er sogar auf die Inhalte Einfluss zu nehmen. Inwieweit dies von den Verlagen

169 Hier kommt vermehrt noch die Möglichkeit des Internets hinzu. So werden mittlerweile auch Emails abgedruckt oder Auszüge aus Internetforen. Allerdings ist bemerkenswert, dass das abgedruckte Forum noch immer Relevanz hat, da diese in den Heften nicht wenig Platz einnehmen und es für die Redaktion mehr Arbeit bedeutet, diese Briefe zu beantworten und aufzubereiten. Vermutlich hat das mit einem Geltungsbedürfnis einiger Leser zu tun, die so die "Ehre" bekommen, innerhalb ihrer Serie abgedruckt zu werden. Jedoch ist dies Spekulation, die weiterer Forschung bedürfte, welche leider nicht innerhalb dieser Arbeit geleistet werden kann. 
inszeniert und gesteuert wird, bleibt zwar unklar, doch die zahlreichen Perry RhodanFanclubs und -Stammtische lassen auf eine rege Beteiligung der Leser schließen. ${ }^{170}$

170 Vgl. Eckhard Schwettmann: Fast alles über Perry Rhodan. Hannover 2009. S. 199ff. 


\section{Produktion}

"Grundlage von Bildung und Kultur ist und bleibt das gedruckte Wort, in welcher Darreichungsform auch immer - als gebundenes Buch, [...] in Zeitschriften-, Zeitungs- oder Heftpublikationen. Lesen ist der beste Weg, sich Bildung und Kultur anzueignen. Es bietet aber auch den Lesenden die Möglichkeit, Abenteuer im Kopf zu erleben, Sehnsüchte der Seele zu stillen oder sich ganz einfach zu unterhalten." ${ }^{\text {171 }}$

Mit diesen Worten zieht die Verlagsgründerin des Bastei Verlags Ursula Lübbe eine direkte Linie von Kultur bis zum Bereich der Heftproduktion - eine Verbindung, die in der Geschichte der Romanhefte bisher nur unter starker Kritik zu ziehen war, was sich in den zahlreichen Debatten über "Schmutz und Schund“ der Heftliteratur widerspiegelt. ${ }^{172}$ Ursula Lübbe zeichnet naturgemäß ein eher positives Bild von den Vorzügen, die Romanhefte bieten. Das zeigt zugleich, wie Frau Lübbe und somit auch ihr Verlag wahrgenommen werden möchten: Als ein Unternehmen, das das Lesen als kulturelle Praxis unterstützt. Hier wird das Lesen selbst zum Bildungsakt, unabhängig davon, welche Qualität der Text hat. Inwieweit „Heftpublikationen“ dabei eine didaktische Funktion übernehmen können, ist ein weites Feld. ${ }^{173}$ Des Weiteren räumt Lübbe auch die eigentliche Funktion dieser Produkte ein: Unterhaltung. Darüber, welchen Stellenwert ein Autor von Romanheften hat, sind die Produzenten und Autoren von Romanheften sich uneinig.

G.F. Unger, Autor diverser Westernhefte, sagt über sein Wirken:

„[...] eine sehr aufbauende, erzieherische Mission, habe ich doch in meinen Romanen die Möglichkeit, immer wieder eine geradlinige und männliche Haltung aufzuzeigen, zu der unbedingt Redlichkeit und Mut gehören. Dies alles ist - so glaube ich - in unserer heutigen Zeit so wichtig." 174

Unger schreibt hier von Werten, die zumindest für sein Genre, entscheidend waren. $\mathrm{Ob}$ dies per Romanheft vermittelbar war (und ist) bleibt fraglich. Er gibt sich allerdings als ein Autor, der an das glaubt, was er schreibt und verleiht so seinen

171 Ursula Lübbes Geleitwort in: Die schwere Kunst der leichten Unterhaltung. Hrsg. von FranzHeinrich Hackel. S. 9.

172 U.a. hier detailliert nachzulesen: Peter Nusser: Trivialliteratur. Oder bei Rudolph Schenda: Volk ohne Buch. Frankfurt am Main 1970.

173 Dies wurde u.a. bereits von Günter Waldmann untersucht in: Theorie und Didaktik der Trivialliteratur.

174 O. A. (Spiegel Online): Schriftsteller G.F. Unger gestorben. (05.08.2005): https://www.spiegel.de/kultur/literatur/0,1518,druck-368473,00.html (Zugriff: 17.08.2019). 
Texten den Anstrich einer vermeintlichen Authentizität. Dies deckt sich durchaus mit der romantisierten Version Ursula Lübbes. Andere Autoren hingegen inszenieren sich weniger und haben eine wesentlich pragmatischere Beziehung zu ihren Werken:

„Heftromanredakteure sind keine Poetikdozenten, sie können kaum mehr tun, als kleine Hinweise dazu geben, wie ein Heftroman formell auszusehen hat. Sie werden für anderes bezahlt. Ein Heftroman schreibt sich nicht von selbst. Diese Lektüre zu verfassen, ist Arbeit und als solche erlernbar." ${ }^{175}$

Dies schreibt Anna Basener, die momentan jüngste Autorin von Romanheften, in ihrem Leitfaden zu Erstellung von Romanheften. Sie stellt den Beruf des RomanheftAutors als ein Handwerk dar und nicht als eine Berufung wie Unger. Überspitzt und doch auf den Punkt brachte es 1984 Ron Sproat mit seinem Essay „Ich war Schwerarbeiter in einer Pornofabrik“. ${ }^{176}$ Der Autor berichtet von seiner Arbeit in einer Redaktion, die am 'Fließband' Romane mit pornographischen Inhalten herstellte, wobei seine Beschreibungen der körperlichen Arbeit an wirklichen Fließbändern gleichen. Innerhalb dieses Bereichs wird kein kreativer Raum geschaffen; die Arbeiter/Autoren erhalten explizite Angaben, wie sie den Text zu gestalten haben:

„1. Jedes Kapitel müßte eine große und lange sexuelle Szene enthalten: je mehr Sex, umso besser.

2. Jedes Kapitel müßte mindestens achtzehn Seiten lang sein.

3. In meiner Kategorie müßte Homosexualität immer anziehend geschildert werden; Heterosexualität, wenn ich ohne sie nicht auskommen könnte, dürfte nur eine Formsache bleiben.

Schließlich Punkt 4: in meinen Romanen dürfen keine religiösen oder rassischen Gruppen erwähnt werden.." ${ }^{177}$

Sproat beschreibt eine stressgefüllte Atmosphäre, in der Autoren gegen die Zeit arbeiten. Sie werden nicht für mangelnde Qualität kritisiert, sondern sollen lediglich eine genügende Anzahl von Seiten produzieren. ${ }^{178}$ Hierbei haben die Autoren keinerlei Bezug zu ihren Lesern, was in diesem Fall durch das Genre bedingt ist, da die Käufer dieser Romane vermutlich eher unbekannt bleiben wollen. Dieses Beispiel zeigt allerdings, dass innerhalb solcher „Romanfabriken“ mehr Arbeit und weniger Kunst vorherrscht. Es ist eben ein Handwerk, das erlernbar ist und für das die

175 Anna Basener: Heftromane schreiben und veröffentlichen. Berlin 2010. S. 10.

176 Ron Sproat: Ich war Schwerarbeiter in einer Pornofabrik. In: Erzählgattungen der Trivialliteratur. Hrsg. von Zedenko Skreb. Innsbruck 1984, S. 275-282.

177 Sproat: Schwerarbeiter in einer Pornofabrik, S. 278.

178 Ebd. S. 278f. 
Autoren eine "Gebrauchsanweisung"179 oder einen Leitfaden à la Basener benötigen. Dies ist ein Schreiben zum Geldverdienen, und nicht um "mit dem Volke, für das [der Autor; Anm. d. A.] schreibt, das Gefühl von der Wahrheit und Schönheit der Religion theilt“. ${ }^{180}$ Eichendorffs Einstellung deckt sich zwar mit der G.F. Ungers, allerdings mit dem Unterschied, dass Eichendorff sich auf eine geschlossene Elite, ein „ideales Bürgertum "181 und Unger sich ausnahmslos auf jeden bezog, daher ist es notwendig, das Identifikationspotenzial der Produzierenden mit ihrem Produkt zu untersuchen. Inwieweit ein Autor sich für sein Produkt engagiert, ist von dem Charakter der Serie oder der Reihe abhängig. Es macht für den Produzierenden durchaus einen Unterschied, ob er alleine eine Serie bestreitet oder ob er ein Rädchen innerhalb einer „Autorenfabrik“ ist, beziehungsweise ob er in diesem Team als schreibendes Individuum zur Geltung kommt oder ob er mit vielen Anderen unter dem gleichen Pseudonym produziert. In diesem Bereich sind viele graduelle Abstufungen möglich. Episodale Genre-Reihen können nach einem Fließbandprinzip relativ leicht abgearbeitet werden, da die einzelnen Hefte nicht auf den vorherigen aufbauen müssen. Die Geschichten brauchen lediglich die Genrekonventionen einzuhalten. Serien mit übergreifenden Serienhelden müssen in der Regel am Ende der Hefte einen Status quo hergestellt haben und dürfen von der Redaktion vorgegebene Maßstäbe, wie beispielsweise das Aussehen der Hauptfiguren, nicht ändern.

Fortsetzungsserien müssen jedoch anders produziert werden: Da jede Folge nicht mit dem gleichen Ausgangspunkt beginnen kann, müssen Serienhersteller genau koordinieren, wie sich die Handlung entwickelt, besonders wenn die Serie in einem Autoren-Team produziert wird. In diesem Fall reicht es nicht, wenn wahllos Autoren nach einer "Gebrauchsanweisung" singuläre Romane abarbeiten. Dies bedarf eines koordinierten Teams, in dem die Arbeitsbereiche spezialisiert werden.

Die Perry Rhodan-Redaktion weist eine hohe Transparenz auf, da die Serie seit langer Zeit Erfolge verbuchen kann und mit ihrer Arbeitsweise gerne wirbt. Mittlerweile gibt es diverse Bücher des Verlags, die sich mit der Produktion ihres „Flaggschiffs" Perry Rhodan beschäftigen. ${ }^{182}$ In diesen Werken sowie bei diversen anderen

179 Ebd.

180 So Joseph Eichendorff 1857. Zitiert nach Schenda: Volk ohne Buch, S.161.

181 Ebd. 162.

182 Mittlerweile gibt es u.a. eine vierbändige "Biographie" der Serie. Michael Nagula: Perry Rhodan. Die Chronik. Bd.1-2. Höfen seit 2011. Bd. 3 ist von Hermann Urbanek. Bd. 4 von Eckhard Schwettmann ist derzeit im Erscheinen (Stand: 15.11.2018). 
Gelegenheiten wirbt der Verlag mit seinen Autoren, die immer seltener unter einem Pseudonym schreiben und ihre echten Namen oft bekannt geben. Die Perry RhodanAutoren haben in ihrem Gebiet einen Kultstatus erreicht.

Da es sich bei den Perry Rhodan-Geschichten um eine extrem weitschweifige Fortsetzungsserie handelt, die von einem Autoren-Team geschrieben wird, muss die Zusammenarbeit streng koordiniert werden. Es könnte sonst zu inhaltlichen Fehlern kommen, welche die Homogenität der Serie gefährden. Aufgrund dessen gibt es im Bereich der Produktion vier Instanzen: Einen Exposé-Autor, die Roman-Autoren, den Lektor und die Künstler.

Die Entwicklung einer Perry Rhodan-Geschichte durchläuft den Produktionsfluss in eben jener Reihenfolge, wobei die Aufgabenverteilung vom Pabel-Moewig-Verlag vorgeschrieben ist, da es den Erscheinungstermin einzuhalten gilt. $\mathrm{Da}$ dies für Romanheftserien mit durchgehendem Handlungsstrang zwingend ist, finden sich solch organisierte Teams auch bei anderen Fortsetunzgsserien wie beispielsweise bei den Bastei-Produktionen Professor Zamorra oder Maddrax. ${ }^{183}$

Je mehr die Verknüpfung der einzelnen Folgen abnimmt, also je episodaler die Folgen werden, desto weniger streng ist das jeweilige Autoren-Team koordiniert. So müssen sich die Autoren bei Jerry Cotton nur an ein grobes „Reihenkonzept“ halten, das die wiederkehrenden Hauptfiguren umfasst. ${ }^{184}$ In der Entwicklung der Nebenfiguren und der Handlung des jeweiligen Heftes haben die Autoren freie Hand, sodass sie eigene Erzähl-Stile einbringen können. ${ }^{185}$ Nur zu Anfang werden Texte neuer Romanheftautoren streng von einem Lektor kontrolliert. ${ }^{186}$ Sie bekommen jedoch kein Exposé als Vorgabe für die Handlung. Für viele Autoren besteht bei ihrer Arbeit kaum ein Unterschied zu anderen Romanheftserien. So berichtet R.H. Baker über seine Arbeit innerhalb der Jerry Cotton-Serie:

„Ich sehe als spezifische Bedingung lediglich, dass wir Autoren uns an das Reihenexposé halten und die Storys in sich stimmig sein müssen. [...] Für mich gibt es bei meiner Arbeit keinen Unterschied zu jedem anderen Roman." 187

183 Hector: Die dunkle Zukunft der Menschheit, S. 14f. Die Autoren schreiben nicht nur für den Bastei-Verlag, sondern auch für andere Verlage wie Pabel-Moewig.

184 Compart: G-man Jerry Cotton, S. 98.

185 Jakuba: G-man Jerry Cotton, S. $257 \mathrm{ff}$.

186 Ebd. S. $303 f$.

187 Compart: G-man Jerry Cotton, S. 98. 
Gleiches berichtet die Autorin Anna Basener für den Bereich der Liebes romane: Für „zirkuläre Serien“ (episodale Serien, die immer mit dem Status quo enden) muss sich der Autor an ein Serienkonzept halten, das das Stammpersonal fest umreißt, sonst aber nichts: ${ }^{188}$ „Hier finden sich Charakterzüge, Aussehen und Hobby der Figuren so wie die Beziehungen untereinander." ${ }^{189}$ Für Reihen müssen die Autoren nicht einmal dies bedenken.

\subsection{Der Exposé-Autor}

Der Exposé-Autor, im Beispiel der Perry Rhodan-Serie ist dies Robert Feldhoff, koordiniert mit einem Chefredakteur, hier: Klaus N. Frick, den groben Handlungsrahmen eines Zyklus. Das sind in der Regel 50 bis 100 Romanhefte, die zusammen eine größere Perry Rhodan-Geschichte erzählen (hierzu mehr in Kapitel 7.2 „Mikround Makroerzählung“). Die Exposé-Autoren, die dem Erfinder der Perry RhodanSerie ${ }^{190}$ K.H. Scheer nachfolgten, waren in der Regel vorher Romanheftautoren, die sich durch ihre Leistungen zur Beförderung zum Exposé-Autor qualifizierten. Einmal im Jahr findet ein Treffen der Autoren und Lektoren statt. ${ }^{191}$ In dieser Phase wird festgelegt, ob es grundlegende Veränderungen in dem Universum von Perry Rhodan geben wird. Dies können Änderungen wie zum Beispiel der Tod wichtiger Charaktere sein, oder dass die Figur Perry Rhodan vorerst nicht mehr Herrscher der Menschheit sein soll. In dieser Anfangsphase können auch grundlegende ideologische Strömungen der Serie beachtet werden, zum Beispiel dass man nicht mehr aktionsbetont schreibt sondern die Politik der Zukunft oder dergleichen in den Vordergrund rückt (hierzu mehr in Kapitel 7. „Narrativer Rahmen der seriellen Narration“). Wenn die inhaltliche Richtung mit all ihren Eventualitäten eindeutig definiert wurde, beginnt der Exposé-Autor zu jedem Romanheft ein Exposé zu schreiben. Darin legt er den Handlungsverlauf sowie Beschreibungen der darin auftauchenden Figuren fest, damit andere Autoren, die gegebenenfalls später anfangen, ein und dasselbe Wesen nicht unterschiedlich beschreiben. Maße für Raumschiffe, ihre Geschwindigkeiten, Kabinenanzahl und so weiter, werden ebenfalls im Exposé festgelegt. Am Ende kann

188 Basener: Heftromane schreiben und veröffentlichen, S. $21 \mathrm{f}$.

189 Ebd.

190 Heutzutage werden Serien-Erfinder im Bereich der Massenmedien auch „Creator“ genannt.

191 Schwettmann: Allmächtiger, S. 221. 
es zwei bis zehn Seiten umfassen ${ }^{192}$ und der Exposé-Autor schneidet es gelegentlich auf den jeweiligen Roman-Autoren zu, ${ }^{193}$ damit seine Stärken und Vorlieben genutzt werden können.

Solche Exposés sind für eine Reihe nicht notwendig. Für die Abfassung eines Romans einer Reihe reicht dem Autor eine „Gebrauchsanweisung" à la Sproat, in der die wichtigsten Konventionen des Genres oder der jeweiligen Reihe vermerkt sind. Bei einer episodalen Serie ist dies ähnlich, nur dass hier die Konventionen der Serie stärker ins Gewicht fallen müssen als bei einer Reihe, da es bei diesen Serien in der Regel durchgehende Hauptfiguren gibt, die nicht verändert werden dürfen und somit immer gleich beschrieben werden müssen. ${ }^{194}$ Deswegen darf die Anzahl der Kinder von Dr. Laurin in der gleichnamigen Serie nicht schwanken, während G.F. Unger beim Verfassen einer Westerngeschichte in seiner Reihe lediglich den Gepflogenheiten des Genres zu folgen braucht. Um so stärker das einzelne Heft in einen größeren Zusammenhang eingebettet ist, um so umfangreicher sind die Konventionen, die der Autor einhalten muss. Daher reicht für das Verfassen von singulären Romanen für eine gesamte Reihe eventuell nur ein einzelnes ExposéBlatt, während für ein einzelnes Perry Rhodan-Heft bereits drei Seiten Exposé benötigt werden.

Somit hat der Exposé-Autor in erster Linie eine koordinierende Funktion innerhalb der Serien-Redaktion. Er entwirft einen Plan, der die Serie als Ganzes umfasst und an den sich die Autoren halten müssen.

\subsection{Der Roman(heft)-Autor}

Das Autorenteam von Perry Rhodan besteht in der Regel aus zirka zehn Autoren. Erhält einer der Roman-Autoren sein Exposé hat er nur begrenzt Zeit, seine Anteile an der Geschichte zu verfassen, da der Roman ungefähr drei Monate vor dem Erscheinen am Kiosk fertiggestellt sein muss. Aufgrund der Fortsetzungsstruktur der Serie können keine anderen Episoden vorgezogen werden. Bei Reihen oder episodalen Serien ist dies immer möglich. Dort können bereits vor ihrem jeweiligen

192 Stache: Perry Rhodan - Überlegungen zum Wandel eine Heftromanserie, S. 85.

193 Schwettmann: Allmächtiger, S. 221.

194 Basener: Heftromane schreiben und veröffentlichen, S. 21f. 
Termin abgefasste Romane vorzeitig gedruckt werden.

Einige Perry Rhodan-Autoren rühmen sich eher ihrer Geschwindigkeit und weniger der Qualität, demgemäß gesteht Hanns Kneifel: „Manchmal hau' ich so ein Ding in fünf Tagen zusammen“195. Jedoch werden die Autoren auch aufgrund finanzieller Aspekte zur 'Schnellschreiberei' animiert, da sie nach Anzahl ihrer Romane vergütet werden und kein festes Autorengehalt erhalten. Allerdings gibt es Prämien, wenn ein Roman abermals aufgelegt wird, was wiederum nur möglich ist, wenn eine Nachfrage besteht. ${ }^{196}$ Auf diese Weise bleibt es für die Autoren reizvoll, einen Qualitätsstandard zu halten.

Die Roman-Autoren bekommen nicht nur die Exposés für ihre eigenen Romane, sondern innen liegen auch diejenigen ihrer Kollegen vor, damit jeder Autor über die Gesamthandlung informiert ist. Sie müssen den groben Rahmen kennen, ebenso wie die Details, da die Autoren gleichzeitig arbeiten und die Romane nicht in der Reihenfolge fertig werden, in der sie erscheinen sollen. Deshalb können sich die Autoren nicht darauf verlassen, dass sie das Manuskript ihres Vorgängers zu sehen bekommen, sondern müssen sich auf die Informationen aus dem Exposé stützen. Autoren, die sich nicht an die Termine oder Exposé-Vorgaben halten, werden entlassen. ${ }^{197}$

Abgesehen von den Exposé-Vorgaben ist der Autor frei in der Entwicklung seiner Geschichte und der Wahl seiner Erzählperspektive. Er kann sie beispielsweise aus der Sicht eines Außerirdischen erzählen, in der ersten Person oder in der StandardForm, der dritten Person. Er ist ebenfalls frei darin, zu entscheiden, ob er mehr aktionsorientiert oder dialoglastig schreibt, insofern die Redaktion nicht explizit eine Richtlinie vorschreibt. Durch Marktstudien versucht der Verlag die Lesevorlieben zu ermitteln, ${ }^{198}$ die sich dann für den Autoren in „expliziten Normen“ ${ }^{199}$ durch den Verlag niederschlagen. Unter Umständen kann der Autor vom Verlag dazu angehalten werden, mehr Dialoge zu verwenden, weil eine Umfrage ergeben hat, dass die Leser sich mehr Dialoge wünschen. Der Autor ist also an das Exposé und an die "Lektoratsvorstellungen" gebunden sowie der "Verlagskontrolle" und dem

195 Hallmann: Perry Rhodan - Analyse, S. 69, Fußnote 54.

196 Stache: Perry Rhodan - Überlegungen, S. 86.

197 Hallmann: Perry Rhodan - Analyse, S. 117.

198 Stache: Perry Rhodan - Überlegungen, S. 80f.

199 Stache: Perry Rhodan - Überlegungen, S. 81. 
„Gattungszwang" unterworfen. ${ }^{200}$

Der "Gattungszwang" stellt nochmals eine Ballung an Normen dar. Zum einen ist die Perry Rhodan-Serie eine Science Fiction-Serie, zum anderen eine Romanheftserie, daher muss der Autor zwar die Science Fiction-Konventionen bedienen, aber nur so weit, wie sie nicht den Gepflogenheiten der Romanhefte widersprechen. Beispielsweise dürften in einem Science Ficiton-Romanheft keine zu komplexen Überlegungen zu Paradoxien der Zeitreise eine Rolle spielen. ${ }^{201}$ Es ist für die Autoren ein Balanceakt zwischen Schablonenhaftigkeit und Innovation, denn eine innovative Geschichte steigert die Wahrscheinlichkeit auf Zuspruch der Leser und somit auf eine Neuauflage. Der Perry Rhodan-Autor H.G. Ewers über die Arbeitsbedingungen:

"[]]ch habe immer die im Exposé vorgegebene rote Linie eingehalten und Anfang und Ende jedes Romans so gestaltet, daß er sich nahtlos in die Serie einfügte. Nur dachte ich mir immer wieder neue Figuren und Handlungsschauplätze aus, denn ich hasse es, vorgegebene Handlungen schematisch abzuhandeln." ${ }^{\prime 202}$

Allzu schematisch zu schreiben, ist ein Problem, das die Autoren nur schwer umgehen können, worin aber auch die Innovation liegt: Die schematische Vorgabe soweit wie möglich zu biegen, ohne mit den „expliziten Normen“ zu brechen.

Auf einige Serien und Reihen trifft sicherlich zu, dass, „[w]enn der Autor sich an die Schreibmaschine setzt, [...] die eigentliche produktive Arbeit schon getan [ist]: Inhalte und Motive stehen bereits fest, sie sind nur noch zu kombinieren. “203 In dem Beispiel zu Ron Sproat ließ sich bereits nachvollziehen, wie dies aussehen kann. „Die Produktion der Trivialliteratur fördert nicht die literarischen Produktivkräfte, sie schöpft sie nur aus. “204 Solche Bedingungen herrschen besonders im Bereich der Reihen vor.

Jedoch trifft dies nicht mehr bei Serien wie Perry Rhodan, Professor Zamorra, Sternenfaust oder Maddrax zu. Zwar müssen auch hier die Autoren innerhalb einer bestimmten Zeit eine gewisse Anzahl von Seiten produzieren. Allerdings stellt sich ihnen auch die Aufgabe, mit ihren vorgeschriebenen Motiven zu variieren. Sie

200 Ebd.

201 Die Diskussion darüber, dass die Perry Rhodan-Serie mehr sei als nur Trivialliteratur, führe hier zu weit. Denn in den Lexika, zählt die Serie zu der Trivialliteratur und die abgehende Meinung stammt hauptsächlich von den Autoren. Hierzu unter anderem: Stache: Perry Rhodan Überlegungen, S. 83.

202 Schwettmann: Allmächtiger, S. 86.

203 Wernsing und Wucherpfennig: Die Groschenhefte. S. 13.

204 Ebd. 
müssen zwar eine komplexere Aufgabe bewältigen als beispielsweise die Autoren der Dr. Laurin-Serie, doch beantwortet dies noch immer nicht hinreichend die Frage nach dem Identifikationspotenzial der Autoren. Eine Antwort findet sich unter anderem in der Entstehungsgeschichte der Perry Rhodan-Serie. Der Autor Clark Darlton, eigentlich Walter Ernsting, berichtet in dem sogenannten „Werkstattband“, wie er mit Karl-Herbert Scheer die Perry Rhodan-Serie konzipierte:

„Damals hockten Karl-Herbert Scheer und ich auf dem Balkon meiner Wohnung [...] in der Sonne und ließen ein kleines Helles gemächlich in uns hineinzischen. Wir unterhielten uns über SF im allgemeinen und besonderen, hauptsächlich letzteres. “205

Darlton inszeniert die Geburtsstunde der Perry Rhodan-Serie wie zwei Autoren über Science Fiction-Literatur sinnieren und betont beständig die Attitüde des trinkenden Autors. Beide waren zu der Zeit bereits etablierte Autoren dieses Genres, doch mussten sie sich ebenso beständig um neue Aufträge bemühen. Er spricht zwar beständig von Fleiß, betont aber ebenso ihre Kreativität und ihren Freigeist:

„Über ein Honorar wurde erst gar nicht gesprochen. Nun gut, wir waren Idealisten [...] und gingen auch einmal ein Risiko ein. " ${ }^{206}$

Sie identifizieren sich mit ihrer Arbeit und streben bei ihrem „Werkstück“ nach Kunstfertigkeit. Allerdings kann das Werk am Ende nicht wie ein Kunstwerk für sich alleine stehen, da es in den Verkauf muss. Insofern sind die Autoren nicht autonom und immer an den Verlag beziehungsweise im Weiteren an den Markt gebunden. Sie identifizieren sich nicht nur mit ihrem produzierten Text, sondern auch mit ihrem Genre. Sie diskutieren über ihr Schriftstellertum als Science Fiction-Autoren.

$\mathrm{Zu}$ dieser Zeit war es nicht ungewöhnlich, dass Science Fiction im RomanheftFormat gelesen wurde und somit ein typisches Medium für jenes Genre war. Sie sahen sich also als Autoren eines narrativen Genres an (hier: Science Fiction) und nicht, wie beispielsweise Anna Basener, als Autoren einer bestimmten Publikationsform (hier: Romanhefte vs. gebundene Romane). So lässt sich nun auch G.F. Ungers Aussage zu Beginn dieses Kapitels erklären. Als ein Autor, der seit geraumer Zeit in seinem Genre schrieb, war er in der Tat ebenfalls ein Idealist, der für seine Texte einstand. Dies ist allerdings nicht vor dem Hintergrund eines klassischen Autor-

205 Clark Darlton: Wie alles begann. In: Perry Rhodan - Werkstattband. Hrsg. von Horst Hoffmann. Rastatt 1986. S. 19-30. S. 19.

206 Ebd. S. 23. 
konzepts wie etwa dem Eichendorffs zu sehen: Hier definiert sich der Autor nicht als einer, der das "Wahre" schafft, sondern vielmehr als ein Autor, der "gute Arbeit leistet“. Dieser Gedanke lässt sich bei Autoren von Serien, die mit einer Fortsetzungsstruktur konzipiert werden, häufig finden und aus der Regelmäßigkeit ablesen, mit der diverse Leserbriefe oder Foren betreut werden. Auf diese Weise bemühen sich die Autoren um ihre Kunden und versuchen in Erfahrung zu bringen, ob das Produkt (in diesem Fall ist die Geschichte gemeint) innen gefiel und was verbessert werden könnte. Innerhalb des Forums können die Autoren für ihre Geschichte beziehungsweise ihr einzelnes Werkstück innerhalb der Serie Rede und Antwort stehen.

Es lassen sich grob zwei Gruppen von Autoren ausmachen: Diejenigen, die rein zum Verdienst schreiben und die Idealisten. Beide sehen sich als Arbeiter, aber der Aspekt der „Identifikation“ unterscheidet sie. Sproat, als Vertreter der reinen „Verdienstautoren“, erträgt lediglich seine Aufgabe: Der Text wird im Akkord herunter getippt, da die Inhalte für den Autor nicht wichtig und für die unbekannte Konsumentenschaft vermutlich nur die Reizwörter entscheidend sind.

Für die Perry Rhodan-Autoren hingegen ist der Plot alles: Sie müssen den Bedingungen eines Genres mit hoher Leserbeteiligung gerecht werden; zudem bemerken Leser inhaltliche Brüche oder Redundanzen und melden dies zurück. Bei Perry Rhodan sind die Autoren selbst ebenfalls Leser solcher Texte. An dieser Stelle verschwimmt die Grenze zwischen Konsumenten und Autoren. Auch wenn die Autoren bei Perry Rhodan Handwerkern gleichen, gilt es bei ihnen einen gewissen Arbeitsethos einzuhalten: Der Kunde darf nicht enttäuscht und die Kollegen nicht hängen gelassen werden. Außerdem muss das Endergebnis so hochwertig sein, dass sie mit sich selbst zufrieden sind. Dies legt den Verdacht nahe, dass die Rhodan-Autoren nach Innovationen in ihrer Arbeit streben und nicht die Stereotypie in Reinform repetieren wollen.

Zwischen diesen beiden Polen, Fließband-Schreiberei bis Handwerksbegeisterung, kann man die bisher genannten Romanheftserien einordnen. Bemerkenswert in diesem Zusammenhang ist, dass besonders die Autoren der Perry Rhodan-Serie nicht reine Romanheft-Autoren sind, sondern auch für andere Medien Serien-Texte schreiben. Perry Rhodan-Autor H.G. Francis schuf unter anderem diverse Dialog- 
vorlagen für die erfolgreichen Hörspiele der Die ???-Serie. ${ }^{207}$ Wiederum andere schreiben für das Fernsehen Drehbücher oder wirken an Comics mit. Diese Autoren sind vielmehr Serien-Autoren denn Romanheft-Autoren.

Ein weiteres Phänomen des Romanheftes ist, dass sich einige Autoren im Eigenverlag versuchten. Dieses Engagement der Autoren widerspricht dem, was zu einer Anonymisierung der Autoren geschrieben wurde, wie beispielsweise der Bericht von Hans Thresen:

„Die 14 Millionen Heftchenromane, die pro Monat in der Bundesrepublik erscheinen - ihre Autoren sind nicht in der Gruppe 47 und nicht im PEN-Club, sie treten nicht öffentlich auf Forumsdiskussionen auf [...].“208

Dem kann das Selbstverständnis von Volker Ferkau beispielhaft gegenübergestellt werden:

„Als Schüler veröffentlichte ich Geschichten in den Wochenendbeilagen verschiedener Tageszeitungen.

Eines war mir stets klar:

ICH WILL SCHRIFTSTELLER SEIN!

Nach einige Jahren im Musikbusiness und einer Management-Karriere im Werbe- und Marketingbereich kam ich wieder zum Schreiben zurück. Inzwischen wurden aus meiner Feder eine Vielzahl Romane veröffentlicht, davon einige Romane ausschließlich als eBook."209

Ferkau rettete seine Mythenland-Serie, die er in Mittland umbenannte, in seinen Eigenverlag, in dem er elektronisch publiziert. Ferkau ist kein Einzelfall, es gab diverse Projekte, in denen Autoren ihre Serie ohne Finanzierung weiterführten und gegebenenfalls versuchten, bei anderen Verlagen unterzukommen oder eben in Form des Eigenverlages ihr Werk zu vermarkten, was besonders im Zeitalter des EPublishing wesentlich leichter möglich ist. Sie nehmen sich selbst als Schriftsteller wahr und diskutieren ihren Gegenstand. Dies ist nicht nur auf die Fantasy begrenzt, sondern findet sich vereinzelt in der Science Fiction wieder und sogar bei Jerry Cotton. Heinz Werner Höber berichtet, wie er mit dem Krimi-Genre und dem Heftformat experimentierte:

207 Schwettmann: Allmächtiger, S. 94.

208 Hans Thresen: Die Romanfabrik. Ein Groschenheftschreiber packt aus. In: Texte zur Trivialliteratur. Über Wert und Wirkung von Massenware. Hrsg. Von Ekkehart Mittelberg, Klaus Peter, Dieter Seiffert. Stuttgart 1971, S. 48-54. S. 48.

209 Homepage von Volker Ferkau: http://www.mittland.de/index.php/autor (Zugriff: 25.03.2013; nicht mehr verfügbar). 
„Der erste Roman spielt in einer einzigen Nacht, innerhalb weniger Stunden, und der zweite setzt im Morgengrauen ein und spielt nur an diesem Tag. Das ist für einen Krimi ziemlich schwierig. Dennoch liebte ich solche dramaturgischen Experimente. Ich schrieb einen Cotton, der innerhalb von zwei Stunden spielt, also genau die Zeit, die ein durchschnittlicher Leser für ein Heft braucht." 210

Romanhefte in Echtzeit als Experiment zu verfassen sowie ein ausgeprägtes Selbstverständnis als Autor eines Genres, sind in den anderen Romanheftgenres bisher nicht aufzufinden, zudem werden hier die Autoren-Pseudonyme immer seltener und sind, wenn sie genutzt werden, transparent. Pseudonyme werden also nicht mehr hauptsächlich zum Schutz der Autoren genutzt, sondern vielmehr wie ein Künstlername oder eine Marke. Demgemäß warben bei diversen anderen Romanheftserien die Verlage damit, dass diverse Autoren aus der Perry Rhodan-Redaktion mitschreiben. Auf einem Titelbild der Orion-Serie steht über dem Episoden-Titel nicht nur der Name des Autors sondern: „Perry-Rhodan-Autor H.G. Ewers“211

Es ist wie Elfi Ligenser, Cheflektorin von Bastei, sagt:

„Pseudonyme sind wichtig. Warum sind Pseudonyme so wichtig? 'Als Karin Schmitt kann man keinen Fürstenroman schreiben', begründet Bastei Cheflektorin Elfi Ligenser. 'Das passt einfach nicht.' Bastei gebe fast allen Autoren - um die 100 - einen anderen Namen. 'Viele wollen auch unter Pseudonym schreiben', betont Kelter-Cheflektor Dr. Andreas Schäfer. Jürgen Duensing zum Beispiel: Er schrieb zuerst mit Verlagspseudonym - mehrere Autoren teilen sich einen Namen -, später unter eigenen. ${ }^{212}$

Das Pseudonym bereitet auf diese Weise das Genre vor und einige Autoren nutzen dies als Genre-Konvention innerhalb der Romanhefte, doch sobald ein Autor erfolgreich ist, gilt sein Name oder sein Pseudonym als Markenzeichen und muss, je nachdem, welches von beiden als erstes erfolgreich war, als Wiedererkennungswert weiter genutzt werden. Dies hat nichts mehr mit der Anonymisierung der Autorenidentität zu tun. Im Gegenteil, es unterstreicht für Autoren wie Ferkau oder G.F. Unger sogar ihr Selbstverständnis als Schriftsteller.

210 Eik: Der Mann der Jerry Cotton war, S. 83.

211 Vgl. Terra Astra Bd. 594/145 Orion. Zeitblockade. H.G. Ewers. 1. Aufl. Pabel-Verlag. Die OrionSerie ist eine Subserie innerhalb der Terra Astra-Reihe, daher die doppelte Bandnummer: Die erste (594) steht für die Reihen-Nummerierung und die zweite (145) steht für die fortlaufende Nummerierung innerhalb der Subserie.

212 Susanne von Mach: Herrscher im wilden Westen. (28.02.2009): https://www.main-netz.de/nachrichten/kultur/kultur/art4214,700806? (Zugriff: 17.08.2019). 


\subsection{Der Lektor}

Der Lektor der Perry Rhodan-Serie sowie Lektoren anderer Fortsetzungsserien sollen die Autoren auf allzu schematisch konstruierte Textstellen aufmerksam machen und darauf achten, dass sich der Text in die Serie einfügt. Deshalb wird zumeist ein besonderes Augenmerk auf den Anfang und das Ende eines jeden Manuskripts gelegt. Der Übergang von einem Heft zum Nächsten muss fließend sein, denn der übergeordnete Erzählstrang, der im Exposé festgelegt wurde, darf nicht durchbrochen werden. Klaus N. Frick, Lektor der Perry Rhodan-Serie seit 1992, bezeichnet das Exposé als „Rahmen der Geschichte“213, in dem die Figuren frei gestaltet werden können. Zudem wird viel Wert darauf gelegt, ob technische Daten richtig sind, denn die bereits erwähnte Pseudowissenschaft ist mit der Zeit so komplex geworden, dass der Perry Rhodan-Autor Peter Terrid ein Handbuch daraus zusammenfassen konnte, ${ }^{214}$ das seitdem allen Autoren als Nachschlagewerk dient. Auf diese Weise soll sichergestellt werden, dass die einzelnen Autoren einander nicht widersprechen und genau wissen, was ein spezielles Raumschiff zu leisten vermag oder wie Figuren zu gestalten sind. Dies soll außerdem verhindern, dass ein Charakter beispielsweise in einem Heft eine Narbe auf der Stirn erhält, in dem nachfolgenden aber ein makelloses Gesicht hat. Solche Fehler bemerken Lesern in der Regel und kritisieren es per Leserbrief. Der Lektor muss daher eine genaue Kenntnis von dem Perry Rhodan-Universum besitzen. Klaus N. Frick:

„Wenn ein Autor in einer Nebenszene einen Cheboparner auftauchen läßt, muß ich als Redakteur und Lektor einfach sofort wissen, wie der aussieht und welche Eigenschaften dieser hat. Denn eins ist klar: Die Leser wissen so etwas genau, und sie lassen Fehler in solchen Fragen nicht durchgehen." ${ }^{215}$

Wesentlich schlichter gestaltet sich das Lektorat von Romanheftreihen, da diese keine durchgehenden Elemente führen. Hier werden lediglich verlagspolitische Entscheidungen umgesetzt, wie die bei Sproat bereits erwähnten „religiösen oder

213 Schwettmann: Allmächtiger, S. 231.

2141991 folgte noch ein fünfbändiges Perry Rhodan-Lexikon, dass ca. 6000 Begriffe aus den ersten 1500 Heften umfasst: Horst Hoffmann und Florian F. Marzin (Hg.): Perry Rhodan Lexikon. 5 Bde. Rastatt 1991.

215 Schwettmann: Allmächtiger, S. 231. 
rassischen Gruppen“216. Anna Basener fasst dies nüchtern zusammen:

Und:

„Das Lektorat eines Heftromans ist kein Gespräch über den Stoff. Autor und Lektor stehen hier nicht im ständigen Dialog..."217

„Das Lektorat des Heftromans muss kostengünstig sein und das kommt dem Leser zugute." 218

Eine günstige Heftproduktion ermöglicht auch einen günstigen Verkaufspreis. Wenn über den „Stoff“, also den Plot, zwischen Lektor und Autor nicht verhandelt wird, bleiben somit nur noch sprachliche oder thematische Kritikpunkte. Denkbar sind Verstöße gegen Genrekonventionen oder gegen verlagsideologische Vorgaben (z. B. Tabuthemen oder sexuelle Anspielungen).

Das Lektorat der Fortsetzungsserien wie Perry Rhodan muss allerdings Inhalte mit den Autoren besprechen, da Inkonsistenzen innerhalb der Handlungsstränge Kritik der Serien-Leser zur Folge hätten. In beiden Fällen hat der Lektor das Konzept der Serie oder der Reihe für den Verlag zu bewahren. Dies unterscheidet sich lediglich im Aufwand und der Genauigkeit des Lektorats: Umso aufwendiger das SerienProdukt, desto aufwendiger das Lektorat. ${ }^{219}$

\subsection{Die Künstler}

Aufgrund der aufmerksamen und strengen Leserschaft von Fortsetzungsserien müssen auch die Zeichnungen auf dem Titelblatt sowie innerhalb des Heftes mit der Beschreibung in den Texten übereinstimmen. Von der Perry Rhodan-Redaktion wird vorgegeben, dass die Darstellungen von Raumschiffen auf dem Cover denen im Text entsprechen müssen, ebenso wie die Darstellungen der Raumanzüge oder außerirdischer Wesen. ${ }^{220}$ Aus diesem Grund erhalten die Künstler die gleichen Exposés, die auch die Autoren erhalten haben. Demnach kann der Leser davon ausgehen, dass die Elemente, die in der Zeichnung zu sehen sind, sich auch in der Geschichte wiederfinden lassen. Zumindest geht der Verlag von dieser Haltung der

216 Sproat: Schwerarbeiter in einer Pornofabrik, S. 278.

217 Basener: Heftromane Schreiben, S. 32.

218 Ebd.

219 Die Hefte der Fortsetzungsserien sind zudem auch meist leicht teurer als die der Reihen oder episodalen Serien. So kostet ein Perry Rhodan-Heft 1,95€ und ein Heft aus der FürstenRoman-Reihe 1,60€ (Stand 2014).

220 Schwettmann: Allmächtiger, S. 220f. 
Leser aus. ${ }^{221}$ Auf diese Weise beeinflusst die Illustration die Leseerwartung an den Text und muss daher von der Redaktion streng überwacht werden, zumal das Titelbild das Erste ist, was der Leser wahrnimmt. Auf der Titelseite sind nicht nur Elemente aus dem Heft dargestellt, sondern meist eine komplette Szene.

Innerhalb des Heftes befinden sich in der Regel Risszeichnungen von Raumschiffen oder Gebäuden. Gelegentlich ist auch die Illustration einer Szene dabei. Da für eine Fortsetzungsserie wie Perry Rhodan das Titelbild unerlässlich für das Erscheinen des Heftes ist und nicht wahllos ein Bild genommen werden kann, untersteht der Künstler demselben Zeitdruck wie die Autoren. Der Künstler liest dazu das Exposé sowie gegebenenfalls das fertige Manuskript und konzipiert aus diesen Informationen ein Cover. Hier ist der Künstler, wie auch die Autoren, bestimmten Regeln unterworfen. Das Bild muss einerseits die bereits genannten Blöcke integrieren (Serientitel, Barcode mit Folgennummer sowie Preis und dem Folgentitel) andererseits, trotz der Informationselemente auf dem Cover, ein attraktives Bild bleiben, das zum Kauf anregt. Perry Rhodan-Illustrator Dirk Schulz hierzu:

„Da muß man nicht unbedingt zu nah am Roman bleiben, sondern in erster Linie an die Wirkung des Motivs am Kiosk denken." ${ }^{222}$

Leser der Fortsetzungsserien achten sehr genau auf Details, weshalb die Künstler nicht ganz so frei sind, wie Schulz es andeutet. Die Konzeption muss konform mit der Verlagsideologie gehen, daher finden sich keine allzu anzügliche oder gewaltverherrlichende Darstellungen auf den Covers.

Der Künstler, der für die Risszeichnungen zuständig ist, unterliegt keinem Zeitdruck wie der Künstler für die Titelbilder, da Risszeichnungen nicht regelmäßig in den Heften erscheinen und zum Teil sogar in einer späteren Ausgabe nachgereicht werden können. Sie müssen nicht unbedingt mit der aktuellen Handlung zu tun haben, sondern sind eher Beiwerk. Trotzdem ist auch hier Detailliebe beim Künstler gefragt, denn es bleibt die Prämisse des kritischen und strengen Lesers. Die Künstler sprechen sich deshalb mit den Autoren direkt ab, wenn Details von Raumschiffen unklar sind. Es kommt dabei auch vor, dass sich Autoren von den Vorstellungen des

221 Ebd.

222 Ebd. S. 182. 
Künstlers inspirieren lassen. ${ }^{223}$ Johnny Bruck ${ }^{224}$, der für diverse andere Romanheftserien und -reihen malte, war zu Beginn der Serie alleine für die Titelbilder verantwortlich, doch mit zunehmenden Erfolg der Perry Rhodan-Serie stellte der Verlag ein Team von Künstlern zusammen. Innenillustrationen konnten damit häufiger erscheinen und für die Spin-off-Serien ebenfalls Titelbilder entwickelt werden, die den gleichen Anforderungen entsprechen wie denen der Hauptserie. Heute verteilen sich die Aufträge in einem Team, wobei es gelegentlich zu gemeinschaftlichen Werken kommt. ${ }^{225}$

Diese Genauigkeit in der Visualisierung einer Szene aus dem Plot des Romanhefts lässt sich ebenso bei den Serien Maddrax, Sternenfaust, Professor Zamorra oder John Sinclair wiederfinden, allerdings sind zu diesen Serien keine Aussagen seitens des Verlags über ihre Arbeitsweise dokumentiert. Diese Serien haben einen festen Leserstamm, der an der Entwicklung des Plots stark interessiert ist und sich in diversen Leserbriefen und Forumsbeiträgen zu Wort meldet.

Bei den Reihen und Serien, die keine Leserkontaktseite führen, lässt sich solch eine Genauigkeit nicht beobachten. Bei innen wird die Covergestaltung zu anderen Zwecken eingesetzt. Sie sollen lediglich eine Stimmung wiedergeben und nicht Andeutungen auf den Plot bieten (dazu später mehr). So können die Hefte solcher Reihen relativ wahllos Cover austauschen und wiederverwenden. Diese stammen in der Regel aus dem Archiv des Verlags und werden nicht extra für die Hefte produziert. Zum Teil lassen Verlage ganze Fotoreihen produzieren, die sie nach Gutdünken als Fundus nutzen. ${ }^{226}$ Diese Fotos werden, zumindest für Liebesromane, eher nach dem Titel als nach den Inhalten den jeweiligen Romanen zugeordnet. ${ }^{227}$ Die redaktionelle Produktion dieser Reihen ist nicht so hermetisch mit den Inhalten verbunden wie die der Fortsetzungsserien. Diese müssen Motive für jedes Heft produzieren lassen. Die Künstler, mit denen sie arbeiten, sind keine reinen Romanheft-Künstler. Einige arbeiten als Comic Zeichner, wie zum Beispiel Dirk Schulz, ${ }^{228}$ oder als Risszeichner für Kinofilme, wie Oliver Scholl ${ }^{229}$. Es sind demnach Künstler, die ebenfalls

223 Ebd. S. $176 f$.

224 Eigentlich Herbert Johannes Bruck.

225 Schwettmann: Allmächtiger, S. 164ff.

226 Basener: Heftromane Schreiben, S. 29.

227 Ebd. S. 28.

228 Schwettmann: Allmächtiger, S. $180 f f$.

229 Ebd. S. 184ff. 
wie die Autoren nicht für einen elitären künstlerischen Bereich wirken, sondern regelmäßig im Bereich der Massenmedien arbeiten. Sie sind Künstler und Autoren für Serien. 


\section{Genres der Romanhefte und ihre Besonderheiten}

Um das 'Romanheft' zu verstehen, ${ }^{230}$ ist es unerlässlich, sich mit den Genres zu beschäftigen. Der Begriff 'Genre' wird in der Forschung seit den 1970ern als eine Untergattung verwendet und soll demgemäß hier als eine Untergattung der sogenannten Trivialliteratur Nutzung finden. ${ }^{231}$ Dabei soll 'Genre' in der vorliegenden Arbeit im weitesten Sinne gemäß der Definition von Harald Fricke verstanden werden:

„Ein Text ist genau dann als zu einem Genre gehörig zu betrachten, wenn er (1) einer „eindeutig abgrenzbaren literarischen Textsorte“ angehört, die (2) zur Entstehungszeit des Textes ,in der jeweiligen Nationalliteratur bereits etabliert“ ist, und er (3) entsprechende "Genresignale" aufweist“. ${ }^{232}$

Die Narrationen der Romanhefte lassen sich in thematisch unterscheidbare Gruppen einteilen, die im Folgenden genauer untersucht werden. Hierbei sind nach Fricke die Zugehörigkeit zur Textsorte und ihre Entstehungszeit für die Ausprägung eines Genres der Romanhefte ausschlaggebend.

Diese narrativ-thematischen Gruppen, in der vorliegenden Arbeit 'Genres' genannt, erhalten in der Forschung zuweilen auch andere Bezeichnungen. So nennt Walter Nutz sie die „klassischen Kategorien des Trivialromans“. Darunter zählt er: 1. Den Frauenroman, 2. den Kriminalroman, 3. den Abenteuerroman und 4. den Wildwestroman. ${ }^{233}$ Es wird sich zeigen, dass diese Kategorien nicht ausreichen und zum Teil nicht mehr zutreffend sind, um die aktuelle Entwicklung im Bereich der Romanhefte zu beschreiben, da sie sich weiterentwickelten. Allerdings wird in der aktuellen Sekundärliteratur vermehrt mit diesen Begriffen gearbeitet, daher muss die Untersuchung ihren Weg über diese Begriffe beginnen.

Die eben genannte Weiterentwicklung der Romanheftgenres entspricht der Aussage Frickes, Genres als historisch kohärente und begrenzte Phänomene wahrzunehmen. ${ }^{234}$ Dies meint, dass Genres keinen losgelösten allgemeingültigen Prinzipien

230 Uwe Wittstock schlägt vor, statt von „Trivialliteratur" eher von "Genreliteratur“ zu sprechen. Vgl. in Hackel (Hg.): Die schwere Kunst der leichten Unterhaltung. S. 91.

231 Vgl. hierzu u.a. Dieter Lamping: Genre. In: Reallexikon der deutschen Literaturwissenschaft. Bd. I A-G. Neubearb. Hrsg. von Klaus Weimar. Berlin 1997, S. 704-705. S. 704.

232 Vgl. ebd. S. 704: Harald Fricke zitiert von Dieter Lamping.

233 Walter Nutz: Der Trivialroman seine Formen, S. 23.

234 Vgl. Lamping S. 704. 
folgen, sondern immer in einem historischen Kontext stehen, dem sie entspringen. Sie sind insofern begrenzt, dass eine Definition eines einzelnen Genres nur für einen bestimmten Zeitraum seine Gültigkeit behält, bis neue Einflüsse das jeweilige Genre dominieren. Beispielsweise waren ausgeprägte militärische Staffagen in den 1960 für das Science-Fiction Genre typisch. Diese wurden in den 1970ern und 1980ern durch komplexe Abenteuer ersetzt, die von philosophischen und wissenschaftlichen Theorien inspiriert waren. ${ }^{235}$

Die Verwendung des Begriffs 'Genre' bietet im Zusammenhang mit dem Romanheft den weiteren Vorteil, dass der Begriff im Medienbereich ähnlich genutzt wird und das Romanheft seine Verbreitung per massenmedialen Vertrieb erfährt. Eggo Müller definiert 'Genre' folgendermaßen:

„Auf dem kulturellen Markt erfolgreiche Artefakte werden zu Vorbildern für die massenhafte Produktion und Distribution immer neuer Artefakte desselben Typs, die den 'Prototypen' variieren. Dadurch entstehen im historischen Prozeß für gewisse Phasen relativ stabile Muster der Produktion und Rezeption kultureller Artefakte“. ${ }^{236}$

Die von Müller genannten 'Prototypen' sind bei den Romanheften unterschiedlichen Ursprungs und entsprechen den oben erwähnten historischen Kontexten, aus denen sie entsprangen. Viel entscheidender für die Untersuchung des Romanheftes als serielle Narration sind die „stabilen Muster der Produktion und Rezeption“: Ein erfolgreicher 'Prototyp' wird zum Muster erhoben, welches wiederum vom Publikum erwartet wird. Das Genre muss als Muster eines Prototyps also bestimmte Rezeptions-Erwartungen erfüllen. Demnach ist es so zu verstehen, dass jedes Genre ein eigenes Muster ausformt. ${ }^{237}$ Welche Muster sich in den Genres der Romanhefte wiederfinden, ist Gegenstand der folgenden Kapitel.

Mit der Wahl eines Genres für eine Romanheftreihe oder -serie entscheidet sich der Verlag somit für eine Zielgruppe an potenziellen Lesern, daher soll anhand der Untersuchung der Romanheftgenres ebenfalls die potenzielle Leserschaft umrissen werden. Es soll hier keine grundlegende Untersuchung über die wirklichen Leser der

235 Hierzu in Kapitel 4.7 „Science Fiction und Space Opera“ mehr.

236 Eggo Müller: Genre. In: Handbuch Populäre Kultur. Hrsg. Von Hans-Otto Hügel. Stuttgart 2003. S. 212-215. S. 213.

237 Hißnauer weist im Zusammenhang zu den Filmgenres auch auf den Ansatz von Andrew Tudor hin, dass Genres nicht nur über ihre tradierten narrativen Muster definiert werden, sondern auch über ihre Intention. Vgl. Christian Hißnauer: Fernsehdokumentarismus. Konstanz 2011. S. 156ff. 
Romanhefte geleistet werden, da es vielmehr um den theoretischen Leser geht, auf den die Romanheftgenres zugeschnitten sind. Hierbei ist es für die vorliegende Betrachtung unerheblich, welche Leser die Verlage tatsächlich erreichen. Dies könnte zudem nur adäquat im Rahmen einer empirischen Studie geschehen und wäre somit eine sozialwissenschaftliche Fragestellung. ${ }^{238}$ Das Augenmerk der folgenden Untersuchung liegt auf der Genre-Auswahl der jeweiligen Verlage: Für welchen Themenschwerpunkt entscheiden sie sich?

\subsection{Identifizierung der Romanheftgenres}

In Abgrenzung von theoretischen Betrachtungen soll nun beleuchtet werden, wie die Verlage ihre Reihen und Serien selbst in thematische Bereiche gruppieren und benennen. Der Bastei-Verlag führt folgende Bereiche in seinem Verlagsprogramm unter Romane: „Krimi\&Action“, „Western\&Helden“, „Grusel\&Horror“, „SF\&Fantasy“ „Adel\&Liebe“, „Ärzte\&Schicksal“ und „Heimat\&Berge“. 239

„Krimi\&Action“ beinhaltet lediglich Kriminalgeschichten, in dem beim Bastei-Verlag aktuell nur die Jerry Cotton-Serie geführt wird. Ähnlich finden sich in den Themenbereichen „Western\&Helden“ sowie „Grusel\&Horror“ jeweils Romanhefte mit Western- beziehungsweise Horrorgeschichten. Der Bereich „SF\&Fantasy“ führt zwar nur eine Serie, die allerdings Science Fiction und Fantasy-Elemente in sich gleichermaßen vereint: Die Maddrax-Serie. Die letzten drei Themengruppen „Adel\&Liebe“, „Ärzte\&Schicksal“ und „Heimat\&Berge“ sind Serien, die allesamt Liebesgeschichten in den Fokus ihrer Narrationen nehmen.

Der Kelter-Verlag führt folgende Themenbereiche: „Arzt“, „Heimat“, „Liebe\&Familie“, „Adel“, „Western“ und „Mystik“. 240 Bis auf „Western“ subsumieren hier alle Bereiche Romanhefte mit Liebesgeschichten. Die Romane im Block „Mystik“ stellen ebenfalls vielmehr Liebesromane als Romane aus dem Bereich der Phantastik dar. Entsprechend wirbt der Verlag für die Gaslicht-Reihe:

„Um Mitternacht werden die kühnsten, leidenschaftlichsten Stories zur Entscheidung gebracht. Nervenkitzel, der unter die Haut geht und dabei immer

238 Vgl. hierzu u.a. Walter Nutz vorbildliche Untersuchung in: Trivialliteratur und Popularkultur.

239 https://www.bastei.de/indices/index_allgemein_22709.html (Zugriff: 17.08.2019).

240 https://www.kelter.de/44-roman (Zugriff: 17.08.2019). 
die romantischen Gefühle der Leserinnen anspricht.“241

Die „romantischen Gefühle“ sollen hier eher die amourösen als die intellektuellen Belange der Leserinnen ansprechen.

Der Cora-Verlag, der tendenziell mehr auf Taschenromane ${ }^{242}$ als auf Romanhefte spezialisiert ist, führt scheinbar eine hohe Bandbreite an Roman-Themen: „Liebesromane“, „historische Romane“, „Krimis“ und „Western“. ${ }^{243}$ Betrachtet man die Themenblöcke des Cora-Verlages genauer, zeigt sich jedoch schnell, dass es sich dabei um Liebesgeschichten handelt, die lediglich mit einschlägiger Staffage aus den jeweiligen Themenbereichen bestückt sind (z. B. ein historisches Setting für eine Liebesgeschichte, anstatt eines historischen Ereignisse im Zentrum des Romans). Ein Beispiel:

„Die Faszination vergangener Zeiten wird in unseren historischen Romanen lebendig. Ob im Mittelalter oder im 19. Jahrhundert, diese Liebesromane nehmen Sie mit auf eine unterhaltsame Zeitreise auf Ritterburgen und Wikingerschiffe. Packende Geschichten, atemberaubende Abenteuer und galante Romanzen in der Welt des englischen Adels erwarten Sie und lassen Sie für eine Weile das Hier und Jetzt vergessen.“244

Wie dies in den einzelnen Serien und Reihen im Detail gewichtet wird, wäre sicherlich aufschlussreich, doch würde es hier zu weit führen.

Der Pabel-Moewig-Verlag fällt aus dieser Betrachtung heraus, da er zum einen keine (narrative) Abteilung „Romane“ im Verlagsprogramm führt und zum anderen lediglich eine einzige Romanheftserie verlegt: Perry Rhodan. Bis 2013 führte der Verlag noch eine zweite Serie Der Landser, auf die ebenfalls eingegangen werden muss, da sie in der Fachliteratur zur Trivialliteratur immer wieder für Kontroversen sorgte.

Innerhalb dieser beiden Serien wurden bis 2013 diverse Sub-Serien geführt. Bei Perry Rhodan waren dies beispielsweise: Perry Rhodan 1. Auflage, Perry Rhodan 5.

241 https://www.kelter.de/52-mystik (Zugriff: 17.08.2019).

242 Taschenromane werden auch gelegentlich als Taschenhefte bezeichnet. (Vgl. hierzu Galle: Volksbücher und Heftromane Bd. 3, S. 249f.) Dies leitet sich vermutlich vom Begriff Taschenbuch ab. Galle vermerkt hierzu: „Der Taschenroman stellt quasi ein Mittelding zwischen Taschenbuch und Heftroman dar, im Format (Digest-Format) etwas größer als ein Taschenbuch, doppelt so dick wie ein Heft, preislich zwischen Taschenbuch und Heftroman angesiedelt, mit einem Glanzpapierumschlag versehen und mit einem größeren Schriftbild sowie ohne Spalteneinteilung ausgestattet." (Ebd. S. 250).

243 https://www.cora.de/collections/zeitgenossische-liebesromane (Zugriff: 17.08.2019).

244 https://www.cora.de/collections/historische-liebesromane (Zugriff: 17.08.2019). 
Auflage, Perry Rhodan Neo, Perry Rhodan Planetenromane und Atlan. ${ }^{245}$ Die beiden Serien Perry Rhodan und Der Landser wurden, wie gesagt, nicht unter der Abteilung "Romane" geführt, sondern separat in den Bereichen "Science Fiction" und „Dokumentation“. Dies ist vermutlich auf die Struktur des übergeordneten Verlagsprogramms zurückzuführen, da der Pabel-Moewig-Verlag sich im Laufe der Zeit auf Zeitschriften spezialisiert hat und narrative Produkte nun hierbei entfallen.

Im Weiteren soll der Fokus vermehrt auf die Verlage Bastei und Kelter gelegt werden, da diese sich auf narrative Romanhefte spezialisiert haben. Somit lassen sich vorerst folgende verlagsübergreifende Themenbereiche für aktuelle sowie für eingestellte Romanheftserien aus der jüngsten Vergangenheit explizieren:

1. Liebesromane mit ihren Subthemen

1.1 Adelsroman

1.2 Arztroman

1.3 Heimatroman

1.4 Familie

2. Western

3. Krimi

4. Horror

5. Science Fiction

6. Fantasy (in diesem Bereich gab es eine hohe Fluktuation von Serien) 7. Historisch

Diese Themenbereiche sollen hier als mögliche Genres der Romanhefte untersucht werden. Auffällig ist, dass schon jetzt die zuvor erwähnten „Kategorien des Trivialromans" nach Nutz (Frauenroman, Kriminalroman, Abenteuerroman, Westernroman) vorliegende Themenbereiche nicht mehr abdecken.

Peter Nusser identifiziert hingegen folgende Untergruppierungen innerhalb des Bereichs der Trivialromane: ${ }^{246}$

a) Familien- und Liebesromane

b) Schauer-, Geheimbund- und Räuberroman

c) Verbrechens-, Mysterien- und Kriminalromane

245 https://www.vpm.de/zeitschriften/science-fiction.html (Zugriff: 17.08.2019). Mittlerweile sind auf der Verlagshomepage nur noch die Hauptserie und Perry Rhodan NEO gelistet.

246 Nusser: Trivialliteratur, S. $57 \mathrm{ff}$. 
d) Reise- und Abenteuerromane

e) Science Fiction

f) Historische und zeitgeschichtliche Romane

g) Heimatromane

Diese Einteilung Nussers dient zwar übergreifend für die gesamte Gattung der Trivialliteratur, jedoch zeigt sich, dass sich einige von seinen Gruppierungen für das Romanheft durchaus nutzen lassen. Die Gruppierungen beziehungsweise Einteilungen von Nutz und Nusser sollen im Folgenden 'Kategorien' genannt werden, um sie der Übersicht halber von dem Begriff 'Genres der Romanhefte' abzugrenzen. Wenn im Folgenden die Rede von 'Genres' ist, ist in der Regel 'Genres der Romanhefte' gemeint.

Den sieben Kategorien Nussers lassen sich leicht aktuelle Genres der Romanhefte zuordnen, zumal die Kategorie der Familien- und Liebesromane die Tradition widerspiegelt, in der auch der Frauenroman aus Nutz' Auflistung steht: Thematik dieser Romane ist die Herstellung von Harmonie in den Familien und die Bedrohung der Sittsamkeit, zumeist die einer jungen Frau, ${ }^{247}$ daher könnte das, was Nutz unter Frauenroman, Berg- und Heimatroman, Arztroman und Sittenroman fasst, leicht unter Nussers Kategorie zusammengeführt werden. Dabei ist zu beachten, dass die Kategorie „Heimatromane“ von Nusser einen anderen Schwerpunkt hat als die von Nutz angeführten „Berg- und Heimatromane“. Im folgenden Kapitel dazu mehr.

\subsection{Der Frauenroman ist ein Liebesroman}

Was 1960 von Nutz als „Frauenroman“ typologisiert wurde, ${ }^{248}$ könnte heute unter den Romanheften als „Liebesroman“ bezeichnet werden. Es wird sich im Weiteren zeigen, dass die Bezeichnung „Frauenroman“ nicht mehr zutreffend ist und vielmehr Verwirrung stiftend als sinngebend ist.

Die Heftreihen, die im Folgenden zu den Liebesromanen gezählt werden sollen, haben ihren Ursprung im sogenannten Frauenroman, der aber nicht auf eine Publikationsform beschränkt war, sondern, wie es die Bezeichnung bereits andeutet, sich hauptsächlich an eine bestimmte Leserschaft richtete. Daher schreibt Nutz: „Frauen- 
romane werden stets für Frauen geschrieben und handeln von Frauen.“249

Diese „Frauenromane“ erschienen in unterschiedlichen Formen: Als Kolportageromane oder als Fortsetzungsromane in Periodika. ${ }^{250}$ Der prominenteste Vertreter für die Verbreitung solcher Frauenromane am Ende des neunzehnten und zu Beginn des zwanzigsten Jahrhunderts war die Gartenlaube. ${ }^{251}$ In dieser Zeitung veröffentlichten die Autorinnen Eugenie Marlitt und Hedwig Courths-Mahler diverse Geschichten, die für die sogenannten Frauenromane nach Nutz von eminenter Bedeutung waren. ${ }^{252}$ Zwar gab es auch diverse andere Autorinnen und Autoren, die in etlichen alternativen Formen publizierten, allerdings sind sie für diese Untersuchung vorerst unerheblich und der Fokus soll auf Courths-Mahler und Marlitt als Stellvertreterinnen des Frauenromans liegen. ${ }^{253}$

Die wiederkehrenden Handlungsstrukturen und Figurenkonstellationen der beiden Autorinnen sind für die Frauen-Romanhefte angeblich noch aktiv. Zumindest sind sich die Experten seit den sechziger Jahren darüber einig. ${ }^{254}$ So schreibt Scheichl über die Romane von Marlitt:

„Die Bücher der Autorin sind bis jetzt mit Hilfe des Schemas von Gut und Böse, von der Liebe und den sich ihr entgegenstellenden Hindernissen dargestellt worden, das sich auch auf Courths-Mahler und, trotz allen gesellschaftlichen Veränderungen, noch auf den Heftroman der Gegenwart anwenden läßt." ${ }^{255}$

Scheichl attestiert, dass sich auch in den Romanheften der 1980er Jahre eine Polarisierung von Gut und Böse finden lässt. Nusser bestätigt in den 1990ern Scheichls Aussage:

„Die ständige Wiederholung derartiger oder ähnlicher Grundverhältnisse [in den Romanen Marlitts], innerhalb derer nur an der Oberfläche variiert wird, ist (nicht nur) im Familien- und Liebesroman bis heute üblich geblieben und

249 Walter Nutz: Konformliteratur für die Frau. In: Trivialliteratur. Hrsg. von Gerhard Schmidt-Henkel, Horst Enders, Friedrich Knilli und Wolfgang Maier. Berlin 1964, S. 65-74. S. 65.

250 Vgl. ebd.

251 Diese Zeitung war für den Gründer Ernst Keil u.a. ein Werkzeug zur Aufklärung des Volkes. Vgl. Sigurd Paul Scheichl: E. Marlitt. In: Erzählgattungen der Trivialliteratur. Hrsg. von Zedenko Skreb. Innsbruck 1984, S.67-112. S. 74f.

252 Vgl. u.a. Nutz: Konformliteratur für die Frau, S. 65.

253 Die Geschichte des Frauenromans aus Sicht des Sammlers lässt sich ausführlich bei Heinz J. Galle nachlesen: Volksbücher und Heftromane. Bd. 3, S. $200 \mathrm{ff}$.

254 Vgl. u.a. Scheichl: E. Marlitt, S. 90, Nutz: Der Trivialroman seine Formen, S. 27ff. oder Nusser: Romane für die Unterschicht, S. 77ff. und Nusser: Trivialliteratur, S. 62.

255 Scheichl: E. Marlitt, S. 90. 
bestimmt auch noch die gegenwärtige Heftromanliteratur.“256

Mit „Grundverhältnissen“ meint Nusser nicht nur die Polarisierung von Gut und Böse, sondern auch sich wiederholende Grundverhältnisse im Bereich der Figuren und Schauplätze. Er bezieht sich dabei auf ein Schema von Scheichl:

„Die 'Fabel’ [die Geschichte in dem Frauenroman] folgt einem festen Schema [...]; das Figureninventar wiederholt sich [...]; die Art und Weise der Figurencharakteristik, die äußeres Aussehen und moralische Bewertung miteinander verquickt, ist stereotypisiert; als Schauplätze fungieren das Schloß oder der Edelsitz, zumindest eine vornehme Villa, um den Luxus des Wohnens als Reiz an die Leser weitergeben zu können [...].“257

Auf die Figuren bezogen, lautet die erste Prämisse des Frauenromans nach Nutz: „Grundsätzlich ist im Frauenroman die Hauptperson eine Frau.“258 Dadurch dominieren sie die Romane dieser Strömung besonders im Bereich der positiv gewerteten Figuren. ${ }^{259}$ Zusätzlich geben die Figuren ihren Charakter durch ihr Äußeres preis, ${ }^{260}$ daher ist die Heldin in der Regel immer schön und ohne Makel, wohingegen die Gegner von Makel gezeichnet sein müssen. Hierbei kennen die Frauenromane angeblich „keine Differenzierung“261, das heißt, es gibt keine Grauzonen zwischen den Polen Gut oder Böse. Die Gegner stellen nach Scheichl in der Regel „Kontrastfiguren“ zu den Heldinnen dar, ${ }^{262}$ wobei diese Figuren keine Persönlichkeiten haben, sondern nach Nusser Stereotypen gleichen, deren Charaktereigenschaften vom Beginn der Geschichte an festgelegt seien und sich nicht mehr entwickeln. ${ }^{263}$ Des Weiteren darf die makellose Heldin laut Nutz in ihrem Leben nur einmal lieben. ${ }^{264}$ Diese Figuren verlieben sich daher in den Geschichten in der Regel zum ersten $\mathrm{Mal}^{265}$ oder stellen fest, dass sie vorher noch nie verliebt waren.

Der Ort der Handlung ist laut Nutz selten lokalisiert und spielt für die Handlung nur eine untergeordnete Rolle. Er dient lediglich zur Begründung der Staffage ${ }^{266}$ denn „[j]ede Passage im Roman, die nicht unmittelbar in Beziehung zur Handlung steht, ist

256 Nusser: Trivialliteratur, S. 62.

257 Ebd.

258 Nutz: Der Trivialroman seine Formen, S. 28.

259 Scheichl: E. Marlitt, S. 83.

260 Ebd. S. 85.

261 Nutz: Der Trivialroman seine Formen, S. 30.

262 Scheichl: E. Marlitt, S. 81f.

263 Nusser: Romane für die Unterschicht, S. 78.

264 Nutz: Der Trivialroman seine Formen, S. 29.

265 Scheichl: E. Marlitt, S. 77.

266 Nutz: Der Trivialroman seine Formen, S. $29 f$. 
unerwünscht." ${ }^{267}$ Der Plot steht immer im Vordergrund und muss letztendlich zum Happy End führen, ${ }^{268}$ welches in der Regel aus einer Heirat oder einer Verlobung besteht. ${ }^{269}$ Zur Überwindung dieser Widerstände ${ }^{270}$ greift das Schicksal oder der Zufall stets entscheidend ein. ${ }^{271}$

Laut Nutz lassen sich diese Handlungs- und Figurenstrukturen auch in den „verwandten Formen des Frauenromans“ wiederfinden, ${ }^{272}$ die unter anderem von Nutz und Nusser von dem Frauenroman abgegrenzt werden. Nutz rubriziert unter den „[V]erwandte[n] Formen des Frauenromans“273 drei Arten:
a) den Heimat- und den Bergroman,
b) den Arztroman und
c) den Sittenroman.

Nutz sieht diese drei Romanformen durchaus im Sinne des Frauenromans, nur dass sie sich im Milieu unterscheiden und so einige Abwandlungen des Schemas begründen. Allerdings verortet er diese drei Romanformen parallel zu dem Frauenroman innerhalb des Bereichs der Romanhefte. Zudem bleibt hierbei offen, in welchen Bereich die Hefte des Adelsromans zugeordnet werden sollten.

Da der Frauenroman die Quelle der dominantesten Handlungsstrukturen innerhalb der zuvor von Nutz genannten Romanarten ist, liegt es nahe, ihm die anderen Arten unterzuordnen. Dabei ergibt sich jedoch das Problem, dass mit den Berg- und Heimatromanen unter anderem auch das männliche Publikum angesprochen werden sollte. ${ }^{274}$ Zudem ist in den meisten Arztromanheften eine männliche Figur titelgebend für die Serie und keine Frau: Dr. Stefan Frank, Dr. Norden, Chefarzt Dr. Holl, Dr. Laurin et cetera.

Romanhefte, die der Romanform nach Nutz den Berg- und Heimatromanen zugeordnet werden, haben zwar ihren Ursprung in Nussers Kategorie „Heimatroman“, jedoch werden sie nicht derselben zugeordnet, da sie von ihrem Inhalt her „Familien- und Liebesromane“ seien. Es ist daher unerlässlich, die Genres der

269 Scheichl: E. Marlitt, S. 79.

270 Nusser: Romane für die Unterschicht, S. 79.

271 Scheichl: E. Marlitt, S. 79.

272 Nutz: Der Trivialroman seine Formen, S. $42 \mathrm{ff}$.

273 Ebd.

274 Ebd. S. 45. 
Romanhefte von den allgemeinen Kategorien der Trivialliteratur nach Nusser zu unterscheiden und nicht gleichzusetzen.

Zudem ist es notwendig, im Bereich des Romanheftes nicht vom „Frauenroman“, sondern vom „Liebesroman“ als Hauptgenre zu sprechen, unter das sich diverse Subgenres ordnen, denn es handelt sich bei den Subgenres Adelsheftromane, Bergund Heimatheftromane und Arztheftromane um Liebesromane, die sich in der Wahl ihres Milieus unterscheiden und nicht zwingend auf Frauen als Leser abzielen. Gabriele Strecker schrieb 1969 dazu:

„Hier befinden wir uns nicht mehr im Gebiet, das Anspruch auf den Namen 'Literatur' hätte, sondern im Reich der Güterproduktion, wo die Ware 'Frauenroman' heißt. Nur das Wort 'Frauenroman' ist gemeinsam mit dem Frauenroman der Marlitt oder der Eschstruth." ${ }^{275}$

Durch die Deklarierung „Liebesroman“ als ein Romanheft-Hauptgenre können auch unzeitgemäße Subgenres, wie zum Beispiel der von Nutz genannte „Sittenroman“276, aufgelöst und neue Subgenres gegebenenfalls aufgenommen werden, ohne dass sich die Genrestruktur im Ganzen verändern würde. Die Milieus der Liebesromanhefte unterliegen in der Regel dem Wandel einer zeitgemäßen Vorstellung eines Milieus. Es würden nach Nutz also keine tatsächlichen Milieus vorgestellt und aufgearbeitet, sondern lediglich eine Vorstellung, die die Autoren davon haben und dem Leser vermitteln wollen. ${ }^{277}$ Auf diese Weise würden Klischees innerhalb des Genres repetiert und gelegentlich aktualisiert.

\subsubsection{Rollenbild der Frau in Liebesromanheften}

Bevor die einzelnen Subgenres des Liebesromanheftes betrachtet werden, soll das Rollenbild der Frau kurz umrissen werden, da Frauenfiguren in der Regel im Vordergrund der Liebesromanheft-Handlungen stehen, selbst wenn die Hauptfigur beispielsweise Dr. Norden oder Dr. Stefan Frank ist. In den Romanen Marlitts und Courths-Mahler, die bisher als Vorbilder der Romanhefte galten, sind Rollenbilder präsent, die nicht mehr auf die aktuelle Gesellschaft zutreffen. Ingrid Müller fasst die Protagonisten in Courths-Mahlers Werken folgendermaßen zusammen:

275 Gabriele Strecker: Frauenträume Frauentränen. Weilheim/Oberbayern 1969. S. 159.

276 Nutz: Der Trivialroman und seine Formen, S. 48f.

277 Ebd. S. 32f. und S. 45. 
„Im Mittelpunkt der Romane stehen fast immer nicht-berufstätige junge Mädchen, die meistens finanziell durch ihre Herkunft gesichert sind. Gegenüber den männlichen Hauptpersonen der Romane, Väter und Ehemännern, zeigen sie völlige Anpassungsbereitschaft unter Verzicht auf eine eigene Persönlichkeitsentwicklung. Als Lohn für die Unterdrückung eigener Strebungen winkt das Happy-End, das als einzige Möglichkeit das Glück garantiert." ${ }^{\text {"278 }}$

Müller geht sogar noch weiter und beschreibt die Figuren in Courths-Mahlers Werken als "unglaubwürdig":

„Sie können aufgrund von Furcht und Abhängigkeit nicht als freie Persönlichkeiten erscheinen. Auch die stets schönen und tugendhaften Frauengestalten sind nur leblose Erscheinungen, die aus beliebig vertauschbaren Eigenschaften bestehen. Ihr aufopferndes, hilfsbereites und fleißiges Verhalten erscheint durch die Häufung des Positiven unglaubwürdig. ${ }^{279}$

In Bezug auf die reale Welt resümiert Müller:

„Den komplexen Rollenerwartungen der Frau in der heutigen Gesellschaft [1978] steht in den Romanen die Regression auf veraltete gesellschaftliche Vorstellungen gegenüber. Nur totale Unterwerfung der Frau, nicht Attribute wie Intelligenz, Aktivität, Kritik scheinen das Glück zu sichern. ${ }^{280}$

Nusser berichtet, dass die Frau zu Zeiten Marlitts für ein wohliges Zusammensein im Heim zu sorgen hatte und dass die Darstellung gewisser Lasterhaftigkeiten in den Liebesromanen dafür sorgte, die Leserinnen in ihrer Sittsamkeit zu bestätigen. ${ }^{281}$ Insofern leuchtet die Bezeichnung „Konformliteratur" in diesem Kontext für jene Texte durchaus ein, doch die Rollenbilder von Marlitt und auch von Courths-Mahler werden bei Nutz ebenso auf die Romanhefte übertragen. Es stellt sich also die Frage, inwiefern Rollenbilder aus dem vorherigen Jahrtausend für heutige Leserinnen und Leser ein Identifikationspotenzial bieten.

Eine mögliche Antwort ist, dass es kein Potenzial gibt, denn Galle arbeitet heraus, wie einige von Courths-Mahlers Geschichten im Zuge einer "Nostalgiewelle“ in den siebziger Jahren ins Fernsehen kommen. ${ }^{282}$ Zudem wurden die Romane von

278 Ingrid Müller: Untersuchungen zum Bild der Frau in den Romanen von Hedwig Courths-Mahler. Bielefeld 1978. (Bielefelder Hochschulschriften Bd. 16), S. 56.

279 Ebd.

280 Ebd.

281 Nusser: Trivialliteratur, S. $58 f$.

282 Galle: Volksbücher und Heftromane Bd. 3, S. 246. 
Courths-Mahler für die Heftform stark gekürzt und den Bedürfnissen der Leser des Romanheftes angepasst: ${ }^{283}$

„In der HEDWIG-COURTHS-MAHLER-Heftausgabe wurden zeitgeschichtliche Hinweise gestrichen, Beschreibungen technischer Geräte modernisiert, alle Begriffe aus dem Militär, die damals gang und gäbe waren, eliminiert sowie ausufernde Landschaftsschilderungen entfernt. “284

Die Texte wurden somit aktuellen Leseanforderungen angepasst. Außerdem sollen im Jahr 199890 Prozent der Courths-Mahler-Heftleser ältere Frauen gewesen sein. ${ }^{285}$ Diese kennen die Geschichten höchstens aus ihrer Kindheit und erfreuen sich eines Nostalgiegefühls bei einer neuerlichen Lektüre. Somit wäre für diese Leserinnen nicht ein spezifisches Rollenbild in den Geschichten ein Identifikationsaspekt, sondern die Erinnerung an die Lektüre selbst, als sie jünger waren. Wobei die Texte auf das neue Medium 'Romanheft' zugeschnitten wurden. Damit konnte der Verlag unter anderem sicherstellen, dass die Narration unerfahrene Courts-Mahler-Leser nicht mit unbekannten Begriffen aus dem Militär oder „ausufernden Landschaftsschilderungen“ konfrontierte. Auch wenn die Courts-Mahler-Geschichten als stärkster Einfluss auf das Hauptgenre „Liebesroman“ galten, mussten sie sich in der Neuauflage im Romanheft-Format den aktuellen Bedingungen unterwerfen.

Hinsichtlich stereotyper Figuren und Handlungsschemata schreibt Walter Nutz 1964 über die Liebesromane: „[Die Frauenromane] sind in ihrer Grundstruktur und in ihrem Gesamtaufbau so identisch, als stammten sie von einem Autor, wenn man von individuellen Schnörkeln absieht“. ${ }^{286}$ Es ergeben sich jedoch ab den 1990ern unterschiedliche Grundstrukturen, wenn man Romanhefte von 1964 mit den zeitgenössischen Exemplaren vergleicht. Nutz hält fest: „Diese Norm, die mit ihren Stereotypen den Mittelpunkt der Frauenromanform darstellt, erfährt nur ab und zu zeitbedingte Abweichungen. "287 Das Prinzip als solches ist demnach in dem Bereich der Romanhefte erhalten geblieben. In den siebziger Jahren beschreibt Franziska RuloffHäny in ihrer Untersuchung über den „modernen“ Trivialroman den Frauentyp folgendermaßen: „Die Heldinnen sämtlicher Romane lassen sich mit der Formel „zart und

283 Ebd. S. 249.

284 Ebd.

285 Ebd.

286 Nutz: Konformliteratur für die Frau, S. 66.

287 Nutz: Der Trivialroman seine Formen, S. 34. 
einsam, passiv, aber doch tüchtig“ beschreiben." ${ }^{288}$

In den Neunzigern nimmt sich die Darstellung der Weiblichkeit in den Romanheften laut Thiel etwas modernisierter aus: „Die Heldinnen des modernen Liebesromans sind intelligent, fleißig, charmant und selbstbewußt. Diese Eigenschaften brauchen sie, um das zu erreichen, was diese Romane allen Heldinnen zuschreiben: beruflichen Erfolg.“ ${ }^{289}$ Dies scheint zunächst, wie Thiel meint, konträr zu der Darstellung im „traditionellen Groschenheft“ ${ }^{290}$ zu sein, denn vormals wurde die Frau als passiv und nur ihre Gegenspielerin als selbstbewusst und aktiv dargestellt. Nach Thiel „kennt [der moderne Liebesroman] keine bipolare Anordnung der Hauptfiguren, keinen Antihelden und keine Antiheldin. “291 Dies kann jedoch eher als Tendenz denn als Ist-Zustand gewertet werden. In aktuellen Heften findet sich gelegentlich noch immer die typische Widersacherin, die ehrgeizig und arrogant ist. So wie beispielsweise in Band 731 „Ich küsse deine Tränen fort" aus der Fürsten-Roman-Reihe: In der Geschichte erhält die Antagonistin Ilona vom Prinzen, der der Heldin zugetan ist, einen Laufpass. In ihrem Ärger darüber enthüllt sich ihr Selbstbewusstsein als Eitelkeit und Arroganz:

„Sie hätte dann zum Hochadel gehört und sich vor bedeutenden Einladungen nicht retten können. Aus der Traum. Sie würde wieder in die Bedeutungslosigkeit versinken und nicht mal ihre Putzfrau würde sie bitten, ihr ein Autogramm zu geben." ${ }^{292}$

Die „neue“ Heldin ist nach Thiel zwar beruflich aktiv, aber sobald es um Liebesangelegenheiten geht, falle sie in ein passives Verhaltensmuster. ${ }^{293}$ Zumindest handelt es sich hierbei nicht mehr um eine Eigenschaft, die den Charakter zur Gänze beschreibt, sondern lediglich einen Aspekt. Allerdings lässt es sich als bemerkenswerte Wandlung begreifen, dass einige der Attribute, die vormals der Widersacherin zugesprochen wurden, nun zum Teil dem Konzept der Heldin zugeordnet sind. Jetzt ist die positive Beschreibung der Heldin auf „ihre sexuelle Attraktivität“ hin angelegt. ${ }^{294}$

288 Franziska Ruloff-Häny: Liebe und Geld. S. 21.

289 Christian Thiel: Liebe, Sex, Karriere. Die Modernisierung des trivialen Liebesromans. Hamburg 1991. S. 22.

290 Ebd.

291 Ebd. S. 15.

292 Fürsten-Roman Bd. 731. Ich küsse deine Tränen fort. Bianca-Maria. 1. Aufl. Bastei-Verlag. S. 26.

293 Thiel: Liebe, Sex, Karriere, S. 22.

294 Ebd. S. $16 f$. 
Neben der Möglichkeit der „neuen“ Heldin, eine Karrierefrau zu sein, deklariert man sie nicht mehr als vorbildliche Hausfrau, um als ideale Frau zu gelten. ${ }^{295}$ Thiel führt das auf den „Lebensentwurf eines großen Teil der Leserinnen“ zurück, der mit solch überholten Frauenbildern kollidiere. ${ }^{296}$ Dies zeigt, dass das Rollenbild der „traditionellen Groschenhefte“ nur noch für die Courths-Mahler-Hefte zutrifft. ${ }^{297}$ Im Vergleich zu „traditionellen“ Liebesromanen wird in den aktuellen Romanheften kaum noch die Stellung der Frau in der Gesellschaft thematisiert. Dies ist lediglich in den CourthsMahler-Heften Thema. Auch aus diesem Grund entsprechen moderne Liebesromane den Werken ihrer Vorgänger nicht mehr, da nun der Fokus stärker auf der Etablierung einer Liebesbeziehung liegt, die nicht der bloßen gesellschaftlichen Absicherung der Heldin dient, denn diese ist zu einer unabhängigen Frau geworden. Die Liebesbeziehung bedeutet in den Liebesromanen somit nicht mehr, wie Müller es beschreibt, die „totale Unterwerfung der Frau“. 298

\subsubsection{Subgenres der Liebesromanhefte}

\section{Adelsromane}

Auffällig auf der Seite der Distribution ist, dass der Bastei- und der Kelter-Verlag jeweils einen Themenbereich führen, in der sie Liebe mit einem Subgenre verknüpfen. Kelter hat „Liebe\&Familie“ zusammengefasst, Bastei „Adel\&Liebe“. In diese Bereiche sortieren die Romanheft-Verlage jene Serien und Reihen ein, welche kein eigenständiges Subgenre gebildet haben, aber dennoch dem Hauptgenre angehören. Die Zuordnung erfolgt vermutlich nicht systematisch, sondern pragmatisch. „Liebe“ könnte hier auch für „Sonstiges“ stehen. Den Kategorien werden sonstige Liebesromane zugeordnet, in denen die Verlage nicht so breit aufgestellt sind wie in

\section{Ebd. S. 23.}

296 Ebd.

297 Strecker sieht die Hefte jedoch noch sehr stark in der Tradition der Courths-Mahler-Romane (vgl. Strecker: Frauenträume, S. 160f.). Dies mag für damals durchaus zutreffend gewesen sein, ist aber nicht mehr auf die heutigen Adelsromanhefte anwendbar. So ist hier auch ein Forschungsdesiderat zu erkennen, dass es zu untersuchen gilt: Inwiefern hat sich das Liebesromanheft seit den sechziger Jahren bis heute verändert? Eine Arbeit mit solch einem Erkenntnisinteresse würde eine umfassende Textanalyse voraussetzen, die einen Zeitraum von 50 Jahren abdecken muss.

298 Müller: Untersuchungen zum Bild der Frau in den Romanen von Hedwig Courths-Mahler. S. 56. 
ihren anderen Themenbereichen. Vermutlich wurde unter anderem aus diesem Grund das Heft-Cover der Silvia-Schicksal-Reihe vergoldet, da die meisten Adelsromane mit einem goldenen Cover als Genre-Signal versehen sind. In diesem Bereich gibt es nur wenige Ausnahmen, was ein Indiz dafür ist, dass hier vermehrt Reihen zu finden sind, die hauptsächlich solche Leser als Zielgruppe haben, die sich nur für das Genre im Allgemeinen interessieren und weniger für eine spezielle Serie. Dies ist jedoch vielmehr als Tendenz denn als Regel zu verstehen, da es in diesem Subgenre ebenfalls Serien gibt, die mit durchgehenden Handlungselementen arbeiten. Die Serie Der kleine Fürst beispielsweise hat eine durchgehende Hauptfigur und die Serie Die junge Gräfin Alexandra arbeitet sogar mit übergreifenden Handlungssträngen.

Die Hefte der Courths-Mahler-Reihen können ebenfalls unter dieses Subgenre gerechnet werden, da sie vermehrt im Milieu des Adels und des Großbürgertums spielen. Es besteht lediglich der Unterschied, dass die Courths-Mahler-Romane eine historische Neuauflage bilden, die bereits im Fall der Erstauflage in der Vergangenheit spielen sollten.

Anders als vielleicht anzunehmen wäre sind die Geschichten der aktuellen Adelsheftromane nicht in der Vergangenheit verortet, als in einem feudalistischen Deutschland noch Könige herrschten, sondern sie sollen in der Gegenwart spielen. Die Handlung ist lediglich im Milieu des heutigen Adels angesiedelt.

\section{Der typische Arztroman ist keine Arzt-Serie ${ }^{299}$}

Dieses Subgenre des Liebesromans darf nicht mit den im Fernsehen ausgestrahlten Arzt-Serien gleichgesetzt werden. Die momentan aktuellen Arzt-Serien wurden größtenteils von der 1994 ausgestrahlten Serie Emergency Room beeinflusst, die sich gerade von einem solchen Arzt-Klischee distanzierte, wie es beispielsweise in der deutschen TV-Serie „Die Schwarzwaldklinik“ zu finden war. ${ }^{300}$ Als die Emergency Room-Serie begann, ihren Fokus verstärkt auf das Privatleben der Figuren zu legen,

299 Dies ist eine Anspielung auf den Unterschied zwischen Arzt(heft)romanen und (TV-)Arzt-Serien, den Studierende gerne in den Seminar-Diskussionen verwischten: Schnell wurden beide Formen zur Arzt-Serie.

300 Thomas Haupts: Emergency Room - Die Notaufnahme. In: Klassiker der Fernsehserie. Hrsg. von Christian Hißnauer und Thomas Klein. Stuttgart 2012, S. 262-267. S. 263. 
wurde ihr vorgeworfen, sich nun doch in den Bereich des Kitschs, „wie es Trivial- und Heftchenliteratur seit Jahrzehnten betreiben“, zu entfernen. ${ }^{301}$ Die aktuellen ArztSerien sind somit eine in den 1990er entstandene Sonderform der Arztfilme. Durch Etablierung diverser TV-Serien ähnlicher Machart wie Emergency Room, wozu etwa Grey's Anatomy oder alphateam - die Lebensretter im OP zu zählen sind, wurde ein nahezu neues Arzt-Genre geschaffen, das einen hohen Anspruch auf Realismus ${ }^{302}$ besitzt.

Der typische Arztroman im Romanheftbereich ist ein Liebesroman, der lediglich im Ärztemilieu angesiedelt ist. Die Darstellung einer Liebesgeschichte ist zwar immer noch eines der Hauptthemen und wird auch wie bei den obigen Liebesromanen zuerst durch Antagonisten verhindert, allerdings liegt bei den Arztromanen immer ein Hindernis durch körperliche Beeinträchtigungen vor: Verletzungen, Krankheiten et cetera. Die Helden müssen in erster Linie zeitweise unter der körperlichen Versehrtheit leiden. Schlussendlich erhalten sie jedoch Unversehrtheit, Liebe und meist auch Geld. Alles fügt sich, keine Fragen bleiben mehr offen, und in der Regel hat dies der Arzt bewirkt. Dieser steht außerhalb der Helden-Antagonisten-Konstellation beziehungsweise greift von außerhalb ein oder berät lediglich. Er selbst gerät nicht in den Konflikt der leidenden Figuren und nur gelegentlich wird eine seiner Krankenschwestern oder Sprechstundenhelferinnen in ein Spannungsverhältnis verwickelt, doch sind diese Randfiguren austauschbar. Dabei dürfen die festen Figuren nicht zu intensiv involviert sein, auch wenn sie starken Einfluss auf die Handlung nehmen, dürfen sie selbst keine Entwicklung erfahren.

Verändern dürfen sich nur das Heldenpaar und die Antagonisten, da diese variable Figuren sind. Die Helden erscheinen mit einem Problem beim Arzt, dessen er sich annimmt, obwohl sie ihn häufig aufgrund körperlicher Belange aufsuchen, haben sie ein seelisches Problem, das viel stärker wiegt. Der Arzt merkt dies sofort und kümmert sich nebenbei um das physische Problem, während das psychische ganz im Vordergrund steht. Das psychische Leiden ist in der Regel mit der Störung der Liebe verbunden. In seiner Funktion als beratende Instanz steht der Arzt über den Dingen und kann auch hier ganz „Gott in weiß“ kompetent beraten. Bisweilen ist der 
Arzt auch mit dem Schicksal in Persona gleichzusetzen. ${ }^{303}$

Als Schauplätze dienen zwar Praxen und Hospitäler, doch die Möglichkeit einer präsenten Staffage wird kaum genutzt, so sind die Arztromane verhältnismäßig frei von Fachvokabeln oder detaillierten Operationen. In der Regel wird lediglich ein „Medikament“ verschrieben, das mit einer Funktion, aber nicht mit einer fachspezifischen Bezeichnung genannt wird:

„Hier ist das Rezept. Bitte holen Sie das Medikament noch heute und beginnen Sie sofort mit der Einnahme. Sie werden sehen, daß es innen bald besser geht. " 304

Der ärztliche Akt bleibt kryptisch und ist lediglich in seiner Signalfunktion als solcher zu erkennen. Das einzige, was die Arztromane mit den oben abgegrenzten ArztSerien gemeinsam haben, ist das bloße Nennen von Themen wie beispielsweise Brustkrebs, Aids, Abtreibung et cetera, jedoch mit dem Unterschied, dass in den Romanheften die Themen zur Handlungs- und Verstrickungsmotivation von Nebenhandlungen in den Hintergrund treten oder gar nach ein paar Seiten vollends verschwinden. In Band Nr. 766 der Dr. Norden-Serie wird die Krebserkrankung der Protagonistin zum auslösenden Moment für den Hauptplot. Doch das Thema 'Krebs' als solches vertieft der Autor des Romanheftes nicht. Er streut lediglich ein paar Schlagworte im Text ein:

„Krebsoperation, Metastasen, Chemotherapie, der ganze medizinische Wortschatz, den sie [und die Leserin des Heftes! Anm. d. Autors] im Laufe ihres Lebens zum Thema Krebs gesammelt hatte, stand auf einmal parat.“305

Differenzierter wird dieses Thema im Romanheft nicht mehr verarbeitet; es stellt lediglich den Auslöser für die Heldin dar, um Urlaub zu machen und sich dabei zu verlieben. Am Ende muss sich die Diagnose natürlich als ungefährlich herausstellen, damit die Helden heiraten können.

Das Hauptthema ist hier dasselbe wie im Adelsroman: Eine Liebesgeschichte. Allerdings spezialisiert auf Liebesgeschichten im medizinischen Umfeld. Hierbei setzen die Verlage verstärkt auf das medizinische Millieu, da sich in den Heften vermehrt Werbung für Medikamente findet: „Gedächtnisprobleme? - Dafür gibt's

303 Stockinger: Logik seriellen Erzählens, S. $99 f$.

304 Dr. Norden Bd. 766. Sommer, Sonne, Leidenschaft. Patricia Vandenberg. Neuauflage. KelterVerlag. S. 9.

305 Ebd. S. 8. 
doch ratiopharm." 306

Im Bereich der Arztromane treten vermehrt Serien mit einer durchgängigen Hauptfigur auf. Jedoch sind die einzelnen Hefte kaum in einen größeren Zusammenhang eingebettet und nur wenige nutzen episodenübergreifende Handlungsstränge wie etwa beim zweitausendsten Heft der Dr. Stefan Frank-Serie. Aber selbst dieses wird von Genre-Experten wie Anna Basener als „etwas besonderes“ wahrgenommen. ${ }^{307}$

\section{Heimatroman ist nicht gleich Heimatroman}

Die Heimat- und Bergromanhefte verkörpern ebenfalls typische Liebesromane, die in einem Dorf auf dem Land oder in den Bergen angesiedelt sind. Allerdings weisen sie noch Anteile der ursprünglichen Heimatromane auf. Nutz sieht den Ursprung dieser Fragmente im zeitgleichen Auftreten vom „Heimgarten“ und den Frauenromanen im Kontext der Gartenlaube. ${ }^{308}$ Er stellt fest, dass beide Formen, die damals bei den Lesern sehr beliebt waren, aufeinander einwirkten. Jedoch lässt Nutz den starken Einfluss der eigentlichen Heimatkunstbewegung um die Jahrhundertwende außen vor, denn das, was Rossbacher in seinem Buch zur „Heimatkunstbewegung und Heimatroman" als die wichtigsten Elemente dieser Gattung identifizierte, ließ und lässt sich auch in den heutigen Romanheften wiederfinden - hingegen stark transformiert. Dies tritt allein schon durch einen historischen Hintergrund in Erscheinung, der in den heutigen „Heimatromanen“ nicht mehr aktiv ist beziehungsweise nicht aktiv wahrgenommen wird und als Staffage in den Hintergrund tritt.

Die damaligen Heimatromane wurden als "'ernste' Literatur“ verstanden und man distanzierte sich von Unterhaltungsautoren wie beispielsweise der Marlitt. ${ }^{309}$ Des Weiteren schreibt Rossbacher: „Die Heimatkunst unterlag keineswegs den Kriterien, mit denen heute zum Beispiel die Lektüre von Heft-Heimatromanen bewertet wird."310 Diese Annahme schließt nicht aus, dass sich die Heimatkunst einer Motivik bediente, die in eben jene Hefte Eingang gefunden hat. Was Nutz als charakteristisch für die

306 Dr. Laurin Bd. 30. Eine Ehe voller Zweifel. Patricia Vandenberg. 2. Aufl. Kelter-Verlag. Siehe Einband Innenseite.

307 Basener: Heftromane Schreiben, S. 22.

308 Nutz: Der Trivialroman seine Formen, S. 42f.

309 Karlheinz Rossbacher: Heimatkunstbewegung und Heimatroman. Zu einer Literatursoziologie der Jahrhundertwende. Stuttgart 1975, S. 99.

310 Ebd. 
Heimat- und Bergromane(hefte) erachtet, nennt bereits Rossbacher als Elemente der Heimatromane:

- Merkmal des Heimatromans ist die „Opposition zur Stadt, Industrie, Arbeiterbewegung“. ${ }^{311}$ Das Dorf als Ort der Geborgenheit wird durch die Stadt im Sinne eines unnatürlichen und chaotischen Ortes kontrastiert. ${ }^{312}$

- Der Dörfler als ein einfacher und eindeutiger Mensch, der nicht wie der Städter zu einer Doppelbödigkeit neigt. ${ }^{313}$ Die Intellektualität wird zu etwas Negativem ${ }^{314}$ und diese Konnotation reicht bis zu einer Abneigung gegen Naturwissenschaften und Neuerungen, ${ }^{315}$ auf diese Weise wird unter anderem eine Naturverbundenheit etabliert.

- Das Fremde und Kapitalistische wird als das Böse verstanden, ${ }^{316}$ das Traditionelle komplementär als das Gute. ${ }^{317}$ Naturgewalten sind symbolisch, ${ }^{318}$ Erbschaften von Haus und Hof bilden zentrale Themen.

Da während und nach dem Ersten Weltkrieg eine "völkisch-patriotisch[e] Haltung“ in der Heimatkunst verbreitet war, ${ }^{319}$ die auch einen ausgeprägten Antisemitismus mit sich brachte, ${ }^{320}$ erhielt der Persönlichkeitsbegriff auch eine „rassische Komponente". ${ }^{321}$ Jedoch geht die Betrachtung Rossbachers nicht über die 1920er Jahre hinaus und es gibt kaum Forschungsliteratur, die sich mit der Entwicklung der Heimatromanhefte dezidiert seit den 1920ern befasst. Selbst die umfassende Untersuchung Maria Presents widmet diesem Zeitraum nur geringe Aufmerksamkeit. ${ }^{322}$ Dabei gilt das Phänomen des Nationalsozialismus in den 1930ern als eine konsequente Weiterführung von Tendenzen, die sich ebenfalls in der Heimatkunst niedergeschlagen hatten und von den Nationalsozialisten instrumentalisiert wurden. ${ }^{323}$ Es wird in diesem

320 Dies gilt besonders im Sektor der Mittelstandsagitation. Vgl. Rossbacher: Heimatkunstbewegung, S. $121 f$. 
Zusammenhang zumeist auf die Vorbilder in der Gartenlaube verwiesen und darauf, dass Heimatromanhefte in der Tradition der Frauenromane zu begreifen seien. ${ }^{324}$ So einfach ist dies jedoch nicht zu beurteilen, da zwischen den Vorgängern in der Gartenlaube und den heutigen Produkten unter anderem zwei Weltkriege liegen, von denen besonders der zweite den Heimatbegriff stark geprägt hat. Aus diesem Grunde kann nun die Untersuchung Andrea Lobensommers weiterhelfen, die versucht, Hefte des Heimat- und Bergromans in ihrer Tradition einzuordnen und angemessen zu deuten, besonders da die „Literatur der Heimatkunstbewegung [...] in vollem Ausmaß teil [hat] an jenem Vorgang, der als Auflösung eines kulturräsonierenden Publikums und Übergang zu einem kulturkonsumierenden beschrieben worden ist. ${ }^{\text {" }} 25$

Lobensommer untersucht zwar keine Heimatromane, aber die Thematisierung von Heimat in Prosatexten zwischen den Jahren 1989 bis 2001, deshalb kann das Ergebnis ihrer Untersuchung dafür genutzt werden, um zu zeigen, wovon das Heimatromanheft handelt beziehungsweise nicht handelt. ${ }^{326}$ Heimat wird aktuell nicht mehr im Sinne von "Nationalisierung" genutzt, sondern in einer historisierten Form eines ehemaligen Klischees, ${ }^{327}$ also als etwas von einem konkreten Ort gelöstes und als eine reine Vorstellung. ${ }^{328}$ Wie Lobensommer versucht, „die Konstante „Territorialität" vom Heimatbegriff abzulösen und zu untersuchen, welche Variante von Heimat dann verwendet“ ${ }^{\star 329}$ wird, so soll hier herausgefunden werden, welche Variante von Heimat die Autoren in den Romanheften realisieren.

Wurde vormals der Begriff „Heimat" beziehungsweise „Heimatromane" an den Patriotismus gebunden und weniger an konkrete Lokalitäten, so ging es dabei um eine „nationale Integration“. ${ }^{330}$ Es wurden also politische und ästhetische Konzepte in den Heimatromanen diskutiert. Im Gegensatz dazu wird in den Romanheften die Heimat lediglich als Staffage genutzt, die die gleichen Gesetzmäßigkeiten aufweist wie ihre Vorgänger, daher deckt sich erneut der Ist-Zustand mit der Aussage Nutz': Die „Heimat" kann nur so ausfallen, „wie er [der Leser. Anm. d. Autors] sie sich vorstellt;

324 Vgl. hierzu u.a. Nutz: Der Trivialroman seine Formen, S. 42ff.

325 Rossbacher: Heimatkunstbewegung, S. 93. Rossbacher bezieht sich hierbei auf Jürgen Habermas.

326 Andrea Lobensommer: Die Suche nach "Heimat". Dissertation. München 2010. u.a. S. 52.

327 Ebd. S. 51.

328 Ebd. S. 52.

329 Ebd. S. 55.

330 Rossbacher: Heimatkunstbewegung, S. 61. 
denn so glaubt er, ist sie auch.“331 Die Heimat der Romanhefte ist zu einer „Wunschvorstellung“ geworden, zu einem Idyll, das nur im Eskapismus der Leser existiert. Lobensommer schreibt über die Möglichkeiten der Wandlung des Heimatkonzeptes: „Gerade für Varianten bietet sich deshalb der Begriffsrand und damit auch die Abkehr von Heimatliteratur oder Heimatfilm an, da konventionelle Sichtweisen eines Begriffs gerade an den Rändern leichter veränderlich sind.“"332

Wie oben bereits aufgezeigt liegt der Ursprung des Heimatkonzepts, das auch noch für die heutigen Romanhefte wirksam ist, im neunzehnten Jahrhundert. Allerdings wurde der Heimatbegriff von den Nationalsozialisten für ihre Version des „Vaterlandes“ verändert. ${ }^{333}$ Nach 1945 ist der Begriff von „Heimat“ nicht mehr politisch aufgeladen wie er es noch zu Zeiten Ganghofers war, sondern er wird als ein „anachronistischer"334 Begriff verstanden. Heimat ist so zu einem Konstrukt geworden, in dem eine zeitlose Idylle geschaffen wird, die den Holocaust, aber auch das Deutschsein im Prinzip ausblendet und lediglich auf ein Idyll 'an sich' zugreift. So gesehen ähnelt Heimat dem Nicht-Ort des Utopias, nur dass die Romanhefte keinerlei gesellschaftskritischen Anspruch erheben. Darin unterscheiden sie sich auch von ihren Vorgängern, die sehr wohl gesellschaftskritisch und politisch ausgeprägt waren, jedoch nicht als Utopien zu betrachten sind. ${ }^{335}$

In den Heften wird Heimat in Bezug auf die Figuren als etwas Angeborenes dargestellt, beziehungsweise als ein Heimweh, das die Figuren jederzeit überkommen kann. ${ }^{336}$ Dieses Konzept deckt sich insofern mit der Theorie Herbert Röhrigs, dass Heimat etwas ist, das man „von Geburt oder zumindest“ seit dem Heranwachsen innehat. ${ }^{337}$ Außerdem finden sich in den Romanheften auch Figuren, die aus der Stadt stammen und im „heimatlichen“ Ort mit der Zeit sozialisiert und schließlich heimisch werden. Dies deckt sich wiederum mit einer völlig gegensätzlichen These von Heiner Treinen, der die „Möglichkeit einer späteren Heimatfindung“ einräumt. ${ }^{338}$ Insofern sind beide Versionen von Heimat in den Heften möglich, wobei die Heimat

331 Nutz: Der Trivialroman und seine Formen, S. 45.

332 Lobensommer: Suche nach Heimat, S. 55.

333 Ebd. S. 69.

334 Present: Waldesrauschen, S. 29.

335 Lobensommer schließt einen möglichen Utopie-Aspekt der Heimatkonzeptionen zu Recht aus. Vgl. Lobensommer 2010, S. 45f. Hier soll es lediglich der Abgrenzung dienlich sein.

336 Present: Waldesrauschen, S. $126 f$.

337 In Lobensommer: Suche nach Heimat, S. 73.

338 Ebd. S. 73. 
als Geburtsort die präsentere Version ist. Allerdings ist die Anpassung einer Figur an einen Heimatort nach Lobensommer immer etwas Passives, das sich auch in den Heften finden lässt:

„Es war das erste Mal, daß er ein Projekt, an dem er arbeitete, in Frage stellte. Was er auf den Fotos sah, das war unberührte Natur". ${ }^{339}$

Der Held der Geschichte wird während seines Aufenthaltes im Dorf immer stärker von den örtlichen Reizen vereinnahmt, bis ihm Skrupel kommen, diese Landschaft zu beschädigen. Des Weiteren bezieht Treinen die „emotionale Ortsbezogenheit“ auf

„die Zugehörigkeit zu einer größeren, örtlich beschränkten Bezugskategorie, die eng mit dem Sozialzusammenhang der Ortsgemeinde in Verbindung steht. Diese Ortsbezogenheit ist durch Ortsnamen symbolisiert. Eine emotionale Ortsbezogenheit betrifft gerade nicht die Herkunftsfamilie“. 340

Dies entspricht durchaus der „Heimat“ in den Romanheften. Darin ist ein Konzept wiederzufinden, das sich mit dem der 1970er deckt: „Einer nostalgischen Erinnerung, einer unerreichbaren Utopie."341 Diese erscheint allerdings innerhalb der Romane nicht als ein symbolischer Ort, sondern als etwas (fiktiv) Konkretes. In den Romanheften kann es stets nur diese eine Heimat sein an eben gerade diesem Ort.

„Beide sind seit über vierzig Jahr‘ hier auf dem Hof, der ihnen eine Heimat geworden ist. Der Tobias hat innen versprochen, daß sie dableiben können, bis der Herrgott sie abberuft, und ich hab' net die Absicht, dieses Versprechen jetzt zu brechen." ${ }^{342}$

Wegzuziehen und den Hof aufzugeben, kommt für die Helden der Heimatromanhefte nicht in Frage und gleicht, wenn es ihnen vorgeschlagen wird, einer Absurdität, da es anscheinend eine Offensichtlichkeit ist: „Sie wußte nicht, ob sie empört oder amüsiert sein sollte“, als der Heldin angeboten wurde, ihren Hof zu verkaufen. ${ }^{343}$

Auf diese Weise wird sich traditioneller Muster bedient: Dialekt, traditionelle Berufe, Familien- und Gemeindegebundenheit, die jedoch für einen fiktiven Ort verwendet werden. Der Ort mag zwar geographisch existieren, aber derjenige Ort, der de facto beschrieben wird, hat mit dem Namensgeber nichts gemein. Er ist ein Heimatort, wie

339 Der Bergpfarrer Bd. 166. Keine Angst vor der Liebe! Toni Waidacher. 2. Aufl. Kelter-Verlag. S. 47.

340 Lobensommer: Suche nach Heimat, S. 74.

341 Ebd. S. 75f. Im Zuge dieser „Nostalgiewelle" erschienen auch die Courths-Mahler-Verfilmungen.

342 Der Bergpfarrer. Bd. 166. S. 27.

343 Ebd. S. 26. 
inn sich der Leser vorstellt. ${ }^{344}$ Es ist also ein idealer Ort (im platonischen Sinne) für eine Liebesgeschichte. Die Werte und Vorstellungen der Figuren aus den Heimatromanen wurden lediglich als Relikte in den Romanheften übernommen und den Bedingungen der Liebesromane angepasst. Der Heimatroman bot dafür beste Voraussetzungen, denn „[d]er Roman der Heimatkunst ist als Roman statischer Verhältnisse beabsichtigt." ${ }^{345}$

Es ließen sich mit Leichtigkeit die schematisch anmutenden Handlungs- und Figurenkonstellationen der Heimatromane für eine industrialisierte Narrationsform wie die Romanhefte nutzbar machen, ohne aber den politischen Kontext zu übernehmen, sondern lediglich tradierte Werte, die, zu einer Klischeevorstellung verkürzt, als Hintergrundfolie für Liebesgeschichten dienen. Dies wurde eventuell durch die Vermarktungsstrategie Eugen Diederichs vorbereitet, der Anfang des neunzehnten Jahrhunderts die Produktion diverser Heimatromane vereinheitlichte und sie so zum „Ideal der Warenästhetik [machte]: das gerade noch durchgehende Minimum an Gebrauchswert [lieferte], verbunden, umhüllt und inszeniert mit einem Maximum an reizendem Schein“. ${ }^{346}$ Mit diesem Schein handwerklich gestalteter Heimatromane sollte Authentizität evoziert werden, die im Widerspruch zu der tatsächlichen industriellen Massenproduktion stand.

Das Konzept des aktuellen Heimatromanhefts hat nichts mit dem in der Forschungsliteratur vertretenen modernen Konzept zu tun, welches Heimat als ein UtopieKonzept wahrnimmt: ${ }^{347}$ Das aktuelle Heimatromanheft ist kein Heimatroman. Es handelt sich vielmehr um einen Liebesroman, der mit einer Staffage arbeitet, die man aus (überholten) Heimatromanen kennt. Ferne exotische Orte dienen letztendlich nur als Kontrastierung zur „'eigentlich' so viel schöneren deutschen Heimat.“348 Dies ist allerdings nicht nur dem Heimatroman vorbehalten, sondern lässt sich auch in allen anderen Liebesromangenres wiederfinden. Darin sind exotische Orte zwar Urlaubsorte, aber selten zentraler Schauplatz des Plots. Der Schauplatz ist stets Deutschland, nur dass dies in der Regel nicht thematisiert, sondern stattdessen vorausgesetzt wird. Lediglich im Heimatroman schreiben die Autoren gelegentlich

\footnotetext{
344 Nutz: Der Trivialroman seine Formen, S. 45.

345 Ebd. S. 157.

346 Wolfgang Haug in Rossbacher: Heimatkunstbewegung, S. 105.

347 Lobensommer: Suche nach Heimat, S. 90ff.

348 Strecker: Frauenträume, S. 161.
} 
von der Heimat als einem explizit deutschen Ort explizit. Jedoch sind dies nicht immer real in Deutschland aufzufindende Orte, sondern die Namen der fiktiven Orte klingen so, als könnte sie der Leser tatsächlich auf einer Landkarte finden:

„'Himmelsspitz' und 'Wintermaid' grüßten mit ihren schneebedeckten Gipfeln den Heimkehrer, und vom nahen Kogler konnte Tobias das Rauschen der Kachlach hören, die oben am Berg in die Klamm stürzte." 349

Die Namen Kogler, Himmelsspitz, Wintermaid und Kachlach finden sich eventuell vereinzelt in Deutschland auf, doch nicht zusammen in einer Region. Auf diese Weise lassen sich fiktive Ortsbezeichnungen als austauschbare Staffage beliebig von den Autoren arrangieren und erscheinen trotzdem wie eine konkrete Ortsbeschreibung.

\section{Familien- und Schicksalsromane}

In den Verlagsprogrammen von Bastei und Kelter gibt es diverse Reihen, die Familien oder Schicksale zum Hauptthema der Liebesgeschichte haben. Diese ließen sich auch als einzelne Subgenres auffassen, folglich wäre das Subgenre des Schicksalsromans so zu verstehen, dass die Handlung nicht in einem bestimmten Milieu, sondern in einer Extremsituation spielt. Diese kann beispielsweise durch einen Unfall oder den Verlust eines geliebten Menschen hervorgerufen werden und ist von dem Milieu unabhängig.

Auf diese Weise wird dem Leser ebenfalls Einblick in einen Bereich oder eine Ausnahmesituation geboten, die er eventuell nicht kennt und die einen Kontrast zu seiner Alltagswelt darstellt. Hierzu könnte man die Romane der Silvia-Schicksal-Reihe zählen.

Der Familienroman behandelt hauptsächlich das Thema 'Familie' im weitesten Sinne: Hier stehen Familien oder Kinder am Zentrum des Handlungsgeschehen, jedoch nicht im Zentrum, denn ähnlich wie in den Arztromanheften sind sie zwar stets am Plot beteiligt und stellen zuweilen einen Katalysator der Handlung dar, aber im Mittelpunkt steht immer die Liebesgeschichte. Kinder nehmen hier eine gewichtigere Rolle ein, da sie häufig als „Mentor“ fungieren, „der die seltsamen 'Erwachsenenhinder-

349 Toni Waidacher: Mit all meiner Liebe. In: Der Bergpfarrer - Werbeband. 3 Romane. Bd. 54. Aufl. unbek. Kelter-Verlag. Im Sammelband dritter Roman. Keine durchgehende Paginierung. S. 3. 
nisse' der Liebe überwindet.“" ${ }^{350}$ „Die Kinder sind immer 'süß'; ihre Funktion ist es vor allem, die Figuren mittleren Alters auf 'Heldentauglichkeit' zu überprüfen." ${ }^{351}$ In diesem Subgenre dürfen vermehrt Verwitwete oder Verlassene mit Kindern erscheinen.

Eine klare Abgrenzung dieser Subgenres ist problematisch, da innerhalb dieser beiden Bereiche nur wenige Romanhefte entstehen. Die Romanheft-Autorin Basener schlägt für eine Abgrenzung zwei Genres vor:

„Familie

Serien um das turbulente Leben bestimmter Familien wie Die Fahrenbachs. Ein Genre für Leser, die Gefallen an nicht nur einer Figur finden, sondern der Vernetzung unterschiedlicher Familienmitglieder und vielen kleine GeschichUnd: ten, die ineinandergreifen etwas abgewinnen können.“352

\section{„Mutter \& Kind}

Ein Liebesroman, der die Mutterkindbindung in den Mittelpunkt stellt. Während der Familienroman sich um die Intrigen und Verbindungen erwachsener Familienmitglieder dreht, steht hier das Verhältnis von Müttern und Kindern im Mittelpunkt. Dieses Genre bringt nicht nur Paare zusammen, sondern sichert Kindern auch Familienidylle." ${ }^{353}$

Dies sind lediglich Beispiele dafür, wie schnell sich mögliche Subgenres ausbilden, aber ebenso gut auch wieder verschwinden können. Die Einteilung Baseners ist zwar durchaus sinnig, aber es stellt sich die Frage, wann und ob sie notwendig wird. Gerade für den Themenbereich „Mutter\&Kind“ gibt es eine hohe Anzahl an Reihen, die zu einer Abgrenzung anhält. Außer der Silvia-Schicksal-Reihe erscheinen nahezu alle Familien- und Schicksals-Reihen beim Kelter-Verlag, der sie in seiner Themengruppe „Liebe\&Familie“ führt.

\section{Anvisierte Zielgruppen}

Insgesamt weist das Genre „Liebesroman“ hauptsächlich Reihen auf und deutet auf eine Leserschaft hin, die wenig an einzelne Hefte gebunden ist, denn diese Geschichten verfügen in jedem Heft über ein neues Repertoire an Hauptfiguren. Bei

350 Basener: Heftromane Schreiben, S. 50.

351 Ruloff-Häny: Liebe und Geld, S. 24.

352 Basener: Heftromane Schreiben, S. 49.

353 Ebd. S. $50 f$. 
den Reihen bildet nur das Romanheftgenre beziehungsweise Thema die Schnittmenge, wohingegen bei einigen Serien ein Stammpersonal die einzelnen Folgen verknüpft, wie beispielsweise in den meisten Arztromanheftserien. Am Ende jeder Folge muss jedoch ein Zustand herrschen, an den jede andere Folge anknüpfen kann und dies sogar ungeachtet ihrer Nummerierung, daher sind Änderungen der Hauptfiguren hier nicht möglich beziehungsweise redaktionell sehr aufwendig und laut Anna Basener bei den Liebesromanen eher selten. ${ }^{354}$ Folglich sind Fortsetzungsserien im Bereich des Liebesromans kaum bis gar nicht zu finden.

Um einer Zielgruppe auf die Spur zu kommen erstellen die Verlage Umfragen, denn die Leser kommen im Bereich der Liebesromanhefte nicht per Leserbrief zu Wort. Der Bastei-Verlag wirbt unter anderem damit, dass ein Großteil seiner Leserinnen nicht so alt sei wie weitestgehend vermutet. ${ }^{355}$ Weiterhin berichtet Bastei aus einer Umfrage von 2017 über seine Leser: ${ }^{356}$

\section{„Frauenroman-Leser/innen}

- sind eine sehr treue Käuferschicht, über $60 \%$ lesen pro Monat acht Romanhefte oder mehr

- sind überdurchschnittlich interessiert an den Themen Kochen/Backen, Reisen, Kosmetik, Mode, Einrichtung/Dekoration.

- achten dabei auf den Preis und werden meist durch Werbung auf die Produkte aufmerksam“357

Dies wird durch die in den Heften abgedruckte Werbung bestätigt und ist nicht nur auf den Bastei-Verlag beschränkt, sondern realisiert sich im gesamten Liebesromanheftgenre mit seinen Subgenres. Die Werbung, die einer Zielgruppe angepasst wird, ist demnach ebenso den Genrekonventionen angepasst. Eine ausführlichere Auswertung soll einer empirischen Arbeit vorbehalten sein und stattdessen wird der Fokus im Folgenden zum Modellleser zurückkehren.

Wie im oben dargestellten Umfrageergebnis gezeigt besteht die vom Verlag ermittelte Zielgruppe aus älteren Hausfrauen, somit zeigt sich ein Gefälle zwischen

354 Basener: Heftromane schreiben und veröffentlichen, S. $22 f$.

355 Bastei-Mediadaten 2017. PDF-Download von: https://www.bastei.de/indices/index_allgemein_69.html (Zugriff: 17.08.2019). S. 2.

356 Quantitative Ergebnisse fremder Erhebungen sind generell mit Vorsicht zu verwenden, da die Konzipierung der Fragestellung für die Fragebögen und die Genauigkeit der Arbeitsweise unbekannt sind. Die quantitativen Ergebnisse sollen hier lediglich der Ermittlung dessen dienen, was dem Verlag hinsichtlich der Darstellung einer Zielgruppe als wichtig erscheint, anstatt ein vollständiges und korrektes Bild des gegenwärtigen Zustandes zu liefern.

357 Bastei-Mediadaten 2012: S. 4. 
den Lesern und den potenziellen Identifikationsfiguren des Adelsromanheftgenres. Claudia Stockinger hat dies als einen „Kontrast“ bezeichnet, der „Zu den genrekonstituierenden Merkmalen“ gehört. ${ }^{358}$ Dieser Kontrast dient lediglich der Unterhaltungswirkung. Der Leser erhält Einblick in die unterschiedlichsten, inm jedoch verschlossenen Milieus: In die Welt des Adels, der Großindustriellen, der Ärzte oder in die Gemeinschaften und Infrastrukturen kleiner Bergdörfer.

\subsection{Der Western}

1962 schrieb Walter Nutz über den Westernroman: „Da das Milieu, nämlich der amerikanische Westen, fest umrissen ist, stehen dem Autor nur Prärien, zerklüftete Berge, Savannen und Wüsten zur Verfügung“359. Kulissen wie Requisiten dieses Genres erweisen sich auf die von Nutz genannten Landschaften begrenzt. ${ }^{360}$

Die Hauptfiguren, die in diesem Genre meist männlich sind, grenzt Jens-Ulrich Davids auf drei Arten ein: „Polizisten“, „Privatleute“, die in einen Konflikt ungewollt hineingezogen werden, und „Privatleute“, die bevorzugt helfen, ähnlich einem Superhelden. ${ }^{361}$ Letzterer weicht laut Davids in seiner äußeren Erscheinung selten von dem Schema des strahlenden, gutaussehenden und sportlichen Helden ab. ${ }^{362}$ Diesem wird stets ein Antagonist gegenübergestellt. Davids beschreibt dies anhand einer Ingroup (die Guten) und einer Outgroup (die Bösen). ${ }^{363}$

Die Typisierungen Davids' und Nutz' sind zwar älteren Datums, jedoch haben sie, was das Genre betrifft, nichts an Aktualität im Hinblick auf die Romanhefte verloren. Dies könnte an der Natur des Genres liegen, ein historisches Setting zu besitzen, welches diverse Klischees und Lesererwartungen evoziert - zumal sich an dem Setting nichts mehr ändern kann. Die Science Fiction etwa muss sich beständig mit dem Wandel der Forschung und der Gesellschaft mitentwickeln. Wirft man einen Blick auf die aktuellen Hefte, scheint sich seit der Studie von Davids (1984) nicht viel

\footnotetext{
358 Stockinger: Logik seriellen Erzählens, S. 97.

359 Nutz: Der Trivialroman seine Formen, S. 52.

360 Ebd.

361 Jens-Ulrich Davids: Das Wildwestromanheft in der Bundesrepublik: Zur inhaltlichen Analyse. In: Erzählgattungen der Trivialliteratur. Hrsg. von Zedenko Skreb. Innsbruck 1984, S. 177-195. Vgl. S. $177 \mathrm{f}$. 
geändert zu haben, was unter anderem daran liegt, dass es zum Teil noch die alten Hefte sind, welche neu aufgelegt werden. Beispielsweise bringt Bastei die Hefte, die G.F. Unger bis 2005 verfasst hat, immer wieder neu heraus, weshalb es in der G.F. Unger-Reihe bereits mehr als 2000 Hefte gibt, obwohl er nur rund 700 Romane geschrieben hat. ${ }^{364}$ Unger, den Hartmut Kasper als „de[n] erfolgreichste[n] WesternAutor[en] der Welt“365 bezeichnet und der „einer der meist verkauften Autoren der deutschen Literaturgeschichte"366 sein soll, wertet seine eigene Arbeit als eine „erzieherische Mission“, um „eine geradlinige und männliche Haltung aufzuzeigen“.367 Ungers Selbstwahrnehmung wird von dem Westernexperten Davids gestützt. In dem Genre findet sich in der Regel immer eine Figur, die alle kämpferischen und moralischen Aufgaben autonom meistert. ${ }^{368}$ Inwieweit sich andere Autoren von allgemeinen Genreströmungen oder direkt von Unger beeinflussen ließen oder ob das Genre de facto von Unger selbst beeinflusst wurde, lässt sich vorerst nicht eindeutig zeigen. ${ }^{369}$ Tatsache ist, dass sich in den Westernheften eine Tradition erhalten hat und Davids Charakterisierung für das Westerngenre im Bereich der Romanhefte noch immer anwendbar ist.

Allerdings ist unklar, wie sich das Genre weiter entwickeln wird, da Unger 2005 verstorben ist und seine Romane im Verlagsprogramm bereits wiederholt werden. Es stellt sich die Frage, wie viele Westernromanhefte wirklich noch aktuell produziert und wie viele nur abermals aufgelegt werden. Die Verlage bieten hier kaum Transparenz. Nur wenige Verweise lassen sich finden, wie zum Beispiel der kurze Vermerk „Neuauflage“, der aber nicht preisgibt, wann die 1. Auflage erschienen ist. Nur bei den Unger-Heften findet sich auf den ersten Seiten meist ein Vermerk:

„Dieser Roman erschien schon einmal in dieser Reihe als Band 906 und im Western-Bestseller als Band 1646." ${ }^{370}$

364 Vgl. Das Autorenportrait auf der Homepage des Bastei-Verlages: https://www.bastei.de/beitrag/standardbeitrag_17000.html (Zugriff: 17.08.2019).

365 Hartmut Kaspar: Den Wilden Westen mit der Seele suchen. (07.12.2004) auf der Homepage von Deutschlandfunk (deutschlandfunk.de): https://www.deutschlandfunk.de/den-wilden-westenmit-der-seele-suchen.700.de.html?dram:article id=82081 (Zugriff: 17.08.2019).

366 Ebd.

367 Spiegel online: Schriftsteller G.F. Unger gestorben. (05.08.2005): https://www.spiegel.de/kultur/literatur/western-held-schriftsteller-g-f-unger-gestorben-a368473.html (Zugriff: 17.08.2019).

368 Davids: Das Wildwestromanheft in der Bundesrepublik (1984), S. $181 \mathrm{f}$.

369 Wenn Unger so bedeutend für die deutsche Literaturgeschichte war, wie Hartmut Kaspar behauptet, ist dies eine Frage, der man durchaus in einer eigenständigen Untersuchung nachgehen sollte.

370 G.F. Unger - Seine grössten Western-Erfolge Bd. 1584. Und jeder bringt den Tod. G.F. Unger. 
Der Autor ist das verknüpfende Element in dieser Reihe, weshalb eine stringente Werknummerierung für den Verlag zweitrangig zu sein scheint und trotzdem auf eine korrekte Identifizierung Wert gelegt wird.

Bei der Jack Slade-Reihe, die ebenfalls im Bastei-Verlag erscheint, besteht die Schnittmenge hingegen zusätzlich in der Figur Lassiter. Jack Slade ist der Name des Autoren gewesen, der die Figur Lassiter erfand. Lassiter ist die Hauptfigur der gleichnamigen Heftroman-Serie, die anscheinend einen so großen Erfolg feierte, dass der Verlag diesen Bezug in einer anderen Romanheftreihe hervorhob, in der die Figur überhaupt nicht auftaucht. Daher nannte sich die Jack Slade-Reihe mit vollem Titel: „Jack Slade - Die heissesten Western des berühmten Lassiter-Autors“. ${ }^{371}$ Auf diese Weise sind die Hefte zum einen über das verknüpfende Element des Autoren Jack Slade vereint, und zum anderen wird präzisiert, wofür er berühmt ist: Die Figur Lassiter.

Die Westernhefte des Kelter-Verlages hingegen arbeiten weniger mit einer Chronologisierung ihrer Westerngeschichten. Die einzelnen Bände sind zwar nummeriert, allerdings bezieht sich dies nicht auf die Möglichkeit folgenübergreifender Serienfiguren oder die bestimmte Edition eines Autoren, wie bei Unger, sondern lediglich auf das Verlagsprogramm. Der Verlag führt zudem diverse Westernsammelbände, in denen unterschiedlichste Autoren, ohne erkennbare Logik, zusammengestellt werden. Zudem ist nicht ersichtlich, ob es sich bei jenen Geschichten in den KelterSammelbänden um Erstveröffentlichungen oder Neuauflagen handelt.

Lassiter, ursprünglich ein Import aus Amerika, stammt von einem Autor, der sich in der Tat Jack Slade nannte. ${ }^{372}$ In den Siebzigern kaufte Bastei die Lizenz des Autornamens und konnte den Namen als Pseudonym weiterverwenden. ${ }^{373}$ Das Autorenteam, das heute hinter dem Pseudonym steckt, produziert aktuell neue Abenteuer von Lassiter und mittlerweile auch andere Geschichten unter dem Label 'Jack Slade'. Die Autoren produzieren aber noch immer im Sinne der

1. Aufl. Bastei-Verlag. S. 4. Diese Reihe ist leicht zu verwechseln mit der Reihe: WesternBestseller G.F. Unger.

371 Vgl. u.a. Jack Slade Bd. 612. Der letzte Kampf des Buscaderos. Jack Slade. 1. Aufl. BasteiVerlag.

372 Hartmut Kasper: Der härteste Mann auf dem deutschen Heftromanmarkt. (16.11.2010) auf der Homepage des Deutschlandfunk: https://www.deutschlandfunk.de/der-haerteste-mann-auf-demdeutschen-heftromanmarkt.700.de.html?dram:article_id=84817 (Zugriff: 17.08.2019).

373 Ebd. 
Charakterisierung Davids. Es greifen darüber hinaus die alten Stereotype auch bei den jungen Western-Autoren. Einer der Lassiter-Autoren beschreibt die Figur folgendermaßen:

„Lassiter glaubt an Gott, er ist also ein ganz normaler Christ, wenn man das so nennen will, wie wohl viele Amerikaner zu der Zeit. [...] Er hat auch dieses Wertesystem. Er tritt immer ganz klar für das Gute ein. Er hilft den Schwachen, und das ist auch wichtig. Lassiter ist kein zynischer Held, er hat gewisse moralische Anforderungen an sich selbst $[. . .]^{“ 374}$

Geradlinigkeit und Redlichkeit hatte zuvor auch Unger als maßgebend für seine Hauptfiguren angeführt. Es handelt sich dabei jedoch um stilisierte Sichtweisen, die keiner lebensnahen Perspektive entsprechen. Die stereotypen Weltbilder sind an ihr Genre gebunden und können ausschließlich dort funktionieren. Sie sind Werte, die lediglich für eine fiktive Welt gelten. Diese wird jedoch von den Verlagen stets aufs Neue historisiert: „Waco ...so war der Wilde Westen in historischen Bildern“ ${ }^{375}$ Auch die Autoren, wie etwa Unger und das Jack Slade-Team, beteuern, dass sie historische Fakten recherchieren. Dennoch bleibt es dabei, dass sie ihre Version dieser Welt in den Heften reproduzieren. Dass Fakten recherchiert werden, mag sicherlich der Fall sein, aber es sind Fakten, die das Setting kolorieren sollen und kein realistisches Bild der Lebensweise vermitteln. Auf diese Weise findet keine Historisierung, sondern eine 'Verkitschung' statt, denn in den Heften werden nur die erfolgreichen Kämpfe der Helden geschildert.

Von den aktuell erscheinenden Romanheften stehen die Westernromane dem Abenteuerroman am nächsten. Hainer Plaul umreißt den „trivialen Abenteuerroman“ vom Begriff „Abenteuer“ ausgehend: Abenteuer als „ein Erlebnis, das sich als außergewöhnlich und aufregend darstellt, so kann Trivialliteratur mit ihrer auf Gefühlsregung zielenden Wirkungsabsicht als die Abenteuerliteratur schlechthin bezeichnet werden.“376 „Gefühlsregung“ bezieht sich in diesem Zusammenhang auf Spannung erzeugende Effekte. Das Abenteuer in der Trivialliteratur entspricht laut Plaul ,jenem Verständnis von Abenteuer, das sich zuerst in der höfischen Ritterideologie des Mittelalters herausgebildet hat und das auch der heutigen, modernen Abenteuer-

374 Ebd.

375 Vgl. u.a. Waco Gesamtausgabe Bd. 119. G.F. Waco. Aufl. unbek. Kelter-Verlag.

376 Hainer Plaul: Illustrierte Geschichte der Trivialliteratur. Leipzig 1983. S. 232. 
Auffassung zugrunde liegt." ${ }^{377}$ Nach Plaul zielt dies auf einen Held ab, der weder Gefahren noch Risiken fürchtet. Dies deckt sich mit Ungers Vorstellung vom Westernhelden, der „Redlichkeit und Mut“ verkörpert. Da Unger diese Eigenschaften (in dem Zitat weiter oben) als Männlichkeit bezeichnet, setzt er diese Männlichkeit mit Heldentum gleich.

Während sich der Abenteuerroman nach Plaul als ein „Reise-Abenteuer“ erweist, in dem „Abenteuer zu Lande, zu Wasser und in der Luft" geschildert werden, ${ }^{378}$ so ist das Genre des Westernromans nach Davids auf seinen „spezifischen geographischen und historischen Hintergrund" festgelegt. ${ }^{379}$ Damit wäre der Westernroman ein Abenteuerroman mit geographisch und historisch eingeschränkter Staffage: Die Abenteuer der Helden müssen im Amerika Mitte des neunzehnten Jahrhunderts stattfinden. ${ }^{380}$

Aktuell findet sich im Verlagsprogramm der Romanheftproduzenten keine ausgewiesene Themengruppe für Abenteuerheftromane, geschweige denn eine Serie oder eine Reihe. Zwar erscheinen gelegentlich für kurze Zeit Abenteuerromanheftserien, doch haben diese bisher nur wenige Ausgaben Bestand gehabt. So erschienen im Zeitraum von 1992 bis 1993 beim Bastei-Verlag 38 Bände der Serie Die Abenteurer. Diese wurde um fünf weitere Bände im Zeitraum von 1996 bis 2000 erweitert. ${ }^{381}$ Den Höhepunkt hatte das Abenteuerromanheft, nach Plaul, „in der Zeit zwischen der Jahrhundertwende und den Jahren des zweiten Weltkrieges“. ${ }^{382}$ Abenteuerromanhefte sind heute zu einer Randerscheinung geworden. Die „Ritterideologie des Mittelalters" in den Abenteuerromanen nach Plaul lässt sich aber noch immer in den Abenteuern der Westernhelden wiederfinden:

„Zwischen 'fahrenden'Rittern der mittelalterlichen Heldendichtung und dem gleichfalls berittenen Jäger und Scout der nordamerikanischen Indianerkriege besteht thematisch gesehen, kaum ein Unterschied; und nicht weniger gleichartig ist die 'Topologie' des Abenteuers, die sich um diese Gestalten entwickelt: Zweikämpfe, Schlachten, Jagden, Naturereignisse [...]."383

\footnotetext{
377 Ebd.

378 Ebd. S. 233.

379 Davids: Das Wildwest-Romanheft in der Bundesrepublik. 1975, S. 61.

380 Vgl. ebd.

381 Knüppel: Allgemeiner Roman-Preiskatalog, S. 103.

382 Plaul: Illustrierte Geschichte der Trivialliteratur, S. 233.

383 Davids zitiert hier H. Frenzel. Vgl. in Davids: Das Wildwest-Romanheft in der Bundesrepublik. 1975, S. 244.
} 
Es stehen die Ritterlichkeit des Helden und seine Taten im Vordergrund der Westernromanhefte. So auch von der Romanfigur Ben Nye:

„Er ist ein unruhiger Wanderer, für den der Krieg lediglich ein Abenteuer war, der sich stets auf die Seite des Schwächeren stellte."384

Damit wird Nye bei seinem ersten Auftreten als ein furchtloser, mutiger Abenteurer dargestellt, der nach Redlichkeit strebt. Dies ist unter anderem auch das, was Unger (siehe weiter oben) als Männlichkeit definierte. Um welchen Krieg es sich genau handelte, wird in der Geschichte nicht spezifiziert. Krieg dient hier nur, um Nye als mutigen Kämpfer darzustellen. Am Ende der Geschichte wird Nye ähnlich den Heldenfiguren alter Sagen zum Helden für jenes Dorf, das er von Banditen befreite:

„Sie alle haben Ben Nye in der Nähe, und wenn sich noch einmal irgendwelches Raubgesindel an den Fluß schleichen sollte, wissen sie, an wen sie sich dann zu wenden haben. Und es sollte diesmal wirklich sehr lange dauern, bis sich noch einmal Banditen ins Pecos-Tal verirrten, denn Ben Nyes Ruf als furchtloser Draufgänger reicht weit über die Grenzen hinaus. " ${ }^{385}$

Selten bis gar nicht wird in den Westernromanen auf die Grausamkeiten der Ausrottung der amerikanischen Ureinwohner eingegangen und es kommt in der Version der Autoren keine Elendsdarstellung vor, nur der Held, sein Abenteuer und die weite Landschaft. Ruloff-Häny grenzt die Männlichkeitsdarstellung im Liebesroman von derjenigen im Wildwestroman folgendermaßen ab:

„Während die Helden von Wildwest-, Abenteuer- und Kriminalromanen ihre Männlichkeit durch Taten beweisen können, ist es den Helden unserer Romane [den Liebesromanen, Anm.d.A.] nicht möglich.“386

Der Held der Liebesromane wird hauptsächlich anhand von Attributen dargestellt. ${ }^{387}$ Doch auch die Westernhelden können zusätzlich zu ihren Heldentaten mit einfachen Attributen abgebildet werden wie beispielsweise: Groß, stark, männlich.

Beide Genres halten an der starren Rollenvorstellung fest, dass der Mann stark sein muss. Dies wird in dem einen Genre ausschließlich attributiv erreicht und in dem anderen zusätzlich durch 'männliche Taten'. Folgert man hieraus, was nicht als männlich gelten kann, lassen sich auch Schlüsse dahingehend ableiten, was sich als

384 Wild West Roman Bd. 51. Ben Nye. Joe Juhnke. Aufl. unbek. Kelter-Verlag. S. 26.

385 Ebd. S. 66.

386 Ruloff-Häny: Liebe und Geld, S. 18.

387 Ebd. 
Rollenbild für die Frauen ergibt: Dass sie zwar zum einen schön, aber eben auch schwach sein müssen, da sie einen starken Mann brauchen:

„Ich war Texaner, und bei uns daheim in Texas waren Frauen jeden Alters etwas, was man achten, respektieren, beschützen und verehren musste. Das wurde uns Männern schon im Jungenalter beigebracht. "388

Des Weiteren ist es die Aufgabe der Frau, den Mann zu pflegen. So ist sie gelegentlich Krankenschwester, Hausfrau und Objekt der Begierde in einem:

„Im Lampenschein erscheint ihm ihr Gesicht wunderschön. [...] Sie lächelt ihm zu. ,Das Wundfieber hält sich in Grenzen', sagt sie. ,Haben Sie Hunger, mein Freund?‘ “389

In den Westernromanheften sind diese Rollen allein schon deshalb obligatorisch, da sie als handlungsmotivierend eingesetzt werden können, etwa wenn ein Held die Ehre einer Frau verteidigen muss. Kontrastierend hierzu drehen sich die Liebesromane auch um das soziale Gefüge der Helden, sodass in einigen Liebesromanen die Rollenbilder scheinbar differenziert aufgegriffen werden. Da hilft auch Dr. Laurin zuweilen bei der Hausarbeit:

„Leon kam zum Staub saugen. 'Das müssten deine Kollegen sehen', meinte Antonia neckend. 'Die machen das auch. Warum auch nicht? Wir haben doch Gleichberechtigung.' 'Wenn nur alle Männer so denken würden'“. 390

Die vermeintlich lustig lockere Szene zwischen Dr. Laurin und seiner Frau zeigt, dass es eben keine Gleichberechtigung im Liebesroman gibt, denn sonst erschiene es nicht bemerkenswert, dass ein Mann beim Haushalt hilft. Folglich sind im Liebesroman die Männlichkeitsvorstellungen nicht viel anders als im Westernroman. Sie werden lediglich in den Heften durch andere Techniken realisiert. ${ }^{391}$

Die von Davids genannten Klischees werden in geringer Variation wiederholt: Der

388 G.F. Unger - Seine grössten Western-Erfolge Bd. 1583. Kriegswinter. G.F. Unger. 1. Aufl. Bastei-Verlag. S. 10.

389 G.F. Unger - Seine grössten Western-Erfolge. Bd. 1584, S. $56 f$.

390 Dr. Laurin Bd. 130. Eine Sünde aus Dr. Laurins Vergangenheit? Patricia Vandenberg. 1. Aufl. Kelter-Verlag. S. 6.

391 Eine Studie zu der Darstellung von Männlichkeit in Trivialromanen liegt von Sandra Scherreiks vor: Endlich der Richtige! Diskurse über Männlichkeit und ihre Spiegelung in Trivialromanen zwischen 1973 und 1996. Kiel 2003. - Allerdings bezieht sich ihre Untersuchung hauptsächlich auf Liebesromane des Cora-Verlags. 
Held ist stattlich, redlich, zäh, mutig, stark und behält immer Recht. ${ }^{392}$ Der Böse zeichnet sich dadurch aus, dass er bedrohlich, ebenfalls stark, unehrlich, unterdrückend und feige ist und sich in der Regel selbst ins Unrecht manövriert. ${ }^{393}$

Üblicherweise sind die Antagonisten des Helden ebenfalls männlich, aber es gibt Ausnahmen, in denen auch Frauen die Position des Antagonisten einnehmen, obwohl sie es sind, die eigentlich beschützt werden müssen. Meist stellen sie eine Art Gewinn für den Helden dar, wenn er das Abenteuer übersteht. ${ }^{394}$ Auf diese Weise wird die Funktion der Frau lediglich auf ein passives Objekt reduziert, was in der Lassiter-Serie sogar in der Auffassung als reines Lustobjekt kulminiert. Dies sind im Wesentlichen die Rollenverteilungen im Westernheft. Sie unterliegen alle bestimmten moralischen Regeln, die zum Teil auch über dem Gesetz stehen. ${ }^{395}$ Auf diese Weise darf der Held gegen das Gesetz verstoßen, ohne dass es zu einem Bruch mit den Genrekonventionen kommt. Dies legitimiert auch Helden, die außerhalb des Gesetzes stehen. Jedoch scheint sich hier ein Wandel abzuzeichnen: Martin Barkawitz, ein Lassiter-Autor behauptet, „dass der Western-Leser kein Interesse mehr hat an Helden, die Anti-Helden sind, also an Outlaw-Helden." 396 Entsprechend wurde der Outlaw Lassiter zu einem Regierungsbeamten modelliert. Durch die übergeordneten moralischen Regeln im Western wird eine Verhaltenssicherheit suggeriert, sodass der Leser dem Helden immer trauen kann und nicht von einer ambivalenten Figur überrascht wird. Zudem lassen sich die Figuren anhand ihres Äußeren identifizieren und einschätzen. ${ }^{397}$ In den Westerngeschichten ist alles eindeutig: Der Held, der Gegner und das Ende.

Die Figur Lassiter scheint in Bezug auf das Westerngenre eine Ausnahme zu bilden, da sie sich in den Abenteuern beständig diversen Frauen annähert:

„Er hatte nicht damit gerechnet dass Miriam Wellington so schnell zur Sache kommen wollte."398

In seinen Abenteuern muss er diverse Fälle für die Regierung lösen und gerät dabei an die eine oder andere Frau, die sich ihm, ähnlich der James Bond-Figur, willig

392 Davids: Das Wildwestromanheft in der Bundesrepublik (1984), S. 177ff.

393 Ebd. S. $182 \mathrm{ff}$.

394 Ebd. S. 180.

395 Ebd. S. $187 \mathrm{ff}$.

396 Kasper: Der härteste Mann auf dem deutschen Heftromanmarkt.

397 Davids: Das Wildwestromanheft in der Bundesrepublik. 1984, S. 190.

398 Lassiter Bd. 1952. Lassiter und der Geisterbison. Jack Slade. 1. Aufl. Bastei-Verlag. S. 15. 
anbietet. Auch wiederholt er betont häufig seinen Namen auf ähnliche Weise:

„'Wie heißen Sie überhaupt?'

'Lassiter, einfach Lassiter."'“399

Die Lassiter-Serie ist eine Mischung verschiedener Genres: Eine Hybridserie. Sie kombiniert den Western mit Elementen aus dem Agenten-Genre:

„Als er wenige Minuten später das Haus durch die Vordertür verließ, hielt er ein unscheinbares Kuvert in der Hand. Obwohl weder ein Adressat, noch ein Absender darauf vermerkt waren, ahnte er bereits, von [w]em das Schreiben stammte. Zweifellos handelte es sich dabei um eine Nachricht der Brigade Sieben, jener geheimen Organisation der Regierung in Washington, von der er regelmäßig seine Aufträge erhielt. [...] [Im Folgenden wird aus dem Brief zitiert. Anm. d. Verf.] Begeben Sie sich auf dem schnellsten Weg nach Chicago und sorgen Sie dafür, dass Joyce Flanaghan unversehrt in Fort Laramie ankommt, wo die Army den weiteren Schutz übernehmen wird. Wie immer war die Nachricht nicht unterschrieben." ${ }^{400}$

So gibt es eine geheime Behörde, die inm auf umständliche Weise und im Geheimen Aufträge zukommen lässt, welche von nationaler Bedeutung sind. Diese Aufgaben sind zumeist mit attraktiven Frauen verknüpft. Des Weiteren stößt Lassiter, natürlich unverhofft, als er seinen Auftrag entgegennehmen will, auf eine willige attraktive Dame:

„'Stimmt', gab Lassiter zu. 'Ich wollte mir vorher nur noch ein bisschen die Füße vertreten. Dann habe ich dich im Garten entdeckt. [...]' [...] 'Meine Güte, ich staune immer wieder, wie klein die Welt ist [...] und welche große Überraschungen sie manchmal bereithält', fügte sie mit einem kurzen Blick auf Lassiters bestes Stück hinzu. “401

Solche Mischungen in Form von Hybridserien lassen sich auch in anderen Romanheftserien erkennen: Die Maddrax-Serie kombiniert Science Fiction mit Horror und die John Sinclair-Serie Horror mit Krimi.

\subsection{Der Krimi ist 'Jerry Cotton'}

In der Verbreitung des Kriminalromans nimmt nach Peter Nusser das Romanheft eine wichtige Stellung ein, da hier die „Heftromankrimis“ besonders erfolgreich waren

399 Ebd. S. 23.

400 Lassiter Bd. 1847. Die Gefangene des Geisterzugs. Jack Slade. 1. Aufl. Bastei-Verlag. S. 15.

401 Ebd. 
und sind. ${ }^{402}$ Besonders die Jerry Cotton-Serie fällt ins Gewicht, ${ }^{403}$ denn mittlerweile wird das Krimi-Genre im Bereich der Romanhefte lediglich durch die Jerry CottonSerie verkörpert, die nach Heinz J. Galle eine der „erfolgreichsten Kriminalserie[n] aller Zeiten" sein soll. ${ }^{404}$ Romanheftliebhaber Galle beschreibt es geradezu wehmütig: „Von den vielen Helden des kriminalistischen Genres ist eigentlich nur ein Protagonist verblieben - Basteis Jerry Cotton!“405

Nach Hickethier und Lützen werden bestehende narrative Genres (wie hier der Krimi) in die jeweiligen Medien und Gattungen transportiert und geraten dort mit innen in eine Wechselwirkung, ${ }^{406}$ daher sollte die Wandlung der Jerry Cotton-Serie in einem entsprechend breiteren Kontext betrachtet werden: „Die Entwicklung des Kriminalromans ist deshalb vor dem Gesamthintergrund der Genre-Entwicklung zu beurteilen." ${ }^{407}$ Wesollek legt dar, wie die Jerry Cotton-Serie mit den Genrekonventionen des Detektivromans bricht:

„Tatsächlich aber wird die Methode des Detektivromans, die in den CottonHeften nur in folgenlosen Selbstcharakterisierungen des Helden fortlebt, in ihnen zum Instrument der Gegenaufklärung depraviert, die Befähigung des Intellekts, Probleme zu lösen, wird durch seine Unterordnung unter Irrationales konterkariert [...] Denn nicht, daß Gefühle, Ahnungen und Zufälle den Helden auch behilflich sind, kennzeichnet die Detektionsmethode der Cotton-Hefte, sondern daß sie innen dominant behilflich sind."408

Nun sieht Nusser den Ursprung der Kriminalromanhefte in der Tradition der Westernhefte, da diese zuvor in diesem Medium erschienen sind und der Krimi darauf lediglich folgte. Das Abenteuer wurde gewissermaßen von der Prärie in die Stadt verlegt. ${ }^{409} \mathrm{Im}$ Zuge dessen wurden diverse Detektivfiguren, wie beispielsweise Nick Carter, geschaffen, ${ }^{410}$ der dem typischen Western-Helden sehr ähnlich sei: Er ist ein guter Kämpfer, instinktiv handelnd und körperlich präsent. Den Kritikpunkten Wesolleks zufolge wäre Nick Carter allerdings auch nicht als reine Detektivfigur einzuordnen, was darin begründet liegt, dass Wesollek bezüglich der Genrefrage von

402 Peter Nusser: Der Kriminalroman. 3. aktualisierte und erw. Aufl. Stuttgart 2003. S. 7.

403 Ebd. S. 8.

404 Heinz J. Galle: Volksbücher und Heftromane. Bd. 1. 2. durchges. Aufl. Lüneburg 2009. S. 160.

405 Galle: Volksbücher und Heftromane. Bd. 1, S. 146

406 Knut Hickethier und Wolf Dieter Lützen: Der Kriminalroman. In: Trivialliteratur. Hrsg. von Annamaria Rucktäschel und Hans Dieter Zimmermann. München 1976, S. 267-295. S. 292.

407 Ebd.

408 Wesollek: Jerry Cotton oder 'Die verschwiegene Welt'. S. 230.

409 Nusser: Der Kriminalroman, S. $107 f$.

410 Ebd. S. 108. 
dem klassischen Detektivroman ausgeht. Die Jerry Cotton-Figur hingegen ist somit nicht korrekt „klassifiziert“ worden. Nusser schreibt Folgendes über die „Elemente und Struktur des idealtypischen Thrillers"411:

„Im Thriller sind im Vergleich zum Detektivroman die 'action' Elemente [...] vorrangig, und zwar eindeutig gegenüber den 'analysis'-Elementen. Die Bewältigung der Aufgabe, die der Held übernommen hat, verläuft nicht als intellektuelle Tätigkeit, sondern als handelnde Auseinandersetzung." 412

Demnach ist Jerry Cotton nicht als eine Figur des Detektivromans zu klassifizieren, sondern eher des Thrillers. Dies deckt sich mit den Aussagen Wesolleks, nur dass sie nicht angemessen zugeordnet wurden. Des Weiteren sortiert Nusser das Krimiheft als wichtiges Element in der Entwicklungsgeschichte des Thrillers ein. Vor diesem Hintergrund ist die Kritik Gerhard Bierwirths, dass die Figur Jerry Cotton für den Niedergang der Detektic-Figur stehe, neu zu bewerten, ${ }^{413}$ da die Romanheftserie scheinbar völlig konform in der Tradition der Kriminalromane steht. Besonders die Aspekte und die Betonung der Gewaltdarstellung stehen, um es nun auch genauer zu formulieren, in der Tradition der „hard-boiled school“, für die folgende Aspekte charakteristisch sind: 414

- Betonung des aktionistischen Erzählelements

- stark zurückgedrängte analysis-Elemente des Detektivromans. Enorme Kraft und Wille des Helden, Kontrolle über seine Gefühle und Gelassenheit gegenüber dem Tod/Verbrechen als Teil der Gesellschaft

- eine Ich-Perspektive

- häufig Gewalt als Selbstzweck dargestellt (,violence is fun')

- ein Demaskierungsanspruch der Gesellschaft

- prinzipielle Gleichheit von Opfer und Mörder mit der Einschränkung, dass einer der Gewinner und einer der Verlierer ist

- keine Reflexion des Falls, sondern aktives Erleben

Auch in den Heften der Jerry Cotton-Serie stehen mehr Aktionen der Figuren und

411 Ebd. S. 48ff.

412 Ebd. S. 48.

413 Gerhard Bierwirth: Zum Beispiel Jerry Cotton. Trivialliteratur als Chance der Literaturwissenschaft. In: Zeitschrift für Literaturwissenschaft und Linguistik. Heft 6 1972. Hrsg. von Helmut Kreuzer et al., S. 95-104. S. 99.

414 Nusser: Der Kriminalroman, S. 48. 
Beschreibungen der Szenerien im Vordergrund, als Reflexionen. In der Regel sind die Geschichten aus der Sicht der Titelfigur Jerry Cotton erzählt. Beschreibungen wie folgende durchziehen die Jerry Cotton-Hefte:

„Als ich den Jaguar nach dem Frühstück aus der Tiefgarage lenkte, war der sturzflutartige Niederschlag in einen steten, intensiven Landregen übergegangen, hinter dem die Häuserzeilen verschwammen wie Korallenriffs in einer pazifischen Lagune." 415

Wenn Cotton Gegnern gegenübersteht, schätzt er die Situation ein und hat sie meist unter Kontrolle. Hierbei ist häufig seine körperliche Fitness ausschlaggebend:

„Ich war größer als er, mindestens zehn Kilo schwerer und besser trainiert. Wenn er es auf einen Zweikampf ankommen ließ, er würde keine Chance gegen mich haben." ${ }^{416}$

Vergleicht man die aktuellen Jerry Cotton-Hefte mit der kurzen Definition von Nusser, so zeigt sich ein entschärftes Bild der Jerry Cotton-Serie, da in der aktuellen Serie Gewaltdarstellungen gemindert sind und das Verbrechen als etwas der Gesellschaft Fremdes suggeriert wird. Gewalt ist in den aktuellen Heften nur eine Notwendigkeit, aber Jerry Cotton will auch keine Gesellschaft demaskieren, sondern sie erhalten:

„Der Fall hatte plötzlich eine ganz andere Dimension angenommen. Hier ging es nicht mehr einfach nur um Mord, sondern um eine enorme Gefahr für die nationale Sicherheit." ${ }^{417}$

Cotton will die Gesellschaft schützen. Gewalt wird in den neuen Heften nicht idealisiert, sondern mechanisiert; sie passiert eben und ist für die Helden ganz normal. Im Vergleich hierzu ein Beispiel aus einem Heft der Jerry Cotton ClassicSerie $^{418}$, als die Gewalt noch mit mehr Metaphorik in Szene gesetzt wurde:

„Und dann ging der Höllentanz los. Irgendeiner schoss. Die Kugel raste wie ein bösartiges Insekt dicht an meinem Ohr vorüber. “419

415 G-man Jerry Cotton Bd. 2942. Das letzte Level ist der Tod. 1. Aufl. Bastei-Verlag. S. 44.

416 G-man Jerry Cotton Bd. 2805. Potent wie der Tod. 1. Aufl. Bastei-Verlag. S. 50.

417 G-man Jerry Cotton Bd. 2803. Datenströme können tödlich sein. 1. Aufl. Bastei-Verlag. S. 23.

418 Seit dem Jahr 2005 stehen die alten Hefte der Jerry Cotton-Serie den neuen Heften zur Seite, allerdings nicht in einer weiteren Auflage, sondern unabhängig von ihnen als eine eigene Reihe, denn die Hefte der Jerry Cotton Classic-Serie sind ohne erkennbares System ausgewählt und sollen vielmehr einen Retrostil verkörpern, folglich wird mit den Classic-Heften keine neue Auflage herausgebracht, sondern eigentlich eine komplett neue Serie. Diese Classic-Hefte sind demnach eine Auswahl des Verlages.

419 G-man Jerry Cotton Classic Bd. 282. Sieben standen gegen uns. 1. Aufl. Bastei-Verlag. S. 59. 
Dies ist eine Situation, die ganz dem Konzept des Thrillers entspricht, denn das Verbrechen hat hier „eine ganz andere Funktion als im Detektivroman." 420 Es geht hier nicht um das „Rätsel, sondern [um das] Ereignis, gegen das man sich wehren kann und muß.“421 In den aktuellen Heften ist das „Ereignis“ tendenziell gemäßigt inszeniert:

„Phil nahm den Mann vom Oberdeck unter Feuer und ich nutzte die Ablenkung, um meine Position zu wechseln. Dann fing ich an zu schießen und gab Phil die Möglichkeit, sich eine neue Deckung zu suchen." ${ }^{222}$

Das „Ereignis“ bleibt zwar erhalten, jedoch ist die Gewalt nicht mehr so intensiv mit Adjektiven versehen („Die Kugel raste wie ein bösartiges Insekt“) und das „Ereignis“ ist viel mehr im Zusammenhang der jeweilige Episode der Serie zu sehen: Die Lösung des Falles beziehungsweise das Überleben der Hauptfiguren ist das „Ereignis“. Somit hat der Bastei-Verlag im Bereich der Kriminalromanhefte eine Leserschaft im Fokus, die nicht am Rätsellösen wie in einer Sherlock HolmesGeschichte, sondern vorwiegend an der 'suspense' interessiert ist. Die anvisierte Zielgruppe ist zwar im weitesten Sinne Krimi-Leser, aber im engeren Sinne ThrillerLeser. Die Lösung des Falles ist hier, obwohl zwar notwendig, doch nur Nebensache. In den älteren Jerry Cotton-Geschichten sind die Verbrechen eher Teil der Gesellschaft. Das soziale Gefüge der Täter und Opfer wird also thematisiert, wobei sie Gelegentlich sogar in sozialem Kontakt zueinander stehen. Wie zum Beispiel ehemalige Häftlinge oder eifersüchtige Ehemänner. So die Figur des jungen Tonio:

„Was ein junger Gangster bei seiner Einlieferung in eine sogenannte Besserungsanstalt an gemeinen Tricks, diebischer Fingerfertigkeit und moralischer Gewissenlosigkeit noch nicht beherrscht, das hat er in der Regel bei seiner Entlassung. [...] Und Tonio sollte daran zerbrechen, dass er Buck Joe kennenlernte." 423

Oder der eifersüchtige Perry Doherty:

„Perry Doherty hatte in der Annahme gemordet, ein betrogener Liebhaber zu sein. Ein tragischer Irrtum, der sein Leben zerstört hatte. “" 424

420 Nusser: Der Kriminalroman, S. 49.

421 Ebd.

422 G-man Jerry Cotton Bd. 2803, S. 60.

423 G-man Jerry Cotton Classic Bd. 282, S. 5.

424 G-man Jerry Cotton Classic Bd. 169. Blutfehde zwischen Wolkenkratzern. 1. Aufl. Bastei-Verlag. S. 65 . 
Die beiden Figuren werden gleichzeitig als Opfer dargestellt, die an ihrem Leben gescheitert sind. Nach der „hard-boiled school“ also die Verlierer darstellen. Während die Hefte der Jerry Cotton-Classic-Serie noch stark die Prägungen der 'hard boiled school' aufweisen, so folgen die Hefte der aktuellen Jerry Cotton-Serie zwar noch immer denen des Thrillers, aber nicht mehr zwingend denen der 'hard boiled school'. Die Helden konsumieren kaum noch Alkohol oder Zigaretten. Diesen Unterschied unterstreicht der Verlag im Prolog der Classic-Hefte:

„Die Romane spielen in einer Zeit, in der Jerry und Phil noch geraucht, Hüte getragen und sich den einen oder anderen Whisky genehmigt haben.. ${ }^{425}$

Inwiefern sie hierbei den aktuellen Thrillern in anderen Medien nahestehen, muss im Detail offen bleiben. Wenn man jedoch moderne erfolgreiche Krimi- beziehungsweise Thriller-Serien wie beispielsweise 24 im Fernsehen verfolgt, wird schnell deutlich, an welchen Vorbildern die Redaktion und die Autoren der Jerry Cotton-Serie sich orientieren. Ähnlich wie Jack Bauer muss auch Jerry Cotton „sein Vaterland gegen die egoistischen, rachsüchtigen oder geldgierigen Intrigen“426 verbrecherischer Organisationen verteidigen:

„Wir haben also einen chinesischen Spionagering zerschlagen und die Mörderin von Stove hinter Gitter gebracht', fasst Phil zusammen [...].“427

Dabei ist auffällig, dass die Jerry Cotton-Serie ihre Themen entsprechend aktueller Strömungen wählt und somit, „vor dem Gesamthintergrund der Genre-Entwicklung“ betrachtet, den aktuellen Konventionen des Thrillers zu folgen und nicht mit ihnen zu brechen scheint. Beispielsweise berichtet Jerry Cotton-Autor Michael J. Parrish, dass er seine Inspirationen hauptsächlich aus dem Fernsehen und dem Tagesgeschehen bezieht. ${ }^{428}$ Sein Jerry Cotton-Band Nr. 2184 „Mein heißer Flirt mit der First Lady“ sei unter anderem an die damals aktuelle Affäre des amerikanischen Präsidenten Bill Clinton mit Monica Lewinsky im Jahr 1998 angelehnt. ${ }^{429}$

425 Vgl. ebd. S. 3.

426 Barbara Schweizerhof: 24. In: Klassiker der Fernsehserie. Hrsg. von Christian Hißnauer und Thomas Klein. Stuttgart 2012, S. 307-312. S. 310.

427 G-man Jerry Cotton Bd. 2803, S. 63

428 Jakuba: G-man Jerry Cotton, S. 277.

429 Ebd. 


\subsection{Horror und Grusel in Romanheften}

Zum Horrorgenre im Bereich der Romanhefte ist von Seiten der Philologie auffallend wenig beigesteuert worden. Die umfassendsten Beiträge stammen hauptsächlich von Liebhabern und Sammlern wie Heinz J. Galle oder Jochen Bärtle, die zahlreiche Romanhefte in diesem Bereich katalogisierten. ${ }^{430}$ Die Philologie hat zwar das Phänomen des Horror-Genres im Allgemeinen erfasst, jedoch reichen diese Untersuchungen im Bereich der Literatur in der Regel bis zu den 1920ern, in denen sich der Film dieses Genres annimmt. Freilich wird auch erklärt, dass es ein Genre ist, das zur Trivialliteratur gehört, jedoch wird an dieser Stelle kaum im Detail weiter geforscht. Es werden zuweilen Klassiker wie H.P. Lovecraft genannt oder auch Schiller, der mit seinem begonnenen "Geisterseher" mehr aus kommerziellen Gründen und weniger wegen intellektueller Huldigung Erfolg hatte. ${ }^{431}$ Die Entwicklung innerhalb des Genres der Romanhefte wird hierbei völlig außer Acht gelassen, ebenso ein "Horror-Boom" in den 1970ern, der laut Bärtle zahlreiche Romanheftserien entstehen lässt. ${ }^{432}$ In dieser Periode wurden etliche Serien und Reihen gegründet, welche das heutige Horror-Genre in Deutschland nach wie vor prägen. An dieser Stelle seien unter anderem die langlaufenden Serien John Sinclair und Professor Zamorra genannt. Dieser Boom bedeutete auch einen immensen Aufschwung für das Romanheft an sich, da die Aufmerksamkeit sich nach der Jerry Cotton-Begeisterung wieder den Heften vom Kiosk zuwandte.

Aktuelle Romanheftserien, die direkt mit Horror in Verbindung gebracht werden können, erscheinen im Bastei-Verlag: John Sinclair, Professor Zamorra, Dorian Hunter sowie die Reihe Gespenster-Krimi finden sich im Verlagssortiment unter "Grusel\&Horror". ${ }^{433} \mathrm{Im}$ Kelter-Verlag finden sich im Romanheft-Bereich unter der

430 Von Jochen Bärtle sei hier auf „Grusel, Grüfte, Groschenhefte. Der deutsche Gruselheftroman von 1968 bis 2008 - Eine Serienübersicht zum 40-jährigen Jubiläum." Norderstedt 2008. hingewiesen oder der "Geisterwald Katalog" von Thomas König (Geisterwald Katalog. Die Heftroman-Bibliographie. Bd. 1 Horror/Grusel\&Mysterie. 2. Aufl. Berlin 2009). Zudem gibt es diverse Internetseiten, die sich mit der Edition der Horror-Hefte auseinandersetzen.

431 Vgl. u.a. hierzu Jürgen Viering: Schauerroman. In: Reallexikon der deutschen Literaturwissenschaft. Bd. III P-Z. Neubearb. Hrsg. von Jan-Dirk Müller. Berlin 2003, S. 365-368. S. 367.

432 Vgl. hierzu Bärtle: Grusel, Grüfte, Groschenhefte, S. 41ff. und Galle: Volksbücher und Heftromane Bd. 1, S. $178 \mathrm{ff}$.

433 Zuweilen wird auch die Maddrax-Serie zu den Horror-Serien gezählt, da sie Elemente beider Genres vermischt. Hier wird sie allerdings im Kapitel zur Science Fiction erwähnt, weil narrative Ausgangssituation und globale Rahmenhandlung einen größeren Science Fiction- als HorrorSchwerpunkt aufweisen. 
Rubrik „Mystik“ die beiden Reihen Gaslicht Der Spannungsroman für die Frau und Irrlicht Unheimliche Geschichten.

\subsubsection{Romanhefthorror beginnt im Kriminalromanheft}

1968 erschien innerhalb der Silber Krimi-Reihe des Zauberkreis-Verlags erstmals ein Horror-Heftroman in Deutschland: ${ }^{434}$ "Das Grauen schleicht durch Bonnards Haus“ mit der Hauptfigur Larry Brent. ${ }^{435}$ Da sich laut Bärtle seit den 1960ern Krimi- und Western-Serien gut verkauften, aber die steigende Popularität der Horrorfilme scheinbar den Romanheften den Rang abzulaufen drohte, erschien die Kombination dieser Genres den Produzenten im Zauberkreis-Verlag naheliegend. ${ }^{436}$

Gemäß dieses Genremixes aus Kriminalroman und Horrorgeschichten waren die ersten Folgen Kriminalfälle mit „unheimlichen und gruseligem Touch“. ${ }^{437}$ Laut König verkauften sich die Silber Grusel Krimi-Hefte sehr gut und andere Reihen und Serien folgten. ${ }^{438} 1973$ brachte der Bastei-Verlag die Gespenster-Krimi-Reihe auf den Markt, ${ }^{439}$ in der die Figur John Sinclair ihren ersten Auftritt hatte und nach 50 Gespenster-Krimi-Folgen ihre eigene Serie bekam. ${ }^{40}$ Auf diese Weise war im Sektor der Romanhefte das Horror-Genre stark an einen Genremix verknüpft und die meisten Serien deshalb Hybridserien. Viele der Hauptfiguren der ersten HorrorRomanhefte sind Ermittler: Larry Brent ermittelte als FBI-Agent in der Psychoanalytischen Spezial-Abteilung (PSA) ${ }^{441}$ und John Sinclair ist bis heute für Scotland Yard im Einsatz. ${ }^{442}$

Ähnlich wie Jerry Cotton erhält John Sinclair von seinem Vorgesetzten Sir James Aufträge zur Ermittlung, nur dass hierbei die Figuren übernatürliche Elemente als etwas Alltägliches ansehen:

„Sir James klopfte auf die Hülle. 'Im Regionalzug ist der Schaffner oder

434 Bärtle: Grusel, Grüfte, Groschenhefte, S. 23.

435 Thomas König: Geisterwald Katalog. Die Heftroman-Bibliographie. Bd. 2 Märchen/Sagen\& Fantasy. Berlin 2001. S. 241. Hauptfigur war Larry Brent, die später eine eigene Serie erhielt.

436 Vgl. Bärtle: Grusel, Grüfte, Groschenhefte, S. $76 f$.

437 König: Geisterwald Katalog, S. 241.

438 Ebd.

439 Vgl. Bärtle: Grusel, Grüfte, Groschenhefte, S. $76 f$.

440 Die erste Sinclair Episode war auch gleichzeitig der Auftakt der Reihe. Vgl. Bärtle: Grusel, Grüfte, Groschenhefte, S. 151.

441 Bärtle: Grusel, Grüfte, Groschenhefte, S. 94.

442 Ebd. S. 161. 
Kontrolleur von einer Frau angefallen worden, die sein Blut trinken wollte, was sie auch geschafft hat.' Ich runzelte die Stirn. 'Hört sich nach einem weiblichen Vampir an.' " 443

Der Kriminal-Einschlag ist bei John Sinclair seit der ersten Ausgabe unverändert erhalten, da es grundlegender Bestandteil der Serie ist. Doch auch bei Professor Zamorra, der zwar kein Ermittler von Scotland Yard oder dem FBI ist, lassen sich Kriminal-Einflüsse erkennen. Ähnlich wie ein Ermittler löst er Fälle im Bereich des Übersinnlichen und wird dafür engagiert:

„Und in einem Fall hatte Zamorra mittels eines magischen Scans im Erdreich unter dem Tate Britain so etwas wie ein unterirdisches zweites Stonehenge orten können [...]. [...] Und deshalb hatte sich Paul Hogarth seines Freundes Zamorra erinnert - sie beide hatten in allen Fällen kooperiert, die mit dem verfluchten Gelände zusammenhingen. ${ }^{\text {"444 }}$

So ist, gemäß Leo Braudy, das Übernatürliche festes Element in der John SinclairSerienwelt. Nach Leo Braudy ist der Horrorroman mit der "gothic novel“ verwandt. ${ }^{445}$ Daher umfasst für inn das Genre 'Horror' beide Formen. Geschichten aus diesem Bereich enden entweder mit einer logischen Erklärung, die ein übersinnliches Moment negiert oder mit einer Erklärung, die es bestätigt:

„Sie [die Aufklärung] bildet die düstere Hintergrundmusik und bewahrt, dem Triumph des Fortschritts zum Trotz, den Zweifel an der menschlichen Natur und das Mißtrauen gegen öffentliche Ordnungen. Folglich enden die 'gothic novels' damals und die Horrorgeschichten heute entweder natürlich [...] oder übernatürlich [...]."446

Der routinierte Umgang der Hauptfiguren mit dem Übernatürlichen unterstreicht, dass nicht die Überraschung der Hauptfigur gegenüber dem phantastischem Element im Vordergrund steht, sondern das Rätselraten beziehungsweise das Ermitteln, was sich hinter dem jeweiligen Ereignis verbirgt. So muss Sinclair ermitteln, warum Vampire in einem Zug Menschen angreifen und Zamorra erforscht das Geheimnis eines verfluchten Geländes. Sie sorgen auf diese Weise in der Welt des Übernatürlichen für Recht und Ordnung.

443 Geisterjäger John Sinclair. Bd. 1705. 1. Aufl. Mein Job in der Horror-Höhle. Jason Dark. BasteiVerlag. S. 8.

444 Professor Zamorra Bd. 954, S. 12.

445 Vgl. hierzu Leo Braudy: Horror. In: Handbuch Populäre Kultur. Hrsg. von Hans-Otto Hügel. Stuttgart 2003, S. 248-255. Die auch der folgenden Betrachtung zu Grunde liegt.

446 Vgl. ebd. S. 249. 
Bei den Ermittlungen Sinclairs wird einerseits Spannung durch die Konfrontation des Helden mit Widersachern aufgebaut, wie in einer Jerry Cotton-Geschichte, nur dass diese nicht menschliche Verbrecher, sondern meist übernatürliche Wesen sind:

„Sie hatten Hunger. Sie mussten unser Blut spüren, und sie würden alles daran setzen, es zu trinken. Ich hatte mich wieder beruhigt und zählte sie durch. Wir hatten es mit sechs Gegnern zu tun." ${ }^{447}$

So wie der kampferprobte Cotton sich auf einen Kampf vorbereitet, zählt Sinclair seine Gegner durch. Nicht anders verhält es sich bei Zamorra, der sich ebenfalls kampftauglich präsentiert:

„Zamorra riss den Blaster hoch, doch von der Seite kam ein weiterer Feind angeflogen und riss inn um. [...] Angriff!, befahl der Professor dem Amulett." ${ }^{448}$

Andererseits wird Spannung nicht nur durch Kampfszenen aufgebaut, sondern auch durch den für die Figuren beängstigenden Kontakt mit übernatürlichen Wesen wie Geistern:

„Das war keine Einbildung gewesen, diese eiskalte Berührung hatte er deutlich gespürt. Zwar war nichts zu sehen gewesen, aber bei dieser Berührung hatte sich die Haut an seinem Nacken zusammengezogen." ${ }^{449}$

Die Autoren beschreiben Szenen, in denen die Figuren unbekannte, unnatürliche Mächte wahrnehmen, die oft lebensbedrohlich für sie sein könnten:

„Ich hatte mehr den Eindruck, dass mich die unsichtbaren Stimmen umzingelt hatten, und der Ring war sogar ziemlich eng gezogen worden. [...] Ich fragte mich, wie gefährlich sie wirklich waren. Auch ich war nur ein Mensch, und über meinen Rücken lief ein kalter Schauer." ${ }^{450}$

Viele dieser Szenen beschreiben die Begegnung der Figur mit dem Übernatürlichen als etwas Vages. Dies entspricht dem, was Ann Radccliff als „terror“ bezeichnet um die Gruselwirkung in Schauerromanen des 18. Jahrhunderts zu beschreiben: ${ }^{451}$ Eine unbestimmbare, gestaltlose Bedrohung verursacht eine Grusel- beziehungsweise Schauerwirkung.

Doch bei angedeuteten Erscheinungen bleibt es in den John Sinclair-Heften nicht.

447 Ebd. S. 56.

448 Professor Zamorra Bd. 961. Nähre deine Wut! Oliver Fröhlich. 1. Aufl. Bastei-Verlag, S. 42.

449 Geisterjäger John Sinclair. Bd. 1707. 1. Aufl. Das Rätsel der toten Bücher. Jason Dark. BasteiVerlag. S. 7.

450 John Sinclair. Bd. 1707, S. 38f.

451 Viering: Schauerroman, S. 367. 
Die Figuren spüren nicht nur Erscheinungen, sondern sie müssen sich auch greifbaren, materialisierten Monstern stellen:

„Das Gesicht war zu einem monströsen Gebilde geworden, in dem sich zahlreiche Mäuler befanden oder einfach nur verschieden große Öffnungen. Aus jeder von ihnen fegte ein Schrei, und keiner hörte sich an wie der andere." ${ }^{\text {"452 }}$

Somit arbeiten die John Sinclair-Autoren mit dem was Radcliff als „horror“ bezeichnet: Schrecken, der durch greifbare Gefahr ausgelöst wird. ${ }^{453}$ Doch dies ist auch in den anderen Serien wie Zamorra oder Dorian Hunter zu finden. Weiter erklärt Braudy, dass der Begriff 'Horror' „auf eine Kombination aus Abscheu und Schrecken, vermischt mit innerlichem Grauen", abziele. ${ }^{454}$ Die Auffassung vertritt auch Hans D. Baumann:

„Die Absicht der Horror-Werke ist es demgegenüber [gegenüber Pornographie], beim Rezipienten Empfindungen von Angst, Grauen, Ekel oder Abscheu zu erwecken. ${ }^{\text {“455 }}$

Mit dem „terror" und "horror" lassen sich zwar Elemente des Schauerromans in den Romanheften ausmachen, doch finden die Parallelen hier ihr Ende, da das Übernatürliche den Hauptfiguren in der Regel als etwas Alltägliches erscheint. Jürgen Viering sieht gerade in dem Nicht-Alltäglichen, das Typische für den Schauerroman, dass dieser das "fiktional dargestellte Übernatürliche [...] nicht wie die voraufklärerische Gespenstergeschichte und das Märchen, wie reine Fantasy - als fraglos geltende Wirklichkeit hin[nimmt], sondern gestaltet es immer [...] - als unerwarteten Einbruch in eine als erklärbar eingeschätzte Wirklichkeit. ${ }^{456}$ Bei John Sinclair hingegen ist beispielsweise ein Angriff von Vampiren kein unerwartetes Ereignis, sondern für die Figuren Routine.

Settings und Staffagen des Schauerromans finden sich allerdings in den Romanheften wieder: So sind viele Schauplätze wilde Landschaften, Klöster oder Höhlen. Die Titelfigur der Serie Professor Zamorra lebt beispielsweise in einem alten Schloss

\footnotetext{
452 John Sinclair. Bd. 1707, S. 63.

453 Viering: Schauerroman, S. 367. Die Kleinschreibung ist von dort übernommen. Wenn in der vorliegenden Arbeit "terror" und "horror" kleingeschrieben werden, bezieht es sich auf die Definition von Radcliff.

454 Ebd.

455 Hans D. Baumann: Horror. Die Lust am Grauen. Basel 1989. S. 83.

456 Ebd. S. 366.
} 
auf dessen Anwesen die Helden regelmäßig Abenteuer erleben:

„Sie verließen das Château und riefen nach den Jugendlichen. Eine Antwort blieb aus. Sie gingen den gesamten Schlosspark ab, [...] prüften die Gegend um die Gräber [...]."457

John Sinclair ermittelt nicht selten auf ähnlichem Terrain sowie in Wäldern und Ruinen:

„Automatisch mußte ich an die alte Ruine denken, wo alles begonnen hatte. $\mathrm{Da}$ hatte ich ebenfalls vor einem Loch gestanden, das man als Eingang bezeichnen konnte. Hier war es ähnlich." ${ }^{458}$

Amulette und magische Gegenstände übernehmen wichtige Funktionen in den John Sinclair, Professor Zamorra oder Dorian Hunter-Geschichten ein. Suko, der Partner John Sinclairs, kämpft beispielsweise mit einem Zauberstab:

„Der Inspektor hockte geduckt auf dem Balken und griff zu seiner stärksten Waffe - dem Stab. In einem tibetanischen Kloster hatte er inn erhalten. Von Buddha sollte er stammen, und wenn Suko ein bestimmtes Wort rief, hielt der Stab die Zeit für Sekunden an.“459

Und Professor Zamorra bedient sich verschiedener magischer Gegenstände:

„Zamorra aktivierte die Radarfunktion des Amuletts. Ein Radar, der nur den Namen mit der Erfindung gemein hatte, mit der man den Luftraum überwachen konnte." ${ }^{460}$

Martin Bell zieht für die Klassifizierung der Dämonenkiller-Romanheftserie den phantastischen Roman heran mit dem Argument dass die „Phantastik scheinbar oder anscheinend Unmögliches in die Gegenwart, bzw. die Vergangenheit hineinholt“. ${ }^{461}$ Allerdings trifft dies auch auf den Bereich der Sciene Fiction zu und ist damit sehr breit gefasst. Horrorliteratur ist nach Kalju Kirde lediglich „ein Segment der phantastischen Literatur" ${ }^{462}$

Für den Horrorfilm verweist Ursula Vossen auf die „dreistufige Nomenklatur des

457 Professor Zamorra Bd. 961, S. 27.

458 Geisterjäger John Sinclair Bd. 297. Der Verräter. Jason Dark. 1. Aufl. Bastei-Verlag, S. 15.

459 Geisterjäger John Sinclair Bd. 340. Der tödliche Golem. Jason Dark. 3. Aufl. Bastei-Verlag, S. 55.

460 Professor Zamorra Bd. 954. Das dunkle Paradies. Adrian Doyle. 1. Aufl. Bastei-Verlag, S. 55.

461 Bell: Muster des Unheimlichen, S. 10. Bell zitiert hier Jens Malte Fischer.

462 Kalju Kirde (et al.): Einführung in die Horrorliteratur. In: Lexikon der Horrorliteratur. Hrsg. von Hans-Joachim Alpers, Werner Fuchs, Ronald M. Hahn. Erkrath 1999, S. 7-26. S. 7. 
Horrorfilms", die Stephen King zur Beschreibung des Horror-Genres erstellte, ${ }^{463}$ die sich auf das Romanheft anwenden lässt. Zumal galt die in den 1970ern aufkommende Horrorfilm-Welle als Auslöser und Inspiration für die Horrorromanhefte. ${ }^{464}$ Der „Schrecken“ ist nur in der Vorstellung des Zuschauers ${ }^{465}$ und entspricht damit Radcliffs "terror". Der "Horror präsentiert sich visuell und konkret erfahrbar", 466 was sich buchstäblich mit Radcliffs „horror" deckt. Die „Ebene des Ekels“ geht einen Schritt weiter und zeigt nicht nur explizit Horror-Elemente, sondern zelebriert „die Auflösung des Körpers“. ${ }^{467}$ Hans Baumann bezeichnet diese Auflösung als „Splatter“:

„Die Splatter-Richtung des modernen Horror-Films folgt allzu oft dem unzufriedenen Rezipienten, dem es um eine unbeschränkte Ausweitung und Befriedigung der Schaulust geht. “468

Bis zu einem gewissen Grad lässt sich die „Ebene des Ekels“ durchaus regelmäßig in den Professor Zamorra-Heften finden:

„Ranken brachen aus seinen Augenhöhlen heraus, schleuderten die Augenäpfel, in denen sich ewiges Entsetzen abzeichnete, mehrere Meter davon und glitten durch die schleimige, dunkle Masse, die mittlerweile eine großflächige Lache auf dem Boden gebildet hatte." ${ }^{\text {"69 }}$

Zwar werden in den John Sinclair-Romanen Körper zersetzt, doch nicht immer so detailliert wie bei Zamorra:

„Als wäre eine kleine Bombe explodiert, so wurde dieses Gesicht, das den Namen nicht mehr verdiente, auseinandergerissen. Es gab von ihm nur noch Fetzen, und die flogen in alle Richtungen davon. ${ }^{4470}$

Die Horrorromanhefte zeigen darüber hinaus weitere starke Einflüsse aus Horrorfilmen, wenn beispielsweise die Figuren auf Horrorfilm-Traditionen verweisen:

„'Ja klar', meinte Asmodis. 'Bei so einer Aktion ist ja auch noch nie was schiefgegangen. $>\mathrm{Hey}$, wir sollten uns trennen, dann sind wir allein und allen Gefahren gegenüber viel anfälliger.< Du hast wohl noch nie einen Horrorfilm gesehen was?'

Fu Long schmunzelte. 'Wenn man bedenkt, dass eigentlich wir diejenigen sind, die in einem Horrorfilm die Bedrohung darstellen, klingt dein Argument

463 Ursula Vossen (Hg.): Filmgenres Horrorfilm. Stuttgart 2004. S. $10 f$.

464 König: Geisterwald Katalog, S. 241.

465 Vossen: Horrorfilm, S. 11.

466 Ebd.

467 Ebd.

468 Baumann: Horror. Die Lust am Grauen. S. 122.

469 Professor Zamorra Bd. 960. In den Nebeln. Anika Klüver. 1. Aufl. Bastei-Verlag. S. 8.

470 John Sinclair. Bd. 1707, S. 63. 
ganz schön armselig.'“471

Die Horrorserien des Bastei-Verlages zielen mit solchen Verweisen auf Leser ab, die sich auch im Filmgenre Horror auskennen. Die Romane handeln in der Regel von typischen Horror-Themen, wie Geister, Dämonen, Werwölfe und Vampire. Diese sind zumeist auch auf den Covern der Hefte abgebildet und wenden sich damit explizit an Horrorgenre-Interessenten.

\subsubsection{Spannungsromane für die Frau}

Bei den sogenannten „Spannungsromanen für die Frau“ aus dem Kelter-Verlag ist das unheimliche Element anders gelagert als bei den Horror-Serien des BasteiVerlages. Aktuell gibt es davon zwei Reihen, die alle im Kelter-Verlag erscheinen: „Gaslicht - Der Spannungsroman für die Frau“ und "Irrlicht - Unheimliche Geschichten“. 1971 brachte der Pabel-Verlag die Gaslicht-Reihe heraus und befand sich damit zeitlich im Fahrwasser des aufkommenden Horror-Booms, der mit der Silber Grusel-Krimi-Reihe Fahrt aufnahm. Mit Untertiteln wie „Liebe und Geheimnis“ oder „Roman um Liebe und Geheimnis“472 zielten die Romane offensichtlich auf Leser von Liebesromanen ab. Später kaufte der Kelter-Verlag die Reihe auf. ${ }^{473}$

Während der siebziger Jahre entstanden weitere Gruselreihen, die sich laut H. J. Galle an eine weibliche Leserschaft wendeten, wie beispielsweise GeheimnisRoman, Spuk-Roman oder Mitternachts-Roman. ${ }^{474}$ Doch während des sogenannten „Seriensterben“ nach Bärtle ${ }^{475}$ verschwanden auch diese in den Achtzigern.

471 Professor Zamorra Bd. 960, S. 24.

472 Bärtle: Geister, Gaslicht, Gänsehaut Mysteriöse Romanzen, romantische Gothics - Der Spannungsroman für Frauen (1971-2013). Version 1.1 als kostenlose PDF downloadbar: http://www.groschenhefte.net/news01.htm (Zugriff: 22.03.2013). S. 29. Die aktualisierte Version 3.2 konnte hier nicht mehr berücksichtigt werden: http://www.groschenhefte.net/ggg_buecher_main.html (Zugriff: 04.05.2019)

473 Die Gaslicht-Reihe hat nicht zwingend etwas mit der alten Gaslicht-Reihe des Pabel-Verlages zu tun, auch wenn Kelter das gesamte Liebesromansegement von Pabel 1997 abgekauft hatte. Die Thematik ist ähnlich und passend, aber die Romane sind neu für die Reihe des KelterVerlages geschrieben und starteten 1999. 1991 knüpfte Kelter an diesen Erfolg der GaslichtReihe Pabels an und brachte zuerst die Irrlicht-Reihe heraus. Danach folgte die neue Version der Gaslicht-Reihe bei Kelter. Die Gaslicht-Reihe Kelters ab 1999 unterscheidet sich von der Irrlicht-Reihe lediglich im Titel und minimal in der Covergestaltung.

474 Galle: Volksbücher und Heftromane Bd. 1, S. 189.

475 Bärtle: Grusel, Grüfte, Groschenhefte, S. $41 \mathrm{ff}$. 
In den Irrlicht- und Gaslicht-Romanen ist das Übernatürliche nicht wie bei Professor Zamorra oder John Sinclair für die Hauptfiguren etwas Alltägliches und entspricht daher eher den Schauerromanen. Gibt es zwar in den Irrlicht- und Gaslicht-Romanen auch die Möglichkeit einer rationalen Erklärung, wird jedoch zuweilen die phantastische Lösung bevorzugt, dass es tatsächlich übernatürliche Elemente gäbe. Beispielsweise wird im Gaslicht-Roman Band 608 „Wenn sich dunkle Schatten nähern" ein beständiges Unwohlsein und Sich-beobachtet-fühlen der Protagonistin geschildert. In dem Heft, wie auch in diversen anderen der beiden Reihen, erfolgen Überlegungen zu Geistern, Spuk, Phantomen und Hexen:

„Aber sie vermochte ihre Gedanken nicht unter Kontrolle zu bringen. Sie dachte an Geister Unglücklicher, die keinen Eingang ins Jenseits fanden und auf der Erde blieben - als unheimliche Spukgestalten. [...] Fröstelnd bildete sich Linda ein, dass sie Tante Nora wiedersehen würde! [...] In diesem Moment erschreckte sie ein Geräusch." ${ }^{476}$

Die Figur denkt zwar lediglich nach und alles passiert in ihrer Phantasie, aber da der Autor diese Phantasie darstellen kann, können Geister beschrieben werden, folglich ist hier alles noch im Rahmen des „Möglichen“, obwohl „Unmögliches“ genannt wird. Die vorherigen Überlegungen zu Geistern und Spukgestalten werden durch eine unbestimmbare Angst aktualisiert. Plötzlich taucht eine fremde Frau auf und es hat den Anschein, als ob sich abermals ein phantastisches Element in der Erzählung materialisiert. Auf diese Weise wird das Phantastische dem Realen (in Gestalt einer Fremden) so nahegebracht, dass der Leser davon ausgeht, es trete nun ein Geist auf. Dies wird allerdings sogleich wieder aufgelöst, denn es handelt sich nur um die Haushälterin, die der Protagonistin nicht bekannt war. Im weiteren Verlauf wird dies allerdings abermals in die Nähe des Phantastischen gerückt, da spekuliert wird, ob die Haushälterin eine Hexe sein könnte. Somit wird das Auftreten der Haushälterin, das zuerst einen Spannungsmoment bildete, aber wieder rationalisiert wurde, abermals zu einem Spannungsmoment umgebildet und schließlich das rationale Erklärungsmoment infrage gestellt. Das Phantastische wird hier dazu genutzt, um eine unmögliche Welt in der möglichen Welt zu verankern, die im Geheimen wirkt und nur von einigen Auserwählten wahrgenommen werden kann (in diesem Fall der Heldin). So weisen die „Spannungsromane für die Frau“ zumindest im Groben Elemente auf,

476 Gaslicht Bd. 608: Wenn dunkle Schatten sich nähern. A.F. Morland. Kelter-Verlag. S. 27. 
die für Schauerromane typisch sind. Die Auflösung des Phantastischen liegt entweder darin begründet, dass alles nur eine Täuschung war, oder es erweist sich als real existierend. Es kann aber auch eine Lösung negiert und die Erklärung nebulös bleiben. ${ }^{477}$ Phantastische Rätsel sind zwar in diesen Heften von den Hauptfiguren zu lösen, jedoch begeben sie sich hierbei immer in eine Liebesgeschichte. In der Regel nimmt Liebe in den Irrlicht- und Gaslicht-Romanen die Funktion einer unbezwingbaren Macht ein, daher steht beispielsweise am Ende des Heftes „Wenn sich dunkle Schatten nähern“: „Die Liebe hatte einen großen Sieg errungen.“ "478 Die Liebe löst hier auch böse Zauber auf:

„Simon hatte sich in einen seelenlosen Eisblock verwandelt. [...] Als der Mann sie noch immer feindselig anstarrte, schlang Kessy die Arme um seinen Hals und küßte inn in wilder Verzweiflung. [...] Zögernd kam Leben in Simon. Er schien aus einem Traum zu erwachen. Sein Blick wurde klarer. Er hielt Kessy fest und erwiderte schließlich sogar ihren Kuß." 479

Diese „Spannungsromane“ mit den diversen Bezeichnungen „Romantasy“480 , „MystikRomane“481 oder auch „Romantic Thriller“482 bedienen sich also der „entfremdenden Elemente“, um so eine Liebesgeschichte aufzubauen. An dieser Stelle liegt ein Genremix vor, in dem, je nach Autor, mal die Liebesroman-Elemente und mal die Anteile des Schauerromans dominieren. Jedoch werden hierbei keinerlei psychologisierende Elemente genutzt, die für einen Schauerroman grundlegend wären, ${ }^{483}$ sondern es wird vielmehr ein Schwerpunkt auf die Spannungswirkung an sich gelegt. Von daher ist die Bezeichnung „Romantic Thriller“ eher treffend, da auch in dieser 'Thriller'-Form das Erlebnis der Spannung das eigentliche Ziel der Narration ist. Damit liegen hier Hybridserien vor, die auf eine Leserschaft von Liebesromanen abzielen, welche sich bei der Lektüre einer Liebesgeschichte gerne gruseln möchten.

Wie bei den Liebesromanen herrschen in diesem Bereich auch Reihen und keine

477 Vgl. hierzu u.a. Marianne Wünsch: Phantastische Literatur. In: Reallexikon der deutschen Literaturwissenschaft. Bd. III P-Z. Neubarb. Hrsg. Von Jan-Dirk Müller. Berlin 2003, S. 71-74.

478 Gaslicht 608. S. 65.

479 Irrlicht Bd. 977. Die teuflischen Jünger. Pamela Francis. Kelter-Verlag. S. 49.

480 Basener: Heftromane schreiben, S. 51.

481 Kategorie des Kelter-Verlags: https://www.kelter.de/52-mystik (Zugriff: 17.08.2019).

482 Diese Bezeichnung wird u.a. vom Kelter-Verlag genutzt (vgl. https://www.kelter.de/52-mystik (Zugriff: 17.08.2019).), aber auch von dem Horror-Genre-Kenner Jochen Bärtle: Geister, Gaslicht, Gänsehaut. Vgl. S. $15 f$.

483 Vgl. Viering: Schauerroman. S. 365ff. 
Serien vor. Die Folgen sind in sich abgeschlossen und bauen nicht aufeinander auf. Gänzlich anders verhält es sich bei den drei Bastei-Serien, die allesamt fortlaufende Handlungsstränge haben. Wobei John Sinclair-Folgen meist in sich abgeschlossen sind, aber durchaus auf vorangegangene Folgen aufbauen. So trennt sich der Bereich der "Romantic Thriller" nicht nur im Schwerpunkt des Themas von den Horror-Kriminalromanheften (Liebe vs. Kriminalfall), sondern auch in der Fortsetzungsart (episodal vs. fortlaufend).

\subsection{Heldenhafte Fantasy}

Blickt man auf den aktuellen Taschenbuchmarkt oder auf den der TV-Serien, ${ }^{484}$ zeigt sich eine weite Verbreitung an Fantasy-Serien, die einen hohen Bedarf an seriellen Narrationen in diesem Genre nahelegen, daher ist es erklärungsbedürftig, dass der Romanheft-Markt dieses Genre nicht nutzt. Die letzte Fantasy-Romanheftserie darf als ein gescheiterter Versuch angesehen werden, mit diesem Genre in dem Romanheft-Sektor Fuß zu fassen: Die Mythenland-Serie erschien 2010 monatlich als Taschenheft. Davor gab es lediglich vereinzelt Romanheftserien, die entweder zu Kleinverlagen überwechselten oder, wie Volker Ferkau mit Mythenland, im Eigenverlag ihr Glück suchten. Auffällig ist, dass die meisten Serien, die in diesem Genre der Romanhefte erschienen, häufig die Form des Taschenheftes wählten oder gar vom Romanheft zum Taschenbuch überwechselten, woraus sich ableitet, dass die Heftform sich in diesem Genre anscheinend nicht gut verkaufte. ${ }^{485}$

Gründe, warum ein Verlag eine Serie absetzt, werden Autoren meist nicht mitgeteilt. So berichtet der Romanheftautor Hugh Walker: „Wir haben nie erfahren, welche roten, oder nicht genug schwarzen, Zahlen die Verlagsleitung veranlaßten, Dragon im April 1975 so abrupt einzustellen. “486 An dieser Anekdote zeigt sich, wie flüchtig Genres im Bereich der Romanhefte sein können. Wird eine Serie im Rahmen eines

484 Man denke hierbei als Beispiel an die "Das Lied von Feuer und Eis"-Romane von George R.R. Martin, die derzeit als TV-Serie "Game of Thrones" verfilmt werden. Der erste Roman erschien 1997 in Deutschland und weitere folgen, während die Verfilmungen ab 2011 in den USA und 2012 in Deutschland ausgestrahlt wurden.

485 Hier besteht weiterer Forschungsbedarf, der in dieser Arbeit leider nicht geleistet werden kann. Dies könnte eventuell im Rahmen einer dezidierten Forschung zum Fantasy-Genre geschehen.

486 Walker, Hugh: Dragon - Erinnerungen und was sonst noch übrig ist. In: Dragons Welt. Hintergründe Inhalte Lexikon. Hrsg. von Hans Kneifel und Roman Sander. Augsburg k.A., S. 13-25. S. 25. Hugh Walker heißt mit bürgerlichem Namen Hubert Straßl. 
Genres von der Leserschaft nicht akzeptiert, so wird sie nicht weiter produziert. Verlage wagen anscheinend auch nicht den Versuch, Genres in ihrer ganzen Vielfalt anzubieten, sondern lediglich das, was auf dem Markt akzeptiert wird. Zudem ist es auch nicht gegeben, dass ein Genre einen stabilen Themenbereich darstellt. 1962 ordnete beispielsweise Nutz im Bereich der Romanhefte die Science Fiction-Serien den Abenteuergeschichten zu. ${ }^{487}$ Damals hatte diese Zuordnung ihre Berechtigung, jedoch lässt sie sich heute nicht mehr anwenden. Ein ähnliches Phänomen lag bereits beim „Frauenroman“ beziehungsweise „Liebesroman“ vor, zudem gibt es aktuell auch kein Abenteuer-Genre, zumindest wird es durch keine Romanheftserie vertreten. Die letzte Abenteuer-Romanheftserie erschien 2011: Der Abenteuer Roman im Kelter-Verlag. ${ }^{488}$

Die einzigen zu ihrer Zeit gut laufenden Romanheftserien in dem Fantasy-Genre waren Dragon in den 1970ern und Mythor in den 1980ern. ${ }^{489}$ Die Mythor-Serie wurde laut dem Perry Rhodan-Autor Michael Nagula jedoch aus unbekannten Gründen gegen Ende der 1980er eingestellt, wie viele andere Serien auch. ${ }^{490}$ Jochen Bärtle weist auf einen ähnlichen Trend im Bereich der Horror-Romanhefte zu der Zeit hin und bezeichnet es als „das Seriensterben“. ${ }^{491}$

Dragon und Mythor beherrschten zu jener Zeit das Fantasy-Romanheftserienfeld und eignen sich als Stellvertreter dieses Romanheftgenres. Beide verfügten über eine Fortsetzungsstruktur, wohingegen das Reihen-Format, wie beispielsweise Fantasy Götter, Krieger und Dämonen sich im Bereich der Romanhefte nicht lange hielt. ${ }^{492}$ Das Konzept eines epischen Handlungsstranges scheint eher akzeptiert worden zu sein als kurze und abgeschlossene Handlungsstränge. Dieser Aspekt muss zwar im Spekulativen bleiben, wird aber in der späteren Betrachtung des Science FictionGenres erneut von Interesse sein (vgl. folgendes Kapitel 4.7 „Science Fiction“).

In den Fantasy-Romanheften der 1970ern bis 1980ern findet sich ein präsenter

487 Nutz: Der Trivialroman seine Formen, S. 23.

488 Stand dieser Erkenntnis: 2018.

489 Nagula: Perry Rhodan. Die Chronik. Bd. 2, S. 490.

490 Ebd. S. 500.

491 Bärtle: Grusel, Grüfte, Groschenhefte, S. 41ff. Bärtle weiß ebenfalls keinen Grund für das sogenannte Seriensterben: „Die Gründe dafür sind auch heute noch spekulativ, da die Inhalte der Krisensitzung und die Verkaufszahlen immer noch als Verlagsinterna gehandhabt werden." Ebd. S. 46.

492 Vgl. König: Geisterwald Katalog. Der Katalog ist verhältnismäßig kurz und entsprechend überschaubar. 
Bezug zu den Science-Fiction-Romanheften derselben Zeit und insbesondere zu der Perry Rhodan-Serie. So wurde beispielsweise 1971 in den Dragon-Heften geworben, dass sie aus der Feder der Perry Rhodan-Autoren stammte:

„Der Pabel Verlag bringt nach sorgfältiger Vorbereitung durch das PerryRhodan-Team die erste deutsche FANTASY-Serie. [...] Alte Legenden, Träume, Phantasie, gekonnt gestaltet von den Perry-Rhodan-Autoren - das alles finden Sie in der neuen DRAGON-Serie."

Zudem sind in die Handlung der ersten Dragon-Hefte Science-Fiction- und FantasyElemente miteinander vermischt, wie beispielsweise ein sternfahrendes Volk, das auf einem fremden Planeten mit Schwertern und Feen agiert. Ende der 1985er ließ der Moewig-Verlag in seine Science-Fiction-Serie Atlan Motive aus dem Fantasy-Genre einfließen:

„Deshalb sollte ATLAN ab Band 500 eine Handlung fortsetzen, die in der Hauptserie PERRY RHODAN begonnen worden war [...] und die Fantasy ... nun, es sollte eine neue Serie starten." ${ }^{494}$

Die meisten Fantasy-Romanheftserien wurden jedoch gegen Ende der 1980er eingestellt und auch aus der Atlan-Serie entfernte der Verlag das Fantasy-Element. ${ }^{495}$ Lediglich die Taschenbuchreihe Terra-Fantasy erfreute sich von 1970 bis 1978 eines durchgängigen Absatzes und erfuhr 1984 eine zweite Auflage. Taschenbücher und nicht Hefte scheinen die Domäne für Fantasy zu sein. Dementsprechend brachte der Weltbild-Verlag die Fortsetzungsserien Dragon sowie Mythor im Jahr 2000 als Taschenbücher neu heraus. ${ }^{496}$ Weitere großangelegte Versuche, eine neue FantasyRomanheftserie zu etablieren, unternahm nach 1986 kein Verlag mehr.

Bemerkenswert ist zudem, dass Mythor und Dragon die Fantasy-Serien sind, die, ähnlich wie Perry Rhodan, durchgehende Handlungsstränge beinhalten. Die Serien vermarktete der Verlag zudem als Produkte aus der Perry Rhodan-Redaktion und stattete sie mit Science-Fiction-Elementen aus. Somit ist offensichtlich, dass der Verlag sichergehen und eine Leserschaft aus dem erschlossenen Bereich der Science-Fiction-Leser rekrutieren wollte. Ähnliches mutmaßt auch Thomas König: „Dragon begann, wohl um S[cience]F[iction]-Lesern den Einstieg zu erleichtern mit

493 Dragon Söhne von Atlantis. Bd. 1. Griff nach Atlantis. William Voltz. 1. Aufl. Pabel-Verlag. S. 1. Vorwort von Günter M. Schelwokat.

494 Nagula: Perry Rhodan. Die Chronik. Bd. 2, S. 491.

495 Vgl. ebd. S. $490 \mathrm{ff}$.

496 Vgl. König: Geisterwald Katalog Bd. 2. 
drei SF-Romanen“. 497

Inhaltlich orientierten sich Dragon und Mythor an dem Subgenre der Fantasy, der sogenannten „heroischen Fantasy“ (häufig auch „heroic fantasy“ genannt, doch die genaue Definition wird im Folgenden diskutiert). Hier wollten die Verlage wohl ebenfalls keine Experimente wagen, denn die erfolgreiche Taschenbuchreihe TerraFantasy publizierte lediglich Romane dieses Subgenres. In Terra-Fantasy finden sich unter anderem viele Geschichten von Lin Carter, L. Sprague De Camp und Robert E. Howard, der die nahezu ikonografische Figur dieses Subgenres erschuf: Conan. ${ }^{498} 499$ Im 21. Jahrhundert erscheint es eindeutig, Geschichten wie Conan, Dragon oder Mythor der Fantasy und insbesondere der heroischen Fantasy zuzuordnen. Dies war aber beispielsweise 1970 und 1980 noch nicht so eindeutig, denn einige der in Deutschland publizierten Geschichten stammten aus Amerika, wo sie in Magazinen mit Titeln wie „The Magazine of Fantastic“ oder „Amazing Stories“ zwischen ScienceFiction-Erzählungen erschienen. ${ }^{500}$ Der Begriff „Fantasy“ bezeichnete damals nicht zwingend das als heute so deklarierte Genre, sondern umfasste auch Texte, die in Deutschland eher der sogenannten „phantastischen Literatur“ zuordenbar sind. ${ }^{501}$ In diesen Magazinen wurden also phantastische Geschichten aller Art versammelt. Einige dieser Geschichten stammen aus den 1930ern. So erschienen beispielsweise Howards erste Geschichten ab 1932 in dem Magazin „Weird Tales“. 502

Hugh Walker, der Geschichten aus diesen Magazinen übersetzte und in der TerraFantasy-Reihe in Deutschland publizierte, berichtete:

„Mein eigenes Interesse an der Fantasy begann irgendwann in den frühen sechziger Jahren im Zuge meiner Beschäftigung mit amerikanischer Science Fiction. [...] Vieles was ich in diesen Jahren kennenlernte, konnte ich in den siebziger Jahren in der Taschenbuchreihe Terra Fantasy auch dem deutschsprachigen Leser vorstellen." ${ }^{503}$

Zu jener Zeit war der Begriff der „Fantasy“ zwar geläufig, doch Geschichten, die zu

497 Ebd. S. 10.

498 Ebd. S. 55ff. Dort findet sich eine Liste aller Autoren der Reihe.

499 Über den Stellenwert der Conan-Figur in der Fantasy-Literatur vgl. u.a. Marcel Feige: Das neue Lexikon der Fantasy. 2. erw. Aufl. Berlin 2003. S: 81ff.

500 Vgl. König: Geisterwald Katalog Bd. 2. S. $55 \mathrm{ff}$.

501 Vgl. auch Helmut W. Pesch: Fantasy - Theorie und Geschichte einer literarischen Gattung. 2. Aufl. Norderstedt 2017. 11ff.

502 Robert E. Howard: Conan Bd. 1. Die Original-Erzählungen aus den Jahren 1932 und 1933. 4. Aufl. München 2011. S. 11. Vorwort des Hrsg. Patrice Louinet und übersetzt von Jürgen Langowski.

503 Walker: Dragon - Erinnerungen und was sonst noch übrig ist. S. $13 \mathrm{f}$. 
dieser Kategorie gehörten, waren in Deutschland nicht vorrätig und laut Walker in Amerika der Science Fiction zugeordnet. Auch das Lexikon der Fantasy-Literatur umgeht eine klare Definition ihres Gegenstandes und begnügt sich damit den Gegenstand als solchen als gegeben zu erfassen:

"Grundsätzlich gehen wir in diesem Lexikon davon aus, dass die FantasyLiteratur als Phänomen existiert und ab einem bestimmten Zeitpunkt - der Bestsellererfolg von J.R.R. Tolkiens LORD OF THE RINGS könnte dabei ein markantes Datum gesetzt haben - erfolgreich unter diesem Namen vermarktet wurde."

Die Herausgeber des Fantasy-Lexikons beziehen sich hier nicht auf die 1937 erschienene Erstausgabe in England, sondern auf die vom Autoren nicht autorisierte Ausgabe 1965 in Amerika. ${ }^{505}$ Dort löste die dreibändige Ausgabe von „Der Herr der Ringe“ eine Kultbewegung aus, die viele Autoren beeinflusste und nicht nur auf Amerika beschränkt blieb. ${ }^{506}$

Der in der vorliegenden Arbeit genutzte Begriff „Fantasy“ stützt sich auf die grob umrissene Definition von Pesch, dass „es sich hier um eine besondere Klasse von Erzähltexten handelt, die eine bestimmte Rezeptionshaltung erfordern (welche, um soweit vorzugreifen, unter anderem darin besteht, daß hier das Übernatürliche nicht als etwas Fremdes angesehen wird, sondern als etwas Gewohntes akzeptiert wird)“ ${ }^{507}$ Die Figuren leben also (ähnlich wie in „Der Herr der Ringe“) in einer Welt, in der phantastische Elemente wie Drachen, Feen und Zauberer alltäglich sind. Das Element des Wunderns oder Rätselns der Figuren über ein phantastisches Phänomen entfällt in dieser Erzähl-Kategorie, denn sie sind diese Phänomene gewohnt. Dies ist gegenläufig zu einer Definition phantastischer Literatur: „Es [das Phantastische] ist das Unmögliche, das unerwartet in einer Welt auftaucht, aus der das Unmögliche per definitionem verbannt worden ist." "508

Um die Fantasy als Genre der Romanhefte zu definieren muss die Strömung nicht bis hin zum Artus-Roman oder antiken Mythologien zurückverfolgt werden, da sie

504 Hans-Joachim Alpers, Werner Fuchs, Ronald M. Hahn, Jörg M. Munsonius und Hermann Urbanek (Hg.): Lexikon der Fantasy-Literatur. Erkrath 2005. S. 7. Vorwort der Hrsg.

505 Vgl. ebd. S. 431.

506 Ebd.

507 Pesch: Fantasy - Theorie und Geschichte. S. 13.

508 Rein A. Zondergeld: Lexikon der phantastischen Literatur. 1. Aufl. Main 1983. S. 11. Zondergeld zitiert hier Caillois, erweitert aber seinen Ansatz u.a. um das Utopische, da seiner Auffassung nach hier sich die Phantastik mit der Science Fiction decke. 
sich in direkter Linie nicht aus älteren Literaturgattungen speist, sondern aus konkreten Werken der amerikanischen Pulp- bzw. Pop-Literatur: Phantastische Erzählungen der 1920er und 1930er Jahren sowie Erzählungen ab 1965, die von Tolkien beeinflusst wurden. Sicherlich haben Werke des phantastischen Abenteuerromans und der antiken Mythologie indirekt die Fantasy-Romanheftserien der 1970er und 1980er geprägt, doch waren diese Einflüsse bereits in den vorangegangenen Erzählungen aufgenommen und transformiert. Pesch schreibt hierzu:

„Fantasy als Genre ist ein Kind der 60er und frühen 70er Jahre. Erst ab dieser Zeit können wir von einem vorwissenschaftlichen Verständnis von Fantasy ausgehen."

Somit laufen die Einflüsse jener Zeit auf die deutschen Fantasy-Romanheftserien der 1970er bis 1980er zusammen und wurden in einigen Fällen überhaupt erst unter der Bezeichnung „Fantasy“ einer Leserschaft präsentiert, denn wie bereits erwähnt, publizierte Walker Erzählungen in der Terra-Fantasy-Reihe, die zuvor im Bereich der amerikanischen Phantastik beziehungsweise Science Fiction kursierten. Der Begriff „Fantasy“ für Romanhefte muss unscharf bleiben, da Autoren und Herausgeber jener deutschen Romanhefte inn ebenso unscharf verwendeten. Lediglich zwei Grundkomponenten treten aus den deutschen Fantasy-Romanheften ab den 1970ern zutage: Abenteuer-Erzählungen in einer fremden Welt, in der das Phantastische zum Alltag gehört und der Held mit körperlicher Kraft seine Probleme löst. Dergestalt beschreibt der Pabel-Verlag sein Versprechen für die kommenden Abenteuer im ersten Mythor-Heft:

„Was ist Fantasy nun eigentlich? ...Mythos und Legende, germanische Saga und keltisches Märchen und indo-germanisches Heldengedicht, Ballade und Epos, die phantastische und ursprünglichste Form des Erzählens ...ein Abenteuer sondergleichen, in einer Welt, wie sie möglicherweise gewesen sein könnte [...], wie sie irgend- oder nirgendwo im Universum existiert." 510

Die vagen Andeutungen lassen jedoch keinen Zweifel zu, dass die Erzählweise aktionsorientiert sein wird und Heldentaten im Vordergrund stehen. Somit liegen genügend Hinweise vor, Mythor der heroischen Fantasy zuzuordnen, die Pesch anlehnend an de Camp folgendermaßen definiert:

509 Pesch: Fantasy - Theorie und Geschichte. S. 25.

510 Mythor Bd. 1. Der Sohn des Kometen. Hugh Walker. 1. Aufl. Pabel-Verlag. S. 3. Leserkontaktseite. 
„E]rstens die Handlung ('a story of action an adventure'), zweitens den Schauplatz ('a more or less imaginary world') und drittens dessen technologischen - oder auch ontologischen - Status ('where magic works and where modern science and technology have not yet been discovered')." ${ }^{511}$

De Camp benutzt synonym für die heroische Fantasy auch die Bezeichnung „Sword und Sorcery". Etwas nonchalanter umreißt Marcel Feigel das Subgenre:

„Helden kämpfen sich schwerterschwingend, köpferollend durch das Böse dieser und anderer (meist mittelalterlicher) Welten. ${ }^{512}$

Das Versprechen des Vorwortes des ersten Mythor-Bandes haltend, finden sich etliche Kampfszenen in der Mythor-Serie. Wie zum Beispiel:

„Mythor stieß eine Verwünschung aus. Er wechselte das Schwert in die linke Hand und focht so weiter." ${ }^{\text {"13 }}$

Allerdings sind die Geschichten der Mythor- und Dragon-Hefte nicht so kampflastig wie das obige Text-Beispiel und die Definition nach Feigel sie erscheinen lassen mögen. Sicherlich sind Kampfszenen Bestandteil der Serien, jedoch nur ein Teil. Vielmehr nehmen die abenteuerliche Reisen der beiden Helden Mythor und Dragon große Teile der Hefte ein. Somit richteten die beiden Serien sich an Leser von Abenteuergeschichten, die zudem eine sich fortsetzende Handlung erwarteten. Die beiden Serien nahmen lediglich eine Strömung der Fantasy auf und versuchten mit Science Fiction-Elementen auch die große Leserschaft dieses Genres anzusprechen.

Diesen Aspekt hat auch die Hybrid-Serie Maddrax beibehalten. In ihr sind Science Fiction-, Horror- und Fantasy-Elemente zu einer Fortsetzungshandlung stark vermischt. Der Held Matthew Drax wird bei einem Kometeneinschlag mit seinem Düsenjet in die Zukunft katapultiert, in der er in einer postapokalyptischen Welt strandet. Dort trifft er schwertschwingende Barbaren und Mutanten. Ähnlich wie Dragon und Mythor reist er durch eine mittelalterliche Welt, um sich mit Muskelkraft durchzuschlagen und das Rätsel seiner Zeitreise zu lösen. Die Serie erscheint seit dem Jahr 2000 bis heute im zweiwöchentlichen Rhythmus. Das Konzept, sich an eine bestehende Leserschaft aus anderen Genres (hier Horror und Science Fiction) zu wenden, ist

511 Pesch: Fantasy - Theorie und Geschichte. S. 33.

512 Marcel Feige: Das neue Lexikon der Fantasy. S. $196 f$.

513 Mythor Bd. 6. Das gläserne Schwert. Peter Terrid. 1. Aufl. Pabel-Verlag. S. 50. 
demnach im Romanheftbereich erfolgreicher als reine Fantasy-Geschichten.

\subsection{Science Fiction und Space Opera}

Die Genres Science Fiction und Fantasy im Bereich der Romanhefte stehen sich, wie oben bereits erwähnt, so nahe, dass einige Werke nur schwer dem einen oder anderen Genre zuzuordnen sind. Hybrid-Serien wie Maddrax oder Dragon sind die Folge. Im Bereich der Romanhefte hat die Science Fiction jedoch eine längere Tradition und war bisher auch das erfolgreichere Genre von beiden, dies belegen langlaufende Serien wie Perry Rhodan und Atlan sowie die Reihe Terra Astra. Die ersten Romanhefte der Dragon-Serie, auf all deren Heft-Covern „Die erste deutsche Fantasy-Serie“ gedruckt stand, besaßen eine Rahmenhandlung, die im Science Fiction-Genre gelagert war. Außerdem stammten fast alle Autoren aus dem Perry Rhodan-Umfeld.

„Versucht man eine Gattungsbestimmung“, so Peter Nusser, „so handelt es sich um Literatur [...], die sich mit den Möglichkeiten der Zukunft beschäftigt und dabei wissenschaftliche Rationalität mit Phantasie vereinbart."514 $\mathrm{Er}$ beschreibt die Eingrenzung dieser Literatur als problematisch, da sich unter dem Begriff „Science Fiction“ viele verschiedene Einflüsse vermischen, wie etwa von den utopischen Romanen, Reiseromanen und phantastischer Literatur. ${ }^{515}$ Die lange Tradition der Science Fiction lässt sich zudem laut verschiedener Darstellungen bis in die Antike zu einer Utopie Platons über die Feuilletonromane Jules Vernes zurückverfolgen. ${ }^{516}$ Für die Romanhefte sind jedoch erst die Entwicklungen Anfang des 20. Jahrhunderts relevant, da sich im Folgenden zeigen wird, dass die Romanheftserien und -reihen in Deutschland nur bestimmte Elemente aus eben diesen Strömungen in ihre Erzählungen aufnahmen. Seit 1920 erschien in den USA von Hugo Gernsback das SFMagazin „Amazing Stories“. Dieses Magazin wird als der Beginn der eigentlichen Science Fiction angesehen oder zumindest des Begriffes. ${ }^{517}$ Die Geschichten darin

514 Nusser: Trivialliteratur, S. 79.

515 Ebd. S. 80f.

516 Vgl. bspw. Hans-Joachim Alpers, Werner Fuchs, Ronald M. Hahn, Wolfgang Jeschke: Lexikon der Science Fiction Literatur. Bd. 1. München 1980. S. $25 \mathrm{ff}$.

517 Ulrich Suerbaum, Ulrich Broich und Raimund Borgmeier: Science Fiction. Stuttgart 1981. S. $51 \mathrm{ff}$. Der Stellenwert Gernsback in diesem Zusammenhang ist streitbar. Sicher ist jedoch, dass dieses Magazin den deutschen Markt damals beeinflusste und es, sei dies nun positiv oder 
waren abgeschlossene Zukunftsgeschichten, die massenmedial verbreitet wurden. Die Themen grenzte Gernsback stark von den 1920 weit verbreiteten „Planetenromanen", die eher Liebesgeschichten mit technischer Staffage waren, ab. ${ }^{518} \mathrm{Ihm}$ war eine Nähe der Geschichten zur Technik- und Wissenschaft wichtig. ${ }^{519}$ Sein Nachfolger im Geiste John W. Campbell weichte das Konzept in seinen Magazinen auf und ließ Geschichten mit Elementen zu, die nicht wissenschaftlich belegte Ideen beinhalteten, wie beispielsweise Raumfahrt in Lichtgeschwindigkeit oder Telepathie. ${ }^{520}$ In den Magazinen von Campbell publizierten später erfolgreiche ScienceFiction-Autoren wie Issac Asimov, Robert A. Heinlein und Ray Bradbury ihre ersten Geschichten. ${ }^{521}$

Diese sich von bloßen Abenteuerromane mit technischer Staffage distanzierenden Geschichten kamen nach Deutschland und wurden übersetzt, wobei das Science Fiction-Genre in Deutschland sich hauptsächlich in der Form des Romanheftes verbreitete, ${ }^{522}$ zudem war es Usus, dass sich deutsche Autoren amerikanische Namen gaben, um so an die Vorbilder anzuknüpfen. ${ }^{523}$

Bis etwa in die 1970er hinein war das Science Fiction-Genre in Deutschland nicht von der Form des Romanheftes zu trennen ${ }^{524}$, und viel entscheidender noch: Es war mit Perry Rhodan gleichzusetzen, denn die 1960er Jahren waren das, was Galle als die „Perry-Rhodan-Phase“ bezeichnet. ${ }^{525}$ Die Perry Rhodan-Serie prägte mit ihrem Erscheinen den Romanheft-Markt, da sie eine ausgeprägte Fortsetzungsstruktur aufwies. Allerdings wurde sie von der Sekundärliteratur in den 1970ern und 1980ern zuweilen als 'Landser im Weltraum' ${ }^{1526}$ verunglimpft und als Serie beschrieben, die einen „militärisch aggressiven Imperialismus“527 betreibe und fördere. Die Kritik stellt

negativ zu bewerten, damit zu dem formte, was heute in Deutschland als Science Fiction vermarktet wird.

518 Suerbaum in: Borgmeier: Science Fiction, S. 52.

519 Ebd. S. 53.

520 Ebd. S. 54f.

521 Ebd. S. 56.

522 Nusser: Trivialliteratur, S. 81.

523 Vgl. Schwettmann: Allmächtiger, S. 26. Um seine eigenen Romane für den Pabel-Verlag Interessant zu machen, nutzte der Romanheftautor Walter Ernsting die Pseudonyme Fred McPatterson und Clark Darlton. Vgl. Nagula: Perry Rhodan. Die Chronik. Bd. 1, S. 52.

524 Vgl. Nusser: Trivialliteratur, S. 81.

525 Galle: Groschenhefte, S. $162 f$.

526 Alpers: Lexikon der Science Fiction Literatur Bd. 1, S. 76.

527 Conrad Suhler: Perry Rhodan - Auf Raketen zurück in die Zukunft. In: Kürbiskern Literatur und Kritik. Hrsg. von W. Fritzsche, F. Hitzer, O. Neumann, H. Stutz, C. Suhler. Heft 4/70. München 1970, S. 588-597. S. 594. 
die Sachlage ein wenig verzerrt da, denn zu jener Zeit war es keine exklusive Besonderheit der Perry Rhodan-Serie, sondern typisch für alle Science FictionGeschichten in jeglichen Medienformen, Kriegsszenarien im Weltraum als Schwerpunkt zu setzen. Sicherlich ist es korrekt, dass in der Perry Rhodan-Serie zu jener Zeit militärisch aggressive, imperiale Gegner auftauchten, doch ist es zu weit gegriffen, dass die Serie solche Haltungen aktiv förderte. Die Kritik hätte sich eher an dem ganzen Science Fiction-Genre (inklusive der amerikanischen Vorlagen) abarbeiten müssen, doch sie stellt es so dar, als sei die Perry Rhodan-Serie ein Einzelphänomen gewesen. Militante Abenteuer in Namen einer Organisation brachten bereits Romanheftserien wie Jim Parker und Mark Powers oder Reihen wie UtopiaZukunftsroman und Ad Astra zu den Lesern. ${ }^{528}$ Die Darstellung militärischer Weltraumabenteuer führte besonders der amerikanische Autor Robert A. Heinlein in seinen Romanen und Erzählungen zu einem Höhepunkt, die auch immer wieder Eingang in diverse Science Fiction-Taschenbuch- oder Romanheftreihen fanden. ${ }^{529}$

Das Subgenre der Science Fiction, die sogenannte „Space Opera“, erfreute sich bereits in den 1920ern in Amerika großer Beliebtheit und kam, wie oben erwähnt, ab 1940 in zahlreichen Übersetzungen nach Deutschland. ${ }^{530}$

„Die Space Opera zeichnet sich durch interstellare Raumfahrt, kosmische Konflikte, klischeehafte Aufteilung in galaktische Bösewichte und interstellare Polizeitruppen und vor allem gigantomanische 'SuperScience' aus." 531

Insbesondere die Perry Rhodan-Serie realisierte in dem Zeitraum von 1961 bis in die 1970er mit ihrem Krieg zwischen den Sternen die damals zeitgemäßen Konventionen der Space Opera: Perry Rhodan reist mit seiner Crew weit in den Weltraum hinaus, kämpft auf verschiedenen Planeten für Gerechtigkeit und trifft in den ersten Heften zumeist auf stereotype Antagonisten (hierzu weitere Details im folgenden Kapitel 4.8 „Der Fall 'Perry Rhodan'“).

Die Serie hat sich bis heute erhalten und ist damit eine der am längsten laufenden Romanheftserien. Hierbei hat sie sich immer den Gegebenheiten des Genres angepasst. ${ }^{532}$ Bis zum Jahr 2012 gab es im Romanheftbereich mit Perry Rhodan nur noch

528 Vgl. diverse Beispiele hierzu bei Galle: Volksbücher und Heftromane Bd. 1, S. $76 f f$.

529 Alpers: Lexikon der Science Fiction Literatur Bd. 1, S. $76 f$.

530 Ebd. S. $59 f f$.

531 Ebd. S. 59.

532 Dies dürfte auch einer der Gründe sein, warum Pabel-Moewig diese Serie nicht verkauft hat. 
drei Science Fiction-Serien, wovon die anderen beiden Serien bei Bastei erschienen: Maddrax und Sternenfaust. ${ }^{533}$ Die Sternenfaust-Serie fällt in die gleiche Kategorie wie Perry Rhodan. Die Maddrax-Serie hingegen stellt einen Genre-Mix aus Horror, Fantasy und Science Fiction dar.

Der anvisierten Zielgruppe zufolge sind Leser dieser drei Serien weniger am Romanheft als am Genre interessiert, denn in den Heften finden sich diverse Werbeanzeigen für andere Science Fiction-Serien, Bücher, Filme, Spiele et cetera. Science Fiction hat im Romanheft Tradition, denn die meist von den Heften distanzierten literarischen Vorgänger publizierten in der Sparte der populären Lesestoffe. Literarische Werke wie von Lem bilden eher Ausnahmen. Sogar Jules Vernes' Werke erschienen seinerzeit im Massenmedium: Dem Feuilleton einer Zeitung beziehungsweise im Unterhaltungsteil.

Für das Romanheft bemerkenswert ist eine hohe Leserbeteiligung in den Science Fiction- und Horror-Serien. In den meisten zuvor behandelten Reihen und Serien bleiben die Leser anonym, die gelegentlich per Umfragen in Statistiken erfasst werden. Doch im Falle dieser beiden Genres gibt es einen regen Austausch zwischen Autor und Leser, demnach sind auch hier mehr Fortsetzungsserien als Reihen zu finden. Aktuell gibt es im Sektor der phantastischen Romanhefte (hier Horror und Science Fiction) sogar überhaupt keine Reihen. ${ }^{534}$ Die zeitgenössischen Leser der Romanhefte sind Serien-Leser. Sie setzen sich, wie es die Leserbriefe und diverse Web-Foren ${ }^{535}$ zeigen, intensiv mit diesen Serien auseinander und wollen von den Autoren mehr Details wissen beziehungsweise fordern diese innerhalb der Serie ein. Dies bezieht sich zuweilen auch auf die „Qualität“:

„Sicher war dieser Roman grenzwertig, was die Thematik und ihre Schilderung angeht." ${ }^{536}$

Zudem weisen sie sich in der Regel als gute Kenner und aufmerksame Leser ihrer jeweiligen Serie aus:

533 Die Sternenfaust-Serie ist mit Bd. 199 „Das Ende“ am 18.09.2012 beendet worden. Die Serie findet dennoch in diese Betrachtung Eingang, da sie noch relativ aktuell ist und somit ein relevantes Bild widerspiegelt.

534 Temporäre Einzelerscheinungen außen vor gelassen, da Verlage gelegentlich spontan eine neue Serie oder Reihe als Experiment auf den Markt bringen.

535 Bspw. zu Perry Rhodan: http://forum.perry-rhodan.net/ (Zugriff 17.08.2019) oder https://www.scifi-forum.de/science-fiction/scifi-universen/perry-rhodan/ (Zugriff 17.08.2019).

536 Maddrax Bd. 185. Ein Alptraum erwacht. Michael M. Thurner. 1. Aufl. Bastei-Verlag. S. 34 Leserbrief. 
„Band 246 'Am Ende aller Zeit'. Und da sind für mich noch so viele Fragen offen. Wer oder was steckt hinter dem Befehlsgeber des Schwarmorganismus oder der Parasitenwächter? Kommt noch ein Roman über das Schicksal der letzten gestrandeten Menschen?"537

Einige Leser kennen nicht nur ihre jeweilige Serie gut, sondern auch die benachbarten Serien. So äußert beispielsweise ein Leser den Wunsch, dass die Hauptfigur der Maddrax-Serie nicht die gleichen Entwicklungen durchmachen soll wie Perry Rhodan: „Macht aus Matt keinen zweiten Perry Rhodan!“538 Ein Leser der Sternenfaust-Serie zeigt sein Wissen zu einschlägigen Werken des Science-FictionGenres:

„Übrigens schmunzele ich mal wieder über Eure Hommagen, weil ich glaube, in den Apri ein wenig die 'Europäer', aus dem Kultbuch '2010', entdeckt zu haben. Sehr anheimelnd finde ich, dass so was immer wieder mehr oder weniger versteckt - und nicht wirklich geklaut wirkend - eingebaut ist, wie das alte terranische Kugelschiff aus 'Perry Rhodan', die Fal'Cie oder die irgendwie an 'Aliens', erinnernde gelegentliche leichte Selbstüberschätzung und Panikstimmung der Marines." ${ }^{339}$

Die eben vorgestellten Leser verweisen in der Regel auf Serien des gleichen oder eines verwandten Genres. Sie kennen sich in ihrem bevorzugten Genre aus und diskutieren Querverweise und metatextuelle Verknüpfungen in den Foren. Hier wird nicht die Daseinsform, ein Romanheft-Leser zu sein, diskutiert, sondern sie diskutieren Science Fiction allgemein. Dies drückt ein Selbstverständnis aus, das sich auch mit dem von Autoren wie Ferkau deckt beziehungsweise dieses ergänzt. Die Leser nehmen die Schreiber dieser Romanheftserien als Autoren wahr, mit denen sie in Kontakt treten können und über die Serie sowie das dazugehörige Genre debattieren können. So gesehen findet hier ein „informeller Fachdisput“ statt, der von den Verlagen unterstützt wird, indem sie Internet-Foren und sogenannte Leserkontaktseiten aktiv betreuen lassen. Folglich ist Helmut W. Pesch unbedingt zuzustimmen:

„Dennoch stimmt es hoffnungsvoll, daß bei aller Passivität des Konsums keine andere moderne literarische Strömung einer derart lebendige Subkultur hervorgebracht hat wie die Genres [Science Fiction, Fantasy und Horror. Anm. d. Autors] der modernen phantastischen Literatur. Es ist ein Engagement, das

537 Maddrax Bd. 287. Meister der Lüge. Christian Schwarz. 1. Aufl. Bastei-Verlag. S. 33 Leserbrief.

538 Maddrax Bd. 277. Xij. Ronald M. Hahn. 1. Aufl. Bastei-Verlag. S. 35 Leserbrief.

539 Sternenfaust Bd. 154. Welt der Naniten. Stan Hamilton. 1. Aufl. Bastei-Verlag. S. 33 Leserbrief. 
auch eine Diskussion über den Wert und Unwert dieser Ausprägungen der modernen Kultur erst möglich macht. "“540

Diese aktiv geförderte Anteilnahme von Rezipienten der Genres Science Fiction, Fantasy und Horror hat sich, wie die zuvor genannten Zitate zeigen, auch im Bereich der Romanhefte erhalten. Eine vergleichbar von den Herstellern unterstützte Leserbeteiligung findet sich nicht in den Liebes- Western oder Kriminalromanheften. Heruntergebrochen auf die serielle Produktion von Erzählungen lassen sich vorläufig so zwei hypothetische Lesertypen exzerpieren, auf die die Hefte zugeschnitten zu sein scheinen beziehungsweise sie begünstigen folgende Rezeptionsvarianten: Einige Romanheftreihen fördern den Typen des nicht wählerischen Genre-Konsumenten, der lediglich innerhalb seines bevorzugten Romanheftgenres liest, und dem dabei egal ist, welcher Roman von welchem Autoren sowie welcher Serie oder Reihe stammt. Dies spiegelt sich unter anderem in Sammelbänden verschiedener Romanheftgenres wider, die keinerlei Hilfestellung bieten, die enthaltenen Erzählungen in einen Gesamtzusammenhang einzubetten. Auf ihrem Cover wird lediglich mit Quantität geworben. Beispielweise ein Kelter-Westernromanheft der Reihe Arizona: „Western - geschrieben von Spitzenautoren. 5 Romane - Sonderpreis“541. Hierbei wird nicht einmal konkretisiert, um welche „Spitzenautoren“ es sich handelt.

In den Romanheftgenres Horror, Fantasy und Science Fiction wird hingegen ein wählerischer Lesertyp gefördert, der eine Serie gezielt auswählt und diese konsequent konsumiert. In den Heften dieser Bereiche sind nicht nur Cover und Erzählung aufeinander abgestimmt, sondern es werden auch Leserbriefe abgedruckt und beantwortet, die größtenteils um die Entwicklung der Fortsetzungshandlung oder die Figuren kreisen. Diese Hefte zielen stärker auf einen Serien-Leser, als auf einen reinen Genre-Leser.

Bei diesem wählerischen Lesertypen reicht beispielsweise nicht der blaue Einband eines Arztromans, nur weil er einen beliebigen Arztroman aus dem jeweiligen Genre lesen will. Der wählerische Leser muss zudem nicht zwingend ein reiner RomanheftLeser sein, sondern ist möglicherweise auch ein Genre-Kenner über das Romanheft

540 Helmut W. Pesch: Science Fiction, Horror, Fantasy. Die modernen Genres der Phantastischen Literatur. In: Phantastische Welten. Märchen, Mythen, Fantasy. Hrsg. von Thomas Le Blanc und Wilhelm Solms. Regensburg 1994, S. 131-143. S. 143.

541 Arizona - Sammelband. Bd. 88. Aufl. unbek. Kelter-Verlag. 
hinaus, wie der oben erwähnte Leserbrief aus der Sternenfaust-Serie zeigt, welcher seine Kenntnisse zu diversen einschlägigen Werken aus dem Bereich der Science Fiction unter Beweis stellt. Demnach achten (hypothetische) wählerische RomanheftLeser stärker auf Kontinuität in der Entwicklung von Handlungssträngen oder den jeweiligen Serienfiguren.

\subsection{Der Fall 'Perry Rhodan'}

Die Perry Rhodan-Serie nimmt unter den Romanheften eine besondere Stellung ein, da sie für Science Fiction-Erzählungen in Deutschland prägend war, weshalb Heinz J. Galle ihr eine eigene Phase in der Entwicklung der deutschen Science FictionRomanhefte ${ }^{542}$ zuschreibt und andere erfolgreiche Serien sie als ihren "großen Bruder"543 bezeichnen. Um aufzuzeigen, warum sich die Perry Rhodan-Serie von anderen Romanheftserien und -reihen abhebt, muss ein wenig weiter ausgeholt werden: Galle gliedert die Geschichte der deutschen Science Fiction-Hefte in drei Phasen:

„[...] in die Versuchsphase, die bis zum Erscheinen der UtopiaZukunftsromane bei Pabel dauerte; in die Stabilisierungsphase, in der einschlägige SF-Serien wie Pilze aus dem Boden schossen; und schließlich in die Perry-Rhodan-Phase." ${ }^{544}$

Die sogenannte "Versuchsphase" bezeichnet den Zeitraum unmittelbar nach dem zweiten Weltkrieg. Zu jener Zeit war es schwierig, eine breite Leserschaft für Zukunftsromane zu begeistern, doch 1953 landete der Lektor von Pabel Kurt Brand mit Jim Parker einen Erfolg. ${ }^{545}$

Die "Stabilisierungsphase" setzte ein: Zusammen mit Walter Ernsting brachte er ab 1954 mehrere Science Fiction-Serien bei Pabel heraus, die sich mehr und mehr etablierten. Dies waren die Utopia-Zukunftsromane, in denen zumeist Übersetzungen von amerikanischen Autoren erschienen. Parallel dazu brachte der Moewig-Verlag ebenfalls Science Fiction-Serien heraus, die gleichsam erfolgreich waren.

Ernsting, Schelwokat und Kurt Bernhardt wechselten nacheinander zum Moewig-

542 Galle: Groschenhefte, S. 162.

543 Hector: Die dunkle Zukunft der Menschheit, S. 10.

544 Galle: Groschenhefte, S. 162.

545 Vgl. ebd. S. $157 f f$. 
Verlag. ${ }^{546}$ Dort bauten Schelwokat und Ernsting 1957 die erfolgreiche Terra-Serie auf, die sofort in Konkurrenz zu den Utopia-Romanen von Pabel stand. Ab 1958 veröffentlichte Ernsting selbst in der Utopia-Reihe.

Vorlauf zur „Perry-Rhodan-Phase“: 1961 ließ der Verlagschef Rolf Heyne Cheflektor Bernhardt und die beiden Autoren Ernsting und Karl-Herbert Scheer das Konzept für eine neue Serie entwickeln. Ernsting und Scheer waren zu diesem Zeitpunkt die populärsten deutschen Science Fiction-Autoren in Deutschland. ${ }^{547}$ In dieser Kombination wurde das Konzept für die spätere Perry Rhodan-Serie geschaffen: Man wollte vorgeben, dass die Serie von amerikanischen Autoren geschrieben wurde, da die meistverkauften Bücher zu jener Zeit von amerikanischen Autoren stammten. ${ }^{548}$ Ernstings Romane wurden zunächst von Pabel abgelehnt, bis er seine Romane unter einem amerikanischen Pseudonym einschickte: Er nannte sich Clark Darlton. ${ }^{549}$ Laut Ursprungsexposé sollte eine nahe Zukunft der Ausgangspunkt sein und die Autoren wählten die erste Mondlandung als Aufhänger für die Geschichte (zehn Jahre später folgte die echte Mondlandung). Die einzelnen Abenteuer sollten nicht abgeschlossen sein, sondern eine fortlaufende Handlung beschreiben, womit sich die Serie von ihren Vorgängern unterschied. Andere Serien hatten zwar zum Teil ein fortlaufendes Thema, aber jedes Heft war in sich abgeschlossen. Wie zum Beispiel die Sun Koh-Serie, in welcher der gleichnamige Held Sun Koh als Erbe von Atlantis jene berühmte versunkene Insel zu finden sucht. Es gab zwar in jedem Heft das gleiche Hauptziel, aber die einzelnen Abenteuer beschäftigten sich immer mit einem neuen Plot pro Heft. Bei Perry Rhodan hingegen war dieses Hauptziel offen: Es handelte sich um die Geschichte der Menschheit in der Zukunft, aber wohin das konkret führen sollte, war für den Leser zunächst nicht ersichtlich. Zu Beginn der Serie plante der Verlag nicht so weit voraus wie bei den aktuellen Zyklen, denn das damalige Team wurden von seinem Erfolg mehr oder weniger überrascht, weshalb Rhodan und seine Crew im ersten Zyklen von einem Abenteuer zum anderen stolperten, ohne dass ein größerer Plan zu erkennen war. Die Handlungsstränge waren zwar heftübergreifend, doch meist nur über wenige Hefte hinweg. Ungefähr ab Band 50 wurden die Perry Rhodan-Geschichten in großangelegten Haupthandlungs-

546 Daten entnommen aus Galle: Groschenheft, S. $157 \mathrm{ff}$.

547 Vgl. Alpers: Lexikon der Science Fiction Literatur. Bd. 1, S. $298 \mathrm{ff}$ und S. 546ff.

548 Vgl. ebd.

549 Vgl. Ursprungsgeschichte in Schwettmann: Allmächtiger, S. $25 f$. 
strängen geplant. ${ }^{550}$

Die Grundkonzeption entwarfen Scheer und Ernsting zwar zusammen, aber Scheer übernahm sofort die Exposé-Redaktion und schrieb dazu den ersten Roman. Ernsting, alias Clark Darlton, blieb von diesem Augenblick an hauptsächlich RomanAutor und Kurt Bernhardt war ihr Lektor. ${ }^{551}$ Mit „Perry Rhodan - Atom-Alarm“ Band 5 kamen weitere Autoren hinzu, da es zu zweit schwierig wurde, einen wöchentlichen Rhythmus beizubehalten. Die ersten Ausgaben waren Ende 1961 zügig ausverkauft und die sogenannte „Perry Rhodan-Phase“ begann. Schon früh hat die Serie als Markenzeichen gewirkt, sodass in diversen anderen Serien und Reihen damit geworben wurde, wenn an ihnen Autoren aus der Perry Rhodan-Serie mitarbeiteten. Dies geschah sowohl innerhalb des eigenen Genres in der Terra Astra-Reihe „PerryRhodan-Autor H.G. Ewers 'Ring des Verderbens'“, 552 als auch in anderen wie der bereits erwähnten Serie Dragon Söhne von Atlantis (vgl. vorheriges Kapitel 4.6 „Heldenhafte Fantasy):

„Der Pabel Verlag bringt nach sorgfältiger Vorbereitung durch das PerryRhodan-Team die erste deutsche FANTASY-Serie"“553

Vor Perry Rhodan gab es größtenteils Reihen mit abgeschlossenen Erzählungen, wie beispielsweise die Terra-Reihe ${ }^{554}$, oder Serien mit einem durchgehenden Helden, wie etwa die Sun Koh-Serie ${ }^{555}$. Diese Serien hatten in der Regel immer abgeschlossene Folgen und somit war es ein Novum in den Romanheften, dass nun eine Serie mit einer Fortsetzungsstruktur erschien. Serien waren die Leser in diesem Romanheftgenre zwar gewohnt, nur nicht solch eine starke Bindung der einzelnen Hefte untereinander durch Hefte übergreifende Handlungsstränge.

Die sogenannte „Fortsetzungsreichweite“ der Perry Rhodan-Folgen war gleich zu

550 Vgl. Nagula: Perry Rhodan. Die Chronik. Bd. 1, S 81f.

551 Kurt Bernhardt war viele Jahre Cheflektor beim Heyne-Verlag und beim Moewig-Verlag. Dort betreute er nicht nur Science Fiction-Romane, sondern auch Romane aus unterschiedlichsten Genres. Vgl. Nagula: Perry Rhodan. Die Chronik. Bd. 1, S. 49 .

552 So auf dem Titelbild des Romanheftes Orion zu lesen: Terra Astra Bd. 504/119 Orion. Ring des Verderbens. H.G. Ewers. 1. Aufl. Pabel-Verlag. Die Orion-Serie ist sie eine Fortführung der "Fernseh-Serie Raumpatrouille" (vgl. ebd. S. 7).

553 Dragon Söhne von Atlantis. Bd. 1. S. 3.

554 Von 1957 bis 1986 im Arthur Moewig-Verlag bei München erschienen. Zu Erscheinungsdaten und Verlagszugehörigkeiten vgl. auch Knüppel: Allgemeiner Roman-Preiskatalog.

555 Sie erschien u.a. 1933 bis 1936 im Verlag A. Bergmann und von 1943 bis 1953 im Planet Verlag. Es folgten diverse Bearbeitungen und Auflagen. Vgl. Knüppel: Allgemeiner RomanPreiskatalog. 
Beginn sehr hoch, da wie bereits erwähnt die Handlung auf bis zu 50 Hefte im voraus per Exposé geplant wurde. „Fortsetzungsreichweite“ ist ein Begriff nach Weber und Junklewitz und beschreibt, wie weit sich Handlungsstränge spannen können. ${ }^{556}$ Folgen fortlaufender Serien haben demnach eine große Fortsetzungsreichweite und in sich abgeschlossene Episoden einer Reihe eine besonders kleine (die Mechanik der Folgen-Verknüpfung wird in Kapitel 7. „Narrativer Rahmen der seriellen Narration“ vertieft). So plante der Verlag damals wie sich die Figur Perry Rhodan innerhalb von 50 Heften zum solaren Herrscher aufschwingt. ${ }^{557}$

Doch auch die sogenannte „Fortsetzungsdichte“ war bei den Perry Rhodan-Heften bereits stark ausgeprägt. Nach Weber und Junklewitz unterscheidet diese dichten Serienformen mit fortlaufenden Handlungssträngen von Serienformen, deren Folgen keinerlei Verknüpfungen aufweisen. ${ }^{558}$ Da jedes Perry Rhodan-Heft auf die erzählten Ereignisse in den vorangegangen Heften aufbaut, ist die Fortsetzungsdichte sehr hoch, denn hierbei geht es auch darum, wie intensiv die Folgen aufeinander verweisen. So wird beispielsweise in dem Perry Rhodan-Heft Band 3 „Götterdämmerung“ gleich auf der ersten Seite auf ein Ereignis aus zwei Heften davor verwiesen:

„Doktor Frank Haggard, der Spezialist für Blutkrankheiten, lächelte Andeutungsweise. Er war erst vor einigen Wochen unter abenteuerlichen Umständen von Bully aus Australien geholt worden, um Crest, den wissenschaftlichen Leiter der Arkonidenexpedition, von der Leukämie zu heilen." 559

In Perry Rhodan-Band 2 „Die dritte Macht“ reist Bully nach Australien, um Doktor Haggard zu suchen und bringt inn zu Perry Rhodan. Im darauffolgenden Band „Die strahlende Kuppel“ wird der Handlungsstrang um Doktor Haggard und Crests Krankheit aufgenommen und weitergeführt, wie Haggard Crest heilt. Dies ist jedoch nicht der einzige Handlungsstrang, der sich über mehrere Hefte erstreckt. In Band 3 wird unter anderem darauf verwiesen, dass die Gruppe um Perry Rhodan zuvor zu Geächteten erklärt wurde, was Band 2 „Die dritte Macht“ ausführte:

„Perry Rhodan, eins Symbol einer weltraumbegeisterten Welt - heute zum Weltfeind Nummer eins erklärt, nickte nachdenklich zu seinen Worten. " ${ }^{560}$

556 Junklewitz und Weber: Das Gesetz der Serie, S. $23 f$.

557 Vgl. Schwettmann: Allmächtiger, S. 33.

558 Junklewitz und Weber: Das Gesetz der Serie, S. 24.

559 Perry Rhodan Bd. 4. Götterdämmerung. Clark Darlton. 4. Aufl. Pabel-Moewig-Verlag. S. 1. 560 Ebd. 
Aufgrund der verschiedenen Verflechtungen mehrerer Ereignisse, die in den Heften immer wieder aufgegriffen werden, müssen Leser jedes Heft verfolgen, wenn sie nichts verpassen wollen. ${ }^{561}$ Doch auch durch regelmäßige Vorankündigungen, welche Handlungsstränge in der nächsten Folge weitergeführt werden, binden die Autoren die Perry Rhodan-Hefte intensiv aneinander:

„Durch den Überraschungsangriff der vereinigten Großmächte ist zwar das Arkonidenschiff auf dem Mond zerstört worden, aber Rhodans Energiekuppel in der Gobi widersteht auch den konzentriertesten Angriffen! Und so ist es nur noch eine Frage der Zeit, bis sich unter den Regierenden der Erde ein Sinneswandel anbahnt - eine Abkehr vom bisherigen engstirnigen, nationalen Denken und eine Hinwendung zum übernationalen, kosmischen Denken. Wie dies geschieht, lesen Sie in GÖTTERDÄMMERUNG von Clark Darlton, dem in der nächsten Woche erscheinenden 4. Band der Perry-Rhodan-Serie. ."562

Auf diese Weise wird explizit genannt, dass sich die kommende Folge mit der politischen Lage auf der Erde auseinandersetzt, die dazu führte, dass Perry Rhodan und seine Mitstreiter zu Staatsfeinden erklärt wurden. Durch die aufeinander aufbauende Erzählweise der Perry Rhodan-Hefte ist die vom Exposé vorgegebene Reihenfolge der einzelnen Hefte entscheidend, damit die Handlung des jeweiligen Heftes verständlich bleibt. Die meisten anderen Serien und Reihen waren nicht so streng koordiniert, wodurch es unproblematisch war, wenn die Redaktion einige Episoden umstellte. Bei einer Serie wie Perry Rhodan war dies nicht mehr möglich und verlangte eine straffe Organisation seitens der Redaktion. Durch die besonders große Fortsetzungsreichweite und die intensive Fortsetzungsdichte der jeweiligen Perry Rhodan-Folgen gehört die Serie zu den besonders progressiven Fortsetzungsserien nach Weber und Junklewitz. ${ }^{563}$ Serien, die wie beispielsweise Jim Parker oder Mark Powers nur ein festes Stammpersonal als durchgehendes Element besitzen, haben dadurch tendenziell eine gemäßigte Fortsetzungsdichte. Die Abenteuer dieser Helden waren innerhalb des jeweiligen Heftes abgeschlossen und auf vorangegangene Abenteuer wurde kaum verwiesen. So berichtet Galle beispielsweise über die Mark Powers-Serie:

561 Mittels Reminder und Zusammenfassungen halten die Autoren jedoch neu einsteigende Leser auf den Laufenden der Handlung eines jeweiligen Heftes. Hierzu mehr in Kapitel 8. „Innere Verknüpfung".

562 Perry Rhodan Bd. 3. Die strahlende Kuppel. K.H. Scheer. 4. Aufl. Pabel-Moewig-Verlag. S. 64. Die besondere Funktion des Ausblicks auf kommende Folgen wird in Kapitel 8.6 „Die Vorankündigung" vertieft.

563 Junklewitz und Weber: Das Gesetz der Serie, S. 23. 
„13 Autoren schrieben ohne Exposé an der Serie, jedes Heft behandelte ein abgeschlossenes Abenteuer. Ohne jegliche Koordination musst der Versuch scheitern: In einem Band hatte man gerade den Mond erreicht, im folgenden Abenteuer tummelten sich die Helden bereits in unserer Galaxis, um dann wiederum damit zu beginnen, eine Weltraumstation im Orbit zusammenzusetzen.“564

Gemäß Galle führte die nicht koordinierte Mark Powers-Redaktion zu inkonsistenten Heftabfolgen und es gab dadurch keinen Verbund zwischen den Folgen.

Zudem war es für die damalige Zeit auch ungewöhnlich, dass mit Perry Rhodan in der Science Fiction eine nur in Deutschland produzierte Serie erschien, war man doch die Übersetzungen aus dem Amerikanischen gewohnt. ${ }^{565} \mathrm{Um}$ hier einer Ablehnung durch die Leser vorzubeugen, hatten die Autoren sich bereits, passend für das damalige Science Fiction-Genre, amerikanische Autoren-Pseudonyme zugelegt.

Diverse Serien versuchten, an diesen Erfolg anzuknüpfen, scheiterten jedoch, da sie nicht so streng koordiniert waren wie die Perry Rhodan-Serie. ${ }^{566}$ Inhaltlich bot sie jedoch nichts ungewöhnlich Neues, sondern folgte auch in der Staffage den damaligen Konventionen der Science Fiction: „Die Serie PERRY RHODAN wurde während ihres fast fünfzigjährigen Bestehens stets vom Zeitgeist beeinflusst, und auch ihre Autoren sind 'Kinder ihrer Zeit'." ${ }^{567}$ Obwohl die Handlungsbögen ungewöhnlich weit konstruiert wurden blieb die Handlung selbst eindimensional und war für die damalige Science Fiction typisch aktionistisch gelagert. Die Handlung einer jeden Episode wurde im darauffolgenden Heft strikt weitergeführt.

Parallel zum Start in den 1960ern von Perry Rhodan in Deutschland erschienen neue Strömungen in der amerikanischen Science Fiction-Szene: Philosophische Überlegungen manifestierten sich in Erzählungen der sogenannten „New Wave“ und verdrängten mit den Jahren naturwissenschaftliche Fiktionen im Science FictionBereich. ${ }^{568}$ Es galt "die Psyche des Menschen zu erforschen“ und nicht mehr den Weltraum. ${ }^{569}$

564 Galle: Volksbücher und Heftromane. Bd. 1, S. 80.

565 Mark Powers war zwar ebenfalls von deutschen Autoren geschrieben, doch entstand sie lediglich als Konkurrenzprodukt zu Perry Rhodan und wurde nach 68 Heften eingestellt. Vgl. hierzu Galle Volksbücher und Heftromane. Bd. 1, S. 80f.

566 Beispiele hierfür waren die Serien: Mark Powers (1962-64 im Pabel-Verlag) oder Ren Dhark (1966-68 im Kelter-Verlag). Vgl. Galle: Groschenhefte, S. 164f.

567 Einführung von Uwe Anton in Nagula: Perry Rhodan. Die Chronik. Bd. 1, S. 20-22. S. 20.

568 Alpers: Lexikon der Science Fiction Literatur, S. $42 f$.

569 Ebd. S. 43. 
Mit dem Wandel der Science Fiction musste sich entsprechend auch die Perry Rhodan-Serie ändern. Jedoch brauchte es seine Zeit, bis die Auswirkungen der New Wave auf dem deutschen Markt heranbrandeten. 1973 wurde Wiliam Voltz ExposéAutor der Perry Rhodan-Serie und brachte „eine humanistische und philosophische Ausrichtung“ gemäß der New Wave ein. ${ }^{570}$ Dementsprechend lockerten sich die rein aktionistischen Schwerpunkte auf. Da die Handlung über 50 Jahre Publikationszeit hinweg entsprechend vielfältig wurde, sind die aktuellen Handlungsstränge nicht mehr so eindimensional wie am Anfang. Dies führte dazu, dass nicht immer im darauffolgenden Heft die Handlung weitergeführt wird, sondern gegebenenfalls ein anderer Handlungsstrang und somit diverse parallele Handlungsschauplätze ermöglicht werden. Zudem sind die Konflikte der Helden gemäß der Wende in den Siebzigern wesentlich komplexer und produzieren keine militaristischen Abenteuer im Weltraum mehr. Außerdem werden philosophische und ethische Probleme thematisiert: In dem 34. Zyklus „TERRANOVA“ wird der Wissenschaftler Laurence Savoire vor die Frage gestellt, was für inn Realität und Leben bedeutet:

„Seid ihr überhaupt die, für die ich euch halte? Wenn ihr in ESCHER aufgegangen seid, dann seid ihr tot. Wie kommt es dann, daß ich euch lebendig vor mir sehe?' 'Lebendig?' [...] Myhr griff nach der Espressotasse und führte sie vor seinen Mund. 'Sollte das hier nicht Appetit in mir wecken, wenn ich lebendig wäre? Aber ich benötige es nicht. Nie mehr.' Achtlos stellte er die Tasse ab. 'Denn ich bin kein Lebewesen im eigentlichen Sinn. Alles, was ich war, alles, was ich immer noch bin, ist Teil der Matrix."“571

Savoire muss sich entscheiden, inwiefern er sein Projekt ESCHER über seine ethischen Werte stellt:

„Da ESCHER schwieg, stellte er eine weitere Frage. 'Du benötigst keine körperlichen Menschen mehr? An die Stelle lebendiger Prozessoren sind ermordete Menschen getreten?' 'Ich bin in der Lage, die Wertung festzustellen, die du durch deine Wortwahl vornimmst. Was du Morde nennst, beurteile ich anders. Sie kamen freiwillig zu mir. Ich biete innen mehr als das, was sie zuvor besaßen. In mir erlangen sie eine höhere Existenzform. "'“572

Savoire weiß nun nicht, ob die Menschen wirklich tot sind und ob er sich gegen sein eigenes Projekt stellen darf und dabei gegebenenfalls Menschenleben riskiert. Das

570 Schwettmann: Allmächtiger, S. 80

571 Perry Rhodan Bd. 2378. Der Erste Kybernetiker. Christian Montillon. 1. Aufl. Pabel-MoewigVerlag. S. 32.

572 Ebd. S. $26 f$. 
Projekt war ursprünglich als eine neue Technik im Einsatz gegen die Bedrohung der Terminalen Kolonne geplant. Savoire muss nun für sich entscheiden, wie er das Leben der Menschen in ESCHER gegen das Leben der gesamten Bevölkerung von Terra aufrechnet: Ein paar Leben für das Wohl aller. Der Wissenschaftler steht vor einem vielschichtigen Problem ohne eindeutige Lösung.

Zwar wurde gesagt, dass militärische Elemente nicht mehr im Vordergrund stehen, doch verschwinden sie auch nicht vollends aus den Perry Rhodan-Geschichten. Sie bilden eher Staffage im Hintergrund oder sind auslösendes Moment für soziale Konflikte der Figuren. Als Beispiel sei hier ein Fall genannt, in dem sich Piraten die Furcht vor der Bedrohung zunutze machen und sich als eine Einheit der Terminalen Kolonne tarnen, um so Planeten auszurauben. Hierbei wird ihnen allerdings das Handwerk von einer Swoon-Familie gelegt. Obwohl die Swoons ständig mit hochmodernen Spionagegeräten hantieren, steht der Vater-Sohn-Konflikt unter ihnen im Vordergrund. Die nahende Bedrohung führt dazu, dass die drei Swoons, der Vater und seine zwei Söhne, ihren Konflikt beilegen, um sich gegenseitig zu retten. Die zweite Ebene der Swoon-Geschichte ist die einer Spionagegeschichte, da die drei Swoons beständig durch das fremde Raumschiff schleichen müssen um eine Verschwörung aufzudecken, die sie nur gemeinsam enttarnen konnten. Hierbei spielen zwar Sensoren, Abhörgeräte und dergleichen eine große Rolle, aber das Hauptaugenmerk liegt weiterhin bei der Figurenkonstellation. ${ }^{573}$

Claus Hallmann kam bei den älteren Heften der Perry Rhodan-Serie zu einer ähnlichen Aussage, dass aus „dem Bereich des Kriminal-, Spionage- und Agentenromans" 574 zahlreiche Klischees übernommen wurden. Jedoch stand bei ihnen „weniger scharfsinnige Überlegungen und Kombinationen im Vordergrund [...], als vielmehr der Einsatz neuer technischer und parapsychologischer Mittel." ${ }^{575}$

Dies hat sich heute insofern gewandelt, als die Figuren zwar viele technische Hilfsmittel nutzen, aber nur ihre gemeinschaftliche Kombinationsgabe sie ans Ziel ihrer Bestrebungen bringt. Dies ist kein Einzelfall, denn in einer anderen Geschichte sollen beispielsweise zwei Geheimagenten auf einem Planeten, der bereits von den Chaosmächten besetzt worden ist, einen Auftrag erledigen. Hierbei müssen sie durch

573 Perry Rhodan Bd. 2372. Plan der Phantome. Christian Montillon. 1. Aufl. Pabel-Moewig-Verlag.

574 Hallmann: Perry Rhodan - Analyse, S. 214.

575 Ebd. 
beständige Finten vor dem Gegner Dantyren fliehen. Während dieser Flucht dämmert dem Agenten Major Hearn, dass sein Kollege Shallowain andere Pläne verfolgt, als er vorgibt, dadurch weiß Hearn nicht mehr, wem er trauen kann. Hierbei spielen technische Geräte kaum eine Rolle, sondern vielmehr die Gespräche zwischen den beiden Hauptakteuren. ${ }^{576}$

Gewisse Erzählelemente vom Beginn der Serie wurden zwar beibehalten, jedoch in ihrem Anspruch geändert, daher gibt es in den aktuellen Zyklen mehr Verwirrspiele, so dass die Dinge nie sind, wie sie auf den ersten Blick erscheinen: Sichtbare Bedrohungen entpuppen sich als nicht die wirkliche Bedrohung und Verbündete sind in Wahrheit Feinde. Hallmann führt noch weitere Vergleiche mit diversen Romanen der Unterhaltungsliteratur auf: Er vergleicht die Perry Rhodan-Serie mit Märchen, Reise-, Abenteuer-, Schauer- und historischen Romanen. ${ }^{577}$ Jedoch sind diese Vergleiche nur für die ersten 1000 Hefte zutreffend. Die aktuellen Hefte haben sich von den alten Motiven und Handlungsstrukturen fortentwickelt, wobei einige Elemente aus den Anfängen als Relikte weitergeführt werden. Die Fähigkeiten der Mutanten beispielsweise vergleicht Hallmann mit den Zauberfähigkeiten der Märchenfiguren. ${ }^{578}$ Die Mutanten sind in den ersten Geschichten etwas Besonderes und keine 'Standardmenschen'. In den heutigen Geschichten sind sie lediglich einige von vielen und ihre Andersartigkeit ist nicht mehr der Anlass für märchenhafte Situationen, sondern für ethnologische Betrachtungen. Mutanten sind zwar in der Welt der Perry Rhodan-Serie (im weiteren Perryversum genannt) alltäglich geworden, aber sie werden zusehends ausgegrenzt, was zu Minderheitenproblematiken führt. Infolgedessen wird der Wissenschaftler Savoire von seinem Vorgesetzten diskriminiert, denn als Diakat hat er nur ein Auge, mit dem er jedoch mehr als normale Menschen wahrnimmt:

„Und was erhalte ich statt dessen? Einen Zyklopen von wer weiß wo."579

Die Elemente des Reise- und Abenteuerromans finden vereinzelt noch immer in den heutigen Geschichten Verwendung, da die Galaktiker weiter in den Weltraum vordringen können, um mehr exotische Lebensformen und -räume zu entdecken, nur

576 Perry Rhodan Bd. 2375.

577 Hallmann: Perry Rhodan - Analyse, S. 194-233.

578 Ebd. S. $195 \mathrm{ff}$.

579 Perry Rhodan Bd. 2377. ESCHER. Christian Montillon. 1. Aufl. Pabel-Moewig-Verlag. S. 19. 
dass diese Begegnungen zu Anfang in Kämpfen mit den primitiven Lebensformen endeten, die größtenteils feindlich gesinnt waren. Demgemäß gab es Kämpfe mit Riesenechsen und dergleichen urweltähnlichen Wesen. ${ }^{500}$ Der heutige Galaktiker ist Forscher und kein Soldat mehr, der Fremdes als potenzielle Bedrohung sieht, sondern als ein Forschungsobjekt:

„Die Forschungsteams hatten überall auf Iquama Sydorrier-Populationen gefunden, die sich in verschiedene Entwicklungsstadien befanden. Aber keine Population hatte bisher einen höheren Status als die Steinzeit-Sydorrier." 581

Zusammenfassend lässt sich sagen, dass die Perry Rhodan-Abenteuer davon abgekommen sind, eine rein handlungsbetonte Lektüre zu sein. Die Tendenzen gehen noch immer in die 'voltzsche' Richtung, nämlich philosophische und humanistische Themen zu entwickeln. ${ }^{582}$ Es herrscht zwar immer wieder Krieg im Universum von Rhodan, jedoch schwingt bei den Geschichten keine latente Glorifizierung des Militärs mehr mit. Der Trend geht intensiver zur Wissenschaft. Die über die Jahre gesteigerte Komplexität der Serie hat ihre ganz eigene Lesergruppe geformt. Die Leser von Perry Rhodan sind eher reine Perry Rhodan-Leser als andere SerienLeser:

„Für einige Leser dürfte dieser Daten-Overkill zwar schwer verdaulich sein, aber vor allem für Altleser und Fans der ATLAN-Minizyklen sollte das Aufgreifen so vieler Geschehnisse und Handlungen des Perryversums zu einem wahren Genuss werden." 583

Auch für genreerfahrene Leser ist es nicht sofort möglich, in diese Serie einzusteigen, ohne einen solchen „Daten-Overkill“ 'verdauen' zu müssen. Für diese Serie kommen keine Leser in Frage, die sich lediglich bei Gelegenheit ein Romanheft kaufen, um eventuell Wartezeit am Bahnhof zu überbrücken. Die Serie bietet zwar diverse Einstiegshilfen, jedoch bekommt nur der Leser einen Einstieg in die Serie, der sich über die Serie informiert. Oberflächliches Konsumieren wird in diesem Fall problematisch, da ein unerfahrener Leser mit der Fülle an Namen und Verstrickungen der Figuren zurechtkommen muss, bis er ein Perry Rhodan-Heft 'runterlesen'

580 Hallmann: Perry Rhodan - Analyse, S. 206ff.

581 Perry Rhodan Bd. 1796. Die Rückkehr der Sydorrier. Susan Schwartz. Pabel-Moewig-Verlag. S. 56.

582 Schwettmann: Allmächtiger, S. 80.

583 Perry Rhodan Bd. 2379. Eschers Liste. Arndt Ellmer. 1. Aufl. Pabel-Moewig-Verlag. S. 61 Leserbrief. 
kann. Mittlerweile gibt es einen riesigen Fundus an Figuren und Elementen, die für die Serie typisch sind und erfahrenen Lesern im Bereich des Science Fiction-Genres wohl bekannt sind. Dies zeigt sich in Leserbriefen, wie weiter oben zitiert, wenn einige Leser nicht möchten, dass ihre Lieblingsfigur zu einem „zweiten Perry“ wird. Hier zeigt sich eine Entwicklung, die dem ähnelt, was Jason Mittell für das amerikanische Fernsehen untersucht hat, dass das Interesse der Massen an komplexen Narrationen steige. ${ }^{584}$ Nach Mittell zeichnet eine komplexe (TV-)Narration aus, dass sie sich von konventionellen Modi episodischer und fortsetzungsorientierter Serienformate abheben. ${ }^{55}$ Die intensive Fortsetzungsdichte der Perry RhodanFolgen war zum Erscheinungs-Zeitpunkt der ersten Hefte untypisch im Bereich der Romanhefte. Komplexe Narrationen stellen nach Mittell Handlungsentwicklungen verstärkt in den Vordergrund. ${ }^{586}$ Die Vorankündigung für kommende Perry RhodanFolgen rafft beispielsweise die wichtigsten Ereignisse des vorliegenden Heftes und verweist darauf, wie sie im nächsten Heft fortgeführt werden. In komplexen Narrationen gibt es laut Mittell diverse episodische Handlungsbögen und fortlaufende Beziehungsdramen. ${ }^{587}$ In den oben genannten Beispielen wäre unter anderem ein episodischer Handlungsbogen, wie Bully den Mediziner Haggard aus Australien holt, während der fortlaufende Handlungsstrang sich mit Perry Rhodans Aufstieg zum solaren Herrscher beschäftigt. Das Kriterium der Beziehungsdramen wird demnach hier nur in Form eines fortlaufenden Handlungsstranges erfüllt (der Wechsel von episodischen und fortlaufenden Handlungssträngen wird in Kapitel 7. „Narrativer Rahmen der seriellen Narration“ ausführlicher besprochen). Dass der Schwerpunkt, ob mehr episodische oder fortlaufende Anteile ausgeprägt werden, häufig durch das Genre bestimmt wird, ${ }^{588}$ lässt sich beim vorliegenden Beispiel nicht eindeutig beantworten, da Serien mit fortlaufenden Handlungssträngen im gesamten Bereich der Romanhefte eher selten sind. Doch es fällt auf, dass sich diese Serienform tendenziell im Bereich der Horror- und Science-Fiction-Romanheften häuft. Beispielsweise: Professor Zamorra, Dorian Hunter, Maddrax, Sternenfaust und Perry Rhodan. Komplexität und Qualität bedingen sich nicht zwangsläufig. ${ }^{589}$ Komplexe

584 Mittell: Narrative Komplexität im amerikanischen Gegenwartsfernsehen, S. 119.

585 Ebd. S. 98.

586 Ebd. S. 105.

587 Ebd. S. 106.

588 Ebd.

589 Ebd. S. 99. 
Narrationen erscheinen oft reichhaltiger und vielschichtiger. ${ }^{590}$ Durch die intensive Fortsetzungsdichte der Perry Rhodan-Hefte beinhaltet jedes Heft Verweise auf vorangegangene Ereignisse oder Figuren, die die aktuelle Handlung beeinflussen. Mit Fortschreiten der Handlung werden dem immer mehr Ereignisse und Figuren hinzugefügt, sodass die Komplexität mit jeder Folge anwächst (Kapitel 8.5 „Wiederholung als Erinnerung“ vertieft Mechaniken der Romanheftserien, die dafür sorgen, dass Leser trotz der Komplexität den Überblick behalten). Mittell erklärt, dass komplexe Narrationen eine Fangemeinde ausformen, mit der sich die Serienproduzenten auseinandersetzen ${ }^{591}$ Auf der sogenannten Leserkontaktseite druckt die Perry Rhodan-Redaktion regelmäßig Leserbriefe ab, die zum Teil beantwortet werden. Außerdem veranstalten Perry Rhodan-Fans alle zwei Jahre eine Convention, an der viele Perry Rhodan-Autoren aktiv teilnehmen. ${ }^{592}$

Mittell grenzt zwar gewissermaßen die „komplexen Narrationen“ von den „fortsetzungsorientierten Serienformaten“ ab beziehungsweise stellt er sie parallel zu den beiden bisher bekannten Narrationspolen (episodal mit geringer Fortsetzungsdichte und -reichweite sowie fortlaufend mit hoher Fortsetzungsdichte und -reichweite), doch kann man die komplexe Narration auch als eine Erweiterung der Fortsetzungsserien mit hoher Fortsetzungsdichte und -reichweite interpretieren. Nach Mittell „zeigt sich [hier] die operationale Ästhetik: Wir erfreuen uns an den Ergebnissen der Unterhaltungsmaschine, während wir darüber staunen, wie sie funktioniert. “593

Der Rezipient hinterfragt bei diesem Serienformat deren Erzählform und seinen eigenen Prozess der Rezeption. Der Anspruch an den TV-Serienzuschauer scheint nach Mittell zu steigen, ${ }^{594}$ doch im Bereich der Romanhefte ist das Feld eher geteilt. Dort gibt es einen großen Anteil rein episodaler Serien und Reihen wie beispielsweise die meisten Liebesromanhefte. Der Anteil der Fortsetzungsserien, die zudem eine komplexere Narrationsfortführung aufweisen, sind gering: Perry Rhodan, Maddrax und Professor Zamorra sind feste Konstanten in diesem Feld. Die Sternenfaust-Serie war ein Beispiel, wie komplexere Romanheftserien untergehen können. In dem Bereich der Romanhefte ist die Option einer ästhetischen Rezeption durch die

590 Ebd.

591 Ebd. S. 104.

592 Vgl. offizielle Homepage der Serie: https://perry-rhodan.net/infothek/links/conventions (Zugriff: 24.03.2019).

593 Mittell: Narrative Komplexität im amerikanischen Gegenwartsfernsehen, S. 118.

594 Ebd. S. 120. 
komplexe Narrationsfortführung bisher nicht auf fruchtbaren Boden gestoßen, wie es im Bereich der TV-Serien jedoch der Fall war.

Unsterblichkeit durch Zellaktivatoren und diverse andere Insider sind untrennbar an die Perry Rhodan-Serie gebunden, sodass solche Begriffe kaum noch in anderen Science Fiction-Romanheftserien verwendet werden können, ohne dem Perryversum zugeordnet zu werden. Dies legt die Überlegung nahe, dem Perryversum, das nicht mehr nur aus der Ursprungsserie Perry Rhodan besteht, sondern aus diversen weiteren Serienablegern und Reihen, ein eigenes Genre im Bereich der Romanhefte zuzugestehen: Sie ist nach Müller zu einem „Prototyp“ geworden, ${ }^{595}$ der als Vorlage für neue Narrationen beziehungsweise Serien und Reihen dient. So finden sich mittlerweile Hörspielserien oder Buchreihen, die in der Welt von Perry Rhodan angesiedelt sind, aber deren Handlungsstränge nicht direkt von der Ursprungsserie abhängig sind. Die Perry Rhodan-Serie begann zwar als sogenannte Space Opera, jedoch hat sie im Laufe der Zeit ihre eigenen Themen und Problemkomplexe entworfen, die nur im Perryversum stattfinden können. Zudem ist eine Erzählung, die mit „Rittern der Tiefe“, „Aktivatorträgern“, „Chaotarchen“ hantiert oder ihre Figuren mit einer „Hyperimpedanz“ oder dem „moralischen Kode“ ringen lässt, eindeutig dem Perryversum zuordenbar.

\subsection{Historischer oder Kriegsroman?}

Folgende Reihe wurde bereits in Verbindung mit der Perry Rhodan-Serie erwähnt: Der Landser. Bei dieser Reihe wird die Genrezuordnung wesentlich schwieriger, da unklar ist, welche Genre-Voraussetzungen man ansetzen kann. Der Pabel-MoewigVerlag deklarierte diese Reihe zeitweise als „Dokumentation“596 und führte auf der Homepage neben den Romanheften auch Magazine mit historischen Schwerpunkten. Im Jahr 2013 stellte der Verlag die Reihe ein. Demnach wurde damals vom Verlag das Bild eines historischen Textes angestrebt, der mit angeblich authentischen Berichten arbeitete. ${ }^{597}$ Dies kündigen auch Unterüberschrift der Reihe „Erlebnisbe-

595 Vgl. Eggo Müller: Genre. S. 213.

596 http://www.vpm.de/zeitschriften/dokumentation.html (Zugriff: 26.03.2013, nicht mehr verfügbar).

597 Hendrik Buhl: Landser Hefte. In: Lexikon der 'Vergangenheitsbewältigung' in Deutschland. Hrsg. von Torben Fischer und Matthias N. Lorenz. 2. unver. Aufl. Bielefeld 2009, S. 115-117. S.116. 
richte zur Geschichte des Zweiten Weltkrieges“ an (Abb. 21) und mit Zusätzen wie in folgenden Beispielen verstärkt:

„1941 - Von Ostpreußen zum Wolchow - Die Kämpfe zu Beginn des Rußlandfeldzugs - Einsatzerinnerungen des Autors"598

Oder:

„Balkan 1942 - Blutige Gefechte mit Freischärlern um die Kontrolle einer Region - Schilderung nach persönlichen Erinnerungen" “599

Um diesen historischen Anspruch weiter zu unterstützen wurden diverse technische Daten oder historische Fotos in den Heften eingebaut. Zudem finden sich verstärkt Endnoten in den Heften; so ist das Bild eines „historischen Magazins“ komplett. Dies schien jedoch nicht für alle Konsumenten so eindeutig zu sein, daher wurde in einer Ausgabe folgende Stellungnahme oder folgendes „Bekenntnis“, wie Ernst Antoni es nennt, ${ }^{600}$ der Redaktion abgedruckt:

„Kriegsgeschichtliche Werke schildern den Verlauf großer Schlachten und Operationen aus der Sicht der Generalstäbe. DER LANDSER jedoch ermittelt Details aus der Sicht des Frontsoldaten; er gibt einen Einblick in die endlose Skala der Schrecken und menschlichen Tragödien, die jeder Krieg mit sich bringt. Dadurch formt sich seine stumme Anklage gegen Gewalt schlechthin."601

Der Ansicht des Verlages widerspricht Hendrik Buhl vehement, da seinem Urteil nach die Hefte eine „Enthistorisierung“ vollziehen, indem sie den „kausalen Zusammenhang zwischen NS-Herrschaft und Weltkrieg“ verschweigen. ${ }^{602}$ Für Buhl können sie den Anschein eines historischen Magazins nicht aufrechterhalten:

„Es handelt sich bei den Landser-Heften nicht, wie von ihren Machern behauptet, um 'pazifistische Leidensprosa einer geschundenen Generation', sondern um den Krieg ästhetisierende Narrative, die ein falsches, verherrlichendes Bild vom Zweiten Weltkrieg etablieren wollen."603

Es bleibt fraglich, ob die Hefte und somit auch der Verlag in der Tat Propaganda betreiben wollten oder lediglich unzeitgemäß waren. Diese Frage kann hier nicht geklärt werden, wirft aber dennoch eine weitere Frage auf: Wer ist die Zielgruppe

598 Der Landser Bd. 2735. Sturmlauf zur Hölle. A. Gütte. Pabel-Moewig-Verlag.

599 Der Landser Bd. 2814. „Alarm! Partisanen“ G.L. Fritz. Pabel-Moewig-Verlag. Sowie Abb. 21.

600 Ernst Antoni: „Landser“-Hefte Wegbereiter für den Rechtsradikalismus. München 1979. S. 19.

601 Der Landser SOS Bd. 191. Die letzte Atlantik-Schlacht. Pabel-Moewig-Verlag. S. 64.

602 Buhl: Landser Hefte, S. 116.

603 Ebd. S. 117. 
dieser Hefte gewesen? Nach dem Urteil Buhls müssten dies Leser sein, die an einem heroisierten Nazi-Deutschland Interesse haben. Hierzu hat bereits 1979 Ernst Antoni die Hefte untersucht, die mit dem Untertitel „Erlebnisberichte zur Geschichte des Zweiten Weltkrieges“ erschienen. ${ }^{604}$ Dabei deckte er auf, dass diverse Verfasser zu einem gewissen Teil in der Tat dabei waren: Als Nazis, genauer gefasst, als Autoren von NSDAP-Propaganda. ${ }^{605}$ Es ist unklar, wie genau sich diese zweifelhaften Anfänge der Reihe auf den letzten Stand der Reihe im Jahr 2013 auswirkten. Die Autoren bleiben in diesem Fall unbekannt und unbenannt, was im RomanheftBereich ungewöhnlich ist, da doch sogar innerhalb der Liebesromanhefte die Verlage mit Autoren oder zumindest mit Pseudonymen werben. ${ }^{606} 2007$ schreibt jedoch Jörg Weigand in seinem Bericht in dem „Jugend Medien Schutz-Report“, dass durch den Wechsel des Chefredakteurs die „historische Authentizität“607 verbessert wurde: „In den Heften dominieren nun die militärischen Fakten, schräg-ideologische Tendenzen und Äußerungen sind rigoros ausgemerzt."608

Ein anderer Aspekt der Kritik lautet, Krieg als Abenteuer zu inszenieren. ${ }^{609}$ Eine Kritik, die so für sich genommen konsequenterweise auch auf andere Romanheftgenres angewandt werden müsste, denn gleichermaßen inszenieren die Verlage in den Western- und Science Fiction-Serien beziehungsweise -Reihen Kämpfe als Abenteuer. ${ }^{610}$ Die Kritik müsste entsprechend spezifiziert werden: Warum muss dieses „historische“ Romanheft unbedingt vor dem Hintergrund des 2. Weltkrieg spielen? Dies knüpft wieder an die Kritik von Buhl an, dass die Landser-Hefte die Geschichte verklären, wenn sie den „kausalen Zusammenhang zwischen NS-Herrschaft und Weltkrieg“ verschweigen, ${ }^{611}$ egal, wie rigoros „schräg-ideologische Tendenzen und Äußerungen" ausgemerzt wurden. Demgemäß ist es irreführend, dass Pabel-Moewig diese Reihe in die Kategorie seines Verlagsprogrammes „Dokumen-

604 Antoni: Landser-Hefte, S. 21.

605 Ebd. S. 21ff.

606 Vgl. hierzu Abb. 1 oder Abb. 9: Ein Roman von Patricia Vandenberg.

607 Jörg Weigand: Zwischen Heldentot und historischer Wahrheit. In: JMS-Report - Oktober 5/2007. S. 8. Download der Pdf von: http://www.jms.nomos.de/fileadmin/jms/doc/JMSReport_07_05.pdf (Zugriff: 17.08.2019).

608 Ebd.

609 Vgl. Walter Nutz: Der Krieg als Abenteuer und Idylle. Landser-Hefte und triviale Kriegsromane. In: Gegenwartsliteratur und Drittes Reich. Hrsg. von Hans Wagener. Stuttgart 1977, S. 265-283. S. $278 \mathrm{ff}$.

610 Was bei Perry Rhodan in den 70ern auch getan wurde.

611 Buhl: Landser Hefte, S. 116. 
tation" eingliederte, da ein dokumentarisches Werk versucht, Wirklichkeit darzustellen und nicht zu verklären. Somit hätte der Verlag suggeriert, dass diese Romanhefte Wirklichkeit rekapitulieren. Jedoch bleibt es schlussendlich unklar, wie viel bewusst und wie viel durch Unvermögen seitens des Verlages in dieser Hinsicht geschieht.

Unabhängig von der problematischen Vorgeschichte der Landser-Reihe soll nun hier die schwierige Frage nach dem eigentlichen Romanheftgenre gestellt werden beziehungsweise danach, welche Vorgänger hierfür in Frage kommen. Walter Nutz sieht diese Hefte stark in der Tradition der damaligen Trivialliteratur beziehungsweise der damals typischen Konzeption von Romanheften und grenzt sie von den Kriegsromanen $\mathrm{ab} .^{612}$

Als die Landser-Reihe 1957 ins Leben gerufen wurde, gab es diverse andere Romanheftreihen, die ebenfalls den 2. Weltkrieg zum Schwerpunkt hatten, und man folgte damals dem allgemeinen Trend einer „aufkommenden Popularisierung von den Krieg thematisierenden Stoffen“. ${ }^{613}$ Dies geschah hier allerdings in der Form eines reinen Unterhaltungsmedium: Dem Romanheft. Die Landser-Reihe unterwarf sich damals dem Gebot des Marktes und gab entsprechend unreflektiert Geschichten von Frontsoldaten heraus. Die Reihe wollte so gesehen nicht zwingend alte Propaganda beschönigen sondern in erster Linie einen Markt bedienen, wobei dies von der Forschung entsprechend (und zu Recht) empfindlich aufgenommen wurde. Ethische Gründe außen vor gelassen wurde mit der Landser-Reihe eine enorm erfolgreiche Romanheftreihe begründet, die 50 Jahre lang ununterbrochen erschien. In diesen Jahren hatte sich im Groben an der Reihe nicht viel verändert und die Frage nach dem Modell-Leser lässt sich nicht abschließend beantworten. Triviale Kriegslektüre hat es schon vor der Landser-Reihe gegeben: Zur Zeit des ersten Weltkrieges ${ }^{614}$ und während des Nazi-Regimes ${ }^{615}$. Jedoch wurden sie hier in der Regel für Propaganda-

612 Nutz: Der Krieg als Abenteuer, S. 277ff. Nutz attestiert ebenfalls die Tendenzen der LandserHefte als fragwürdig. Gerade in der Form des Trivialromans sieht er das Problem der LandserHefte: „Wenn diese Hefte nicht zur Individualbeschreibung und zur literarischen Bewältigung des Krieges zu rechnen sind, wenn ihre dargestellten Fakten manchmal nicht stimmen oder zu Unwesentlichem verkümmern, dann kann nur der Unterhaltungswert gefragt sein. Aus diesem Grunde sind sie praktisch unhistorisch und geben zur Frage des Verhältnisses der Gegenwart zu dem Geschehen des Dritten Reiches kaum ernstzunehmende Antwort." (Ebd. S. 280).

613 Buhl: Landser Hefte, S. 116.

614 Vgl. hierzu Rudolph Schenda: Die Lesestoffe der kleinen Leute. München 1976. S. 78ff.

615 Eine Übersicht bietet u.a. Heinz J. Galle: Volksbücher und Heftromane. Bd. 2. 2. durchges. Aufl. Lüneburg 2009. S. $257 \mathrm{ff}$. 
zwecke genutzt. Es ist unwahrscheinlich, dass der Pabel-Moewig-Verlag diese Reihe politisch nutzen wollte, trotzdem hat die Darstellung des Inhaltes berechtigte Kritik hervorgerufen, die es schwierig macht, die Reihe lediglich auf ein Konsumgut zu reduzieren. Einige wichtige Fragen müssen offen bleiben: Wer ist bis 2013 Zielgruppe dieser Hefte gewesen? Soldaten, die sich für Geschichten ihres Umfeldes interessieren? Militär-Liebhaber? Historiker?

Nach dem Urteil des Jugend-Medien-Schutzes war die Landser-Reihe demnach kein „Wegbereiter für den Rechtsradikalismus“ mehr und ab 1999 wurde ein Historiker Chefredakteur dieser Reihe. ${ }^{616}$ Demnach kann für den Zeitraum bis 2013 also von einer für Geschichte begeisterten Leserschaft ausgegangen werden beziehungsweise davon, dass der Pabel-Moewig-Verlag eine solche anstrebte. In Hinblick auf die Ergebnisse von Walter Nutz sind die Leser interessiert an einer auf Spannung setzenden Abenteuergeschichte, die den Zweiten Weltkrieg zum Hintergrund hat. Sie sind, wie aus dem „JMS-Report“ zu erfahren ist, zudem an dem historischen Aspekt interessiert, sodass entsprechend Fakten und Daten in die Erzählung einfließen müssen. Dies macht es den Lesern möglich, die Erzählung in ihrem historischen Kontext zu rekonstruieren oder zumindest in Gedanken zu simulieren, ähnlich wie ein erfahrener Perry Rhodan-Leser die Angaben von Raumschiffsgeschwindigkeiten oder Entfernungen zwischen den Sonnensystemen auf ihre Korrektheit überprüft oder Unstimmigkeiten im Gefüge ihres Serien-Universums bemerken. So stellt beispielsweise ein Perry Rhodan-Leser folgende Überlegung zum Verbrauch von Transmittern in einem Leserbrief auf:

„[W]enn man bedenkt, dass Fusions- und NUG-Schwarzschild-Kraftwerke auf Basis der Hypertropzapfung schier unbegrenzte Energiemengen zur Verfügung stellen und je nach Standort, Einzugsgebiet, Alternativtransportmittel etc. täglich einige Millionen Menschen dieses Transportmittel benutzen, sollte eine Benutzung so gut wie kostenlos sein, oder?"617

Doch der einschlägige Schwerpunkt der Landser-Erzählungen, die ausschließlich während des zweiten Weltkriegs angesiedelt sind, liegt die Bezeichnung „Kriegsromanheft" näher als „historisches Romanheft“.

616 Weigand: Zwischen Heldentot und historischer Wandel.

617 Perry Rhodan Bd. 2184. Orakel in Gefahr. Arndt Ellmer. 1. Aufl. Pabel-Moewig-Verlag. S. 66. 


\section{Erzählökonomie und Serieninsider}

\subsection{Erzählökonomie}

Im Folgenden sollen Feststellungen Nussers zur "Sprache der Groschenhefte"618 unter dem Aspekt einer 'Erzähl-Ökonomie' betrachtet werden. Dies meint, dass Wertungen gegenüber der Leserschaft und der Heftinhalte außen vor bleiben und im Weiteren der Fokus auf den Nutzen jener sprachlichen Phänomene für eine serielle Narration gelegt werden soll. Nusser unterscheidet „Redensarten“ und „Sentenzen“. ${ }^{619}$ Die Redensarten werden, als „formelhafte Wendungen" ${ }^{620}$ eingesetzt, die vereinfacht Sachverhalte umreißen können. Ob sie heutzutage immer noch zur „Normierung von Sachverhalten“621 in Romanheften genutzt werden, bleibt fraglich, aber: „Sie unterstützen damit in den Groschenheften die Typisierung der Figuren, den Klischeecharakter des Geschehens, sie helfen das Lesetempo zu beschleunigen“. ${ }^{622}$

Auf diese Weise erhält der Leser schneller einen direkten Zugriff auf Umstände innerhalb der Geschichte. Dies geschieht nicht zwingend durch „Normierung von Sachverhalten“, sondern durch eine vereinfachte Nutzung von Attributen, so ist eine schöne Frau schön, ohne dass der Autor diese Schönheit genauer definiert. Aber ihre Funktion in der Szene, in der sie (gerafft) beschrieben wird, ist damit innerhalb weniger Worte eindeutig umrissen.

Gegebenenfalls zählt der Autor weitere Körperteile auf, die er ebenfalls bloß als „schön" benennt: Haare, Beine, Gesicht, Lächeln et cetera. Demgemäß wird die Heldin Mira in einem Romanheft in mehreren Stellen charakterisiert und zu Beginn des Heftes ausführlicher vorgestellt:

„Wie lang, gerade und wohlgeformt ihre Beine waren [...]. Und wie fest der Oberkörper sein mußte, wie gerade und makellos gewachsen." "623

Doch im Verlauf der Handlung ist dies lediglich auf kurze Attribute begrenzt:

618 Nusser: Romane für die Unterschicht, S. 88ff.

619 Ebd. S. 90ff.

620 Ebd. S. 90f.

621 Ebd. S. 91.

622 Ebd.

623 Die großen Fürsten Bd. 1. Geheimnis um die Thronerbin. Bettina Rosen. Aufl. unbek. KelterVerlag. S. 20. 
„Jetzt trug Emir [ein Pferd; Anm.d.A.] seine junge, schöne Herrin.“624

„Mit der Schnelligkeit, die er nun schon kannte, war sie auf den schlanken, langen Beinen. ${ }^{\text {"625 }}$

Mit nur wenigen Attributen wird die Gestalt der Heldin Mira in den Textpassagen umrissen und ist für die Geschichte eines Romanhefts erschöpfend dargestellt: Die schöne junge Frau mit den schlanken Beinen. Neben Figuren aus anderen Romanheften wirkt die Heldin Mira geradezu ausführlich beschrieben, denn in den meisten Heften bedenken die Autoren ihre Figuren mit weniger Attributen. Beispielsweise wird die Gefährtin Sheila der Hauptfigur Sam Concho aus der Westernserie Captain Concho lediglich wiederholt als „hübsche Frau“ vorgestellt:

„Die hübsche Frau war innen [...] nachgeritten [...].“626

„Concho war von Sheilas Anblick überwältigt. Ihr hübsches Gesicht war gerötet [...].“627

„Sam Concho nickte Sheila knapp zu und die junge und hübsche Frau verließ das Fort." "628

Dieses einzelne, aber sehr allgemein gehaltene Attribut „hübsch“ reicht hier aus, um die gesamte Figur darzustellen. Die Figur Sheila ist 'die' „hübsche Frau“, womit alles an ihr hübsch ist: „Ihre hübschen Augen strahlten.“629 Zum einen kann der Leser nach seinen Vorstellungen von 'hübsch' die Figur in seiner Vorstellung ausformen, da der Begriff entsprechend offen ist, und zum anderen wird der Begriff in dieser Geschichte hauptsächlich nur in Verbindung mit der Figur Sheila eingesetzt, aber nicht mit anderen. Damit ist der Begriff innerhalb dieses Romanhefts temporär neu konnotiert und nutzt zudem die lesereigenen Konzepte des Attributs 'hübsch'.

In den Romanheften werden nicht viele Worte verwendet, um Figuren ausschweifend zu charakterisieren, sondern die Autoren beschränken sich auf eine limitierte Auswahl, die in den jeweiligen Geschichten zu 'Signalwörtern' avancieren, wie beispielsweise bei der Figur Sheila.

624 Ebd. S. 24.

625 Ebd. S. 26.

626 Captain Concho Der Rebell aus Texas Bd. 8. Der Kampf um Port Isabel. Bill Murphy. 1. Aufl. Bastei-Verlag. S. 8. Dies ist eine der wenigen episodalen Westernserien.

627 Ebd. S. 10.

628 Ebd. S. 14.

629 Ebd. S. 11. 
Durch eine "erzählzeitlich[e] Raffung “630 kann in kürzester Zeit viel erzählt und in komplexe Situationen eingeführt werden, so wie in diesem Beispiel:

„Frau Dina und ihre Tochter wurden von Frau von Herder und ihrem Gatten sehr herzlich begrüßt. Und die bereits anwesenden Gäste umringten sofort von allen Seiten die beiden Damen, die in der Gesellschaft sehr beliebte und gefeierte Erscheinungen waren." ${ }^{\text {6631 }}$

Es wird lediglich benannt, aber nicht dargestellt, dass die Frauen sehr beliebt sind. Damit ist die Position der beiden Damen in der Gesellschaft für das Romanheft hinreichend dargestellt, worauf im Folgenden die Handlung der Liebesgeschichte vorangetrieben werden kann. Diese Form der „Raffung“ lässt sich auch für die Darstellung historischer Hintergründe, wie im Westerngenre, nutzen:

„Es begann damals in Texas, wenige Wochen nach Ende des Krieges, den der Süden verloren hatte. Texas war von den Truppen der Sieger wie ein besiegtes Land besetzt und die Steuereintreiber der Yankees trieben unter dem Schutz der 'Blaubäuche' - so nannte man die Unionssoldaten - überall ihr erbarmungsloses Unwesen. “632

Mit wenigen Worten wird die Ausgangslage für das kommende Abenteuer umrissen, womit die Unruhen, in denen der Held sich wiederfinden wird, hinreichend erklärt sind. Im Verlauf der Geschichte wird dieser Hintergrund nicht weiter entwickelt. Er ist lediglich die Begründung für den Aufbau einer feindlichen Umgebung für den Helden. Die „Sprache der Groschenhefte“ muss nicht zwingend aus Phrasen bestehen. Allerdings werden diverse Techniken benutzt, um komplexe Sachverhalte einfach und knapp darzustellen beziehungsweise zu benennen. Mittels Redensarten und Sentenzen lässt sich dies natürlich leichter bewerkstelligen. Es gilt aber auch zu bedenken, inwiefern Phrasen vom Genre abhängig sein können.

Nussers Beispiel der Sentenzen lässt sich nur begrenzt anwenden. Er spricht hierbei von „sprachliche[n] Preziositäten, die insbesondere im Frauenroman zur atmosphärischen Kennzeichnung der Lebensbedingungen des Adels [...] herangezogen werden und den Klischeevorstellungen der Leser von den Verhaltensweisen dieser Schichten entsprechen. “633 Die in der Tat aber nur der adeligen Schicht entsprechen

630 Nusser: Romane für die Unterschicht, S. 91.

631 Hedwig Courths-Mahler Bd.156. Das stolze Schweigen. Hedwig Courths-Mahler. Aufl. unbek. Bastei-Verlag. S. 6.

632 G.F. Unger Bd. 1583, S. 3.

633 Nusser: Romane für die Unterschicht, S. 94. 
und beim Erscheinen der Werke ein 'stilistisches Relikt' darstellten, da die Autorin Hedwig Courths-Mahler bereits zu Lebzeiten Bezug auf eine vergangene Epoche mit veralteten Werten nahm. Nicht ohne Grund bezeichnet sie (oder der Verlag) ihre Geschichten als „Märchen für Erwachsene“. ${ }^{634}$

Demnach trifft die Aussage der Sentenzen nur auf einen speziellen Teil der Romanhefte zu - eventuell auch nur auf diese Reihe, denn innerhalb des Genres des Liebesromans gibt es Unterschiede: Die Hefte Die Welt der Hedwig Courths-Mahler sind zwar Liebesromane, die ein ähnliches Setting wie die Romane von CourthsMahler nutzen, weisen sie aber, ähnlich wie die Jack Slade-Hefte, kaum Sentenzen auf. Zudem waren die Geschichten der Courths-Mahler bereits zu Zeiten Nussers Analyse als Neuauflagen erschienen und für eine aktuelle Untersuchung der Sprache der Romanhefte veraltet: Nussers Werk erschien 1973, die Texte Hedwig CourthsMahler wurden jedoch zwischen 1905-1954 verfasst, ${ }^{635}$ wobei der Höhepunkt ihrer Schaffenszeit in den 1920ern lag. ${ }^{636}$ Ingrid Müller bezeichnet 1978 den Erfolg der Courths-Mahler-Geschichten im Bastei-Verlag als eine „Hinwendung [der Leser; Anm. d. A.] zu Vergangenem“.637

Die Texte der Romanhefte bleiben in der Regel an der Oberfläche und treten selten in eine psychologisierende Tiefe, was durch die vermehrte Verwendung von Phrasen ermöglicht wird. Figuren werden zwar nicht tiefgründig hinterfragt, aber es lassen sich auf diese Weise komplexe Sachverhalte schnell umreißen. Die Figur des James Irving stellt der Autor in dem Westernheft Jack Slade Band 612 mittels der Phrase „vom Leben gezeichnet“ plastisch dar und deutet gleichzeitig an, dass er ein erfahrener Mann ist:

„James Irving beugte sich vor, so dass sein vom Leben tief gezeichnetes Gesicht im Schein der Lampe deutlicher zu sehen war."638

Dergestalt wird zum einen ein zerfurchtes Gesicht skizziert und zum anderen die Wertung eingeflochten, dass er viel erlebt hat. Mittels einer simplen Phrase kann hier ein optischer Eindruck vermittelt und sogleich eine entsprechende Wertung der Figur

634 https://www.bastei.de/indices/index_allgemein_1867568.html (Zugriff: 17.08.2019).

635 Gustav Sichelschmidt: Hedwig Courths-Mahler Deutschlands erfolgreichste Autorin. Bonn 1967. (Bonner Beiträge Bd. 16). S. 32.

636 Ebd. S. 35.

637 Müller: Untersuchungen zum Bild der Frau in den Romanen von Hedwig Courths-Mahler. S. 11.

638 Jack Slade Bd. 612, S. 7. 
vorgenommen werden. Doch über diese simple Darstellung hinaus erfährt die Figur keine tiefgehende Charakterisierung. Es wird lediglich genannt, dass Irving vom Leben gezeichnet ist, aber wie sich das in dem Verhalten der Figur ausdrückt, führt der Autor nicht aus. Die Phrasen dürfen einen Gemütszustand lediglich signalisieren, also, ob die Figur beispielsweise böse, nett oder besonnen ist.

Nusser schließt aus diesen dargestellten „erzählzeitlichen Raffungen“, dass die Autoren sich den „kognitiven und affektiven Mustern, die Wirklichkeit zu deuten,“ der Leser anpassen. ${ }^{639}$ Hiermit deutet er einen begrenzten Intellekt der Rezipienten an. Welchen Durchschnitts-IQ die Leserschaft besitzt, kann jedoch nur eine empirische Studie zutage fördern. Vielmehr lohnt hierbei wieder ein Blick auf den Markt, für den die Romanhefte produziert werden. Die Hefte erscheinen als Periodika am Kiosk und nicht in einer Buchhandlung. Dies legt nahe, dass sie für ähnliche Lesesituationen wie Zeitungen oder Zeitschriften gedacht sind und damit als ein Konsumgut, das häufig nebenbei gelesen wird. Ein unkonzentriertes Leseverhalten liegt somit näher. Diese mögliche Verwendungssituation offenbart einen eher am Konsum beziehungsweise Konsumverhalten orientierten Verkauf, als an einer möglichen intellektuellen Bildung der Gesellschaft. Die Produzenten stellen sich also auf Leser ein, die beispielsweise im Zug, im Bus oder in der Pause zwischendurch lesen; Orte an denen auch Zeitungen konsumiert werden. Eine Werbung des Bastei-Verlages legt diese Vermutung nahe:

„Reisen durch die Welt der Phantasie! In der U-Bahn, auf dem Sofa, in der Arbeitspause, im Bett oder auf dem Balkon: Lesende Menschen nehmen Urlaub von ihrem Alttag, heben ab in ferne Wirklichkeiten, träumen sich in fremde Schicksale hinein und lassen sich dabei nur ungern stören. Gehen auch Sie mit Bastei auf Reisen durch die Welt der Phantasie!"640

Ebenfalls problematisch ist der Maßstab, der hier angelegt wird. Nusser vergleicht die Romanhefte mit hoher Literatur. Diesem Vergleich können die Romanhefte natürlich nicht standhalten, da sie unter anderen Voraussetzungen produziert wurden (und werden). Die Verlage konzipierten sie nicht für den Literatur- sondern für den Unterhaltungsbereich; genauer gesagt: Als eine per Massenmedium verbreitete

639 Nusser: Romane für die Unterschicht, S. 94.

640 Vgl. Homepage des Bastei-Verlages: https://www.bastei.de/indices/index_allgemein_29.html (Zugriff: 17.08.2019). 
Unterhaltungslektüre. ${ }^{641}$

Sprache und Inhalte der Romanhefte sind durch ihre Raffung leicht zugänglich und wirken daher schnell trivial, da sie die Figuren nicht psychologisieren und der Plot stark aktionsbetont ist. Innerhalb der Literatur gelten sie als minderwertig, jedoch stehen sie außerhalb dieser Debatte ${ }^{642}$ und zwar buchstäblich, wenn man auf die Verkaufsfläche schaut: Im Buchhandel wird man keine Lassiter-Hefte kaufen können, ${ }^{643}$ sie sind rein als Produkte des massenmedialen Vertriebs gedacht.

\subsection{Serieninsider}

In einigen Serien lassen sich Bezeichnungen und Begriffe finden, die nicht in erster Linie den Konventionen des Genres entspringen, sondern ein Produkt der jeweiligen Serie zu sein scheinen, daher gibt es zwar in der John Sinclair-Serie Begriffe, die für das Horrorgenre typisch sind, doch wurden sie speziell für diese tendenziell episodale Serie modifiziert. Beispielsweise gibt es bei John Sinclair statt den bisher 'bekannten' Vampiren: „Supervampire“, „Halbvampire“ und sogar „Dracula II“. ${ }^{644}$ Der Begriff 'Vampir' wird bei John Sinclair modifiziert und zu einer Pseudo-Fachvokabel ausgeformt: Es gibt nun nicht mehr lediglich Vampire, sondern in der Serie wird zwischen Halbvampiren und Supervampiren unterschieden. Die Modifikationen sind in diesem Fall kein Ergebnis von Genrekonventionen, sondern entspringen der Eigenart der John Sinclair-Serie, die über ihre lange Laufzeit diverse Eigenarten ausprägte und so mit konventionellen Genre-Vokabeln eigene, John Sinclair-spezifische Begriffe ausformte. So wissen einige Sinclair-Kenner sofort, dass „Der Spuk“ keinen Fluch, sondern eine Figur meint, da es zu einem Insider der Serie geworden ist.

Wie weitreichend solche Serien-Insider sein können und wie sie sich entwickeln, lässt sich anhand der langjährigen Erfolgsgeschichte der Perry Rhodan-Serie zeigen,

641 Eine Frage der in Kapitel 9. „Das serielle Produkt als Massenkunstwerk“ nachgegangen wird.

642 Zur "Schmutz und Schund-Debatte“ soll noch in Kapitel 10. „Schlussbetrachtung" einiges gesagt werden, denn die Literaturwissenschaft darf nicht „auf die Frage verzicht[en], was es bedeutet, von eben dem Kunstverständnis auszugehen, das auch die triviale Literatur voraussetzt“ und nicht die 'hohe Literatur'. Vgl. Wernsing und Wucherpfennig: Die Groschenhefte, S. 3. Vgl. hierzu Kapitel 2. „Distribution und Erscheinungsbild“.

644 Geisterjäger John Sinclair. Bd. 1705, S. 8. 
die ein spezielles Vokabular, welches nur für dieses Serienuniversum typisch ist, ausgeformt hat. Dies macht es allerdings notwendig inhaltlich weiter auszuholen, um die Entwicklung gewisser Begriffe, auch in Hinblick auf Genrekonventionen, adäquat darstellen zu können.

Der Plot beginnt 1961 mit der ersten Mondlandung, bei der Major Perry Rhodan und seine Crew auf Außerirdische stoßen: Die beiden menschenähnlichen Arkoniden Thora und Crest. Anfangs sehen die Außerirdischen verächtlich auf die menschliche Rasse herab und wollen Rhodan sowie seine Crew loswerden. Diese wehren sich erfolgreich dagegen und Rhodan kann die Arkoniden davon überzeugen, dass Menschen für sie nützlich sind. Arkoniden sind zwar eine hochentwickelte Rasse, die sich aber auf ihre hochentwickelte Technik blind verlassen, sodass sie neuen Krankheiten ohnmächtig gegenüberstehen. Wie es der Zufall will, ist der Arkonide Crest krank und die Menschen haben geeignete Mittel, ihn zu pflegen (vgl. auch Kapitel 4.8 „Der Fall 'Perry Rhodan'“). Die Arkoniden gehen einen Handel mit Rhodan ein und für die Heilung von Crest erhält er technisch hochentwickelte Instrumente. Dank seiner Fähigkeit als sogenannter „Sofortumschalter"645 wusste Rhodan die Situation günstig zu nutzen. Mit der Unterstützung der Arkoniden errichtet er in der Wüste Gobi einen Stützpunkt und gleichzeitig ein neues Machtzentrum der Erde: Eine dritte Weltmacht, welche „die Dritte Macht“ genannt wird, ${ }^{646}$ mit der er einen drohenden Atomkrieg verhindert, der sich zwischen Ost- und Westmächten angebahnt hatte. Rhodan baut seine "Dritte Macht“ aus und im Verlauf entwickelt seine Gruppe immer bessere Raumschiffe, mit denen Rhodan und seine Freunde weiter in das All vordringen. Dadurch ziehen sie die Aufmerksamkeit anderer Mächte auf sich, welche die Menschheit bedrohen. Die globale Bedrohung nutzt Rhodan, um die Menschheit zu einen; er macht sie zu „Terranern“. Unterscheidungen wie Amerikaner oder Deutscher gibt es fortan auf der Erde beziehungsweise „Terra“ nicht mehr. Unter der Leitung von Rhodan schwingen sich die „Terraner“ zu einer bedeutenden Weltraummacht auf: „Das solare Imperium“. Die „Terraner“ entwickeln und verbreiten sich in der Galaxie, wobei sie fortwährend gegen fremde Bedrohungen antreten müssen. Die „Superintelligenz ES“ spielt bei vielen Abenteuern eine Rolle, da sie immer

645 Dies bezeichnet Rhodans Fähigkeit „sich äußerst rasch auf neue Situationen ein[zu]stellen“. Vgl. Hoffmann und Marzin: Perry Rhodan Lexikon Bd. Q-V, S. 26. Artikel über: Rhodan, Perry.

646 Die Hefte erschienen ab den 1960ern als die beiden Weltmächte USA und Sowjetunion sich den Kalten Krieg lieferten. 
wieder den „Terranern“ Rätsel zum Lösen aufgibt. Im Zuge dieser Abenteuer stoßen sie auf andere Superintelligenzen, erfahren mehr aus den großen kosmischen Zusammenhängen, müssen zwischenzeitlich die Erde aus dem Sonnensystem versetzen, Rhodan wird von den "Terranern“ abgewählt und wieder als Herrscher eingesetzt. Bei all diesen Abenteuern verstreuen sich die "Terraner" in der ganzen Galaxis und kolonisieren etliche Planeten. Die veränderten Lebensbedingungen mutieren die Gene der Kolonisten, da diese sich den unterschiedlichen Lebensbedingungen anpassen. Im 35. Zyklus der Serie schreibt man das Jahr 1346 Neue Galaktische Zeitrechnung; ${ }^{647}$ dies entspricht 4933 n. Chr. und nichts Geringeres als die gesamte Galaxis ist bedroht: Die Chaosmächte besetzen die Galaxis, doch Figuren, Gegenstände sowie Perry Rhodan-spezifische Vokabeln aus dem Anfang der Serie sind noch immer von Relevanz und wurden weiter entfaltet.

Ebenso sind die Figuren Thora und Crest, auch wenn sie aus der Serie ausgeschieden sind, noch immer für das Serienvokabular von Relevanz. Nach Crest wurden einige Raumschiffe benannt und Thora diente als Namensgeberin für eine Straße in Terrania-City (der Hauptstadt der Erde), die noch nach mehr als 1000 Folgen als Schauplatz für Abenteuer dient: ${ }^{648}$

„Kowa wandte sich schließlich dem Nachbargebäude zu. Savoire las die Hausnummer - Thora Road 2218 [...].“649

Auf diese Weise bleiben beide Figuren der Serie indirekt erhalten. Ebenso wie die Rakete „Stardust“ mit der Perry Rhodan im ersten Heft auf dem Mond landete:

„Sparks erzählte ihr von dem Vorfall am STARDUST-Monument. 'Ich bin zu spät gekommen', schloss sie. 'Ein Irrer auf Rhodans legendärer Rakete, das hätte schon was hergemacht [...].' "650

Die Rakete ist als Denkmal in der Hauptstadt der Menschheit errichtet, um die Bewohner sowie die Leser an Perry Rhodans erste Abenteuer mit den Arkoniden zu erinnern. Die Namen "Thora" und "Crest" stehen nach mehr als 2000 Heften nicht mehr allein für die beiden Figuren, sondern bezeichnen nun auch andere Gegenstände oder Orte. Im Handlungsverlauf wurden diese Namen neu vergeben und ent-

647 Die Perry Rhodan-Serie ist nicht in Staffeln, sondern in Zyklen eingeteilt.

648 Vgl. zur "Thora-Road“ u.a. den Glossar in: Perry Rhodan Bd. 2378. S.69. Und zu „Crest“ vgl. die entsprechenden Einträge in: Hoffmann und Marzin: Perry Rhodan Lexikon Bd. A-E.

649 Perry Rhodan Bd. 2377, S. 21.

650 Perry Rhodan Bd. 2376. Tolle Tage in Terrania. Leo Lukas. 1. Aufl. Pabel-Moewig-Verlag. S. 18. 
sprechend modifiziert. Daher ist es nicht immer eindeutig, wen Perry Rhodan meint, wenn er von "Crest“ spricht: Meint er das Raumschiff oder seinen verstorbenen Freund Crest? Um dieser Doppeldeutigkeit zu entgehen, schreiben die Autoren Raumschiffnamen in der Perry Rhodan-Serie in Großbuchstaben. Auf diese Weise sieht der Leser wortwörtlich wann die Figur Crest und wann das Gefährt CREST gemeint ist. Damit besonders handlungsrelevante Hintergründe im Romantext für die Leser nicht untergehen, erläutern die Autoren einzelne Begriffe und Namen ausführlicher im Glossar (vgl. hierzu auch Kapitel 8.5 „Wiederholung als Erinnerung“). Das Glossar bietet damit eine Übersicht der wichtigsten Serienvokabeln bei Perry Rhodan.

Die ersten Perry Rhodan-Hefte waren gemäß damaliger Genrekonventionen lediglich Aktions-Romane mit futuristischen Staffagen, zwischen denen sich die Helden mit Fäusten und Schusswaffen bekämpften. Zu den Zweikampfbeschreibungen treten vermehrte Beschreibungen technischer Geräte, die sich hauptsächlich mit den Waffensystemen der Raumschiffe befassen:

„Der zweite Mikrobeschleuniger war betriebsbereit. Rhodan und Crest bauten inn in den Strukturtaster ein und wußten, daß der neue Schwingkreis mit dem alten gekoppelt, in der Lage war, zirkular polarisierte Gravitationsstrahlung zu empfangen und auch auszusenden und damit den Wirkungsbereich des Gerätes um eine Dimension erhöhte."651

„Mikrobeschleuniger“, „Strukturtaster“, diese Begriffe muten auf den ersten Blick wie fachsprachliche Ausdrücke an, sind jedoch semantische 'Black Boxes', die keinen realen Bezug haben. Es sind pseudowissenschaftliche Begriffe, welche die Illusion einer wirklichen Technik erzeugen. Für den Bereich der Science Fiction ist das zwar nicht ungewöhnlich, doch in der Perry Rhodan-Serie wird es massiv genutzt. ${ }^{652}$ Gelegentlich erklären die Autoren einige dieser Begriffe, aber nur scheinbar, da diese wiederum mit kryptischen 'Black Boxes' erklärt werden. Sie erweckt den Anschein erklärbar zu sein, und nur ein Kenner jener Fachsprache könne die Erklärung verstehen. Ähnlich wird mit einer technischen Fachsprache in den Landser-Romanen umgegangen:

„Vom Maschinenleitstand aus bestätigte jetzt der Leitende Ingenieur(LI)

651 Perry Rhodan Bd. 16. Die Geister von Gol. Kurt Mahr. 4. Aufl. Pabel-Moewig-Verlag. S. 29.

652 Hallmann: Perry Rhodan - Analyse, S. 182ff. 
Fregattenkapitän (Ing.) Liebhard, dem Kommandanten, daß der Kessel 1 im 1. Kesselraum durch einen Überhitzer-Rohrreißer ausgefallen ist. Die Mittelmaschine kann nur noch Umdrehungen für 27 Seemeilen leisten. Das bedeutet, daß die Geschwindigkeit des Schlachtschiffes auf 28,5 Seemeilen zurückgeht."653

Die Pseudo-Technik wird zwar in den aktuellen Heften weiterhin kultiviert, sie steht jedoch nicht mehr so stark im Vordergrund. Ebenso fehlt den heutigen Passagen, die sich mit Technik befassen, der militärisch kurzgefasste und 'zackige' Stil, wie er zu Beginn typisch war. Der militärische Drill der handelnden Figuren war in den ersten Heften noch präsent und führte dazu, dass sich die militärische Hierarchie unter ihnen in den Kampfszenen abzeichnete: ${ }^{654}$

„Der Orter meldete sich. 'Unter uns ist unübersichtliches Gebiet, Sir. Scheint ein Gebirge zu sein. Höhenunterschied bis zu zwanzigtausend Meter."“655

Oder:

„Rhodan nickte.

'Beschußdauer?'

'So lange bis nichts mehr da ist!'

[...] 'Gut' stimmte Bull zu. 'Ich regle den Beschuß auf zwanzig Sekunden!'

$[\ldots]$

'Dreihunderttausend! Sie beschleunigen weiter!

Und ein paar Minuten später:

'Sie bremsen! Sie bleiben auf der Stelle stehen!'

Rhodan reagierte sofort.'

'Feuer!' befahl er." ${ }^{656}$

Nicht nur die Sätze der Figuren sind kurz und knapp gehalten, sondern auch der Erzähltext selbst ist reduziert. So nickt Perry Rhodan lediglich, ohne dass der Autor seinen Gesichtsausdruck oder Reaktionen der anderen Figuren beschreibt. Nur die Handlungen der Figuren werden genannt: Nicken, Zustimmen, Reaktion und Befehl. Dem Leser wird der Eindruck eines Teams suggeriert, das wie eine Maschine agiert und reagiert, da emotionale Tönungen außen vor bleiben. Nackte Zahlen für Zeiträume, Größen und Entfernungen sind Gegenstand ihrer Dialoge. Welche

653 Der Landser SOS Bd. 138. Untergang der 'Glorius'. Autor und Aufl. unbekannt. Pabel-MoewigVerlag. S. 20.

654 Vgl. hierzu Kapitel 4.8 „Der Fall 'Perry Rhodan'“, sowie Hallmann: Perry Rhodan - Analyse, S. $211 \mathrm{ff}$.

655 Perry Rhodan Bd.16, S. 17.

656 Perry Rhodan Bd. 5. Atom-Alarm. Kurt Mahr. 4. Aufl. Pabel-Moewig-Verlag. S. 59. Die Absatzgliederung ist original aus dem Heft übernommen. 
Bedeutung sie für die Figuren haben, wird nicht genannt. Der Leser muss ein Kenner sein oder es sich aus den folgenden Handlungen erschließen, um zu verstehen, ob beispielsweise in der beschriebenen Szene 20 Sekunden Beschuss lang oder kurz sind. In den heutigen Ausgaben wird eine ähnliche Situation tendenziell folgendermaßen dargestellt:

„'Da ist etwas', sagte Major Harimon Ettel langsam, ohne den Blick von seinem Pult zu nehmen. 'Da... Verdammt, Leute, da ist was...' Major Sonja Darrows schwenkte ihren Sitz herum und blickte ihren Orteroffizier fragend an. 'Wenn du dich vielleicht etwas klarer ausdrücken könntest...?'“657

Der militärische Drill der Figuren steht nicht mehr im Vordergrund und die Besatzung ist keine funktionierende Masse, sondern erlebende Individuen: Die Vorgesetzten sprechen mit ihren Mitarbeitern auf einer persönlichen Ebene und begegnen ihnen nicht als funktionierende Soldaten. Dies rührt unter anderem daher, dass nun vermehrt soziale und ethische Konflikte im Vordergrund stehen, ${ }^{658}$ was durch Voltz angeregt wurde, damit eine "humanistische und philosophische Ausrichtung“ in die Serie Eingang finden konnte. ${ }^{659}$ Voltz folgte damit dem Trend der New WaveBewegung in den 1960ern und 1970ern, die philosophische und psychologische Themen in der Science Fiction etablierte (vgl. u.a. Kapitel 4.7. „Science Fiction und Space Opera“). Schwettmann schreibt hierüber bezogen auf die Perry Rhodan-Serie:

„Waren die Romane in den 60ern noch von der Zeit des Kalten Krieges geprägt und von kämpferischer Action durchzogen, so kam in den 70er Jahren immer stärker eine humanistische Ausrichtung ins Spiel, was sicherlich von der aufkommenden Friedensbewegung beeinflusst wurde."660

Die Raumschiffe sind nicht mehr Wunderwaffen des Militärs, sondern Wunderwerke der Wissenschaft. Die Figuren, die diese Technik entwickeln und bedienen, werden nun zum Thema und nicht die Technik allein.

Die lange Laufzeit hindurch konnten sich diverse Perry Rhodan-Vokabeln erhalten, die in der Zeit, in der sie geprägt wurden, den Genrekonventionen entsprachen und damals durchaus für die Science Fiction-Leser zeitgemäß waren. Aus heutiger Sicht

657 Perry Rhodan Bd. 2380. Es kam aus der Sonne. Horst Hoffmann. 1. Aufl. Pabel-Moewig-Verlag. S. 17.

658 Der Wandel innerhalb der Redaktion ist ausführlicher nachzulesen bei Nagula: Perry Rhodan. Die Chronik Bd. 2, S. $551 \mathrm{ff}$.

659 Schwettmann: Allmächtiger, S. 80.

660 Schwettmann: Allmächtiger, S. 38. 
sind Bezeichnungen wie „Aktivatorchip“ oder "Sofortumschalter" eher befremdlich und Begriffe wie "Chaotender" oder „Hyperimpedanz" sind selbst für Genre-Kenner kryptisch, wenn sie nicht Perry Rhodan-Kenner sind. Zu Beginn der Serie gab es in den Beschreibungen der Actionszenen eine Nähe zu Wildwestromanheften ${ }^{661}$ und in den Technik-Beschreibungen zu Landser-Romanen, ${ }^{662}$ die sich heute nicht mehr in den Perry Rhodan-Heften niederschlagen. Die Serie hat solch eine Fülle an eigenen Insider-Begriffen geschaffen, dass sie beständig daraus schöpfen kann. Ähnlich verhält es sich mit der John Sinclair-Serie, nur steht ihr noch nicht solch eine Bandbreite aus Insider-Begriffen zur Verfügung.

Für die Fortsetzungsserien scheint es eine natürliche Entwicklung zu sein, dass sie begriffliche Serien-Insider ausprägen. Erleichtert doch ein passendes Schlagwort die Beschreibung eines komplexen Sachverhaltes, denn es ist leichter, in einer Perry Rhodan-Geschichte nur zu benennen, dass Rhodan ein "Ritter der Tiefe“ ist, als zu beschreiben, warum der Held mit einigen Superintelligenzen in Kontakt treten kann. Würde dies beständig, wie im folgenden Textbeispiel, umfassend dargestellt werden, würde die Lesbarkeit der Geschichte darunter leiden:

„Ritter der Tiefe - kosmischer Wächterorden, der vor 2,2 Millionen Jahren die Porleyter ablöste und deren Regeln und Zielsetzungen zur Schaffung und Bewahrung einer harmonischen, kosmischen Ordnung übernahm. Sitz des Wächterordens ist der Dom Kesdschan auf dem Planeten Khrat. Jeder der alten Ritter der Tiefe bekämpft mit seinen Helfern (Orbiter) die Bestrebungen der negativen Mächte im Universum und gab nach seinem Tode einen Teil seines Geistes in den Dom Kesdschan ab, wo auch jedes neue Mitglied des Ordens den psionischen Ritterschlag erhält - Perry Rhodan im Jahr 425 NGZ."663

Das Phänomen dieser Insider-Vokabeln ist zwar aus einer für das Genre typischen

661 Hartmut Kasper hat ausführlich die Nähe der 'Space Operas' zu den 'Horse Operas' am Beispiel der Perry Rhodan Serie dargestellt. Vgl. Hartmut Kasper: Perry Rhodan - der Erbe der Space Opera. In: Das Science Fiction Jahr 2004. Hrsg. von Sascha Mamczak und Wolfgang Jeschke. München 2004, S. 69-98.

662 Klaus-Peter Klein: Zukunft zwischen Trauma und Mythos: Science-fiction Zur Wirkungsästhetik, Sozialpsychologie und Didaktik eines literarischen Massenphänomens. Stuttgart 1976. S. 112. Klein schreibt, dass allerdings alle Science-Fiction-Hefte von einem Militarismus durchdrungen sind und zieht im Weiteren Vergleiche zwischen der Perry Rhodan-Figur und einem faschistoiden Führer. Eine ähnliche Auffassung vertritt auch Conrad Suhler: Perry Rhodan - Auf Raketen zurück in die Zukunft. Vgl. u.a. dort S. 594: „Nicht nur die Inhalte der Serie künden von autoritärer Herrschaft, aggressivem Imperialismus und technokratischer Rationalität, auch die Sprache tut es."

663 Vgl. Hoffmann und Marzin: Perry Rhodan Lexikon Bd. Q-V, S. 33. Die Textstelle dient lediglich der Illustration und ist im Original wesentlich länger. 
Situation heraus entstanden, doch die Erhaltung und die weitere Verwendung solcher Vokabeln entspringt den Bedürfnissen der langfristig geführten seriellen Narration. Da die Serie mit ihrem fortlaufenden Plot immer mehr Ereignisse sowie Figureninventar akkumuliert, ist es für den aktuellen Handlungsstrang erzählökonomischer, auf diese nur zu verweisen, als sie in der jeweiligen Geschichte zu erläutern, auch wenn die Hintergründe wichtig für ein umfassendes Verständnis sind. Das obige Textbeispiel offenbart, wie zahlreich die zusätzlichen Verknüpfungen zu weiteren Figuren und Schauplätzen sind, die Leser zudem in dem Serien-Lexikon nachschlagen können: „Porleyter“, „Dom Kesdschan“, der Planet „Khrat“ und die „Orbiter“.

Ein unerfahrener Leser kann diese Hintergründe in dem Perry Rhodan-Glossar am Ende des Heftes oder im Internet nachschlagen. Andere langlaufende Serien bieten mittlerweile auch diese Möglichkeiten, weshalb es beispielsweise ein John SinclairLexikon $^{664}$ gibt. Professor Zamorra und Maddrax arbeiten hingegen lediglich mit erläuternden Fußnoten. ${ }^{665}$

Diese Art der Bündelung von weiterführenden und vertiefenden Informationen würde der von Nusser erwähnten „Raffung“ entsprechen, bei der mit Signalwörtern auf Ereignisse innerhalb des Serienuniversums kurz verwiesen wird, ohne diese tatsächlich auszuführen. Demgemäß sind „Ritter der Tiefe“, „Arkoniden“ oder „Supervampir“ Signalbegriffe. Sie sind dem erfahrenen Leser geläufig und er weiß um die Hintergründe sowie die damit verbundenen Eigenschaften. Der unerfahrene Leser muss hingegen diese Begriffe vorerst als kryptisch hinnehmen und kann nur durch entsprechende Hilfestellungen (vgl. Kapitel 8.4 „Redundanzen während der Rezeption“, 8.5 „Wiederholung als Erinnerung“ und 8.6 „Die Vorankündigung“) diese Vokabeln dekodieren.

Dies setzt allerdings ein umfangreich ausgeprägtes Serienuniversum voraus und ist daher hauptsächlich in den tendenziellen Fortsetzungsserien zu finden. Die Ausformung von Serien-Insidern ist demnach nicht vorrangig vom Romanheftgenre abhängig, aber indirekt, da einige Genres eher zu bestimmten Serienformen tendieren als andere: So finden sich im Bereich der Romanhefte eher Science FictionSerien mit Fortsetzungsstruktur und unter den Liebesromanheften eher abge-

664 Delfs: John Sinclair-Lexikon.

665 Auf die weiterführenden Hilfsangeboten für Leser wird in Kapitel 8. „Innere Verknüpfung. Oder: Die serielle Narration." detailliert eingegangen. 
schlossene Erzählungen pro Heft.

Rainer Stache wertet „[s]olche Begriffsschöpfungen“ bei Perry Rhodan als ein Mittel, die Leser tiefer in die Fiktion der jeweiligen Narration hineinzuziehen. ${ }^{666}$ Die SerienInsider sind für inn bei der Perry Rhodan-Serie Teil des „Spiel“-Aspekts, der den Leser als einen Serien-Kenner auszeichnet und inn in seinem Wissen bestätigt. ${ }^{667}$ Auf den „Spiel“-Aspekt wird in Kapitel 8.4 „Redundanzen während der Rezeption“ vertieft eingegangen, da die Ausformung von Serienvokabular auf Verknüpfungen innerhalb der Serie fußt.

666 Stache: Perry Rhodan Überlegungen, S. 109.

667 Ebd. S. 109f. 


\section{Halbwertszeit von Serienfiguren}

In langlaufenden Romanheftserien mit einem festen Figureninventar wie beispielsweise John Sinclair und Perry Rhodan sammeln die Figuren gelegentlich Erinnerungen und Eigenschaften. Inwieweit dies die Figuren verändert oder ob sie starr bleiben, soll im Folgenden untersucht werden. Hierbei zeigt sich, dass die „Halbwertszeit" einer Serienfigur, also wie lange sie Teil der Serie ist, sich auf ihre Entwicklung auswirken kann.

Besonders Figuren im Bereich der Liebesromane wurden eingehend von der Forschung wahrgenommen. Franziska Ruloff-Häny schreibt beispielsweise: „Die Helden der Frauenromane sind keine Gestalten, sie sind Typen, die aus einer Addition von Eigenschaften mit positiven Vorzeichen bestehen.“668 Diese "Typen“ lassen sich allerdings nicht nur in den Liebesromanen wiederfinden, sie sind Merkmal diverser anderer Genres der Romanhefte. So werden beispielsweise auch in den Westernheften die Helden stark gerafft dargestellt. Lediglich die Auswahl der Adjektive wird nach der Art des Genres gesetzt, deshalb sind im Western die „wiederkehrenden Details" als Beschreibung der athletischen Gestalt des männlichen Helden „zur Formel: 'breitschultrig und schmalhüftig' erstarrt". 669

„Klischees" beziehungsweise geraffte Darstellungen von männlichen und weiblichen Helden werden laut Lieselotte Brodbeck in diversen Romanheften gleichermaßen genutzt, nur dass es in den jeweiligen Romanheftgenres leichte Akzentverschiebungen gibt: Beispielsweise stehe in den Liebesromanen zwar der weibliche Held in der Regel im Vordergrund, allerdings gehört „[z]um positiven männlichen Helden [...] die große sportliche Erscheinung “. ${ }^{670}$ Die Männerfiguren beider Beispiele gehen in eine ähnliche Richtung, dass Männlichkeit mit Stärke assoziiert wird. Lediglich die Ausprägung zeigt leichte Nuancenverschiebungen: Für den Liebesroman mag es daher genügen, wenn der Mann als 'sportlich' oder 'athletisch' benannt wird. Im Wildwest- oder Kriminalromanheft können die männlichen Helden ihre Männlichkeit zusätzlich durch ihre Fähigkeiten demonstrieren. ${ }^{671}$

668 Ruloff-Häny: Liebe und Geld, S. 18.

669 Davids: Das Wildwest-Romanheft in der Bundesrepublik. 1975, S. 63.

670 Liselotte Brodbeck: Roman als Ware. Zur Analyse der Liebesromanhefte. Basel 1974. S. 17.

671 Vgl. Ruloff-Häny: Liebe und Geld, S. 18. 
Nach der Prämisse der „Addition“ von Attributen werden laut Ruloff-Häny „Typen“ ausgeformt. Allerdings werden auf diese Weise nicht nur Helden dargestellt, sondern auch ihre Antagonisten erhalten die entsprechenden (negativen) „Vorzeichen“. Dies lässt sich weiter fassen und die Figuren in zwei Lager trennen, denen die entsprechenden positiven oder negativen Vorzeichen zugeordnet werden: Gut und Böse beziehungsweise In- und Outgroup.

Es ist bezeichnend, dass Davids, um es für die Westernromanhefte zu verwenden, das Konzept der In- und Outgroup von Gertrud Willenborg übernimmt, ${ }^{672}$ die es bereits für die Courths-Mahler Werke nutzte. ${ }^{673}$ Des Weiteren wenden Wernsing und Wucherpfennig das Konzept auf sämtliche Genres der Romanhefte an. ${ }^{674}$ HansHerbert Wintgens überträgt außerdem die beiden polarisierenden Gruppen auf den "gesamte[n] Figurenkatalog der Konformliteratur“675.

Die Figuren sind in der Regel eindeutig einer von beiden Gruppen zuordenbar. „Zwischenstufen sind ausgeschlossen“676, was zudem die Entstehung von vielschichtigen Helden unwahrscheinlich macht. Christian Thiel konstatiert für den modernen Liebesroman jedoch Gegenteiliges, dass es keine Gegenspieler für die Helden mehr geben muss und somit die Verteilung auf In- und Outgroup hinfällig wäre. ${ }^{677}$ Diese These ist jedoch nicht haltbar, sobald man eines der aktuellen Liebesromanhefte aufschlägt, denn in ihnen lassen sich noch immer klare Antagonisten identifizieren (vgl. u.a. Kapitel 4.2 „Der Frauenroman ist ein Liebesroman“).

Dies liegt jedoch nicht nur am Romanheftgenre 'Liebesroman', sondern auch an der jeweiligen Serienform ('Serie' im weitesten Sinne). Es zeigt sich, dass die Serienform starken Einfluss darauf hat, inwiefern Figuren gemäß bekannten Genrekonventionen geformt werden, oder ob sie davon abweichen: Innerhalb der Reihen ist das Konzept der In- und Outgroup unproblematisch anwendbar, doch im Bereich der Serien, unabhängig davon ob sie tendenziell episodal oder fortlaufend sind, lassen sich Abweichungen finden. In der John Sinclair-Serie lässt sich beispielsweise

672 Liselotte Brodbeck verweist zwar nicht auf Willenborg, verwendet aber ebenfalls dieses Konzept für das Liebesromanheft. In: Brodbeck: Roman als Ware, S. 16f.

673 Davids: Das Wildwest-Romanheft in der Bundesrepublik. 1975, S. $97 f$.

674 Wernsing und Wucherpfennig: Die Groschenhefte, S. 63ff.

675 Hans-Herbert Wintgens: Trivialliteratur für die Frau. Stuttgart 1979. S. 18. Sein Ansatz soll hier jedoch nicht weiterverfolgt werden, da seine Ergebnisse sich nur auf einen Korpus von Liebesromanen und nicht anderen Genres stützt.

676 Wernsing und Wucherpfennig: Die Groschenhefte, S. 65.

677 Thiel: Liebe, Sex, Karriere, S. 15. 
beobachten, wie die wiederkehrende Nebenfigur Justine Cavallo die Seite wechselt:

„Irgendwann hatte es mal so kommen müssen, aber mit großer Wahrscheinlichkeit hatte der letzte Fall damit zu tun, in den wir zusammen mit Justine geraten waren. Da hatte sie ihre Hemmungen über Bord geworfen und sich gewandelt. [...] Sie brauchte Blut, und das holte sie sich auch. Natürlich waren wir dagegen gewesen, aber wir hatten es nicht geschafft, sie zu ändern."678

Demnach war sie von vornherein eine ambivalent angelegte Figur, die nun von der Ingroup in die Outgroup gewechselt war. Eine ähnliche Konstellation findet sich auch in der Professor Zamorra-Serie. In Band 960 „In den Nebeln“ ergibt es sich, dass einer der erbittertsten Feinde von Professor Zamorra sich mit inm verbündet:

\begin{abstract}
„Asmodis seufzte frustriert und wandte sich inm wieder zu. 'Na schön', sagte er, 'würdest du mir dann wenigstens ein paar Informationen geben, wenn du mir nicht schon persönlich helfen willst?' In den Worten klang ein recht eindeutiges 'Du Feigling', mit, doch da der Dämon es nicht laut ausgesprochen hatte, beschloss Zamorra, es um den lieben Friedens willen zu ignorieren. $\mathrm{Er}$ war sich durchaus im Klaren darüber, dass Asmodis das Recht hatte, den einen oder anderen Gefallen einzufordern. “679
\end{abstract}

Es ist unschwer zu erkennen, dass die beiden Figuren eigentlich als Widersacher angelegt waren, da sogar der Held unwillig ist, einem Verbündeten zu helfen. Aber es gibt genügend Ereignisse, die sie verbinden, sodass sein ehemaliger Widersacher sogar ein Recht auf einen Gefallen hatte. In diesem Fall wechselt temporär eine eigentlich eindeutig der Outgroup zugeordnete Figur in den Bereich der Ingroup. In diesen Beispielen zeigt sich, dass in einigen Serien der Romanhefte mit dem Prinzip der In- und Outgroup gespielt wird, da so bekanntes Stamminventar umgewertet wird. Doch der erfahrene Leser der jeweiligen Serie hat stets die ehemalige negative oder positive Konnotierung der Figur in Erinnerung. Falls dies nicht der Fall ist, wird er mittels Einschüben und Kommentaren im Haupttext wieder daran erinnert. Auf diese Weise hat auch ein unerfahrener Leser die Möglichkeit, die Ambivalenz der Figur wahrzunehmen. Die stärkste Ausprägung von Ambivalenz im Bereich der Romanhefte findet sich wohl bei der Hauptfigur der Vampira-Serie, in welcher sie selbst eigentlich der Outgroup zuzurechnen ist:

„Lilith Eden ist die Tochter einer Vampirin und eines Sterblichen. In ihr

678 Geisterjäger John Sinclair Bd. 1706. Lockvogel der Nacht. Jason Dark. 1. Aufl. Bastei-Verlag. S. $18 f$.

679 Professor Zamorra Bd. 960, S. 10. 
vereinen sich beide Seiten: die böse, Blut zu trinken, sich Menschen untertan zu machen und erst nachts zu voller Kraft zu gelangen, und die gute Seite, die bei Lilith überwiegt, obwohl sie sich nicht von den Erbanlagen ihrer Mutter befreien kann." 680

In den Romanen wird stets mit der Gefahr gespielt, dass die Hauptfigur doch noch fragwürdige Dinge tut, auch wenn sie dies nicht will. Sie bleibt allerdings eine Figur, die zwischen beiden Seiten oszilliert. ${ }^{681}$ Waren dies bisher hauptsächlich Beispiele für Figuren, die sich nur zwischen den beiden Polen In- oder Outgroup bewegen, gibt es aber durchaus noch eine Erweiterung dieser Problematik, nämlich die, dass Figuren überhaupt nicht mehr in ein solches Schema zu pressen sind und das Konzept von In- und Outgroup nicht mehr greift. In den neueren Folgen der Perry Rhodan-Serie lassen sich häufig wiederkehrende Nebenfiguren finden, die weder eindeutig gut noch eindeutig böse sind.

„Sie hatten keine Chance, Vastrear zu retten. [...] Nicht Satwa, die den beiden Vatrox am nächsten stand, denn sie war wie betäubt. Keineswegs wegen der Morde an Kruuper und dem Klon, deren sie Zeuge geworden war, sie war nichts anderes von den Vatrox gewohnt. Sondern wegen des Schmerzes, den Sinnafoch und Vastrear empfanden. Vatrox kannten kein Mitgefühl. Eigentlich. Aber die Trauer um Kruuper, einen plumpen Okrivar mit Sprachfehler, hatte eine rasende Wut in Sinnafoch entflammt. Und Vastrear trauerte um einen misslungenen Klon. Ein Kunstwesen ohne Wert, jederzeit millionenfach reproduzierbar."682

Die Vatrox sind in diesem Beispiel die Outgroup zu Perry Rhodans Ingroup, die Terraner:

„Als die Frequenz-Monarchie aus einem jahrtausendelangen Ruheschlaf erwacht, beanspruchen ihre Herren, die Vatrox, sofort die Herrschaft über das Transportsystem und mehrere Galaxien. Die Terraner und ihre Verbündeten wehren sich erbittert" ${ }^{\prime 63}$

Die Fronten werden in dem zitierten Prolog eindeutig abgesteckt: Ingroup = Terraner versus Outgroup $=$ Vatrox. Damit ist für den unerfahrenen Perry Rhodan-Leser eindeutig dargelegt, wie er die Figuren zu bewerten hat. Allerdings wird diese

680 Vampira Bd. 3. Besessen. Adrian Doyle. 1. Aufl. Bastei-Verlag. S. 34.

681 Nach Bärtle gilt die Vampira-Serie als innovativ im Bereich der ausschweifenden Erotik und besonders im Bereich einer angeblich komplexen Handlungsführung. Vgl. Bärtle: Grusel, Grüfte, Groschenhefte, S. 355f.

682 Perry Rhodan Bd. 2585. Der Tanz der Vatrox. Frank Borsch. 1. Aufl. Pabel-Moewig-Verlag. S. 4.

683 Ebd. S. 4, Prolog. 
Eindeutigkeit der Fronten dadurch aufgebrochen, dass die Gegner nicht mehr als bloß böse inszeniert werden, sondern als Wesen mit Gefühlen und anderen Zielen, als nur jenes, die Terraner zu vernichten. Die Folge „Der Tanz der Vatrox“ vertieft, dass die eigentlichen Gegner noch andere Beweggründe für ihre Handlung haben, als nur Gegner von Perry Rhodan zu sein. ${ }^{684}$

Doch was ist mit anderen langlaufenden Serien mit durchgehender Hauptfigur wie Beispielsweise Lassiter oder Dr. Norden? Diese Serien zeichnen sich durch eine starke Tendenz zu einem episodalen Aufbau aus, die kaum bis nie Entwicklungen mit in die nächste Episode forttragen. In diesen Serien machen Helden keine Entwicklung durch, lediglich das Personal der stets wechselnden Episodenfiguren darf Entwicklungen durchmachen. Doch da ihre Auftritte von kurzer Dauer sind können sie in ihrer Ausprägung nicht allzu ambivalent werden und sind immer einer Front zuzuordnen. Auch das wiederkehrende Personal, wie zum Beispiel in den Arztserien Dr. Norden oder Dr. Laurin, dürfen nicht zwischen den Fronten oszillieren, da sie dem Leser in ihrer Konstanz eine Orientierung geben müssen. Die oben vorgestellten Abweichungen sind nur in Serien möglich, in denen sich Leser zum einen auskennen und zum anderen genügend Raum für eine derartige Entwicklung geboten wird, da mit einer differenzierten Ambivalenz auch eine Komplexität der Narration einhergeht. Widersprüchliche Figuren können zwar gerafft dargestellt werden, jedoch macht ihre ambivalente Anlage sie zu einem unsicheren Faktor für den Leser, da auch für den erfahrenen Leser nicht unbedingt klar ist, welchen Figuren er seine Sympathie angedeihen lassen soll. In dem Perry Rhodan-Heft „Oase der Wissenden“ werden beispielsweise zwei Figuren klar voneinander abgegrenzt. Die eine Figur ist gut und Sympathieträger, die andere Figur der Böse:

„Kruuper hatte um den Veteranen getrauert - niemand sonst tat es, [...] und als das Schicksal inn später in die Fänge Sinnafochs geworfen hatte, hatte er sich in seiner Verzweiflung der Schilderungen des Chirurgen erinnert. Seine Aussichten, hatte er sich ausgerechnet, das Sterben nicht fürchten zu müssen; standen leidlich gut. Gut genug jedenfalls, um das Wagnis einzugehen. Kruuper wollte nicht das Werkzeug Sinnafochs werden." ${ }^{685}$

So sinniert der Sympathieträger Kruuper über seine Überlebenschancen dem Feind

684 Vgl. ebd.

685 Perry Rhodan Bd. 2566. Oase der Wissenden. Frank Borsch. 1. Aufl. Pabel-Moewig-Verlag. S. 11. 
Sinnafoch, eigentlich sein Herr, nicht endgültig in die Hände zu fallen. Kruuper, der als reflektierende und Mitgefühl empfindende Figur eingeführt wird, steht der Sinnafochs gegenüber. Sinnafoch wiederum wird als ein Gegenspieler Perry Rhodans inszeniert:

„Es war kein beliebiges terranisches Raumschiff gewesen, das er der sicheren Vernichtung entgegengeschickt hatte. Es war das Schiff Perry Rhodans gewesen, des verfluchten unsterblichen Terraners, der die Existenz der Frequenz-Monarchie bedrohte. Der all das bedrohte, wofür Sinnafoch nicht nur ein Leben, sondern Dutzende gegeben hatte."

In Rhodan personifiziert sich für Sinnafoch die absolute Bedrohung und er ist somit für ihn der Erzfeind, da aber Perry Rhodan die Hauptfigur und Sympathieträger der Serie ist, wird der erfahrene Leser wissen, dass der Vatrox es nicht schaffen kann. Doch die Position des Antagonisten gegenüber Rhodan wird stückweise aufgebrochen und außer gerafften Charakterzügen einer Antagonistenfigur zeigen sich auch die eines Sympathieträgers:

„Das Schicksal hatte Kruuper kein Dasein im ruhigen Abseits vergönnt. Sinnafoch hatte inn zu seinem Werkzeug gemacht. Kruuper hatte es nicht vermocht, sich wieder aus seinem Blick zu entfernen. Und der Blick des Vatrox war furchtbar: Mal stand Kälte in ihm, mal Wut, mal Grausamkeit. In diesem Moment las der Okrivar ein neues Gefühl in Sinnafochs Augen: Mitgefühl.“687

Diese neuen Charakterzüge des Antagonisten Sinnafochs werden als eine unerwartete Neuerung inszeniert. Allerdings ändert die Neuerung in Sinnafochs Charakter vorerst nichts an seiner Position zu Perry Rhodan. Die Fronten bleiben aufrechterhalten, nur mit dem Unterschied, dass der Antagonist bei dem Leser Sympathiewerte erhält. Im weiteren Verlauf der Serie streuen die Autoren immer wieder Situationen in den Handlungsverlauf ein, welche die Wandlung Sinnafochs stückweise darstellen, denn wenn die Wandlung des Antagonisten zu plötzlich erscheint, kann es passieren, dass die Wandlung als Bruch oder Widerspruch mit dem bisherigen Verlauf aufgefasst und nicht vom Leser akzeptiert wird. Ein ähnliches Beispiel in einem Kommentar zur Maddrax-Serie:

„Ich lobe fast immer und habe so gut wie nie Kritik [...]. Aber eine Sache fand ich sehr unglaubwürdig. Der Part von Crow. Er möchte Mutter vernichten,

686 Ebd. S. 16. Da der Vatrox immer wiedergeboren wird, sind hier seine eigenen Leben gemeint, welche er geopfert hatte.

687 Ebd. S. 17. 
zumindest verhindern, dass sie in den Schacht geworfen wird. Anfangs dachte ich 'Meine Güte, du bist Kroow, schlachtest Massen von Soldaten ab, holst bewaffnete Fluggeräte vom Himmel, besiegst am Ende sogar den Zerstörer und bekommst diese paar Dörfler nicht unter Kontrolle?! [...]' Und kurz darauf las ich eine absolut nicht nachvollziehbare Erklärung von wegen 'Kroow geht die Muffe [...]'.'688

Der Leser kritisiert, dass die sonst als furchtlos dargestellte Figur Kroow ein Problem wegen Angst nicht lösen konnte. Somit liegt hier ein Bruch mit der bisherigen Charakterdarstellung vor, den die Autoren für den Leser nicht genügend vorbereitet hatten.

Romanheft-Serienfiguren sind in der Regel nicht nach einem psychologischen Konzept ausgearbeitet, sondern entweder der In- oder Outgroup zugeordnet. Da sie allerdings keine festgelegte Psyche haben, sondern lediglich Attribut-Träger sind, können ihnen, ohne das es logische Brüche gäbe, nicht einfach neue Attribute hinzugefügt werden. Ohne erklärende Einführung neuer Attribute führt es wie bei der Figur Kroow dazu, dass Leser es als unpassend wahrnehmen.

Entscheidend ist auch, dass das zusätzliche Attribut nicht dazu führt, dass die Figur von der Ingroup zur Outgroup oder umgekehrt wechseln müsste. Falls eine Figur durch Verwicklungen des Plots dazu hingeführt wird, es doch zu tun, kann dies nicht plötzlich geschehen, da ein Wechsel zwischen den Fronten für den Leser vorbereitet sein will. Bei langlaufenden Serien wie beispielsweise Perry Rhodan finden sich zwar eher ambivalente Figuren und Figuren die, wie Sinnafoch, eine eigene Typisierung aufweisen, die sich jedoch nur aus der Entwicklung der jeweiligen Serie erklärt.

Die vielfältigen Varianten an Serienfiguren lassen sich anhand des Figureninventars einer Romanheftserie mit besonders langer Laufzeit wie Perry Rhodan illustrieren. Da sich die Romanheft-Autoren an Exposévorgaben halten müssen, sind $\mathrm{Ab}$ weichungen in den Figurenbeschreibungen minimal. Diese Vorgaben stellen insofern einen expliziten Konsens für die Autoren dar. Es gibt aber auch einen indirekten Konsens, der durch die Kenntnis der Texte ihrer Vorgänger entsteht, an denen sich die anderen Autoren orientieren. Da die Entwicklung der Figuren allein vom ExposéAutor ausgeht und den Roman-Autoren nicht viel Zeit zur Ausarbeitung eigener Ideen

688 Maddrax Bd. 304. Allein gegen alle. Sascha Vennemann. 1. Aufl. Bastei-Verlag. S. 33 ein Leserbrief. 
bleibt, bekommen die Figuren selten psychologischen Tiefgang. Sie werden in der Regel nur oberflächlich durch ihr Aussehen und gegebenenfalls einiger auffälliger Eigenheiten charakterisiert, welche zuvor der Exposé-Autor festlegte.

Jede Figur wird mit bestimmten Adjektiven beschrieben, die ihre Individualität ausmachen müssen. Ein Beispiel für einen individuellen Charakterzug ist, dass eine als 'schlau' charakterisierte Figur in der Serie immer 'schlau' antwortet. Dies wird dem Leser nicht mit einer subtilen Technik des Autors suggeriert, sondern schlichtweg ausformuliert, dass diese Antwort schlau war, zudem muss jedes Heft ohne Vorwissen verständlich sein. Da die Hefte nur einen begrenzten Umfang haben und die Eigenschaften jeder auftretenden Figuren im jeweiligen Heft wiedergegeben werden müssen, sind diese zwangsläufig nur kurz und plakativ dargestellt:

„Der da hereinkam, war Tanaka Seiko, einer von Rhodans fähigsten Mutanten." 689

Auf diese Weise muss nicht lange vorbereitet werden, dass der Mutant fähiger als die anderen ist. Die individuellen Charaktereigenschaften, die nichts anderes als Personenbeschreibungen sind, greifen die Autoren immer wieder auf und verwenden sie ohne große Varianz. Einem Ritual gleich wird immer wieder betont, dass Reginald Bull poltert oder laut ist, ${ }^{690}$ Perry Rhodan seinem Ruf als 'Sofortumschalter' gerecht wird, indem er schnell oder sofort reagiert ${ }^{691}$, oder dass eine Frau besonders hübsch ist. ${ }^{692}$ Über diese Attribute hinaus werden die Figuren jedoch nicht psychologisiert. Reginald Bull bleibt der 'Polterer', Rhodan der 'Sofortumschalter' und die Frau 'die Hübsche'693; mehr als das sind die Figuren meist nicht. Der Charakter der Figur ist entweder nur polternd oder nur hübsch. Diese Skizzenhaftigkeit hilft den Autoren Fehler zu vermeiden, denn die Figuren können sich nicht charakterlich verändern. An ihren reduzierten Charakteren kann nicht viel entwickelt werden, wenn ein Held zum Beispiel einfach nur grob oder schön ist. Diese Attribut-Ansammlung ist demnach der Wiedererkennungswert der Figuren. Würde dieses Attribut-Gefüge verändert werden, ist das Risiko gegeben, dass die Leser es als einen Bruch wie bei dem erwähnten Kroow-Beispiel wahrnehmen.

689 Perry Rhodan Bd. 16, S. 12.

690 Schwettmann: Allmächtiger, S. 54.

691 Ebd. S. 44ff.

692 Zur Stereotypie der Figuren vgl. auch Nutz: Trivialliteratur und Popularkultur, S. 63 f.

693 Vgl. hierzu das Bsp. aus Kapitel 5. „Erzählökonomie und Serieninsider“. 
Feste Attribut-Gefüge bieten aber auch den Vorteil, dass die Figuren schnell identifizierbar sind. Wenn beispielsweise vom 'Sofortumschalter' die Rede ist, dann wissen selbst neue Perry Rhodan-Leser, dass die Figur Perry Rhodan gemeint ist. Bei Serien mit einem großen Figureninventar ist dies besonders wichtig, da hier die Gefahr größer ist, den Überblick zu verlieren.

Die inhaltliche Struktur lässt die Figuren lediglich als Requisiten erscheinen. Figuren, die gewisse Attribute in die Handlung einbringen, wie zum Beispiel stark oder schlau, werden in Situationen gebracht, die sie nur mit ihren spezifischen Charaktereigenschaften lösen können. Wenn die Handlung beständig voranschreitet und keine Konstanten bietet, ist es für den Leser hilfreich, in den Figuren feste Variablen innerhalb der Serie zu finden. Die spezifischen Charaktereigenschaften sind bei den Figuren konstant und können für den Leser auf diese Weise Bezugspunkte darstellen. Die Autoren müssen keine tiefgehende psychische Darstellung der Figuren herausarbeiten, wenn diese einen Schicksalsschlag erfährt, denn sie werden lediglich gerafft mit Attributen wie groß und klein umrissen und es reicht daher unter Umständen aus, zu schreiben, dass der Held betrübt war.

Der Titelfigur der Serie Perry Rhodan wird eine Gruppe zur Seite gestellt, die zum Teil aus festen Mitgliedern besteht und einige andere werden immer wieder ausgetauscht. Figuren, die sich im engeren Freundeskreis oder in Einsatztrupps Rhodans befinden, sind beständiger in die Serie integriert als Figuren, die außerhalb dieses 'inner-circle' stehen.

Dass einige Figuren intensiv in einen Handlungsstrang eingebunden ist, hat noch keinen Einfluss darauf, wie lange sie innerhalb der Serie bleiben. Solange sie nicht in das soziale Umfeld von Rhodan integriert sind, werden diese auch nicht dauerhaft in der Serie verankert. Eine Figur beispielsweise, genannt Overhead, bringt viele Freunde von Rhodan in Gefahr, ${ }^{694}$ wodurch dieser gezwungen ist, eine aufwendige Rettungsaktion zu starten. Im Zuge dessen rettet er nebenbei die Erde und neue Helden werden in die Serie aufgenommen. Hierdurch erscheint auch der Kadett Julian Tifflor in der Serie, der einen Wendepunkt im Kampf gegen den Overhead bringt und sich zu einem festen Bestandteil der Crew Rhodans entwickelt. Bestimmte Figuren werden soweit zu einem festen Bestandteil der Serie, dass die Autoren sie

694 Perry Rhodan Bde. 25-27. 
nicht mehr entfernen oder allzu sehr verfremden. Diese Informationen erhalten die Autoren unter anderem über die Leserkontaktseite von den Lesern selbst. ${ }^{695}$ Figuren, die soweit integriert wurden, haben sich charakterlich dahingehend idealisiert und stilisiert, dass sie inzwischen unveränderlich geworden sind und sich als 'idealisierte Helden' bezeichnen lassen.

Wobei 'ideal' sich hier nur lose an der platonischen „Idee" orientiert, dass die Idee (oder wie hier das Ideal) ein Urbild ist. Idealisierte Helden sind demgemäß also zu einem Urbild ihrer selbst erhöht. So erhöhte Figuren sind in ihrer spezifischen Ausprägung fixiert, die, wann immer die Figur in einer Erzählung erscheint, dargestellt wird. Perry Rhodan bleibt bis in alle Ewigkeit DER Sofortumschalter. Diese Ausprägung kann keine andere Figur mehr für sich beanspruchen. Zudem kann Rhodan auch nicht zu DEM Teleporter werden, da sein Repertoire an Eigenschaften endgültig fix ist. Meist sind die darin eingeschlossenen Eigenschaften oder Eigenarten auch so speziell, dass sie sich anderen Figuren nicht zuordnen lassen. Wenn eine neue Figur als Sofortumschalter mit einer kleinen Narbe am Nasenflügel beschrieben würde, würden erfahrene Perry Rhodan-Leser darin Perry Rhodan sehen. Die Figur könnte sogar mit einem anderen Namen betitelt sein und es würde nichts daran ändern, dass diese Eigenschaften sowie Eigenarten Teile des Urbildes bleiben, die nun mal zu dem gesamten Urbild gehören, dem jeweiligen idealisierten Helden und in diesem Beispiel: Perry Rhodan.

Der Eigenschaften-Katalog für idealisierte Figuren ist also fixiert und wird nicht mehr erweitert. Eine Veränderung in diesem Katalog würde zum einen den Lesererwartungen widersprechen und zum anderen den Produktionsrhythmus der Autoren gefährden, da Unstimmigkeiten auftreten können. Um solche Komplikationen zu vermeiden, ist es für die Autoren einfacher sich an die Exposéangabe zu halten. Selbst eine von den Exposé-Autoren vorbereitete Änderung kann bei den Lesern zu Protesten und Verwirrung führen (hierzu mehr unter 6. „Halbwertszeit von Serienfiguren"). Die Figur Gucky war Bestandteil der Rhodan-Gruppe und sollte trotzdem aus der Serie gestrichen werden. In dem sozialen Umfeld von Rhodan zu sein ist zwar ein notwendiges, aber kein hinreichendes Indiz, um als Held die Serie unbeschadet zu überstehen. Es zeigt lediglich eine Tendenz an: Helden, die eine längere

695 Vgl. Kapitel 2. „Distribution und Erscheinungsbild“. 
Zeit in der Peripherie des idealisierten Kerns unverändert überstanden haben, werden in den Kern aufgenommen. Diejenigen, die zwar enge soziale Kontakte zu Rhodan haben, aber nicht zum idealisierten Kern gehören, können jedoch noch Änderungen erfahren. Die soziale Bindung zu Rhodan ist eine notwendige Bedingung, um in den Kern aufgenommen zu werden. Die letztlich hinreichende Bedingung ist die quantitative Stellung in der Serie. Helden, die lange genug in der Peripherie des Kerns überdauerten, steigen in der Hierarchie auf und rücken dem Kern näher (diese Struktur veranschaulicht das Schalenmodell in der Grafik im Anhang). In der Art und Weise, wie Leser Figuren in die Peripherie-Hierarchie einordnen, kann diese Hierarchie auch bestimmte Lesererwartungen erwecken. Wenn eine Figur aus dem Kern in Gefahr gerät, kann der Leser sich sicher sein, dass diese überlebt. Es bleibt für den Leser nur noch die Frage offen, wie sich die Figur befreit. Bei Figuren aus der I. Peripherie ist diese Sicherheit nicht mehr vollends gewährleistet. Je höher die Distanz zum Kern ist, desto geringer werden die Überlebenschancen für die Figur, wobei die Stellung einiger Figuren zwischen der I. und der II. Peripherie alternieren kann. So gelangen Figuren aus der I. Peripherie irgendwann in die II. zurück. Der Außerirdische Crest, mit dem sich Rhodan am Beginn der Serie anfreundet, begleitet inn lange Zeit bei seinen Abenteuern und steht inm jederzeit mit Ratschlägen zur Seite. Er wird also zu einem Charakter der I. Peripherie. Später taucht er allerdings immer seltener auf, und es wird häufig lediglich erwähnt, dass er bei Rhodan war:

„Perry Rhodan konferierte gerade mit Crest und Thora über die Möglichkeiten der interstellaren Kolonisation, als ein durchdringendes Summen ertönte." “966

Crest ist somit in die II. Peripherie abgesunken und nimmt kaum mehr an der laufenden Handlung teil.

Veränderungen sind ab der I. Peripherie möglich, doch nehmen sie einen hohen Stellenwert ein, wohingegen Änderungen in der II. und III. Peripherie weniger gewichtet werden. Je weiter vom Kern entfernt, desto weniger fällt die Veränderung der Figur ins Gewicht. Diese Veränderungen schlagen sich auch in der Quantität des Textes nieder. Der Tod Crests nimmt ein ganzes Heft in Anspruch, ${ }^{697}$ wohingegen der Tod

696 Perry Rhodan Bd. 48. Rotes Auge Beteigeuze. Clark Darlton. 4. Aufl. Pabel-Moewig-Verlag. S. 61.

697 Perry Rhodan Bd. 99. Ein Freund der Menschen. William Voltz. 4. Aufl. Pabel-Moewig-Verlag. 
des Mutanten Ernst Ellert in nur eineinhalb Seiten geschildert wird ${ }^{698}$ Ellert war von Anfang an immer nur in der II. Peripherie, wohingegen Crest sich lange genug in der I. befand, was seinem Ableben mehr Gewicht gibt.

Die Figuren der III. Peripherie haben im weitesten Sinne mit Rhodan zu tun. Sie stehen zwar auch im positiven Umfeld zu Rhodan, tauchen aber meist nur ein Abenteuer lang auf. Dies kann eine Heftlänge umfassen, geht aber selten über die Länge eines Zyklus hinaus. Sie sind meist Hilfesuchende, Diplomaten, mit denen Rhodan verhandelt oder vereinzelte Besatzungsmitglieder unter Tausenden. ${ }^{699}$ Diese Figuren sind lediglich Beiwerk des Roman-Autors und selten in dem Exposé vorgegeben. Sie stellen häufig den „Jedermann“ des Serien-Universums dar, mit denen der Autor seine Geschichte frei gestalten und an ihnen seine Phantasie demonstrieren kann.

In der Maddrax-Serie sind die Hauptfiguren zwar noch nicht so offensichtlich 'seriell idealisiert', allerdings gibt es einen erkennbaren 'Kern'. Die Hauptfigur Matthew Drax und seine Partnerin Aruula sind seit Beginn der Serie ein Team. Dieses Team wird im Laufe der Zeit immer wieder ergänzt, jedoch verschwinden diese Figuren entweder als wiederkehrende Nebencharaktere oder scheiden gänzlich als Episodencharaktere aus. In Folge 277 kommt die Figur Xij im gleichnamigen Maddrax-Band hinzu. ${ }^{700}$ Xij wird im weiteren Verlauf so weit in die Serie eingebunden, dass sie die Partnerin Aruula zu verdrängen scheint, ${ }^{701}$ doch schließlich scheidet sie, ähnlich wie die CrestFigur bei Perry Rhodan, aus der Serie aus. ${ }^{702}$ Sie stirbt zwar nicht, doch ist sie in einer anderen Dimension gefangen, was für den Verlauf der Handlung auf das Gleiche hinausläuft. Allerdings ist hierbei die Option offengehalten, sie jederzeit wieder in die Serie zu integrieren, falls Unmut bei den Lesern aufkommen sollte. Die Figur Xij hat es nicht von der „I. Peripherie“ in den „Kern“ geschafft und umgekehrt: Aruula wurde nicht aus dem „Kern“ des Helden-Inventars verdrängt. Die „Schurken“, also die Antagonisten der Helden, sind in dieser Serie häufig nur eine episodale

698 Perry Rhodan Bd. 7. Invasion aus dem All. Clark Darlton. 4. Aufl. Pabel-Moewig-Verlag. S. 54f. Ellert stirbt nicht im eigentlichen Sinne, sein Geist wird in Zeit und Raum geschleudert, was allerdings einem Tod gleich kommt.

699 In der TV-Serie Raumschiff Enterprise werden solche Figuren von den Serien-Kennern „Red Shirts" genannt, da es episodale Besatzungsmitglieder in roter Uniform sind, die früh aus der Serie ausscheiden bzw. häufig nur eine Episode überleben.

700 Maddrax Bd. 277.

701 Vgl. beispielsweise: Maddrax Bd. 322. Götterdämmerung. Mia Zorn. 1. Aufl. Bastei-Verlag.

702 Maddrax Bd. 349. In der Domäne. Manfred Weinland. 1. Aufl. Bastei-Verlag. 
Bedrohung, doch lassen sich auch diese in der Regel schnell identifizieren.

Je episodaler eine Serie wird, desto häufiger müssen Konstanten hergestellt beziehungsweise als solche bestätigt werden. Dies geht bei stark episodalen Serien so weit, dass am Ende einer jeden Folge der Status Quo hergestellt ist (hierzu Kapitel 8. „Innere Verknüpfung. Oder: Die serielle Narration“ mehr).

Die Helden Jerry Cotton und Phil Decker stellen den "Kern“ der Jerry Cotton-Serie dar. Diese werden in der Regel in ihren Abenteuern lediglich von wenigen Nebencharakteren gerahmt. Mr. High und Helen, die in die "I. Peripherie“ einzuordnen sind, nehmen kaum Einfluss auf die Handlung und sind bei den meisten Fällen eher stilles Inventar im Hintergrund. Des Weiteren gibt es auch einige Figuren in der "II. Peripherie“, wobei diese nur bei Cotton-Kennern als Nebencharaktere wiedererkannt werden können, da sie zu selten in der Serie erscheinen. ${ }^{703}$

Innerhalb der Jerry Cotton-Serie oszillieren die Figuren nicht zwischen den Peripherien, denn ihre Positionen werden am Ende einer Folge immer wieder bestätigt. So steigen die Figuren Malcolm Snyder und Jimmy Stone, „Vernehmungsspezialisten" ${ }^{404}$, nicht in die „I. Peripherie“ auf, geschweige denn in den „Kern“. Ihre Stellung innerhalb der Serie darf nicht modifiziert werden, da sonst der Status Quo am Ende der Folge gefährdet wäre.

Wesentlich kompakter ist das Gefüge in der Dr. Laurin-Serie. Hier bildet die Familie Dr. Laurins den idealisierten „Kern“, um den herum es nur eine Peripherie an Nebencharakteren gibt. Die Nebenfiguren sind hier noch weniger ausgeprägt als beispielsweise in der Jerry Cotton-Serie.

Innerhalb der Dr. Laurin-Serie fokussieren die Autoren ihre Handlungen stark auf die singuläre Episodenfigur, weshalb eine zu starke Abweichung der Hauptfiguren von eben diesem Fokus ablenken könnte. Dies ist laut Basener eine für den Bereich der Liebesromanhefte typische Ausprägung:

„Diese Figuren ändern mit viel Mut und Engagement das Leben des Gastpersonals ihrer Serie, nicht ihr eigenes. Selten passiert innen etwas, das ins Serienexposé eingetragen und von allen Autoren bedacht werden

703 Compart: G-man Jerry Cotton, S. 36f.

704 Ebd. 


$$
\text { muss.“705 }
$$

Den Hauptfiguren darf nach Basener nicht so viel zustoßen, dass der Verlag die grundlegenden Serienexposés, die Attribut-Sammlungen der Figuren, anpassen müsste. Daraus folgt, dass in Liebesromanheften der Kern des Figureninventars von vornherein festgelegt und unveränderlich ist.

705 Basener 2010, S. 22. 


\section{Narrativer Rahmen der seriellen Narration}

\subsection{Typologien}

Serien im engeren Sinne haben einen großen Handlungsstrang, der alle Folgen der Serie umrahmt. Dieser gibt eine Gesamtstruktur vor, in die sich die einzelnen Folgen einreihen. Zur analytischen Erfassung dieses narrativen Rahmens liegen bereits mehrere Typologien vor.

Schon 1983 hat Eco ein Konzept entwickelt, wie man serielle Phänomene typisieren kann. Er schlägt „Reprise“, „Kopie“, „Serie“ und „Saga“ vor. ${ }^{706}$ Die „Reprise“ ist als eine Wiederaufnahme und Weiterführung einer bestehenden Narration zu verstehen. ${ }^{707}$ Die „Kopie" hingegen ist eine Neuinterpretation einer bestehenden Narration, welche auch meist als „Remake“ bezeichnet wird. ${ }^{708}$ Die „Serie“ ist, nach Eco, eine Narration, in der sich das Phänomen des Seriellen auf die Narration direkt auswirkt. Jede Folge der Serie ist angefüllt mit Wiederholungen. Wie diese aussehen, wird von Eco nicht weiter spezifiziert, da sie für seine Typologie vorerst nicht relevant sind. ${ }^{709}$ Eine "Saga" liegt vor, wenn eine Narration voranschreitend und umfassend die Geschichte einer Person oder Familie erzählt. ${ }^{710}$

Für die weitere Untersuchung der Serialität der Romanhefte soll Ecos „Serien“-Begriff (im engeren Sinne) in den Fokus rücken. Die anderen Typen lassen sich zwar zum Teil in einigen Romanheftserien oder -reihen wiederfinden, doch stellen diese Grenzfälle dar, die hier außen vor bleiben müssen, denn der Grundtypus, der sich in der breiten Masse der Romanhefte finden lässt, ist der der Eco'schen „Serie“. Wie sich im Verlauf zeigen wird, nehmen die Rahmenbedingungen der seriellen Vermarktung starken Einfluss auf die narrative Struktur der Romanhefte. Dies entspricht allerdings eher einer rudimentären Typologisierung, denn auch wenn Eco kleine Unterkategorien einräumt sind die seriellen Phänomene noch nicht hinreichend bestimmt. Hier bietet die Typologie von Jörg Türschmann weiteren Aufschluss:

„Das Feuilleton und die Serie sind 'Archetypen' des mehrteiligen Erzählens.

706 Eco: Spiegel und andere Phänomene, S. $155 \mathrm{ff}$.

707 Ebd. S. 158.

708 Ebd. S. 159.

709 Ebd. S. 159ff.

710 Ebd. S. $161 f$. 
Sie sind es in einem typologischen Sinn, weil sie den historischen Mischformen zugrunde liegen. Die Merkmale des mehrteiligen Erzählens werden daher [...], zunächst vorläufig, entweder dem Feuilleton oder der Serie zugeordnet[.]" ${ }^{\prime 111}$

Die Typologie ist zwar für Fernsehserien bestimmt, doch aufgrund ihrer Gemeinsamkeit, beide massenhaft verbreitete serielle Narrationen zu sein, liegen Fernsehserien und Romanheftserien derart dicht beieinander, dass die Typologie auch hier greift.

Die Begriffe „Feuilleton“ und „Serie“ nach Türschmann sind zudem gleichbedeutend mit den Begriffen „Fortsetzungsserie“ und „episodale Serie“, die hier bereits Verwendung fanden, daher sollen diese Begriffe weiterhin und synonym gebraucht werden. Entsprechend weist Türschmann auf die Typologie von Omar Calabrese hin, der die beiden Begriffe „prosekutiv“ und „akkumulativ“ verwendet und sich dabei rein auf die Episodenverknüpfung bezieht. ${ }^{712}$ Calabreses Begrifflichkeiten beinhalten außerdem einen direkten Hinweis auf die innere „Mechanik“ der beiden „Archetypen“, wie Türschmann sie bezeichnet: die Fortsetzungsserie ist fortschreitend und die episodale Serie ist akkumulierend. Auf diese Weise stellen sie zwei gegensätzliche Serientypen dar, zwischen denen sich die seriellen Narrationen bewegen, daher soll im Folgenden von einer Tendenz zu einem dieser Archetypen ausgegangen werden. Dementsprechend kann eine Serie beispielsweise rein episodal konstruiert sein, sie kann aber auch nur „tendenziell episodal“ sein, mit diversen Abweichungen, bei denen einige Folgen gewisse Handlungsstränge aufweisen, die folgenübergreifend sind. González Requena sieht diese Serientypen durch ein „Netz von miteinander verknüpften Konflikten“ strukturiert. ${ }^{713}$ Die Strukturierung kann allerdings auch über das Geflecht der Handlungsstränge beschrieben werden (vgl. Kapitel 8. „Innere Verknüpfung").

Die akkumulative Episodenserie ist nach Türschmann achronologisch und die prosekutive Fortsetzungsserie chronologisch strukturiert. ${ }^{714}$ Dies mag auf die reinen Archetypen zutreffen, jedoch wird diese Auftrennung diffizil, sobald serielle Narrationen erscheinen, deren Folgen zwischen diesen Typen wechseln. Es macht die Typologie

711 Türschmann: Aspekte einer Typologie von Fernsehserien, vgl. S. 100.

712 Ebd. S. 103.

713 Ebd. S. $103 f$.

714 Ebd. S. $101 \mathrm{ff}$. 
flexibler, wenn das Verhältnis dieser Aspekte anders gewichtet wird, sodass eine akkumulative Episodenserie nicht zwingend achronologisch ist, dafür aber eine achronologisch strukturierte Serie zwingend akkumulativ. Damit ließen sich einerseits Serien erfassen, deren Folgen abgeschlossen sowie chronologisch gestaffelt sind, und andererseits Serien, mit abgeschlossenen aber von einer Chronologie unabhängigen Folgen. Doch sobald die Folgen achronologisch gestaffelt werden, können sie nur schwerlich aufeinander aufbauen und müssten daher eher in sich abgeschlossen sein. Zwar ist eine Serie denkbar, die achronologische Folgen aneinander reiht, während die Folgen dennoch aufeinander verweisen, doch wäre solch ein Konzept nur schwer zu rezipieren und von daher im Bereich der massenhaft verbreiteten seriellen Narration eher selten. Das gleiche Verhältnis gilt für die prosekutive Fortsetzungsserie, bei der somit eine chronologische Struktur eine prosekutive Mechanik voraussetzen würde, allerdings nicht umgekehrt, denn eine serielle Narration kann nur schwerlich zwischen einer achronologischen und einer chronologischen Struktur oszillieren.

Hierzu einige Beispiele: Die Dr. Laurin-Serie ist eine Serie, in der die Folgen lediglich akkumuliert werden, und ist daher eindeutig eine Episodenserie, zudem lassen sich die Folgen theoretisch in ihrer Reihenfolge vertauschen, da sie, abgesehen von ihrer Nummerierung, inhaltlich nicht aufeinander aufbauen. Jede Episode ist eine abgeschlossene Geschichte aus dem Leben von Dr. Laurin. Diese Serie entspricht durchweg dem Archetypen der Episodenserie.

Eine Folge der Professor Zamorra-Serie hingegen endet zumeist offen oder erzählt diverse Handlungsstränge nicht gänzlich aus, welche somit auf die folgenden Hefte verweisen. Da sich die Reihung der Folgen nicht ändern lässt, sind die Folgen in dieser prosekutiven Fortsetzungsserie chronologisch organisiert. Allerdings kann es einige Folgen geben, welche die offenen Handlungsstränge nicht weiterführen und nur eine einzelne Geschichte erzählen, die zudem innerhalb dieser Folge auch zu Ende geführt wird. Diese Serie entspricht zwar in weiten Teilen dem Archetypen der Fortsetzungsserie, aber nicht ausschließlich.

Die Maddrax-Serie liegt zwischen diesen beiden Typen. Ihre Geschichten sind nahezu in jedem Heft abgeschlossen, jedochlassen sich ihre Folgen nicht untereinander vertauschen, da sie chronologisch organisiert sind. Die Ereignisse der jeweiligen 
Folgen sind entscheidend für die nachfolgenden Geschichten und doch gibt es nur wenige Folgen mit übergreifenden Handlungssträngen. So gesehen existiert hier keine prosekutive Erzählung, die auf einen Zielpunkt hinausläuft, und dennoch sind die Folgen chronologisch strukturiert.

In der Typologie von Türschmann wird das Vorhandensein oder Fehlen von „biografischen Ellipsen“ als Distinktionsattribut verwendet. ${ }^{715}$ Durch die chronologische Verknüpfung der Folgen des „Feuilleton“ seien nach Türschmann „biographische Ellipsen“ der Hauptfigur möglich. „Biographische Ellipsen“ meinen hier NichtErzähltes aus dem Leben des Protagonisten. „Serien“ sind nach Türschmann hingegen achronologisch und weisen daher keine „biografischen Ellipsen“ auf.

Dies ist für den Bereich der Romanhefte weniger relevant, da die meisten Romanheft-Figuren statisch und skizzenhaft bleiben und daher biografische Veränderungen der Hauptfiguren in den meisten Serientypen der Romanhefte nicht im Vordergrund stehen. ${ }^{716}$ Bezogen auf die „biographische Ellipse“, fallen demnach nahezu alle Romanheftserien in den Bereich von Türschmanns „Serien“-Begriff.

Wiederum würde einiges, das für den episodalen Archetypen gemäß Türschmanns Typologie sprechen würde, im Bereich der Romanhefte auch auf die Fortsetzungsserien zutreffen. Zur besseren Übersicht hier die Typologie Türschmanns: ${ }^{717}$

\begin{tabular}{|c|c|c|}
\hline & $\begin{array}{c}\text { Feuilleton } \\
\text { (Fortsetzungsserie) }\end{array}$ & $\begin{array}{c}\text { Serie } \\
\text { (Episodenserie) }\end{array}$ \\
\hline Geschichtlichkeit & $\begin{array}{c}\text { Historisierung des } \\
\text { Ursprungs }\end{array}$ & Reproduktion des Status Quo \\
\hline Endlosigkeit & Durch Einfügung & Durch Verlängerung \\
\hline Gesamtstruktur & Geschlossen & Offen \\
\hline Episode & Offen, Etappe & Geschlossen, Mini-Drama \\
\hline $\begin{array}{c}\text { Erzählstruktur der } \\
\text { Folgen }\end{array}$ & Rhythmisch variabel & Schematisch \\
\hline $\begin{array}{c}\text { Haupt- und } \\
\text { Nebenhandlungen }\end{array}$ & Beides vorhanden & Akt-Schema in jeder Folge \\
\hline Reihenfolge der Teile & Kausal-chronologisch & Beliebig \\
\hline
\end{tabular}

715 Ebd. S. 102ff.

716 Vgl. Kapitel 6. „Halbwertszeit von Serienfiguren“.

717 Türschmann: Aspekte einer Typologie, S. 100f. Hervorhebung durch den Autor. 


\begin{tabular}{|c|c|c|}
\hline Temporalität & Chronologie & Achronologie \\
\hline Verknüpfung der Folgen & $\begin{array}{c}\text { Cliffhanger, 'Familie', } \\
\text { prosekutiv }\end{array}$ & $\begin{array}{c}\text { 'Tick' des Helden, } \\
\text { akkumulativ }\end{array}$ \\
\hline Prototyp & Nicht vorhanden & expositorisch, mythologisch \\
\hline Hauptfiguren & Alterung & Soziale Rollen \\
\hline Nebenfiguren & $\begin{array}{c}\text { Bekannte und } \\
\text { Verwandte }\end{array}$ & In einer einzigen Folge \\
\hline Figurenkonstellation & 'Familie' & Öffentlichkeit \\
\hline Gefahrensituation & Verändern den Helden & Belassen die Identiät \\
\hline Handlungsraum & $\begin{array}{c}\text { 'Familiär' und } \\
\text { geschlossen }\end{array}$ & Genrespezifisch und offen \\
\hline
\end{tabular}

Diverse Punkte lassen sich nicht auf den Bereich der Romanhefte übertragen. Die Verknüpfung der Folgen der Episodenserie nur über einen 'Tick' des Helden zu erfassen, wäre zu kurz gefasst. Es verhält sich eher so, dass die tendenziell episodal strukturierten Serien über ein "Thema“ miteinander verknüpft werden. In der Maddrax-Serie wäre das beispielsweise die Reise der Hauptfiguren durch eine dystopische Version der Erde, in der sie diverse Abenteuer erleben. In der Dr. Laurin-Serie werden die Folgen nur lose über die Hauptfigur miteinander verknüpft, dessen einziger 'Tick' darin besteht, Arzt zu sein und Liebende zusammenzuführen, wobei dies nicht immer zwingend durch Dr. Laurin geschieht, sondern gelegentlich auch durch seine Familie. Es ist vielmehr ein "Thema“, oder auch "das Thema“, das in den jeweiligen Heften realisiert wird. Man könnte es, um hier auf Hickethier zu rekurrieren, auf dessen „doppelter Formstruktur" Türschmann aufbaut, als „Gesamtzusammenhang" bezeichnen. ${ }^{718}$

Von dem Konzept eines die Folgen verbindenden Gesamtzusammenhang ausgehend lassen sich Romanheftreihen als stark episodal strukturierte Serien typisieren: Jedes Heft ist in sich abgeschlossen und hat keinen Handlungsstrang, der auf eines der anderen Hefte innerhalb der Reihe rekurriert. Dennoch sind die jeweiligen Hefte einer Reihe über einen spezifischen Aspekt verbunden: Bei den Romanheftreihen kann dieser Gesamtzusammenhang allerdings sehr weit gefasst sein, sodass sie nur über das Romanheftgenre und den Titel der Reihe miteinander 
verknüpft sind. Beispielsweise bündelt der Kelter-Verlag in seiner Arizona-Reihe (vgl. Kapitel 4.3. „Der Western“) in jedem Band fünf Erzählungen. Jeder Band hat inhaltlich nichts gemeinsam mit dem anderen als das Romanheftgenre "Western". Eine expliziter gefasste Verknüpfung kann in einigen Reihen der gemeinsame Autor beziehungsweise das Autor-Pseudonym sein, wie zum Beispiel G.F. Unger oder Jack Slade.

Die weiteren Punkte, die in Türschmanns Typologie in der Spalte "Serie" nach dem Aspekt der Verknüpfung folgen (Prototyp, Hauptfiguren, Nebenfiguren, Figurenkonstellation, Gefahrensituation, Handlungsraum, Rhetorische Figur), lassen sich im Bereich der Romanhefte in vielen Fällen auf beide Serienformen übertragen: Die episodalen und Fortsetzungsserien. Ab dem Punkt „Prototyp“ lässt sich Türschmanns Modell nur bedingt für die Romanhefte nutzen. Der Prototyp ist in beiden RomanheftSerientypen expositorisch (hierzu mehr in Kapitel 8. „Innere Verknüpfung“). Die Alterung der Hauptfiguren wird in den Romanheften selten thematisiert. Ihr Interagieren in der Handlung steht im Vordergrund (vgl. Kapitel „6. Halbwertszeit von Serienfiguren"). Die Halbwertszeit der Nebenfiguren kann varieren. Die Figurenkonstellation ist häufig vom jeweiligen Romanheftgenre abhängig: Beim Liebesroman sind es häufig Verwandte, in den Jerry Cotton-Heften interagieren die Protagonisten häufig mit für sie fremden Personen (vgl. Kapitel 4.2 „Der Frauenroman ist ein Liebesroman“ und 4.4 „Der Krimi ist 'Jerry Cotton'“). Gefahrensituation verändern den Helden in der Regel nicht (vgl. Kapitel 6. „Halbwertszeit von Serienfiguren“) und der Handlungsraum bleibt "genrespezifisch und offen“.

Der Gesamtzusammenhang muss nicht immer inhaltlicher Natur sein. Der Begriff "Thema" wurde in diesem Zusammenhang zwar eingeführt, doch suggeriert dieser Begriff eine inhaltlichen Verbindung, was, wie beim Beispiel der Romanheftreihen, nicht immer der Fall sein muss. Außerdem kann ein inhaltliches Thema theoretisch zusätzlich neben einer verknüpfenden Instanz auftreten. Eine andere Begrifflichkeit bereitet terminologisch weniger Probleme: „Makrostruktur“.

Die Makrostruktur der episodalen Serie Dr. Laurin organisiert die Folgen nicht untereinander, sondern klammert sie lediglich mittels eines inhaltlichen Themas. Die Makrostruktur stellt hier lediglich eine Hülle für eine Akkumulation von Episoden dar, da die Episoden nicht in ein größeres Ganzes eingebettet sind. Die Folgen in einer 
tendenziell akkumulierenden Serie sind hauptsächlich durch das Thema der Serie geprägt und nicht durch eine Hierarchisierung. Dadurch ergibt sich, dass die Folgen stets am Ende den Status Quo herstellen müssen, da sie sonst beginnen würden, die Folgen zu hierarchisieren. Würde jedoch die Folge einer akkumulierenden episodalen Serie grundlegende Veränderungen in ihrem Serienuniversum präsentieren, dann müsste das nachfolgende Heft diese Änderungen übernehmen. Dieses Phänomen ist gelegentlich in einigen tendenziell episodalen Serien zu beobachten. Dies sind die sogenannten 'Doppelfolgen'. In solchen Folgen wird ein Handlungsbogen gespannt, der nicht in dem üblichen Umfang beendet werden kann, und es wird zuweilen bei den Doppelfolgen die Möglichkeit genutzt, den Anschein zu erwecken, dass große Veränderungen in das Leben der Helden eindringen könnten. Folglich würde am Ende der ersten Doppelfolge höchstwahrscheinlich ein Cliffhanger erfolgen, in dem beispielsweise eine wichtige Hauptfigur zu sterben scheint, doch gemäß der akkumulierenden Struktur muss spätestens am Ende der zweiten Doppelfolge der übliche Status Quo wieder hergestellt sein. Dies zeigt allerdings, sobald eine starke Änderung im Serienuniversum auftaucht, müssen die Folgen untereinander organisiert werden. Dies ist im Bereich der tendenziell episodalen Romanhefte ein großes Risiko, da sie auf eine Käuferschaft abzielen, die nicht geflissentlich jede Folge innerhalb der Chronologie liest, zudem wäre es auf diese Weise für den Verlag schwieriger, alte Hefte in eine Erstauflage 'hineinzuschmuggeln', was im Bereich der Liebesromane gängige Praxis ist. Besonders eindrücklich zeigt sich das bei der Beschaffenheit der Reihe: Innerhalb dieser Serienform sind die Folgen lediglich über ihren Titel, das zugehörige Romanheftgenre sowie teilweise durch den Autoren miteinander verknüpft. Sobald eine Folge innerhalb dieser Reihe auf eine andere verweisen würde, bestünde eine stärkere Verbindung zwischen diesen beiden Folgen innerhalb der Reihe als zwischen den anderen Folgen. Wäre die Verbindung dergestalt, dass eine Folge offen endete und in der anderen weitergeführt würde, so würde sie die andere Folge an sich chronologisch hierarchisieren. Solch eine Folge wäre im Bereich der Reihe oder der stark episodalen Serien problematisch, da sie sonst nicht alleinstehend konsumiert werden könnte, was zudem den wahrscheinlichen Lesererwartungen der Konsumenten widersprechen würde. Die Hefte der Reihe „G.F. Unger - Seine grössten Western-Erfolge“ enthalten jeweils ein abge- 
schlossenes Abenteuer. Nur über das Genre und den Autorennamen wird diese Reihe zusammengehalten. Unter den einzelnen Folgen herrscht, trotz durchgehender Bandnummerierung, keine Strukturierung (vgl. Kapitel 4.3 „Der Western“).

Auf diese Weise können die Abenteuer innerhalb der Reihe beliebig eingeschoben werden und das sogar mehrfach. Die Reihe akkumuliert so achronologisch Folgen bis hin zu deren Doppelungen.

Weber und Junklewitz bringen für eine Unterscheidung zwischen Episodenserien und Fortsetzungsserien das „Konzept des Kontinuums“ ein. ${ }^{719}$ Nach diesem Konzept bewegen sich Serien „zwischen den beiden Idealtypen der Episoden- und der

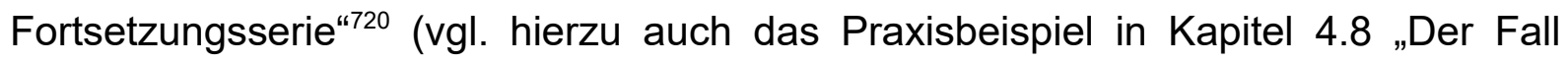
'Perry Rhodan'“).

Je näher beispielsweise eine Serie dem Idealtyp der Fortsetzungsserie ist, desto eher entspricht sie Serien mit progressiver Erzählweise. Weber und Junklewitz erwähnen außerdem, dass die Kontinuität im Bereich der Fortsetzungsserien zunehme. Den „Grad“ einer solchen Kontinuität, nennen Weber und Junklewitz „intraseriale Kohärenz“. ${ }^{721}$ Innerhalb der intraserialen Kohärenz unterscheiden sie zwei Merkmale in den Serien Kontinuitäten ansammeln:

Die „Fortsetzungsreichweite“ gibt an, wie weit sich Handlungsstränge spannen können. Rein episodale Serien oder Reihen hätten nach dieser Definition beispielsweise eine besonders geringe Fortsetzungsreichweite. ${ }^{722}$

Mit der „Fortsetzungsdichte“ bezeichnen Weber und Junklewitz das Verhältnis, wie intensiv Folgen aufeinander rekurrieren, also wie viele Folgen der Rezipient konsumieren müsste, um der Handlung folgen zu können. ${ }^{723}$ Aus diesen beiden Variablen erstellen Weber und Junklewitz das Profil einer Serie (die intraseriale Kohärenz). Die Perry Rhodan-Serie hat demgemäß eine sehr hohe Fortsetzungsdichte, ${ }^{724}$ da nahezu jedes Heft mit einem „Cliffhanger" endet und eine sehr große Fortsetzungsreichweite, da der Haupthandlungsstrang sich über 100 Hefte erstrecken kann. Die intraseriale

719 Junklewitz und Weber: Das Gesetz der Serie, S. 23. Sie nutzen ein Konzept, das bereits von Gaby Allrath, Marion Gymnich und Carola Surkamp genutzt wurde in: Introduction: Towards a Narratology of TV Series. In: Narrative Strategies in Television Series. Houndsmille 2005. Hrsg. von Gaby Allrath und Marion Gymnich. S. 1-43.

720 Ebd. S. 23.

721 Ebd. S. 23.

722 Ebd. S. 24.

723 Ebd.

724 Hierzu ausführlicher in Kapitel 4.8. „Der Fall 'Perry Rhodan'“. 
Kohärenz der Perry Rhodan-Serie ist demnach sehr hoch.

In der Maddrax-Serie spannen sich Haupthandlungsstränge teilweise über zehn bis 50 Hefte. Ihre Fortsetzungsreichweite ist demnach geringer als die von Perry Rhodan. Ebenso ist die Fortsetzungsdichte der Maddrax-Serie geringer, da viele Hefte den Haupthandlungsstrang nicht voranbringen und in sich abgeschlossen sind. Maddrax' intraseriale Kohärenz ist somit niedriger als bei Perry Rhodan.

Noch geringer ist die intraseriale Kohärenz bei der Dr. Laurin-Serie, denn die Fortsetzungsreichweite und -dichte ist immer auf eine Folge begrenzt. Kein Handlungsbogen dieser Serie überschreitet eine Folge und der Leser braucht kein vorangegangenes Heft lesen, um die Handlung in der jeweils aktuellen Folge zu verstehen.

Dr. Laurin hat hingegen immer das gleiche Set an Serienfiguren: Dr. Laurin, seine Familie und Mitarbeiter. Ebenso differiert selten die Auswahl an Themen und Brüche in den Genrekonventionen sind unwahrscheinlich. Um eine intraseriale Kohärenz nutzbar zu bestimmen, fehlen in dem Definitionsansatz explizite Parameter, inwiefern die Fortsetzungsdichte gegenüber der -reichweite zu gewichten sei, daher soll im Folgenden weiterhin die Tendenz zu einer eher progressiven oder einer eher akkumulierenden Serie benannt werden.

Im Bereich der progressiven Serien sind die Folgen durch eine Makroerzählung strukturiert. Um dies im Folgenden umfassend darzustellen, soll die langlaufende Perry Rhodan-Serie analysiert werden. Auf diese Weise kann zudem gezeigt werden, wie sich die Serienpraxis bei progressiven Serien im Romanheftbereich durch die Jahre entwickelt hat.

\subsection{Mikro- und Makroerzählung}

Die scheinbar niemals endende Erzählung von der Geschichte der Mensch heit in der Zukunft ist in größere Handlungsabschnitte unterteilt: Die sogenannten Zyklen. Sie umfassen in der Regel 50 bis 100 Hefte. Am Ende eines jeden Zyklus wird eine längere Handlungseinheit abgeschlossen. ${ }^{725}$ Darin geht es meist um bedeutende

725 Zyklus ist demnach ähnlich der Staffel, oder Season, wie man es aus dem TV-Bereich kennt. Allerdings sind Staffeln nicht immer inhaltlich abgeschlossen, wie die Zyklen bei Perry Rhodan. Staffeln bezeichnen im TV-Bereich das Ende einer Produktion (z. B. werden damit auch Verträge von Schauspielern begrenzt: Ein Vertrag für bspw. drei Staffeln). Zyklen stellen bei Perry Rhodan abgeschlossene „Handlungsblöcke“ dar (vgl. Nagula: Perry Rhodan. Die Chronik. Bd. 1, S. 81). 
Veränderungen, welche die Lebewesen um Perry Rhodan betreffen. Der Zyklus ist eine mehrere Hefte umfassende abgesteckte Rahmenhandlung, an der sich die Geschichten der Romanhefte orientieren. Mittels eines Prologs werden die Romane immer wieder auf den Rahmen zurückgeleitet. Der Zyklus stellt eine Makroerzählung dar, wobei die Mikroerzählung die einzelnen Romane sind. Allerdings ist ein Romanheft nicht gleich zwingend eine Mikroerzählung. Diese kann sich gegebenenfalls auch über mehrere Hefte erstrecken. Es unterscheidet sich zudem von Mikroerzählung zu Mikroerzählung, inwiefern sie die Makroerzählung voranbringen. Mikroerzählungen können gelegentlich abschweifen und erzählen eine Geschichte, die keine direkten Auswirkungen auf die Makroerzählung hat. Sie können beispielsweise die Lebensgeschichte eines bis dahin fremden Außerirdischen erzählen, welcher in der Regel eine Figur der III. Peripherie ist. Hierzu ein Beispiel: Rhodan, Bull, Atlan und noch ein paar andere sind in dem Raumschiff des übermächtigen Wesens Aachthor gefangen. An Bord dieses Schiffes entdecken die Helden konservierte Leichname fremder Wesen - die Kospien. Sie besitzen ein „Multifunktionsorgan“, durch das Rhodan und seine Freunde die Geschichte eines jener Wesen erfahren. Es hieß Vestibor und war Wissenschaftler im Dienste Aachthors. Die Erzählung erscheint zunächst nur als eine Nebenhandlung, doch ist sie damit nicht unwichtig, da sie erklärt, wie Vestibor in die Geschichte verwickelt ist, und so den folgenden Ereignissen eine Hintergrundgeschichte gibt. Denn das, was Vestibor für Aachthor entwickeln sollte, haben die Galaktiker bereits kennen gelernt. Es geht dabei um ein planetengroßes Raumschiff aus einem seltenen Metall. Die Herkunft des Metalls stellt zunächst ebenso ein Rätsel dar wie die Frage, welche Pläne Aachthor bis dahin verfolgt hatte. ${ }^{726}$ Die Geschichte Vestibors bringt nun die Hintergründe zutage. Allerdings ist die ausführliche Narration Vestibors Lebensgeschichte nicht zwingend für die Makrohandlung relevant. Sie ist mehr Kolorit als dass sie die Haupthandlung voranbringt.

Vestibors Geschichte beleuchtet lediglich einen Aspekt der Haupthandlung und verleiht der Serie nebenbei durch eine phantasiereiche Erzählung Exotik. Vestibor ist keine handlungstragende Figur in der Haupthandlung, sondern eine von vielen aus Aachthors Umfeld. Er ist ein Zeuge vergangener (fiktiver) Ereignisse. Seine

Perry Rhodan Bd. 1795. 
Geschichte fällt aus der vorherigen Rahmenerzählung heraus, da ganz andere Aspekte in Vestibors Fokus liegen. Ihm geht es primär darum, zu erfahren, was mit seinem Elternteil ${ }^{727}$ geschah, und weniger darum, das fremde Metall zu entwickeln. Das Projekt für Aachthor, das für Rhodan von Interesse ist, spielt in Vestibors Geschichte nur eine Nebenrolle.

Außerhalb dieser Mikroerzählung rekapituliert Rhodan, was er von Vestibor erfahren hat, womit innerhalb der Erzählung eine narrative Redundanz entsteht. Der Leser kann so auch ohne die Lektüre Vestibors Lebensgeschichte den Haupthandlungsstrang verstehen.

Weiterhin gibt es auch Mikroerzählungen, die direkt bei Rhodan an der Front spielen. In diesen Mikroerzählungen erzählen die Autoren jene (die Makroerzählung verändernden) Ereignisse. Ein Beispiel aus demselben Zyklus der Vestibor-Geschichte: In der Geschichte verlaufen zwei Front-Geschichten parallel. Eine spielt bei Rhodan, der sich auf dem Raumschiff von Aachthor befindet, die andere bei Ronald Tekener, ein Mitglied aus der Crew und Figur der II. Peripherie. ${ }^{728}$ Tekener leitet die Evakuierung mehrerer Millionen Galaktiker von den sogenannten „Levels“. „Levels“ sind die Planeten, die Aachthor für sein Projekt genutzt hatte. Dies liegt jedoch bereits mehrere Jahrtausende zurück und die Levels wurden in der Zwischenzeit von Galaktikern besiedelt. Nun will Aachthor sein Projekt beenden und stellt ihnen ein Ultimatum, in dessen Zeitrahmen sie die Planeten verlassen sollen. Diese beiden Erzählstränge sind keine geschlossenen Mikroerzählungen wie die Geschichte Vestibors. Sie sind Ausschnitte aus der Makroerzählung, da sie diese direkt voranbringen: Rhodan bringt mehr über die Pläne Aachthors in Erfahrung und Tekener evakuiert weiterhin Galaktiker. Dieser Zyklus, genannt „Hamamesch“, ist selbst Teil eines Zyklus: „Das große kosmische Rätsel““ ${ }^{729}$

Demnach finden sich in der Perry Rhodan-Serie übergeordnete Zyklen, die sogenannten „Großzyklen“. Innerhalb der Teilzyklen werden zwar große Handlungsstränge abgeschlossen, doch sind diese Teil eines übergeordneten Handlungsstrangs: Der Großzyklus „Das große kosmische Rätsel“ ist in vier Zyklen unterteilt, in denen Rhodan mehrere Rätsel lösen muss, die ihm von der gottähnlichen Super-

727 Da die Rasse der Kospien Zwitterwesen sind, gibt es bei innen keine zugewiesenen Geschlechter.

728 Perry Rhodan Bd. 1794. Plan der Auferstehung. H.G. Francis. 1. Aufl. Pabel-Moewig-Verlag.

729 Schwettmann: Allmächtiger, S. 41. 
intelligenz ES gestellt wurden. Ein Großzyklus bedeutet für die darin zusammengefassten Zyklen, dass sie, nicht wie sonst, eine komplett abgeschlossene Geschichte umfassen. Obschon Perry Rhodan eine endlose Serie ist, werden am Ende eines Zyklus Handlungsstränge zu einem Ende geführt, bis eine neue Bedrohung erscheint und neue Ereignisse sich entfalten können. In den ersten Zyklen gibt es kaum abgeschlossene Mikroerzählungen. Meist sind es nur Intermezzi Rhodans während seines Einsatzes für die Menschheit. Diese sind zudem direkter an der Makroerzählung beteiligt als die heutigen Mikroerzählungen. Aktuell werden größere erzählerische 'Umwege' gemacht, die Handlungsstränge breiter angelegt und Nebenhandlungen füllen ganze Hefte aus, die in den ersten Ausgaben nur absatzweise auftauchten.

Mit dem Beginn eines neuen Zyklus gehen auch häufig Zeitsprünge einher. Zwischen den Zyklen können entweder sieben Jahre oder sogar 695 Jahre vergangen sein. Die Zyklen stellen lediglich Geschichtsabschnitte der Menschheit dar, welche das eigentliche Grundkonzept der Serie ist. ${ }^{730}$ Die Geschichte der Menschheit kann nicht abgebrochen werden. Das Beispiel der Perry Rhodan-Serie zeigt, wie groß eine progressive Serie Fortsetzungsreichweiten ausformen kann.

Die Maddrax-Serie ist ein exzellentes Beispiel für eine Mischform, an der sich beide Aspekte skizzieren lassen: Sie hat eine akkumulierende Episodenstruktur, bei der die Folgen jedoch aufeinander verweisen. Dies geschieht tendenziell in der Form eines Rückgriffs auf bereits geschehene Abenteuer. So werden diese Abenteuer akkumuliert und bilden für die jeweils aktuelle Folge einen Fundus, aus dem geschöpft werden kann. Die meisten Folgen sind in sich abgeschlossen, doch es bleibt ein Verweis auf ein großes Ganzes:

„'War dieses Wesen nun ein Gott oder nicht?', fragte Aruula zweifelnd. 'Und welche Rolle spielte das Pflanzengeschöpf?' 'Ich weiß nur eines: Ein Gott war Oguul keinesfalls', entgegnete Matt. 'Wohl eher ein weiteres Beispiel dafür, dass niemand Gott spielen sollte bei der Erschaffung von Leben.' 'Du denkst, die Daa'muren stecken dahinter?' 'Es wäre zumindest nicht abwegig. Denk an GRÜN. Auch er entstand durch ihre Experimente mit Pflanzen. [...] Egal - sie sind beide vernichtet.' Damit verdrängte er die düsteren Gedanken und atmete die frische Morgenluft ein. Sie klärte seinen Kopf. Auf dieser Erde, die er Stück für Stück neu für sich entdeckte, gehörten Wunder und gestaltgewordene Albträume zum Alltäglichen. ${ }^{\text {"731 }}$

730 Vgl. W. Ernsting an Schwettmann abgedruckt in: Schwettmann: Allmächtiger, S. 65.

731 Madddrax Bd. 290. In den Gärten von Sha'mar. Michael M. Thurner. 1. Aufl. Bastei-Verlag. S. 
Dieses Beispiel zeigt zum einen, wie gegen Ende des Heftes das vorangegangene Abenteuer, also die Mikroerzählung, von den Helden rekapituliert wird, und zum anderen, wie dieses Abenteuer in den Gesamtzusammenhang, die Makroerzählung, des Serienuniversums eingeordnet wird. Sogar das Thema der Serie wird expliziert: „Auf dieser Erde, die er Stück für Stück neu für sich entdeckte, gehörten Wunder und gestaltgewordene Albträume zum Alläglichen. ${ }^{732}$ Damit wird auf andere Abenteuer und Begegnungen verwiesen, wie beispielsweise die „Daa 'muren“ oder "GRÜN“. Im Vergleich zu der Perry Rhodan-Serie, die eine hauptsächlich progressive Struktur aufweist, hat die Maddrax-Serie eine tendenziell akkumulierende Struktur, die progressive Elemente implementiert, wobei die Elemente von der fortschreitenden Handlung gelegentlich erweitert werden.

Horace Newcomb macht eine ähnliche Feststellung an der TV-Serie Magnum: Eine Folge ist zwar narrativ in sich abgeschlossen, doch enthält sie Elemente, die auf vorangegangene Folgen verweisen. ${ }^{733}$ Durch die in sich abgeschlossene Folge haben so einerseits Rezipienten, die nur eine oder wenige Folgen konsumieren, Vergnügen an der Folge, andererseits erfreuen sich erfahrene Serienzuschauer an den zusätzlichen Rückverweisen. Newcomb nennt dieses Phänomen „cumulative narrative." ${ }^{734}$

Solch eine kumulative Narration ermöglicht dem Rezipienten eine Vertrautheit innerhalb des Serienuniversums, da gelegentlich auf Vergangenes und bei erfahrenen Rezipienten somit auch auf Bekanntes zurückgegriffen werden kann. ${ }^{735}$ Die Produzenten einer kumulativen Serie werden allerdings nicht das Risiko eingehen, unerfahrenen Rezipienten eine unzugängliche Serie anzubieten, da die Folgen eine in sich abgeschlossene Mikroerzählung präsentieren. Die Folgen sind trotz akkumulativer Struktur chronologisch hierarchisiert. Nur ist die Makrostruktur hier keine Makroerzählung, sondern ein Thema, das in allen Folgen mehr oder weniger realisiert wird. Im Falle der Maddrax-Serie ist es die Reise der Hauptfiguren durch eine apokalyptische Welt. Die Dr. Laurin-Serie, die als eine reine episodale Serie 64.

732 Ebd.

733 Horace M. Newcomb: Magnum: The Champagne of TV. In: Channels of communication. Mai/Juni (1985), S. 23-26. S. 24.

734 Ebd.

735 Ebd. 
betrachtet werden kann, akkumuliert ihre Folgen nur lose innerhalb ihrer Makrostruktur, da die Folgen nicht aufeinander rekurrieren und sie zudem keine Informationen über die Hauptfigur enthüllen, die folgende Episoden wieder aufnehmen. In dem Laurin-Universum sind die Hauptfiguren so, wie sie erscheinen. Nur selten wird „Eine Sünde aus Dr. Laurins Vergangenheit" aufgedeckt, ${ }^{736}$ die sich jedoch in der Regel als Irrtum herausstellt, da jede Folge dieser Serie im Status Quo enden muss. Die Magnum-Serie (wie die Maddrax-Serie) hingegen verbindet ihre Folgen zusätzlich mit Rückverweisen. ${ }^{737}$

In der Magnum-Serie gibt es allerdings noch Rückblenden aus dem vergangenen Leben der Hauptfigur, die allerdings nicht als (serieller) Rückverweis zu verstehen sind. Diese Rückblenden rekurrieren auf eine noch nicht erzählte Vergangenheit, wobei dieser Fundus potenziell unerschöpflich ist. Eco typologisiert diese Wiederholungsform als eine Unterkategorie der Serie, als eine "Serie mit Schleifenstruktur", ${ }^{738}$ bei der die Serie in die Vergangenheit hinein expandiert. ${ }^{739}$

Reine Episodenserien im Bereich der Romanhefte akkumulieren nicht so nachhaltig wie die Magnum-Serie Informationen über ihre Hauptfiguren: Wenn von Ex-Affären Dr. Laurins gesprochen wird, so sind diese lediglich in dem betreffenden Heft existent. Viele Romanhefte mit ausgeprägter episodaler Serienform haben kein "Seriengedächtnis" und nutzen also nicht die Technik der kumulativen Narration. Das heißt, wenn in diesen Serien neue Facetten, alte Freunde oder verlorene Verwandte der Hauptfiguren auftauchen, dann haben diese Elemente lediglich eine 'Lebensdauer' für die jeweilige Folge, da die Wiederherstellung des Status Quo zum Heftende für sie bindend ist. Andernfalls ist die Konstanz ihres Themas gefährdet. Regelmäßige Serienleser werden in diesem Fall nicht mit vertiefenden Rückverweisen belohnt.

\footnotetext{
736 Dr. Laurin Bd. 130.

737 Betreffs der Magnum-Serie siehe Newcomb: Magnum, S. 24.

738 Eco: Spiegel und andere Phänomene, S. $160 f$.

739 Ebd. und Newcomb: Magnum, S. 25.
} 


\section{Innere Verknüpfung. Oder: Die serielle Narration.}

\subsection{Die drei Phasen - Einführung, Verlauf und Ende}

Der Anfang einer Makroerzählung ist immer der Auftakt zu einer neuen Geschichte im Perry Rhodan-Universum und übernimmt somit eine essentielle Funktion, denn ein guter Anfang einer Geschichte entscheidet darüber, ob weitergelesen wird oder nicht. In dem ersten Perry Rhodan-Heft werden die Helden eingeführt und eine folgenschwere Begegnung löst die Handlung aus (vgl. Kapitel 4.8. „Der Fall 'Perry Rhodan"“ und 7.2 „Mikro- und Makroerzählung“). Diese 'Initialphase' ist eine Exposition und stellt die Hauptfiguren, Ort sowie Zeit der Handlung vor. Es wird nicht nur die Handlung initiiert, sondern auch in die Welt der Erzählung eingeführt. Jörg Türschmann kommt bei einer Untersuchung des Anfangs der Feuilletonroman-Serie Les Mystères de Paris zu folgendem Schluss: „Die Funktion der Initialphase bestimmt sich aus dem Verhältnis zwischen der Werbung für eine serielle Erzählung in periodischer Distribution und den Episoden. “740

Dieses erste Kapitel, oder auch erste Folge, des Feuilletonromans muss einerseits den Charakter der kommenden Folgen widerspiegeln und bewerben, aber andererseits auch gleichzeitig in die Erzählung überleiten. Es wird somit nicht nur die Handlung initiiert, sondern vor allem das Interesse des Lesers geweckt. In dem ersten Heft von Perry Rhodan dient ein Vorwort als Exposition und führt in die Örtlichkeiten sowie die wichtigsten Handlungsmotivationen ein:

„Flammenspeere durchzuckten die Nacht, als die STARDUST inmitten einer Feuersäule abhebt und die Erde hinter sich lässt. Ihr Ziel ist der Mond. Chefpilot und Expeditionsleiter der STARDUST ist ein Major der US Space Force.

Sein Name: PERRY RHODAN!

[...] Die STARDUST landet. Sie könnte nach einer kleinen Reparatur auch wieder starten, wenn nicht...

Ja, wenn nicht auf dem Mond etwas wäre, das die Rückkehr des irdischen Raumschiffes unter allen Umständen verhindern will." ${ }^{741}$

Die Exposition ist zum Teil auch formal in das Textbild eingebaut, denn ein Textblock

740 Türschmann: Spannung in Zeitungsliteratur, S. 232.

741 Perry Rhodan Bd. 1. Unternehmen STARDUST. K.H. Scheer. 4. Aufl. Pabel-Moewig-Verlag. S. 5. 
auf der folgenden Seite, listet die wichtigsten Figuren auf:

„Major Perry Rhodan - Kommandant der STARDUST und Erbe des Universums Captain Reginald Bull - Elektronik Ingenieur der STARDUST $[\ldots]{ }^{k 1742}$

Mit vagen Andeutungen wird auf eine spannende Handlung aufmerksam gemacht, die im Heft nachzulesen sein soll. Wenn der Leser nun auf dieses vage Versprechen von Spannung und einer mysteriösen Macht eingeht, lässt er sich auch auf den Auftakt einer Serie ein, die ihn beim ersten Heft mit einem mehr oder weniger offenen Ende zurücklässt beziehungsweise mit dem Versprechen, dass in den nächsten Heften weitere spannende Abenteuer nachzulesen sein werden. Der Prolog erfüllt insofern das, was Türschmann unter der „inszenierte[n] Diskrepanz zwischen Rahmen und Geschichte “743 versteht, dass er "Werbung für eine serielle Erzählung in periodischer Distribution" macht, die aber nicht vollständig in der jeweils vorliegenden Folge beziehungsweise Heft vorliegt: So wirbt der Prolog für Perry Rhodan als Erben des Universums, doch diesen Aspekt thematisieren die Autoren erst in den Heften darauf.

Allerdings erfolgt in jeder Perry Rhodan-Folge solch eine Einführung in die Haupthandlung. Der Prolog in den ersten Perry Rhodan-Hefte ist noch nicht so umfangreich wie in den aktuellen Bänden und beschränkt sich auf Höhepunkte der vorangegangenen Episoden, um den Ansatz der folgenden Erzählung herzustellen. Dies steigert sich kontinuierlich mit der Zeit und diversen Heften, da der Prolog immer mehr transportieren muss. Aktuelle Perry Rhodan-Hefte versprechen in ihrem Prolog eine Geschichte von epischen Ausmaßen, aber im Heft bekommt der Leser nur einen winzigen Teil zu lesen. So bewirbt der Prolog in jedem Heft lediglich die Makroerzählung und verweist nur am Rande auf den eigentlichen Teil, der in der vorliegenden Folge zu lesen sein wird:

„[...]

Wenn die Bewohner der Galaxis aber eine Chance gegen TRAITOR haben wollen, müssen die Terraner unter Perry Rhodans Führung mächtige Instrumente entwickeln. Aus diesem Grund wird auf Terra fieberhaft geforscht. Wissenschaftler arbeiten unter höchster Geheimhaltung an neuen Technologien - dazu zählt auch die mysteriöse Einrichtung namens ESCHER. Alles scheint sich zu verändern, als ein neues Objekt auftaucht: ES KAM AUS

742 Ebd. S. 6.

743 Türschmann: Spannung in Zeitungsliteratur, S. 232. 


\section{DER SONNE..."744}

Der Prolog verweist also auf vorangegangene Geschehnisse und versucht die einzelne Episode in den Gesamtzusammenhang der Serie einzubetten. Die Handlung der Mikroerzählung ist (gegebenenfalls) abgeschlossen, aber die Makroerzählung nie. Es gibt somit einen Unterschied zwischen dem versprochenen Erzählrahmen und der Erzählung in den jeweiligen Folgen.

Die Diskrepanz zwischen den regelmäßig versprochenen Andeutungen im Prolog und der eigentlich erzählten Geschichte kann auch als Spannungsträger für die Distribution der ganzen Serie gesehen werden. Der Prolog gibt jeder Folge einen Ausblick auf einen viel weiteren Rahmen, der über das einzelne Heft hinausgeht und somit auf die anderen Episoden indirekt verweist: Um alles zu erfahren, was die Autoren in den Prologen andeuten, zum Beispiel die "Einrichtung namens ESCHER", die in einem Prolog nur erwähnt wird, im Roman selbst aber nicht vorkommt, muss der Leser weitere Hefte konsumieren.

Bei beiden Serien Les Mystères de Paris und Perry Rhodan spannen die Autoren einen Rahmen um die eigentliche Erzählung. In der von Türschmann gewählten Serie erzeugt den Rahmen ein die Geschichte kommentierender Autor ${ }^{745}$, bei Perry Rhodan ist der gewählte Rahmen ein von der eigentlichen Handlungsebene getrennter Prolog, welcher nur die wichtigsten Elemente der Geschichte hervorhebt.

Auf diese Weise haben die Expositionen beider Serien letztendlich dieselbe Funktion: Sie wollen die Aufmerksamkeit des Lesers auf bestimmte Aspekte lenken und ihn anleiten, wie er die gesamte Serie wahrzunehmen hat. In der Serie von Sue soll der Leser auf die Fremdartigkeit und die Exotik des Pariser Alltags achten, die in der Serie allein von der Unterwelt hervorgebracht wird. Bei Perry Rhodan soll sich der Leser zunächst auf eine unbekannte Macht im Hintergrund fixieren.

Der regelmäßige Prolog der Perry Rhodan-Serie gleicht dem aus dem TV-Bereich bekanntem „was bisher geschah...“ (oder auch „previously on...") und verfolgt nach Meteling den Zweck „einer auf die wichtigsten Daten beschränkten Inhaltsangabe, die den Wieder-, oder eben sogar: Erst-Einstieg ermöglicht“746. Gemäß Türschmann

744 Perry Rhodan Bd. 2380.

745 Türschmann: Spannung in Zeitungsliteratur, S. 232ff.

746 Arno Meteling, Isabell Otto, Gabriele Schabacher: „Previously on...“ In: 'Previously on ...' Zur Ästhetik der Zeitlichkeit neuerer TV-Serien. Hrsg. von Arno Meteling, Isabell Otto und Gabriele Schabacher. München 2010, S. 7-16. S. 8. 
hat die Serie „bei jeder Folge mit der Initiierung des Lesers in die Lektüre zu kämpfen" ${ }^{477}$. Indem aber jedes Perry Rhodan-Heft grob in die Handlung einführt und für den weiteren Verlauf wirbt, steht eine beständige Einführung für neue Leser bereit.

Ähnlich verhält es sich bei der Maddrax-Romanheftserie, die ebenso wie Perry Rhodan einen fortlaufenden Erzählstrang hat. Zu Anfang der Erzählung erfolgt ein kurzer Prolog, der für die spannende Handlung wirbt, worauf zwei Seiten später ein längerer Prolog die Handlung des Heftes in den Gesamtzusammenhang einordnet. Bei Serien ohne übergreifenden Handlungsstrang, wie zum Beispiel Jerry Cotton, bleibt es bei einer werbenden Funktion, da in keine komplexe Handlung eingeführt werden muss:

„William wusste nicht, wie er hierhergekommen war. Wahrscheinlich hatte er gestern Abend wieder mal zu viel getrunken. Verwundert starrte er hinauf zu dem altmodischen Kronleuchter an der Decke über seinem Bett. [...] Lancaster fühlte sich merkwürdig unwohl. Wahrscheinlich lag das an dem vielen Whiskey in seinem Magen. An seinem Gesicht spürte er einen warmen Atem. Er wandte den Kopf." ${ }^{478}$

Der Textabschnitt hat keine weitere Funktion, als eine spannende Szene mittels eines Cliffhangers zu initiieren. Bei Liebesromanheften-Serien wie Dr. Laurin oder Dr. Norden findet sich beispielsweise gar kein Prolog in den Heften. Bei Westernreihen wie Arizona oder Wild West Roman vom Kelter-Verlag sind ebenfalls keine Prologe vorhanden. Die Handlung in solchen Serien beziehungsweise Reihen ist auch ohne einführenden Prolog nachvollziehbar, somit besteht hier kein Risiko, dass der Leser aufgrund von Verständnisschwierigkeiten abspringt. Wenn ein Prolog in den Romanheftserien und -reihen ohne übergreifenden Handlungsstrang vorhanden ist, dann nur als anregende Einführung wie im obigen Jerry Cotton-Beispiel.

Wie bereits erwähnt hat das erste Heft noch eine andere wichtige Funktion, die dem Auftakt der Serie zukommt: „Die spektakuläre Anfangsepisode“"749. Das erste Perry Rhodan-Heft ist die grundlegende Initiierung in die Perry Rhodan-Serie. Auch hier lässt sich auf Türschmann verweisen:

747 Türschmann: Spannung in Zeitungsliteratur, S. 235. Er bezieht diese Aussage allerdings nur auf den Feuilletonroman.

748 G-man Jerry Cotton Bd. 2691. Doppeltes Spiel. 1. Aufl. Bastei-Verlag.

749 Türschmann: Spannung in Zeitungsliteratur, S. 234. 
„Das erfolgreiche Ansprechen des Leser ist also das Ergebnis der eindringlichen Wirkung der ersten Romanfolgen und gleicht der des Pilotfilms einer Fernsehserie."

Die Perry Rhodan-Autoren wählten einen Ausgangspunkt, der damals noch in naher Zukunft lag. Das erste Heft fing mit der ersten Mondlandung an, als in der realen Welt noch niemand den Mond betreten hatte. Für Science Fiction-Leser ist es ein potenziell reizvoller Aspekt, wenn eine Science Fiction-Geschichte mit einem Ereignis beginnt, dessen Umsetzung in der Realität in erreichbarer Zukunft möglich und somit für den Leser greifbarer erscheint. Auf dem Mond trifft Rhodan Außerirdische, die Arkoniden, welche zu seinen Verbündeten werden. Aus dieser Begegnung resultieren nicht nur weitere Abenteuer, sondern ein fester Figurenstamm und eine technische Überlegenheit des Helden, die ihn zu einer Art Superheld werden lässt, somit sind die wichtigsten Figuren und ihre Motivationen eingeführt. Innerhalb des ersten Heftes änderte sich aber auch das Versprechen an potenzielle Leser: Die Geschichte begann mit der Option für Abenteuer auf dem Mond und endete schließlich weit davon entfernt und eröffnete dem Leser Abenteuer in der ganzen Galaxis. Mit der Überbietung der eigentlichen Erwartung wurde inm gleichzeitig das Potenzial der Serie vor Augen geführt beziehungsweise wurde er für die distributive Struktur der Erzählung angeworben. Auf diese Weise trägt die erste Perry RhodanFolge auch alle Grundzüge der nachfolgenden, denn sie steht stellvertretend für die gesamte Serie. In der ersten Folge zeigt jede Figur zum ersten Mal ihre Charaktereigenschaften, die in allen weiteren Folgen immer wieder von Bedeutung sein werden: Perry Rhodan, der Sofortumschalter und Reginald Bull, der Polterer (Vgl. Kapitel 6. „Halbwertszeit von Serienfiguren“). Aber genauso müssen immer bedeutendere Wendungen für die Menschheit enthüllt werden. Das ist das eigentliche Versprechen, das dem Leser gegeben wird: Alle nachfolgenden Hefte werden genauso sein wie das erste. Genauso spektakulär, spannend, furios, actionreich oder besonders und immer ein wenig mehr von dem, was erwartet wurde.

Da Perry Rhodan eine sehr umfangreiche Serie ist, werden die unterschiedlichen Makroerzählungen in Zyklen unterteilt, somit gibt es für jeden neuen Zyklus auch

750 Ebd. S. 235. 
eine eigene Initialphase: Ein Heft, in dem der Auftakt zu dem neuen Zyklus initiiert wird. Dieses Heft steht ganz in seiner Funktion als Initial-Heft: In der Regel hat es doppelt so viele Seiten wie das Standard-Heft, es gibt farblich abgesetzte Textblöcke, die explizit darauf hinweisen, dass ein besonderes Heft vorliegt: Band 100 „Der Zielstern - Eine neue Epoche der Weltraumfahrt bricht an..."751, Band 1300 „Erweiterter Romanumfang, Weltcon-Poster und großer Einstiegsteil“752, Band 2400 „Zyklusstart: 'Negasphäre' Doppelter Umfang“753 oder Band 2600 „Neuroversum - eine neue Ära beginnt!“754. Die werbenden Überschriften deuten bereits an, dass „eine neue Ära beginnt“ und für die Menschheit im Perry Rhodan-Universum, die am Ende des vorangegangen Zyklus zu Ruhe gekommen ist, entscheidende Ereignisse bevorstehen:

„In der Milchstraße schreibt man das Jahr 1469 Neuer Galaktischer Zeitrechnung - das entspricht dem Jahr 5056 christlicher Zeitrechnung. Der furchtbare, aber kurze Krieg gegen die Frequenz-Monarchie liegt inzwischen sechs Jahre zurück. Die Bewohner der Erde erholen sich langsam von den traumatischen Ereignissen. [...] Doch längst lauert eine ganz andere Gefahr, von der die Bewohner der Milchstraße bislang nichts ahnen können. Sie hat etwas mit kosmischen Entwicklungen zu tun, hat aber auch ganz direkte Auswirkungen auf die Erde - und auf Perry Rhodan selbst. Denn jetzt startet DAS THANATOS-PROGRAMM..."755

Die Einführung des Lesers in das Perry Rhodan-Universum ist ein Formelement, das direkten Einfluss auf den Text nimmt. Wie in den Prolog-Beispielen zu sehen war, haben diese Textabschnitte einen explizit werbenden Charakter. Es werden in den progressiven Serien Informationen gegeben, die sich hauptsächlich auf die Makroerzählung beziehen und weniger auf die folgende Mikroerzählung. So verweist der Prolog bei innen auf einen größeren Rahmen und dadurch indirekt auf eine distributive Struktur. Dies lässt vermuten, dass die periodisch distributive Struktur bei progressiven Serien die serielle Narration dominiert.

Serien und Reihen ohne progressive Struktur haben schlichtweg nicht das Problem, dass sie in jeder Folge den Leser in eine komplexe Handlung einführen müssen, da sie keine Folgen übergreifenden Handlungsstränge besitzen: Sie sind ohne Vorwissen in sich verständlich, daher können sie auch auf eine Initiierung per Prolog

$751 \quad$ K.H. Scheer. 3. Aufl. Pabel-Moewig-Verlag.

752 Die Gänger des Netzes. Kurt Mahr und Ernst Vlcek. 1. Aufl. Pabel-Moewig-Verlag.

753 Robert Feldhoff. 1. Aufl. Pabel-Moewig-Verlag.

754 Uwe Anton. 1. Aufl. Pabel-Moewig-Verlag.

755 Ebd. 
verzichten.

Episodentitel und Titelbild der meisten Romanhefte geben Lesern bereits einen ersten Eindruck dessen, was sie in den Heften erwartet. ${ }^{756}$ Beispielsweise zeigt des Frontcover von Band 166 der (nicht progressiven) Serie Der Bergpfarrer eine junge Frau und einen jungen Mann in Trachtenkleidung vor einer Alpenlandschaft. Episodentitel ist „Keine Angst vor der Liebe! Es wird sich alles fügen..." (vgl. Abb. 5). Auf diese Weise werden dem Leser für die in dem Heft enthaltene Handlung alle wichtigen Informationen signalisiert: Es geht um eine Liebesbeziehung in einer idyllischen Berggegend.

Das Versprechen, das dem Leser gegeben wurde, wird mehr oder weniger in den nachfolgenden Episoden eingelöst. Dies könnte man als die 'Verlaufsphase' bezeichnen. Wenn das, was in der vorigen Phase initiiert wurde, nicht zum Tragen kommt, laufen die Autoren Gefahr, mit den Erwartungen der Leser zu brechen. Bei Sue sind das die dunkelsten Geheimnisse der Unterwelt von Paris und bei Perry Rhodan das Schicksal der Menschheit in der Zukunft. In dem ersten Heft wurde der Aufstieg der Menschheit in den Weltraum versprochen, diesen Weg dorthin muss jedes folgende Heft erfüllen.

In den Romanheftserien und -reihen ohne übergreifenden Handlungsstrang beschränkt sich das Versprechen in erster Linie auf die Einhaltung der jeweiligen Romanheftgenre-Konventionen: Beispielsweise führt der zuvor zitierte Prolog der Jerry Cotton-Serie in eine potenziell spannende Szene ein, die dem Bereich der Kriminalromanhefte entspricht. ${ }^{757}$ Sofern sich das Heft also auch insgesamt mit den Konventionen seines Romanheftgenres deckt, eine abgeschlossene ThrillerGeschichte zu erzählen, erfüllt es bereits innerhalb des Heftes sein Versprechen an den Leser. Die Verlaufsphase bei Romanheftserien und -reihen ohne fortschreitenden Handlungsstrang ist demnach auf das jeweilige Heft beschränkt und gleichzeitig mit jedem neuen Heft wieder aktiv. ${ }^{758}$ Das erste Heft ist hinsichtlich dem Verhältnis von Versprechen und Erfüllung mit jedem darauf folgendem Heft identisch. ${ }^{759}$

756 Vgl. hierzu auch Kapitel 2. „Distribution und Erscheinungsbild“.

757 Vgl. hierzu Kapitel 4.4 „Der Krimi ist 'Jerry Cotton'“. Die aktuellen Jerry Cotton-Geschichten entsprechen eher den Thrillern aus dem TV-Bereich.

758 Doppelfolgen stellen seltene Ausnahmen dar.

759 Dies steht und fällt in der Praxis, inwiefern das Heft den jeweiligen RomanheftgenreKonventionen entspricht. 
Bei progressiven Serien ist das Verhältnis von Versprechen und Erfüllung pro Folge unterschiedlich. Als Vertreter der Romanheftserien mit übergreifenden Handlungssträngen soll die Perry Rhodan-Serie eingehender untersucht werden: Bei den progressiven Serien zeigt sich die zuvor erwähnte Diskrepanz von versprochener Erzählung und der eigentlichen Erzählung. Die Erzählung, die folgt, beschäftigt sich nicht eingehend mit der Zukunft der Menschheit, sondern immer mit einem konkreten Abenteuer. Die Zukunft der Menschheit ist vielmehr ein Leitmotiv in den einzelnen Folgen, das angestrebt beziehungsweise von dem nur ein Aspekt dargeboten wird. Das bedeutet für die einzelne Erzählung, dass ihre Handlung immer von dem Leitmotiv abgeleitet ist. Das Leitmotiv ist nicht mit der Makroerzählung zu verwechseln, denn es ist vielmehr die Quintessenz der Perry Rhodan-Serie und nicht ihr Erzählrahmen. Zum Vergleich ein Prolog-Beispiel:

„Wenige Tage nach dem tragischen Tod seiner geliebten Frau legt Perry Rhodan, der solare Administrator, den Plan vor, mit einem Blitzangriff der gesamten terranischen Raumflotte das arkonidische Positronengehirn auszuschalten, das sich trotz immer noch bestehender Druuf-Gefahr als Terras Hauptgegner erweist. [...] Doch der Angriffsbefehl läßt auf sich warten, denn der Stützpunkt selbst, auf dem die wichtigsten Männer des Solaren Imperiums weilen, wird zur ATOMHÖLLE..."760

Der Prolog umreißt kurz die Makroerzählung über den Krieg der Menschen gegen das Positronengehirn und fokussiert am Schluss, worum es in dem folgenden Heft gehen wird. Hierbei skizziert der Prolog, in welchen politischen Verhältnissen die Menschheit sich befindet, und gibt auch einen Ausblick darauf, dass die folgende Handlung unmittelbaren Einfluss auf das Leitmotiv, also das Schicksal der Menschheit in der Zukunft, hat. Aber die eigentliche Handlung in Band 79 beschäftigt sich damit, wie Perry Rhodan und sein Gefolge einem Atomangriff ausweichen. Dieses Abenteuer hat zunächst keinen direkten Bezug zu der Zukunft der Menschheit. Ähnliches findet sich auch in dem Prolog-Beispiel weiter oben aus Band 2380 „Es kam aus der Sonne“. Es wird berichtet, wie die Menschheit sich gegen einen übermächtigen Feind verteidigen könnte und dass sie schon an diversen Technologien forscht. Dieser Handlungsstrang wird jedoch durch das Auftauchen eines fremden Objektes zwischenzeitlich unterbrochen, damit wird zum einen der Fortlauf der Makroerzählung herausgezögert und zum anderen kommt nur indirekt das Leitmotiv

760 Perry Rhodan Bd. 79. Die Atomhölle von Gray Beast. Kurt Mahr. 4. Aufl. Pabel-Moewig-Verlag. 
zum Tragen, denn die Abenteuer der Figuren haben in der Regel auch Auswirkungen auf die gesamte Menschheit. Das Leitmotiv durchzieht Makro- wie Mikroerzählung. Nur ist es in der Mikroerzählung nicht unbedingt so präsent wie in Handlungssträngen, die die Makroerzählung voranbringen. Allerdings ist die Mikroerzählung immer auf das Leitmotiv zurückzuführen, da es die generelle Erzählmotivation ist.

Ebenso wie über den Handlungsverlauf ein Versprechen abgegeben wurde, wurde eins für die Figuren abgegeben: Deshalb mussten die Autoren die Figur Perry Rhodan als Führungsperson immer weiter formelhaft ausbauen (vgl. hierzu Kapitel 6. „Halbwertszeit von Serienfiguren“) ebenso die Figur Reginald Bull als Rhodans zweiten Mann. Die Hauptfiguren sind Elemente, die die Handlung voranbringen, da Perry Rhodan-Geschichten aktionistisch und spannungsorientiert sind. Ihre Abenteuer und Schicksale sind verknüpft mit dem der Menschheit. Von daher ist es auch schwierig für die Produzenten der Perry Rhodan-Serie, Hauptfiguren aus der Geschichte herauszunehmen: Einmal in die Serie eingeführt, erweitern sie das Perry Rhodan-Universum, das mit jedem Heft weiter expandiert. Sie treiben die Handlung voran und in der Handlung wird das Leitmotiv "Das Schicksal der Menschheit in der Zukunft" realisiert, welches in der ersten Folge seine Initiierung erfuhr.

Die Perry Rhodan-Serie ist zwar noch nicht abgeschlossen und wird es in absehbarer Zeit auch nicht sein, aber es gibt dennoch einzelne partielle Abschlüsse. Jeder Zyklus bringt eine Makroerzählung zum Abschluss. Es werden dort Handlungsstränge und Spannungskurven beendet. Dies kann in einer Folge geschehen oder über mehrere verteilt sein, daher lässt sich hier von einer 'Abschlussphase' sprechen. Für den allerersten Zyklus ist das letzte Heft, Band 99, die komplette Abschlussphase, denn in inm wird der Aufbau des "Solaren Imperiums" mehr oder weniger fertiggestellt und eine der Hauptfiguren scheidet dauerhaft aus. Es gibt jedoch keinen abrupten Abbruch oder ein langwieriges Ausklingen der Handlung, da jede Folge ein sich beständiges Entwickeln der Gesamtsituation war. In Band 99 heißt es:

„Perry Rhodan und seine Getreuen haben seit den Tagen der 'Dritten Macht', die nach vielen Konflikten die politische Einigung der irdischen Menschen herbeiführte, einen langen und harten Weg zurückgelegt. [...] Weil sie auch in größter Not nicht resignierten oder aufgaben, sondern nach Auswegen suchten, schafften sie es, das Solare Imperium der Menschheit zu erhalten 
und sogar auszuweiten." ${ }^{761}$

In dem Band wird abschließend auf die vorherigen 98 Folgen zurückgeblickt. Mit dem Tod einer Hauptfigur „beginnt gleichzeitig eine neue Epoche in der zukünftigen Menschheitsgeschichte." ${ }^{762}$ Dies ist lediglich der Verweis auf den Beginn des nächsten Zyklus.

Da Perry Rhodan so viele Handlungsstränge innerhalb eines Zyklus fortführt, lösten die Autoren mehrere Hefte vor dem endgültigen Abschluss des Zyklus Konflikte diverser Handlungsstränge auf. Die meisten Zyklen sind bei Perry Rhodan nach 99 Heften beendet. Um den umfangreichen Konflikt der Galaktiker gegen Traitor und die sogenannte Terminale Kolonne zu beenden, werden bereits acht Folgen vor dem Zyklusende Auflösungen in Aussicht gestellt:

„Mit dem PERRY RHODAN-Roman der nächsten Woche blendet die Handlung um - hin zu einer Aktion, die langfristig eben dem Ziel dienen soll, TRAITOR zurückzuschlagen.“763

Damit folgen die Autoren der Romanhefte einer Strategie, die Türschmann bereits für die Feuilletonromane aufdeckt:

„Um das Interesse der Leser wachzuhalten, ist auch dessen Erwartungen einer abgeschlossenen Erzählhandlung zu respektieren. Dieser Abschluss erfolgt zwar nicht immer, muss aber in Aussicht gestellt werden."764

Aus diesem Grunde wählte beispielsweise der Feuilletonautor Frédéderic Soulié meist ein offenes Ende für seine Geschichten, um „das Interesse des Lesers nicht durch einen abrupten Abfall der Handlung zu lähmen, sondern weiter zu lenken beziehungsweise langsam ausklingen zu lassen. "765

Bei episodalen Serien und Reihen wird hingegen kein Ende der Narration vorbereitet: Das letzte Heft unterscheidet sich in seiner Erzählweise nicht von den vorangegangenen. Bei beiden Serienformen bietet sich daher die Möglichkeit, sie ohne hohen Planungsaufwand endlos fortzuführen ${ }^{766}$ oder kurzfristig jederzeit zu beenden.

761 Perry Rhodan Bd. 99. Prolog.

762 Ebd. S. 64.

763 Perry Rhodan Bd. 2391. Die Schwarze Zeit. Wim Vandemaan. 1. Aufl. Pabel-Moewig-Verlag. S. 60.

764 Türschmann: Spannung in Zeitungsliteratur, S. 233.

765 Margarethe Tanguy Baum: Der Historische Roman im Frankreich der Julimonarchie. Frankfurt a.M. 1981. S. 88.

766 Sofern die Hauptfigur nicht in der ursprünglich geplanten letzten Folge verstarb. 


\subsection{Erste Bestimmung serieller Regelmäßigkeiten}

In Kapitel 2. „Distribution und Erscheinungsbild“ und in Kapitel 3 „Produktion“ wurde die äußere Erscheinungsform und Entstehung der Romanhefte untersucht, um darzustellen, in welchem Publikationsrhythmus sowie welcher Publikationsform Romanheftserien wie Perry Rhodan erscheinen. Bei der Konzeption der Perry Rhodan-Serie flossen Elemente anderer Gattungen ein, wie zum Beispiel das Exotische eines Reise- und Abenteuerromans (vgl. Kapitel 4.8 „Der Fall 'Perry Rhodan'“). Eine Formelhaftigkeit der Figurenbeschreibungen unterstützt die Raffung der Erzählgeschwindigkeit. Inwiefern dies besonders bei Fortsetzungsserien mit umfangreichen Handlungssträngen notwendig ist, vertieft Kapitel 5. „Erzählökonomie und Serieninsider".

Hierbei wurde aber noch nicht geklärt, ob und welche inhaltlichen Regelmäßigkeiten es gibt. Melzer hat den Schematismus der Trivialliteratur in sechs „Elementarsätze“ zusammengefasst, welche die Autoren von ihrem Verlag vorgelegt bekamen ${ }^{767}$ : Erstens soll der Roman gleich zu Anfang Spannung aufbauen; beispielsweise mittels Dialoge. Zweitens soll darauf folgend in das soziale Umfeld der Hauptpersonen eingeführt und dann zum zweiten Handlungsschwerpunkt übergeleitet werden. Drittens sollen dramatische Höhepunkte mit „emotionalen Auflösungen“ wechseln. Viertens sollen stereotype Helden, denen kontrastierende Gegenspieler entgegengesetzt werden können, zu finden sein. Fünftens soll das Handlungspanorama sich durch den gesamten Text hindurchziehen und nicht konzentriert abgehandelt werden. Sechstens darf das Finale des Textes nicht vorab angedeutet werden. ${ }^{768}$

Da in progressiv erzählenden Romanheftserien wie Perry Rhodan der Text häufig aktionsorientiert ist, bietet es sich an, mit Dialogen und 'action' zu beginnen; ausführlich berichtende Anfänge bilden hier eine Ausnahme. Jedoch kann dem zweiten Elementarsatz weder widersprochen noch zugestimmt werden, da es jedem Autoren überlassen ist, ob er ausführlich in das soziale Umfeld der Hauptfigur einführt. Allerdings kann dem widersprochen werden, dass sich eine feste Regelmäßigkeit hierzu

767 Helmut Melzer: Trivialliteratur I Forschungsproblematik - Didaktik - Textanalyse. 3. erw. Aufl. München 1978. (Analysen zur deutschen Sprache und Literatur), S. 15ff.

768 Vgl. ebd. S. 16f. 
bei Perry Rhodan ausmachen ließe.

Die dramatischen Höhepunkte gemäß des dritten Punktes sind bei Perry Rhodan Situationen, in denen die Hauptfiguren vor außergewöhnlichen Situationen stehen oder außergewöhnliche Entdeckungen machen; emotionale Höhepunkte sind hingegen selten. Ähnlich ergeht es auch den Figuren in Maddrax oder Professor Zamorra. Der vierte Punkt der stereotypen Helden/Figuren entspricht dem der Raffung der Figurenbeschreibungen (vgl. Kapitel 5. „Erzählökonomie und Serienvokabeln“).

Das Handlungspanorama von progressiv erzählenden Serien wie Perry Rhodan erstreckt sich, im Hinblick auf Melzers fünften Punkt, nicht nur über den ganzen Text eines Heftes, sondern oft über bis zu 50 Hefte, wenn man das Handlungspanorama als eine Makroerzählung annimmt. Da es sich bei Perry Rhodan um eine potenziell endlose Serie handelt und somit wahrscheinlich ist, dass das Ende innerhalb des Textes niemals angedeutet wird, ist der sechste und letzte Punkt wesentlich komplexer. Wenn man bei einem Perry Rhodan-Heft das Heft-Ende mit dem Schluss einer Geschichte gleichsetzen will, dann enden die meisten Hefte offen, betrachtet man aber in diesem Fall ein Zyklusende als vorläufiges Ende, so ist es eher ein ausklingendes Ende und nicht abrupt ohne überraschende Wendung.

Ausgeprägt episodal erzählende Romanheftreihen, als Gegenpol zu den progressiv erzählenden Serie, tendieren hingegen stärker zu dem von Melzer beschriebenen Schema. So beginnt beispielsweise Band 731 „Ich küsse deine Tränen fort“ aus der Fürsten-Roman-Reihe mit einem Autounfall, der die Hauptfiguren im Verlauf der Handlung zusammenbringt:

„Eine Detonation ließ sie zusammenfahren. Entsetzt sahen [sie], wie der Wagen zu brennen begann. Glück für den Ohnmächtigen, dass sie rechtzeitig zu Stelle gewesen waren. Sonst..." ${ }^{\text {"69 }}$

Im Anschluss des Unfalles werden die sich sorgenden Eltern des verletzten Prinzen eingeführt. In die Textpassage streut die Autorin sogleich weitere Infos zur Hauptfigur ein:

„Die Nachricht vom Autounfall ihres einzigen Sohnes Fabian hatte das Fürstenpaar wie ein Schock getroffen. Ihr Chauffeur Hans Klinger hatte sie sogleich in die Klinik gefahren [...]." ${ }^{\text {"70 }}$

769 Fürsten-Roman Bd. 731. Ich küsse deine Tränen fort. Bianca-Maria. 1. Aufl. Bastei-Verlag, S. 5. 770 Ebd. S. 6. 
Auf diese Weise führt die Autorin dem Leser sogleich das soziale Umfeld der Hauptpersonen vor: Der Prinz ist ein Einzelkind. Die Eltern haben offensichtlich eine emotionale Bindung zu ihrem Sohn und die Familie ist gut betucht, da sie sich einen eignen Chauffeur leisten können. Aus der Begegnung am Unfallort zwischen der weiblichen und der männlichen Hauptfigur entwickelt sich eine Liebesbeziehung, die gemäß des dritten Punktes nach Melzer beide in wechselnde „dramatische Höhepunkte" verwickelt. Die Hauptfigur Corinna muss sich den eifersüchtigen Anfeindungen und offensiven Annäherungen ihres Arbeitskollegen stellen:

„'Aus dir spricht die pure Eifersucht. Dabei hast du nicht einmal ein Recht dazu. Wir sind kein Paar.'

'Das liegt leider nicht an mir', konterte er. Er zog den Wagen scharf um die Kurve. 'Ich liebe dich, ich bin verrückt nach dir. Wir beide wären das ideale Paar, aber du willst ja nicht."'771

Ebenfalls finden sich auch die gerafften Figurenbeschreibungen. So wird in diesem Fall die Mutter des Prinzen mit dem Attribut „schön“ typisiert:

„Trotz ihrer fünfundfünfzig Jahre war sie noch immer eine schöne Frau mit brünettem Haar und tiefbraunen Augen [...]."772 Und:

„Auch heute noch war er verliebt wie damals, als inm die schöne Gräfin von Sythen begegnete [...]."

Das Handlungspanorama erstreckt sich in den Heften der Fürsten-Roman-Reihe über eine Episode beziehungsweise Heft und das Finale wird ebenso bis zum Eintreten nicht angedeutet. Dies ist kein Phänomen, das nur beim Liebesromanheft auftritt, sondern sich auch in den anderen Romanheftgenres wiederfindet. Beispielsweise unterhält sich die Hauptfigur Ty Shannon in dem Westernromanheft „Und jeder bring den Tod" ${ }^{\text {"774 }}$ gleich zu Beginn mit der zweiten Hauptfigur Judy Mahoun, die inm berichtet, wie sie in einer Art Zwangsehe missbraucht wird. Daraus entwickelt sich innerhalb des Heftes die Handlung, wie Ty Shannon Judy von ihrem Peiniger befreit und er die Aufgabe erst im letzten Absatz beendet, als Ty Shannon seinen Widersacher erschießt:

771 Ebd. S. 21.

772 Ebd. S. 8.

773 Ebd. S. 8.

774 G.F. Unger - Seine grössten Western-Erfolge Bd. 1584. 
„Er [Tys Gegner; Anm. d. A.] sieht, wie sich die beiden Mündungsfeuer zu einem einzigen vereinen. Und die beiden Ladungen Indianerschrot lassen inm keine Chance." 775

Aufgrund der einschlägig episodalen Erzählweise, wird die komplette Handlung innerhalb eines Heftes abgeschlossen. Mittels geraffter Figurenbeschreibungen sowie Hinweise auf die Lebensumstände der Hauptfiguren zeichnet der Autor seinen Lesern ein kompaktes Bild der relevanten Figuren.

Besonders die Handhabung des „Handlungspanoramas“ unterscheidet sich zwischen den progressiven Serien und den episodalen Reihen, da es innerhalb der Reihen keine Makroerzählung gibt, lediglich ein Thema als Makrostruktur (vgl. auch Kapitel 7.2 „Mikro- und Makroerzählung“). Ebenso lässt sich Melzers Punkt der wechselnden dramatischen Höhepunkte nicht 1:1 auf progressive Serien übertragen. Lediglich in den Aspekten zu den Hauptfiguren wie Raffung und soziale Hintergründe gibt es Übereinstimmungen in episodalen wie progressiven seriellen Romanheftnarrationen.

Um Regelmäßigkeiten innerhalb der Serie auszumachen, bedarf es allerdings weiterer Betrachtungen: Es ist auffällig, dass die Figuren-Gruppe um Rhodan durch äußere Umstände aufgeteilt wird und jedes Mitglied sein eigenes Abenteuer erlebt. Das Autoren-Team bereitet unterschiedlichen Handlungsstränge vor, die durch die Ursprungssituation miteinander verbunden werden, womit unterschiedliche Abenteuer an unterschiedlichen Schauplätzen möglich sind. Das auslösende Moment für die Aufteilung der Crew ist in der Regel ein fremdes kosmisches Phänomen. Dieses kann ein Angriff einer fremden Lebensform oder eine sonderbare Strahlung sein. Hierbei werden die Figuren nicht von einander separiert, sondern in der Regel in Paare oder kleinen Grüppchen aufgeteilt. Im ersten Zyklus der Serie hat das auslösende Moment die Crew noch zusammen mit Rhodan getroffen und sie nicht sofort voneinander getrennt. Die Trennungen der Helden finden im ersten Zyklus meist nur vereinzelt statt und beschränken sich auf die Länge eines einzelnen Heftes, worauf sie im nächsten Heft in der Regel wieder vereint sind. Aus diesem Grunde gibt es zu Anfang der Serie - anders als in späteren Zyklen ab ungefähr Band 1000 - kaum unterschiedliche Schauplätze, zwischen denen hin und her gesprungen werden 
muss. Durch die Einführung Atlans entstand jedoch ein zweiter Schwerpunkt neben Rhodan, der es ermöglichte, eine parallele Handlungsführung zu etablieren. Nachdem sich der Kern der idealisierten Helden herauskristallisiert hatte, konnten auch deren Abenteuer längere Handlungsstränge erhalten. Nachdem William Voltz die Gründungsautoren als Exposé-Autoren ablöste, ${ }^{776}$ stellte sich eine Regelmäßigkeit in der Aufteilung der Figuren ein. Serien wie Professor Zamorra oder John Sinclair, die ebenfalls ein großes Figuren-Repertoire besitzen, arbeiten mit ähnlichen Erzählweisen, nur in der Regel auf ein Heft beschränkt.

Im 26. Zyklus „Die Hamamesch“ sind beispielsweise Millionen Galaktiker süchtig nach der Droge „Imprint“. Sie beginnen danach zu suchen beziehungsweise werden von einer unbekannten Kraft angelockt und verschwinden. Rhodan macht sich auf die Suche nach ihnen, wobei er in die Gewalt Aachthors gerät, während Tekener versucht, die Galaktiker zu evakuieren (näheres hierzu unter anderem in Kapitel 6. „Halbwertszeit von Serienfiguren“ sowie 7.2 „Mikro- und Makroerzählung“, der Zyklus umfasst die Bände 1750 bis 1799). In dem 34. Zyklus „TERRANOVA“ (der Zyklus beginnt bei Band 2300 und geht bis 2399) besetzt eine fremde Macht mehrere Planeten und Rhodan baut eine Verteidigungsfront gegen die sogenannten Chaosmächte auf, wodurch er in eines ihrer Raumschiffe gelangt. Dort löst er entscheidende Rätsel, ebenso wie er sie auf dem Raumschiff des Wesens Aachthors lösen musste, und unterdessen leitet Bull alleine die Verteidigung des Sol-Systems. Rhodan dringt also immer zu den gefährlichsten und mächtigsten Gegnern vor, ist in Situationen, die nur er lösen kann, während seine Gehilfen diverse Schlachten weiterführen. Diese Ausgangssituation gilt für einen Zyklus, aber nicht für das einzelne Heft, da sie sich über alle Hefte erstreckt und nicht in jedem Heft expliziert wird. Inwiefern eine Folge die Ausgangssituation explizit thematisiert ist davon abhängig, wie geballt der Redakteur den Lesern weitere Infos um Perry Rhodan und somit auch vom Haupthandlungsstrang zukommen lassen möchte.

Die Regelmäßigkeit in der die Ausgangssituation thematisiert wird liegt im Ermessen des Exposé-Autors, aber nicht bei den ausformulierten Geschichten der Romanheftautoren. Die einzelnen Hefte sind hinsichtlich ihrer inhaltlichen Struktur sowie teilweise ihres Sprachstils sehr verschieden, da von den jeweiligen einzelnen Heften

776 Vgl. u.a. Nagula: Perry Rhodan. Die Chronik. Bd. 1, S.108f. 
die Innovation ausgeht. In ihnen geht es nicht immer explizit darum, wie die Gruppe separiert wird und Rhodan anschließend die Welt rettet, sondern es geht stückchenweise zu jeder Etappe: Von vornherein werden nicht zwei Handlungsschauplätze eröffnet, sondern es wird ein Phänomen eingeführt, das letztendlich dazu führt, dass sich die Gruppe aufteilt. Die darauffolgenden Hefte zeigen zwar nicht unbedingt die Tendenz dahin, dass Rhodan verschwindet - sei er entführt oder beim Feind eingeschmuggelt, jedoch führen die Mikroerzählungen schlussendlich zu dem Teil, der für die Makroerzählung relevant ist, dass Rhodan beispielsweise auf das Schiff Aachthors gelangt. In der Maddrax-Serie ist es beispielsweise innerhalb der ersten Hefte die Suche der Hauptfigur Matthew Drax nach seinen Freunden.

Das einzelne Heft der progressiven Serien leidet also nicht unter einem Schematazwang, was den Handlungsablauf betrifft. Nach Prugger sind einzelne Folgen einer Serie meist einem Thema gewidmet, demgemäß wird in einer Krimiserie beispielsweise Sterbehilfe und ihre Strafbarkeit thematisiert und in einer Arztfolge Drogenmissbrauch. ${ }^{777}$ Aber dies geschieht laut Prugger in der Regel bei „Episodenserien“, 778 Serien, deren einzelne Folgen abgeschlossene Geschichten mit einem festen Figureninventar darstellen. In "finalen“ und „offenen Serien“779 ist dies nach Prugger nur selten zu finden und die Handlungsstränge werden erst am Abschluss der kompletten Serie aufgelöst. Die Perry Rhodan-Serie hingegen bedient sich einer Mischtechnik beider Vorgehensweisen: Die Serie an sich ist potenziell endlos, aber jeder Zyklus stellt einen Abschluss eines größeren Handlungsabschnitts dar. Dieser ist vergleichbar mit dem auflösenden Ende einer „finalen“ Serie, bei der am Schluss sämtliche Handlungsstränge zu Ende erzählt werden.

Auf der Ebene der Makroerzählung sind die einzelnen Folgen offen und eröffnen zuweilen neue Handlungsstränge, allerdings führen die Autoren einige Handlungsstränge auch innerhalb weniger Hefte zu einem Ende. Dies entspricht den Mikroerzählungen, die über eine Folge oder mehr eine kurze Geschichte berichten. Die Mikroerzählung hat zwar Anteil an der Makroerzählung, kann aber für sich abgeschlossen werden. Die Mikroerzählung lässt sich als eine Thema-Folge wie die einer Episodenserie betrachten, in der, einem Intermezzo ähnlich, kurz von einer Randfigur

777 Prisca Prugger: Wiederholung, Variation, Alltagsnähe. In: Endlose Geschichten. Hrsg. von Günter Giesenfeld. Hildesheim 1994, S. 90-113. S. $104 f$.

778 Ebd.

779 Ebd. S. 105. 
und ihren Problemen erzählt wird. Trotzdem ist es nicht die Primärfunktion des Heftes innovativ zu sein, dies kommt an zweiter Stelle, denn an erster ist das Heft immer Teil des Ganzen. Mikroerzählungen machen das einzelne Heft nicht zu einem unabhängigen Werk, da sie lediglich unabhängige Qualitäten innerhalb der Serie darstellen, die unter anderem dazu beitragen, dem Leser das Gefühl zu geben, dass nicht alle Handlungsstränge ins Endlose laufen, sondern einige auch abgeschlossen werden. Mikroerzählungen finden meist ihren Ursprung in der Makroerzählung und können deshalb nur selten als unabhängige Erzählungen fungieren. Alle Umstände, die in einer Mikroerzählung verwendet werden, entspringen der langwierigen Entwicklung der Serie.

Ein Beispiel aus einer progressiven Serie: Der Perry Rhodan-Band 2385 „Im Mesoport-Netz“ enthält die (Mikro-)Erzählung, wie das Sonnensystem der Telomon aus ihrem Universum in das Perry Rhodan bekannte Universum versetzt wird. Dies verursachte der sogenannte „Hyperschock“, als die „Kosmokraten“ die „Hyperimpedanz" erhöhten, was wiederum auf der (Makro-)Erzählung des 34. Zyklus „Sternenozean“ beruht. ${ }^{780}$ Das Schicksal der Telomon wäre demnach nicht ohne die Erhöhung der „Hyperimpedanz“ zu erzählen, aber die Erzählung vom Kampf Rhodans gegen die Chaosmächte wäre durchaus auch ohne die der Telomon erzählbar. Eine Mikroerzählung, wie die der Telomon, ist einer jener Handlungsstränge, welcher in den Silberbänden zugunsten einer strafferen Handlungsführung herausgekürzt werden würde. Aber dadurch, dass die Mikroerzählungen ihre Wurzeln in den Zyklen haben, schwingt latent mit, dass sie nur ein kleiner Teil des großen Ganzen sind. Neue Probleme und Aufgaben tauchen für Rhodan und die Galaktiker auf, aber diese haben in der Regel einen Bezug zu älteren Begebenheiten. Hierin zeigt sich das beständige Fortschreiten der Serie. Jede Aktion erzwingt eine Reaktion, hat Folgen, sodass dem Leser immer wieder neue Entwicklungen vorgeführt werden, die gegebenenfalls sein Interesse auf kommende Ereignisse wecken.

Ähnliche Mischtechniken finden sich auch in den anderen progressiven Serien, nur sind sie nicht ganz so stark durchmischt. Beispielsweise beginnt und endet in der Maddrax-Serie eine Mikroerzählung pro Heft. Jede Folge ist eine Etappe (Mikroerzählung) auf dem Weg der Hauptfigur Matthew Drax, seine Freunde wiederzu-

780 Perry Rhodan Band 2200 bis 2299. 
finden (Makroerzählung): So muss er sich in Band 3 Wettkämpfen in einem Kolosseum stellen, um Hinweise zu erhalten, dass er weiter im Norden suchen muss, wo er sich in Band 4 mit einem Stamm Affenmenschen auseinandersetzt.

Bei Serien mit stark ausgeprägter episodaler Erzählweise wie Jerry Cotton finden sich hingegen durchaus Folgen mit einem einschlägigen Themenschwerpunkt wie beispielsweise Computer-Hacker (vgl. Band 2803 „Datenströme können tödlich sein“) oder illegal gehandelte Medikamente (vgl. Band 2805 „Potent wie der Tod“). Da die episodale Serie keine Makroerzählung hat, wird keinerlei Handlungsstrang in die nächste Folge übernommen, der dort weitergeführt werden müsste. Durch den auf eine Folge beschränkten Erzählrahmen der episodalen Serien ist es somit leichter, Themen-Folgen nach Prugger in den Folgenablauf zu integrieren.

Jede neue Folge der progressiven Serien enthält Ereignisse, die Folgen nach sich ziehen. Auf diese Weise sind die Folgen miteinander verzahnt, und es wird nicht, wie in rein episodalen Serien, der Status Quo angestrebt, dass der Held am Ende jeder Folge wieder am Anfang steht. Nach Hickethier ist die Folge einer episodischen Serie $^{781}$ nach folgendem Schema aufgebaut:

$<$ Harmonie $>$ < Störung der Harmonie $><$ Wiederherstellung der Harmonie $>782$

Dieses Schema ist zwar für TV-Serien wie Bonanza zugeschnitten, hat aber auch Gültigkeit für Serien außerhalb des TV-Bereichs. Übertragen auf eine progressiv erzählende Serie wie Perry Rhodan, ergibt sich folgendes stark vereinfachtes Schema für mehrere Folgen eines Zyklus:

Folgen der Initialphase:

$<$ Harmonie der Makrostruktur-A> <Harmonie der Mikrostruktur-B> <Störung der Harmonien $\mathrm{A}+\mathrm{B}><$ Wiederherstellung der Harmonie $\mathrm{B}>$

Folgen der Verlaufsphase:

<Harmonie der Mikrostruktur-C> <Störung der Harmonie C> <Harmonie A weiterhin gestört $><$ Wiederherstellung der Harmonie $\mathrm{C}>$

Folgen der Abschlussphase:

781 Knut Hickethier: Die Fernsehserie und das Serielle des Programms. In: Endlose Geschichten. Hrsg. von Günter Giesenfeld. Hildesheim 1994, S. 55-71. S. 60.

782 Ebd. 
<Harmonie der Mikrostruktur-Z> <Störung der Harmonie Z> $<$ Wiederherstellung der Harmonien Z + A >

Da die Autoren mikrostrukturelle Handlungsstränge bei Perry Rhodan jedoch nicht immer innerhalb einer Folge auflösen, bestehen einige Folgen komplett aus $<$ Störungen der Harmonien> ohne <Wiederherstellung irgendeiner Harmonie>. Wenn nun in der Perry Rhodan-Serie jede Folge aber einen weiteren Aspekt des Gesamtkonzeptes preisgibt, erfolgt somit auch in jeder Folge eine <teilweise Wiederherstellung der makrostrukturellen Harmonie>.

Zudem stellt sich die Frage, was das stets Wiederkehrende, das Serielle in den jeweiligen Folgen ist: Auf der Ebene des Plots lassen sich in Serien zunächst keine vordergründigen Regelmäßigkeiten ausmachen, doch auf der Ebene der Figuren durchaus. Nach Prugger baut der Serienkonsument eine Beziehung zu den Serienhelden auf. ${ }^{783}$ Dies geschieht in der Regel bei „Endlosserien“, die über einen längeren Zeitraum hinweg produziert werden. ${ }^{784}$ Prugger bezieht sich hierbei auf ein Vertrauen des Konsumenten, das sich entwickelt, wenn die Intentionen der Serienfigur für ihn berechenbar werden. Der Konsument kann einschätzen, was der Held tun beziehungsweise nicht tun würde, ${ }^{785}$ dergestalt werden die Figuren Perry Rhodan, John Sinclair, Matthew Drax oder Professor Zamorra nach Jahren zu 'guten Bekannten' einer festen Leserschaft.

Die Hefte sollen stets Interesse wecken, das heißt, dass sie jede Woche eine neue Absonderlichkeit präsentieren müssen, weshalb die Autoren ihre Figuren in jedem Heft mit einer fantastischen Begebenheit konfrontieren, die sich auch auf das folgende Heft bezieht, die Situation wird also nicht komplett aufgelöst. Die Figur handelt in der Situation gemäß ihrer Exposévorgaben, in der ihr Charakter festgelegt wurde. Hierzu ein Beispiel: In Band 2380 „Es kam aus der Sonne“ taucht ein fremdes Objekt aus der Sonne des Solsystems auf. Rhodan und seine Leute erfahren, dass es ein Dunkler Ermittler, eines der gefährlichsten Raumschiffe ihres Gegners, ist. Dieses Raumschiff gibt innen Rätsel auf und aufgrund Rhodans Kombinationsgabe

783 Prisca Prugger: Wiederholung, Variation, Altagsnähe, S. $102 f$.

784 Ebd.

785 Ebd. 
gelangt er zusammen mit dem Roboter Nuskoginus sowie Gucky an Bord des Raumschiffes. Dies ist auch der Moment, der Rhodan von der Gruppe separiert, an dieser Stelle endet das Heft und erst das nächste nimmt den Erzählfaden wieder auf. Allerdings kann es auch passieren, dass die Autoren den Erzählstrang nicht sofort wieder aufnehmen, sondern gegebenenfalls erst ein paar Hefte später.

In dem darauffolgenden Heft sieht sich Rhodan mit der ungewöhnlichen Konstruktion des Schiffes konfrontiert. Hierbei stellt er Vermutungen über die Eigenschaften des rätselhaften Schiffes an, welche sich später teilweise bestätigen, jedoch nicht vollständig, da dies erst in einem späteren Heft geschieht und sich so immer weiter daran anknüpfen lässt. Nach Knut Hickethier soll damit eine Ambivalenz zwischen dem Einzelteil und der Einflechtung desselben in das größere Ganze bewahrt bleiben. Das innovative Moment einer einzelnen Folge steht somit dem Gesamtkonzept der Serie gegenüber. Beides soll in jeder einzelnen Folge in Einklang gebracht werden und zwar so, dass es konstante und neu hinzutretende Erzählmomente gibt: Bekannte Schemata und die Variation dieser Schemata. ${ }^{786}$

Hickethier schreibt, dass Serien „immer auch Ketten von Zeiteinheiten“ sind. ${ }^{787}$ Auf diese Weise zwingt die serielle Narration dem Leser einen „Leserhythmus“788 auf, da sich ihm innerhalb dieser Zeiteinheiten bestimmte "Spannungspunkte“ in einer bestimmten Häufigkeit anbieten. Löst die Serie gewisse Handlungsknoten nicht in der erwarteten Zeit auf, befriedigt sie nicht den Leser. Das hieße, wenn beispielsweise eine Mikroerzählung über eine Figur der III. Peripherie nicht aufgelöst wird oder eine gewisse Anzahl an Heften (zehn oder mehr) übersteigt, dann läuft die Serie Gefahr, das Leseverhältnis zu stören.

Durch das Aufzwingen eines Leserhythmus ist es möglich, Rezeptionsgewohnheiten bei Konsumenten aufzubauen. Der Ablauf einer Perry Rhodan-Folge lässt sich folgendermaßen zu einer möglichen Rezeptionserwartung zusammenfassen: 1. Die Figur wird mit einer außergewöhnlichen Situation konfrontiert. 2. Die Figur verhält sich dabei nach ihren typischen Eigenschaften. Beispiel: Gucky macht einen Witz, Reginald Bull poltert, Rhodan schaltet sofort und hat einen Überblick (siehe Kapitel 6. „Halbwertszeit von Serienfiguren“). Auf diese Weise entsteht eine Kombination aus

786 Hickethier: Die Fernsehserie und das Serielle des Programms, S. 58f.

787 Hickethier: Die Fernsehserie und das Serielle des Fernsehens, S. 13.

788 Ebd. 
Unerwartetem und dem Leser bekannten 'Mustern'. 3. Das Heft endet offen mit einem Spannungsumbruch, auch Cliffhanger genannt.

Dieses Konzept, welches seit den ersten Heften Verwendung findet, ist eine „periodische Neuinszenierung “789, die jede Woche ein Perry Rhodan-Heft durchläuft und scheinbar etwas Neues bietet. Die Wiederholung liegt auf der Ebene serieninterner Regelmäßigkeiten, die zu einem großen Anteil durch die Figuren hergestellt werden, während auf der Plotebene die Erzählung beständig voranschreitet.

Es soll einerseits die Nachfrage der Leser befriedigen und sich andererseits „regenerieren“, also neugierig machen. ${ }^{790}$ Mit der seriellen Erzählform geht ein „Versprechen des Forterzählens der Geschichte"791 einher, ebenso das Wiedererscheinen der vorgestellten Figuren, die den Leser durch die Geschichte begleitet haben, also ist „ein Versprechen damit auch [verbunden], teilhaben zu dürfen an diesen anderen Erlebniswelten, in denen sich die Figuren mit ihren Abenteuern bewegen."792

\subsection{Das Kalkül von Konstanz und Variation}

Wenn Franz K. Stanzel in „Theorie des Erzählens“793 auf eine Dynamisierung und Schematisierung bei längeren Erzähltexten aufmerksam macht ${ }^{794}$, dann meint er im Prinzip nichts anderes als Variation und Konstanz. Die Dynamisierung ist eine Variation des Erzählstiles während eines Erzählvorgangs. ${ }^{795}$ Sie dient dazu, die Übermittlung der Erzählung an den Leser zu beleben ${ }^{796}$, da eine zu konsequente Fortführung eines einheitlichen Erzählstils den Leser ermüden könnte. Dem scheinbar widersprüchlich gegenübergestellt gibt es ebenso in längeren Narrationen die Tendenz zur Schematisierung beziehungsweise zu Konstanten, denn bestimmte Erzähltechniken werden innerhalb eines langen Erzählvorgangs repetiert und können so eine Konstante bilden.

Stanzel bezieht dies bei umfassenden Einzelwerken auf eine Erschöpfung des

789 Peter Bekes: Kommunikative Texttheorie - Kybernetische Modelle zur Beschreibung von Trivialliteratur. Regensburg 1976. (Hochschulschriften Literaturwissenschaft 12). S. $325 f$.

790 Ebd.

791 Hickethier: Die Fernsehserie und das Serielle des Fernsehens. S. 30.

792 Ebd.

793 Franz K. Stanzel: Theorie des Erzählens. 5. unveränderte Aufl. Göttingen 1991.

794 Vgl. Ebd. S. 89ff.

795 Ebd.

796 Ebd. S. 107. 
Autors, der nicht bis zum Ende konsequent das „Erzählprofil“ aufrechterhalten könne. ${ }^{797}$ Dies findet aber seine Entsprechung bei dem Leser, der sich nicht "die ganze Zeit über im Zustand des Betroffenseins über die Fragwürdigkeit oder Banalität seines eigenen Bezugsfeldes befindet“. ${ }^{798}$ Hieraus ergebe sich laut Stanzel bei längeren Narrationen notgedrungen ein Wechsel von Schematisierung und Dynamisierung oder (wie Winkler es beschreibt) ein „Kalkül aus Konstanz und Variation“. ${ }^{799}$ Winkler geht es allerdings um "nicht-mechanische Serialität", die Produzenten bewusst als eine "Strategie“ bei Serien einsetzen. ${ }^{800}$

Damit eine serielle Narration durch zu massive Konstanz für den Leser nicht langweilig gerät, muss die Narration entsprechend 'dynamisiert' werden. Dies ist jedoch nur in einem gewissen Maße möglich, da die Narration sonst für den Leser unübersichtlich wird. Eine zu dynamische Narration, also eine Erzählung, die beständig in all ihren narrativen Aspekten variiert, wie beispielsweise mehrere verschiedene progressive Erzählstränge mit je wechselnden Hauptfiguren und ohne Stützen für den Leser, wie zum Beispiel inhaltliche Rückverweise oder redundante geraffte Figurendarstellungen, wäre nur schwer über längeren Zeitraum überschaubar. Dynamisierung und Konstanz müssen sich die Waage halten.

Stanzel spricht von einer „Abflachung des Erzählprofils“ zum Ende einer längeren Narration hin. ${ }^{801}$ Die serielle Narration kann, wenn man davon ausgeht, dass die einzelnen Folgen in gewisser Weise narratologisch miteinander verknüpft sind, als längere Narration aufgefasst werden. Demnach entspräche die „Abflachung des Erzählprofils“ in den Romanheften der zurückgenommenen Position der Erzählinstanz, ${ }^{802}$ nur mit dem Unterschied, dass diese Abflachung nicht zum Ende innerhalb eines Heftes stattfindet, sondern permanent realisiert ist. Die Hefte sind, so gesehen, wie das Ende eines langen Romans konzipiert. Die einzelnen Folgen weisen zum

797 Ebd. S. $103 f$.

798 Ebd. S. 108.

799 Winkler: Technische Reproduktion und Serialität, S. 44.

800 Ebd. S. 44.

801 Stanzel: Theorie des Erzählens, S. 107.

802 Der Erzähler tritt bei abgeflachten Erzählprofilen als solcher in der Regel nicht zutage und wird nicht Teil der Erzählung (vgl. u.a. Martinez und Scheffel: Einführung in die Erzähltheorie, S. 67f.). In den meisten Heften findet sich eine interne Fokalisierung (gemäß der Definition von Genette in ebd. S.63f.): Der Leser begleitet die Figuren durch die Handlung und erfährt genauso viel wie sie. Allerdings nutzen nicht selten einige Liebesromane die Nullfokalisierung, also einen Erzähler, der mehr weiß als die Figuren, um den Lesern das mögliche Happy End anzudeuten. Nach Stanzel wäre das der sogenannte auktoriale Erzähler (vgl. Franz K. Stanzel: Typische Formen des Romans. 2. durchge. Aufl. Göttingen 1965. S. 18f.). 
einen die gleichen Erzählstrategien auf, zum anderen sollen sie aber auch das Interesse des Lesers aufrechterhalten. Eine längere Lektüre kann die Dauer eines kompletten Heftes sowie mehrere Hefte meinen.

Dass die Romanhefte tendenziell den Leser nicht überanstrengen, deckt sich mit Stanzels Frage „des Verhältnisses zwischen dem Roman der hohen Literatur und dem Trivialroman". ${ }^{803}$ Doch müssen die Romanhefte nicht als literarische Narration, sondern als serielle Narration beurteilt werden: Vermeintlich stereotypisierte Figurenbeschreibungen sind daher als geraffte Beschreibungen anzusehen, die einen komplexen Plot auf nur wenigen Seiten (64 Seiten) ermöglichen (vgl. Kapitel 5.1 „Erzählökonomie“). Die Verwendung etablierter Figurenkonstellationen helfen dem Leser ohne Vorkenntnisse Figuren sofort einzuordnen. Besonders bei tendenziell episodalen Serien, wie zum Beispiel den meisten Liebes- und Westernromanen, finden sich häufig wiederkehrende Figurenkonstellationen (vgl. Kapitel 4.2 „Der Frauenroman ist ein Liebesroman“ sowie Kapitel 4.3 „Der Western“) und geraffte Figurenbeschreibungen.

Die Dynamisierung erfolgt hier lediglich über den Plot. In beiden Romanheftgenres, Liebes- und Wildwestroman, herrschen tendenziell akkumulierende Serien und Reihen vor. Da diese Serien ihre Folgen nicht über Handlungsstränge miteinander verknüpfen - wie dies die Regel bei einer längeren Narration wäre -, müssen sie über andere Elemente ihr Folgen verknüpfen. Bei den Reihen geschieht dies nur noch lose über das Genre und den Autor. Serien mit starker Tendenz zur episodalen Struktur verknüpfen ihre Folgen über eine titelgebende Hauptfigur. Doch nicht nur die Verknüpfungselemente dienen hier zur Wahrung einer Konstanz, sondern auch die Redundanz der Erzählweise. Dies gibt den Lesern eine Konstante in der Art und Weise, wie sie die Romane zu lesen haben: Auf der Ebene der Figuren gibt es hierfür die gerafften Beschreibungen und in der Dramaturgie lässt sich stets eine ähnliche Figurenkonstellation ausmachen (vgl. Kapitel 4.2 „Der Frauenroman ist ein Liebesroman“ und Kapitel 4.3 „Der Western“). Diese Form der Redundanz zielt auf die Lesegewohnheiten der Rezipienten ab und kann somit als eine „geschulte“ Redundanz gesehen werden. ${ }^{804}$ Sie lässt sich hauptsächlich bei den akkumulierenden

803 Stanzel: Theorie des Erzählens, S. 107.

804 Der Aspekt eines Produktes dass seinen Nutzer „schult“, wird in Kapitel 9. „Das serielle Produkt als Massenkunstwerk" vertieft. 
Serien finden. Doch wird sich im Folgenden zeigen, dass es noch weitere Formen der eingewöhnten Rezeption gibt.

Die Wahl der Serienform, tendenziell episodal oder tendenziell progressiv, beeinflusst den narrativen Inhalt der Hefte, inwiefern das Figureninventar gehandhabt wird (vgl. Kapitel 6. „Halbwertszeit von Serienfiguren“), wie Spannungsbögen im Plot gesetzt werden (vgl. Kapitel 7. „Narrativer Rahmen der seriellen Narration“) und sogar in welcher Weise bestimmte Formulierungen im Text erscheinen (vgl. Kapitel 5.2 „Serieninsider“). Darüber hinaus lassen sich bei stark episodalen Serien, in denen das Figureninventar weniger konstant ist als in progressiven Serien und es zudem keine Verknüpfung über fortgesetzte Handlungsstränge gibt, eine standardisierte Aufmachung in der Cover-Gestaltung ausmachen (vgl. Kapitel 2. „Distribution und Erscheinungsbild“). Hingegen ist bei den progressiven Serien die Cover-Gestaltung wesentlich variabler.

Da stark episodale Serien und Reihen kaum über vordergründige Konstanten im Inhalt verknüpft sind, muss dies die äußere Form übernehmen und akzentuieren. Die nicht gleich offensichtlichen Kontinuitäten dieser Hefte, wie beispielsweise durch regelmäßiges Lesen der Serie trainierte Rezeptionserwartungen (vgl. Kapitel 8.2 „Erste Bestimmung serieller Regelmäßigkeiten“), werden von unaufmerksamen Lesern nur unbewusst wahrgenommen (vgl. Kapitel 8.4 „Redundanzen während der Rezeption“), wohl aber werden sie die Aufmachung bewusst wahrnehmen und wiedererkennen. Hier zeigt sich, dass Kontinuität und Varianz sowohl auf der formalen als auch auf der inhaltlichen Ebene zum Tragen kommen. Wenn inhaltliche Elemente, wie beispielsweise die Figuren und der Plot, variabel werden, dann müssen sich formale Elemente, wie beispielsweise die Cover-Gestaltung, verfestigen. Dies gilt allerdings auch für die inhaltliche Ebene: Wenn der Plot, wie bei Perry Rhodan, progressiv ist, verfestigt sich auch zusehends das Figureninventar. Würde hingegen ein großer Teil des Figureninventars variieren, oder sogar komplett ausgetauscht werden, muss der Inhalt Kontinuität bieten. Das Kalkül aus Konstanz und Variation ist bei den Romanheften unterschiedlich ausgewogen realisiert, denn einige Reihen neigen zu einem hohen Grad an Konstanz, während einige Fortsetzungsserien stark variieren (sowohl in der Covergestaltung, als auch im 
Figureninventar; beispielsweise die Sternenfaust-Serie).

In einer tendenziell progressiven Serie (wie beispielsweise Maddrax) gibt es ebenfalls durchgehende Hauptfiguren, die zu einem gewissen Grad stereotypisiert sind, jedoch nur innerhalb der Serie. Wie weiter oben ausgeführt, akkumuliert diese Serie zwar diverse Abenteuer, doch wird immer wieder auf andere Abenteuer und Gegner verwiesen. Auf diese Weise schaffen Redundanzen von Informationen in der Maddrax-Serie eine Konstanz, die sich mit der Variation der Figurenkonstellationen und den unterschiedlichen Plots die Waage halten muss. Die Folgen sind zwar nicht immer durch einen Cliffhanger verbunden, dennoch sind sie von der Makrostruktur nicht nur geklammert, sondern auch hierarchisiert. Die Redundanzen dienen den Lesern als Einführung und Erinnerung. Würden diese Wiederholungen als Erinnerung nicht erfolgen, könnte die progressiv serielle Narration für den Leser unübersichtlich geraten.

Dies muss jedoch nicht per Rückverweis oder Rückgriff auf Schemata erfolgen. Über eine Andeutung lässt sich die Aufmerksamkeit des Lesers gezielt vorbereiten. Hieraus ergeben sich unterschiedliche Typen von Redundanzen, die im Folgenden untersucht werden sollen: Redundanzen in der Rezeption, Wiederholung als Erinnerung und die Vorankündigung.

\subsection{Redundanzen während der Rezeption}

Dem Leser wird im Bereich der progressiven Fortsetzungsserien regelmäßig von bereits erfolgten Ereignissen berichtet. Doch im Bereich der reinen episodalen Serien wie beispielsweise Dr. Laurin oder G.F. Unger wird vordergründig kein Ereignis repetiert. Die Redundanz ist bei innen tiefer in der Struktur ihrer Narrationsform verankert. Dies meint beispielsweise die aus dem Bereich der Liebesromane bekannte Dreieckskonstellation oder die Verwendung geraffter Figurendarstellungen. Der Leser der episodalen Serien erfährt eine Redundanz der Dramaturgie, die inn vermutlich nicht langweilen wird, sondern, nach Eco, unterhält, „weil sie scheinbar seine prognostischen Fähigkeiten prämiiert: er ist glücklich, weil er entdeckt, daß er voraussagen kann, was geschehen wird, und weil er den Eintritt des Erwarteten 
genießt."805

Die Redundanzen der Rezeption umfassen in der seriellen Narration noch weitere Aspekte: Winkler schreibt, dass Fernsehserien eine besondere Nähe zum Fernsehen haben, weil sie eine bestimmte Art von Redundanz des Alltages imitieren. ${ }^{806}$ Mit dieser Redundanz ist die Alltäglichkeit an sich gemeint, dass jeden Tag das Gleiche passiert und jedes Mal etwas variiert. Diese Redundanz bewertet Winkler durchaus positiv und setzt sie einer mechanischen Redundanz entgegen, einer absoluten Wiederholung, die "schwer zu ertragen ist“. ${ }^{807}$ Es geht bei dieser positiven Redundanz um die Wiederholung bestimmter Abläufe im Altag. Die Serie wiederholt nicht Abläufe des alltäglichen Lebens, sie übernimmt lediglich den Aspekt, regelmäßig im Leben der Konsumenten zu erscheinen und selbst gewisse Regelmäßigkeiten vorzuführen. Aber dabei darf die Serie nicht vollständig redundant sein, sie darf nur die Grenze kurz davor berühren. ${ }^{808}$

Der Leser widmet sich wiederholt der Lektüre einer bestimmten Serie, jedoch wird inm dabei jedes Mal von einem neuen Ereignis aus dem Serien-Universum seiner Wahl erzählt. Narratologisch bezeichnet entspricht dies der „Frequenz“: „Ein einmaliges Ereignis wird einmal oder wiederholt erzählt, ein wiederholtes Ereignis wird wiederholt oder einmal erzählt." ${ }^{809}$ Martinez und Scheffel leiten hiervon drei Typen von Wiederholungsbeziehungen ab. Die für den Bereich der Romanhefte interessanteste ist die „singuläre Erzählung“: Ein Ereignis wird einmal erzählt. Jedoch kann es mehrere Ereignisse geben, so ergibt sich: Es wird n-mal erzählt, was sich nmal zutrug. ${ }^{810}$ Dies wäre die Wiederholung innerhalb eines Textes. Wenn man nun, vorerst behelfsmäßig, eine Serie als einen „Text“ sieht, so lässt sich untersuchen, inwiefern sich innerhalb dieses „Textes“ die Frequenz der Narration verhält. Hierbei ist zu beobachten, dass nahezu alle Serienformen der Romanhefte singuläre Erzählungen beinhalten, die ihre geradlinigen Handlungen ebenso geradlinig weiterführen. Diese Handlung beschränkt sich entweder nur auf ein Heft oder ist über mehrere Hefte gespannt. Vordergründig ist zunächst der repetitive Anlass für eine Narration,

805 Eco: Spiegel und andere Phänomene, S. 160.

806 Hartmut Winkler: Technische Reproduktion und Serialität, S. 45.

807 Ebd. S. 44f.

808 Ebd.

809 Martinez und Scheffel: Einführung in die Erzähltheorie, S. $45 \mathrm{f}$.

810 Ebd. S. 45. 
daher gibt es alle zwei Wochen einen neuen Anlass für die Maddrax-Serie, den "Text“ (also die Serie) zu erweitern (um eine weitere Folge). Diese Narrations-Frequenz ist durch ihr Medium getaktet. Ähnlich einer TV-Serie zu einem bestimmten Datum: Einmal die Woche oder alle 14 Tage. An einem bestimmten Ort: TV-Sender beziehungsweise Kiosk.

Dies ist jedoch nicht nach Genette zu sehen, denn innerhalb der Serien wird das wiederholte Erscheinen in der realen Welt nicht als Wiederholung wahrgenommen. Die repetitive Aufnahme der Narration wird nicht thematisiert. Es kann lediglich als narrativ repetitiv festgehalten werden, dass die Helden wiederholt zum Einsatz kommen und wiederholt neue Abenteuer bestehen müssen. Für episodale Serien und Reihen lässt sich dies ohne Probleme feststellen, bei Serien mit ausgeprägter Fortsetzungsstruktur jedoch gibt es Konflikte, daher wird es in der Perry RhodanSerie schwierig, eindeutig festzustellen, wann das eine Abenteuer abgeschlossen ist und wann ein neues beginnt. Dies lässt sich in dieser Serie nur durch die Mikro- und Makroerzählung klar darstellen. Der Abschluss einer Makroerzählung ist in der Perry Rhodan-Serie ein eindeutiger Abschluss eines großen Abenteuers. Die einzelnen Folgen stellen somit dar, wie immer wieder in diversen Versatzstücken die Makroerzählung abgeschlossen werden soll. Auf diese Weise nehmen die Autoren in der Perry Rhodan-Serie repetitiv die Narration auf, um diverse Schauplätze des gleichen Abenteuers darzustellen. So gesehen wird hier auch jedes Mal das Abenteuer vorangebracht, jedoch, da die Serie komplex ist, lassen sich hierfür immer unterschiedliche Helden nutzen. Auf diese Weise kommt es zu diversen parallelen Handlungssträngen, die jene diversen Schauplätze ermöglichen.

Es gibt, wie bereits erwähnt, in den Romanheftserien keine explizit erzählte Wiederholung eines Ereignisses, sondern primär die Wiederholung des Erzählaktes an sich. Doch was ist der immer wiederkehrende Aspekt des Erzählens? Bei Serien mit ausgeprägtem Fortsetzungscharakter verlangen die nicht zu Ende erzählten Handlungsstränge eine Wiederaufnahme des Erzählaktes. Doch was ist mit Serien, die eine ausgeprägte episodale Struktur haben? Warum wird in der Dr. Laurin- oder Jerry Cotton-Serie jede Woche auf ein Neues die Narration wiederaufgenommen? Für Dr. Laurin, und ebenso für die anderen Arzt-Serien, ist es ein neuer Patient, der nicht nur 
physische Leiden hat, sondern auch Probleme im Liebesleben:

„Sie bekommen wieder mal eine illustre Patientin, Frau Jana Imhof.“811

Für den Ermittler Jerry Cotton ist ein weiterer Fall die Berechtigung der fortwährenden Narration:

"Ich habe Sie und Phil bereits angemeldet, Jerry. Wir übernehmen die Ermittlungen [...].' formulierte unser Chef gleich darauf unseren neuen Auftrag." ${ }^{12}$

Ähnliche Gründe lassen sich für die anderen episodalen Serien ebenso finden. Bei den episodalen Serien gibt es kaum eine Veranlagung für ein Seriengedächtnis. Das bedeutet, dass die Begebenheiten aus den vorangegangenen Episoden für die jeweils aktuelle Episode nicht relevant sind. So kommt es, dass die wichtigen Serienfiguren sich fast nie an vorherige Fälle oder Patienten erinnern. Wenn sie sich doch erinnern, dann ist es in der Regel eine inszenierte Erinnerung, der keine Episode aus dem jeweiligen Serienuniversum zugrunde liegt.

Die John Sinclair-Serie ist eine der wenigen Serien, die ein ausgeprägtes Seriengedächtnis bei episodaler Struktur hat. Die Fortsetzungsserien müssen aufgrund ihrer Natur immer ein Seriengedächtnis haben, da sie sonst inkonsistent werden. Die zyklische Aufnahme der Narration schlägt sich jedoch nicht im Text als ein Zyklus nieder. Da die meisten episodalen Serien ohnehin kein Seriengedächtnis haben, ist dieser Aspekt für sie weniger von Relevanz. Bei den Fortsetzungsserien wäre dieser Aspekt allerdings durchaus relevant, denn die Autoren könnten die Zeitspanne, die in der realen Welt verrinnt, bis das nächste Heft erscheint, für ihre Narration instrumentalisieren, indem sie beispielsweise wirklich exakt eine Woche in dem Serienuniversum wie in der realen Welt verstreichen lassen, was jedoch nicht geschieht. Überhaupt wird selten der Verlauf von Zeiträumen explizit thematisiert, sofern es nicht um Zeitreisen geht, ${ }^{813}$ daher kann zwischen zwei Folgen eine Woche oder ein Jahr vergangen sein. Auf die Konsistenz der Serie hat es kaum Einfluss. ${ }^{814}$ Somit ergibt

811 Dr. Laurin Bd. 30, S. 3.

812 G-men Jerry Cotton Bd. 2804. Weiße Weste - schmutzige Hände. 1. Aufl. Bastei-Verlag. S. 4.

813 Hier wäre der theoretische Ansatz der biographischen Ellipse die Türschmann erwähnt (vgl. Türschmann: Aspekte einer Typologie von Fernsehserien, S. 101f.). Doch außerhalb des Erzähltextes gibt es im Figureninventar der Romanhefte keine Veränderungen, somit wäre die biographische Ellipse hier vorerst nicht relevant.

814 Es hat lediglich Einfluss, wenn der Zeitsprung innerhalb der Serie zu groß wird. So gab es beispielsweise in der Perry Rhodan-Serie zwischen den Zyklen "M 87" und "Die Cappins" einen 
sich für die Fortsetzungsserien der Romanhefte, dass in ihnen jede neue Folge irgendwo in dem fiktiven Zeitverlauf ansetzt und die Geschichte vorantreibt. Aber es gibt keine fiktive Rhythmik, die der realen entsprechen würde, wie beispielsweise jede Woche am Kiosk zu erscheinen. So gesehen ist die Frequenz der Narration in den Romanheften für die Figuren nicht existent. Sie ist lediglich für den Leser präsent, für den in jeder Folge oder Episode ${ }^{815}$ die Erzählung weitergeführt oder komplett neu aufgenommen wird. Somit gibt es nicht nur feste Regelmäßigkeiten im Erscheinungshythmus, sondern auch darin, wie die Narration aufgenommen wird. Also ob eine neue kleine Geschichte (eine Episode) angefangen oder ob eine bestehende weitergeführt wird.

Es gibt in den Heften durchaus Mikroerzählungen, die auf eine Vergangenheit zurückblicken, doch ist diese in der Regel nie Bestandteil der Makroerzählung gewesen. Diese Rückblicke sind sozusagen 'Pseudorückblicke', da sie sich auf keine existierende Folge beziehen. Doch hierzu später mehr. Die Erzählung der Romanhefte findet, egal ob akkumulierende oder progressive Struktur, immer im Hier und Jetzt statt. Selbst fingierte Rückblicke bilden Mikroerzählungen, die, obwohl sie in der Vergangenheit spielen sollen, als gegenwärtige Ereignisse erzählt sein können. Doch auch hierzu im nächsten Kapitel 8.5 „Wiederholung als Erinnerung“ mehr.

Demnach gibt es in den Romanheften keine bloßgelegte Iteration, keine thematisch erfasste, sondern lediglich die Wiederholung, die geschieht: Das regelmäßige Erscheinen der Hefte und das wiederholte Aufnehmen oder Weiterführen der Narration. Folgendes Verhältnis herrscht dabei vor: Dem Leser suggeriert die serielle Narration, dass ihm jedes Mal etwas Neues präsentiert wird. Jedoch geschieht dies nur scheinbar, denn ihm wird lediglich in neuer „Verpackung“ das Gleiche erzählt.

In den Romanheften wird nicht offen mit Regelmäßigkeiten variiert. Dies bedeutet, dass Autoren oder Verlage nicht explizit aussprechen, dass sie das Gleiche präsentieren. Da nicht die alte „Verpackung“ mit neuem Inhalt geliefert wird, ${ }^{816}$ gibt es eine

Zeitsprung von fast 1000 Jahren. Dadurch ergab sich eine Leerstelle welche die Leser stark verwirrte, da diverse neue Elemente und Figuren eingeführt wurden (vgl. Michael Nagula: Perry Rhodan. Die Chronik. Bd. 1, S. 298f.). Im Folgenden wurde vom Verlag nie wieder solch ein massiver Zeitsprung angestrebt. Zudem finden die Zeitsprünge bei Perry Rhodan in der Regel zwischen den Zyklen statt und nicht innerhalb eines Zyklus.

815 Bisher wurde in der Forschung keine eindeutige Terminologie ausgeformt. Mein Vorschlag wäre daher folgender: Episode als Fortsetzung einer Episodenserie, wäre bereits begrifflich prädestiniert und Folge bliebe als Fortsetzung eine Fortsetzungsserie.

816 Dies findet sich lediglich bei der Perry Rhodan NEO-Serie, welche das Konzept der Ursprungs- 
Iteration des Erzählaktes an sich. Primär bestimmt das regelmäßige Erzählen die Rezeptionsgewohnheit des Lesers und sekundär erst die Erzählung per se.

\subsection{Wiederholung als Erinnerung}

In den Perry Rhodan-Heften werden bestimmte Informationen wiederholt, um den Hintergrund unterschiedlicher Figuren oder Situationen zu erläutern. Dies dient dazu, dass neue Leser in die Serie einsteigen und erfahrene Leser ihr Wissen aktualisieren können. Demnach ist die Redundanz von Fakten einerseits eine Einführung in das Was-Bisher-Geschah und andererseits eine Akzentuierung und Aktualisierung dessen, was wichtig für den weiteren Verlauf der Handlung ist.

Diese Redundanz ist bei einer Fortsetzungsserie wie Perry Rhodan nahezu zwingend, da es sonst schwierig für neue Leser wird, sich in der Serie zurechtzufinden. Zudem können diese Redundanzen in einigen Fällen sogar ehemaligen Lesern den Wiedereinstieg in die Serie ermöglichen. Die Initialphase bietet ebenfalls eine Einführung für neue Leser. Betrafen die drei Phasen (Initial, Verlauf und Abschluss) vormals eher die Rahmung der seriellen Narration, geht es nun um Konstanten innerhalb der Narration.

Bei episodalen Serien hingegen ist diese Redundanz von Fakten, wie sie in den Fortsetzungsserien vorkommen, weniger zwingend, gegebenenfalls sogar überflüssig und wird von den Autoren kaum verwendet, da jede Folge unabhängig von ihrer vorherigen Folge verständlich ist. Sie ist mehr oder weniger frei von ihrer Verkettung. Die Redundanzen, die vermehrt in episodalen Serien erscheinen, haben den Charakter eines 'narrativen Rituals', denn wenn beispielsweise die Hauptfigur Lassiter aus der gleichnamigen Westernserie immer wieder als „der Mann von der Brigade Sieben" vorgestellt wird, ${ }^{817}$ ist dies zwar ein Verweis darauf, dass er ein Agent dieser Institution ist, aber ob diese Information dem Leser bekannt ist oder nicht, ändert nichts an der Verständlichkeit der Serie. Innerhalb der Lassiter-Serie stellt diese Redundanz eher eine Insider-Information dar, die die Erwartungshaltung der erfahrenen Lassiter-Leser befriedigen soll. ${ }^{818}$ Bei einer Fortsetzungsserie wie

serie aufnimmt und aktualisiert. Dies stellt allerdings ein Novum im Bereich der Romanhefte dar.

817 Lassiter Bd. 1952, S. 7.

818 Vgl. Kapitel 8.4 „Redundanzen während der Rezeption“. 
Perry Rhodan hingegen macht es einen Unterschied, ob Hintergründe über Figuren genannt werden oder nicht. Doch hierzu später mehr.

Zunächst zur Form bei Perry Rhodan: Die Einführung in das Was-Bisher-Geschah findet sich in der Regel in der Form eines Prologs auf der ersten Seite wieder. Da die Perry Rhodan-Serie weitschweifig ist, kann der Prolog hier nicht umfassend sein, sondern nennt lediglich die wichtigsten Fakten, die für die Erzählung des jeweiligen Heftes von Relevanz sind. Da sich jeder Zyklus meist einem einzigen komplexen Problem widmet, ist der Großteil des Prologs von Heft zu Heft gleich und variiert nur in einigen Sätzen. Hier Auszüge aus zwei Prologen (Unterstreichungen vom Autor): Band 2585:

„Rhodan muss anscheinend das PARALOX-ARSENAL finden, um ES helfen zu können - aber dazu gibt es bisher keine verwertbare Spur."

Band 2586:

„Rhodan muss das PARALOX-ARSENAL finden um ES helfen zu können oder der Superintelligenz anderweitig ausreichend Psi-Materie zuführen."

Der Prolog von Band 2585 hält sich vage, da erst das folgende Heft diesen Handlungsstrang ausführt. Zudem wird auf einen anderen Schauplatz umgeblendet. Im Prolog von Band 2586 ist der Prologteil hingegen eindeutiger, da sich in diesem Heft den Aspekten zugewandt wird, die im vorherigen nur angedeutet wurden. Diese Praxis ist allerdings nicht nur für die Perry Rhodan-Serie typisch, sondern wird von Autoren anderer Serien ebenfalls genutzt. Zudem muss ein einführender Prolog nicht zwingend am Anfang stehen, damit ein Leser eingeführt werden kann, daher ist auf der ersten Heftseite der Maddrax-Serie zwar auch ein Prolog zu finden, jedoch dient er nicht einer informativen Einführung, sondern beginnt mit einer ersten Spannungssituation, die den Leser zum Weiterlesen anregt. Anregungen dieser Art fungieren sozusagen als 'Einstimmungs-Prolog', da diese Form der Einleitung auch einen Ausblick auf die potenzielle Stimmung innerhalb des Romanhefts bietet.

Der informative Prolog folgt in der Maddrax-Serie in der Regel auf der fünften Seite. Da die Serie ihren Schwerpunkt auf die Mikroerzählungen der einzelnen Hefte setzt, beginnt sie mit einem Stimmungs-Einstieg in die einzelne Episode und nicht in den eigentlichen Serienkomplex. Die Einstiegshilfe für den Serienkomplex ist somit zweit-

819 Perry Rhodan Bd. 2585, Unterstreichung vom Verfasser.

820 Perry Rhodan Bd. 2586. Die Sektorknospe. Wim Vandemaan. 1. Aufl. Pabel-Moewig-Verlag. Unterstreichung vom Verfasser. 
rangig und nicht basal notwendig für das Verständnis der aktuellen Handlung wie bei der Perry Rhodan-Serie. Die Maddrax-Serie stellt, wie oben bereits ausgeführt, einen 'Zwitter' dar, der episodale Serienform mit einer Fortsetzungsstruktur kombiniert. ${ }^{821}$ Eingangs einen Prolog mit Spannungsauftakt zu setzen, findet sich zumeist bei Romanheftserien, die einen ausgeprägten episodalen Charakter haben, wie zum Beispiel Jerry Cotton oder John Sinclair, bei denen die Reihenfolge der Episoden nur von marginaler Bedeutung ist. Diese Serien sind ohne Einführung in ihr Serienuniversum verständlich und setzen hauptsächlich auf Spannung. Anders ist es bei Perry Rhodan, die Hefte des jüngeren Drei-Viertels der Serie setzen auf die Komplexität der Handlung. Das erklärt, warum der wiederholende Prolog bei Perry Rhodan an solch einer exponierten Position gesetzt wird.

Um die Serie verstehen und somit auch konsumieren zu können, ist es notwendig, dass für den Leser Fakten wiederholt und in Bezug zueinander gesetzt werden, da die Serie eine Fülle von Figuren, Schauplätzen und Gegenständen aufweist, die immer wieder eine Rolle spielen und über solch eine lange Laufzeit (über 40 Jahre) komplex miteinander verknüpft sind. Metaphorisch gesprochen gleicht diese Serie einer 'Informationskrake': Zu jeder Welt, jedem Gegenstand, jeder Figur gibt es eine Vorgeschichte, die wiederum relevant für einen weiteren Handlungsstrang ist, wobei solch ein Handlungsstrang sich unter Umständen nicht in der Hauptserie Perry Rhodan finden muss. Dieser kann auch in einem der sogenannten Planetenromane wieder auftauchen oder in die Spin-off-Serie Atlan $^{822}$ Eingang gefunden haben, daher ist es notwendig, die wichtigsten Fakten um eine Figur herum kurz zu benennen beziehungsweise dem erfahrenen Perry Rhodan-Leser in Erinnerung zu rufen. Diese Erinnerungen oder 'Reminder' verknüpfen im Fließtext in der Regel nicht, wann und wo diese Fakten nachzulesen sind, sondern wiederholen sie schlichtweg, als ob sie das erste Mal benannt würden.

„Eine Gestalt materialisierte vor ihnen, ein kleiner Terraner mit asiatischen Gesichtszügen. 'Man hat mir deinen Ruf weitergeleitet', sagte Tako Kakuta. Hinter dem Japaner lag ein ähnliches Schicksal, wie es Betty Toufry durchlitten hatte. Auch er war während der Second-Genesis-Krise gestorben und nach weiteren Verwicklungen in ES aufgegangen, bis er jüngst wieder

821 Vgl. Kapitel 7.2 „Mikro- und Makroerzählung“.

822 Die Atlan-Serie erfährt 2013 eine editorische Neuauflage ähnlich wie die Perry Rhodan-Serie in ihren Silberbänden. 
freigegeben worden war. Kakuta verfügte über die Gabe der Teleportation." ${ }^{823}$

Der erfahrene Perry Rhodan-Leser kennt Tako Kakuta ebenso wie die genannten Informationen aus dem Textbeispiel. Der Neuleser wird jedoch nicht wissen, dass Kakuta Japaner und Teleporter ist und von der Second-Genesis-Krise betroffen war. Für den erfahrenen Leser ist dies lediglich eine Auffrischung bekannten Wissens. ${ }^{824}$ Interessant ist zudem, was hier nicht geschieht: Eine bekannte Figur aus der Serie wird zwar vorgestellt, aber es wird nicht umfassend über sie berichtet. Nur das, was für die Begegnung mit Betty Toufry von Relevanz ist, wird erzählt. So schreiben die Autoren unter anderem nichts darüber, dass Kakuta schon bei den ersten Abenteuern von Perry Rhodan dabei war. Weitere Hintergrundinformation zu Kakuta lassen sich unter anderem in dem Perry Rhodan-Lexikon wiederfinden, in dem der Verlag für die Serie relevantes Wissen zusammengestellt hat:

„Kakuta, Tako - Mutant der Dritten Macht, später ständiges Mitglied des Mutantenkorps bis zum Jahr 2909. Der Teleporter wird am 6.10.1945 als Kind strahlungsgeschädigter Eltern in Hiroshima geboren. Er ist klein und relativ schmächtig, als er 1971 zu Perry Rhodan stößt. Das Gesicht mit der vorgewölbten Stirn wirkt etwas kindlich. Kakuta kommt während der SecondGenesis-Krise ums Leben, später Weiterexistenz als körperloser Altmutant und Aufgehen in ES [...]." ${ }^{\text {" } 25}$

Jedoch wird in der kurzen Vorstellung in dem Heft nicht erklärt, was die „SecondGenesis-Krise" ist beziehungsweise wird dies erst im Glossar erläutert. ${ }^{826}$ Die Eigenschaften Kakutas vertiefen die Autoren nicht weiter, nennen diese lediglich und die Handlung nimmt ihren weiteren Verlauf. Der Reminder über Kakuta ist zwar eine Erklärung dafür, wieso er bei Betty Toufry auftaucht und wieso er sich teleportieren kann, aber er ist nicht zwingend handlungstragend, obschon Kakutas Auftauchen die Handlung beeinflusst. Die Gewichtung liegt hier eher im informativen als im erzählerischen Bereich und die Erwähnung der „Second-Genesis-Krise“ lässt sich vom erfahrenen Leser schnell überfliegen, weshalb diese Reminder in der Regel einen geringen Umfang haben.

823 Perry Rhodan Bd. 2580. Handelsstern im Visier. Christian Montillon 1. Aufl. Pabel-MoewigVerlag. S.13.

824 Vgl. hierzu Kapitel 8.4 „Redundanzen während der Rezeption“.

825 Hoffmann und Marzin: Perry Rhodan Lexikon. Bd. F-K, S. 231. Eine aktuellere Quelle würde die Internetseite „Perrypedia“ (https://www.perrypedia.proc.org/wiki/Hauptseite (Zugriff: 17.08.2019)) oder die Homepage der Serie (https://perry-rhodan.net/ (Zugriff: 17.08.2019)) darstellen. Allerdings sind diese Quellen überaus detailliert.

826 Perry Rhodan Bd. 2580, S. 69. 
Ein direkter Verweis stellt das Glossar dar. In inm wird direkt auf Jahreszahlen und Daten des Perryversums verwiesen und ebenso, in welchen Perry Rhodan-Heften oder Büchern die vorangegangenen Abenteuer sich nachlesen lassen. Da die Perry Rhodan-Hefte immens viele Figuren mit sich führen, die immer wieder in die aktive Handlung eingeflochten werden, können diese Verweise in der Regel nur indirekt bleiben, da sie den Lesefluss erheblich stören würden. Wäre solch ein Reminder ausführlicher, könnte er den Leser von der eigentlichen Handlung ablenken. Diese kurzen Rückbezüge sollen lediglich die Figur gerafft charakterisieren und in dem komplexen Zusammenhang der Serie verorten.

Eine andere, direktere Technik ist es, diesen Rückbezug als Fußnote zu setzen, was sich bei den Serien Maddrax und Professor Zamorra finden lässt. In diesen Serien werden Details erläutert oder explizit Hefte angeben, in denen relevante Textstellen nachzulesen sind. Details werden zwar innerhalb der Serie und ihres chronologischen Ablaufs verortet, allerdings nicht in den komplexen Sachverhalt einsortiert wie bei Perry Rhodan. Dies rührt zum Teil von einer reinen Platzökonomie her, da es bei Perry Rhodan schwerlich möglich ist, alle relevanten Textpassagen aufzuzählen. Zudem ist es für das Verständnis des aktuellen Handlungsgeschehens effektiver, zu erfahren, welche Funktion eine Figur hat, und weniger, wo sie bereits auftauchte.

Bei den rein episodal aufgebauten Serien sind solche Rückbezüge nicht zu finden, beispielsweise sind die Hefte der Jack Slade-Reihe unterschiedliche Westerngeschichten, die lediglich über das Genre und den Autor zusammengehalten werden. Dessen Name fungiert nur noch als Marke, nachdem er selbst verstorben ist und andere Autoren unter dieser Marke weitere Geschichten akkumulieren. ${ }^{827}$ Allerdings gibt es episodale Serien, die eine durchgehende Hauptfigur haben. Bei ihnen hat das einzelne Heft keine Auswirkung auf die Handlung der folgenden Hefte oder die Hauptfigur. Zum Teil ist die Reihenfolge der Hefte völlig unerheblich, da sie nicht miteinander verknüpft werden. Am Ende der Folgen dieser Serien muss der Status Quo wiederhergestellt sein. Egal, wie hart der Kampf von Jerry Cotton gegen die Verbrecher war, in der darauffolgenden Episode wird nichts von Narben oder Blessuren zu lesen sein.

Bei der John Sinclair-Serie gibt es zwar Verweise auf vorherige Fälle, jedoch sind

827 Kasper: Der härteste Mann auf dem deutschen Heftromanmarkt. 
diese Verweise eher Ausschmückung der Figur John Sinclair als handlungstragend und geben ihr eine vermeintliche Tiefe, wenn sie sich an diverse Fälle erinnert:

„Nein, nicht schon wieder!, dachte ich. Mir fiel der letzte Fall ein." ${ }^{828}$

Aber die Ereignisse der vorherigen Fälle nehmen keinerlei Einfluss auf den Charakter der Figur Sinclair und nur bedingt auf die aktuelle Handlung. ${ }^{829}$ Es spielt für den weiteren Verlauf der Serie keine Rolle, ob der Bezug auf ein früheres Abenteuer von Sinclair wirklich in einem der Hefte erzählt wurde oder nicht. Dieser Bezug ist lediglich Staffage innerhalb der Serie und stellt keine aktive Handlungsverflechtung dar, da dieser Bezugspunkt in der Vergangenheit von John Sinclair liegt und somit keinen Einfluss auf die aktuelle Handlung nimmt. Zudem hat dieser Verweis an sich auch keine Auswirkungen auf das Geschehen. Hätte er dies, würde der Bezug vergangene Handlung mit dem aktuellen Handlungsstrang verknüpfen. Dies würde den Rückverweis für den Verlauf der Serie notwendig machen, da dann unter anderem die Hierarchisierung der Folgen eine Rolle spielen würde, um die jeweiligen Folgen der Serie verstehen zu können.

Diese Rückverweise sind jedoch nicht mit den Analepsen zu verwechseln. ${ }^{830}$ Generell sind diese Reminder abzugrenzen von den konventionellen Erzähltechniken. Es gibt innerhalb der Serien unterschiedliche Narrationsarten, welche die entsprechenden Techniken aufweisen. Daher würde eine Erzählung in der Perry Rhodan-Serie, die mit Rückblicken (Analepsen) arbeitet, trotzdem Reminder verwenden, um den Ansprüchen der Komplexität der Serie gerecht zu werden. Somit stellt sich dem Narratologen die Frage nach der Zeitlichkeit in der Serie Perry Rhodan: Die geschilderten Ereignisse befinden sich in der Regel im Hier und Jetzt der fiktiven Welt. Nur einzelne Mikroerzählungen reflektieren eine Vergangenheit, jedoch ist dies nicht der Regelfall der Serie. Die Fokalisierung ist zumeist auf den aktionistischen Plot bezogen. Dies liegt vermutlich in der Regel an der nicht klar definierten Position des Erzählers, welche nur in Ausnahmefällen konkretisiert ist. Zum Beispiel bei Episoden mit Atlan, in denen diese Figur als Ich-Erzähler fungiert. Zuweilen gibt es

828 Geisterjäger John Sinclair Bd. 1705, S. 14.

829 Allerdings gibt es diverse Abenteuer, die mehrere Hefte umspannen können. Aber es gibt noch keinen alleinstehenden Handlungsstrang, der in der John Sinclair-Serie eine Makrostruktur formen würde. Bzw. müsste man dies detailliert in den mehr als 1800 Heften untersuchen, was den Rahmen dieser Arbeit sprengen würde.

830 Vgl. hierzu u.a. Martinez und Scheffel: Einführung in die Erzähltheorie. 
auch einige Mikroerzählungen, in welchen eine Episodenfigur als Erzähler fungiert. Jedoch stellen diese Fälle eine Ausnahme dar. Die Reminder sind zwar keine Anachronien im streng narratologischen Sinne, aber sie sind trotzdem noch immer zeitliche Rückgriffe. Sie verweisen auf Geschehnisse in der Chronologie zurück und doppeln sie damit zum Teil. Es bietet sich an, die Reminder nach dem Modell von Genette zu erklären. ${ }^{831}$ Ähnlich wie Genette die Analepsen aufgliedert, sollen im Folgenden Reminder untersucht werden. Wenn A-D beispielsweise die Abfolge innerhalb des Textes darstellt, so stellt dann 1-4 die Abfolge in der Zeit der erzählten Welt dar (hier bei Perry Rhodan natürlich einer fiktiven). ${ }^{832}$ Der Aufbau einer simplen Analepse könnte beispielsweise so aussehen: A2-B3-C1-D4. Womit C1 dann die eigentliche Analepse darstellt. Sie erzählt von Ereignissen, die in der Zeit zurückliegen, aber noch nicht erzählt wurden. Dies ist ein entscheidender Punkt. Das Ereignis liegt zwar zurück, ist aber für den Leser neu, da es vorher noch nie erzählt wurde.

Bei einem Reminder verhält es sich nun folgendermaßen: A2-B3-C2-D4. C2 stellt hier den Reminder dar, der Bezug auf etwas nimmt, das zwar, wie bei der Analepse, in der Vergangenheit liegt, aber bereits erzählt wurde, nämlich in A2. Dies ist das Entscheidende für den Reminder: Das Ereignis wurde zuvor erzählt. Bei einer langlaufenden Serie wie Perry Rhodan können diese Reminder wie Analepsen erscheinen. Das ist zum einen dadurch bedingt, dass der kontinuierliche Leser es schlichtweg vergessen hat, was sich 1000 Hefte zuvor zugetragen hat. Des Weiteren können solche Reminder für neue Leser Quasi-Analepsen darstellen, da sie mittendrin einsteigen und ihnen Fakten, die dem erfahrenen Leser bekannt sind, in der Tat noch nicht erzählt wurden. Für einen neuen Leser der Perry Rhodan-Serie ist es durchaus wichtig zu erfahren, was Tako Kakuta alles kann und wie er zu der Figur Betty Toufry steht. Allerdings rekurriert das Textbeispiel nicht nur auf einen Bezugspunkt in der Vergangenheit, sondern auf mehrere. Unter anderem verweist das Beispiel darauf, dass er ein Opfer der Second-Genesis-Krise war, die in Band $408^{833}$ stattfand und er später (in Band 983) in dem Überwesen ES aufging ${ }^{834}$. Damit nimmt die Textstelle in Band 2580 („Handelsstern im Visier“) ${ }^{835}$ Bezug auf Ereignisse, die über 1500 Hefte

831 Genette: Die Erzählung, S. 18ff.

832 An dieser Stelle halte ich mich nicht sklavisch an Genettes Nummerierung. Ich übernehme nur das Prinzip.

833 Perry Rhodan Bd. 408, erschien am 13. Juni 1969.

834 Perry Rhodan Bd. 983, erschien am 24. Juni 1980.

835 Erschienen am 28. Januar 2011. 
vorher erzählt wurden, also auf Hefte, die vor dreißig Jahren erschienen sind.

Umso weiter ein Bezugspunkt zurück liegt, umso wahrscheinlicher ist es, dass diverse Geschichten darauf folgen, die diesen Bezugspunkt beeinflussen und somit relevant für den aktuellen Handlungsstrang sein könnten, daher muss entsprechend viel gerafft werden. Zwar formten diverse Geschichten die Figur Tako Kakuta, doch der Autor muss sich auf das Relevante beschränken, damit seine Erzählung nicht vom eigentlichen Geschehen abdriftet. Hierbei ist also nicht die fiktive Zeit entscheidend, sondern, wie viel wirklich erzählt wurde. Umso mehr erzählt wurde, desto stärker muss gerafft werden, um die relevanten Informationen umreißen zu können. Folglich könnte ein Ereignis, das in beispielsweise zwei oder drei vorangegangenen Heften erzählt wurde, aber sich angeblich tausend Jahre zuvor ereignete, trotzdem in seiner Gänze repetiert werden, da faktisch noch nicht so viel erzählt wurde, eben nur zwei bis drei Hefte lang. Deshalb muss Relevantes über die Figur Aachthor ${ }^{836}$ nicht gerafft werden und der Autor kann es kurz berichten, da von ihr schlichtweg noch nicht viel erzählt wurde, außer, dass sie vor tausenden von Jahren ihre Reise begann.

In der Reichweite der Rückverweise kann man auch die Bedeutung einer Serienfigur ablesen. Je weiter und häufiger die Rückbezüge sind, umso wichtiger ist die Figur für die Serie. Die Rückverweise bilden eine Konstante in dem Gefüge. ${ }^{837}$ Der zeitliche Umfang der Bezugspunkte, auf den diese Rückbezüge verweisen, ist unterschiedlich. Das können Ereignisse sein, die mehrere Jahre dauerten oder nur einen Tag. Ihr Umfang hat keinerlei Auswirkung auf den Reminder, zudem er selbst nie als eine „Basiserzählung“ fungieren könnte. ${ }^{838}$ Somit sind der hier erläuterte Rückbezug sowie die Vorausdeutung im folgenden Kapitel keine Anachronien im Sinne Genettes ${ }^{839}$. Sie unterbrechen zwar die eigentliche Erzählung, indem sie auf Erzählstränge verweisen, die zeitlich zurückliegen, aber sie stellen nicht „zeitlich gesehen eine zweite Erzählung dar" ${ }^{\text {«80 }}$.

Zwar können die redundanten Rückbezüge, die Reminder, auch in nicht-seriellen Narrationen vorkommen, doch sind sie dort eher fakultativ, während sie in der seriel-

836 Siehe Kapitel 7.2 „Mikro- und Makroerzählungen“.

837 Siehe Kapitel 6. „Halbwertszeit von Serienfiguren“.

838 Genette: Die Erzählung, S. 27.

839 Vgl. ebd.

840 Ebd. 
len Narration obligatorisch sind. Die Notwendigkeit narrativ redundanter Elemente unterscheidet die serielle Erzählweise von der nicht-seriellen.

\subsection{Die Vorankündigung}

Die Vorankündigung funktioniert eher als 'Appetizer'. Ähnlich dem Reminder, der eine 'Nicht-Analepse' ist, stellt die Vorankündigung bei Perry Rhodan eine 'Nicht-Prolepse' dar. Im eigentlichen Fließtext der Serie sind Vorausdeutungen selten anzutreffen. Vielmehr findet man am Ende des Heftes die Vorschau auf die kommenden Folgen. Allerdings ist das, was in dieser Vorschau erzählt wird, nicht in die laufende Erzählung eingebunden, sondern steht als Paratext an exaltierter Stelle. Das, was in der Vorschau an Informationen gegeben wird, wird anders als in der Prolepse an späterer Stelle wieder aufgenommen und somit wiederholt. Bei dieser Information ist von vornherein klar, dass sie redundant wird. Abermals ist hier das Schema von Genette zur Veranschaulichung nützlich:

Die simple Prolepse würde folgendermaßen aussehen, wenn man das vorgestellte Modell konsequent erweitert: E7-F5-G6-H8-i9. Die Prolepse, also die vorgezogene Erzählung, ist hier E7. Der Erzählstrang würde mit einem Teil aus der Zukunft beginnen und der weitere Verlauf würde sich zu diesem Punkt (E7) hin entwickeln, ohne diesen dabei direkt zu wiederholen, sondern von diesem Punkt ausgehend (E7) weitererzählen (H8).

Die Ankündigung, und weniger eine Vorausdeutung, die hier vorliegt, würde sich demnach so gestalten:

\section{E7-F5-G6-H7-i8.}

Als eine Sequenz für zwei Hefte könnte dies Folgendermaßen aussehen:

\section{A2-B3-C2-D4-E7 / F5-G6-H7-i8}

Das vorgestellte Beispiel ist stark vereinfacht, denn in den Heften sind etliche Reminder zu finden, zumal hier die Reminder des Folgeheftes außer Acht gelassen wurden. E7 wird am Ende des ersten Heftes berichtet und im zweiten Heft in $\mathrm{H} 7$ erzählt.

Dieses Phänomen ist nicht rein auf die Perry Rhodan-Serie beschränkt, sondern 
lässt sich bei diversen anderen Serien wiederfinden. Die Serien, die ebenfalls übergreifende Handlungsstränge besitzen, nutzen diese Ankündigung anders als jene, die rein episodal erzählen. Die Jerry Cotton-Serie gibt lediglich einen Ausblick auf das kommende Abenteuer der Helden, ohne dabei irgendwelche Handlungsstränge aus dem aktuellen Heft aufzugreifen:

„Weiße Weste - schmutzige Hände

Barry Meyers, ein Enthüllungsjournalist, wurde mitten auf dem Broadway in seinem Auto in die Luft gesprengt. Er hatte kurz zuvor angekündigt, eine Serie über den Auftragskiller Henry Fowler zu veröffentlichen, basierend auf den Gesprächen, die er mit dem verurteilten Mörder im Gefängnis geführt hatte. Anscheinend bekamen einige Leute Angst, dass Fowler zu viel ausgeplaudert hatte..." ${ }^{841}$

Es ist lediglich ein werbender Text, der eine Spannungshandlung andeutet. Die Ankündigungstexte aus den Fortsetzungsserien scheinen dies vordergründig auch zu tun, allerdings nehmen sie Handlungsstränge aus dem aktuellen Heft mit auf und beziehen sich auf die kommende Folge. Ein Beispiel aus der Serie Professor Zamorra:

„Asmodis schöpfte Hoffnung. Vielleicht ist noch nicht alles verloren, vielleicht kann er seine Schmach doch noch zum Guten wenden! Doch er braucht Hilfe, bevor er sich auf den Weg macht, Anzeichen für diese These zu suchen. Er findet sie in einem Mann, der ein mächtiger Verbündeter sein könnte - oder ein mächtiger Feind...

\section{In den}

Nebeln

In 14 Tagen ist es soweit. Eine neue Autorin, Anika Klüver, wird erzählen, wie Asmodis sich Verbündete für sein neues Großprojekt sucht! [...]“842

Der Ankündigungstext repetiert zum einen, wieweit die Figur Asmodis mit ihren Zielen gekommen ist, zum anderen spekuliert der Text über das, was noch kommen könnte: „Vielleicht ist noch nicht alles verloren“843. Des Weiteren folgt eine Andeutung, wie sich diese Spekulation erfüllen könnte: „Er findet sie in einem Mann“844, auf diese Weise wird vorbereitet, inwiefern das folgende Heft an das aktuelle anknüpft, und darüber hinaus relevante Informationen vermittelt, die sich der Leser merken sollte: Asmodis und seine Ziele. Der Erzählstrang um Professor Zamorra ist demnach vorerst nicht relevant und der Leser erfährt aus dem Ankündigungstext, dass

841 G-man Jerry Cotton Bd. 2803, S. 66.

842 Professor Zamorra Bd. 959, S. 66.

843 Ebd.

844 Ebd. 
Asmodis in dem folgenden Heft einen Verbündeten finden wird, von dem zweifelhaft ist, ob er inm trauen kann. Dies ist in dem Heft jedoch nicht bloß ein Nebenstrang, es ist quasi das Leitthema des folgenden Heftes. Insofern erzeugt diese Information eine Redundanz, da in der nächsten Folge nichts anderes passiert, als angekündigt wurde. Ähnlich ist es bei den Perry Rhodan-Heften. Ein Beispiel:

„Der Stalwart Agrester und die Eindringlinge in den Handelsstern scheinen Gegner zu sein, obwohl sie bestimmte Ziele teilen. Wie die sich zuspitzende Situation weitergeht, ist Thema des nächsten Romans. " 845

Mit einem Satz wird kurz das Wichtigste aus dem aktuellen Heft umrissen und im nächsten wird das Thema, auf das sich der Leser konzentrieren soll, explizit angesprochen. Hierbei nimmt die Redundanz dem Leser keine Neuigkeit vorweg, da das aktuelle Heft mehr oder weniger offen endet und der Leser somit eine Fortsetzung dieses Konfliktes erwartet. Diese Ankündigung ist für den Leser eher eine Versicherung, dass es überhaupt mit dem Erzählstrang weitergeht, was in der Perry Rhodan-Serie nicht immer gegeben sein muss, wie das nächste Beispiel zeigt:

„Welche Möglichkeiten dem Stalwart Agrester und den galaktischen Eindringlingen bleiben, wird die Zukunft erweisen. Wir wenden uns mit dem nächsten Roman wieder Perry Rhodan selbst zu, der sich erneut auf dem Weg nach TALIN ANTHURESTA befindet." ${ }^{846}$

Hier wird der Leser lediglich darauf verwiesen, dass der aktuelle Handlungsstrang eventuell irgendwann wieder aufgenommen wird, doch ist dies kein Versprechen der Redaktion, dass die Fortführung dieses einen Handlungsstrangs wirklich erfolgt. Außerdem wird angekündigt, welcher Handlungsstrang im nächsten Heft fortgesetzt wird. Dies bedingt sich aus der weitverzweigten Handlungsstruktur der Serie (vgl. Kapitel 7.2 „Mikro- und Makroerzählung“). Es gibt diverse parallel laufende Stränge, die immer wieder schlaglichtartig aufgenommen und wenige Hefte lang fortgeführt werden, um sich dann wieder einem anderen Schauplatz zuzuwenden. Durch diese Ankündigungen kann die Serie gewährleisten, die Leser nicht durch allzu unerwartete Handlungssprünge zu verprellen. Der Leser wird so regelrecht auf die kommende Folge vorbereitet. ${ }^{847}$

845 Perry Rhodan Bd. 2581. Wunder in Gefahr. Leo Lukas. 1. Aufl. Pabel-Moewig-Verlag. S. 59.

846 Perry Rhodan Bd. 2582. Ein Kind der Funken. Leo Lukas. 1. Aufl. Pabel-Moewig-Verlag. S. 63.

847 Gemäß der bisherigen Begriffsfindung Reminder für das Phänomen des seriellen Rückbezuges, wäre der für das Phänomen der seriellen Vorankündigung sinnige Begriff: Preparer. 
Darüber hinaus kann er sich aber auch innerhalb der großen Handlungszusammenhänge orientieren. Durch kurzes Umreißen der relevanten Informationen und die Redundanzen wird für inn immer wieder nur das Nötigste an Wissenswertem über die Handlung der Serie zusammengestellt. Teilweise werden auf diese Weise Gespräche zwischen Figuren instrumentalisiert, um dem Leser damit eine Auffrischung zu geben:

„Mondra verlangte eine Abgleichung der Fakten und persönlichen Erlebnisse. Sie brauche, erklärte sie rigoros, diese Prozedur, um wieder Boden unter die Stiefel zu bekommen." ${ }^{488}$

Darauf folgt eine längere Zusammenfassung dessen, was in den vorherigen Heften bisher geschah. Diese „Abgleichung der Fakten“ rafft jedoch nur Informationen zusammen, die sich auf die Figur Mondra und ihr Team beziehen, daher ist es für den Leser nicht notwendig, sich bei all diesen komplexen Verstrickungen alles merken zu müssen, da er darauf vertrauen kann, dass ihn die Serie erinnert und vorbereitet.

848 Perry Rhodan Bd. 2581, S. 6. 


\section{Das serielle Produkt als Massenkunstwerk}

Bisher wurde der serielle Produktionsprozess aufgezeigt, der durch Arbeitsaufteilung unter den Autoren und anderen Künstlern sowie durch Exposés ermöglicht wird und damit die Frage thematisiert, wie sich das Serielle im Text widerspiegelt. Jedoch ist hierbei noch nicht hinreichend geklärt worden, welche Rolle der Konsument in Hinblick auf diese Aspekte einnimmt.

Das Serielle ist in der Regel ein Produkt der Industrie, da die "Großserienproduktion" ${ }^{489}$ einen hohen "Automatisierungsgrad“" ${ }^{500}$ erfordert, wodurch ein bestimmtes Maß an Vereinheitlichung die massenhafte Verbreitung vereinfacht und dadurch beschleunigt. Die massenhafte Verbreitung orientiert sich in der Regel am Markt und ist somit schließlich am Kunden orientiert. ${ }^{851}$ Die Vereinfachung der Herstellung ist jedoch nur ein Teilaspekt der seriellen Produktion - wie bereits thematisiert wurde, begünstigt das Serielle auch das Konsumenten-Verhältnis. Das bedeutet unter anderem, dass bei dem Konsumenten Erwartungen erweckt werden, indem das Produkt regelmäßig in einer nahezu gleichen Form mit leichten Variationen erscheint. Erwartungshaltungen einzuhalten bedeutet eine intensive Kundenorientierung, weswegen der Verleger sich eher als Geschäftsmann auf dem ökonomischen Feld sehen muss, ${ }^{852}$ da die Nachfrage den Absatz beeinflusst: „Das bewirkt auch, warum auf dem Markt Erfolg hat, wer Erfolg hat", ${ }^{, 853}$ denn wer sich an dem orientiert, was Konsumenten wünschen, wird auch einen Abnehmer finden.

\subsection{Eine Serie 'massenmedialästhetisch' untersucht}

Nach Bourdieu ist Erfolg eine Gütegarantie für Produzenten wie für das Publikum. ${ }^{854}$ Demnach bleibt ein Produkt mit hoher Wahrscheinlichkeit erfolgreich, wenn es sich

849 Burkhard Welkener: Organisation der Produktion in Industrieunternehmen mit Groß-Serien- und Massenproduktion unter besonderer Berücksichtigung internationaler Standortstruktur. Wirt.wiss. Diss. Gießen 1985. S. 24.

850 Ebd.

851 Ebd. S. 23ff.

852 Pierre Bourdieu: Die Regeln der Kunst - Genese und Struktur des literarischen Feldes. Übersetzt von Bernd Schwibs und Achim Russer. Titel des franz. Originals: Les règles de l'art. Genèse et structure du champ littéraire. (Paris 1992). Frankfurt a.M. 2001. S. $237 f f$.

Ebd. S. 238.

854 Ebd. 
etabliert hat und seine Auflagenhöhe als Erfolgsreferenz funktioniert. Von daher ist ein komplett neues Produkt risikobehaftet für Geschäftsleute wie beispielsweise Romanheft-Verleger. Im Folgenden wird untersucht, wie die Verleger das Problem bei der Perry Rhodan-Serie lösten, da unter anderem die Gründungsautoren in der Science Fiction-Szene keine Unbekannten waren. Die Serie kann somit als mustergültiger Vertreter für Romanheftserien stehen, die als tendenzielle Fortsetzungsserien konzipiert sind, denn die Untersuchung einer tendenziellen Fortsetzungsserie verspricht eine vielfältige Bandbreite an seriellen Strategien.

Um das spezifische Perry Rhodan-Konzept zu ergründen, ist es notwendig, zu untersuchen, inwiefern die Serie sich in das Konzept der modernen Massenmedien einfügt, da es von Bedeutung ist, in welchen Bereichen sich die Perry Rhodan-Serie wie andere Massenprodukte verhält und in welchen sie als Romanheftserie innovativ wird. Kagelmann skizziert die Unterhaltungsliteratur folgendermaßen: Sie wird massenhaft verbreitet und ist für einen schnellen problemlosen Konsum gedacht, ${ }^{855}$ denn die Literatur soll für alle Bevölkerungsschichten leicht verständlich sein, was durch die Wiederholung „bekannter, stereotyper inhaltlicher Elemente“ ermöglicht wird. ${ }^{856}$ Die Handlung darf nicht zu komplex werden; „Linearität der Handlungsführung“, sowie bekannte Normen und Wertvorstellungen sollen beibehalten werden. Die Handlung soll lediglich Spannung erzeugen. Die Produktion muss stets neue Elemente aufnehmen können, wobei traditionelle Schemata und Themen beibehalten werden müssen.

Aktuelle Ereignisse aus der Umwelt sollen zwar Verwendung finden, aber einen eventuell innovativen Charakter dieser Elemente nicht übernehmen. ${ }^{857}$ Die Unterhaltung soll zudem die Erwartungshaltungen der Leserschaft erfüllen und sich ihr anpassen. ${ }^{858}$ Der Beschreibung Kagelmanns ist zwar weitestgehend zuzustimmen, jedoch geht er nicht konkret auf die Bedeutung der einzelnen Punkte ein. Um zu ergründen, was für eine Art Massenkunstwerk die Perry Rhodan-Serie ist, ist es erforderlich auszuloten, inwiefern sie den anderen Massenkunstwerken entspricht. Noél Carroll, der intensiv auf die Bestimmung des Massenkunstwerkes an sich ein-

855 Jürgen $\mathrm{H}$. Kagelmann: Modellvorstellungen psychisch abweichenden Verhaltens in der Unterhaltungsliteratur. Berlin 1982. S. 109f.

856 Ebd.

857 Ebd. S. 110.

858 Ebd. 
gegangen ist, nennt im Wesentlichen die gleichen Aspekte wie Kagelmann. Durch eine intensive Beschäftigung mit Carrolls Konzept soll ein Ausblick auf das Gesamtkonzept der Perry Rhodan-Serie ermöglicht werden, das wiederum aufschlussreich im Hinblick auf den Bereich der Romanhefte generell ist. Die Kriterien, die Carroll benennt, sollen eine Richtlinie für ein allgemeines Konzept eines Massenkunstwerkes darstellen. Im weiteren Verlauf soll sich zeigen, inwieweit sich die Perry RhodanSerie an dieser Linie bewegt und in welchen Fällen die Serie abweicht.

Die mass society (Massengesellschaft) hatte ihren Aufstieg in Verbindung mit dem Kapitalismus, der Urbanisierung und der Industrialisierung. In dieser Phase hatte die mass art (Massenkunst) ihren entscheidenden Auftritt. Es begann mit den Druckpressen, welche die ersten potenziellen Massenkunstarten produzierten: Zeitschriften und Romane. ${ }^{859}$ Die Perry Rhodan-Serie war zu Anfang auch nur eine von zahlreichen Romanheftserien, bis der Verlag schließlich die ersten Perry Rhodan-Bücher herausbrachte. Die Erfinder von Perry Rhodan kommen aus dem Fachbereich der Massenkunst, speziell der Science Fiction. Die Serie wurde eigens für diese Sparte konzipiert. Welchen Stellenwert die Genrewahl in Hinblick Massenmedium hatte und welche Verpflichtungen damit einhergehen, davon soll später die Rede sein. Zunächst ist der Zweig des Massenkunstwerkes an sich interessant. Das Massenkunstwerk ist ein Produkt, das für einen großen Verbraucherkreis zugänglich ${ }^{860}$ und für eine größtmögliche Menge an Menschen leicht verständlich sein soll. ${ }^{861}$ Der Aspekt der leichten Zugänglichkeit ist ein wichtiger Punkt für Carroll, er betont, dass das Werk extrem benutzerfreundlich sein muss, damit es eine große Anzahl von Menschen ohne Anstrengung verstehen können. ${ }^{862}$ Es soll so benutzerfreundlich sein, dass sogar uneingeweihte Konsumenten einen sofortigen Zugang zu dem Werk haben. ${ }^{863}$

Wie sieht dies nun bei der Perry Rhodan-Serie aus? Neueinsteiger werden durch die Prologseite instruiert (siehe hierzu Kapitel 2. „Distribution und Erscheinungsbild“). Allerdings wird der Neueinsteiger nicht umfassend genug darüber informiert, wie

859 Carroll: Philosophy of Mass Art, vgl. S. 186.

860 Ebd. S. 188.

861 Ebd. S. 191.

862 Ebd. S. 192.

863 Ebd. 
Rhodan auf dem Mond gelandet ist und wie daraufhin die Geschicke der Menschheit in kosmische Angelegenheiten verstrickt werden, sondern der Leser wird lediglich darüber aufgeklärt, was sich im vorigen Heft zugetragen hatte. Er wird dergestalt informiert, dass er alle Handlungsstränge der vorliegenden Folge in den größeren Zusammenhang grob einordnen kann (vgl. Kapitel 8.1 „Die drei Phasen Einführung, Verlauf und Ende“). Doch ein Neuleser wird nicht sofort alle Hintergründe der Makroerzählung erfahren, da die Perry Rhodan-Serie zu umfangreich ist. Teilweise erfährt er nicht einmal alle Hintergründe einer Mikroerzählung, wenn diese mehrere Hefte umfasst. Egal bei welchem Heft der Leser einsetzt, er wird immer mitten in der Geschichte beginnen, ohne ausführlich vorbereitet worden zu sein. Die Benutzerfreundlichkeit ist hinsichtlich des Verständnisses der Handlungsstränge bei Perry Rhodan beeinträchtigt.

In den tendenziell episodalen Serien und den Reihen besteht dieses Problem nicht, da die einzelnen Hefte in der Regel abgeschlossen sind und somit immer eine abgeschlossene Mikroerzählung pro Heft vorliegt. Der Neuleser kann bei episodalen Serien wesentlich schneller einsteigen, da, wenn zusätzliche Informationen für den Konsum eines Heftes erforderlich sind, ein Prolog alles abdeckt. Aber auch Genrekonventionen helfen dem Leser durch bekannte Staffage, Plot- sowie Figurenkonstellationen einen sofortigen Zugang zur Handlung zu finden. Wenn ein Leser beispielsweise ein Heft aus der G.F. Unger-Reihe oder der Jerry Cotton-Serie wählt, muss zum Verständnis dieses Heftes kein Prolog aushelfen. In diesen Fällen werden Prologe meist nur für einen stimmungsvollen Einstieg verwendet (vgl. Kapitel 8.1 „Die drei Phasen - Einführung, Verlauf und Ende“).

Wenn nun der unerfahrene Perry Rhodan-Leser nicht zuvor von einem erfahrenen eingewiesen wurde, wird er sich trotz vieler unverständlicher Informationen zügig in die Serie einlesen können. Dies fördern unter anderem die Mikroerzählungen: Wenn der unerfahrene Leser nicht unbedingt die Makroerzählung kennt, wird er doch nach spätestens zwei Heften in die Mikroerzählung eingestiegen sein. Auf diese Weise können die Mikroerzählungen einem unerfahrenen Leser helfen, schrittweise in die Serie einzusteigen. Der Leser kann zunächst die Geschichte verfolgen, die er versteht. Mit der Zeit wird er die anderen Handlungsstränge auch verstehen können. Zudem fügt der Verlag in einigen Ausgaben Zyklen-Übersichten ein und häufig wird 
auch für weitere Produkte aus der Perry Rhodan-Serie geworben, die den Leser zusätzlich informieren, dies sind beispielsweise das Perry Rhodan-Lexikon, Internetseiten oder Infobroschüren. Zum Verständnis aktuell verwendeter Pseudofremdwörter helfen der Perry Rhodan-Kommentar und der Perry Rhodan-Glossar (siehe Kapitel 2. „Distribution und Erscheinungsbild“). Des Weiteren wiederholen die Autoren im Fließtext eines jeden Heftes kleine Details, damit diese das Gedächtnis des erfahrenen Lesers über bestimmte Fakten 'auffrischen' oder dem unerfahrenen Leser diese Fakten verständlich machen. Die eingestreuten Informationen erfolgen häufig gänzlich unmotiviert, demgemäß wird beispielsweise in einigen Heften immer wieder betont, dass Reginald Bull ein Aktivatorträger ist. Der Aktivatorchip ist ein Gerät, das dem Träger eine relative Unsterblichkeit verleiht ${ }^{864}$ und zum Teil benutzen die Autoren diesen Begriff auch als Synonym zum Namen der Figur:

„Shallowain erschien auf dem Trojaner. 'Es wird Zeit, Bull dass du mir Glück wünschst!', rief er provozierend. Der Aktivatorträger beobachtete ihn genau, jede seiner Bewegungen." ${ }^{865}$

Es ist nicht speziell für die Mikroerzählung jenes Heftes erforderlich, zu wissen, dass Bull ein Aktivatorträger ist, aber generell für die gesamte Serie. Diese Wiederholung findet nicht nur heftübergreifend statt, sondern auch zyklusübergreifend. Bull ist ein fester Bestandteil der Serie, deshalb ist es für den Leser entscheidend zu wissen, dass Bull solch ein Gerät trägt. Der unerfahrene Leser, der das Gerät nicht kennt, wird schnell merken, dass es etwas Besonderes ist, da die Autoren es wie ein Statussymbol einsetzen: „Der Aktivatorträger“. Hinzu kommt die besondere Funktionsweise des Geräts:

„Die Bilder aus dem Versorger waren an ihm vorbeigezogen, ohne dass er sie bewusst wahrgenommen hätte. Reginald Bull schreckte jäh aus seinen Gedanken auf, als seine Kopfhaut prickelnd spannte und eine eisige Kälte sein Rückgrat hinabfuhr. Zugleich registrierte er die belebenden Impulse seines Aktivatorchips. “866

Die wiederholte Erinnerung an den Aktivatorchip ist nicht auf die Figur Bulls beschränkt. Es wird auch für andere Aktivatorträger verwendet:

„'Perry!' Der Aktivatorträger schüttelte sich erneut. Gucky stand über inm,

864 Der Chip hält inn jung und gesund, schützt ihn aber nicht vor einer tödlichen Verletzung.

865 Perry Rhodan Bd. 2374, S. 39.

866 Ebd. S. 24f. 
betrachtete inn besorgt aus seinen großen Augen." ${ }^{867}$

Diese Information charakterisiert also einen wichtigen Bestandteil der Serie, aber nicht die laufende Handlung an sich. Es gibt hingegen Reminder, die sich durchaus auf einen Zyklus beschränken. Sie werden meist am Anfang eines Heftes ausführlich in die Erzählung verwoben, aber im weiteren Verlauf nur kurz angesprochen - wie im Beispiel der Figur Reginald Bull als Aktivatorträger. Wie bereits erläutert, ist Michael Rhodan, der Sohn Perry Rhodans, zu einem Doppelwesen mit dem Namen Dantyren transformiert, weshalb repetierend betont werden muss, dass Michael Rhodan Dantyren ein Dual, ein Doppelwesen ist:

„Es ging endlich voran. Der Dual, der nach wie vor auf seine Einstufung wartete, hätte zufrieden sein sollen. Er konnte es nicht. Vor allem die DantonKomponente des Zweierwesens vermochte die Gedanken an die Bedrohung nicht abzuschalten, die über CRULT schwebte."

Im weiteren Text des Heftes wird immer wieder daran erinnert, dass Dantyren aus zwei Hälften besteht. Aus gegebenen Gründen ist es nur wahrscheinlich, dass die Figur des Dantyren auf diesen Zyklus beschränkt bleibt. Dantyren ist ein Produkt eines Feindes von Rhodan, der Terminalen Kolonne, die deshalb ebenfalls wiederholt erklärt wird. Da die Terminale Kolonne der Hauptanlass des Zyklus ist, wird sie bereits im Prologtext benannt. Die zyklusinternen Reminder unterstützen das Verständnis der aktuellen Handlung, da jedes Heft in die Zyklushandlung eingebettet ist. Zudem dienen sie der Benutzerfreundlichkeit. Gelegentlich gibt es auch Wiederholungen, die sich auf ein einzelnes Heft beziehungsweise auf eine Mikroerzählung beschränken. Dies wird in der Regel in der Serie herangezogen, um die Stimmung bestimmter Orte zu charakterisieren, und danach immer wieder in einer ähnlichen Form in repetiert. So wird das Innere eines Dunklen Ermittlers, ein Raumschiff der Terminalen Kolonne, immer wieder als unnatürlich beschrieben und als ein Ort der den Menschen die Sinne verwirrt:

„Sie schlug die Augen auf - und schloss sie sofort wieder, als sie das Grau der pulsierenden Wände sah. Schon der Anblick verstärkte ihre Übelkeit." ${ }^{669}$

Alle Szenen, die in dem Raumschiff spielen, werden ähnlich beschrieben und laufen

867 Perry Rhodan Bd. 2382, S. 48.

868 Perry Rhodan Bd. 2363, S. 6.

869 Perry Rhodan Bd. 2381. Der Dunkle Ermittler. Uwe Anton. 1. Aufl. Pabel-Moewig-Verlag. S. 18. 
auf folgende Schlussfolgerung hinaus: Dass die Menschen dort an Bord vom Raumschiff selbst nicht erwünscht sind:

„Es lag einfach an der Natur des Schiffes, dass Menschen hier nicht wohlgelitten waren." 870

Dies wiederholt der Autor im Text mehrmals ohne große Variationen:

„Sie gehörten nicht hierher, und das Schiff strahlte diese Botschaft auf einem unbekannten mentalen Weg wie eine permanente, verletzende Missbilligung gegen sie aus. " 871

Ähnlich wie die Beschreibungen der Figuren wird das Raumschiff nach bestimmten Richtlinien dargestellt. Diese verwenden die Serien-Autoren, wie in einem Ritual, immer wieder. Die Repetition der Darstellung erhöht die Wahrscheinlichkeit, dass auch jeder Leser verstanden hat, worauf es bei dem Schiff ankommt: Die Ablehnung der Menschen. Auf dieselbe Weise wird innerhalb einer Mikroerzählung immer wieder die Fremdheit und Bedrohlichkeit eines Gebäudes heraufbeschworen:

„Sein neuer Freund wies auf eine lang gestreckte, vier Meter hohe Hecke. Sie schirmte alles perfekt ab. Simpel, aber effektiv. Natürlich verbarg sie nur die ersten Stockwerke des gewaltigen turmartigen Bauwerks dahinter. Grau, unauffällig und nach oben verjüngt ragte es nach Savoires Einschätzung mindestens zweihundert Meter hoch auf. Es besaß einen sechseckigen Grundriss. Und es strahlte etwas Unheimliches aus. Diesen Eindrucks konnte sich Savoire nicht erwehren, vielleicht wegen der ebenso unpraktischen wie unzeitgemäßen engen, schießschartenartigen Fenster." ${ }^{872}$

Es entsteht der Eindruck eines ungemütlichen, kantigen Turmes, ähnlich einem mittelalterlichen Wehrturm, mit Schießscharten und einem sechseckigen Grundriss. Diese Charakterisierung wiederholt der Autor in der Mikroerzählung mehrmals, um diesen sogenannten „Escherturm“ zu beschreiben:

„Sie sahen das Gebäude in seiner vollen Größe von 250 Metern. Der Grundriss war sechseckig, man sah es am Kantenverlauf des Gesims. Das ESCHER-Haus besaß schmale, hohe Fenster, die an Schießscharten erinnerten. Entsprechend seiner Funktion wirkte es unauffällig, beinahe schon auffällig unauffällig in einer so bunten Metropole wie Terrania." ${ }^{873}$

Wiederholungen, die sich nur innerhalb einer Mikroerzählung abspielen, sind für das

870 Ebd. S. 29.

871 Ebd.

872 Perry Rhodan Bd. 2377, S. 18.

873 Perry Rhodan Bd. 2379, S. 7. 
Verständnis der kompletten Serie nicht relevant. Sie helfen dem Leser lediglich, ohne große Konzentration die vorliegende Handlung verfolgen zu können. Durch die Wiederholung der Charakterisierung bestimmter Orte oder Gegenstände braucht der Leser sein Gedächtnis nicht zu strapazieren, wie der Ort beschaffen war, es wird ihm immer wieder vor Augen geführt.

Dies führt zu einem weiteren Punkt der leichten Zugänglichkeit: Der Simplizität. Hiermit ist keine möglichst schlichte Handlung gemeint, denn dafür ist die Handlung in der Perry Rhodan-Serie zu komplex. Es geht hierbei um die Simplizität der Elemente, die verwendet werden: Die Figuren. In Kapitel 6. „Halbwertszeit von Serienfiguren“ wurde untersucht, wie die Autoren Figuren einsetzen und welche wiederkehrenden Regeln sie dabei beachten. Dies hat zum einen produktionsökonomische Gründe, zum anderen aber auch den Effekt, dass erfahrene Leser sofort wissen, wie einige Figuren reagieren werden. Bei Reginald Bull beispielsweise wissen die erfahrenen Leser, dass sein ungestümes polterndes Wesen inn in Probleme bringen wird. Anhand dieser oberflächlichen Merkmale weiß auch der unerfahrene Leser, wie Bull reagieren wird, da diese Merkmale dermaßen plakativ dargestellt wurden, dass Fehlinterpretationen unwahrscheinlich sind. Folglich unterstützt eine Stereotypisierung der Serienfiguren die Eindeutigkeit und Einheitlichkeit ihrer Beschreibungen.

Die Spaltenform des Fließtextes trägt ebenfalls dazu bei, dass der Leser sich nicht allzu sehr anstrengen muss, um den Text zu lesen. Durch den schmalen Textblock verliert der Blick nicht so schnell die Zeile und durch häufige Absätze wird der Text in kleinen Sinnabschnitten präsentiert (siehe Kapitel 2. „Distribution und Erscheinungsbild“). Das erleichtert zum einen die intellektuelle und zum anderen die rein optische Aufnahme. Das macht die Hefte zur optimalen Gelegenheitslektüre, die sich bequem an öffentlichen Plätzen, in der Bahn et cetera konsumieren lässt (ähnlich wie Magazine und Zeitungen). Die Heftseiten sind ausführlich beschriftet mit Seitenzahlen, Kapitel-Titeln und Hefttitel, sodass dem Leser immer bewusst ist, welche Ausgabe er gerade liest und an welcher Stelle er sich befindet. Damit ist die äußerliche Konzeption ebenso auf eine Benutzerfreundlichkeit abgestimmt wie die inhaltliche.

Trotz eines einleitenden Prologs und zahlreichen Wiederholungen sind besonders 
die Perry Rhodan-Geschichten reichhaltig an von den Autoren erdachten Pseudofremdwörtern (vgl. Kapitel 5.2 „Serieninsider“). Diese werden nicht immer erklärt und erschließen sich nicht unbedingt aus dem Zusammenhang. Nach Carroll gibt es kaum Massenkunstwerke, die unverständlich sind, sondern höchstens solche, die ein spezialisiertes Publikum bedienen, aber auch für Science Fiction-Experten bleiben viele dieser Begriffe unverständlich. Wie kann also eine Serie trotz zahl reicher Kryptizismen so erfolgreich werden? ${ }^{874}$

Die Antwort liegt hier in der Entwicklungsgeschichte der Serie. Zu Beginn wurden nur wenige Pseudobegriffe verwandt, erst mit der Zeit kamen neue hinzu. Durch den steigenden Erfolg konnten sich die Produzenten auch mehr solche Blackbox-Begriffe erlauben, da mehr Stammleser hinzukamen, die es akzeptierten (vgl. Kapitel 5.2 „Serieninsider"). Da in der deutschen Science Fiction-Gemeinde Perry Rhodan seit jeher präsent war und häufig deutsche Science Fiction mit Perry Rhodan in einem Atemzug genannt wurde, war es damals unwahrscheinlich, dass Perry Rhodan durch zu viele Insiderbegriffe neue Leser verprellte (vgl. Kapitel 4.7 „Science Fiction“ und Kapitel 4.8 „Der Fall 'Perry Rhodan'“). Jedoch muss auch ein erfahrener Science Fiction-Leser sich erst in das Perry Rhodan-Vokabular hineinlesen. Die Perry Rhodan-Serie hat sich zwar nicht dezidiert von Trends in der Science Fiction abgegrenzt, aber dennoch eine Insidergruppe geschaffen. Doch das Fachvokabular wurde nicht in die Serie eingeführt, um vorsätzlich unverständlich zu sein. Vielmehr war die Anhäufung der Fachbegriffe ein schleichender Prozess über zirka 45 Jahre hinweg. Sie haben sich schlichtweg angesammelt (vgl. Kapitel 5. „Erzählökonomie und Serieninsider").

Dies bedeutet nun für die Zugänglichkeit, dass es unwahrscheinlich ist, dass die Serie Nicht-Science-Fiction-Leser anzieht. Auch Science-Fiction-Lesern hilft ihr Genrewissen nicht, wenn sie das Perry Rhodan-Vokabular nicht kennen. Sie sind höchstens gewöhnt, dass Science Fiction-Autoren Pseudofremdwörter gelegentlich verwenden, und dass sie als Leser diese lernen müssen. Aber nach Carroll soll das Massenkunstwerk die Massen beherrschen. ${ }^{875}$ Die vielen Pseudofremdwörter machen die Perry Rhodan-Geschichten unzugänglicher als andere Science Fiction-

874 Im Bereich der Science Fiction ist es nicht unüblich, auf Pseudofremdwörter zu treffen. Doch die Perry Rhodan-Serie hat eine unüblich umfassende Fülle dieser Pseudofremdwörter.

875 Carroll: Philosophy of Mass Art, S. 192. 
Geschichten wie beispielsweise die Maddrax-Serie. Wie aber kommt die Serie zu so einer hohen Lebensdauer?

Das Produkt muss laut Carroll zunächst die Aufmerksamkeit eines potenziellen Lesers auf sich ziehen. ${ }^{876}$ Dies geschieht bei Perry Rhodan vorerst durch das aufwendig gestaltete Deckblatt (siehe Kapitel 2. „Distribution und Erscheinungsbild“) mit ungewöhnlichen Titeln. Zu Beginn der Serie wurde mit bereits bekannten Namen der Autoren geworben: Ernsting und Scheer hatten zu dem Zeitpunkt einige erfolgreiche Veröffentlichungen. Des Weiteren warb der Verlag damals mit dem Slogan „PERRY RHODAN - der Erbe des Universums - Die große WELTRAUM - Serie“ (Serientitelblock, siehe Kapitel 2. „Distribution und Erscheinungsbild“). Hier war zudem eine Anspielung auf „SUN KOH - der Erbe von Atlantis“ eingesetzt, um so die Liebhaber der alten Serie anzusprechen. Dies enthielt auch den Hinweis, dass die Perry Rhodan-Serie, im Gegensatz zu den anderen Science Fiction-Reihen, eine durchgehende Serie wie Sun Koh war. Perry Rhodan war nicht etwas komplett Neues, sondern lediglich aus bewährten Elementen zusammengesetzt. Auf diese Weise entstand ein Wiedererkennungseffekt. Leser, die sich damals bereits für Sun Koh und ähnliche Serien interessierten, würden sich auch für das neue Produkt Perry Rhodan interessieren (so vermutlich die Marketingstrategie). Heute wird mit dem Slogan „Die größte Science Fiction-Serie“ geworben - wobei die Produzenten allerdings auch hier auf Altbewährtes setzten, nämlich auf den vorangegangenen Erfolg der Serie selbst und nicht auf den anderer Serien. Durch das Deckblatt soll der erste Kontakt hergestellt werden, dann wird der Leser gegebenenfalls den Prologtext überfliegen, um zu erfahren, worum es in dem Heft geht. Durch die Fülle an Namen und Ereignissen, die in der Regel im Prologtext erwähnt werden, kann der Leser erahnen, dass diese Serie komplex ist.

Ist der Leser nach diesen ersten Eindrücken gewillt das Heft zu lesen, wird die nächste Funktion des Massenkunstwerks entscheidend. Es soll das Interesse des Konsumenten aufrechterhalten. ${ }^{877}$ Wie bereits erwähnt, sind die Titelbilder einiger Fortsetzungsserien mit dem Inhalt so abgestimmt, dass der Leser auf dem Bild nur Elemente wiederfindet, die in dem Heft auch vorkommen. Angesichts dessen ist der

876 Ebd. S. 195.

877 Ebd. 
Anspruch gesichert, dass der Text die Erwartungen erfüllt, die das Titelbild geweckt haben könnte. Der Fließtext soll verständlicherweise bei dem Leser Interesse wecken und hat deshalb den Anspruch interessant und spannend zu sein. Es wird von den Autoren ein gewisses Maß an Qualität abverlangt, was im Verlag von Perry Rhodan unter anderem dadurch motiviert wird, dass sie für erfolgreiche Geschichten Prämien erhalten.

Das entscheidende Element, das ein Interesse an dem Verlauf der Serie aufrechterhalten soll, ist der Schlusstext (siehe Kapitel 2. „Distribution und Erscheinungsbild“). Dieser Preparer gibt einen Ausblick auf das nächste Heft und verknüpft zugleich die Handlung des aktuellen Heftes mit der kommenden (vgl. Kapitel 8.6 „Die Vorankündigung“). Bei tendenziell episodalen Serien erfolgt in der Regel lediglich eine Ankündigung der nächsten Episode.

Nicht nur das bloße Interesse an der Geschichte soll angesprochen werden, sondern auch Vorlieben der Science Fiction-Liebhaber - also der Genreleser - für Wissenschaft und Technik. Deshalb erscheint vierwöchentlich als Beilage im Heft das Perry Rhodan-Journal. Dem vergleichbar erscheinen in den Jerry Cotton-Heften Berichte zu Verbrechen und in den Landser-Heften historische Bilder und Datenblätter. In dem Journal wird etwa eine Auswahl an neuesten Erkenntnissen aus der Forschung berichtet; in der Regel zur Weltraumforschung.

Die Pseudofremdwörter der Perry Rhodan-Serie bleiben problematisch in Bezug auf den Anspruch leicht zugänglich zu sein und ein erstes Interesse zu erwecken. Die Perry Rhodan-Serie wird dem Anspruch (des masenmedialen Kunstwerks nach Carroll) nicht gerecht, beim ersten Kontakt verständlich zu sein. Ihre Komplexität erfüllt eher die Erwartungen einer Gruppe von Lesern, die sich von anderen abgrenzt. Perry Rhodan enthält Insider-Informationen, die nur für erfahrene Leser verständlich sind.

Immer wieder erklärt die Serie die nötigsten Informationen und ein unerfahrener Leser wird nach kurzer Zeit lernen, wie er die Geschichte zu verstehen hat beziehungsweise wie ihre Erzählweise funktioniert. Insofern erfüllt die Serie wiederum einen weiteren Anspruch eines Massenkunstwerkes, seine Konsumenten eigenständig zu trainieren ${ }^{878}$ - nur benötigt dieser Vorgang längere Zeit. Einem neuen

878 Ebd. S. 193. 
Perry Rhodan-Leser stellen sich potenziell größere Verständnisschwierigkeiten als beispielsweise einem G.F. Unger-Leser bei der Wildwestroman-Lektüre, da er einerseits zahlreiche Reminder zu bereits begonnenen Handlungssträngen verstehen muss, um der aktuellen Handlung folgen zu können und andererseits ist er mit einem umfangreichem Serien-Vokabular konfrontiert. Aber durch die große Stammleserschaft kann Perry Rhodan sich diese 'Einstiegsschwelle' erlauben. Die Serie hat aus dieser Hürde eine Tugend gemacht und bietet am Ende vieler Hefte 'Einstiegshilfen' in Form fiktiver Lexikonartikel. Diese Lexikonartikel führen den Lesern vor Augen, dass es in der Perry Rhodan-Serie zu jedem Fremdwort eine Hintergrundgeschichte gibt. Kennt der Leser sich mit dem Aufbau des Heftes aus, weiß er sofort wo er neue Pseudofremdwörter nachschlagen kann. Auf diese Weise schult die Serie ihren Leser.

Die Handlung der Perry Rhodan-Serie ist zugänglich durch die zahlreichen Stützen. Eine rein episodale Serie wie Jerry Cotton braucht keine inhaltlichen Stützen für seine Leser, da der Ausgangspunkt bei episodalen Serien immer der Status Quo ist. Je komplexer der Inhalt wird, umso mehr Stützen benötigt die Serie.

Ein Serienleser - also bei diesem Beispiel der Perry Rhodan-Leser - muss nur daran interessiert sein, sich auf das Heft einzulassen, das er liest. Es ist möglich, jederzeit bei einem beliebigen Heft einzusteigen; um jedoch ein Leser zu werden, der die (Fortsetzungs-)Serie vollständig verfolgen kann, das heißt zu wissen, in welchem Kontext alle geschilderten Ereignisse stehen, sollte man etwa drei Hefte in Folge lesen. Zwei Hefte könnten innerhalb der Perry Rhodan-Serie unter Umständen zu wenig sein, da sehr häufig beim Folgeheft ein anderer Handlungsstrang weitererzählt wird als im vorangegangenen Heft. Doch das dritte Heft nimmt in der Regel wieder den Handlungsstrang des ersten Heftes einer solchen Sequenz auf. Gemäß dieser Lesart wäre dem unerfahrenen Perry Rhodan-Leser die Chance gegeben, seine Erfahrungen mit dem ersten Heft auf das dritte anzuwenden. Zumal würden Reminder eines einzelnen Heftes nicht ausreichen, um einen neuen Leser umfassend ins Bild zu setzen, doch die Lektüre weiterer Hefte würde den Leser entsprechend "schulen“. Das Verständnis der Serie hängt demnach nicht von einem besonderen Vorwissen ab, sondern von dem Willen des Leser, sich durch die Serie 'schulen' zu lassen. 
Carroll schreibt zu dieser Problematik, dass Konsumenten häufig meinen, ein Produkt sei nicht verständlich, was aber nur daher rührt, dass sie sich nicht auf das Produkt eingelassen haben. ${ }^{879}$ Perry Rhodans Konzeption ist genrespezifisch, so wie die anderer Romanheftserien und -reihen auch. Deshalb sind für Romanheftserien immer die speziellen Genreerwartungen der Leser relevant. Ein Massenkunstwerk ist darauf ausgerichtet, Erwartungen zu erfüllen. ${ }^{880}$ Ein entscheidender Punkt bei einer Serie wie Perry Rhodan, die sich entsprechend lange gehalten hat. Vor 45 Jahren waren die Vorstellungen von einer Science Fiction-Serie andere als heute. In den 1950er Jahren interessierten sich Science Fiction-Leser für militaristische Abenteuer $^{881}$ und die Eroberung des Weltraums. ${ }^{882}$ Damalige Leser erwarteten Kampfhandlungen mit technisch hochentwickelten Waffen im Weltraum, zudem stand die Entwicklung der Raumfahrt im Interesse der Öffentlichkeit. ${ }^{883}$

Die Perry Rhodan-Serie folgte diesem Genretrend, indem sie mit einer Militärexpedition zum Mond begann und die Besatzung in Kampfhandlungen verwickelte. Dieser 'Krieg der Sterne' ist ein Element in der Science Fiction, das nicht mehr wegzudenken ist und mit der Zeit immer weiter in den sogenannten Space Operas stilisiert wurde. ${ }^{884}$ Diese entwickelten sich von der rein technisch orientierten Linie fort zu den eher exotischen Aspekten der Raumfahrt. ${ }^{885}$ Die Perry Rhodan-Serie machte diese Wandlung allerdings nicht vollständig mit. Aktionsorientierte Weltraumschlachten bleiben immer ein roter Faden in den Geschichten (vgl. Kapitel 4.7 „Science Fiction und Space Opera“). Aber die Serie ist auch nicht mehr der „LandserKriegsroman des Weltraums“ par excellence. ${ }^{886}$ In der Serie ist ein Krieg zwar meist Aufhänger für eine Ausgangsposition, aber einige Mikrogeschichten orientieren sich thematisch an der New Wave (vgl. Kapitel 4.7 „Science Fiction und Space Opera“). ${ }^{887}$ Diese Entwicklung begann mit der Hinwendung zu humanistischen Tendenzen, daher

\footnotetext{
879 Ebd. S. 205.

880 Ebd. S. 193.

881 Manfred Nagl: Science Fiction in Deutschland. Tübingen 1972. S. 199. Viele Science FictionLeser lasen vermehrt die Landser-Romane.

882 Ebd. S. 202f.

883 Nagl: Science Fiction in Deutschland, S. $206 f$.

884 Alpers: Lexikon der Science Fiction Literatur. Bd. 1, S. $59 \mathrm{ff}$.

885 Ebd. S. 63.

886 So wird die Serie jedenfalls in Alpers: Lexikon der Science Fiction Literatur Bd. 1 dargestellt. Vgl. S. $76 f$.

887 Tendenz in den 70ern sich mehr mit der Psyche der Menschen zu beschäftigen. Vgl. hierzu u.a. Hans-Joachim Alpers, Werner Fuchs, Ronald M. Hahn (Hg.): Reclams Science Fiction Führer. Stuttgart 1982. S. 485.
} 
wird beispielsweise in der Mikrogeschichte um den Wissenschaftler Savoire (vgl. Kapitel 4.8 „Der Fall 'Perry Rhodan'“) die Bedeutung von Realität thematisiert. Die Perry Rhodan-Serie versucht mehrere Gebiete der Science Fiction abzudecken. Ein Leser, der mit den klassischen Erwartungen einer Raumschlacht an den Text geht, wird ebenso befriedigt wie ein Leser, der sich dafür interessiert, wie ein Mensch sich fühlt, wenn sein Gehirn in ein kollektives Bewusstsein integriert wird (siehe die Figur Savoire). Diesen Anspruch erfüllt nicht jedes Heft gleichzeitig, aber wechselweise durch die unterschiedlichen Stile der Mikrogeschichten.

Auch in den anderen Genres gab es einen entsprechenden Wandel oder Akzentverschiebungen in den Konventionen (vgl. Kapitel 4. „Genres der Romanhefte und ihre Besonderheiten"). Aber es geht bei den Lesererwartungen nicht nur um genrespezifische Erwartungen, sondern auch um die Erwartungen des Gewohnten. Da das Massenkunstwerk selbst unterrichtet, wie es zu lesen ist, folgt es bestimmten Regelmäßigkeiten. Diese prägt sich der Leser ein und erwartet sie in den folgenden Heften. Dazu gehören auch die Erklärungen einiger Pseudofremdwörter, wobei selbst die erfahrenen Leser nicht alle Begriffe kennen können. Durch eine gezielte Abdeckung möglicher Genretrends und Lesererwartungen lässt sich bei einer spezialisierten Leserschaft ein größtmögliches Spektrum von ihren Interessen abdecken.

Laut Carroll ist die Formelhaftigkeit des Massenproduktes ebenfalls ein Teil der zu erfüllenden Erwartungen des Lesers. ${ }^{888}$ Die Formelhaftigkeit bezieht sich hierbei auf die klare Trennung von Gut und Böse. Diese gibt es auch bei Perry Rhodan, nur dass diese zwei Gegenpole nicht unbedingt durch eine einzelne Figur verkörpert sind. Zudem hat sich in Kapitel 6. „Halbwertszeit von Serienfiguren“ gezeigt, dass die Serie eigene Stereotypen entwickelte, die sich schnell erkennen und wiedererkennen lassen. Vom Genre abhängige Stereotypen zu verwenden hingegen ist eine Praxis, die ausgiebig in den tendenziell episodalen Serien und Reihen Anwendung findet.

Bei Perry Rhodan besteht indes die entscheidende Formelhaftigkeit eher in der Einbindung der Figuren, sodass der Leser schnell lernen kann, welche Figuren Langzeit-Bedeutung (Kern bis II. Peripherie) haben und welche einen einmaligen Auftritt (III. Peripherie). Jedoch erfährt der Leser nur, welche ungefähre Tragweite ihr Handeln für die Makroerzählung hat, aber kaum etwas darüber, was weiter mit der

888 Carroll: Philosophy of Mass Art, S. 194. 
Figur passiert, sofern diese nicht Teil des erzählerischen Kerns ist. Es bleibt deshalb für den Leser spannend, ob die Figur überlebt und es können sich Tendenzen in der Entwicklung einiger Figuren abzeichnen, sodass ein erfahrener Leser das Ende einer Figur bereits erahnen kann. Doch geht dies nicht streng formelhaft vonstatten, sondern wird gegebenenfalls nach den Erwartungen der Leser entschieden, wie zum Beispiel im Falle Guckys.

Eine formelhaft strukturierte Geschichte ist leicht zu verfolgen und macht sie zugänglicher. ${ }^{889}$ Diese Formelhaftigkeit und der Anspruch, die größtmögliche Menge an Menschen zu erreichen, führt zu einer Homogenität, ${ }^{890}$ welche wiederum das Produkt benutzerfreundlicher macht. Die Homogenität erreicht der Verlag bei Perry Rhodan durch strenge Exposévorgaben, welche aus der progressiven Handlungsstruktur resultieren.

Das Höchstmaß an Homogenität wird durch die Wechselwirkung zwischen der Exposévorgabe und der vorherrschenden Formelhaftigkeit der Figuren erreicht. Hingegen variieren die Stile der Mikroerzählungen. Elemente, die ein Exposé nicht fixiert, dürfen die Autoren frei und innovativ entwickeln, wodurch eine Mannigfaltigkeit unter den Heften entstehen kann. Allerdings werden Elemente, die im Exposé festgelegt sind, von allen Autoren gleich beschrieben und in ihre Geschichte sinnvoll eingebaut. Auf diese Weise lassen sich Innovation und Homogenität miteinander kombinieren beziehungsweise zeigt sich hier ihre Wechselwirkung: Ein Balanceakt zwischen Anteilen von Homogenität und Innovation. Die Homogenität beziehungsweise Formelhaftigkeit ermöglicht eine leichtere (inhaltliche) Zugänglichkeit und Verständlichkeit, jedoch müssen auch genügend neue Elemente geboten werden, um für den Konsumenten relevant (beziehungsweise interessant) zu bleiben.

Andersherum betrachtet ermöglicht gerade erst die Homogenität, Neuerungen zu akzentuieren. Dies meint, dass gerade der Freiraum der Autoren im Bereich der Mikroerzählungen nur durch die konstante Struktur der Rahmenbedingungen (Exposévorgaben, starre Hauptfiguren, Textumfang) sichtbar wird; allerdings nur für den kontinuierlichen Rezipienten. Die konstanten Arbeitsvorgaben bieten den Autoren trotzdem ein wenig Spielraum, innerhalb der strengen Richtlinien zu variieren. Erst dies ermöglicht überhaupt Innovationen, denn ohne Regeln gibt es auch keinen Ver- 
stoß gegen Regelungen, womit sich eine scheinbar „paradoxe Innovationskraft wiederholten Erzählens“"891 ergibt.

\subsection{Massenkunstwerk oder nur Produkt?}

Im Folgenden soll mitnichten eine Diskussion darüber eröffnet werden, was Kunst ist und wo sie heute steht. Allerdings muss auf die Argumente von Carroll zurückgegriffen werden, um das Romanheft im Bereich der massenmedialen Kunstwerke genauer zu verorten. Nach Carroll ist das Avantgardekunstwerk ein Kunstwerk, das kompliziert und nur durch intellektuelle Leistungen erfassbar sein soll. ${ }^{892}$ Es soll mit Erwartungen brechen, sie untergraben und sich als ein Original herausstellen - also beinahe gegenteilig zu dem, was Romanhefte und das Massenkunstwerk anstreben. Das Avantgardekunstwerk nutzt in einigen Fällen die Möglichkeiten des Massenmediums, wodurch es aber noch nicht zum Massenkunstwerk wird. Auf diesem Wege will das Avantgardekunstwerk den Massenkonsum problematisieren.

Carroll grenzt die Massenkunst von der „Popular Art“ ab, beziehungsweise er definiert sie als eine Unterkategorie der „Popular Art“. 893 „Popular Art“ ist etwas, was alle konsumieren, doch sieht Carroll einige begriffliche Problematiken: Der Begriff ist unhistorisch. Er kann die Kunst des Volkes zum einen meinen, zum anderen aber auch beliebte Kunst. Der Begriff der „Mass Art“ hingegen ist historisch verortbar, da das massenmediale Kunstwerk erst ab dem Zeitpunkt der Industrialisierung möglich war $^{894}$ - das Zeitalter, in dem unter anderem auch der Feuilletonroman seinen Anfang nahm, welcher die Grundbedingungen für das Romanheft begünstigte.

Auf diese Weise ist "Mass Art" eine genauere Bezeichnung, da sich die Massenkunstwerke nur in den Gesellschaften finden lassen, die massenhaft konsumieren. ${ }^{895}$ Im Vergleich dazu ist „Popular Art“ viel allgemeiner und nicht alles, was „Popular Art“ ist, muss „Mass Art“ sein. Dies könnten beispielsweise Boxkämpfe oder Musicals sein, die nicht immer über Massenmedien verbreitet werden. Erst die Ausstrahlung dieses Ereignisses wäre eventuell ein massenmediales Kunstwerk.

891 Kelleter: Populäre Serialität. Eine Einführung, S. 26.

892 Ebd. S. 191.

893 Ebd. S. $184 \mathrm{ff}$.

894 Ebd.

895 Ebd. S. $185 f$. 
„Mass Art is Art" ${ }^{496}$, nur demnach keine Avantgardekunst. Die Massenkunst hat ihren Ursprung in der traditionellen Kunst insofern, als dass ihre verschiedenen Ausprägungen Erweiterungen der Kunstgattungen sind:: ${ }^{897}$ Malerei, darstellende Kunst, Schauspiel, Dichtkunst und Schriftstellerei. Sie enthält, kurz gefasst, kreative Arbeit in einem Werkstück, welches nicht passiv ist, sondern in Interaktion mit seinem Rezipienten tritt. Dies ist in Hinblick auf das Romanheft ein streitbarer Punkt, denn in einigen Romanheftserien wird in einem Forum die Qualität des Werkes diskutiert. Hierbei wird beachtet, in welchem Format (begrenzte Produktionszeit, limitierte Seitenanzahl, Einhaltung der Genre- und Serienkonventionen) das Werkstück produziert wurde. Außerdem äußern die Leser in den Foren Wünsche, die die Autoren gelegentlich in die Serie einfließen lassen. Diverse andere Romanheftserien und reihen weisen diesen Diskurs nicht auf. Dies lässt sich über die serielle Form aufteilen: Die tendenziellen Fortsetzungsserien haben ausnahmslos ein Forum. Die tendenziellen episodalen Serien und die Reihen haben kein solches Forum. Letztere serielle Ausprägung fällt für die vorliegende Betrachtung heraus. Somit bleiben lediglich die tendenziellen Fortsetzungsserien übrig. In diesem Bereich der Romanhefte scheinen sich potenzielle Ansätze für mögliche Aspekte eines massenmedialen Kunstwerkes finden zu lassen. In dem Bereich der tendenziellen Fortsetzungsserien der Romanhefte werden die Produkte mit ihren Rezipienten diskutiert und in einigen Fällen auch entsprechend angepasst. Einige Autoren wie beispielsweise Heinz Werner Höber sind durchaus offen für Experimente (vgl. Kapitel 3 „Produktion“). Doch zeigt sich hier schlussendlich, dass es im Bereich der Romanhefte nur potenzielle Ansätze sind. Einige Autoren mögen sich selbst als Künstler und Schriftsteller verstehen, doch ihre Produkte im Bereich der Romanhefte werden nicht als solche rezipiert, geschweige denn rezensiert.

Das Romanheft hat seinen Ursprung in den traditionellen Künsten wie der Schriftstellerei. Zudem sind diverse Werke aus der Evolutionskette der Romanhefte nachträglich zu 'Literatur' erhoben worden, wie beispielsweise einige Feuilletonromane. Folglich lag der Griff zu anderen Strömungen aus diesem Bereich für Vergleiche zur Beschreibung des Phänomens "Romanheft" nahe, doch waren diese in der Regel nicht zutreffend. Wahrscheinlicher ist, dass die Serienform selbst, egal in welcher

896 Ebd. S. 197.

897 Ebd. 
massenmedialen Ausprägung, in den Fokus einer künstlerisch-ästhetischen Debatte gerät. Das Romanheft würde sich lediglich, wie es bisher immer seine Natur war, dieser Strömung anpassen. Insofern ist es konsequent, dass gut laufende Fortsetzungsserien wie Perry Rhodan oder Maddrax auf lange Sicht das Medium wechseln, in welchem die serielle Narration die besten „Umweltbedingungen“ findet: E-Books, Audiobooks et cetera. So finden sich beispielsweise unter den E-Books auf der Google-E-Book-Verkaufsplattform "Google Play Bücher" Dr. Norden- oder Maddrax-Hefte. Auf der Hörspiel-Verkaufsplattform „Audible“ finden sich entsprechend John Sinclair- oder Perry Rhodan-Hörbücher und -Hörspiele.

Der Text wird zum einen auf mehreren Ebenen vermarktet, zum anderen wird er neu interpretiert. Dies bietet die Möglichkeit einen ganz neuen Kundenkreis zu erschließen, der lieber hört als liest. Darüber hinaus eröffnet es auch die Chance für AltLeser den gleichen Stoff in einer neuen medialen Form neu zu erleben und nochmals zu konsumieren. Da es auch einen starken Trend zum Hörbuch gibt, ist es für die Verlage eine Option sich neu in den Markt einzugliedern. Ein Lassiter-Hörbuch kann jetzt neben einem Hörbuch von „Herr der Ringe“ vermarktet werden. Das Hörspiel und Hörbuch sind nur eine Variante des Medienwechsels: Unter anderem gab es eine John Sinclair-TV-Serie, Jerry Cotton-Kinofilme, Perry Rhodan-Comics, ein Maddrax-Rollenspiel, Perry Rhodan-Brett- und Videospiele sowie diverse Internetauftritte. ${ }^{898}$ Kathrin Buck hingegen prognostizierte, dass das Romanheft der Konkurrenz moderner Medien standhalten wird, ${ }^{899}$ doch da immer mehr Presse-Erzeugnisse von Print in den digitalen Sektor hinüberwechseln, ist es wahrscheinlicher, dass das Romanheft den gleichen Weg geht.

898 Vgl. für die Verfilmungen u.a. Christopher Klaese: Vom Bahnhofskiosk auf die deutsche Leinwand - Deutsche Romanheftverfilmungen. In: Die Jerry-Cotton-Filme. Als Jerry Cotton nach Deutschland kam. Hrsg. von Joachim Kramp und Gerd Naumann. Stuttgart 2011, S. 133143. S. $139 f f$.

899 Buck: Der Heftroman, S. 111. 


\section{Anhang - Abbildungen}

Alle Abbildungen in der vorliegenden Arbeit erfolgen dem Zitatrecht gemäß $\S 51$ UrhG.

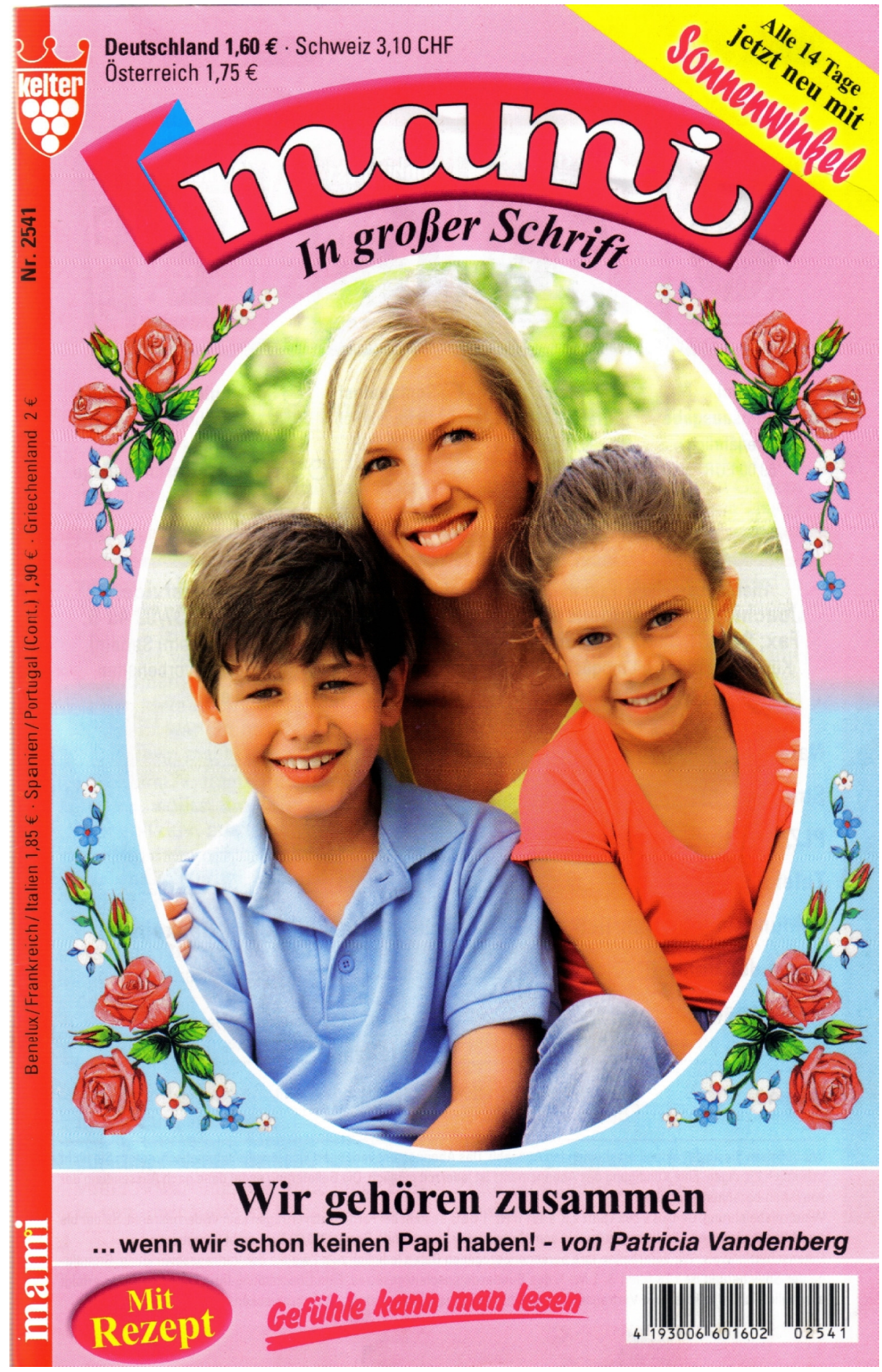

Abbildung 1: Frontcover - Mami Bd. 2541. Wir gehören zusammen. Patricia Vandenberg. 1. Aufl. Kelter-Verlag. 


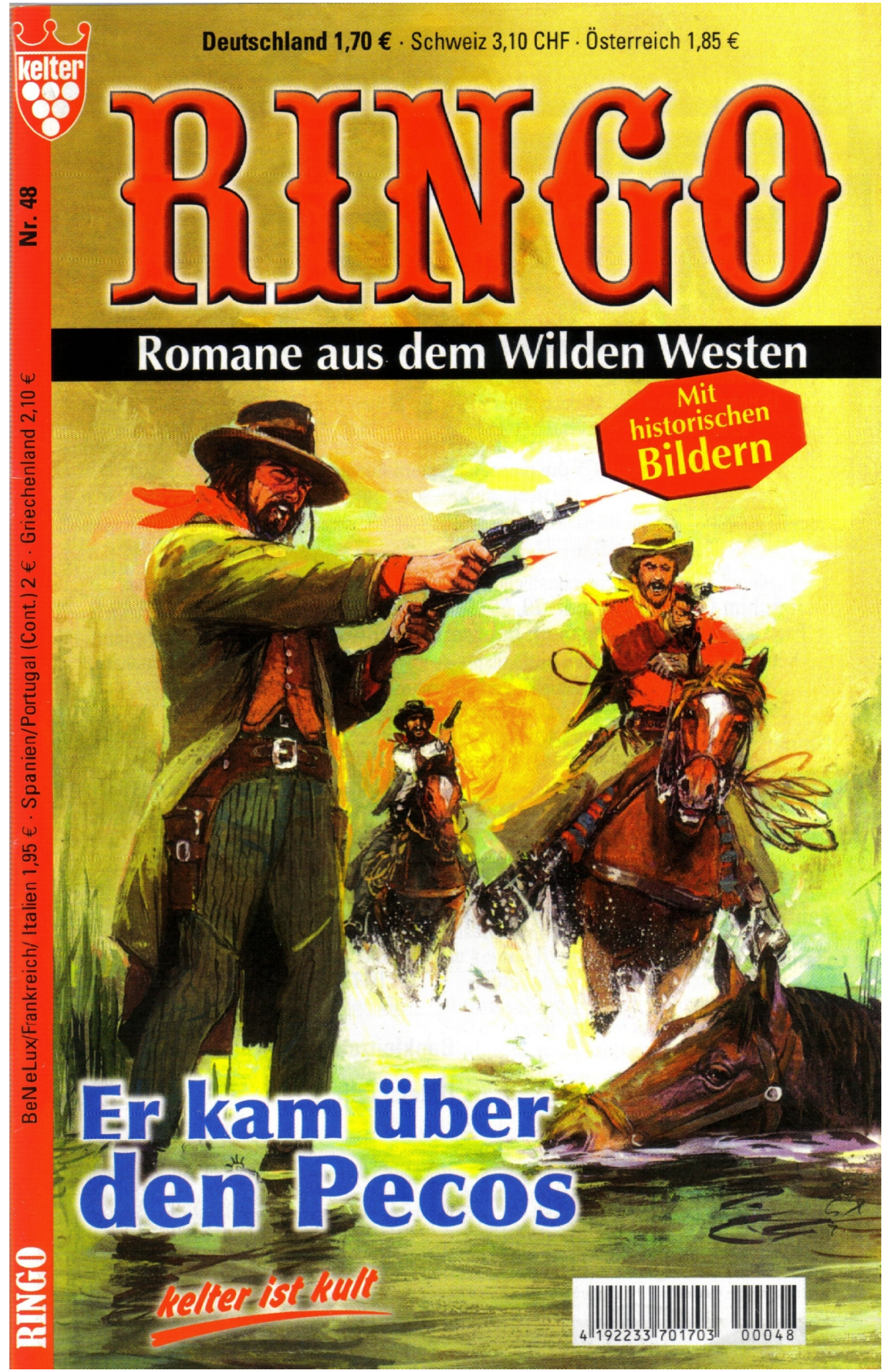

Abbildung 2: Frontcover - Ringo Bd. 48. Er kam über den Pecos. Ringo. Aufl. unbek. Kelter-Verlag. 


\section{Gefühle kann man lesen}

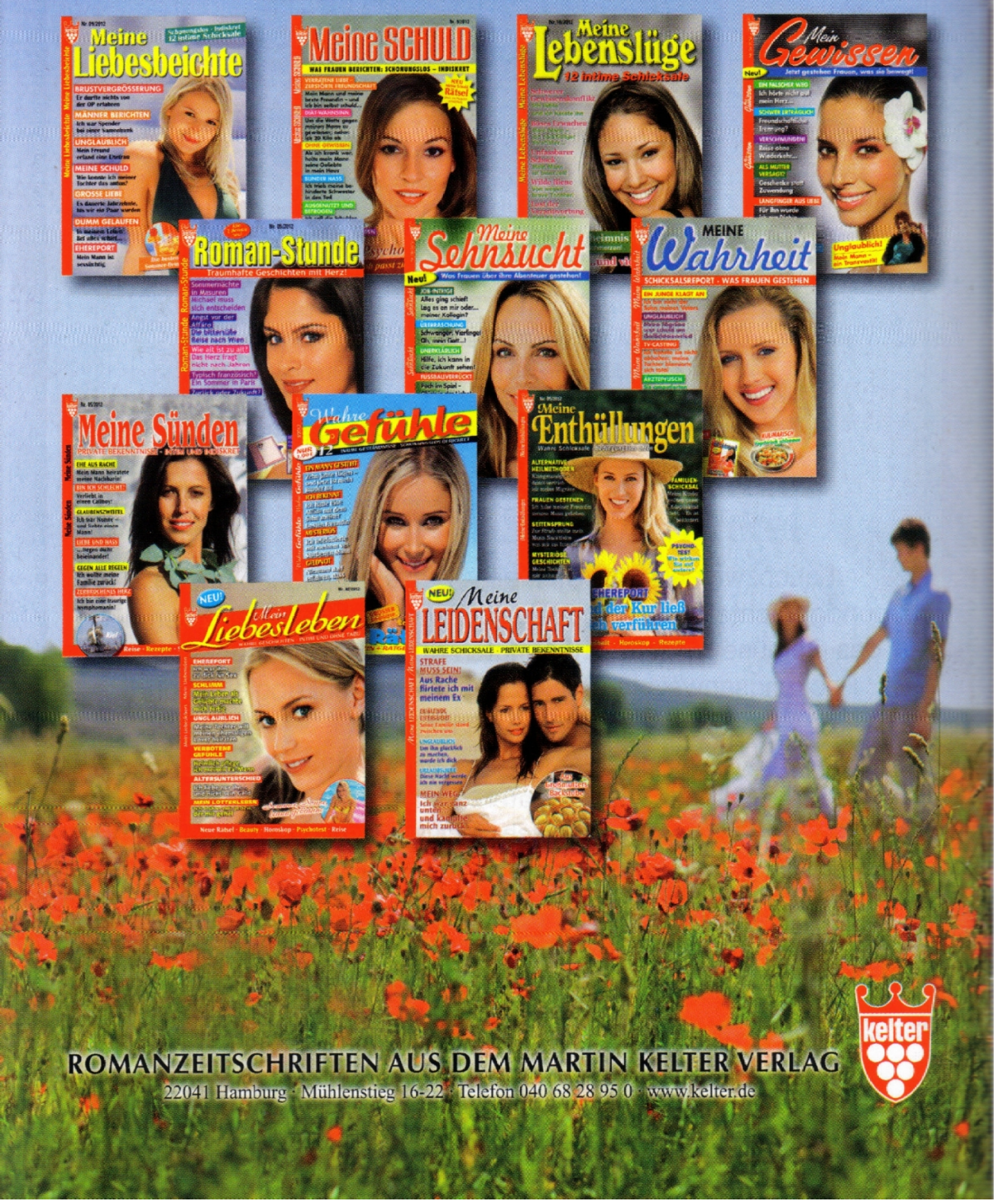

Abbildung 3: Backcover - Mami Bd. 2541. 

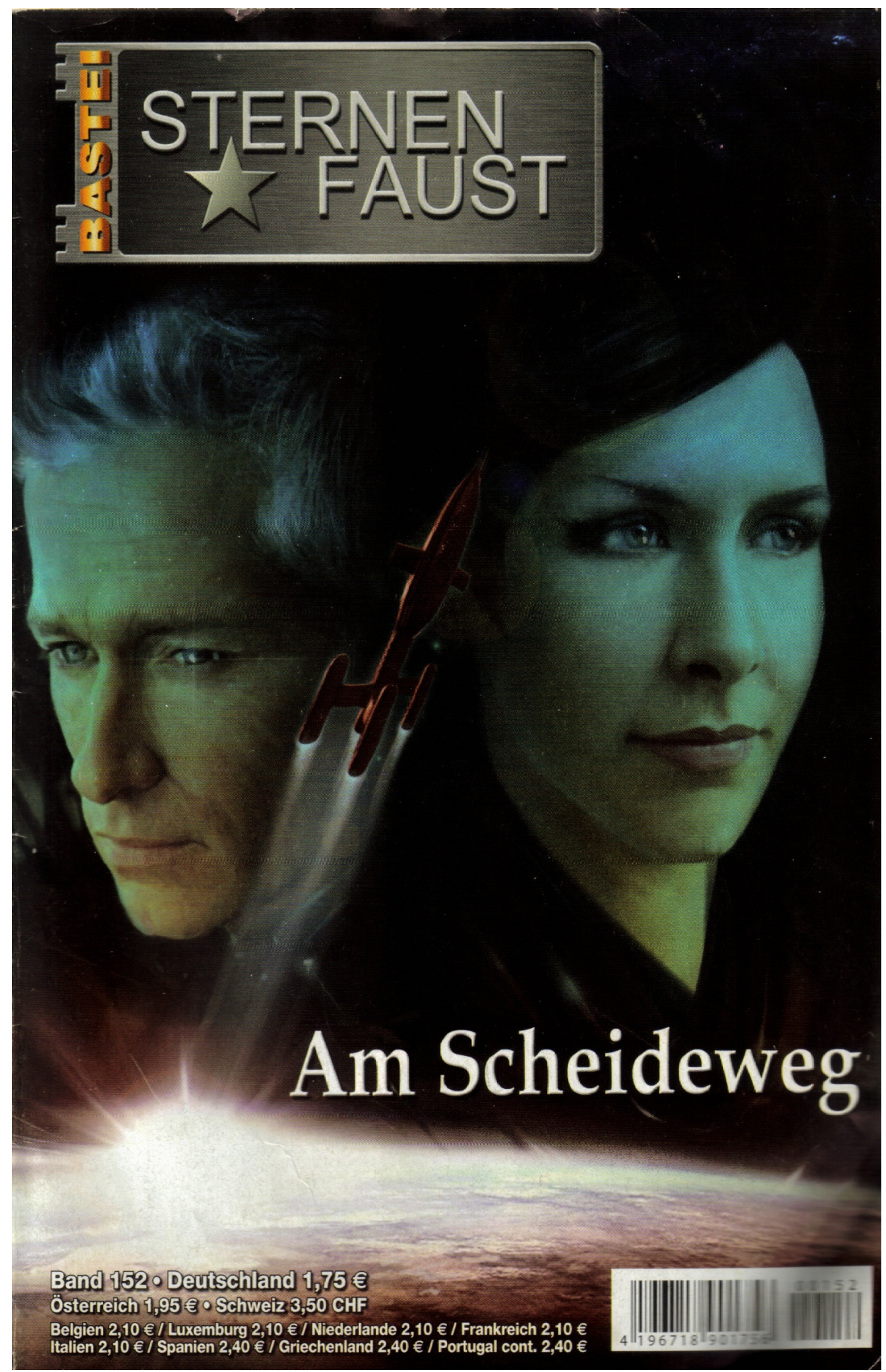

Abbildung 4: Frontcover - Sternenfaust Bd. 152. Am Scheideweg. Simon Borner. 1. Aufl. Bastei-Verlag. 


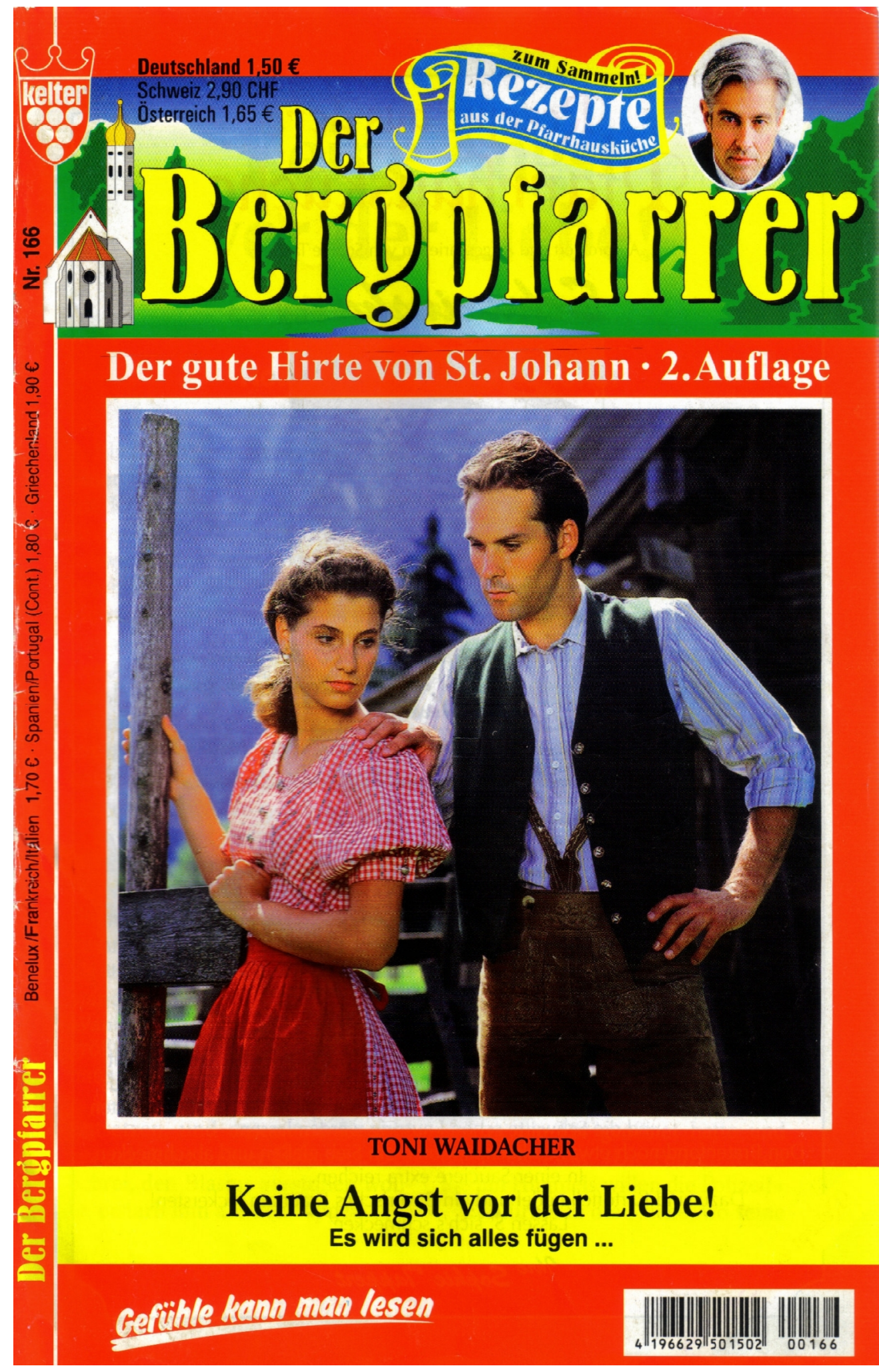

Abbildung 5: Frontcover - Der Bergpfarrer Bd. 166. Keine Angst vor der Liebe! Toni Waidacher. 2. Aufl. Kelter-Verlag. 


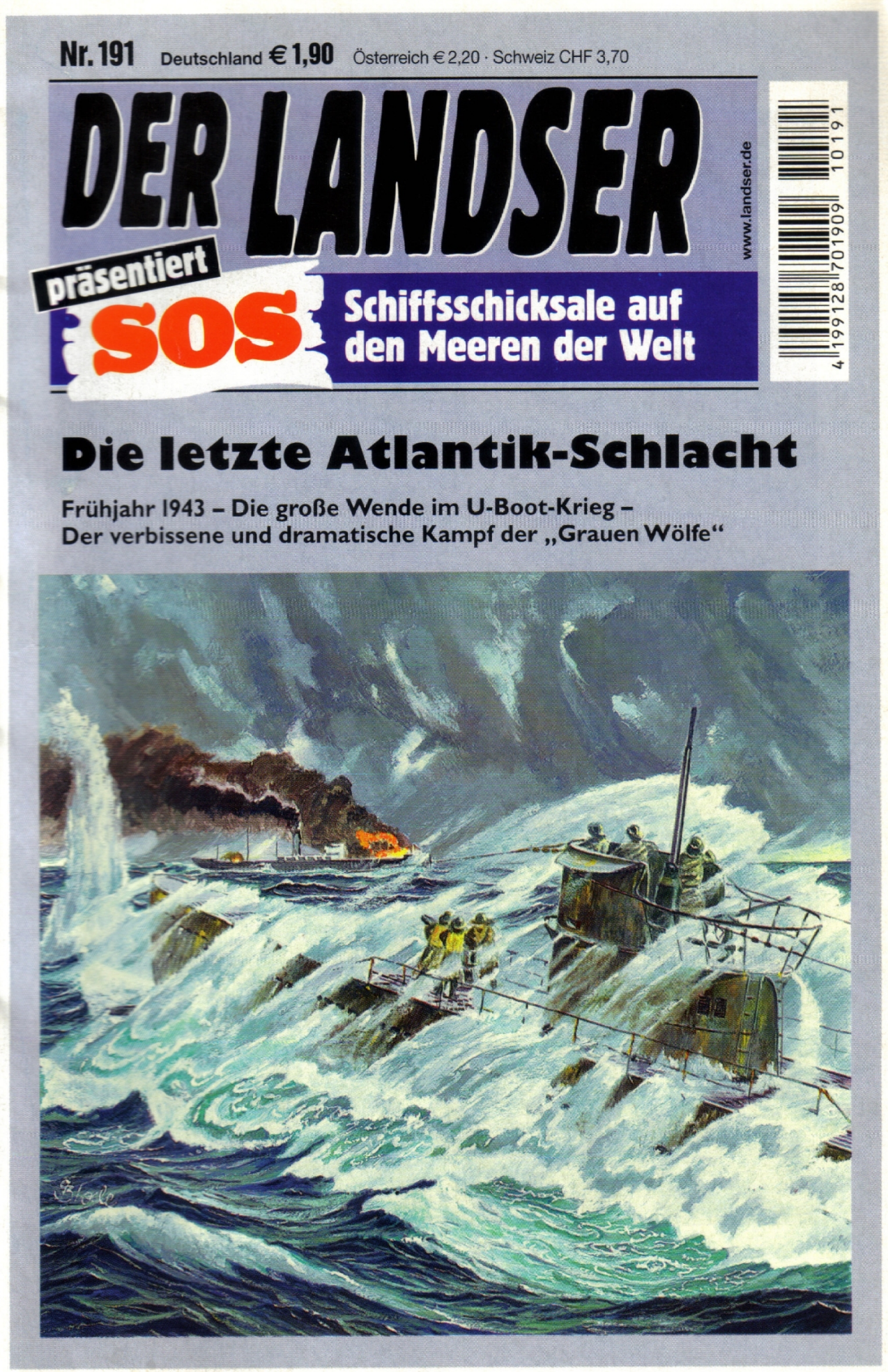

Abbildung 6: Frontcover - Der Landser SOS Bd. 191. Die letzte Atlantik-Schlacht. Autor und Aufl. unbekannt. Pabel-Moewig-Verlag. 


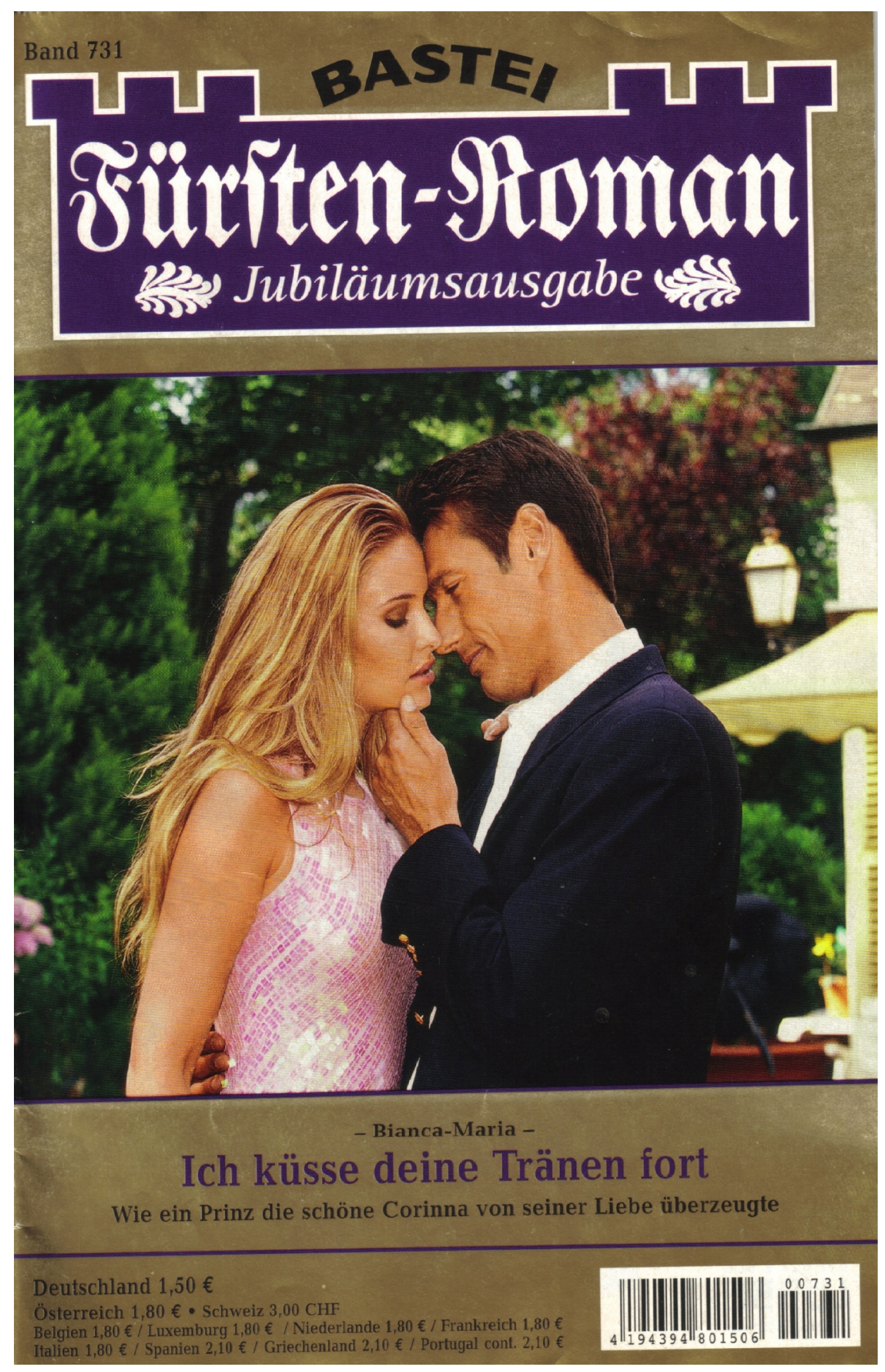

Abbildung 7: Frontcover - Fürsten-Roman Bd. 731. Ich küsse deine Tränen fort. Bianca-Maria. 1. Aufl. Bastei-Verlag. 


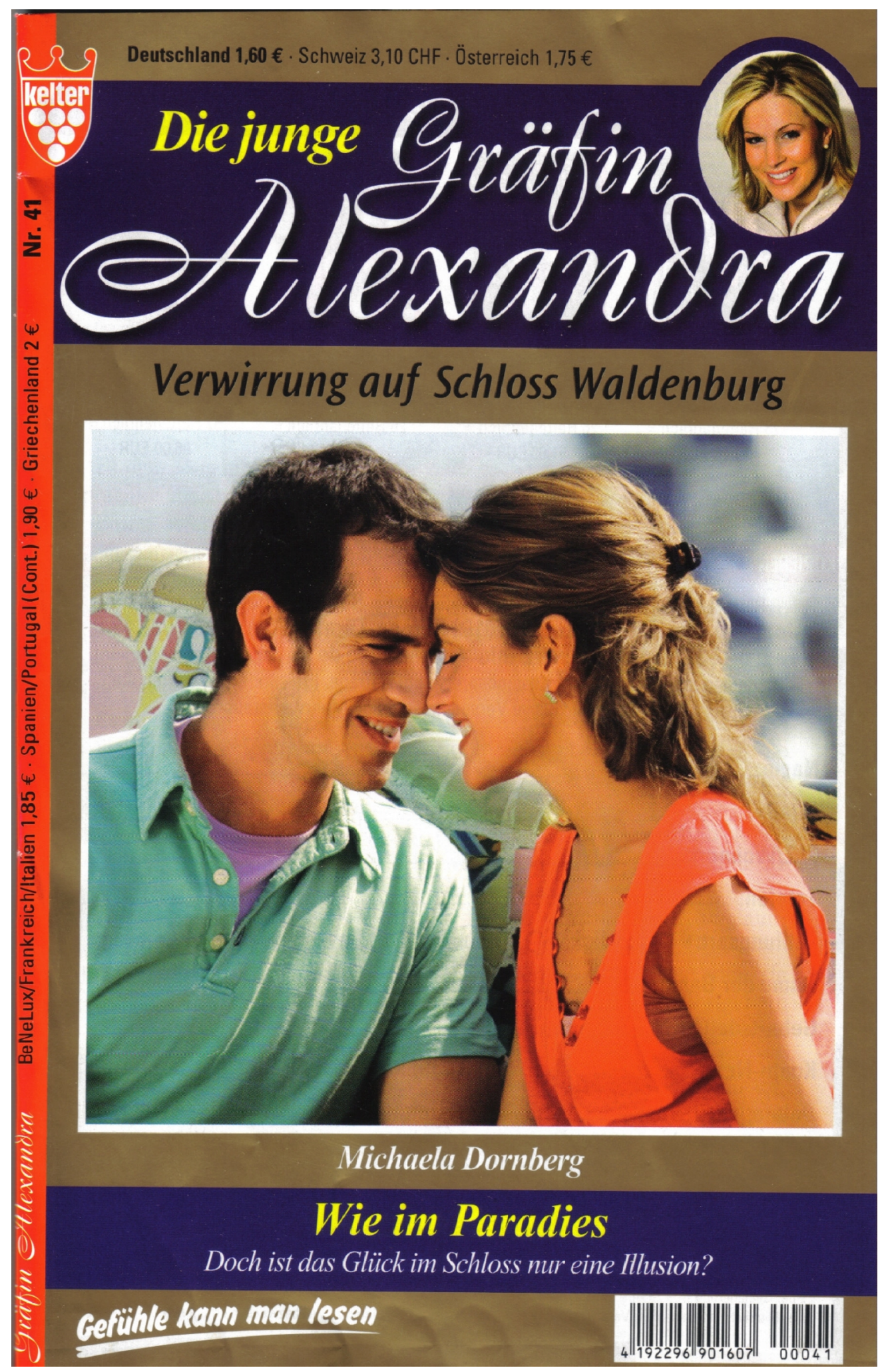

Abbildung 8: Frontcover - Die junge Gräfin Alexandra Bd. 41. Wie im Paradies. Michaela Dornberg. Aufl. unbek. Kelter-Verlag. 


\section{Nächste Woche erscheint: \\ Familie - nein danke!}

\section{Ob unser Bruder es sich anders überlegt?}

Roman von Jutta von Kampen

Als derVater des jungen Arztes Jürgen stirbt, hinterlässt er zwei mutterlose Kinder aus zweiter Ehe, den achtjährigen Jochen und die zehnjährige Delia. Recht unwillig übernimmt er es, sich zumindest um eine gute Unterbringung der beiden zu kümmern. Jochen und Delia gehen jedoch fest davon aus, dass der junge Modearzt, ihr Halbbruder, die Praxis ihresVaters übernimmt. Loretta, das Kindermädchen der beiden, geht fest davon aus, dass Jürgen bei den Kindern bleibt. Jürgen gerät mehr und mehr in einen Zwiespalt. Die Kinder wachsen ihm ans Herz, Loretta imponiert ihm und - noch viel mehr: Er verliebt sich in sie ...

\section{Lesen Sie in 14 Tagen: \\ IM SONNENWINKEL \\ Hochzeit im Sonnenwinkel}

Wird es ein Glück von Dauer sein?

Roman von Patricia Vandenberg

Falls Romane und Răısel vergriffen, einfach nachbestellen unter Tel.: 02237 - 92496

Dieser Titel erscheint im MARTIN KELTER VERLAG GmbH \& Co. KG, Mühlenstieg 16 - 22, 22041 Hamburg. Verleger: Gerhard Melchert Internet: http://www.kelter.de und E-Mail: info@kelter.de Auslieferung Osterreich: PRESSE GROSSVERTRIEB AUSTRIA TRUNK GmbH, 5081 Anif. Auslieferung Schweiz: VALORA SCHWEIZ AG, Muttenz. Auslieferung Luxemburg: VALORA SERVICES LUXEMBOURG. Export in weitere Länder: DPV Worldwide $\mathrm{GmbH}$, Hamburg. Anzeigenverwaltung: Büttner Medien GmbH, Siegmund-Freud-Str. 77a, 60435 Frankfurt, Tel. $069 / 756190-0$ z Zt. Anzeigenpreisliste Nr.43 gültig. Printed in Germany by MERO-DRUCK GmbH \& Co. KG, 21502 Ger Geesthacht. Romanhefte (Ratsehefte) durren nicht verliehen oder zu gewerbsmaßngem Umete Manuskripte und Bildvorlagen übernimmt der Verlag keine Gewähr. Dieser Roman ist unter Berücksichtigung des Gesetzes über

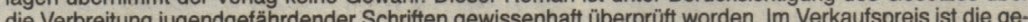
setzliche MwSt. enthalten.

Unsere Partner im Bahnhof und Flughafen:

Dargestellte Personen auf den Titelbildern stehen mit dem Roman in keinem Zusammenhang. 


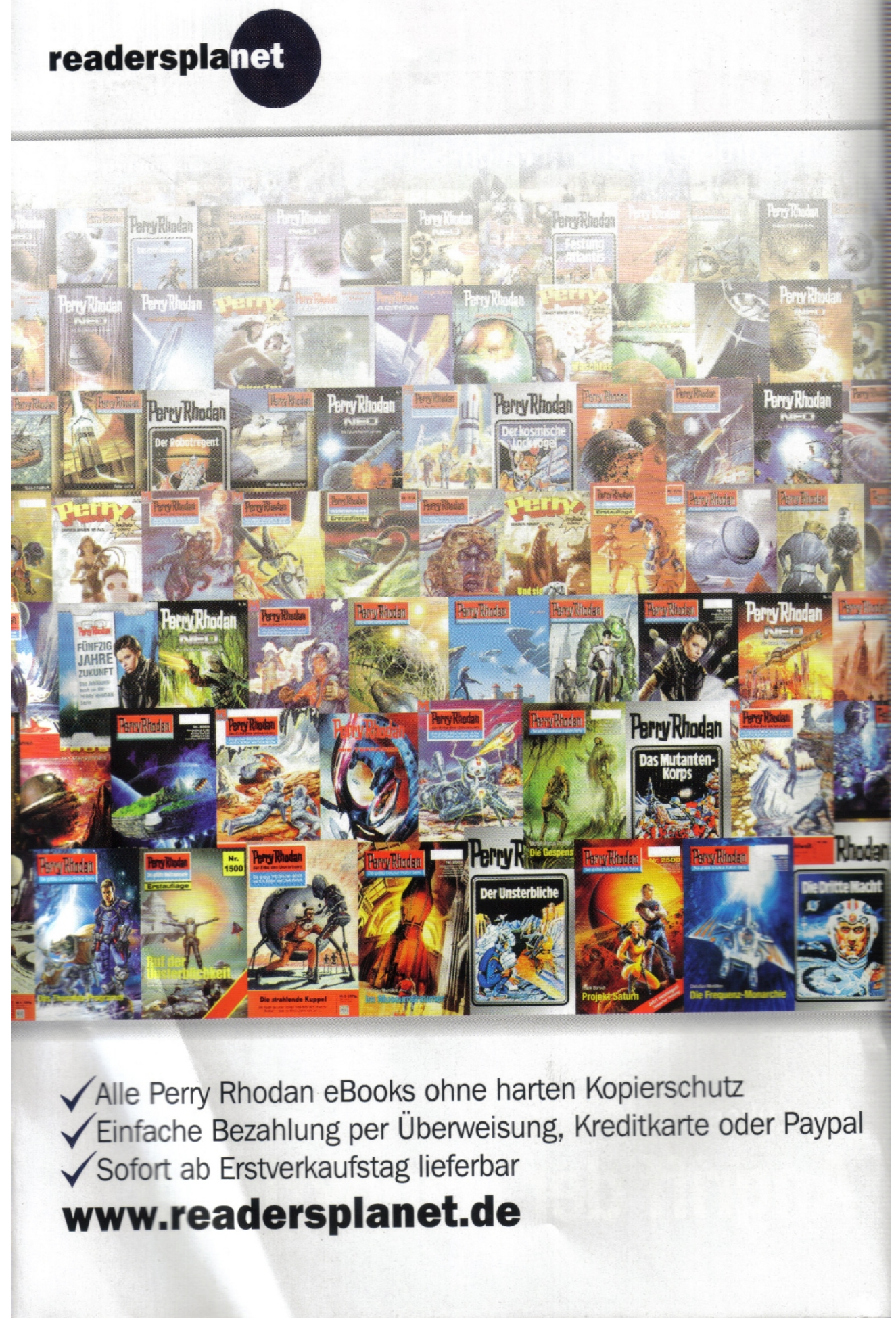

Abbildung 10: Coverinlay - Perry Rhodan Bd. 2686. Angriff der Nanokrieger. Leo Lukas. 1. Aufl. Pabel-Moewig-Verlag. 
"Schlimmstenfalls baust du den Schutz eben wieder auf.«

"Der Ausgang dieses Experiments ist ungewiss."

»Geht das?«, wiederholte Toufec eindringlich. »Dann mach's! «

Zunächst war das Abtasten zwar befremdend, doch nicht unbedingt unangenehm.

Toufec spürte die Gegenwart eines mächtigen, erhabenen Wesens, dessen Aufmerksamkeit er kaum zu verdienen glaubte. Dass dieses Wesen seiner gewahr wurde, kam geradezu einer Herablassung gleich.

Er nahm die Demütigung hin, aus freien Stücken. Noch hatte er das Gefühl, die Kontrolle über sich selbst zu behalten. Die unbekannte Präsenz erschien ihm als schlangenartige Kreatur, rot glühend, huldvoll, heilsam, makellos.

Toufec wollte länger von diesem wunderbaren Wesen betrachtet werden. Der Drang verstärkte sich, dem Antuu sein Innerstes zu öffnen, sein
Herz auszuschütten, sich ihm ganz und gar zu offenbaren.

Wer sonst zeigte solches Interesse an seinen Sorgen und Nöten? Toufec wusste sich angenommen, umhegt, aufgehoben in grenzenlosem Verständnis.

Er konnte dem Antuu alles sagen, alles. Und er tat es.

\section{1.}

Das Scheitern

Die Szenerie wandelte sich langsam, aber unaufhaltsam.

Er stand auf einer Düne. Um ihn erstreckte sich Wüste, mit rotem Sand bedeckt, eingeschlossen von Sandsteinfelsen, die zu bizarren Formen erodiert waren.

Toufec kannte diese Dünen. Sie erreichten beeindruckende Höhen von bis zu 180 Metern. Das kam von den starken, plötzlichen Winden. Die Nefud war bekannt dafür.

Ja. Er befand sich in der Wüste Nefud und blickte auf die Oase Tiamat, auf die prachtvollen Dattelpalmen,

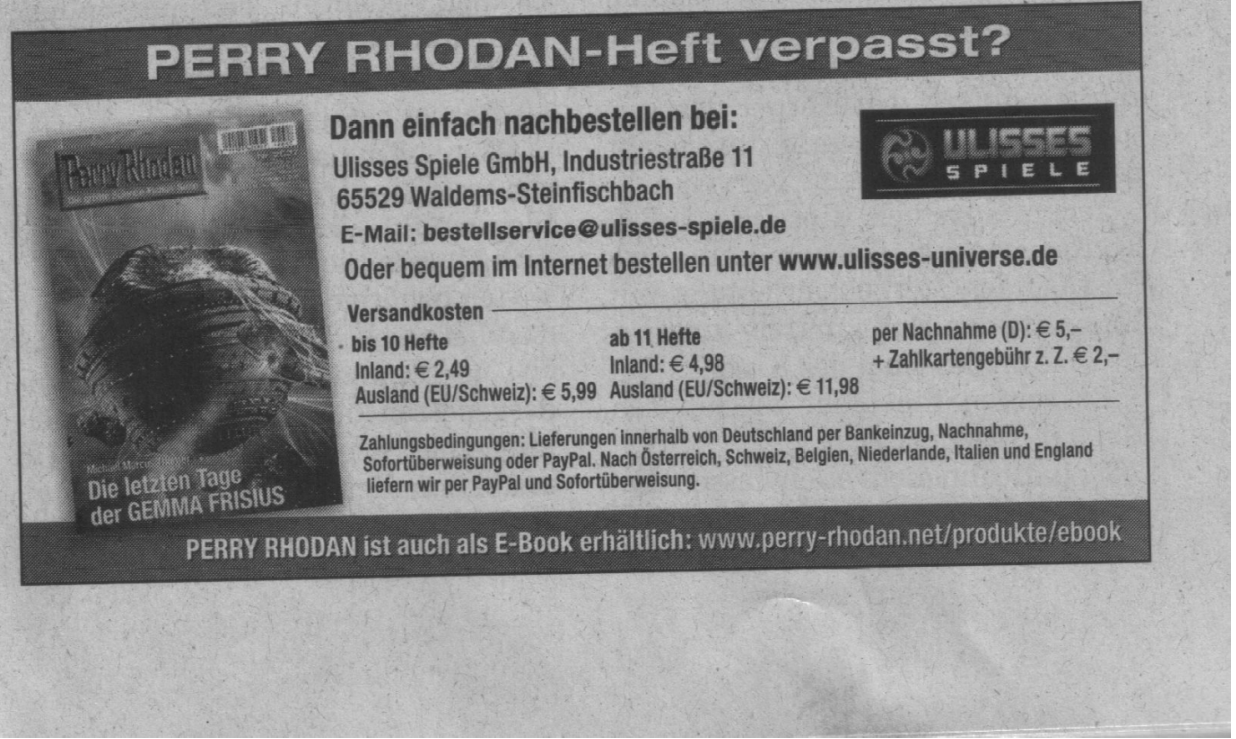

Abbildung 11: Nachbestellung - Perry Rhodan Bd. 2686. 
„Nicht auf der Stelle. Wir haben das Nanomaterial zu gleichen Teilen aufgenommen."

Toufec erinnerte sich. $\mathrm{Zu}$ diesem Zeitpunkt hatte er dieses Vorgehen für eine tadellose Idee gehalten. »Dir fehlt es an Substanz. Du musst erst zusätzliche Nanogenten generieren.«

$$
\text { "Ja.« }
$$

"Mach hin!«

„Stirb, Abtrünniger! « Das kam von einer dritten Stimme.

Toufec wirbelte herum.

Madison Clay hielt einen Gegenstand in der Hand, eine Art.Prügel. Muskete, war das die Bezeichnung? »Für König und Vaterland«, brüllte er.

Ihm gegenüber stand, ebenso wacklig, Samuel Knox. Auch er hatte eine vorsintflutlich aussehende Schusswaffe.

Ehe Toufec eingreifen konnte, feuerten die beiden aufeinander. Absurd, sie waren längst die besten Freunde geworden, die sich nur aus $\mathrm{Spa}$ mit der alten Geschichte neckten.

Doch diese Geschichte hatte sie wieder eingeholt. Abermals befanden sie sich im Krieg, in der Schlacht am Brandywine Creek. Aus Spaß war Ernst geworden, blutiger Ernst.

Gleichzeitig schossen sie und kippten gleichzeitig um, tödlich getroffen. Kein Irrtum war möglich, denn zwei Nanogenten-Schwärme lösten sich von ihnen, aus Knox' Holster wie aus Grays Patronengurten, und strömten zu Pazuzu.

»Jetzt müsste es doch schneller funktionieren!«, rief Toufec.
"Noch zwei Minuten«, sagte stoisch der Dschinn.

Der Horror ging weiter.

Barizza Dooh schwang eine Machete.

Wie von Sinnen hackte er auf die Trommel in seiner anderen Hand ein. Toufec versuchte, ihm in den Arm zu fallen, aber erneut kam er zu spät.

Dooh war schneller. Er hackte sich die Finger ab, die Hand, den Arm unterhalb des Ellenbogens.

Blut spritzte wie eine Fontäne. Fassungslos glotzte der Schwarzafrikaner den Stumpf an. Dann verdrehten sich seine Augen, bis nur noch das Weiße zu sehen war. Alle Kräfte verließen ihn. Er fiel zu Boden, ein blutüberströmter Haufen Mensch.

Mit weit aufgerissenem Mund stand Masuka unter einem Wasserfall, der aus dem Nichts auf sie niederprasselte. Sie schluckte und schluckte. Salz-

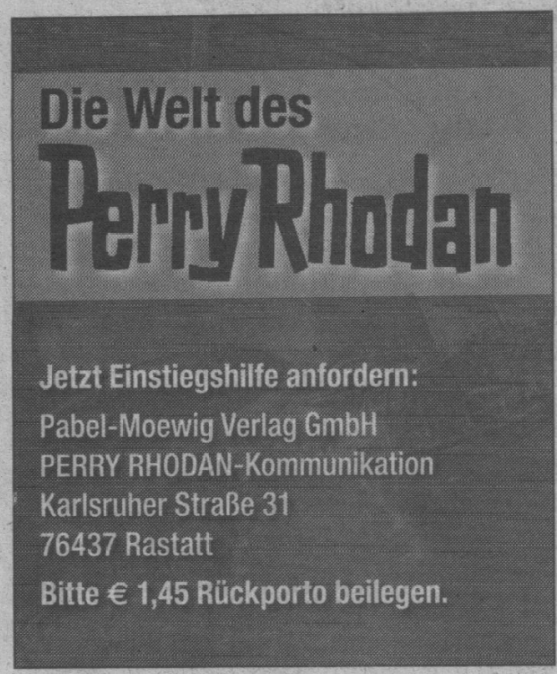

Abbildung 12: Einstiegshilfe - Perry Rhodan Bd. 2686. 
aber jedes Mal unterdrückt, wenn sie aufflackern. Weil er nämlich eigenständiges Denken nicht zulassen kann, will er seine Macht nicht gefährden."

Diese Argumentation, musste Ynirt zugeben, klang nachvollziehbar. Fast als Beweis wertete er, dass er insgeheim fürchtete, jeden Moment würde der Antuu seine neu erwachte Skepsis bemerken und gleich wieder zuschlagen.

Der Fremde erriet Ynirts Gedanken. »Ich könnte dich aus dem mentalen Würgegriff des Schlangenwesens befreien. Dazu müsste ich ihm zuerst den Zugriff auf deinen Kopf versperren. Aber ich mache es nur, wenn du mir zuvor dein Einverständnis gibst."

„Schneidest du mir dabei etwas weg?

»Im Gegenteil.« Der Zweibeiner lachte. »Ich trete dir etwas von mir ab. Ein Pulver, eine Art Medizin, ja? Sie wirkt dann nach einiger Zeit gegen die Impulse der Schlange, ähnlich wie ein Schirm gegen Regen.«

"Du musst nicht mit mir reden, als wäre ich ein Kind. - Wird mich dein Pulver manipulieren?

„Nein. Aber es wird dich vor der Manipulation durch das, was du für den Antuu hältst, bewahren. «

„Willst du etwa unterstellen, er wäre nicht echt?

"Genau. Sondern ein Popanz, den die wahren Schurken dir vorgaukeln. Die Völker dieser Welt werden seit Langem aufs Gemeinste betrogen."

Ynirt wurde heiß und kalt. Er ahnte, dass er überaus gefährliches Terrain betreten hatte.

Um harmlosere Gedanken bemüht, stellte er sich den heimatlichen Tswejun vor. Da fielen ihm die in den

\section{Porry Thodell auf der Leipziger Buchmesse 2013}

Auf der diesjährigen Leipziger Buchmesse vom 14. bis 17. März 2013 ist PERRY RHODAN wieder mit einem eigenen Messestand vertreten. Die größte Science-Fiction-Serie der Welt präsentiert sich mit ihrer Vielfalt in Halle $\mathbf{2 . 0}$ am Stand $\mathbf{G} \mathbf{3 1 0}$.

Einige der Autoren und Illustratoren stehen von Freitag bis Sonntag für Autogramm- und Fragestunden zur Verfügung.

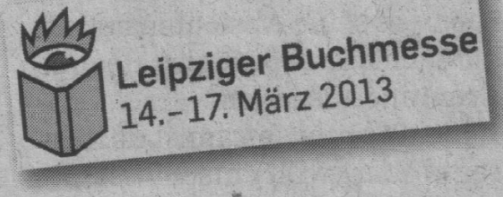

Änderungen vorbehalten!

Abbildung 13: Event - Perry Rhodan Bd. 2686. 


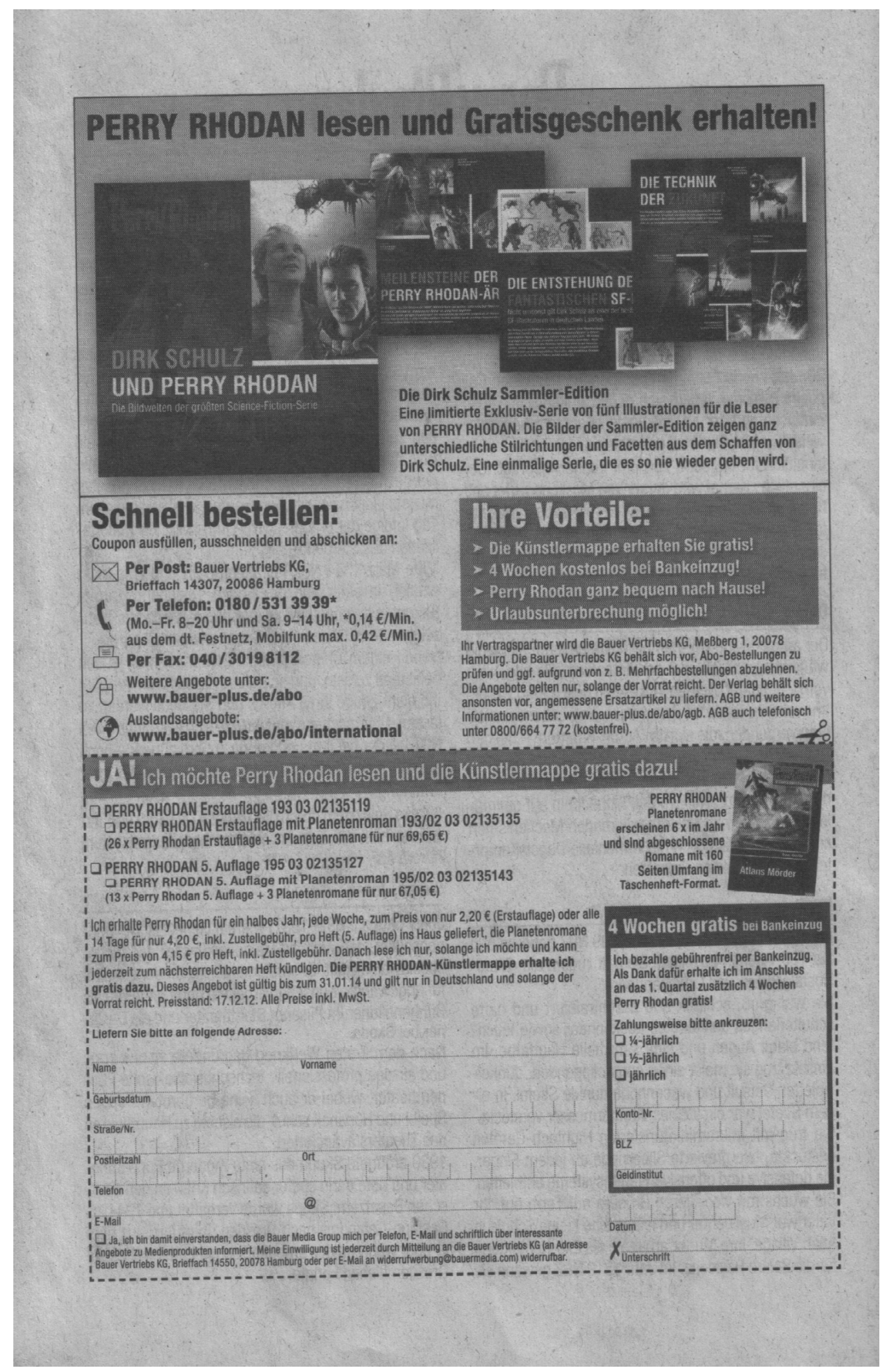

Abbildung 14: Abo - Perry Rhodan Bd. 2686. 


\section{Die Schlacht uss Jefra hat begonnen}

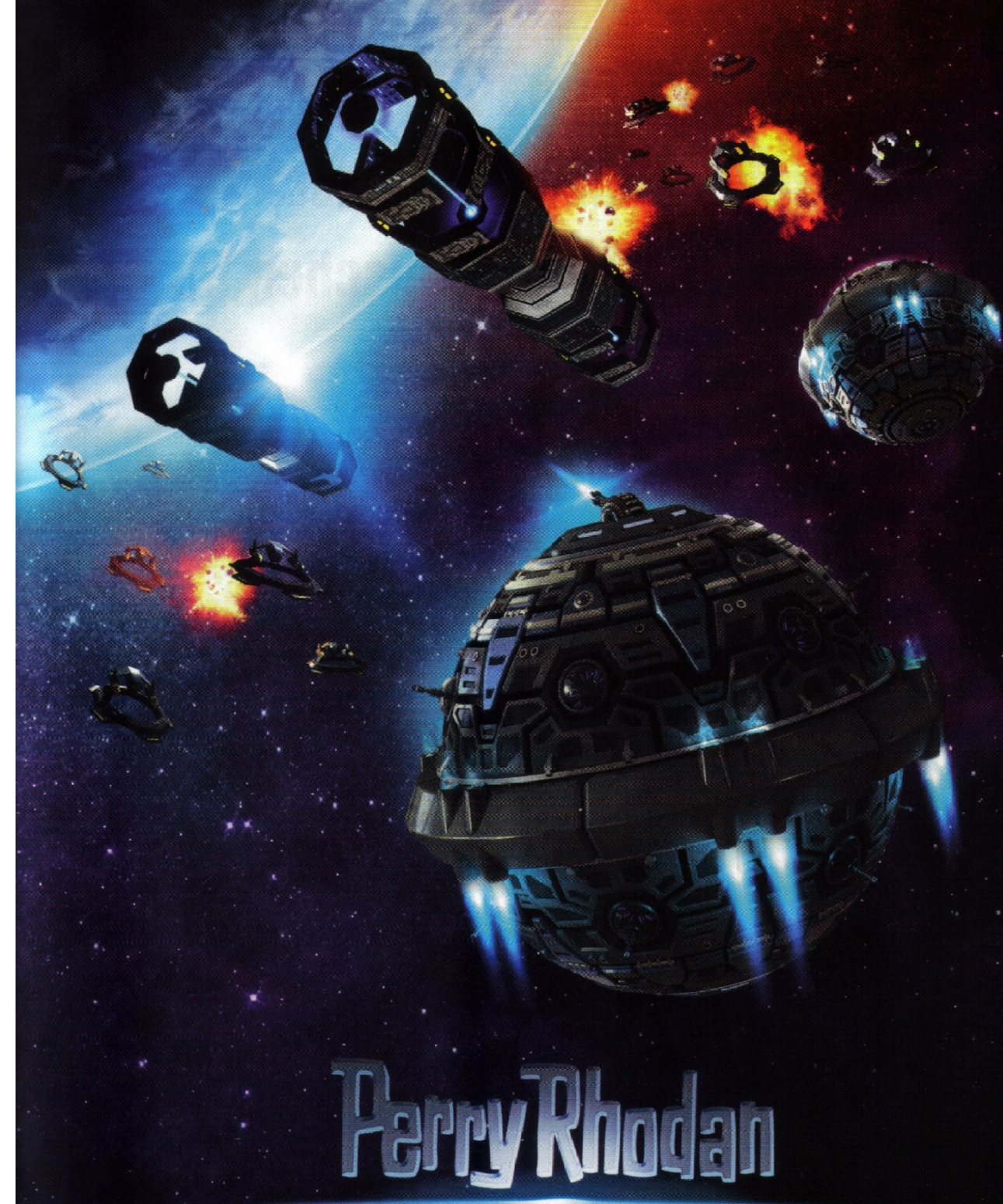

KAMPF чM TERRA.

Das galaktische Strategiespiel

\section{GAMOPOLIS.COM GappStore}

Abbildung 15: Backinlay - Perry Rhodan Bd. 2686. 

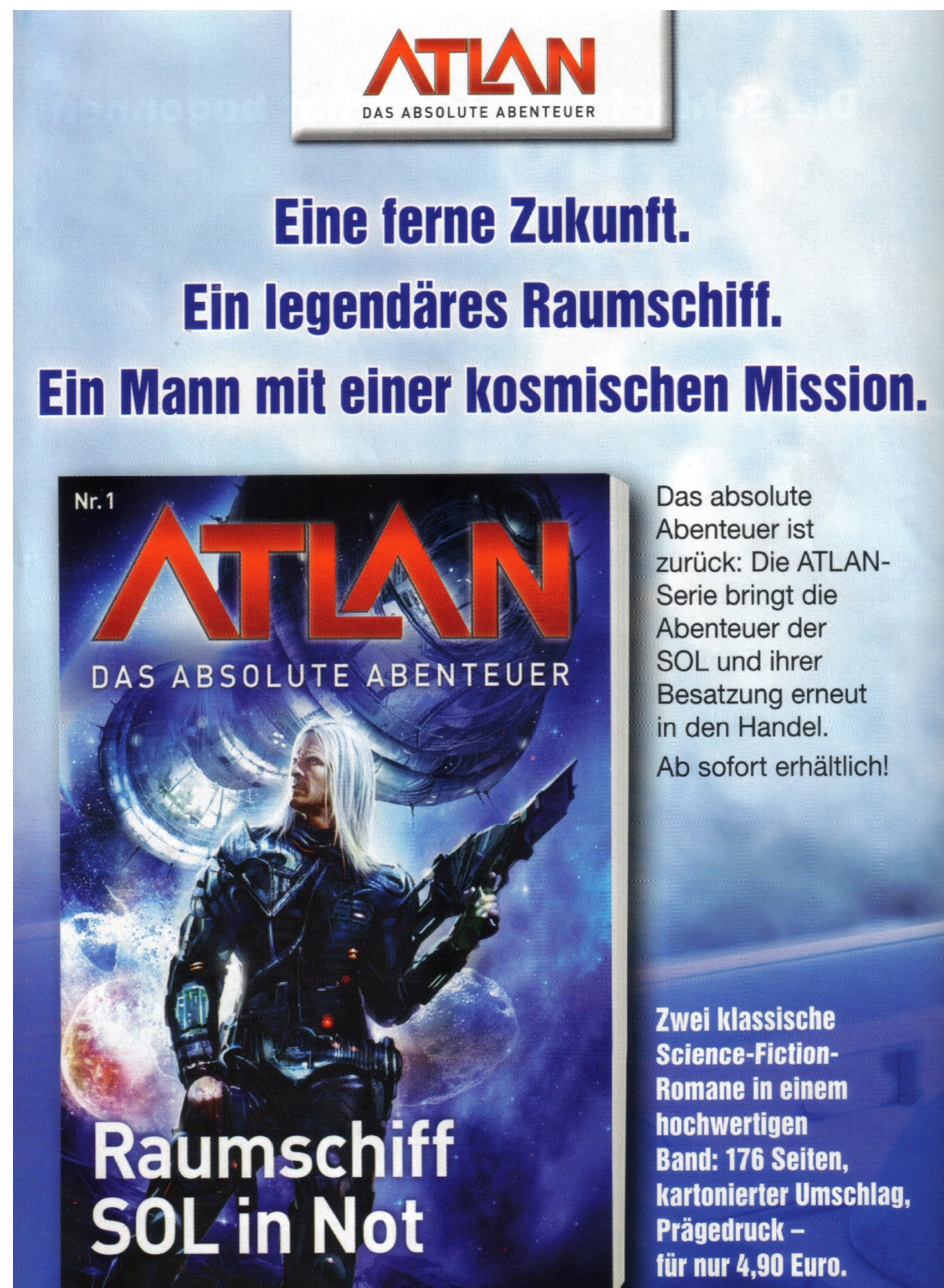

Das absolute Abenteuer ist zurück: Die ATLANSerie bringt die Abenteuer der SOL und ihrer Besatzung erneut in den Handel. Ab sofort erhältlich!

Zwei klassische

Science-FietionRomane in einem hochwertigen Band: 176 Seiten, kartonierter Umschlag, Prägedruck fïr nur 4,90 Euro.

Als gedruckten Roman giht's ATLAN ẗherall im Zeitschriftenhandel. Das E-Book giht's bei allen bekannten E-Book-Portalen.

Abbildung 16: Backcover - Perry Rhodan Bd. 2686. 


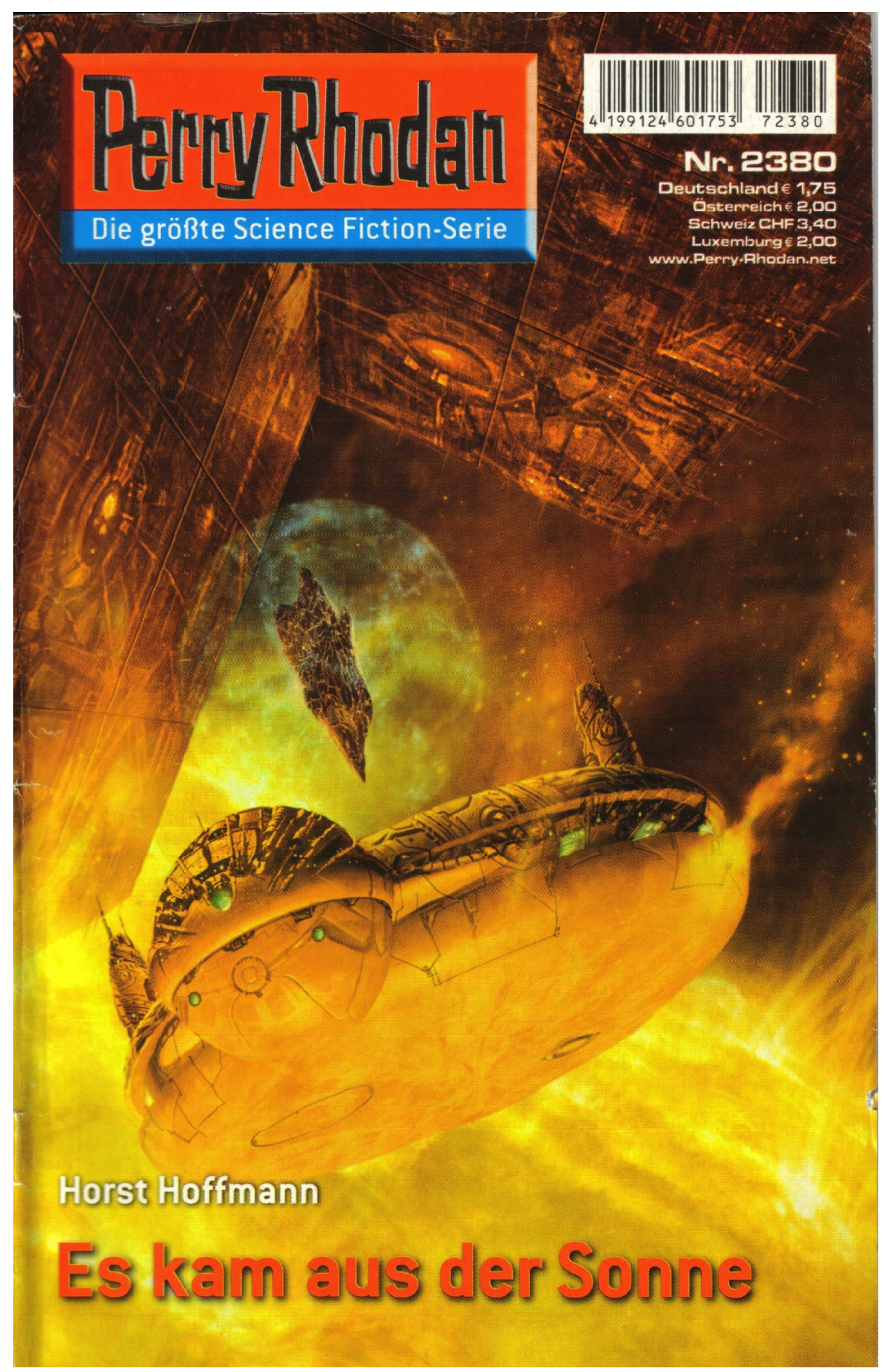

Abbildung 17: Frontcover - Perry Rhodan Bd. 2380. Es kam aus der Sonne. Horst Hoffmann. 1. Aufl. Pabel-Moewig-Verlag. 


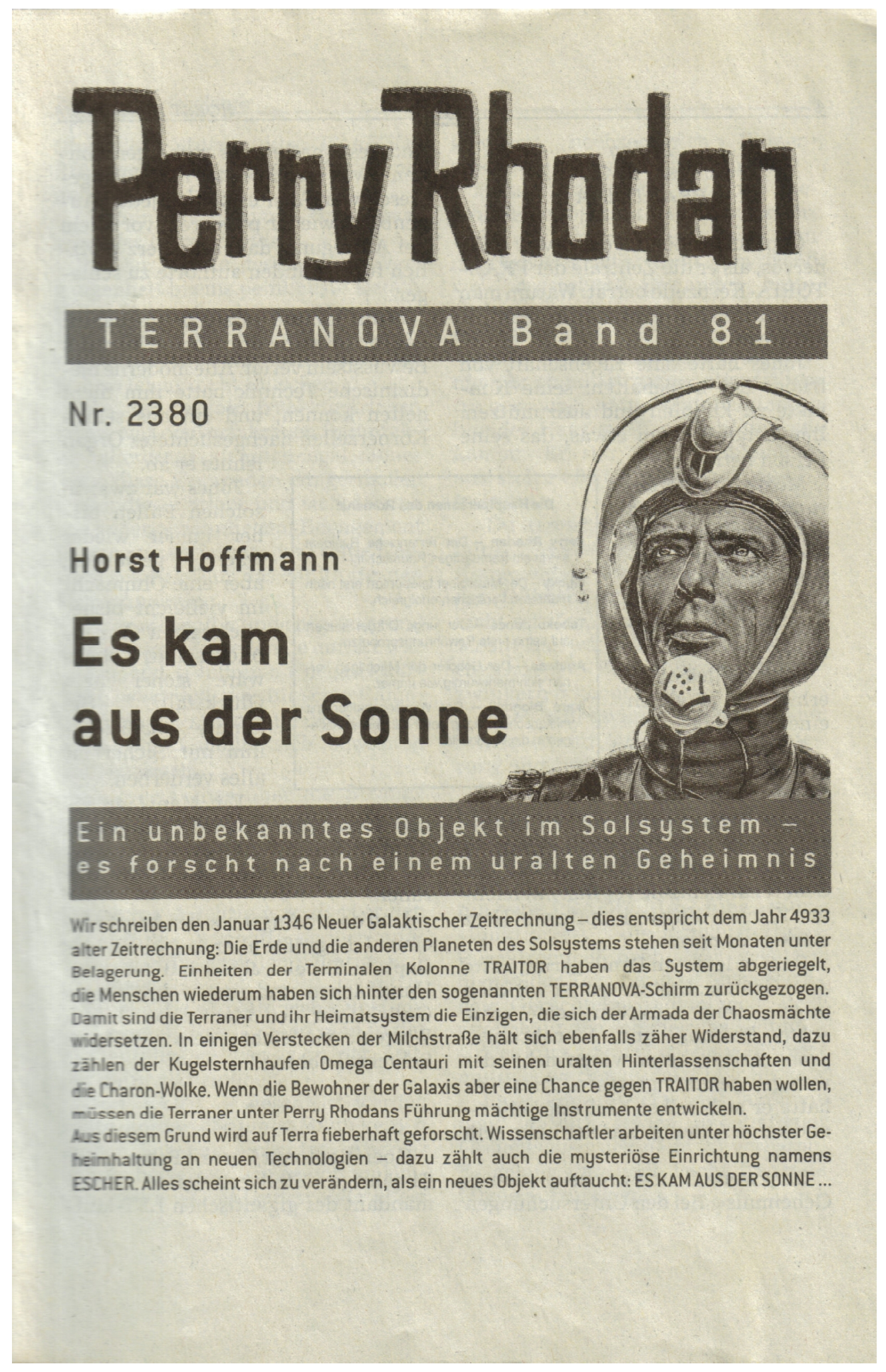

Abbildungen 18: Prolog - Perry Rhodan Bd. 2380. 

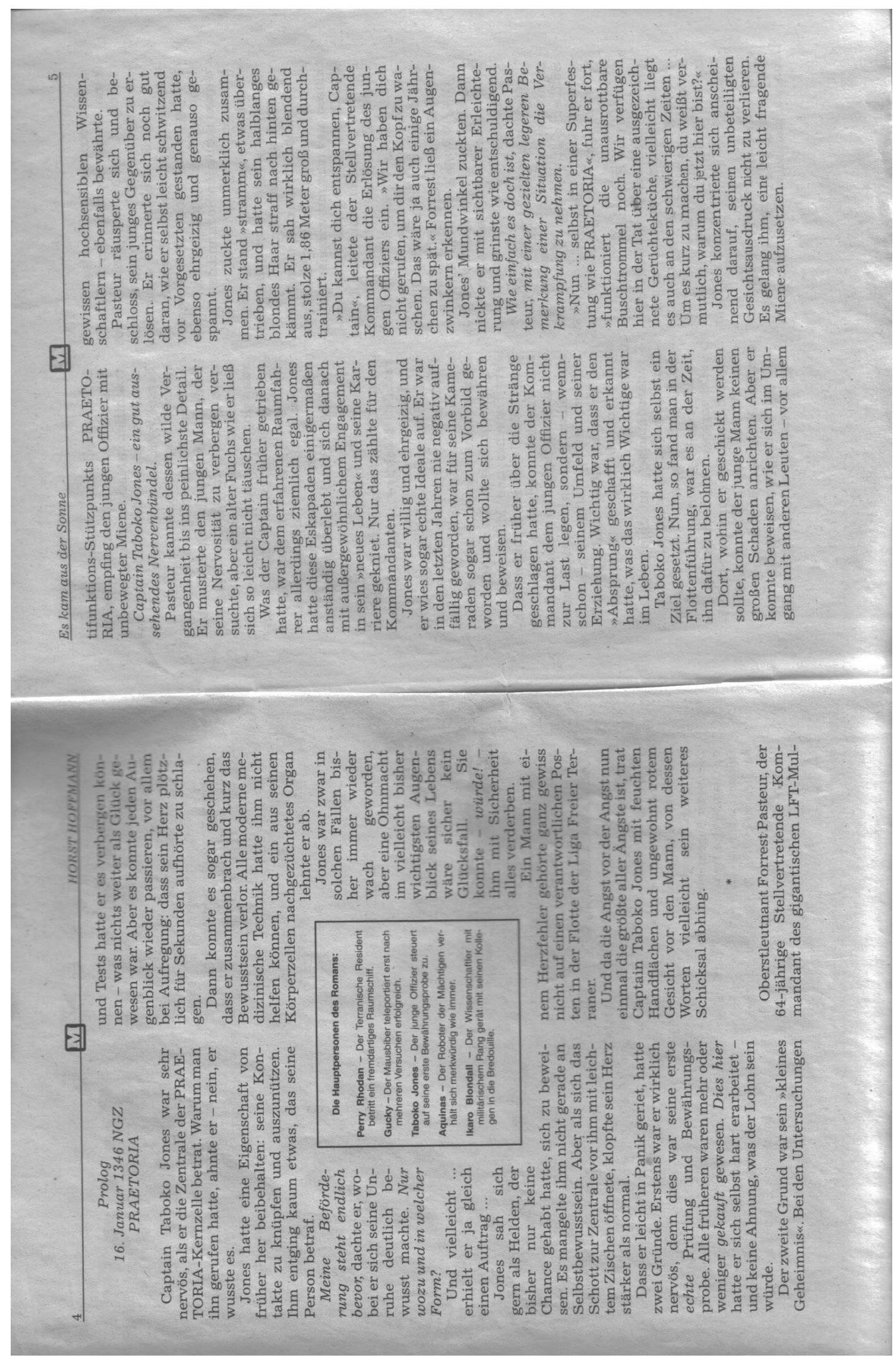

Abbildung 19: Text S. 4-5 - Perry Rhodan Bd. 2380. 

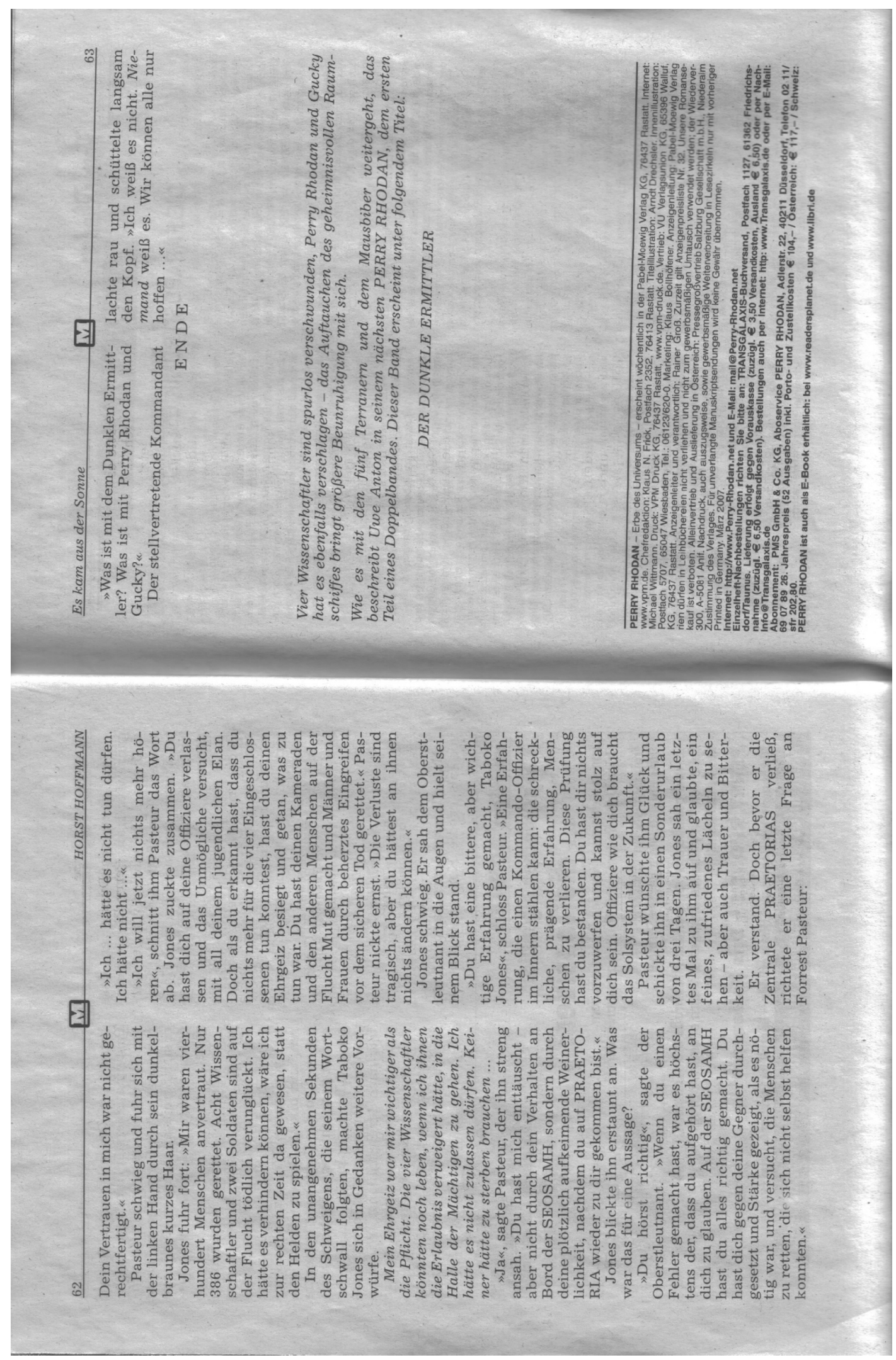

Abbildung 20: Text S. 62-63 - Perry Rhodan Bd. 2380. 

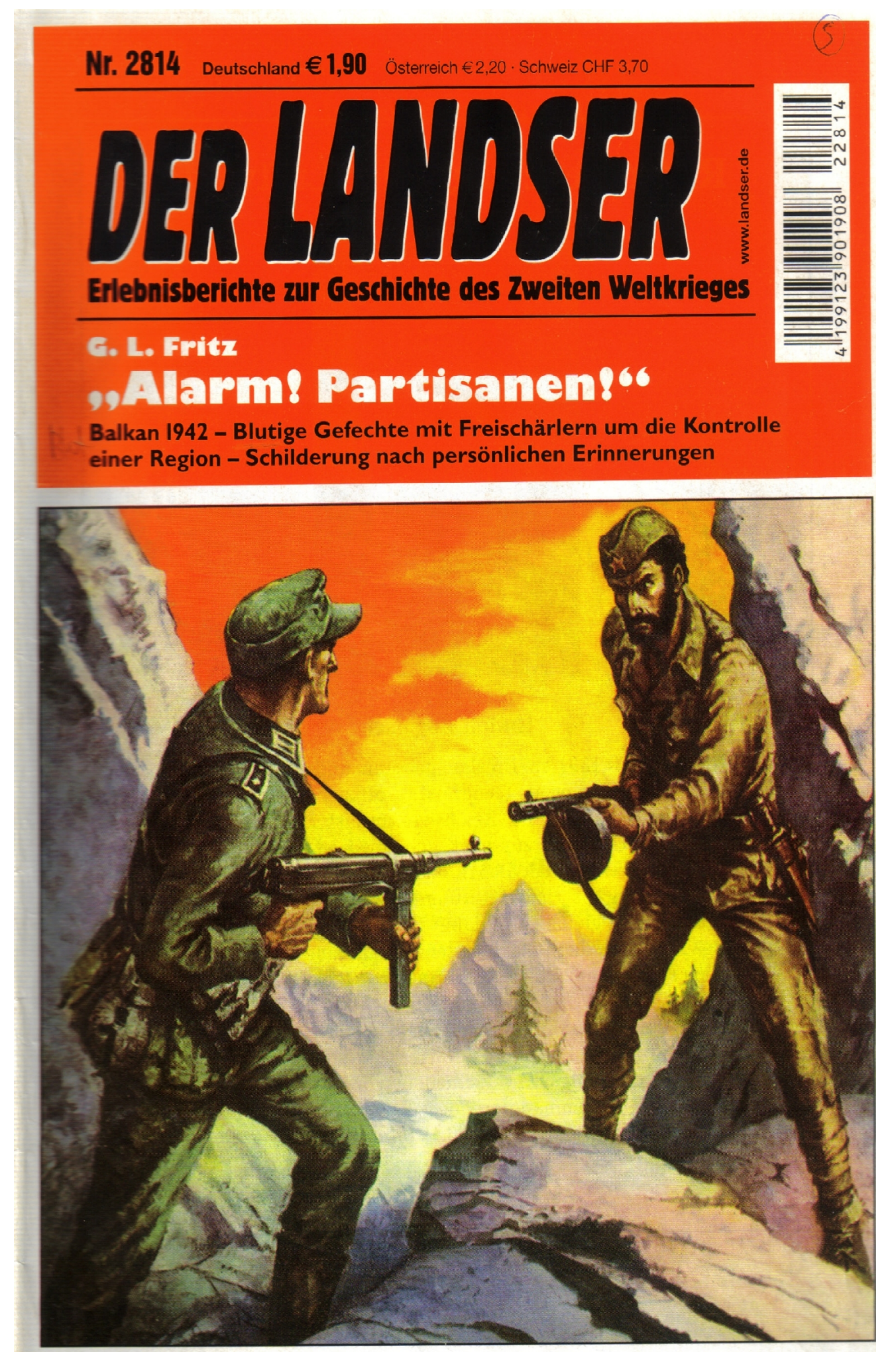

Abbildung 21: Frontcover - Der Landser Bd. 2814. „Alarm! Partisanen“ G.L. Fritz. Aufl. unbek. Pabel-Moewig-Verlag. 


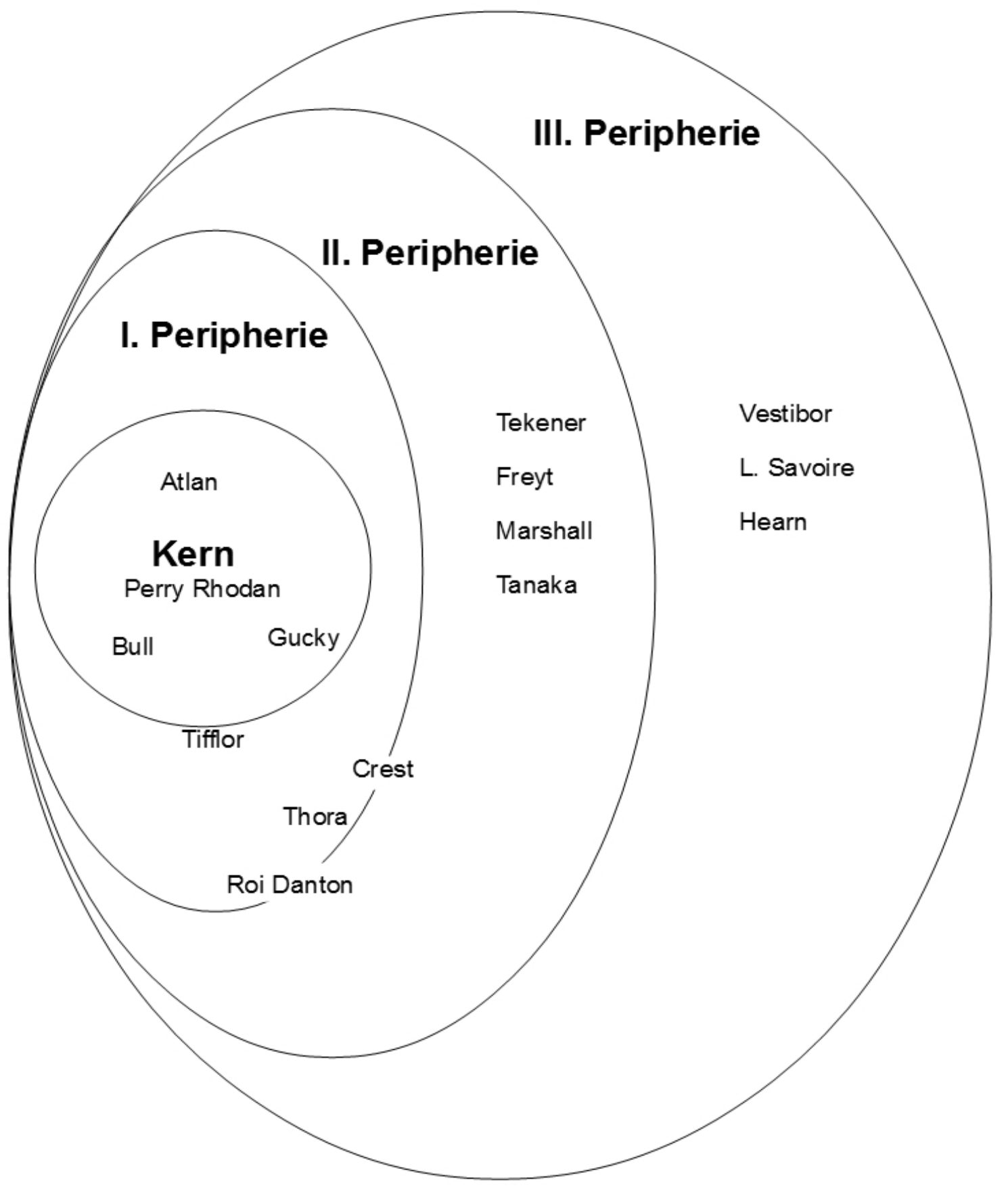

Grafik - Schalenmodell zu der Perry Rhodan-Serie 


\section{Literaturverzeichnis}

\section{Primärliteratur}

\section{Romanhefte (nach Verlag)}

\section{Bastei-Verlag:}

Captain Concho Der Rebell aus Texas Bd. 8. Der Kampf um Port Isabel. Bill Murphy. 1. Aufl. Bastei-Verlag.

Die Welt der Hedwig Courths-Mahler Bd. 123. Am Anfang war es Lüge. Autor und Aufl. unbk. Bastei-Verlag.

Fürsten-Roman Bd. 731. Ich küsse deine Tränen fort. Bianca-Maria. 1. Aufl. BasteiVerlag.

Geisterjäger John Sinclair Bd. 297. Der Verräter. Jason Dark. 1. Aufl. Bastei-Verlag. Geisterjäger John Sinclair Bd. 340. Der tödliche Golem. Jason Dark. 3. Aufl. BasteiVerlag.

Geisterjäger John Sinclair Bd. 1705. Mein Job in der Horror-Höhle. Jason Dark. 1. Aufl. Bastei-Verlag.

Geisterjäger John Sinclair Bd. 1706. Lockvogel der Nacht. Jason Dark. 1. Aufl. Bastei-Verlag.

Geisterjäger John Sinclair Bd. 1707. Das Rätsel der toten Bücher. Jason Dark. 1. Aufl. Bastei-Verlag.

G.F. Unger - Seine grössten Western-Erfolge Bd. 1583. Kriegswinter. G.F. Unger. 1. Aufl. Bastei-Verlag.

G.F. Unger - Seine grössten Western-Erfolge Bd. 1584. Und jeder bringt den Tod. G.F. Unger. 1. Aufl. Bastei-Verlag.

G.F. Unger - Seine grössten Western-Erfolge Bd. 1585. Green-River-Weide. G.F. Unger. 1. Aufl. Bastei-Verlag. 
Hedwig Courths-Mahler Bd.156. Das stolze Schweigen. Hedwig Courths-Mahler. Aufl. unbek. Bastei-Verlag.

Jack Slade Bd. 612. Der letzte Kampf des Buscaderos. Jack Slade. 1. Aufl. BasteiVerlag.

G-man Jerry Cotton Bd. 2691. Doppeltes Spiel. 1. Aufl. Bastei-Verlag.

G-man Jerry Cotton Bd. 2803. Datenströme können tödlich sein. 1. Aufl. BasteiVerlag.

G-man Jerry Cotton Bd. 2804. Weiße Weste - schmutzige Hände. 1. Aufl. BasteiVerlag.

G-man Jerry Cotton Bd. 2805. Potent wie der Tod. 1. Aufl. Bastei-Verlag.

G-man Jerry Cotton Bd. 2942. Das letzte Level ist der Tod. 1. Aufl. Bastei-Verlag.

G-man Jerry Cotton Classic Bd. 169. Blutfehde zwischen Wolkenkratzern. 1. Aufl. Bastei-Verlag.

G-man Jerry Cotton Classic Bd. 282. Sieben standen gegen uns. 1. Aufl. BasteiVerlag.

Lassiter Bd. 953. Carol und die Kopfgeldjäger. Jack Slade. 3. Aufl. Bastei-Verlag.

Lassiter Bd. 1847. Die Gefangene des Geisterzugs. Jack Slade. 1. Aufl. BasteiVerlag.

Lassiter Bd. 1952. Lassiter und der Geisterbison. Jack Slade. 1. Aufl. Bastei-Verlag.

Lassiter Bd. 1979. Auf Todesfährte in Sonora. Jack Slade. 1. Aufl. Bastei-Verlag.

Maddrax Bd. 185. Ein Alptraum erwacht. Michael M. Thurner. 1. Aufl. Bastei-Verlag.

Maddrax Bd. 287. Meister der Lüge. Christian Schwarz. 1. Aufl. Bastei-Verlag.

Maddrax Bd. 277. Xij. Ronald M. Hahn. 1. Aufl. Bastei-Verlag.

Maddrax Bd. 290. In den Gärten von Sha'mar. Michael M. Thurner. 1. Aufl. BasteiVerlag.

Maddrax Bd. 304. Allein gegen alle. Sascha Vennemann. 1. Aufl. Bastei-Verlag.

Maddrax Bd. 322. Götterdämmerung. Mia Zorn. 1. Aufl. Bastei-Verlag. 
Maddrax Bd. 349. In der Domäne. Manfred Weinland. 1. Aufl. Bastei-Verlag.

Professor Zamorra Bd. 954. Das dunkle Paradies. Adrian Doyle. 1. Aufl. BasteiVerlag.

Professor Zamorra Bd. 959. Asmodis' Hölle. Christian Schwarz. 1. Aufl. BasteiVerlag.

Professor Zamorra Bd. 960. In den Nebeln. Anika Klüver. 1. Aufl. Bastei-Verlag.

Professor Zamorra Bd. 961. Nähre deine Wut! Oliver Fröhlich. 1. Aufl. Bastei-Verlag.

Sternenfaust Bd. 152. Am Scheideweg. Simon Borner. 1. Aufl. Bastei-Verlag.

Sternenfaust Bd. 154. Welt der Naniten. Stan Hamilton. 1. Aufl. Bastei-Verlag.

Sternenfaust Bd. 153. Anschlag auf den Konsensdom. Stan Hamilton. 1. Aufl. BasteiVerlag.

Vampira Bd. 3. Besessen. Adrian Doyle. 1. Aufl. Bastei-Verlag.

Western-Bestseller G.F. Unger Bd. 1572. Drei Asse. G.F. Unger. Neuaufl. BasteiVerlag.

\section{Kelter-Verlag:}

Arizona - Sammelband. Bd. 88. Aufl. unbek. Kelter-Verlag. Dritter von Fünf Romanen. Keine durchgehende Paginierung.

Der Bergpfarrer Bd. 166. Keine Angst vor der Liebe! Toni Waidacher. 2. Aufl. KelterVerlag.

Der Bergpfarrer - Werbeband. 3 Romane. Bd. 54. Aufl. unbek. Kelter-Verlag.

Die großen Fürsten Bd. 1. Geheimnis um die Thronerbin. Bettina Rosen. Aufl. unbek. Kelter-Verlag.

Die junge Gräfin Alexandra Bd. 41. Wie im Paradies. Michaela Dornberg. Aufl. unbek. 
Kelter-Verlag.

Dr. Laurin Bd. 30. Eine Ehe voller Zweifel. Patricia Vandenberg. 2. Aufl. Kelter-Verlag.

Dr. Laurin Bd. 130. Eine Sünde aus Dr. Laurins Vergangenheit? Aufl. unbek. Patricia Vandenberg. 1. Aufl. Kelter-Verlag.

Dr. Norden Bd. 766. Sommer, Sonne, Leidenschaft. Patricia Vandenberg. Neuauflage. Kelter-Verlag.

Gaslicht Bd. 608: Wenn dunkle Schatten sich nähern. A.F. Morland. Aufl. unbek. Kelter-Verlag.

Irrlicht Bd. 977. Die teuflischen Jünger. Pamela Francis. Aufl. unbek. Kelter-Verlag.

Mami Bd. 2541. Wir gehören zusammen. Patricia Vandenberg. 1. Aufl. Kelter-Verlag.

Ringo Bd. 48. Er kam über den Pecos. Ringo. Aufl. unbek. Kelter-Verlag.

Waco Gesamtausgabe Bd. 119. G.F. Waco. Aufl. unbek. Kelter-Verlag.

Wild West Roman Bd. 50. Die Fährte im Sand. G.F. Wego. Aufl. unbek. Kelter-Verlag.

Wild West Roman Bd. 51. Ben Nye. Joe Juhnke. Aufl. unbek. Kelter-Verlag.

\section{Pabel-Moewig-Verlag:}

Der Landser Bd. 2735. Sturmlauf zur Hölle. A. Gütte. Aufl. unbek. Pabel-MoewigVerlag.

Der Landser Bd. 2814. „Alarm! Partisanen“ G.L. Fritz. Aufl. unbek. Pabel-MoewigVerlag.

Der Landser SOS Bd. 138. Untergang der 'Glorius'. Autor und Aufl. unbekannt. Pabel-Moewig-Verlag. 
Der Landser SOS Bd. 191. Die letzte Atlantik-Schlacht. Autor und Aufl. unbekannt. Pabel-Moewig-Verlag.

Dragon Söhne von Atlantis. Bd. 1. Griff nach Atlantis. William Voltz. 1. Aufl. PabelVerlag.

Mythor Bd. 1. Der Sohn des Kometen. Hugh Walker. 1. Aufl. Pabel-Verlag.

Mythor Bd. 6. Das gläserne Schwert. Peter Terrid. 1. Aufl. Pabel-Verlag.

Perry Rhodan Bd. 1. Unternehmen STARDUST. K.H. Scheer. 4. Aufl. Pabel-MoewigVerlag.

Perry Rhodan Bd. 3. Die strahlende Kuppel. K.H. Scheer. 4. Aufl. Pabel-MoewigVerlag.

Perry Rhodan Bd. 4. Götterdämmerung. Clark Darlton. 4. Aufl. Pabel-Moewig-Verlag.

Perry Rhodan Bd. 5. Atom-Alarm. Kurt Mahr. 4. Aufl. Pabel-Moewig-Verlag.

Perry Rhodan Bd. 7. Invasion aus dem All. Clark Darlton. 4. Aufl. Pabel-MoewigVerlag.

Perry Rhodan Bd. 15. Die Spur durch Raum und Zeit. Clark Darlton. 4. Aufl. PabelMoewig-Verlag.

Perry Rhodan Bd. 16. Die Geister von Gol. Kurt Mahr. 4. Aufl. Pabel-Moewig-Verlag.

Perry Rhodan Bd. 17. Planet der sterbenden Sonne. Kurt Mahr. 4. Aufl. PabelMoewig-Verlag.

Perry Rhodan Bd. 18. Die Rebellen von Tuglan. Clark Darlton. 4. Aufl. Pabel-MoewigVerlag.

Perry Rhodan Bd. 25. Der Overhead. Kurt Mahr. 4. Aufl. Pabel-Moewig-Verlag.

Perry Rhodan Bd. 26. Duell der Mutanten. Clark Darlton. 4. Aufl. Pabel-MoewigVerlag.

Perry Rhodan Bd. 27. Im Banne des Hypno. Clark Darlton. 4. Aufl. Pabel-MoewigVerlag.

Perry Rhodan Bd. 40. Aktion gegen Unbekannt. Clark Darlton. 4. Aufl. Pabel-MoewigVerlag.

Perry Rhodan Bd. 41. Der Partner des Giganten. Clark Darlton. 4. Aufl. Pabel- 
Moewig-Verlag.

Perry Rhodan Bd. 48. Rotes Auge Beteigeuze. Clark Darlton. 4. Aufl. Pabel-MoewigVerlag.

Perry Rhodan Bd. 50. Der einsame der Zeit. K.H. Scheer. 4. Aufl. Pabel-MoewigVerlag.

Perry Rhodan Bd. 54. Der Zweikampf. K.H. Scheer. 4. Aufl. Pabel-Moewig-Verlag.

Perry Rhodan Bd. 67. Zwischenspiel auf Siliko V. Kurt Brand. 4. Aufl. Pabel-MoewigVerlag.

Perry Rhodan Bd. 78. Thoras Opfergang. Kurt Brand. 4. Aufl. Pabel-Moewig-Verlag.

Perry Rhodan Bd. 79. Die Atomhölle von Gray Beast. Kurt Mahr. 4. Aufl. PabelMoewig-Verlag.

Perry Rhodan Bd. 99. Ein Freund der Menschen. William Voltz. 4. Aufl. PabelMoewig-Verlag.

Perry Rhodan Bd. 100. Der Zielstern. K.H. Scheer. 3. Aufl. Pabel-Moewig-Verlag.

Perry Rhodan Bd. 408. Amoklauf der Mutanten. William Voltz. 1. Aufl. Moewig-Verlag.

Perry Rhodan Bd. 656. Der Geheimnisträger. Clark Darlton. 3. Aufl. Pabel-MoewigVerlag.

Perry Rhodan Bd. 983. Der Ort der Stille. Clark Darlton. 1. Aufl. Pabel-Verlag.

Perry Rhodan Bd. 1300. Die Gänger des Netzes. Kurt Mahr und Ernst Vlcek. 1. Aufl.

Pabel-Moewig-Verlag.

Perry Rhodan Bd. 1791. Die Brut. Peter Terrid. 1. Aufl. Pabel-Moewig-Verlag.

Perry Rhodan Bd. 1794. Plan der Auferstehung. H.G. Francis. 1. Aufl. Pabel-MoewigVerlag.

Perry Rhodan Bd. 1795. Die Farbe Alenant. Ernst Vlcek 1. Aufl. Pabel-MoewigVerlag.

Perry Rhodan Bd. 1796. Die Rückkehr der Sydorrier. Susan Schwartz. 1. Aufl. PabelMoewig-Verlag.

Perry Rhodan Bd. 2184. Orakel in Gefahr. Arndt Ellmer. 1. Aufl. Pabel-MoewigVerlag.

Perry Rhodan Bd. 2351. Die gefallenen Mächtigen. Uwe Anton. 1. Aufl. PabelMoewig-Verlag.

Perry Rhodan Bd. 2363. Atem der Finsternis. Horst Hoffmann. 1. Aufl. Pabel-Moewig- 
Verlag.

Perry Rhodan Bd. 2367. Rekruten des Chaos. Arndt Ellmer. 1. Aufl. Pabel-MoewigVerlag.

Perry Rhodan Bd. 2370. Die Milliardenstadt. Michael Marcus Thurner. 1. Aufl. PabelMoewig-Verlag.

Perry Rhodan Bd. 2372. Plan der Phantome. Christian Montillon. 1. Aufl. PabelMoewig-Verlag.

Perry Rhodan Bd. 2374. Der Trojaner. Hubert Haensel. 1. Aufl. Pabel-Moewig-Verlag.

Perry Rhodan Bd. 2375. Dantyrens Jagd. Hubert Haensel. 1. Aufl. Pabel-MoewigVerlag.

Perry Rhodan Bd. 2376. Tolle Tage in Terrania. Leo Lukas. 1. Aufl. Pabel-MoewigVerlag.

Perry Rhodan Bd. 2377. ESCHER. Christian Montillon. 1. Aufl. Pabel-Moewig-Verlag.

Perry Rhodan Bd. 2378. Der Erste Kybernetiker. Christian Montillon. 1. Aufl. PabelMoewig-Verlag.

Perry Rhodan Bd. 2379. Eschers Liste. Arndt Ellmer. 1. Aufl. Pabel-Moewig-Verlag.

Perry Rhodan Bd. 2380. Es kam aus der Sonne. Horst Hoffmann. 1. Aufl. PabelMoewig-Verlag.

Perry Rhodan Bd. 2381. Der Dunkle Ermittler. Uwe Anton. 1. Aufl. Pabel-MoewigVerlag.

Perry Rhodan Bd. 2382. Der refaktive Sprung. Uwe Anton. 1. Aufl. Pabel-MoewigVerlag.

Perry Rhodan Bd. 2391. Die Schwarze Zeit. Wim Vandemaan. 1. Aufl. PabelMoewig-Verlag.

Perry Rhodan Bd. 2400. Zielzeit. Robert Feldhoff. 1. Aufl. Pabel-Moewig-Verlag.

Perry Rhodan Bd. 2416. Mythos Scherbenstadt. Christian Montillon. 1. Aufl. PabelMoewig-Verlag.

Perry Rhodan Bd. 2417. Sklave der Menschheit. Horst Hoffmann. 1. Aufl. PabelMoewig-Verlag.

Perry Rhodan Bd. 2420. Ketschuas Mondflug. Christian Montillon. 1. Aufl. PabelMoewig-Verlag.

Perry Rhodan Bd. 2424. Die Thermodyn-Zentrale. Hubert Haensel. 1. Aufl. Pabel- 
Moewig-Verlag.

Perry Rhodan Bd. 2566. Oase der Wissenden. Frank Borsch. 1. Aufl. Pabel-MoewigVerlag.

Perry Rhodan Bd. 2580. Handelsstern im Visier. Christian Montillon 1. Aufl. PabelMoewig-Verlag.

Perry Rhodan Bd. 2581. Wunder in Gefahr. Leo Lukas. 1. Aufl. Pabel-Moewig-Verlag.

Perry Rhodan Bd. 2582. Ein Kind der Funken. Leo Lukas. 1. Aufl. Pabel-MoewigVerlag.

Perry Rhodan Bd. 2585. Der Tanz der Vatrox. Frank Borsch. 1. Aufl. Pabel-MoewigVerlag.

Perry Rhodan Bd. 2586. Die Sektorknospe. Wim Vandemaan. 1. Aufl. Pabel-MoewigVerlag.

Perry Rhodan Bd. 2587. Krieg in der Schneise. Christian Montillon. 1. Aufl. PabelMoewig-Verlag.

Perry Rhodan Bd. 2588. Aufmarsch der Titanen. Arndt Ellmer. 1. Aufl. Pabel-MoewigVerlag.

Perry Rhodan Bd. 2598. Tod einer Superintelligenz. Marc A. Herren. 1. Aufl. PabelMoewig-Verlag.

Perry Rhodan Bd. 2600. Das Thanatos Programm. Uwe Anton. 1. Aufl. PabelMoewig-Verlag.

Perry Rhodan Bd. 2686. Angriff der Nanokrieger. Leo Lukas. 1. Aufl. Pabel-MoewigVerlag.

Terra Astra Bd. 504/119 Orion. Ring des Verderbens. H.G. Ewers. 1. Aufl. PabelVerlag.

Terra Astra Bd. 594/145 Orion. Zeitblockade. H.G. Ewers. 1. Aufl. Pabel-Verlag.

\section{Sonstige:}

Blaulicht-Reihe Bd. 36. Der Leichenräuber. R.L. Stevenson. 1. Aufl. (1963). Das Neue Berlin. 


\section{Taschenbücher}

Howard, Robert E.: Conan Bd. 1. Die Original-Erzählungen aus den Jahren 1932 und 1933. 4. Aufl. München 2011. Übersetzungen von Lore Strassl, Jürgen Langowski und Erik Simon.

Voltz, William (Hg.): Perry Rhodan Silberband 6. Der Robotregent. Rastatt 1980. 


\section{Sekundärliteratur}

Ackermann, Kathrin und Moser-Kroiss, Judith (Hg.): Gespannte Erwartungen. Berlin 2007.

Alpers, Hans-Joachim; Fuchs, Werner; Hahn, Ronald M. und Jeschke, Wolfgang: Lexikon der Science Fiction Literatur. Bd. 1. München 1980.

Alpers, Hans-Joachim; Fuchs, Werner und Hahn, Ronald M. (Hg.): Reclams Science Fiction Führer. Stuttgart 1982.

Alpers, Hans-Joachim; Fuchs, Werner und Hahn, Ronald M.: Lexikon der Horrorliteratur. Erkrath 1999.

Alpers, Hans-Joachim; Fuchs, Werner; Hahn, Ronald M.; Munsonius, Jörg M. Und Urbanek, Hermann (Hg.): Lexikon der Fantasy-Literatur. Erkrath 2005.

Allrath, Gaby und Gymnich, Marion (Hg.): Narrative Strategies in Television Series. Houndsmille 2005.

Allrath, Gaby; Gymnich, Marion und Surkamp, Carola: Introduction: Towards a Narratology of TV Series. In: Narrative Strategies in Television Series. Houndsmille 2005. Hrsg. von Gaby Allrath und Marion Gymnich. S. 1-43.

Antoni, Ernst: „Landser“-Hefte Wegbereiter für den Rechtsradikalismus. München 1979.

Arbeitsgruppe Massenliteratur: Verwertbare Unmündigkeit: Zur Romanheftserie Jerry Cotton. In: Ästhetik \& Kommunikation. Beträge zur politischen Erziehung. Jg. 2, H. 5-6, Rowohlt. Reinbek Februar 1972. S. 49-57.

Arndt, Astrid; Deupmann, Christoph; Korten, Lars: Logik der Prosa. Göttingen 2012.

Bachleitner, Norbert: Kleine Geschichte des deutschen Feuilletonromans. Tübingen 1999.

Bärtle, Jochen: Grusel, Grüfte, Groschenheft. Der deutsche Gruselheftroman von 1968 bis 2008 - Eine Serienübersicht zum 40-jährigen Jubiläum. Norderstedt 2008.

Bärtle, Jochen: Geister, Gaslicht, Gänsehaut: Mysteriöse Romanzen, romantische Gothics - Der Spannungsroman für Frauen (1971-2013). Version 1.1 als kostenlose PDF downloadbar:

http://www.groschenhefte.net/news01.htm (Zugriff: 22.03.2013).

Erweiterte Version 3.2 unter:

http://www.groschenhefte.net/ggg_buecher_main.html

(Zugriff: 04.05.2019). 
Bärtle, Jochen: Götzen, Gold und Globetrotter. Deutsche Abenteuer-Heftromane von 1960 bis 2015 - mit Übersicht der wichtigsten Nachkriegsserien. Norderstedt 2016.

Bärtle, Jochen: Goblins, Götter, Greifenreiter. Fantasy im deutschen Heftroman von 1973 bis 2012 - über die seltenen Ausflüge in phantastische Welten. Norderstedt 2017.

Basener, Anna: Heftromane schreiben und veröffentlichen. Berlin 2010.

Baum, Margarethe Tanguy: Der Historische Roman im Frankreich der Julimonarchie. Frankfurt a.M. 1981.

Baumann, Hans D.: Horror. Die Lust am Grauen. Basel 1989.

Bayer, Dorothee: Der triviale Familien- und Liebesrom im 20. Jahrhundert. 2. erw. Aufl. Tübingen 1971.

Beissel, Rudolf: Von Atala bis Winnetou. Die 'Väter des Western-Romans'. Braunschweig 1978.

Bekes, Peter: Kommunikative Texttheorie - Kybernetische Modelle zur Beschreibung von Trivialliteratur. Regensburg 1976. (Hochschulschriften Literaturwissenschaft 12).

Bell, Martin: Muster des Unheimlichen. Struktur und Ideologie des Heftromans am Beispiel der Gruselserie Dämonenkiller. Uelvesbüll 2011.

Bendix, Regina; Hämmerling, Christine; Maase, Kaspar und Nast, Mirjam: Lesen, Sehen, Hängenbleiben. Zur Integration serieller Narrative im Alltag ihrer Nutzerinnen und Nutzer. In: Populäre Serialität. Narration - Evolution Distinktion. Zum seriellen Erzählen seit dem 19. Jahrhundert. Hrsg. von Frank Kelleter. Bielefeld 2012, S. 295-319.

Benjamin, Walter: Das Kunstwerk im Zeitalter seiner technischen Reproduzierbarkeit. Frankfurt a.M. 2007.

Bierwirth, Gerhard: Zum Beispiel Jerry Cotton. Trivialliteratur als Chance der Literaturwissenschaft. In: Zeitschrift für Literaturwissenschaft und Linguistik. Heft 6 1972. Hrsg. von Helmut Kreuzer et al., S. 95-104.

Le Blanc, Thomas und Solms, Wilhelm (Hg.): Phantastische Welten. Märchen, Mythen, Fantasy. Regensburg 1994.

Borgmeier, Raimund; Broich, Ulrich und Suerbaum, Ulrich: Science Fiction. Stuttgart 1981.

Bourdieu, Pierre: Die Regeln der Kunst - Genese und Struktur des literarischen 
Feldes. Übersetzt von Bernd Schwibs, und Achim Russer. Titel des franz. Originals: Les règles de l'art. Genèse et structure du champ littéraire. (Paris 1992). Frankfurt a.M. 2001.

Braudy, Leo: Horror. In: Handbuch Populäre Kultur. Hrsg. von Hans-Otto Hügel. Stuttgart 2003, S. 248-255.

Brauerhoch, Annette: Kapitale Mythen, oder 'Lernen, worum es überhaupt geht.' Universität GH Siegen 1993. (Arbeitshefte Bildschirmmedien 39).

Brodbeck, Liselotte: Roman als Ware. Zur Analyse der Liebesromanhefte. Basel 1974.

Buck, Kathrin: Der Heftroman. Historische, kommunikative und bibliothekarische Aspekte einer gering geschätzten Literaturform. Saarbrücken 2011.

Buhl, Hendrik: Landser Hefte. In: Lexikon der 'Vergangenheitsbewältigung' in Deutschland. Hrsg. von Torben Fischer und Matthias N. Lorenz. 2. unver. Aufl. Bielefeld 2009, S. 115-117.

Carroll, Noël: A Philosophy of Mass Art. Oxford 1998.

Compart, Martin: G-man Jerry Cotton. Köln 2010.

Dark, Jason: John Sinclair - Der Geisterjäger und seine Freunde. Bergisch Gladbach 1996.

Darlton, Clark: Wie alles begann. In: Perry Rhodan - Werkstattband. Hrsg. Von Horst Hoffmann. Rastatt 1986, S. 19-30.

Davids, Jens-Ulrich: Das Wildwest-Romanheft in der Bundesrepublik. 2. erw. Aufl. Tübingen 1975.

Davids, Jens-Ulrich: Das Wildwestromanheft in der Bundesrepublik: Zur inhaltlichen Analyse. In: Erzählgattungen der Trivialliteratur. Hrsg. Von Zedenko Skreb Innsbruck 1984, S. 177-195.

Delfs, Rainer und Mette, Michael: John Sinclair-Lexikon. Bergisch Gladbach 1997.

Domagalski, Peter: Trivialliteratur. Geschichte. Produktion. Rezeption. Freiburg 1981.

Eco, Umberto: Über Spiegel und andere Phänomene. Übersetzt von Burkhart Kroeber. 3. Aufl. München 1993.

Eco, Umberto: Streit der Interpretationen. Übersetzt von Rolf Eichler. Hamburg 2005.

Eco, Umberto: Zwischen Autor und Text. In: Texte zur Theorie der Autorschaft. Übersetzt von Hans Günter Holl. Hrsg. von Fotis Jannidis, Gerhard Lauer, 
Matias Martinez und Simone Winko. Stuttgart 2012. S. 279-294.

Eichner, Susanne; Mikos, Lothar und Winter, Rainer (Hg.): Transnationale Serienkultur. Theorie, Ästhetik, Narration und Rezeption neuer Fernsehserien. Wiesbaden 2013.

Eichner, Susanne; Mikos, Lothar und Winter, Rainer: Einleitung. In: Transnationale Serienkultur. Theorie, Ästhetik, Narration und Rezeption neuer Fernsehserien. Hrsg. von Susanne Eichner, Lothar Mikos und Rainer Winter. Wiesbaden 2013, S. 9-20.

Eik, Jan: Der Mann der Jerry Cotton war. Erinnerungen des Bestsellerautors Heinz Werner Höber. Berlin 1996.

Ellerbrock, Beate; Ellerbrock, Jürgen und Thieße Frank: Perry Rhodan. Untersuchung einer Science Fiction-Heftromanserie. 2. Aufl. Gießen 1977.

Faulstich, Werner und Thomsen, Chr.W. (Hg.): Seller, Stars und Serien - Medien im Produktverbund. Heidelberg 1989.

Faulstich, Werner und Lemke, Ina: Der Produktverbund von Fernsehen und Buch. Eine Fallstudie zu 'Wer erschoss Boro.' In: Seller, Stars und Serien - Medien im Produktverbund. Hrsg. von Werner Faulstich und Chr.W. Thomsen. Heidelberg 1989 , S. 213-265.

Faulstich, Werner: Serialität aus kulturwissenschaftlicher Sicht. In: Endlose Geschichten. Hrsg. von Günter Giesenfeld. Hildesheim 1994, S. 46-71.

Feige, Marcel: Das neue Lexikon der Fantasy. 2. erw. Aufl. Berlin 2003.

Fetzer, Günther: Wertungsprobleme in der Trivialliteraturforschung. München 1980.

Fischer, Ludwig: Heftromane. In: Hansers Sozialgeschichte der deutschen Literatur. Hrsg. von Rolf Grimmiger. Bd. 10. München 1986, S. 546-564.

Fischer, Torben und Lorenz, Matthias N. (Hg.): Lexikon der 'Vergangenheitsbewältigung' in Deutschland. 2. unver. Aufl. Bielefeld 2009.

Frick, Klaus N.: Das große Perry Rhodan Fanbuch. München 1996.

Friedrich, Hans-Edwin: Science Fiction in der deutschsprachigen Literatur. Ein Referat zur Forschung bis 1993. Tübingen 1995.

Fritzsche, W.; Hitzer, F.; Neumann, O.; Stutz, H. und Suhler, C. (Hg.): Kürbiskern Literatur und Kritik. Heft 4/70. München 1970.

Fritzsche, W.; Hitzer, F.; Neumann, O.; Stutz, H. und Suhler, C. (Hg.): Kürbiskern Literatur, Kritik, Klassenkampf. Heft 1/75. München 1975. 
Fröhlich, Vincent: Der Cliffhanger und die serielle Narration: Analyse einer transmedialen Erzähltechnik. Bielefeld 2015.

Galle, Heinz J.: Groschenhefte - Geschichte der deutschen Trivialliteratur. Berlin 1988.

Galle, Heinz J.: Populäre Lesestoffe. Groschenhefte, Dime, Novels und Penny Dreadfuls aus den Jahren 1850 bis 1950. Köln 2002.

Galle, Heinz J.: Volksbücher und Heftromane. Bd. 1. 2. durchges. Aufl. Lüneburg 2009.

Galle, Heinz J.: Volksbücher und Heftromane. Bd. 2. 2. durchges. Aufl. Lüneburg 2009.

Galle, Heinz J.: Volksbücher und Heftromane. Bd. 3. 2. durchges. Aufl. Lüneburg 2009.

Geiger, Klaus F.: Kriegsromanhefte in der BRD - Inhalte und Funktionen. Tübingen 1974.

Genette, Gérard: Stimme. In: Moderne Erzähltheorie. Hrsg. von Karl Wagner. Wien 2002, S. 213-270.

Genette, Gérard: Die Erzählung. 3. durchgesehene korrigierte Aufl. Übersetzt von Andreas Knop. Überprüft und berichtigt von Isabel Kranz. Paderborn 2010.

Giesenfeld, Günter (Hg.): Endlose Geschichten. Serialität in den Medien. Hildesheim 1994.

Giesenfeld, Günter: Serialität als Erzählstrategie in der Literatur. In: Endlose Geschichten. Hrsg. von Günter Giesenfeld. Hildesheim 1994, S. 1-11.

Göbel, Klaus und Schemme, Wolfgang (Hg.): Jerry Cotton. Du lebst zu lange, Gman! Stuttgart 1984.

Göbel, Klaus: Jerry Cotton und seine ersten 50 Jahre. Romangeschichte als Zeitgeschichte. In: Die schwere Kunst der leichten Unterhaltung. Hrsg von Franz-Heinrich Hackel. Köln 2004. S. 147-161.

Göttlich, Udo; Albrecht, Clemens und Gebhardt, Winfried (Hg.): Populäre Kultur als repräsentative Kultur. Die Herausforderung der Cultural Studies. 2. erw. Aufl. Köln 2010.

Grimmiger, Rolf (Hg.): Hansers Sozialgeschichte der deutschen Literatur. Bd. 10. München 1986. 
Hackel, Franz-Heinrich (Hg.): Die schwere Kunst der leichten Unterhaltung. Köln 2004.

Hallenberger, Gerd und Keim, Heinrich: Die Zukunft als Ware. In: Kürbiskern Literatur, Kritik, Klassenkampf. Hrsg. Von W. Fritzsche. Heft 1/75. München 1975. S. 76-90.

Hallmann, Claus: Perry Rhodan - Analyse eine Science-Fiction-Romanheftserie. Frankfurt 1979.

Haupts, Thomas: Emergency Room - Die Notaufnahme. In: Klassiker der Fernsehserie. Hrsg. von Christian Hißnauer und Thomas Klein. Stuttgart 2012, S. 262-267.

Hector, Robert: Die dunkle Zukunft der Menschheit. 250 Mal MADDRAX. Norderstedt 2009.

Hickethier, Knut und Lützen, Wolf Dieter: Der Kriminalroman. In: Trivialliteratur. Hrsg. von Annamaria Rucktäschel und Hans Dieter Zimmermann. München 1976, S. 267-295.

Hickethier, Knut: Die Fernsehserie und das Serielle des Fernsehens. Lüneburg 1991.

Hickethier, Knut: Die Fernsehserie - eine Kette von Verhaltenseinheiten. In: Serie, Kunst im Alltag. Hrsg. von Peter Hoff und Dieter Wiedmann. Berlin 1992, S. 1118.

Hickethier, Knut: Die Fernsehserie und das Serielle des Programms. In: Endlose Geschichten. Hrsg. von Günter Giesenfeld. Hildesheim 1994, S. 55-71.

Hickethier, Knut: Serie. In: Handbuch Populäre Kultur. Hrsg. von Hans-Otto Hügel. Stuttgart 2003, S. 397-403.

Hienger, Jörg (Hg.): Unterhaltungsliteratur - Zu ihrer Theorie und Verteidigung. Göttingen 1976.

Hienger, Jörg: Spannungsliteratur und Spiel. Bemerkungen zu einer Gruppe populärer Erzählformen. In: Unterhaltungsliteratur - Zu ihrer Theorie und Verteidigung. Hrsg. von Jörg Hienger. Göttingen 1976, S. 32-54.

Hilger, Josef: Raumpatrouille. Die phantastischen Abenteuer des Raumschiffes ORION. Erw. Neuauflage Berlin 2005.

Hißnauer, Christian und Jahn-Sudmann, Andreas (Hg.): medien - zeit - zeichen. Marburg 2007.

Hißnauer, Christian: Fernsehdokumentarismus. Konstanz 2011. 
Hißnauer, Christian und Klein, Thomas (Hg.): Klassiker der Fernsehserie. Stuttgart 2012.

Hißnauer, Christian; Scherer, Stefan und Stockinger, Claudia: Föderalismus in Serie. Die Einheit der ARD-Reihe Tatort im historischen Verlauf. Paderborn 2014

Hißnauer, Christian; Scherer, Stefan und Stockinger, Claudia (Hg.): Zwischen Serie und Werk. Fernseh- und Gesellschaftsgeschichte im „Tatort“. Bielefeld 2014.

Hoff, Peter und Wiedmann, Dieter (Hg.): Serie, Kunst im Alltag. Berlin 1992. (Beiträge zur Film- und Fernsehwissenschaft; Jg. 33, Bd.43).

Hoffmann, Horst (Hg.): Perry Rhodan - Werkstattband. Rastatt 1986.

Hoffmann, Horst und Marzin, Florian F. (Hg.): Perry Rhodan Lexikon. 5 Bde. Rastatt 1991.

Hoffmann, Horst und Marzin, Florian F. (Hg.): Perry Rhodan Lexikon. Bd. A-E. Rastatt 1991.

Hoffmann, Horst und Marzin, Florian F. (Hg.): Perry Rhodan Lexikon. Bd. F-K. Rastatt 1991.

Hoffmann, Horst und Marzin, Florian F. (Hg.): Perry Rhodan Lexikon. Bd. Q-V. Rastatt 1991.

Hügel, Hans-Otto (Hg.): Handbuch Populäre Kultur. Stuttgart 2003.

Hügel, Hans-Otto: Einleitung. In: Handbuch Populäre Kultur. Hrsg. Von Hans-Otto Hügel. Stuttgart 2003, S. 1-22.

Hügel, Hans-Otto: Romanheft. In: Handbuch Populäre Kultur. Hrsg. von Hans-Otto Hügel. Stuttgart 2003, S. 376- 383.

Hügel, Hans-Otto: Durchsichtigkeit des Populären. Welterfahrung und Kennerschaft im Romanheft. In: Lob des Mainstreams. Zu Begriff und Geschichte von Unterhaltung und Populärer Kultur. Hrsg. von Hans-Otto Hügel. Köln 2007, S. 246-271.

Hügel, Hans-Otto Hügel (Hg.): Lob des Mainstreams. Zu Begriff und Geschichte von Unterhaltung und Populärer Kultur. Köln 2007.

Irsigler, Ingo; Jürgensen, Christoph und Langer, Daniela: Zwischen Text und Leser. München 2008.

Jahn-Sudmann, Andreas und Kelleter, Frank: Die Dynamik serieller Überbietung. In: Populäre Serialität. Narration - Evolution - Distinktion. Zum seriellen Erzählen seit dem 19. Jahrhundert. Hrsg. von Frank Kelleter. Bielefeld 2012, S. 205-224. 
Jakuba, Friedrich: G-man Jerry Cotton. Nichts als Wahrheit und Legenden. Köln 2003.

Jannidis, Fotis; Lauer, Gerhard; Martinez, Matias und Winko, Simone (Hg.): Texte zur Theorie der Autorschaft. Stuttgart 2012.

Jeschke, Wolfgang und Mamczak, Sascha (Hg.): Das Science Fiction Jahr 2004. München 2004.

Junklewitz, Christian und Weber, Tanja: Das Gesetz der Serie. Ansätze zur Definition und Analyse. In: Medienwissenschaft 25.1 (2008), S.13-31.

Junklewitz, Christian und Weber, Tanja: To be continued ... Funktion und Gestaltungsmittel des Cliffhangers in aktuellen Fernsehserien. In: 'Previously on...' Zur Ästhetik der Zeitlichkeit neuerer TV-Serien. Hrsg. von Arno Meteling, Isabell Otto und Gabriele Schabacher. München 2010, S. 111-132.

Kagelmann, Jürgen $\mathrm{H}$.: Modellvorstellungen psychisch abweichenden Verhaltens in der Unterhaltungsliteratur. Berlin 1982.

Kasper, Hartmut: Den Wilden Westen mit der Seele suchen. (07.12.2004) auf der Homepage von Deutschlandfunk (deutschlandfunk.de): https://www.deutschlandfunk.de/den-wilden-westen-mit-der-seelesuchen.700.de.html?dram:article_id=82081 (Zugriff: 17.08.2019).

Kasper, Harmut: Der härteste Mann auf dem deutschen Heftromanmarkt (16.11.2010) auf der Homepage von Deutschlandfunk (deutschlandfunk.de): https://www.deutschlandfunk.de/der-haerteste-mann-auf-dem-deutschenheftromanmarkt.700.de.html?dram:article_id=84817 (Zugriff: 17.08.2019).

Kasper, Hartmut: Perry Rhodan - der Erbe der Space Opera. In: Das Science Fiction Jahr 2004. Hrsg. von Wolfgang Jeschke und Sascha Mamczak. München 2004, S. 69-98.

Kelleter, Frank: Serien als Stresstest. In: Frankfurter Allgemeine Zeitung Nr. 30 (4. Februar 2012), S. 31.

Kelleter, Frank (Hg.): Populäre Serialität: Narration - Evolution - Distinktion. Zum seriellen Erzählen seit dem 19. Jahrhundert. Bielefeld 2012.

Kelleter, Frank: Populäre Serialität. Eine Einführung. In: Populäre Serialität: Narration - Evolution - Distinktion. Zum seriellen Erzählen seit dem 19. Jahrhundert. Hrsg. von Frank Kelleter. Bielefeld 2012, S. 11-48.

Kirde, Kalju (und die Hg.): Einführung in die Horrorliteratur. In: Lexikon der Horrorliteratur. Hrsg. von Hans Joachim Alpers, Werner Fuchs, Ronald M. 
Hahn. Erkrath 1999, S. 7-26.

Klaese, Christopher: Vom Bahnhofskiosk auf die deutsche Leinwand - Deutsche Romanheftverfilmungen. In: Die Jerry-Cotton-Filme. Als Jerry Cotton nach Deutschland kam. Hrsg. von Joachim Kramp und Gerd Naumann. Stuttgart 2011, S. 133-143.

Klein, Albert und Hecker, Heinz: Trivialliteratur. Opladen 1977. (Grundstudium Literaturwissenschaft Hochschuldidaktische Arbeitsmaterialien Bd. 10).

Klein, Klaus-Peter: Zukunft zwischen Trauma und Mythos: Science-fiction Zur Wirkungsästhetik, Sozialpsychologie und Didaktik eines literarischen Massenphänomens. Stuttgart 1976.

Klein, Thomas: Die Simpsons. In: Klassiker der Fernsehserie. Hrsg. Von Christian Hißnauer und Thomas Klein. Stuttgart 2012, S. 217-226.

Kneifel, Hans und Sander, Roman (Hg.): Dragons Welt. Hintergründe Inhalte Lexikon. Augsburg k.A. (vermutlich 1990).

Knüppel, Joachim; Knüppel, Werner und Rhode, Helmut: Allgemeiner RomanPreiskatalog. 10. erw. Aufl. Hamburg 2011.

Knüppel, Joachim; Knüppel, Werner und Rhode, Helmut: Allgemeiner RomanPreiskatalog. 11. erw. Aufl. Hamburg 2016.

König, Thomas: Geisterwald Katalog. Die Heftroman-Bibliographie. Bd. 1 Horror/ Grusel\&Mysterie. 2. Aufl. Berlin 2009.

König, Thomas: Geisterwald Katalog. Die Heftroman-Bibliographie. Bd. 2 Märchen/ Sagen\&Fantasy. Berlin 2001.

Krah, Hans: Serie. In: Reallexikon der deutschen Literaturwissenschaft. Bd. III P- Z. Hrsg. von Jan-Dirk Müller. Berlin 2003, S. 431-435.

Krah, Hans: Erzählen in Folge. Eine Systematisierung narrativer Fortsetzungszusammenhänge. In: Strategien der Filmanalyse - reloaded. Hrsg. von Michael Schaudig. München 2010, S. 85-114.

Krämer, Reinhold: Die gekaufte 'Zukunft'. Zu Produktion und Rezeption von Science Fiction in der Bundesrepublik Deutschland nach 1945. Frankfurt a.M. 1990 (Sonderdruck aus dem „Archiv für Geschichte des Buchwesens“ Band 34).

Kramp, Joachim und Naumann, Gerd (Hg.): Die Jerry-Cotton-Filme. Als Jerry Cotton nach Deutschland kam. Stuttgart 2011.

Kreuzer, Helmut: Trivialliteratur als Forschungsproblem. In: Texte zur Trivialliteratur. Über Wert und Wirkung von Massenware. Hrsg. von Ekkehart Mittelberg, Klaus 
Peter und Dieter Seiffert. Stuttgart 1971. S. 142-154.

Lamping, Dieter: Genre. In: Reallexikon der deutschen Literaturwissenschaft. Bd. I A-

G. Neubearb. Hrsg. von Klaus Weimar. Berlin 1997, S. 704-705.

Langenbucher, Wolfgang: Der aktuelle Unterhaltungsroman. Bonn 1964.

Lobensommer, Andrea: Die Suche nach "Heimat". Dissertation. München 2010.

Lübbe, Stefan: Das Romanheft oder Der Un-heimliche Bestseller. In: Die schwere Kunst der leichten Unterhaltung. Hrsg. von Franz-Heinrich Hackel. Köln 2004, S. 10-13.

Maase, Kaspar und Kaschuba, Wolfgang (Hg.). Schund und Schönheit. Populäre Kultur um 1900. Köln 2001.

Maase, Kaspar: Jenseits der Massenkultur. In: Populäre Kultur als repräsentative Kultur. Die Herausforderung der Cultural Studies. Hrsg. Von Udo Göttlich, Clemens Albrecht, Winfried Gebhardt. 2. erw. Aufl. Köln 2010, S. 80-105.

Maase, Kaspar: Was macht Populärkultur politisch? Wiesbaden 2010.

Maase, Kaspar; Müller, Sophie: Das Sammeln populärer Heftserien zwischen Kanon, Archiv und Fanszene. In: Populäre Serialität. Narration - Evolution - Distinktion. Zum seriellen Erzählen seit dem 19. Jahrhundert. Hrsg. von Frank Kelleter. Bielefeld 2012, S. 321-338.

von Mach, Susanne: Herrscher im wilden Westen. (28.02.2009):

https://www.main-netz.de/nachrichten/kultur/kultur/art4214,700806? (Zugriff: 17.08.2019).

Martinez, Matias und Scheffel, Michael: Einführung in die Erzähltheorie. 6. Aufl. München 2005.

Martus, Steffen und Spoerhase, Carlos (Hg.): Gelesene Literatur: Populäre Lektüre im Zeichen des Medienwandels. München 2018. (Text+Kritik. Zeitschrift für Literatur. Sonderband XII/18).

Meteling, Arno; Otto, Isabell und Schabacher, Gabriele(Hg.): 'Previously on ...' Zur Ästhetik der Zeitlichkeit neuerer TV-Serien. München 2010. (Mediologie Bd. 24).

Meteling, Arno; Otto, Isabell und Schabacher, Gabriele: „Previously on..." In: 'Previously on ...' Zur Ästhetik der Zeitlichkeit neuerer TV-Serien. Hrsg. Von Arno Meteling, Isabell Otto und Gabriele Schabacher. München 2010, S. 7-16.

Melzer, Helmut: Trivialliteratur I Forschungsproblematik - Didaktik - Textanalyse. 3. erw. Aufl. München 1978. (Analysen zur deutschen Sprache und Literatur). 
Mielke, Christine: Zyklisch - serielle Narration. Erzähltes Erzählen von 1001 Nacht bis zur TV-Serie. Berlin 2006.

Mittelberg, Ekkehart; Peter, Klaus und Seiffert, Dieter (Hg.): Texte zur Trivialliteratur. Über Wert und Wirkung von Massenware. Stuttgart 1971.

Mittell, Jason: Narrative Complexity in Contemporary American Television. In: the Velvet light trap, no. 58, Fall 2006, S. 29-40.

Mittell, Jason: Narrative Komplexität im amerikanischen Gegenwartsfernsehen. In: Populäre Serialität. Hrsg. von Frank Kelleter. Übersetzt von Frank Kelleter, Christiane Focking und Annika Lamer. Englisches Original: Narrative Complexity in Contemporary American Television. In: the Velvet light trap, no. 58, Fall 2006. S. 29-40. Bielefeld 2012, S. 97-122.

Müller, Eggo: Genre. In: Handbuch Populäre Kultur. Hrsg. Von Hans-Otto Hügel. Stuttgart 2003. S. 212-215.

Müller, Ingrid: Untersuchungen zum Bild der Frau in den Romanen von Hedwig Courths-Mahler. Bielefeld 1978. (Bielefelder Hochschulschriften Bd. 16).

Müller, Jan-Dirk (Hg.): Reallexikon der deutschen Literaturwissenschaft. Bd. III P-Z. Neubearb. Berlin 2003.

Nagl, Manfred: Science Fiction in Deutschland. Tübingen 1972.

Nagula, Michael: Perry Rhodan. Die Chronik. Bd.1. Höfen 2011.

Nagula, Michael: Perry Rhodan. Die Chronik. Bd.2. Höfen 2012.

Nast, Mirjam: Perry Rhodan lesen. Zur Serialität der Lektürepraktiken einer Heftromanserie. Dissertation. Bielefeld 2017.

Newcomb, Horace M.: Magnum: The Champagne of TV. In: Channels of communication. Mai/Juni (1985), S. 23-26.

Nusser, Peter: Romane für die Unterschicht. Groschenhefte und ihre Leser. Stuttgart 1973.

Nusser, Peter: Massenpresse, Anzeigenwerbung, Heftromane. Stuttgart 1976.

Nusser, Peter (Hg.): Arbeitstexte für den Unterricht Science Fiction. Stuttgart 1989.

Nusser, Peter: Trivialliteratur. Stuttgart 1991.

Nusser, Peter: Der Kriminalroman. 3. aktualisierte und erw. Aufl. Stuttgart 2003.

Nusser, Peter: Trivialliteratur. In: Reallexikon der deutschen Literaturwissenschaft. 
Bd. III P-Z. Neubearb. Hrsg. von Jan-Dirk Müller. Berlin 2007, S. 691- 695.

Nutz, Walter: Der Trivialroman seine Formen und seine Hersteller. Köln 1962. (Kunst und Kommunikation 4).

Nutz, Walter: Konformliteratur für die Frau. In: Trivialliteratur. Hrsg. von Gerhard Schmidt-Henkel, Horst Enders, Friedrich Knilli und Wolfgang Maier. Berlin 1964, S. $65-74$.

Nutz, Walter: Der Krieg als Abenteuer und Idylle. Landser-Hefte und triviale Kriegsromane. In: Gegenwartsliteratur und Drittes Reich. Hrsg. von Hans Wagener. Stuttgart 1977, S. 265-283.

Nutz, Walter: Trivialliteratur und Popularkultur. Vom Heftromanleser zum Fernsehzuschauer. Eine literatursoziologische Analyse unter Einschluß der Trivialliteratur der DDR. Wiesbaden 1999.

Pesch, Helmut W.: Science Fiction, Horror, Fantasy. Die modernen Genres der Phantastischen Literatur. In: Phantastische Welten. Märchen, Mythen, Fantasy. Hrsg. von Thomas Le Blanc und Wilhelm Solms. Regensburg 1994, S. 131-143.

Pesch, Helmut W.: Fantasy - Theorie und Geschichte einer literarischen Gattung. 2. Aufl. Norderstedt 2017.

Pforte, Dietger: Bedingungen und Formen der materiellen und immateriellen Produktion von Heftromanen. In: Trivialliteratur. Hrsg. von Annamaria Rucktäschel und Hans Dieter Zimmermann. München 1976, S. 30-60.

Plaul, Hainer: Illustrierte Geschichte der Trivialliteratur. Leipzig 1983.

Prentler, Peter F.: 'Star Wars'. Geschichte und Struktur eines Megaerfolgs im MedienProduktverbund. In: Seller, Stars und Serien - Medien im Produktverbund. Hrsg. von Werner Faulstich und Chr. W. Thomsen. Heidelberg 1989, S. 149181.

Present, Maria: Wohlfeiles heimatliches Waldesrauschen. Wien 1993.

Prisca Prugger: Wiederholung, Variation, Alltagsnähe. In: Endlose Geschichten. Hrsg. von Günter Giesenfeld. Hildesheim 1994, S. 90-113.

Ricœur, Paul: Die Spiele der Zeit. In: Moderne Erzähltheorie. Hrsg. von Karl Wagner. Wien 2002, S. 363-388.

Rossbacher, Karlheinz: Heimatkunstbewegung und Heimatroman. $\mathrm{Zu}$ einer Literatursoziologie der Jahrhundertwende. Stuttgart 1975.

Rucktäschel, Annamaria und Zimmermann, Hans Dieter (Hg.): Trivialliteratur. München 1976. 
Ruloff-Häny, Franziska: Liebe und Geld. Der moderne Trivialroman und seine Struktur. Dissertation. München 1976.

Schaudig, Michael (Hg.): Strategien der Filmanalyse - reloaded. München 2010. (diskurs film Münchener Beiträge zur Filmphilologie Bd. 11).

Scheichl, Sigurd Paul: E. Marlitt. In: Erzählgattungen der Trivialliteratur. Hrsg. Von Zedenko Skreb. Innsbruck 1984, S. 67-112.

Schenda, Rudolph: Volk ohne Buch. Frankfurt am Main 1970.

Schenda, Rudolph: Die Lesestoffe der kleinen Leute. München 1976.

Scherreiks, Sandra: Endlich der Richtige! Diskurse über Männlichkeit und ihre Spiegelung in Trivialromanen zwischen 1973 und 1996. Kiel 2003.

Schmidt-Henkel, Gerhard; Enders, Horst; Knilli, Friedrich und Maier, Wolfgang (Hg.): Trivialliteratur. Berlin 1964.

Schutte, Jürgen (Hg.): Erfahrung und Ideologie - Studien zur massenhaft verbreiteten Literatur. Berlin 1983.

Schweizerhof, Barbara: 24. In: Klassiker der Fernsehserie. Hrsg. von Christian Hißnauer und Thomas Klein. Stuttgart 2012, S. 307-312.

Schwettmann, Eckhard: Allmächtiger! Faszination Perry Rhodan. Höfen 2006.

Schwettmann, Eckhard: Fast alles über Perry Rhodan. Hannover 2009.

Sichelschmidt, Gustav: Hedwig Courths-Mahler Deutschlands erfolgreichste Autorin. Bonn 1967. (Bonner Beiträge Bd. 16).

Skreb, Zdenko und Baur, Uwe (Hg.): Erzählgattungen der Trivialliteratur. Innsbruck 1984.

Spinner, Kaspar H.: Das vergällte Lesevergnügen. Zur Didaktik der Unterhaltungsliteratur. In: Unterhaltungsliteratur - $\mathrm{Zu}$ ihrer Theorie und Verteidigung. Hrsg. von Jörg Hienger. Göttingen 1976, S. 98-116.

Sproat, Ron: Ich war Schwerarbeiter in einer Pornofabrik. In: Erzählgattungen der Trivialliteratur. Hrsg. von Skreb und Baur. Innsbruck 1984, S. 275-282.

Stache, Rainer: Perry Rhodan - Überlegungen zum Wandel eine Heftromanserie. Tübingen 1986.

Stanzel, Franz K.: Typische Formen des Romans. 2. durchge. Aufl. Göttingen 1965. 
Stanzel, Franz K.: Theorie des Erzählens. 5. unveränderte Aufl. Göttingen 1991.

Steffan, Hans-Ulrich: Das große John Sinclair Quiz-Buch. Bergisch Gladbach 1989.

Stierle, Karlheinz: Die Struktur narrativer Texte. In: Moderne Erzähltheorie. Hrsg. Von Karl Wagner. Wien 2002.

Stockinger, Claudia: Die Logik seriellen Erzählens. Der Groschenroman. In: Logik der Prosa. Hrsg. von Astrid Arndt, Christoph Deupmann und Lars Korten. Göttingen 2012, S. 91-108.

Stockinger, Claudia: Das All dort draußen zeigt uns, wer wir sind. Die Leseuniversen der Groschenhefte. In: Gelesene Literatur: Populäre Lektüre im Zeichen des Medienwandels. Hrsg. von Steffen Martus und Carlos Spoerhase. München 2018. (Text+Kritik. Zeitschrift für Literatur. Sonderband XII/18). S. 83-95.

Stockinger, Claudia: An den Ursprüngen populärer Serialität. Das Familienblatt Die Gartenlaube. Göttingen 2018.

Strecker, Gabriele: Frauenträume Frauentränen. Weilheim/Oberbayern 1969.

Suhler, Conrad: Perry Rhodan - Auf Raketen zurück in die Zukunft. In: Kürbiskern Literatur und Kritik. Hrsg. von W. Fritzsche, F. Hitzer, O. Neumann, H. Stutz, C. Suhler. Heft 4/70. München 1970, S. 588-597.

Teuscher, Gerhard: Perry Rhodan, Jerry Cotton und Johannes Mario Simmel. Darstellung zu Theorie, Geschichte und Vertretern der Trivialliteratur. Stuttgart 1999.

Thiel, Christian: Liebe, Sex, Karriere. Die Modernisierung des trivialen Liebesromans. Hamburg 1991.

Thresen, Hans: Die Romanfabrik. Ein Groschenheftschreiber packt aus. In: Texte zur Trivialliteratur. Über Wert und Wirkung von Massenware. Hrsg. Von Ekkehart Mittelberg, Klaus Peter, Dieter Seiffert. Stuttgart 1971, S. 48-54.

Türschmann, Jörg: Aspekte einer Typologie von Fernsehserien. In: medien - zeit zeichen. Hrsg. von Christian Hißnauer und Andreas Jahn-Sudmann. Marburg 2007, S. 100-108.

Türschmann, Jörg: Spannung und serielles Erzählen. Vom Feuilletonroman zur Fernsehserie. In: Gespannte Erwartungen. Hrsg. von Kathrin Ackermann und Judith Moser-Kroiss. Berlin 2007, S. 201-219.

Türschmann, Jörg: Spannung in Zeitungsliteratur. Romananfang und serielles Erzählen am Beispiel des frühen französischen Feuilletonromans. In: Zwischen Text und Leser. Hrsg. von Ingo Irsigler, Christoph Jürgensen und Daniela Langer. München 2008, S. 225-246. 
Urbanek, Hermann: Perry Rhodan. Die Chronik. Bd. 3. Höfen 2013.

Viering, Jürgen: Schauerroman. In: Reallexikon der deutschen Literaturwissenschaft.

Bd. III P-Z. Neubearb. Hrsg. von Jan-Dirk Müller. Berlin 2003, S. 365-368.

Vossen, Ursula (Hg.): Filmgenres Horrorfilm. Stuttgart 2004.

Wagener, Hans (Hg.): Gegenwartsliteratur und Drittes Reich. Stuttgart 1977.

Wagner, Karl (Hg.): Moderne Erzähltheorie. Wien 2002.

Waldmann, Günter: Theorie und Didaktik der Trivialliteratur. 2. erg. Aufl. München 1977.

Walker, Hugh: Dragon - Erinnerungen und was sonst noch übrig ist. In: Dragons Welt. Hintergründe Inhalte Lexikon. Hrsg. Von Hans Kneifel und Roman Sander. Augsburg k.A., S. 13-25.

Weddige, Hilkert: Einführung in die germanistische Mediävistik. 4. Aufl. München 2001.

Weigand, Jörg: Zwischen Heldentot und historischer Wahrheit. In: JMS-Report Oktober 5/2007. S. 8. Download der Pdf von:

http://www.jms.nomos.de/fileadmin/jms/doc/JMS-Report_07_05.pdf (Zugriff: 17.08.2019).

Weiland, Gudrun: 'Von einem sensationellen Erlebnis zum anderen getrieben...': Kriminalheftromane und die Zeitgestalt 'Serialität' in den 1920er und 1930er Jahren. Göttingen 2017.

Weimar, Klaus (Hg.): Reallexikon der deutschen Literaturwissenschaft. Bd. I A-G. Neubearb. Berlin 1997.

Welkener, Burkhard: Organisation der Produktion in Industrieunternehmen mit GroßSerien- und Massenproduktion unter besonderer Berücksichtigung internationaler Standortstruktur. Wirt.wiss. Diss. Gießen 1985.

Wesollek, Peter: Jerry Cotton oder 'Die verschwiegene Welt'. Bonn 1976.

Wernsing, Armin Volkmar und Wucherpfennig, Wolf: Die Groschenhefte: Individualität als Ware. Wiesbaden 1976.

Weinrich, Harald: Tempus. Besprochene und erzählte Welt. 6. Aufl. München 2001.

Winkler, Hartmut: Technische Reproduktion und Serialität. In: Endlose Geschichten. Hrsg. von Günter Giesenfeld. Hildesheim 1994, S. 38-45. 
Winter, Rainer: Fernsehserien als Kult. In: Transnationale Serienkultur. Theorie, Ästhetik, Narration und Rezeption neuer Fernsehserien. Hrsg. von Susanne Eichner, Lothar Mikos und Rainer Winter. Wiesbaden 2013, S. 67-86.

Wintgens, Hans-Herbert: Trivialliteratur für die Frau. Stuttgart 1979.

Wünsch, Marianne: Phantastische Literatur. In: Reallexikon der deutschen Literaturwissenschaft. Bd. III P-Z. Neubarb. Hrsg. von Jan-Dirk Müller. Berlin 2003, S. 71-74.

Zimmermann, Hans-Dieter: Trivialliteratur? Schema-Literatur! 2. Aufl. Stuttgart 1982.

Zondergeld, Rein A.: Lexikon der phantastischen Literatur. 1. Aufl. Main 1983. 


\section{Internetlinks}

\section{Bastei-Verlag:}

https://www.bastei.de/beitrag/standardbeitrag_17000.html (Zugriff: 17.08.2019). https://www.bastei.de/indices/index_allgemein_1867568.html

(Zugriff: 17.08.2019).

https://www.bastei.de/indices/index_allgemein_22709.html (Zugriff: 17.08.2019).

https://www.bastei.de/indices/index_allgemein_29.html (Zugriff: 17.08.2019).

https://www.bastei.de/indices/index_allgemein 599.html?buchstabe=K

(Zugriff: 17.08.2019).

Mediadaten (PDF):

http://www.bastei.de/indices/index_allgemein_69.html (Zugriff: 17.08.2019).

Bundesverband Deutscher Buch-, Zeitungs- und Zeitschriften-Grossisten: https://www.pressegrosso.de/branche/gemeinsame-erklaerung.html

(Zugriff: 17.08.2019).

https://www.pressegrosso.de/branche/pressevertrieb.html (Zugriff: 17.08.2019).

\section{Cora-Verlag:}

https://www.cora.de/collections/historische-liebesromane (Zugriff: 17.08.2019).

https://www.cora.de/collections/zeitgenossische-liebesromane

(Zugriff: 17.08.2019)

\section{Deutschlandfunk:}

Kasper, Hartmut: Den Wilden Westen mit der Seele suchen. (07.12.2004):

https://www.deutschlandfunk.de/den-wilden-westen-mit-der-seele-

suchen.700.de.html?dram:article id=82081 (Zugriff: 17.08.2019).

Kasper, Hartmut: Der härteste Mann auf dem deutschen Heftromanmarkt. (16.11.2010):

https://www.deutschlandfunk.de/der-haerteste-mann-auf-dem-deutschen-

heftromanmarkt.700.de.html?dram:article id=84817 (Zugriff: 17.08.2019).

\section{Kelter-Verlag:}

https://www.kelter.de/52-mystik (Zugriff: 17.08.2019).

https://www.kelter.de/44-roman (Zugriff: 17.08.2019).

\section{Pabel-Moewig-Verlag:}

http://www.vpm.de/zeitschriften/dokumentation.html (Zugriff: 26.03.2013; nicht mehr verfügbar).

https://www.vpm.de/zeitschriften/science-fiction.html (Zugriff: 17.08.2019).

\section{Perry Rhodan:}

https://www.perrypedia.proc.org/wiki/Hauptseite (Zugriff: 17.08.2019).

https://perry-rhodan.net/ (Zugriff: 17.08.2019).

https://forum.perry-rhodan.net/ (Zugriff 17.08.2019).

https://www.scifi-forum.de/forum/science-fiction/scifi-universen/perry-rhodan/ 
(Zugriff 17.08.2019).

https://perry-rhodan.net/infothek/links/conventions (Zugriff: 24.03.2019).

\section{Spiegel online:}

O.A.: Schriftsteller G.F. Unger gestorben. (05.08.2005): https://www.spiegel.de/kultur/ literatur/western-held-schriftsteller-g-f-unger-gestorben-a-368473.html (Zugriff: 17.08.2019).

\section{Sonstige:}

Bärtle, Jochen (Homepage: groschenhefte.net):

http://www.groschenhefte.net/grusel_serien/vampira_th/vampira th01.htm

(Zugriff: 23.03.2013; nicht mehr verfügbar).

Bärtle, Jochen: Geister, Gaslicht, Gänsehaut: Mysteriöse Romanzen, romantische Gothics - Der Spannungsroman für Frauen (1971-2013). Version 1.1, als kostenlose PDF downloadbar:

http://www.groschenhefte.net/news01.htm (Zugriff: 22.03.2013; nicht mehr verfügbar).

Erweiterte Version 3.2 unter:

http://www.groschenhefte.net/ggg_buecher_main.html

(Zugriff: 04.05.2019).

Ferkau, Volker (Homepage): http://www.mittland.de/index.php/autor

(Zugriff: 25.03.2013; nicht mehr verfügbar).

Grundgesetz Artikel 5: http://www.gesetze-im-internet.de/gg/art_5.html

(Zugriff: 17.08.2019).

von Mach, Susanne: Herrscher im wilden Westen. (28.02.2009):

https://www.main-netz.de/nachrichten/kultur/kultur/art4214,700806?

(Zugriff: 17.08.2019).

Weigand, Jörg: Zwischen Heldentot und historischer Wahrheit. In: JMS-Report Oktober 5/2007. S. 8. Download der PDF von:

http://www.jms.nomos.de/fileadmin/jms/doc/JMS-Report_07_05.pdf

(Zugriff: 17.08.2019). 


\section{Erklärung}

\section{Eidesstattliche Versicherung}

Hiermit versichere ich an Eides statt, dass ich die eingereichte Dissertation „Serialität der Romanhefte“ selbständig und ohne unerlaubte Hilfe verfasst habe. Anderer als der von mir angegebenen Hilfsmittel und Schriften habe ich mich nicht bedient. Alle wörtlich oder sinngemäß den Schriften anderer Autorinnen oder Autoren entnommenen Stellen habe ich kenntlich gemacht. Die Abhandlung ist noch nicht veröffentlicht worden und noch nicht Gegenstand eines Promotionsverfahrens gewesen.

Göttingen, 23.07.2014

Björn Lorenz 


\section{Danksagung}

Diese Arbeit ist ein langwieriger Prozess gewesen, der ohne die Hilfe von zahlreichen Menschen nicht möglich gewesen wäre. Für beständigen Rat, Anregungen und Hilfestellungen während der Betreuung dieser Dissertation danke ich insbesondere Claudia Stockinger und Gerhard Lauer.

Unermüdlich haben mich bei dieser Arbeit auch meine Freunde und Familie begleitet sowie tatkräftig unterstützt. Mein Dank gilt daher: Miclas Schwartz, Christian und Bridgitte Schwartz, Sandra Hoffmann, Dennis Jacobi, Kim Willhöft, Stephan Leu, Caroline Appelt, Elisabeth Anhalt, Philipp Heine, Katharina Lukoschek, Philipp Böttcher, Mirjam Nast, Svenja Dittrich, Lea Heyne.

Aber mein besonderer Dank gilt Christian Hißnauer, der stoisch etliche Versionen gegenlas, kommentierte und mich mit vielen konstruktiven Ratschlägen förderte. 